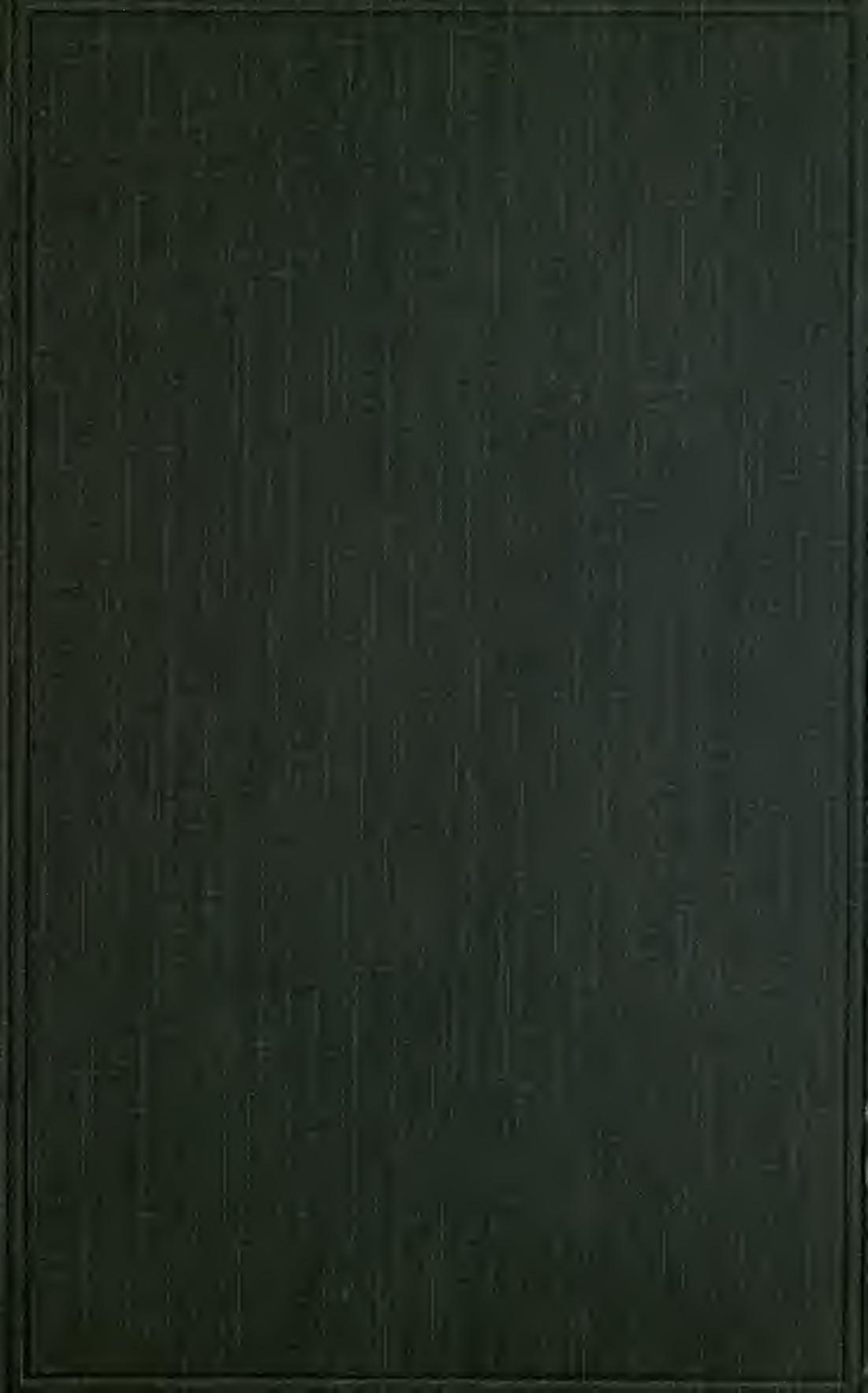




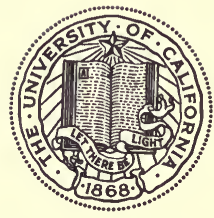

THE LIBRARY

OF

THE UNIVERSITY

OF CALIFORNIA

LOS ANGELES 




\section{ESSAYS ON EVOLUTION}

\section{I $889-1907$}

BY

\section{EDWARD BAGNALL POULTON, D.Sc., M.A.}

Hon. LL.D. Princeton, F.R.S., V-P.L.S., F.Z.S., F.G.S., F.E.S. HOPE PROFESSOR OF ZOOLOGY IN THE UNIVERSITY OF OXFORD FELLOW OF JESUS COLLEGE, OXFORD

MEMBRE HONORAIRE DE LA SOCIÉTÉ ENTOMOLOGIQUE DE BELGIQUE CORRESPONDING MEMBER OF THE ACADEMY OF SCIENCE, NEW YORK AND THE SOCIETY OF NATURAL HISTORY, BOSTON

\section{OXFORD}

AT THE CLARENDON PRESS 
HENRY FROWDE, M.A.

PUHLISHER TO THE UNIVERSITY OF OXFORD

LONDON, EDINBURGH

NEW YORK AND TORONTO 


\section{RAPHAEL MELDOLA, F.R.S.}

WHOSE EARLIER WRITINGS, UNDER THE INSPIRING INFLUENCE OF CHARLES DARWIN AND ALFRED RUSSEL WALLACE, WERE THE FOUNDATION OF A FRIENDSHIP AND A LIFE-WORK 



\section{PREFACE}

THE essays on evolution included in this book have not been placed in the order of their original publication, but are grouped according to the relationship of the subjects with which they deal. The first is concerned with the time in which evolution took place, and is a reply to the late Lord Salisbury's contention that the age of the habitable globe is not sufficient for the process as conceived by Darwin and Wallace. The second attempts to define the material which has been subject to organic evolution-species. The third contrasts the DarwinWallace with the Lamarck-Spencer theory of evolution. Heredity, the arbiter between the two rival theories, forms the subject of the fourth and fifth essays. The sixth deals with a neglected episode in the history of modern views on heredity and evolution, and shows how they were born out of due time but afterwards died in the mind of James Cowles Prichard, the great anthropologist. The seventh, discussing Huxley's attitude towards Natural Selection, maintains that above all it is the experience of the student of living nature which inspires confidence in the theory. The eighth and ninth essays form the natural continuation of the argument of the seventh, and show that the immense number of facts grouped under Mimicry are consistent with an interpretation based on Natural Selection, and inconsistent with other attempted explanations. The argument of the 
seventh, eighth, and ninth essays being concerned with the value of the visible surface of animals in the struggle for life, it was considered appropriate to include under the tenth head, and to illustrate by many examples, a comprehensive classification of the various uses which external colouring and appearance may subserve.

It will, I think, be realized that, although the separate essays were delivered as addresses or published on various occasions and at very different dates, they are the expression of a continuous line of thought, and therefore fall together as naturally as if they had been written at one time, for the purposes of the present volume.

A certain amount of overlap is necessary in essays dealing with closely related subjects. Any inconvenience from this cause and the scattered use of examples, inevitable in an essay, will be removed by consulting the Appendix and the analytical index, to the preparation of which much time and labour have been devoted.

Wherever the progress of knowledge has led to modification of statement or conclusion the necessary alterations have been made. These are in the form of footnotes whenever the importance and interest of the advance is such as to call for prominence. In other cases I have not hesitated to alter the text. Whether right or wrong, the arguments and conclusions in this volume of essays represent my views at the present moment.

It will be observed that the style of the third essay differs from that of all the others. This is because it is the revised shorthand record of an address, spoken not read. The seventh (hitherto unpublished) and ninth addresses were also spoken, but the corresponding essays were written subsequently from the notes. They there- 
fore contain much that was omitted from want of time and the interruption caused by the exhibition of numerous illustrations. The last and longest essay has been written for the present volume. Its title, The Place of Mimicry in a Scheme of Defensive Coloration, formed the subject of a lecture delivered seventeen years ago. I have now attempted to discuss the same question, replacing the standpoint of 1890 by that of 1907 , and directing special attention to the advance which has been made in the interval between these two dates.

Mendelism and Mutation, which occupy so large a share of public attention at the present moment, are not directly discussed in any of the essays. The relation of these interesting modern researches and speculations to older theories of evolution is briefly considered in an introductory chapter, in which it is maintained that the conclusions supported in the present volume are inconsistent with a theory of evolution by Mutation, inconsistent with the views often expressed by Mendelians, but not inconsistent with the discoveries of Mendel himself.

A full reference to the original source of publication will be found in the introductory note to those essays which have already appeared. I desire to thank the administrative bodies of scientific societies and the proprietors of journals for permission to reprint from the publications under their control.

Much invaluable assistance has been rendered by kind friends in the preparation of this volume or of the original addresses. A large part of the first essay on the age of the earth could never have been written without the help of Professor Perry, F.R.S., who has now kindly contributed a note ( $p .15$ ) on the bearing of the discovery of 
Radium upon the argument founded on the life of the sun. The hiatus in my argument caused by the want of any reference to the evolution of land-plants has now been to some extent filled by a brief summary of the main conclusions, prepared for me by my kind friend Dr. D. H. Scott, F.R.S. ; also by a quotation from an address by Professor A. C. Seward, F.R.S. I well remember how much I owed to the kind help of my friend Sir Ray Lankester, F.R.S., in the difficult task of summing up in a few words the chief conclusions as to the origin and history of each of the main branches of the animal kingdom. And essential parts of the second and fifth essays are due to his published writings, or have sprung from the memory of discussions with him.

In rewriting large parts of the fourth essay I owe a great debt to Dr. J. W. Jenkinson for valuable suggestions and criticism. Without the help of one who is devoting his life to the subject, I should have shrunk from the attempt to display in a few pages the main conclusions of the modern embryologist as to the potentialities latent in the germ, and their gradual emergence into actuality during the developmental history of the individual.

It is unnecessary to speak here individually of all the numerous friends who have rendered the kindest assistance in the preparation of this volume, and especially of essays VII-X, dealing with Protective Resemblance and Mimicry. All such help is fully acknowledged in the pages of the work. I wish, however, especially to thank my friends Dr. F. A. Dixey and Mr. Guy A. K. Marshall. Not only do their researches contribute a most important element to this volume, but I also owe them a deep debt 
of gratitude for continual advice and criticism, and for most efficient assistance in correcting proofs and verifying references.

I have attempted to express my indebtedness to Professor Meldola, F.R.S., by dedicating this volume to him. His writings were the original stimulus to which I owe the work of my life, and during nearly a quarter of a century devoted to that work I have relied probably even more than I am myself aware upon his sympathy and help. The great names of Darwin and Wallace are associated with Meldola's in the dedication, thus expressing, although very insufficiently, my sense of an immeasurable debt of gratitude. The life and immortal work of Darwin are a heritage of inspiration to every naturalist. To Alfred Russel Wallace I owe not only the stimulus of epoch-making thoughts, but the incalculable influence of long years of friendship and encouragement.

\section{EDWARD B. POULTON.}

OXFORD,

March 31, 1908. 



\section{CONTENTS}

PAGE

Introduction: Mutation, Mendelism, and Natural

SElection . . . . . . . . . xiii

I. A Naturalist's Contribution to the DisCUSSION UPON THE AGE OF THE EARTH (Liverpool, 1896) • • • • • . I

If- 'What is a Species?' (London, 1904) • . 46

IIf- Theories of Evolution (Boston, 1894) • • 95

IV. Theories of Heredity (Oxford, I889) • . I20

V. The Bearing of the Study of Insects upon the Question 'Are Acquired CharacTERS HEREDITARY ?’ (London, I905) • . 139

VI. A Remarkable anticipation OF MOderN Views on Evolution (1897) • . . . 173

VII. Thomas Henry Huxley and the Theory of Natural Selection (Birmingham, 1905) • 193

ViII. Natural Selection the Cause of Mimetic RESEMBLANCE AND COMMON WARNING COLOURS (London, 1898 ) . • • . . 220

IX. Mimicry and Natural Selection (Berlin, I9or) 27 I

X. The Place of Mimicry in a Scheme of Defensive Coloration (Leeds, 1890) . . 293 Appendix: A Classification and INDEX OF THE EXAmples OF Mimicry QUOTED in THE TEXT $\cdot 3^{83}$ Analytical Index . 


\section{ERRATA}

p. 3, l. 15. For 'Jenkins's' read 'Jenkin's'.

p. 199, l. 13. For 'road' read 'roads'.

p. 240, l. 2. For 'Dismorphina' read 'Dismorphia'.

p. 272, 1. 4 from bottom. Place 'Heliconine' between 'Danaine' and 'Nymphaline'.

p. 274. Further consideration has led to the conclusion that Anosia plexippus originally invaded North America from the tropics of the Old World and not from tropical America. The argument on p. 274 is not affected.

p. 277, lines 8, 9 from bottom. For 'and Heliconinae' read '(Danaoid Heliconidae)'.

p. 288, lines 18, 19. For 'thyodamus' read 'thyodamas'. 


\section{INTRODUCTION}

\section{MUTATION, MENDELISM, AND NATURAL SELECTION}

THE essays in this volume do not deal with the questions of Mutation and Mendelism which are so much discussed at the present time. It did not come in my way to examine them carefully until quite recently. When, however, I did look into the English publications on these subjects and the earlier work of Bateson on Variation, I was almost startled at the narrowness and prejudice which were continually apparent. Bateson's writings appear to me to have introduced a new and most regrettable element into scientific controversy. I cannot therefore let this book go to press without the following pages. The writings to which I have alluded are injurious to Biological Science, and a hindrance in the attempt to solve the problem of Evolution, for the following reasons :-

I. The amount of dogmatism concerning work with which the writer is evidently imperfectly acquainted.

2. The assumptions made by Mutationists on the slenderest evidence.

3. The appropriation under the name of Mendel of results which the present generation owes to Weismann.

4. The exaggerated estimate of the importance for 
Evolution of, first, Bateson's work on Variation, secondly Mendel's interesting discovery.

5. The contemptuous depreciation of other lines of investigation directly inspired by the work and teaching of Darwin and Wallace.

6. The natural consequence of this last:-a widespread belief among the ill-informed that the teachings of the founders of modern biology are abandoned.

I should wish to add that, although solely responsible for the contents of this Introductory chapter, I did not venture to publish it without consulting a number of the leading zoologists and botanists in this country. Without a single exception my friends agreed with the general line of argument, and felt with me that the protest was called for.

\section{Evolution, Continuous or Discontinuous.}

Although the word 'Mutation' is so much in evidence in the opening years of this century-as if it implied some new and illuminating idea-the conception of the origin of species by sudden steps is in reality very old.

The terms Continuous and Discontinuous are of course merely relative, as Bateson has clearly expressed it :'In proportion as the transition from term to term is minimal and imperceptible we may speak of the Series as being Continuous, while in proportion as there appear in it lacunae, filled by no transitional form, we may describe it as Discontinuous.' 1 Judged by this statement, parts of the series of species in the Organic World are discontinuous, parts continuous. It is the discontinuity

${ }^{1}$ Materials for the Study of Variation, London, 1894, p. 15. Hereafter quoted as $O$ n Variation. 
which strikes Bateson ${ }^{1}$ and those who follow him $;{ }^{2}$ but it is the continuity which rather aggressively impresses the great majority of those whose lives are devoted to the study of species. The work of the systematist would be immensely facilitated by that very discontinuity which is always eluding him, but obtrudes itself upon Bateson. The letters of Darwin quoted on pp. 59, 60 and 67 of the present work are almost pathetic in their statement of difficulties due to continuity in Cirrhipedes.

How are we to account for the discontinuous parts of the series? Is discontinuity a result of gradual growth, or did it spring into existence ready made? Ever since the appearance of the Origin of Species, the great majority of naturalists have believed the former ; the latter is maintained by a small group of active workers who, sometimes called 'Mutationists', sometimes 'Mendelians', would in this country be more correctly termed 'Batesonians'. It would be absurd to attempt to account for the sharp discontinuity in the series of mature individuals by supposing that each member of it suddenly came into existence full grown. Similarly, in attempting to account for the discontinuity of species it is surely unreasonable to neglect all study of the birth and growth of species which are going on all over the world. Blinded by the assurance of the dogmatic statement that the problem can only be attacked in one

1 "We see all organized nature arranged in a discontinuous series of groups differing from each other by differences which are Specific.' 1. c., p. $\mathbf{r} 6$.

Variation may teach us 'the origin of that Discontinuity of which Species is the objective expression'. l, c., p. 17.

2 ' The species riddle presents itself definitely as the problem of the existence of a series of discontinuous groups of creatures, sharply marked off the one from the other . . R. H. Lock, in Variation, Heredily and Evolution, London, 1906, p. 11 . 
way, ${ }^{1}$ Batesonians are heedless of all investigation into the geographical distribution of species and the changes on the borders of their range. The Zoological Museum at Tring is pre-eminent for exact and thorough researches of this kind, and the conclusions to which they lead are well expressed by Rothschild and Jordan :'Geographical varieties... represent various steps in the evolution of daughter-species.' And again, with special reference to the believer in discontinuity :- 'Whoever studies the distinctions of geographical varieties closely and extensively, will smile at the conception of the origin of species per saltum.' 2

Nor is there any reason to wonder at the confidence felt by these naturalists. It is explained on pp. 50-4 of this work how it is that the evolution which has occurred in time is preserved in the distribution of certain species in space. Bateson's observations lead him to certain conjectures as to what has happened in the past. The student of geograplical distribution is recording history ; and it is in the geographical distribution of varieties rather than in 'Variation' that we do indeed see, and that without the chance of failure, 'Evolution rolling out before our eyes.' 3

1 'I am convinced that the investigation of heredity by experimental methods offers the sole chance of progress with the fundamental problems of evolution.' Bateson, in Report British Association, 1904, p. 579. It must be the same restriction to a point of view which, with all its vast importance, is limited, that led Bateson to maintain, on p. 575 of the same Report, 'that the survey of terrestrial types by existing methods is happily approaching completion.' These words will sound somewhat ironical to any naturalist who has had to do with museums, and knows something of the difficulty in getting material worked out. There are unfortunately very few animal groups concerning which Bateson's statement is correct.

2 Nov. Zool., 1903, vol. x, p. 492.

3 Bateson, On Variation, p. 17. 


\section{The Subjective Element in Fudging of Discontinuity.}

The amount of discontinuity in a series of living forms cannot be inferred with safety from superficial appearances. Notwithstanding the statement of R. H. Lock, ${ }^{1}$ especial caution is necessary when the differences are those of colour. Discontinuous colour impressions are of course due to different rates of vibration in the different parts of a continuous series. The discontinuity is in ourselves, and not in the object. It is in every way probable that the chemical changes by which a pigment is transformed are excessively minute, although the impression produced on our senses is so great. A change in the colours of a butterfly's wing would doubtless appear as an important discontinuity, while a slight modification of venation in the same wing might well appear as an example of continuous evolution. And yet it is well known that a very small change in venation more truly represents specific difference than does the largest change in colour.

\section{De Vries's Evidence in Favour of Mutation.}

Although the term Mutation might just as well have been applied to evolution of any kind, even the slowest and most imperceptible, it is employed to designate a theory of modification by large and sudden steps. ${ }^{2}$ Uninstructed statements-commonly encountered just now in the press-inform the world that Natural Selection is entirely dispensed with by modern writers on Mutation

1 'Definite alterations in the colour of offspring as compared with their parents seem almost necessarily to be of this nature': viz. discontinuous. l. c., p. 124.

2 'Species arise by mutation, by a sudden step in which either a single character or a whole set of characters together become changed.' Variation, Heredity and Evolution, R. H. Lock, London, 1906, p. 144. 
and Mendelism. This is of course an error : Mutation without Selection may be left to those who desire to revive Special Creation under another name. But the error is a not unnatural outcome of the depreciatory and contemptuous tone adopted by the leader of Mendelism in this country. Passing onwards from one to another, contempt is easily translated into an open expression of disbelief, and for a little day we hear on all sides that the central thoughts of Darwin and Wallace were in vain. But even while these random assertions are being made, De Vries in Holland and Bateson in England are maintaining that Natural Selection is necessary to the theories of evolution they support-necessary indeed, but, as Bateson teaches, so commonplace as to be unworthy of investigation. ${ }^{1}$

Mutation was of course well known to Darwin. It came before him in a rather extreme but unmistakable form in that clever but discredited work, the Vestiges, and what he thought of it is clearly expressed in the Introduction to the Origin:- 'The author of the "Vestiges of Creation " would, I presume, say that, after

1 'To prove the reality of Selection as a factor in evolution is, as I have said, a work of supererogation.' Report British Association, 1904, p. 578 .

'That the dread test of Natural Selection must be passed by every aspirant to existence, however brief, is a truism which needs no special proof. Those who find satisfaction in demonstrations of the obvious may amply indulge themselves by starting various sorts of some annual, say French poppy, in a garden, letting them run to seed, and noticing in a few years how many of the finer sorts are represented.' l. c., p. 577 .

It is by no means obvious why, in any particular case, the finer sorts are supplanted. If our object is to ascertain how living things have become what they are (the problem as put by Bateson), a solution can never be attained unless the details of the selective process are studied at least as fully and thoroughly as the material which is subjected to selection. 
a certain unknown number of generations, some bird had given birth to a woodpecker, and some plant to the misseltoe, and that these had been produced perfect as we now see them; but this assumption seems to me to be no explanation, for it leaves the case of the coadaptations of organic beings to each other and to their physical conditions of life, untouched and unexplained.' 1 The modern mutationist also admits ${ }^{2}$ that adaptation is not explained by his hypothesis, but his way of dealing with this deficiency is at one time to pour contempt upon adaptation as a subject for investigation $;^{3}$ at another to assume that it is so difficult that the attempt is hardly worth a trial. ${ }^{4}$

The only important evidence adduced in favour of Mutation in Nature is to be found in the behaviour of certain Oenotheras (Evening Primroses), first studied by De Vries and subsequently by many other naturalists. ${ }^{5}$ Oenothera lamarckiana, supposed to be an American plant introduced into Europe but unknown in the wild state in America, is the form which De Vries found to be throwing off species, as he believes them to be, in all directions. The Dutch botanist also tested about a hundred native species of varied genera, every one of which gave, as

3 Origin of Species, 1859, pp. 3,4 .

2 'Nor have we any definite light on the problem of adaptation. ...' Bateson, l. c., p. $5^{87}$.

${ }^{3}$ See p. xviii n. I.

4 On Variation, W. Bateson, London, r894, pp. ro-13.

${ }^{5}$ The latest memoirs are (I) Mutations, Variations, and Relationships of the Oenotheras by D. T. Macdougal, A. M. Vail and G. H. Shull, Carnegie Institution of Washington, 1907. A full list of publications is appended: pp. 9I-2; (2) On the Variations of the Evening Primrose by G. A. Boulenger, F.R.S., Journal of Botany, October, 1907. A good general account will be found in R. H. Lock's Variation, Heredity and Evolution, London, 1906, chapter v. 
regards 'real mutability', a negative result. ${ }^{1}$ The lethargy of the Dutch plants, contrasted with the volcanic energy of the American, appears to have wounded De Vries's national pride so sharply that he felt bound to meet the situation with a hypothesis which gave promise of equal powers to his compatriots. He found comfort in the startling speculation 'that species are subject to comparatively short periods of mutability which recur at relatively long intervals, and that all the species he examined except the $E$ nothera were in this intermediate stable period of their existence '. ${ }^{2}$

It would be interesting and probably amusing to hear the words with which a speculative edifice equally vast, on a foundation equally insecure, if such were possible, would be assailed by the leader of Mutation in England, had it been erected in relation to continuous evolution.

The comparison between the other plants and the Oenothera did not apparently lead De Vries to conjecture that there might be something wrong with the latter, even though the original wild plant was unknown. 'It is unfortunate,' as R. H. Lock remarks, 'from the point of view of de Vries' interpretation of this case that the behaviour of $O$. Lamarckiana should suggest in some respects, as Bateson has pointed out, the phenomena of hybridization.' ${ }^{3}$ The supposed fact 'that the species appears to exhibit the same phenomenon in other localities' ${ }^{4}$ is, however, brought forward by Lock in support of De Vries's hypothesis. Well, the form O. lamarckiana

${ }^{1}$ Hugo De Vries, Species and Varieties, London, 1905, p. 520.

${ }^{2}$ R. H. Lock, l. c., p. 140 . Lock adds somewhat laconically, 'Direct proof of this suggestion is naturally out of the question.' By a printer's error the word 'stable' in the above-quoted passage appears as 'staple' in the original.

\footnotetext{
8. l. c., p. 278.

4 Ibid.
} 
has been studied at Ia Garde St. Cast, on the coast of Brittany, in 1899,1904 , and 1907 by G. A. Boulenger, F.R.S., and also by Mr. Charles Bailey at St. Anne's-onthe-Sea, North Lancashire, and neither of these naturalists finds the same phenomenon exhibited, although the latter observer appears to have discovered about two of De Vries's 'species'. Boulenger's conclusions are quoted in full in the following paragraph :-

'To sum up, I would suggest the possibility of the Mutations-theorie being based on false premisses. De Vries has assumed, without any justification, that Enothera Lamarckiana is a natural species. The fact that it was originally described from a garden flower, grown in the Paris Jardin des Plantes, and that, in spite of diligent search, it has not been discovered wild anywhere in America, favours the probability that it was produced by crossing various forms of the polymorphic E. biennis, which had previously been introduced in Europe. If it be so, and the onus probandi of the contrary rests with the mutationists, we have no evidence of mutations in the phenomenon observed by De Vries, but simply one of those cases of Mendelian disjunction of hybrids to which he was the first to call the attention of the naturalists of the present generation. The characters of several parent forms, which may, for all we know, have originated through fluctuating variation, have remained latent in some individuals of $\mathscr{E}$. Lamarckiana and reappear in different combinations, thus producing the appearance of distinct "species," each definable by several characters, springing up under our eyes.' ${ }^{1}$

In the recent work of Macdougal, Vail and Shull we are told that 'fixed hybrids constituting species were secured in combinations of $O$. lamarckiana and $O$. cru-

1 Journal of Botany, October, 1907. 
ciata'.1 Such forms (it is, I submit, extremely unsafe to speak of them as species) may, in the future, either spontaneously or under some external stimulus break up into their components, repeating the history which Boulenger believes to have occurred in O. lamarckiana itself.

As this chapter was passing through the press an interesting letter on Specific Stability and Mutation, by Sir W. T. Thiselton-Dyer, appeared in Nature. ${ }^{2}$ The author, after describing a number of Mutations which have occurred in cultivated plants, comes to the following conclusion:-'In all these cases I think we may safely infer from the persistent specific stability at the commencement of cultivation that the changes which subsequently occur would not have occurred in nature. . . . The evidence, on the other hand, that such changes follow cultural conditions as a result is simply overwhelming. ...'

\section{Mutation and the Facts of Mimicry, Ec.}

The very same ideas of Discontinuity and Mutation, the same revolt of the clay against the power of the potter, arose again and again in the interval between the appearance of the Origin and this modern revival. The formula 'before a thing can be selected it must be' had been repeated by Cope, Semper, Eimer, and many another naturalist, long before it assumed the more picturesque form given to it by Bateson :- 'The creature is beheld to be very good after, not before its creation.' ${ }^{3}$

1 Carnegie Institution of Washington, 1907, 1. c., p. 89.

2 Nov. 28, 1907, pp. 77-9.

3 Report British Association, 1904, p. 578: also on p. 577 :'Selection is a true phenomenon; but its function is to select, not to create.' 
Mutation is the importunate hypothesis, at length admitted on account of its importunity.

Darwin's view, that Selection is the paramount power in the production of species, is made very clear by his metaphor of an architect constructing a beautiful building out of the fragments of broken stone at the foot of a precipice. ${ }^{1}$ For the purposes of the controversy of the hour, a more appropriate metaphor is that of the artist. Pictorial effects could no doubt be obtained from time to time by the simple method of throwing colours at a screen : occasionally, perhaps, such 'Mutations' would be superior to anything which an artist could achieve by adding here a little and there a little to the developing picture. It would hardly be reasonable to infer from a few such successes that the proper function of the artist is merely to wait for the appropriate Mutation, and to cease producing effects by the accumulation of minute increments-in fact 'to select not to create'. The essential difficulty about the chance method is that it could never yield representations of particular objects. Now there is an important section of the organic world where the metaphor passes into reality. I refer to the countless thousands of cases in which there has been evolved on the surface of an animal a picture of some portion of its environment-the unending instances of Protective Resemblance and the still more striking examples of Mimicry.

It is as unlikely that a key could be made to fit a complicated lock by a number of chance blows upon a blank piece of metal, as that the elaborate pattern on the wings of a butterfly should have been reproduced on those of its mimic by Mutation.

It is necessary to state very prominently that the 1 Variation under Domestication, London, 1875, vol. ii, pp. 426-7. 
question of a Müllerian as against a Batesian interpretation of the facts of Mimicry (so fully discussed in the present volume) is of no importance to the present argument. The metaphor in the preceding paragraph sufficiently indicates why it is that the facts of Mimicry are themselves inconsistent with an evolution based on discontinuous variation.

I should be the last to maintain that the followers of any other subject are bound to go into the details of Cryptic Resemblance and Mimicry, and I should have been well pleased if Mendelian workers had confined themselves to the interesting and indeed exciting lines of inquiry started by Mendel. But they have by no means been content with this. R. H. Lock, in his recent work, Variation, Heredity and Evolution, ${ }^{1}$ refers to Mimicry, \&c., apparently without making himself in any way acquainted with the work that has been done in these subjects. His suggestion of alternative interpretations had been made long ago, and met long ago, as may be seen in the eighth essay in the present volume, originally published in 1898. It is well known that in the Hope Department of the Oxford University Museum a special study of Mimicry has been made and special illustrative sets of specimens brought together. I should have been only too pleased to show the material to this author, or to any other naturalist. It is not fair controversy, after utterly neglecting what has been done, to profess to sum up the evidence for Mimicry in these words : 'Several supposed examples of this phenomenon have been described in the case of different genera of tropical butterflies.' $2^{2}$

1 London, 1906.

2 R. H. Lock, 1. c., p. 51. The following statement on the subject of Protective Resemblance is also very misleading:- Examples of this 
If, instead of attempting to criticize without knowledge, R. H. Lock were to make a careful study of the subject, he would find much that bears upon his own opinions and beliefs. The influence of the organism itself upon the direction taken by Natural Selection can be clearly proved in numbers of cases. For in Mimicry the changes have often been so rapid, that we may see the finished product and the stages of its preparation living side by side, and we can safely conclude that the type of the original non-mimetic pattern determined the evolution of one mimetic likeness rather than any other.

In order to facilitate this study, I had intended to add an eleventh essay, which might serve as a guide to the most striking examples of Mimicry to be found in any large collection of butterflies. But I found that anything like an adequate introduction to the subject in butterflies alone would require a book to itself. In the meantime, until that volume appears, as it will, I hope, at no distant date, the instances mentioned in the last three essays will, if examined in any collection, give some conception of the subject. A study of the examples described in the various memoirs referred to will convey full information of the state of existing knowledge, but such a task would be an arduous one.

If believers in Mutation will do me the honour not to accept my statements of mimetic resemblance, but will merely use them as a guide to the species themselves, I have no doubt that they will recognize some of the difficulties in the way of an interpretation based on a hypothesis of discontinuous evolution. Reversing the order of discovery, the study should begin with the

kind in which the shape of an animal leads to its concealment are comparatively infrequent, although a considerable number might be collected, (1. c., pp. 50-r). 
Ethiopian Region, and, proceeding through the Oriental and Australian, reach its final culmination in the astonishingly complex associations and the wonderful resemblances, perfect in the minutest details, of the Neotropical Region.

Confidence in the theory of Gravitation is, I believe, founded on indirect evidence. A continually widening knowledge of the systems and movements of the Cosmos remains ever consistent with the theory. The knowledge itself will always be of the deepest interest, even if Gravitation should ultimately be refuted or extended out of recognition. So, to compare small things with great, is it with the theory of Natural Selection and the evidence of Mimicry. The great mimetic combinations of the various degrees-grouped like planets and satellites round centres of primary and secondary importance-sweep along the path of Evolution, just as the gravitational systems drift through space, without disturbing their internal relationships. A rapidly-increasing knowledge of the mimetic systems still remains consistent with Natural Selection, and, whatever be the fate of this great theory, the facts must always be interesting in a high degree. And as to the ultimate fate of the theory we may use with far greater confidence than in 1859 the words with which Darwin sent the Origin of Species to Asa Gray:- 'I cannot possibly believe that a false theory would explain so many classes of facts as I think it certainly does explain. On these grounds I drop my anchor, and believe that the difficulties will slowly disappear.' 1

\section{Mendelism and Natural Selection.}

The relationship of Natural Selection to this recentlyknown discovery will, I think, appear most clearly by the

${ }^{1}$ Life and Letters of Charles Darwin, London, 1887 , vol. ii, p. 217. 
discussion of a single case. Its consideration will also serve to show the wide divergence between the true bearing of the discovery itself and the claims of Mendelians.

'The thrum-eyed condition of the primrose has been shown by Bateson and Gregory to be a Mendelian dominant to the pin-eyed condition, so that we have here the solution, so far as solution is possible, of a biological problem to which Darwin devoted the greater part of a volume.' 1

Let us inquire what Darwin did achieve in the pages referred to; for Lock only leads his readers to infer that the great naturalist failed to find a solution.

I. In the first place, Darwin examined not only the primrose, but all the heterostyled plants of which he could obtain specimens, paying special attention to such points as the diameter of the pollen-grains, the structure of the stigma, \&c. For he would by no means accept differences in length of stamen and pistil alone as sufficient evidence of the heterostyled condition.

2. After proving that the plants were truly heterostyled, he showed in all available species, by numbers of laborious experiments, that one form of a heterostyled plant is only fully fertilized by pollen from an individual of the other form (or one of the other forms in the case of trimorphic heterostyled plants).

3. He proved that when the stigma receives pollen from a form the same as its own, together with pollen from the other form, the latter is prepotent.

4. As regards some of the species, he proved, by covering with a net, that the visits of insects are necessary

${ }^{1}$ R. H. Lock, Variation, Heredity and Evolution, London, 1906, p. 201. Darwin's volume referred to is Different Forms of Flowers (London, 1877 ). 
for fertilization. As regards some he showed the proportion in which the different forms exist in the wild state in various localities.

5. He proved in many species that when a plant was artificially fertilized by pollen from the same form, that form immensely preponderated in the offspring.

6. Such a union as that last described, which he called 'illegitimate', never yielded the full number of offspring. From these facts he reached the following conclusion given in his own words: 'The results of crossing such flowers in an illegitimate manner, I believe to be very important, as bearing on the sterility of hybrids ; although these results have been noticed by only a few persons.' ${ }^{1}$

7. Incidentally he produced much evidence that the primrose, cowslip, and Bardfield oxlip are true species, and that the common oxlip is a hybrid between the cowslip and the primrose, the latter investigation involving many crossing experiments.

8. Finally, he concluded with an extraordinarily interesting and illuminating discussion on the distribution of heterostyled species throughout the families of plants, on the advantages of the heterostyled condition as compared with other methods of securing cross-fertilization, and on the steps by which plants may have become heterostyled.

This last part of Darwin's great memoir is a conspicuous example of the reasoning so severely condemned by W. Bateson in his work on Variation. ${ }^{2}$ I have now summed up, far too briefly, the main results to the exposi-

${ }^{1}$ Life and Letters of Charles Darwin, London, 1887, vol. i, p. 97. Certain aspects of this question are discussed on pp. 90-4 of the present volume.

${ }^{2}$ Materials for the Study of Variation, London, r 894, pp. 10-13. See also parts of the Preface to that book. 
tion of. which 'Darwin devoted the greater part of a volume' - in fact the whole volume up to p. 277 , the last page being 345 . Of the great central discovery he says in his Autobiography: 'I do not think anything in my scientific life has given me so much satisfaction as making out the meaning of the structure of these plants '; ${ }^{1}$ and again, a few pages later: 'No little discovery of mine ever gave me so much pleasure as the making out the meaning of heterostyled flowers.' 2

And now what have Bateson and Gregory done that makes their work the only possible solution of the problem upon which Darwin made all these fruitful investigations?

Mendel published his discovery in 1866 , but it was ' entirely lost sight of until the same facts were independently rediscovered in 1899 by de Vries working in Holland, by Correns in Germany, and by Tschermak in Austria '. ${ }^{3}$ Bateson and Gregory in England then applied the rediscovery to the characters upon which depend the heterostyled condition of the primrose. In Lock's triumphant statement quoted on p. xxvii we are told that in the result the thrum-eyed condition (stamens high up, pistil short) was a Mendelian dominant to the pineyed condition (stamens low down, pistil long). ${ }^{4}$ Accepting this account, what does it amount to? Beginning with two parents, one thrum-eyed and one pin-eyed, the next or second generation would have the appearance of thrum-eyed. Breeding these together, a quarter of the

'Life and Letters, vol. i, p. 91.

${ }^{2}$ Ibid., vol, i, p. 97.

${ }^{3}$ R. H. Lock, l. c., pp. 1 78-9.

- This, however, is not Bateson's own account of his result; for he says:- 'It is doubtful if "thrum" ever breeds true, as both the other types can do .... The third type here referred to is the mid-styled or intermediate condition. See Report British Association, 1904, p. $586 \mathrm{n}$. 
third generation would be pure thrum-eyed, and bred together for any number of generations would yield no other form; another quarter would similarly be pure pineyed, while the remaining half would have the appearance of thrum-eyed, but when tested by breeding would behave in the same manner as the second generation. Pursuing this process to infinity, if it were possible to do so, ${ }^{1}$ we should be confronted by two sets of individuals equal in number, one thrum-eyed, the other pin-eyed. The word 'dominant', then, only means that the individuals which in each generation contain both conditions, the individuals whose offspring will in the course of future generations divide themselves equally between the two camps -that these have the superficial appearance of one condition alone, and that the thrum-eyed. The pineyed condition, equally present, as is proved by breeding, but not superficially evident, is called ' recessive'.

'Dominant,' then, implies no permanent superiority, but describes a superficial appearance which analysis proves to be misleading.

It has been necessary to say all this, although often said before; because it is important to explain as clearly as possible what is the nature of the 'solution' at which, accepting Lock's account, Bateson and Gregory have arrived. And it is desirable that this knowledge should be available for those who have not studied the elements of Mendelism as well as for those who have.

What does the 'solution' amount to? Merely this, -the knowledge that the two conditions 'thrum-eye' and 'pin-eye', so far as they follow Mendelian laws, do

${ }^{1}$ In this particular example there is little doubt that the experiment would soon come to an end. Darwin's results, as stated in 6 on p. xxviii, indicate that it would be impossible to produce many generations by 'illegitimate' unions. 
not combine in successive generations, but may be shown by an appropriately arranged experiment gradually to become divided between two groups of individuals. Existing information as to the occurrence of these two forms in Nature is given an arithmetical precision we did not possess before; furthermore we are led back to a fascinating picture of the distribution of the antecedents of 'thrum-eye' and 'pin-eye' among the germ-cells, and of their unions in fertilization.

In order to do justice to Mendel and because of the value and interest of the inference, it is necessary to explain in few words and as simply as possible what is the nature of this picture of events we can never hope to see with the microscope. The fertilized germ or zygote from which all the higher animals develop is a single cell of which the essential or nuclear elements are contributed equally by the two parents. It has been proved by observation that these essential parts of germ-cells (or gametes) are reduced by half as a preparation for the reception of a fresh half in fertilization or zygosis. Thus it is that the starting-point of the individual is a single cell and not a double cell. What Van Beneden and others have seen with the microscope in the gamete and the fertilized germ, Mendel's discovery enables the mind to see in the material germinal basis of certain single hereditary characters. Here, too, the material precursor of a character at the starting-point of the individual is made up of two parts, the allelomorphs, one from each parental gamete. In the case of yellow and green cotyledoned peas originally investigated by Mendel, we may call the allelomorphs of the yellow character and the green character respectively $\mathrm{Y}$ and $\mathrm{G}$. In the first cross between a pure yellow and a pure green pea it is obvious that all the gametes of the one parent would carry $\mathrm{Y}$ and 
all those of the other G. In fertilization therefore $G$ must unite with $\mathrm{Y}$ and the fertilized ovum must contain YG. The germ, containing the two different allelomorphs of such a pair of Mendelian characters, is called a heterozygote. All the peas produced by these heterozygotes were superficially indistinguishable from the pure yellow parent. Yellowness of the cotyledon is therefore dominant over greenness. In the development of the germ-cells (gametes) from which the next generation will arise it is obvious that the precursors of the Mendelian characters in question can only be represented by half of what they will become after fertilization. This might be effected by each gamete coming to possess in the course of its development both $\mathrm{Y}$ and $\mathrm{G}$ of half the normal size; or it might be brought about by each gamete possessing either $Y$ or $G$, but never both. Mendel proved that the facts (in characters that follow his principle) are invariably consistent with the latter alternative. For, assuming that the allelomorphs $Y$ and $G$ are thus scattered singly among the gametes produced by each individual, it follows that half the gametes will contain each a single $\mathrm{Y}$, and half each a single G. Hence in the event of self-fertilization, a gamete containing $\mathrm{Y}$ will on the average meet and unite with one containing $Y$ as often as one with $G$; and $G$ similarly will unite with $G$ as often as with $Y$. A quarter of the individuals of the following generation will therefore be developed from a fertilized germ containing YY, hence called a homozygote; another quarter from the other homozygote GG, while half will arise from the heterozygote YG. But yellowness being dominant, the latter individuals will superficially resemble those developed from YY, and the generation will produce approximately three yellow peas to one green. And this is precisely what Mendel obtained by experiment. He 
then proved by breeding further generations (I) that these green peas contain the character in a pure state and yield no other colour; (2) that one third of the yellow peas are similarly pure; (3) that the remainder or half the generation are heterozygotes, which when interbred behave in precisely the same manner as the second generation exclusively composed of heterozygotes. Continuing the process to infinity the yellows and greens would sort themselves out into two equal bodies of pure yellow and pure green respectively.

I should be the last to undervalue these results, but their true worth is not enhanced by such astonishing exaggeration as that which appears in the passage I have quoted from R. H. Lock on p. xxvii. The human mind is so constituted that a touch of megalomania is to be expected, is even to be regarded with sympathy, in the first flush of a new victory over the unknown; and I have always felt that the revelation of 'the underworld of gametes' ${ }^{1}$ by Mendel's discovery is a fascinating and arresting addition to knowledge. But to suppose that the problem of Evolution is thereby solved, or likely to be solved, is unreasonable. Lock's statement not only reveals a grotesque exaggeration of the importance of the results achieved, but also conveys the impression that the Mendelian is to some extent paralysed by the contemplation of his own work. He seems to say,'We have solved the mystery so far as it can be solved, and all that is now expected of us is to apply and apply again the Mendelian principle to one strain after another.' Such an outlook does not offer much hope of progress in solving the problem of Evolution.

'How have living things become what they are, and what are the laws which govern their forms?' These

1 Bateson, Report British Association, 1904, p. 583 . 
xxxiv MUTATION, MENDELISM, ETC.

are the words in which Bateson at the outset of his work $^{1}$ truly states the problem to be solved. Hardly any assistance in this solution is afforded by the Mendelian discovery. In the case of heterostyled plants, Darwin had already proved that both forms exist in Nature, and that in fact the offspring do arrange themselves in two groups of approximately equal numbers. The gametic explanation of this, although intensely interesting, carries us no step further on the road of Evolution. Furthermore, Darwin showed what is the meaning of the heterostyled condition in the life of the plant, and thus explained how it was that the character has been selected, and incorporated into the structure of the species. To look on this record and on that, and maintain that Darwin failed to solve the problem which the Mendelian has now solved, is, to put it as mildly as possible, unreasonable and absurd.

It is probable that the part played by Mendel's principle in evolution is limited to the prevention, in certain cases, of the supposed 'swamping effect of intercrossing'. Interbreeding between a species and its variety could not obliterate or weaken the latter when the relationship of the two forms is Mendelian. As explained on pp. xxix, $\mathrm{xxx}$, a Mendelian variety would never really fuse with the parent form, but would sooner or later emerge pure in some future generation. On the other hand, the characters of the variety, unless favoured by selection, are prevented by the same principle from penetrating the mass of the species. The average numbers of adults in successive generations remaining constant, the number of adult descendants of a new variety (with fertility equal to that of the parent species) would, unless subject to discriminative selection, remain constant also.

\section{On Variation, p. I.}


A good example of the contact between a species and subspecies is described on pp. 68,69. Such cases require investigation on Mendelian lines. If it be found that the intermediates between the two butterflies (Amauris), which are believed to interbreed on the eastern shore of the Victoria Nyanza, split up according to the Mendelian principle, it will be obvious that this principle is helpful in keeping the species and subspecies apart. It is much to be hoped that work of this kind will be undertaken in a large number of cases, selecting forms from points along the line where different geographical varieties of a species come into contact.

In the meantime the existence of abundant hybrids ${ }^{1}$ which do not immediately resolve themselves into their components throws doubt upon the extent of the application of Mendel's principle. It is probable, however, as R. H. Lock clearly explains, that the discovery will have a most important bearing upon the art of the breeder of both plants and animals. In this domain it is difficult to see how the results can fail to be as far-reaching as they will be beneficent. It must be remembered, however, that results can only be obtained when the characters obey the law of Mendel ${ }^{2}$. Beyond this the only chance of disappointment appears to lie in the possibility of the Mendelian characters proving, in the long run, to be less fixed than they are in the early series of generations.

${ }^{1}$ Such as that arising from Oenothera lamarckiana and O. cruciata; probably also $O$. lamarckiana itself (see p. xxi). Mendel concluded from his experiments that the hybrids of Hieracium reproduce themselves like true species, and Wichura obtained the same result in Salix.

2 Correns concludes that while crosses between varieties of plants do, hybrids between species do not, follow the Mendelian principle. See Variation in Animals and Plants, H. M. Vernon, London, 1903, pp. 159, 160. This work supplies an excellent introduction to the whole subject. 
xxxvi MUTATION, MENDELISM, ETC.

\section{No Essential Divergence between Mendelism and Natural Selection.}

The divergence between the Darwinian and the Mendelian has been exaggerated. Differences have been assumed that do not exist. Thus Bateson, after explaining that the blue Andalusian fowl is the heterozygote product of mating a black parent with a parent of a peculiar white, and that it splits up into the parental strains on the Mendelian principle (see pp. xxix, xxx), continues:'Selection will never make the blues breed true; nor can this ever come to pass unless a blue be found whose germ-cells are bearers of the blue character-which may or may not be possible. If the selectionist reflect on this experience he will be led straight to the centre of our problem. There will fall, as it were, scales from his eyes, and in a flash he will see the true meaning of fixation of type, variability, and mutation, vaporous mysteries no more.' 1 This is really no novelty, no falling of scales from the eyes, for we have been aware, ever since Weismann's researches and illuminating thoughts on the germ-cells, that no characters except those predetermined in the germ are available for evolution. The same calm appropriation by Bateson of Weismann's conclusions is seen in the following passage :- We can answer one of the oldest questions in philosophy. In terms of the ancient riddle, we may reply that the Owl's egg existed before the Owl. . . .' ${ }^{2}$ But the same answer was given, as the outcome of Weismann's investigations, long before the re-discovery of Mendel's work. The following statement was first made by Weismann in 1883 : 'Natural Selection, while it apparently decides between

${ }^{3}$ Report British Association, 1904, p. 579.

${ }^{2}$ Ibid., 1904, pp. 587-8. Quoted by R. H. Lock, 1. c., p. 277. 
individuals of various degrees of strength, is in truth operating upon the stronger and weaker germs.' ${ }^{1}$ I fully admit the importance of Mendel's discovery in increasing our knowledge of the constitution and relationships of germ-cells, but this by no means justifies the appropriation under his name of results which the present generation owes to Weismann. ${ }^{2}$

${ }^{1}$ Essays upon Heredity, Oxford, and ed., r891, vol. i, p. 85. The same thought is expressed in Weismann's term 'blastogenic'. It also appears in the following sentence (1. c., p. 84):-'The perfection of form of an organ does not however depend upon the amount of exercise undergone by it during the life of the organism, but primarily and principally upon the fact that the germ from which the individual arose was predisposed to produce a perfect organ.' The very same idea was published by $\mathrm{J}$. C. Prichard in 1826 , as may be seen on $\mathrm{p} .183$ of the present work, where these words occur:- '... whatever varieties are produced in the race, have their beginning in the original structure of some particular ovun or germ, ...'

${ }^{2}$ An example of the respect with which Bateson treats this great discoverer is to be found on p. 573 of his work, On Variation. Without in any way meeting the difficulty which Weismann attempted to face, without any discussion of Weismann's hypothesis, Bateson simply waves the solution aside, concluding in these words:- 'We may doubt indeed whether the ideas associated with that flower of speech, "Panmixia," are not as false to the laws of life as the word to the laws of language.' It would be interesting to know something of the height of linguistic attainment from which Bateson pours his scorn on a far greater and much older man than himself. The unscholarly use of the 'behold' of Genesis in the passage I have quoted on p. xxii throws some light on Bateson's capacity as a critic ; but however necessary it may be for him to borrow the information, he can always supply the scorn.

The absorption of the results of other workers in part explains, and is in part the outcome of, the extraordinarily exaggerated importance which is attached to the extremely interesting and valuable work of Mendel. The following statement was made by Bateson in 1904 :- 'It will aid appreciation of the change coming over evolutionary science if it be realised that the new knowledge of heredity and variation rather replaces than extends current ideas on those subjects' (Report British Association, 1904, p. 574). R. H. Lock (1.c., p. 265) also uses these words:'There can be no sort of doubt that Mendel's brief paper is the most 
There is no dispute between Darwinians and Mutationists as to the germinal origin of variation and hereditary individual difference of every kind and degree. Darwinians hold that evolution has proceeded by small steps : Mutationists hold that it has advanced by large ones. That I believe to be the sole essential difference, and the reconciliation will come when, joining hands with the student of geographical distribution, and undeterred by cheap sneers about 'ingenious persons' and 'demonstrating the obvious', Darwinians shall have proved that the relations of an organism to its environment are so accurately and elaborately adjusted that any advance by large variation is only possible as a very rare coincidence. In that day the Mutationist will discover that 'something mistakably like continuous evolution' has occurred.'

There are indications that Mutation would still be claimed as the method of evolution, even if advance by large variations were to be abandoned. Any such contention has been effectively dealt with by F. A. Dixey: - If it be replied that a well-adapted type must have arisen, not by one or more large mutations, but by a series important contribution of its size which has ever been made to biological science.' A subject is injured rather than advanced by such language. Excessive inflation naturally tends to undue depression. Mendel's principle has not yet been applied to a large number of species, and important exceptions have been already revealed. (Bateson, Report British Association, 1904, p. 581.)-Complications have appeared which are as yet imperfectly understood and have immensely increased the complexity of an explanation which appeared at first to be of singularly beautiful simplicity. The hypothetical germinal mechanism which a few years ago seemed to accommodate the facts so comfortably is already beginning to creak and groan. I am not aware that such an assertion as Lock's has ever been made for the Darwin-Wallace essay of $185^{8}$, with nearly half a century of prolific work as the firstfruits of its harvest.

1 'When the unit of segregation is small, something mistakably like continuous evolution must surely exist.' Bateson, 'in Report British Association, 1904, p. 577 n. 


\section{MUTATION AND SMALL VARIATION $x x x i x$}

of mutations both numerous and minute, we should wish to know how such mutations are to be distinguished from continuous variations. To say, with de Vries, that selection of individual differences is powerless to raise permanently the mean of a species, seems perilously like begging the question. As soon as the mean had been permanently raised, the result would be claimed as a mutation.' 1 The position is as follows. Darwin assumed that selection of minute differences would permanently raise the mean of the species. De Vries and others believe they have proved that selection of certain minute differences cannot thus raise the mean. Should this conclusion be hereafter established it is obvious that the variational material for evolution would be reinforced by no new category. The only effect would be to reduce the old category. The power which Darwin and others believed to reside in minute variations generally would be shown to exist in a part and not the whole of these. Our knowledge would be widened by the revelation of weakness in the part taken away, not by the strength of the part left behind; and there would be no justification for speaking of the variations included in the latter as Mutations.

I should have thought that Bateson, instead of urging upon us the facts we had learnt so long ago, would have had his own eyes opened by the blue Andalusian, and that he would have been driven to realize the uselessness for evolution of many a result which the breeder can attain. He might even have been led to include in the category of things valueless for the study of evolution not only composite forms which cannot be depended upon to reproduce themselves by heredity, but also the great mass of teratological phenomena-supernumerary toes and

${ }^{1}$ Nature, vol. Ixxv, 1907, April 18, p. 579. 
fingers, double hands and feet, abnormal horns, displaced appendages, etc.-which form so large a part of a work $^{1}$ whose object is to assist in solving the problem of Species. I am very far from undervaluing the study of such material, but its high importance and interest consist in the light thrown upon the development of the individual, and not upon the question as put by Bateson himself: 'How have living things become what they are, and what are the laws which govern their forms?'

Not only does the leader of Mendelism in this country appropriate the discoveries and illuminating thoughts of Weismann, but he also erroneously claims the protecting aegis of Darwin. Thus in 1904 he said: 'Darwin gave us sound teaching when he compared man's selective operations with those of Nature.' ${ }^{2}$ But this statement gives an entirely wrong impression of Darwin's views. Darwin even tells us that he was 'deceived by single variations offering such simple illustrations, as when man selects'. And from the first he had always thought the minute differences between individuals of more importance for Natural Selection and Evolution than the large, simple variations on which man relies. After reading Fleeming Jenkin's article in the North British Review for June 1867 , he concluded that the individual differences are paramount. $^{3} \quad$ I am here referring to Darwin's views, not

1 On Variation.

2 Report British Association, 1904, p. 577. The error of his leader has been repeated by $\mathrm{R}$. H. Lock only so recently as Nov. 14,1907 . In a letter to Nature of that date he writes:-

'If Dr. Archdall Reid discards Darwin's opinion, based as it was upon an unequalled experience, that domestic and natural varieties have arisen by essentially the same process, he may find himself landed among a crowd of unsuspected difficulties.'

${ }^{3}$ Darwin wrote in a letter to Wallace, dated January 22, 1869:-I always thought individual differences more important than single variations, but now I have come to the conclusion that they are of para- 
to the Fleeming Jenkin argument of the 'swamping effect of intercrossing'. There is no doubt that this argument is affected by the Mendelian discovery (see p. xxxiv). Nor is there any dispute about the vast importance of the study of Artificial Selection. The point at issue is whether Darwin considered the selection of man and that of Nature to be essentially the same process.

7. Antagonism Promoted between Studies, all of which are Needed for Attacking the Problem of Evolution.

Long before the rediscovery of the Mendelian principle, Bateson, in his work, On Variation, did his best to disparage other lines of inquiry, again and again asserting that his own study was the only one in which lay any hope of solving the problem of evolution. 'Codlin's the friend, not Short,' was the dogma rather than the advice which he issued to the world. Little effect was mount importance, and in this I believe I agree with you. Fleeming Jenkin's arguments have convinced me.' The sentence is ambiguous and was misunderstood by Wallace. Darwin wrote again on February 2 :'I must have expressed myself atrociously; I meant to say exactly the reverse of what you have understood. F. Jenkin argued in the "North British Review" against single variations ever being perpetuated, and has convinced me, though not in quite so broad a manner as here put. I always thought individual differences more important; but I was blind and thought that single variations might be preserved much oftener than I now see is possible or probable. I mentioned this in my former note merely because I believed that you had come to a similar conclusion, and I like much to be in accord with you. I believe I was mainly deceived by single variations offering such simple illustrations, as when man selects,' He also wrote on May 2, 1869, to Victor Carus :- 'I have been led... to infer that single variations are even of less importance, in comparison with individual differences, than I formerly thought.' Francis Darwin remarks concerning Fleeming Jenkin's article, 'It is not a little remarkable that the criticisms, which my father, as I believe, felt to be the most valuable ever made on his views should have come, not from a professed naturalist but from a Professor of Engineering.'

The above quotations are to be found in Life and Letlers, Lond., 1887 , vol. iii, pp. 107 and rog. See also pp. $2-4$ of the present work. 
produced until Mendel's extremely interesting discovery became known, and was in its turn proclaimed by Bateson as the only hope of evolutionary salvation. Mendel himself was evidently a modest as well as a great man, and by no means inclined to enthrone his important principle as the Juggernaut of Biological Science. It is due to the followers of Mendel that the new deity threatens to exercise a malignant influence on the study of Nature. No man is likely to continue the labours of investigation with enthusiasm and persistence when he is convinced, or even half convinced, by the overweening assurance of another that his subject is barren and useless. If such converts were likely to be added to the number of Mendelian investigators there would be some compensating gain; but men cannot always turn to entirely new lines of work, nor is the result usually satisfactory when they attempt to do so after long years at very different inquiries, pursued with very different methods. The spirit of investigation is as the wind that bloweth where it listeth. It may be possible to arrest the current of inquiry, without the power of diverting it into a fresh direction.

I should be sorry if the above remarks were considered to imply any want of sympathy with the efforts of the energetic and enthusiastic workers on Mendelian problems at Cambridge. The subject and the work itself are deserving of the warmest appreciation. I am only taking exception to the quite unnecessary depreciation of other subjects and other workers.

By a curious irony, the very department of biology that more than any other has produced classical work at Cambridge, the splendid subject of Embryology, is one of those specially selected for depreciation. And here, too, most harm is likely to be done; for a great tradition is one of the noblest and most fruitful incentives to research. 
In order, if possible, to diminish any such injurious effect, however transient, I propose to direct attention to the reason given by Bateson for dissatisfaction with Embryology as an aid in studying the problem of Species - the reason which he places in the forefront, very clearly stating it in the preface to his work, On Variation. He tells us that after working at the anatomy and development of Balanoglossus, he attempted to show the bearing of the facts upon questions of relationship and descentinvolving in this case the ancestry of the Vertebrates. He was dissatisfied with the uncertainty which must, in the present state of our knowledge, attend an attempt to solve about the most obscure and difficult problem in the whole realm of zoology. A few of the main facts concerning the past history of the Vertebrates are given on pp. 26, 30 and 3 I of the present volume. It will there be seen that the stupendous problem to which the Embryology of a living organism could not give a decisive answer, was nothing less than the reconstruction of a particular episode in the course of evolutionary history at the period when the oldest fossiliferous rocks were laid down, or probably very much earlier. For this reason the study of Embryology was to be discouraged, and Variation proclaimed as our only hope, although not one particle of evidence was brought forward to show that Variation could tell us even as much as Embryology about the ancestry of the Vertebrates in Cambrian or preCambrian times.

Bateson does not hesitate to compare his opponents to Procrustes. $^{1}$ But there is a method beside which the Procrustean is commonplace. Instead of making the observations fit the hypothesis, a more original method is to discourage the study by which awkward facts are 1 Report British Association, 1904, p. 578. 
likely to be yielded. That, in few words, is the treatment accorded by Bateson to adaptation.

\section{The Study of Adaptation Stimulates and does not Bar the Way of Inquiry.}

Professor J. B. Farmer, F.R.S., has recently maintained that the explanation which Natural Selection offers of the origin and growth of certain adaptive features in plants, not only fails to explain the phenomena, but actually stands in the way of an inquiry into the sequence of events by which they are developed in the individual. ${ }^{1}$ Such a conclusion seems to me at variance with the constitution of the human mind, and the psychology of curiosity. Any point of view which makes a set of scientific facts more interesting to man increases the probability of their forming the material of investigation. A few days ago I was passing some cases

1 Presidential Address to Botanical Section of British Association, 1907. I refer to the following passages:-

'... I would venture to express the opinion that much real harm is done by the toleration of an uncritical habit of mind, all too common, as to the significance of structures which are regarded as adaptive responses to stimuli of various sorts. It is not enough to explain the appearance of a structure on the ground of its utility ; properly speaking, such attempts, so far from providing any explanation, actually tend to bar the way of enquiry just where scientific investigation ought to commence.'

- That many of the responses to such stimuli are of a kind to render the organism "adapted" to its environment no one, of course, will dispute; but to put forward the adapledness as an explanation of the process is both unscientific and superficial. The size and the spherical shape of duckshot are admirably adapted to the purposes for which duckshot is used; but this affords no insight into the necessary sequence of cause and effect, which makes the melted lead assume the characters in question as it falls down the shot-tower.'

'But many people still find consolation and satisfaction in an anthropomorphic and somewhat slipshod application of a kind of doctrine of free-will to matters that really call for rigorous examination into the causes which, under given conditions, must inevitably and of necessity bring about their definite result,' Report, pp. 675-6. 
of Oriental butterflies and moths which had been exposed to light for a long period of years. I noticed that the pigments of the moths had as a whole faded far more than those of the butterflies. ${ }^{1}$ It at once occurred to me that stable pigments are far more necessary for the butterfly exposed to the light of a tropical sun, than for the moth flying in the evening or at night. Hence a much higher level of stability would be selected in the pigments of butterflies than in those of moths. Professor Farmer would of course maintain that this is one of the 'teleological explanations that really explain nothing, but rather bar the way of scientific inquiry' (see p. 74 n. 2 of the present work). I, on the contrary, believe that it explains a great deal. It explains the reason why pigments with particular qualities were selected, and have now come to be characters of certain species. It does not pretend to explain how it was that pigments with these qualities were there to be selected; but, so far from barring the way, this suggestion actually points the road to scientific inquiry. As a matter of fact, a further investigation into the chemical nature of these pigments, and the steps by which they arise in the individual, is now more probable than it was before the suggestion was made. It is precisely the same with regard to the example brought forward by Professor Farmer in his Address (p. 676):-'One of the commonest responses to the stimulus of wounding, in the higher plants, is the formation of a layer of cork over the injured and exposed tissue. No one can deny that this is a reaction of great utility, checking as it does the undue evaporation of water, and the entrance of other parasitic organisms. And yet I suppose that no one would go so far as to seriously

${ }^{1}$ Confirmatory evidence was afforded by the condition of the dayflying moths and the shade-loving and crepuscular butterflies. 
maintain that the obviousness of these advantages satisfactorily explains why the cork layer is produced.' On the contrary, these advantages, if scientifically proved to be conferred, probably do explain why it is that the power of forming cork was selected, and has come to be a character of the higher plants. They do not explain how the layer is formed ; but, so far from barring the way, it is quite clear that the proof of important advantages conferred adds immensely to the interest of the cork, and greatly increases the probability of the student undertaking an investigation into the sequence of events by which it is produced in the individual plant.'

The attempts to answer the questions 'Why' and 'How'- 'To what end?' and 'In what way?'-by no means interfere with each other. These two sides of investigation, on the contrary, provide mutual assistance and encouragement. There are always these two questions to be answered with reference to any natural phenomenon, and both must be answered if the facts are to be fully understood. Any one who is foolish enough to maintain that the answer to one of these questions

${ }^{1}$ My friend Professor S. H. Vines, F.R.S., has kindly drawn my attention to the following interesting and relevant passages from Whewell's History of the Inductive Sciences (vol. iii, $3^{\text {rd }}$ edition, p. 390):- 'Cuvier's merit consisted, not in seeing that an animal cannot exist without combining all the conditions of its existence; but in perceiving that this truth may be taken as a guide in our researches concerning animals:- that the mode of their existence may be collected from one part of their structure, and then applied to interpret or detect another part.' This bears out the argument that knowledge of the use or purpose of a structure or a property acts as a stimulus to investigation.

Furthermore, in his Philosophy of the Inductive Sciences, Whewell says (vol. ii, p. 78), 'The idea of a Final Cause is an essential condition in order to the pursuing our researches respecting organized bodies.' Again (p. 90), 'The doctrine of a purpose in organization has been sometimes called the doctrine of the Conditions of Existence.' 
provides also the answer to the other, deserves criticism; but it is irrelevant to criticize the aim of an inquiry because of the mistaken views of the inquirer.

Every scientific man will agree that careless and slipshod work must be discouraged; and it will probably be admitted that the study of adaptation, unless undertaken in a spirit of rigid self-criticism, is especially likely to produce an unsatisfactory result. But who is so much interested as the serious student of adaptation in keeping the subject at a high scientific level ? The most notable protest $^{1}$ against facile speculation based on Natural Selection that has ever appeared in this country was written by so thorough a Darwinian as Sir William Thiselton-Dyer, and it is hardly necessary to state that it was the work and not the subject that he criticized. The younger men who have devoted themselves to the problems of adaptation under my guidance would be the last to say that they have found the road of investigation a broad and easy one. And, when the necessary precautions are taken, there is no more fruitful study in Biological Science than the one which we owe to the central discovery of Darwin and Wallace.

\section{The Motive Force of Investigation.}

These attempts to disparage one subject and exalt another naturally raise the question, 'Why do we investigate at all ?' It was by curiosity, as I have heard Sir Michael Foster say, that our first parents lost the Garden of Eden; but, in transmitting this same curiosity to their descendants, they gave us a golden bridge by which we may re-enter Paradise. The ultimate justification of all scientific research is, 'I do it because it interests me: I want to find out.' Any further motive-the well-being

${ }^{1}$ The article Deductive Biology in Nature, vol. xxvii, 1883, pp. 554-5. 
of humanity, the pursuit of gain, the gratification of ambition-only tends to bias and mar the inquiry. We want to know why. That is all. Whither the knowledge we accumulate is tending no one can tell. One of the greatest men of all time said that we are like children picking up shells on the shore of the ocean. A realization of the truth of the saying might save us from carrying the likeness still further, by quarrelling over our little collections.

For myself and my own work I should greatly prefer to have said nothing, or only to have used words suggested by the old-world reply to the fears of the timid and the inexperienced:- 'The sun-darkening cloud of arrows is much less deadly than it looks : no great harm will be done : in the meantime we can fight all the better in the shade.' But this comfortable course is shut out, and that for two reasons-because of an immeasurable debt due to the past, because of heavy responsibilities incurred for the future.

Naturalists who are striving to carry on, however imperfectly, a great tradition, can neglect the attempt to depreciate their own work, but they cannot be indifferent to an attack which falls on those who created the tradition -on the founders of modern Biological Science. As for the future, the thoughts of Darwin and Wallace are potent as ever to inspire and direct the labours of the young biologist. I do not speak without knowledge; for many a student of nature has come to me for guidance, and I have not directed them in vain to this source. Not without the strongest protest shall the work which has meant, and still means, so much to them be assailed by the unscientific and, I must add, the unworthy weapon of contempt. 


\section{A NATURALIST'S CONTRIBUTION}

\section{TO THE DISCUSSION UPON}

\section{THE AGE OF THE EARTH}

The Presidential Address read to the Zoological Section of the British Association, September 17,1896 . Reprinted from the Report of the Meeting of the Association held at Liverpool, r 896, p. 808.

Revised: additional footnotes and terminal note.

A VERy brief study of the proceedings of this Section in bygone years will show that Presidents have exercised a wide choice in the selection of subjects. At the last Meeting of the Association in this City in 1870 the Biological Section had as its President the late Professor George Rolleston, a man whose remarkable personality made a deep impression upon all who came under his influence, as I have the strongest reason for remembering, inasmuch as he was my first teacher in zoology, and I attended his lectures when but little over seventeen. His address was most characteristic, glancing over a great variety of subjects, literary as well as scientific, and abounding in quotations from several languages, living and dead. A very different style of address was that delivered by the distinguished zoologist who presided over the Meeting. Professor Huxley took as his subject The History of the Rise and Progress of a Single Biological Doctrine.

Of these two types I selected the latter as my example, and especially desired to attempt the discussion, however inadequate, of some difficulty which confronts the zoologist at the very outset, when he begins to reason from the facts around him, a difficulty which is equally obvious and of equal moment to the highly trained investigator and the man who is keenly interested in the results obtained by others, but cannot himself lay claim to the position and 
authority of a skilled observer-to the naturalist and to one who follows some other branch of knowledge, but is interested in the progress of a sister science.

Two such difficulties were alluded to by Lord Salisbury in his interesting Presidential Address to the British Association at Oxford in 1894 , when he spoke of 'two of the strongest objections to the Darwinian explanation' of evolution-viz. the theory of Natural Selection-as appearing 'still to retain all their force'. The first of these objections was the insufficiency of the time during which the earth has been in a habitable state, as calculated by Lord Kelvin and Professor Tait, one hundred million years being conceded by the former, but only ten million by the latter. Lord Salisbury quite rightly stated that, for the evolution of the organic world as we know it, by the slow process of Natural Selection, at least many hundred million years are required; whereas, 'if the mathematicians are right, the biologists cannot have what they demand. ... The jelly-fish would have been dissipated in steam long before he had had a chance of displaying the advantageous variation which was to make him the ancestor of the human race.'

The second objection was that 'we cannot demonstrate the process of Natural Selection in detail; we cannot even, with more or less ease, imagine it'. 'In Natural Selection who is to supply the breeder's place?' 'There would be nothing but mere chance to secure that the advantageously varied bridegroom at one end of the wood should meet the bride, who by a happy contingency had been advantageously varied in the same direction at the same time at the other end of the wood. It would be a mere chance if they ever knew of each other's existence-a still more unlikely chance that they should resist on both sides all temptations to a less advantageous alliance. But unless they did so the new breed would never even begin, let alone the question of its perpetuation after it had begun.'

Professor Huxley, in seconding the vote of thanks to the President, said he could imagine that certain parts of the address might raise a very good discussion 
in one of the Sections, and I have little doubt that he referred to these criticisms and to this Section. When I had to face the duty of preparing this address, I could find no subjects better than those provided by Lord Salisbury.

At first the second objection seemed to offer the more attractive subject. It was clear that the theory of Natural Selection as held by Darwin was misconceived by the speaker, and that the criticism was ill-aimed. Darwin and Wallace, from the very first, considered that the minute differences which separate individuals were of far more importance than the large single variations which occasionally arise - Lord Salisbury's advantageously varied bride and bridegroom at opposite ends of the wood. In fact, after Fleeming Jenkins criticisms in the North British Review for June, 1867, Darwin abandoned these large single variations altogether. Thus he wrote in a letter to Wallace (February 2, 1869): 'I always thought individual differences more important; but I was blind, and thought single variations might be preserved much oftener than I now see is possible or probable. I mentioned this in my former note merely because I believed that you had come to a similar conclusion, and I like much to be in accord with you.' ${ }^{1}$ Hence we may infer that the other great discoverer of Natural Selection had come to the same conclusion at an even earlier date. But this fact removes the whole point from the criticism I have just quoted. According to the Darwin-Wallace theory of Natural Selection, individuals sufficiently advantageously varied to become the material for a fresh advance when an advance became necessary, and at other times competent to maintain the ground previously gainedsuch individuals existed not only at the opposite ends of the wood, but were common enough in every colony within its confines. The mere fact that an individual had been able to reach the condition of a possible bride or bridegroom would count for much. Few will dispute that such individuals 'have already successfully 
run the gauntlet of by far the greatest dangers which beset the higher animals [and, it may be added, the lower animals also]-the dangers of youth. Natural Selection has already pronounced a satisfactory verdict upon the vast majority of animals which have reached maturity.' 1

But the criticism retains much force when applied to another theory of evolution by the selection of large and conspicuous variations, a theory which certain writers have all along sought to add to or substitute for that of Darwin. Thus Huxley from the very first considered that Darwin had burdened himself unnecessarily in rejecting per saltum evolution so unreservedly. ${ }^{2}$ And recently this view has been revived by Bateson's work on variation and by DeVries' researches on Oenother a lamarckiana. I had at first intended to attempt a discussion of this theory, together with Lord Salisbury's and other objections which may be urged against it; but the more fully the two were considered, the more pressing became the claims of the criticism alluded to at first-the argument that the history of our planet does not allow sufficient time for a process which all its advocates admit to be extremely slow in its operation. I select this subject because of its transcendent importance in relation to organic evolution, and because I hope to show that the naturalist has something of weight to contribute to the controversy which has been waged intermittently ever since Lord Kelvin's paper On Geological Time ${ }^{3}$ appeared in 1868 . It has been urged by the great worker and teacher who occupied the Presidential Chair of this Association when it last met in Liverpool that biologists have no right to take part in this discussion. In his Anniversary Address to the Geological Society in 1869 Huxley said: 'Biology takes her time from geology.

1 Poulton, Colours of Animals, p. 308.

2 See his letter to Darwin, November 23, 1859: Life and Letters, vol. ii.

${ }^{3}$ Trans. Geol. Soc., Glasgow, vol. iii. See also On the Age of the Sun's Heat, Macmillan, March, 1862 : reprinted as Appendix to Thomson and Tait, Natural Philosophy, vol. i. part 2, second edition; and $O n$ the Secular Cooling of the Earth, Royal Society of Edinburgh, 1862. 
If the geological clock is wrong, all the naturalist will have to do is to modify his notions of the rapidity of change accordingly.' This contention is obviously true as regards the time which has elapsed since the earliest fossiliferous rocks were laid down. For the duration of the three great periods we must look to the geologist; but the question as to whether the whole of organic evolution is comprised within these limits, or, if not, what proportion of it is so contained, is a question for the naturalist. The naturalist alone can tell the geologist whether his estimate is sufficient, or whether it must be multiplied by a small or by some unknown but certainly high figure, in order to account for the evolution of the earliest forms of life known in the rocks. This, I submit, is a most important contribution to the discussion.

Before proceeding further it is right to point out that obviously these arguments will have no weight with those who do not believe that evolution is a reality. But although the causes of evolution are greatly debated, it may be assumed that there is no perceptible difference of opinion as to evolution itself, and this common ground will bear the weight of all the zoological arguments I shall advance to-day.

It will be of interest to consider first how the matter presented itself to naturalists before the beginning of this controversy on the age of the habitable earth. I will content myself with quotations from three great writers on biological problems-men of extremely different types of mind, who yet agreed in their conclusions on this subject.

In the original edition of the Origin of Species (1859), Darwin, arguing from the presence of trilobites, Nautilus, Lingula, \&c., in the earliest fossiliferous rocks, came to the following conclusion (pp. 306,307): 'Consequently, if my theory be true, it is indisputable that before the lowest Silurian stratum was deposited long periods elapsed, as long as, or probably far longer than, the whole interval from the Silurian age to the present day; 
and that during these vast yet quite unknown periods of time the world swarmed with living creatures.'

The depth of his conviction in the validity of this conclusion is seen in the fact that the passage remains substantially the same in later editions, in which, however, Cambrian is substituted for Silurian, while the words 'yet quite unknown' are omitted, as a concession, no doubt, to Lord Kelvin's calculations, which he then proceeds to discuss, admitting as possible a more rapid change in organic life, induced by more violent physical changes. ${ }^{1}$

We know, however, that such concessions troubled Darwin much, and that he was really giving up what his judgement still approved. Thus he wrote to Wallace on April 14, 1869: 'Thomson's views of the recent age of the world have been for some time one of my sorest troubles....'A And again, on July I 2, 1871, alluding to Mivart's criticisms, he says: 'I can say nothing more about missing links than what I have said. I should rely much on pre-Silurian times; but then comes Sir W. Thomson, like an odious spectre.'

Huxley's demands for time in order to account for pre-Cambrian evolution, as he conceived it, were far more extensive. Although in 1869 he bade the naturalist stand aside and take no part in the controversy, he had nevertheless spoken as a naturalist in 1862 , when, at the close of another Anniversary Address to the same Society, he argued from the prevalence of persistent types 'that any admissible hypothesis of progressive modification must be compatible with persistence without progression through indefinite periods' ; and then maintained that 'should such an hypothesis eventually be proved to be true...the conclusion will inevitably present itself that the Palaeozoic, Mesozoic, and Cainozoic faunae and florae, taken together, bear somewhat the same proportion to the whole series of living beings which have occupied this globe as the existing fauna and flora do to them '.

Herbert Spencer, in his article on Illogical Geology ${ }^{1}$ Sixth ed. 1872 , p. 286. 
in the Universal Review for July, I $859,{ }^{1}$ uses these words : 'Only the last chapter of the earth's history has come down to us. The many previous chapters, stretching back to a time immeasurably remote, have been burnt, and with them all the records of life we may presume they contained.' Indeed, so brief and unimportant does Herbert Spencer consider this last chapter to have been that he is puzzled to account for 'such evidences of progression as exist'; and finally concludes that they are of no significance in relation to the doctrine of evolution, but probably represent the succession of forms by which a newly upheaved land would be peopled. He argues that the earliest immigrants would be the lower forms of animal and vegetable life, and that these would be followed by an irregular succession of higher and higher forms, which 'would thus simulate the succession presented by our own sedimentary series'.

We see, then, what these three great writers on evolution thought on the subject: they were all convinced that the time during which the geologists concluded that the fossiliferous rocks had been formed was utterly insufficient to account for organic evolution.

Our object to-day is first to consider the objections raised by physicists against the time demanded by the geologist, and still more against its multiplication by the student of organic evolution; secondly, to inquire whether the present state of palaeontological and zoological knowledge increases or diminishes the weight of the threefold opinion quoted above-an opinion formed on far more slender evidence than that which is now available. And if we find the conclusion sustained, it must be considered to have a very important bearing upon the controversy.

The arguments of the physicists are three :-

First, the argument from the calculated secular change in the length of the day the most important element of which is due to tidal retardation. It has been known for a very long time that the tides are slowly increasing the

${ }^{1}$ Reprinted in his Essays, 1868, vol. i. pp. 324-76. 
length of our day. Huxley explains the reason with his usual lucidity: 'That this must be so is obvious, if one considers, roughly, that the tides result from the pull which the sun and the moon exert upon the sea, causing it to act as a sort of break upon the solid earth.' 1

A liquid earth takes a shape which follows from its rate of revolution, and from which, therefore, its rate of revolution can be calculated.

The liquid earth consolidated in the form it last assumed, and this shape has persisted until now, and informs us of the rate of revolution at the time of consolidation. Comparing this with the present rate, and knowing the amount of lengthening in a given time due to tidal friction, we can calculate the date of consolidation as certainly less than I,000 million years ago.

The argument is fallacious, as many mathematicians have shown. The present shape tells us nothing of the length of the day at the date of consolidation; for the earth, even when solid, will alter its form when exposed for a long time to the action of great forces. As Professor Perry said in a letter to Professor Tait : ${ }^{2}$ 'I know that solid rock is not like cobbler's wax, but $\mathrm{I}, 000$ million years is a very long time, and the forces are great.' Furthermore, we know that the earth is always altering its shape, and that whole coast-lines are slowly rising or falling, and that this has been true, at any rate, during the formation of the stratified rocks.

This first argument is dead and gone. ${ }^{3}$ We are, indeed, tempted to wonder that the physicist, who was looking about for reasoning by which to revise what he conceived to be the hasty conclusions of the geologist as to the age of the earth, should have exposed himself to such an obvious retort in basing his own conclusions as to its age on the assumption that the earth, which we know to be always changing in shape, has been

1 Anniversary Address to Geol. Soc. 1869.

2 Nature, January 3,1895 .

${ }^{3}$ It must not be forgotten, however, that this argument and those which follow it have done good work in modifying the unreasonable demands of geologists a quarter of a century ago. 


\section{ROTATION AND SHAPE OF THE EARTH 9}

unable to alter its equatorial radius by a few miles under the action of tremendous forces constantly tending to alter it, and having 1,000 million years in which to do the work.

With this flaw in the case it is hardly necessary to insist on our great uncertainty as to the rate at which the tides are lengthening the day.

The spectacle presented by the geologist and biologist, deeply shocked at Lord Kelvin's extreme uniformitarianism in the domain of astronomy and cosmic physics, is altogether too comforting to be passed by without remark; but in thus indulging in a friendly tu quoque, I am quite sure that I am speaking for every member of this Section in saying that we are in no way behind the members of Section $\mathrm{A}$ in our pride and admiration at the noble work which he has done for science, and we are glad to take this opportunity of congratulating him on the half-century of work and teaching-both equally fruitful-which has reached its completion in the present year [1896].

The second argument is based upon the cooling of the earth, and this is the one brought forward and explained by Lord Salisbury in his Presidential Address. It has been the argument on which perhaps the chief reliance has been placed, and of which the data-so it was believed-were the least open to doubt.

On the Sunday during the meeting of the British Association at Leeds (1890), I went for a walk with Professor Perry, and asked him to explain the physical reasons for limiting the age of the earth to a period which the students of other sciences considered to be very inadequate. He gave me an account of the data on which Lord Kelvin relied in constructing this second argument, and expressed the strong opinion that they were perfectly sound, while, as for the mathematics, it might be taken for granted, he said, that they were entirely correct. He did not attach much weight to the other arguments, which he regarded as merely offering support to the second.

This little piece of personal history is of interest, 
inasmuch as Professor Perry has now provided us with a satisfactory answer to the line of reasoning which so fully satisfied him in 1890 . And he was led to a critical examination of the subject by the attitude taken up by Lord Salisbury in I894. Professor Perry was not present at the meeting, but when he read the President's address, and saw how other conclusions were ruled out of court, how the only theory of evolution which commands anything approaching universal assent was set on one side because of certain assumptions as to the way in which the earth was believed to have cooled, he was seized with a desire to sift these assumptions, and to inquire whether they would bear the weight of such far-reaching conclusions. Before stating the results of his examination, it is necessary to give a brief account of the argument on which so much has been built.

Lord Kelvin assumed that the earth is a homogeneous mass of rock similar to that with which we are familiar on the surface. Assuming, further, that the temperature increases, on the average, $\mathrm{I}^{\circ} \mathrm{F}$. for every fifty feet of depth near the surface everywhere, he concluded that the earth would have occupied not less than twenty, nor more than four hundred, million years in reaching its present condition from the time when it first began to consolidate and possessed a uniform temperature of $7,000^{\circ} \mathrm{F}$.

If, in the statement of the argument, we substitute for the assumption of a homogeneous earth an earth which conducts heat better internally than it does towards the surface, Professor Perry, whose calculations have been verified by $\mathrm{Mr}$. O. Heaviside, finds that the time of cooling has to be lengthened to an extent which depends upon the value assigned to the internal conducting power. If, for instance, we assume that the deeper part of the earth conducts ten times as well as the outer part, Lord Kelvin's age would require to be multiplied by fifty-six. Even if the conductivity be the same throughout, the increase of density in the deeper part, by augmenting the capacity for heat of unit volume, implies a longer age than that conceded 
by Lord Kelvin. If the interior of the earth be fluid or contain fluid in a honeycomb structure, the rate at which heat can travel would be immensely increased by convection currents, and the age would have to be correspondingly lengthened. If, furthermore, such conditions, although not obtaining now, did obtain in past times, they will have operated in the same direction.

Professor Tait, in his letter to Professor Perry (published in Nature of January 3, I895), takes the entirely indefensible position that the latter is bound to prove the higher internal conductivity. The obligation is all on the other side, and rests with those who have pressed their conclusions hard and carried them far. 'These conclusions have been, as Darwin found them, one of our 'sorest troubles'; but when it is admitted that there is just as much to be said for another set of assumptions leading to entirely different conclusions, our troubles are at an end, and we cease to be terrified by an array of symbols, however unintelligible to us. It would seem that Professor Tait, without, as far as I can learn, publishing any independent calculation of the age of the earth, has lent the weight of his authority to a period of ten million years, or half of Lord Kelvin's minimum. But in making this suggestion he apparently feels neither interest nor responsibility in establishing the data of the calculations which he borrowed to infer therefrom a very different result from that obtained by their author.

Professor Perry's object was not to substitute a more correct age for that obtained by Lord Kelvin, but rather to show that the data from which the true age could be calculated are not really available. We obtain different results by making different assumptions, and there is no sufficient evidence for accepting one assumption rather than another. Nevertheless, there is some evidence which indicates that the interior of the earth in all probability conducts better than the surface. Its far higher density is consistent with the belief that it is rich in metals, free or combined. Professor Schuster concludes that the internal electric conductivity 
must be considerably greater than the external. Geologists have argued from the amount of folding to which the crust has been subjected that cooling must have taken place to a greater depth than 120 miles, as assumed in Lord Kelvin's argument. Professor Perry's assumption would involve cooling to a much greater depth.

Professor Perry's conclusion that the age of the habitable earth is lengthened by increased conductivity is the very reverse of that to which we should be led by a superficial examination of the case. Professor Tait, indeed, in the letter to which I have already alluded, has said: 'Why, then, drag in mathematics at all, since it is absolutely obvious that the better conductor the interior in comparison with the skin, the longer ago must it have been when the whole was at $7,000^{\circ} \mathrm{F}$.: the state of the skin being as at present?' Professor Perry, in reply, pointed out that one mathematician who had refuted the tidal retardation argument ${ }^{1}$ had assumed that the conditions described by Professor Tait would have involved a shorter period of time. And it is probable that Lord Kelvin thought the same; for he had assumed conditions which would give the result - so he believed at the time-most acceptable to the geologist and biologist. Professor Perry's conclusion is very far from obvious, and without the mathematical reasoning would not be arrived at by the vast majority of thinking men.

The 'natural man' without mathematics would say, so far from this being 'absolutely obvious', it is quite clear that increased conductivity, favouring escape of heat, would lead to more rapid cooling, and would make Lord Kelvin's age even shorter.

The argument can, however, be put clearly without mathematics, and, with Professor Perry's help, I am able to state it in a few words. Lord Kelvin's assumption of an earth resembling the surface rock in its relations to heat leads to the present condition of things, namely, a surface gradient of $\mathrm{I}^{\circ} \mathrm{F}$. for every fifty feet, in 100,000,000 years, more or less. Deeper than

${ }^{1}$ Rev. M. H. Close in R. Dublin Soc., February, 1878. 
I 50 miles he imagines that there has been almost no cooling. If, however, we take one of the cases put by Professor Perry, and assume that below a depth of four miles there is ten times the conductivity, we find that after a period of $10,000,000,000$ years the gradient at the surface is still $I^{\circ} \mathrm{F}$. for every fifty feet; but that we have to descend to a depth of 1,500 miles before we find the initial temperature of $7,000^{\circ} \mathrm{F}$. undiminished by cooling. In fact the earth, as a whole, has cooled far more quickly than under Lord Kelvin's conditions, the greater conductivity enabling a far larger amount of the internal heat to escape; but in escaping it has kept up the temperature gradient at the surface.

Lord Kelvin, replying to Professor Perry's criticisms, quite admits that the age at which he had arrived by the use of this argument may be insufficient. Thus, he says, in his letter: ${ }^{1}$ 'I thought my range from 20 millions to 400 millions was probably wide enough, but it is quite possible that I should have put the superior limit a good deal higher, perhaps 4,000 instead of 400.'

The third argument was suggested by Helmholtz, and depends on the life of the sun. If the energy of the sun is due only to the mutual gravitation of its parts, and if the sun is now of uniform density, 'the amount of heat generated by his contraction to his present volume would have been sufficient to last eighteen million years at his present rate of radiation.' ${ }^{3}$ Lord Kelvin rejects the assumption of uniform density, and is, in consequence of this change, able to offer a much higher upward limit of 500 million years.

This argument also implies the strictest uniformitarianism as regards the sun. We know that other suns may suddenly gain a great accession of energy, so that their radiation is immensely increased. We only detect such changes when they are large and sudden, but they prepare us to believe that smaller accessions may be much more frequent, and perhaps a normal occurrence in the evolution

1 Nature, January 3, 1895 .

2 Newcomb's Popular Astronomy, p. 523. 
of a sun. Such accessions may have followed from the convergence of a stream of meteors. Again, it is possible that the radiation of the sun may have been diminished and his energy conserved by a solar atmosphere.

Newcomb has objected to these two possible modes by which the life of the sun may have been greatlylengthened, that a lessening of the sun's heat by under a quarter would cause all the water on the earth to freeze, while an increase of much over half would probably boil it all into steam. But such changes in the amount of radiation received would follow from a greater distance from the sun of $15 \frac{1}{2}$ per cent., and a greater proximity to him of 18.4 per cent., respectively. Venus is inside the latter limit, and Mars outside the former, and yet it would be a very large assumption to conclude that all the water in the former is steam, and all in the latter ice. Indeed, the existence of water and the melting of snow on Mars are considered to be thoroughly well authenticated. It is further possible that in a time of lessened solar radiation the earth may have possessed an atmosphere which would retain a larger proportion of the sun's heat; and the internal heat of the earth itself, great lakes of lava under a canopy of cloud for example, may have played an important part in supplying warmth.

Again we have a greater age if there was more energy available than in Helmholtz's hypothesis. Lord Kelvin maintains that this is improbable because of the slow rotation of the sun, but Perry has given reasons for an opposite conclusion.

The collapse of the first argument based on tidal retardation, and of the second based on the cooling of the earth, warn us to beware of a conclusion founded on the assumption that the sun's energy depends, and has ever depended, on a single source of which we know the beginning and the end. It may be safely maintained that such a conclusion has not that degree of certainty which justifies the followers of one science in assuming that the conclusions of other sciences must be wrong, and in disregarding the evidence brought forward by workers in other lines of research, 
We must freely admit that this third argument has not yet fully shared the fate of the two other lines of reasoning. Indeed, Professor Sir George Darwin, although not feeling the force of these latter, agrees with Lord Kelvin in regarding 500 million years as the maximum life of the sun. ${ }^{1}$

We may observe, too, that 500 million years is by no means to be despised: a great deal may happen in such a period of time. Although I should be sorry to say that it is sufficient, it is a very different offer from Professor Tait's ten million. ${ }^{2}$

In drawing up this account of the physical arguments, I owe almost everything to Professor Perry for his articles in Nature (January 3 and April 18, I 895), and his kindness in explaining any difficulties that arose. I have thought it right to enter into these arguments in some detail, and to consume a considerable proportion of our time in their discussion. This was imperatively necessary, because they claimed to stand as barriers across our path, and, so long as they were admitted to be impassable, any further progress was out of the question. What I hope has been an unbiased examination has shown that, as barriers, they are more imposing than

1 British Association Reports, 1886, pp. 514-18.

${ }^{2}$ Professor Perry has kindly sent me a few lines on the bearing of the discovery of Radium upon the problem. 'At the time when your address was delivered,' he writes, 'I thought that the sun's heat argument was the one that was most difficult to meet. But now, the discovery of Radium has disposed of it as well as the conclusions founded on conductivity. The duration of Radium itself is known to be only a few thousand years, but quantity of Radium indicates quantity of that substance, probably Uranium, whose exceedingly slow change is constantly producing Radium.

'I. The heat conductivity argument. This is completely disposed of even if Mr. Strutt has overestimated the amount of Radium in rock. Suppose only $\frac{1}{20}$ th of what he has assumed from his measurements and we have the possibility of multiplying Lord Kelvin's age by 1,000 or more.

'2. The sun's heat argument. Assume that there is Radium in the sun and this gives us almost any multiple we please to imagine of the total energy assumed by Helmholtz. We are now in a position to say that the physicist can make no calculation either as to the probable or possible age of life on the earth.' Nov. 8, 1906. 
effective; and we are free to proceed, and to look for the conclusions warranted by our own evidence. In this matter we are at one with the geologists; for, as has been already pointed out, we rely on them for an estimate of the time occupied by the deposition of the stratified rocks, while they rely on us for a conclusion as to how far this period is sufficient for the whole of organic evolution.

First, then, we must briefly consider the geological argument, and I cannot do better than take the case as put by Sir Archibald Geikie in his Presidential Address to this Association at Edinburgh in 1892.

Arguing from the amount of material removed from the land by denuding agencies, and carried down to the sea by rivers, he showed that the time required to reduce the height of the land by one foot varies, according to the activity of the agencies at work, from 730 years to 6,800 years. But this also supplies a measure of the rate of deposition of rock; for the same material is laid down elsewhere, and would of course add the same height of one foot to some other area equal in size to that from which it was removed.

The next datum to be obtained is the total thickness of the stratified rocks from the Cambrian system to the present day. 'On a reasonable computation these stratified masses, where most fully developed, attain a united thickness of not less than 100,000 feet. If they were all laid down at the most rapid recorded rate of denudation, they would require a period of seventy-three millions of years for their completion. If they were laid down at the slowest rate, they would demand a period of not less than 680 millions.'

The argument that geological agencies acted much more vigorously in past times he entirely refuted by pointing to the character of the deposits of which the stratified series is composed. "We can see no proof whatever, nor even any evidence which suggests that on the whole the rate of waste and sedimentation was more rapid during Mesozoic and Palaeozoic time than it is to-day. Had there been any marked difference in this 
rate from ancient to modern times, it would be incredible that no clear proof of it should have been recorded in the crust of the earth.'

It may therefore be inferred that the rate of deposition was no nearer the more rapid than the slower of the rates recorded above, and, if so, the stratified rocks would have been laid down in about 400 million years.

There are other arguments favouring the uniformity of conditions throughout the time during which the stratified rocks were laid down, in addition to those which are purely geological and depend upon the character of the rocks themselves. Although more biological than geological, these arguments are best considered here.

The geological agency to which attention is chiefly directed by those who desire to hurry up the phenomena of rock formation is that of the tides. But it seems certain that the tides were not sufficiently higher in Silurian times to prevent the deposition of certain beds of great thickness under conditions as tranquil as any of which we have evidence in the case of a formation extending over a large area. From the character of the organic remains it is known that these beds were laid down in the sea, and there are the strongest grounds for believing that they were accumulated along shores and in fairly shallow water. The remains of extremely delicate organisms are found in immense numbers, and over a very large area. The recent discovery, in the Silurian system of America, of trilobites, with their long delicate antennae perfectly preserved, proves that in one locality (Rome, New York State) the tranquillity of deposition was quite as profound as in any locality yet discovered on this side of the Atlantic.

There are, then, among the older Palaeozoic rocks a set of deposits than which we can imagine none better calculated to test the force of the tides; and we find that they supply evidence for exceptional tranquillity of conditions over a long period of time.

There is other evidence of the permanence, throughout the time during which the stratified rocks were 
deposited, of conditions not very dissimilar from those which obtain to-day. Thus the attachments of marine organisms, which are permanently rooted to the bottom or on the shores, did not differ in strength from those which we now find-an indication that the strains due to the movements of the sea did not greatly differ in the past.

We have evidence of a somewhat similar kind to prove uniformity in the movements of the air. The expanse of the wings of flying organisms certainly does not differ in a direction which indicates any greater violence in the atmospheric conditions. - Before the birds had become dominant among the larger flying organisms, their place was taken by the flying reptiles, the pterodactyls, and before the appearance of these we know that, in Palaeozoic times, the insects were of immense size, a dragon-fly from the Carboniferous rocks of France being upwards of two feet in the expanse of its wings. As one group after another of widely dissimilar organisms gained control of the air, each was in turn enabled to increase to the size which was best suited to such an environment, but we find that the limits which obtain to-day were not widely different in the past. And this is evidence for the uniformity in the strains due to wind and storm no less than to those due to gravity. Furthermore, the condition of the earth's surface at present shows us how extremely sensitive the flying organism is to an increase in the former of these strains, when it occurs in proximity to the sea. Thus it is well known that an unusually large proportion of the Madeiran beetles are wingless, while those which require the power of flight possess it in a stronger degree than on continental areas. This evolution in two directions is readily explained by the destruction by drowning of the winged individuals of the species which can manage to live without the power of flight, and of the less strongly winged individuals of those which need it. In the far more stormy, treeless Kerguelen Land, the whole of the known insect fauna, except two Diptera and probably a moth, is wingless.

The size and strength of the trunks of fossil trees afford, 
as Professor George Darwin has pointed out, evidence of uniformity in the strains due to the condition of the atmosphere.

We can trace the prints of raindrops at various geological horizons, and in some cases found in this country it is even said that the eastern side of the depressions is the more deeply pitted, proving that the rain drove from the west, as the great majority of our storms do to-day.

When, therefore, we are accused of uniformitarianism, as if it were an entirely unproved assumption, we can at any rate point to a large body of positive evidence which supports our contention, and the absence of any evidence against it. Furthermore, the data on which we rely are likely to increase largely, as the result of future work.

After this interpolation, chiefly of biological argument in support of the geologist, I cannot do better than bring the geological evidence to a close in the words which conclude Sir Archibald Geikie's address : 'After careful reflection on the subject, I affirm that the geological record furnishes a mass of evidence which no arguments drawn from other departments of Nature can explain away, and which, it seems to me, cannot be satisfactorily interpreted save with an allowance of time much beyond the narrow limits which recent physical speculation would concede.'

In his letter to Professor Perry, ${ }^{1}$ Lord Kelvin says:-

'So far as underground heat alone is concerned, you are quite right that my estimate was 100 million, and please remark $^{2}$ that that is all Geikie wants; but I should be exceedingly frightened to meet him now with only 20 million in my mouth.'

We have seen, however, that Geikie considered the rate of sedimentation to be, on the whole, uniform with that which now obtains, and this would demand a period of nearly 400 million years. He points out furthermore that the time must be greatly increased on account of the breaks and interruptions which occur in the series, so that we shall probably get as near an estimate as is possible from the data which are available by taking 450

'Nature, Jan. 3, 1895.

'P. L. and A., vol. ii. p. 87 . 
million years as the time during which the stratified rocks were formed.

Before leaving this part of the subject, I cannot refrain from suggesting a line of inquiry which may very possibly furnish important data for checking the estimates at present formed by geologists, and which, if the mechanical difficulties can be overcome, is certain to lead to results of the greatest interest and importance. Ever since the epoch-making voyage of the Challenger, it has been known that the floor of the deep oceans outside the shallow shelf which fringes the continental areas is covered by a peculiar deposit formed entirely of meteoric and volcanic dust, the waste of floating pumice, and the hard parts of animals living in the ocean. Of these latter only the most resistant can escape the powerful solvent agencies. Many observations prove that the accumulation of this deposit is extremely slow. One indication of this is especially convincing: the teeth of sharks and the most resistant part of the skeleton-the ear-bones-of whales are so thickly spread over the surface that they are continually brought up in the dredge, while sometimes a single haul will yield a large number of them. Imagine the countless generations of sharks and whales which must have succeeded each other in order that these insignificant portions of them should be so thickly spread over that vast area which forms the ocean floor. We have no reason to suppose that sharks and whales die more frequently in the deep ocean than in the shallow fringing seas; in fact, many observations point in the opposite direction, for wounded and dying whales often enter shallow creeks and inlets, and not uncommonly become stranded. And yet these remains of sharks and whales, although well known in the stratified rocks which were laid down in comparatively shallow water and near coasts, are only found in certain beds, and then in far less abundance than in the oceanic deposit. We can only explain this difference by supposing that the latter accumulate with such almost infinite slowness as compared with the continental deposits that these remains form an 
important and conspicuous constituent of the one, while they are merely found here and there when looked for embedded in the other. The rate of accumulation of all other constituents is so slow as to leave a layer of teeth and ear-bones uncovered, or covered by so thin a deposit that the dredge can collect them freely. Sir John Murray calculates that only a few inches of this deposit have accumulated since the Tertiary Period. These most interesting facts prove furthermore that the great ocean basins and continental areas have occupied the same relative positions since the formation of the first stratified rocks ; for no oceanic deposits are found anywhere in the latter. We know the sources of the oceanic deposit, and it might be possible to form an estimate, within wide limits, of its rate of accumulation. If it were possible to ascertain its thickness by means of a boring, some conclusions as to the time which has elapsed during the lifetime of certain species-perhaps even the lifetime of the oceans themselves-might be arrived at. Lower down the remains of earlier species would probably be found. The depth of this deposit and its character at deeper levels are questions of overwhelming interest; and perhaps even more so is the question as to what lies beneath. Long before the Challenger had proved the persistence of oceanic and continental areas, Darwin, with extraordinary foresight, and opposed by all other naturalists and geologists, including his revered teacher, Lyell, had come to the same conclusion. His reasoning on the subject is so convincing that it is remarkable that he made so few converts, and this is all the more surprising since the arguments were published in the Origin of Species, which in other respects produced so profound an effect. In speculating as to the rocks in which the remains of the ancestors of the earliest known fossils may still exist, he suggested that, although the existing relationship between the positions of our present oceans and continental areas is of immense antiquity, there is no reason for the belief that it has persisted for an indefinite period, but that at some time long antecedent to the earliest known fossiliferous rocks 'continents may have 
existed where oceans are now spread out ; and clear and open oceans may have existed where our continents now stand.' Not the least interesting result would be the test of this hypothesis, which would probably be forthcoming as the result of boring into the floor of a deep ocean ; for although, as Darwin pointed out, it is likely enough that such rocks would be highly metamorphosed, yet it might still be possible to ascertain whether they had at any time formed part of a continental deposit, and perhaps to discover much more than this. Such an undertaking might be carried out in conjunction with other investigations of the highest interest, such as the attempt to obtain a record of the swing of a pendulum at the bottom of the ocean.

We now come to the strictly biological part of our subject-to the inquiry as to how much of the whole scheme of organic evolution has been worked out in the time during which the fossiliferous rocks were formed, and how far, therefore, the time required by the geologist is sufficient.

It is first necessary to consider Lord Kelvin's suggestion that life may have reached the earth on a meteoritea suggestion which might be made the basis of an attempt to rescue us from the dilemma in which we were placed by the insufficiency of time for evolution. It might be argued that the evolution which took place elsewhere may have been merely completed, in a comparatively brief space of time, on our earth.

We know nothing of the origin of life here or elsewhere, and our only attitude towards this or any other hypothesis on the subject is that of the anxious inquirer for some particle of evidence. But a few brief considerations will show that no escape from the demands for time can be gained in this way.

Our argument does not deal with the time required for the origin of life, or for the development of the lowest beings with which we are acquainted from the first formed beings, of which we know nothing. Both these processes may have required an immensity of time; but as we know 
nothing whatever about them, and have as yet no prospect of acquiring any information, we are compelled to confine ourselves to as much of the process of evolution as we can infer from the structure of living and fossil forms-that is, as regards animals, to the development of the simplest into the most complex Protozoa, the evolution of the Metazoa from the Protozoa, and the branching of the former into its numerous Phyla, with all their Classes, Orders, Families, Genera, and Species. But we shall find that this is quite enough to necessitate a very large increase in the time estimated by the geologist.

The Protozoa, simple and complex, still exist upon the earth in countless species, together with the Metazoan Phyla. Descendants of forms which in their day constituted the beginning of that scheme of evolution which I have defined above, descendants, furthermore, of a large proportion of those forms which, age after age, constituted the shifting phases of its onward progress, still exist, and in a sufficiently unmodified condition to enable us to reconstruct, at any rate in mere outline, the history of the past. Innumerable details and many phases of supreme importance are still hidden from us, some of them perhaps never to be recovered. But this frank admission, and the eager and premature attempts to expound too much, to go further than the evidence permits, must not be allowed to throw an undeserved suspicion upon conclusions which are sound and well supported, upon the firm conviction of every zoologist that the general trend of evolution has been, as I have stated it, that each of the Metazoan Phyla originated, directly or indirectly, in the Protozoa.

The argument founded on the meteorite hypothesis would, however, require that the process of evolution went backward on a scale as vast as that on which it went forward, that certain descendants of some central type, coming to the earth on a meteorite, gradually lost their Metazoan complexity and developed backward into the Protozoa, throwing off the lower Metazoan Phyla on the way, while certain other descendants evolved all the higher Metazoan groups. Such a process would shorten 
the period of evolution by half, but it need hardly be said that all available evidence is entirely against it.

The only other assumption by means of which the meteorite hypothesis might be used to shorten the time is even more wild and improbable. Thus it might be supposed that the evolution which we believe to have taken place on this earth, really took place elsewhere-at any rate as regards all its main lines-and that samples of all the various phases, including the earliest and simplest, reached us by a regular meteoric service, which could only have attained to its culminating delivery at some time after the completion of the scheme of organic evolution. Hence the evidences which we study would point to an evolution which occurred in some unknown world with an age which even Professor Tait has no desire to limit.

If these wild assumptions be rejected, there remains the supposition that, if life was brought by a meteorite, it was life no higher than that of the simplest Protozoona supposition which leaves our argument intact. The alternative supposition, that one or more of the Metazoan Phyla were introduced in this way while the others were evolved from the terrestrial Protozoa, is hardly worth consideration. In the first place, some evidence of a part in a common scheme of evolution is to be found in every Phylum. In the second place, the gain would be small; the arbitrary assumption would only affect the evidence of the time required for evolution derived from the particular Phylum or Phyla of supposed meteoric origin.

The meteoric hypothesis, then, can only affect our argument by making the most improbable assumptions; for which, moreover, not a particle of evidence can be brought forward. ${ }^{1}$

We are therefore free to follow the biological evidence fearlessly. It is necessary, in the first place, to expand

${ }^{1}$ The arguments here set forth are only intended to oppose certain rash deductions which might be drawn from Lord Kelvin's meteoric hypothesis. They are in no way opposed to the hypothesis itself; still less do they imply that any such conclusions were ever reached by Lord Kelvin. 
somewhat the brief outline of the past history of the animal kingdom, which has already been given. Since the appearance of the Origin of Species, the zoologist, in making his classifications, has attempted as far as possible to set forth a genealogical arrangement. Our purpose will be served by an account of the main outlines of a recent classification, which has been framed with a due consideration for all sides of zoological research, new and old, and has met with general approval. Professor Lankester divides the animal kingdom into two grades, the higher of which, the Enterozoa (Metazoa), were derived from the lower, the Plastidozoa (Protozoa). Each of these grades is again divided into two sub-grades, and each of these is again divided into Phyla, corresponding more or less to the older Sub-Kingdoms. Beginning from below, the most primitive animals in existence are found in the seven Phyla of the lower Protozoan subgrade, the Gymnomyxa. Of these unfortunately only two, the Reticularia (Foraminifera) and Radiolaria, possess a structure which renders possible their preservation in the rocks. The lowest and simplest of these Gymnomyxa represent the starting-point of that scheme of organic evolution which we are considering to-day. The higher order of Protozoan life, the sub-grade Corticata, contains three Phyla, no one of which is available in the fossil state. They are, however, of great interest and importance to us as showing that the Protozoan type assumes a far higher organization on its way to evolve the more advanced grade of animal life. The first-formed of these latter are contained in the two Phyla of the subgrade Coelentera, the Porifera or Sponges, and the Nematophora or Corals, Sea-Anemones, Hydrozoa and allied groups. Both of these Phyla are plentifully represented in the fossil state. It is considered certain that the latter of these, the Nematophora, gave rise to-the higher sub-grade, the Coelomata, or animals with a coelom or body-cavity surrounding the digestive tract. This latter includes all the remaining species of animals in nine Phyla, five of which are found fossil-the Echinoderma, Gephyrea, Mollusca, Appendiculata, and Vertebrata. 
Before proceeding further, I wish to lay emphasis on the immense evolutionary history which must have been passed through before the ancestor of one of the higher of these nine Phyla came into being. Let us consider one or two examples, since the establishment of this position is of the utmost importance for our argument. First, consider the past history of the Vertebrata,- - of the common ancestor of our Balanoglossus, Tunicates, Amphioxus, Lampreys, Fishes, Dipnoi, Amphibia, Reptiles, Birds, and Mammals. Although zoologists differ very widely in their opinions as to the affinities of this ancestral form, they all agree in maintaining that it did not arise direct from the Nematophora in the lower subgrade of Metazoa, but that it was the product of a long history within the Coelomate sub-grade. The question as to which of the other Coelomate Phyla it was associated with will form the subject of one of our discussions at this meeting, and I will, therefore, say no more upon this period of its evolution, except to point out that the very question itself, 'the ancestry of Vertebrates,' only means a relatively small part of the evolutionary history of the Vertebrate ancestor within the Coelomate group. For when we have decided the question of the other Coelomate Phylum or Phyla to which the Vertebrate ancestor belonged, there remains of course the history of that Phylum or those Phyla earlier than the point at which the Vertebrates diverged, right back to the origin of the Coelomata; while, beyond and below, the wide gulf between this and the Coelentera had to be crossed, and then, probably after a long history as a Coelenterate, the widest and most significant of all the morphological intervals-that between the lowest Metazoon and the highest Protozoon-was traversed. But this was by no means all. There remains the history within the higher Protozoan sub-grade, in the interval from this to the lower, and within the lower sub-grade itself, until we finally retrace our steps to the lowest and simplest forms. It is impossible to suppose that all this history of change can have been otherwise than immensely prolonged; for it will be shown below that all the available evidence 
warrants the belief that the changes during these earlier phases were at least as slow as those which occurred later.

If we take the history of another of the higher Phyla, the Appendiculata, we find that the evidence points in the same direction. The common ancestor of our Rotifera, earthworms, leeches, Peripatus, centipedes, insects, Crustacea, spiders and scorpions, and forms allied to all these, is generally admitted to have been Chaetopodlike, and probably arose in relation to the beginnings of certain other Coelomate Phyla, such as the Gephyrea and perhaps Mollusca. At the origin of the Coelomate sub-grade the common ancestor of all Coelomate Phyla is reached, and its evolution has been already traced in the case of the Vertebrata.

What is likely to be the relation between the time required for the evolution of the ancestor of a Coelomate Phylum and that required for the evolution, which subsequently occurred, within the Phylum itself? The only indication of an answer to this question is to be found in a study of the rate of evolution in the lower parts of the animal kingdom as compared with that in the higher. Contrary, perhaps, to anticipation, we find that all the evidences of rapid evolution are confined to the most advanced of the smaller groups within the highest Phyla, and especially to the higher Classes of the Vertebrata. Such evidence as we have strongly indicates the most remarkable persistence of the lower animal types. Thus in the Class Imperforata of the Reticularia (Foraminifera) one of our existing genera (Saccamina) occurs in the Carboniferous strata, another (Trochammina) in the Permian, while a single new genus (Receptaculites) occurs in the Silurian and Devonian. The evidence from the Class Perforata is much stronger, the existing genera Nodosaria, Dentalina, Textularia, Grammostomum, Valvulina, and Nummulina all occurring in the Carboniferous, together with the new genera Archaediscus (?) and Fusilina.

I omit reference to the much-disputed Eozoon from the Laurentian rocks, far below the horizon which for 
the purpose of this address I am considering as the lowest fossiliferous stratum. We are looking forward to the new light which will be thrown upon this form in the communication of its veteran defender, Sir William Dawson, whom we are all glad to welcome.

Passing by the Radiolaria, with delicate skeletons less suited for fossilization, and largely pelagic and therefore less likely to reach the strata laid down along the fringes of the continental areas, the next Phylum which is found in a fossil state is that of the Porifera, including the sponges, and divided into two Classes, the Calcispongiae and Silicospongiae. Although the fossilization of sponges is in many cases very incomplete, distinctly recognizable traces can be made out in a large number of strata. From these we know that representatives of all the groups of both Classes (except the Halisarcidae, which have no hard parts) occurred in the Silurian, Devonian, and Carboniferous systems. The whole Phylum is an example of long persistence with extremely little change. And the same is true of the Nematophora: new groups indeed come in, sometimes extremely rich in species, such as the Palaeozoic Rugose corals and Graptolites; but they existed side by side with representatives of existing groups, and they are not in themselves primitive or ancestral. A study of the immensely numerous fossil corals reveals no advance in organization, while researches into the structure of existing Alcyonaria and Hydrocorallina have led to the interpretation of certain Palaeozoic forms which were previously obscure, and the conclusion that they find their place close beside the living species.

All available evidence points to the extreme slowness of progressive evolutionary changes in the Coelenterate Phyla, although the Protozoa, if we may judge by the Reticularia (Foraminifera), are even more conservative.

When we consider later on the five Coelomate Phyla which occur fossil, we shall find that the progressive changes were slower and indeed hardly appreciable in the two lower and less complex Phyla, viz., the Echinoderma, and Gephyrea, as compared with the Mollusca, Appendiculata, and Vertebrata. 
Within these latter Phyla we have evidence for the evolution of higher groups presenting a more or less marked advance in organization. And not only is the rate of development more rapid in the highest Phyla of the animal kingdom, but it appears to be most rapid when dealing with the highest animal tissue, the central nervous system. The chief, and doubtless the most significant, difference between the early Tertiary mammals and those which succeeded them, between the Secondary and Tertiary reptiles, between man and the mammals most nearly allied to him, is a difference in the size of the brain. In all these cases an enormous increase in this, the dominant tissue of the body, has taken place in a time which, geologically speaking, is very brief.

When glancing later on over the evolution which has taken place within the Phyla, further details upon this subject will be given, although in this as in other cases the time at our disposal demands that the exposition of evidence must largely yield to an exposition of the conclusions which follow from its study. And undoubtedly a study of all the available evidence points to the conclusion that in the lower grade, sub-grades, and Phyla of the animal kingdom evolution has been extremely slow as compared with that in the higher. We do not know the reason. It may be that this remarkable persistence through the stratified series of deposits is due to an innate fixity of constitution which has rigidly limited the power of variation; or, more probably perhaps, that the lower members of the animal kingdom were, as they are now, more closely confined to particular environments, with particular sets of conditions, with which they had to cope, and, this being successfully accomplished, Natural Selection has done little more than keep up a standard of organization which was sufficient for their needs; while the higher and more aggressive forms ranging over many environments, and always prone to encounter new sets of conditions, were compelled to undergo responsive changes or to succumb. But whatever be the cause, the fact remains, and is of importance for our argument. When the ancestor of one of the higher Phyla was associated 
with the lower Phyla of the Coelomate sub-grade, when further back it passed through a Coelenterate, a higher Protozoan, and finally a lower Protozoan phase, we are led to believe that its evolution was probably very slow as compared with the rate which it subsequently attained. But this conclusion is of the utmost importance; for the history contained in the stratified rocks nowhere reveals to us the origin of a Phylum. And this is not mere negative evidence, but positive evidence of the most unmistakable character. All the five Coelomate Phyla which occur fossil appear low down in the Palaeozoic rocks, in the Silurian or Cambrian strata, and they are represented by forms which are very far from being primitive, or, if primitive, are persistent types, such as Chiton, which are now living. Thus Vertebrata are represented by fishes, both sharks and ganoids; the Appendiculata by cockroaches, scorpions, Limulids, Trilobites, and many Crustacea; the Mollusca by Nautilus and numerous allied genera, by Dentalium, Chiton, Pteropods, and many Gastropods and Lamellibranchs; the Gephyrea by very numerous Brachiopods, and many Polyzoa; the Echinoderma by Crinoids, Cystoids, Blastoids, Asteroids, Ophiuroids, and Echinoids. It is just conceivable, although, as I believe, most improbable, that the Vertebrate Phylum originated at the time when the earliest known fossiliferous rocks were laid down. It must be remembered, however, that an enormous morphological interval separates the fishes which appear in the Silurian strata from the lower branches, grades, and classes of the Phylum in which Balanoglossus, the Ascidians, Amphioxus, and the Lampreys are placed. The earliest Vertebrates to appear are, in fact, very advanced members of the Phylum, and, from the point of view of anatomy, much nearer to man than to Amphioxus. If, however, we grant the improbable contention that so highly organized an animal as a shark could be evolved from the ancestral vertebrate in the period which intervened between the earliest Cambrian strata and the Upper Silurian, it is quite impossible to urge the same with regard to the other Phyla. It has been shown above that when these appear in the Cam- 
EARLIEST FORMS OF HIGHER PHYLA 3 I

brian and Silurian, they are flourishing in full force, while their numerous specialized forms are a positive proof of a long antecedent history within the limits of the Phylum.

If, however, we assume for the moment that the Phyla began in the Cambrian, the geologist's estimate must still be increased considerably, and perhaps doubled, in order to account for the evolution of the higher Phyla from forms as low as many which are now known upon the earth; unless, indeed, it is supposed, against the weight of all such evidence as is available, that the evolutionary history in these early times was comparatively rapid.

To recapitulate, if we represent the history of animal evolution by the form of a tree, we find that the following growth took place in some age antecedent to the earliest fossil records, before the establishment of the higher Phyla of the Animal Kingdom. The main trunk representing the lower Protozoa divided, originating the higher Protozoa; the latter portion again divided, probably in a threefold manner, originating the two lowest Metazoan Phyla, constituting the Coelentera. The branch representing the higher of these Phyla, the Nematophora, divided, originating the lower Coelomate Phyla, which again branched and originated the higher Phyla. And, as has been shown above, the relatively ancestral line, at every stage of this complex history, after originating some higher line, itself continued down to the present day, throughout the whole series of fossiliferous rocks, with but little change in its general characters, and practically nothing in the way of progressive evolution. Evidences of marked advance are to be found alone in the most advanced groups of the latest highest products-the Phyla formed by the last of these divisions.

It may be asked how is it possible for the zoologist to feel so confident as to the past history of the various animal groups. I have already explained that he does not feel this confidence as regards the details of the history, but as to its general lines. The evidence which 
leads to this conviction is based upon the fact that animal structure and mode of development can be, and have been, handed down from generation to generation from a period far more remote than that which is represented by the earliest fossils; that fundamental facts in structure and development may remain changeless amid endless changes of a more general character; that especially favourable conditions have preserved ancestral forms comparatively unchanged. Working upon this material, comparative anatomy and embryology can reconstruct for us the general aspects of a history which took place long before the Cambrian rocks were deposited. This line of reasoning may appear very speculative and unsound, and it may easily become so when pressed too far. But applied with due caution and reserve, it may be trusted to supply us with an immense amount of valuable information which cannot be obtained in any other way. Furthermore, it is capable of standing the very true and searching test supplied by the verification of predictions made on its authority. Many facts taken together lead the zoologist to believe that $\mathrm{A}$ was descended from $C$ through $B$; but if this be true, $B$ should possess certain characters which are not known to belong to it. Under the inspiration of hypothesis a more searching investigation is made, and the characters are found. Again, that relatively small amount of the whole scheme of animal evolution which is contained in the fossiliferous rocks has furnished abundant confirmation of the validity of the zoologist's method. The comparative anatomy of the higher Vertebrate Classes leads the zoologist to believe that the toothless beak and the fused caudal vertebrae of a bird were not ancestral characters, but were at some time derived from a condition more conformable to the general plan of vertebrate construction, and especially to that of reptiles. Numerous secondary fossils prove to us that the birds of that time possessed teeth and separate caudal vertebrae, culminating in the long lizard-like tail of Archaeopteryx.

Prediction and confirmation of this kind, both zoological and palaeontological, have been going on ever 
EVOLUTION WITHIN HIGHER PHYLA 33

since the historic point of view was adopted by the naturalist as the outcome of Darwin's teaching, and the zoologist may safely claim that his method, confirmed by palaeontology so far as evidence is available, may be extended beyond the period in which such evidence is to be found.

And now our last endeavour must be to obtain some conception of the amount of evolution which has taken place within the higher Phyla of the Animal Kingdom during the period in which the fossiliferous rocks were deposited. The evidence must necessarily be considered very briefly, and we shall be compelled to omit the Vertebrata altogether.

The Phylum Appendiculata is divided by Lankester into three branches, the first containing the Rotifera, the second the Chaetopoda, the third the Arthropoda. Of these the second is the oldest, and gave rise to the other two, or at any rate to the Arthropoda, with which we are alone concerned, inasmuch as the fossil records of the others are insufficient. The Arthropoda contain seven Classes, divided into two grades, according to the presence or absence of antennae ${ }^{1}$ - the Ceratophora, containing the Peripatoidea, the Myriapoda, and the Hexapoda (or insects); the Acerata, containing the Crustacea, Arachnida, and two other classes (the Pantopoda and Tardigrada) which we need not consider. The first Class of the antenna-bearing group contains the single genus Peripatus-one of the most interesting and ancestral of animals, as proved by its structure and development, and by its immense geographical range. Ever since the researches of Moseley and Balfour, extended more recently by those of Sedgwick, it has been recognized as one of the most beautiful of the connecting links to be found amongst animals, uniting the antenna-bearing Arthropods, of which it is the oldest member, with the Chaetopods. Peripatus is a magnificent example of the far-reaching conclusions of zoology, and of its superiority

1 The so-called antennae of Crustacea are developed very differently from true antennae. 
to palaeontology as a guide in unravelling the tangled history of animal evolution. Peripatus is alive to-day, and can be studied in all the details of its structure and development; it is infinitely more ancestral, and tells of a far more remote past than any fossil Arthropod, although such fossils are well known in all the older of the Palaeozoic rocks. And yet Peripatus is not known as a fossil. Peripatus has come down, with but little change, from a time, on a moderate estimate, at least twice as remote, and probably many times as remote, as the earliest known Cambrian fossil. The agencies which, it is believed, have crushed and heated the Archaean rocks so as to obliterate the traces of life which they contained were powerless to efface this ancient type, for, although the passing generations may have escaped record, the likeness of each was stamped on that which succeeded it, and has continued down to the present day. It is, of course, a perfectly trite and obvious conclusion but not the less one to be wondered at, that the force of heredity should thus far outlast the ebb and flow of terrestrial change throughout the vast period over which the geologist is our guide.

If, however, the older Palaeozoic rocks tell us nothing of the origin of the antenna-bearing Arthropods, what do they tell us of the history of the Myriapod and Hexapod Classes?

The Myriapods are well represented in Palaeozoic strata, two species being found in the Devonian and no less than thirty-two in the Carboniferous. Although placed in an Order (Archipolypoda) separate from those of living Myriapods, these species are by no means primitive, and do not supply any information as to the steps by which the Class arose. The imperfection of the record is well seen in the traces of this Class; for between the Carboniferous rocks and the Oligocene there are no remains of undoubted Myriapods.

We now come to the consideration of insects, of which an adequate discussion would occupy a great deal too much of your time. An immense number of species are found in the Palaeozoic rocks, and these are con- 
sidered by Scudder, the great authority on fossil insects, to form an Order, the Palaeodictyoptera, distinct from any of the existing Orders. The latter, he believes, were evolved from the former in Mesozoic times. These views do not appear to derive support from the wonderful discoveries of $M$. Brongniart ${ }^{1}$ in the Upper Carboniferous of Commentry in the Department of Allier in Central France. Concerning this marvellous assemblage of species, arranged by their discoverer into 46 genera and IOI species, Scudder truly says:-

' Our knowledge of Palaeozoic insects will have been increased three or four fold at a single stroke. ... No former contribution in this field can in any way compare with it, nor even all former contributions taken together'. ${ }^{2}$

When we remember that the group of fossil insects, of which so much can be affirmed by so great an authority as Scudder, lived at one time and in a single locality, we cannot escape the conclusion that the insect fauna of the habitable earth during the whole Palaeozoic period was of immense importance and variety. Our knowledge of this single group of species is largely due to the accident that coal-mining in Commentry is carried on in the open air.

Now, these abundant remains of insects, so far from upholding the view that the existing orders had not been developed in Palaeozoic times, are all arranged by Brongniart in four out of the nine Orders into which insects are usually divided, viz. the Orthoptera, Neuroptera, Thysanoptera, and Homoptera. The importance of the discovery is well seen in the Neuroptera, the whole known Palaeozoic fauna of this Order being divided into 45 genera and 99 species, of which 33 and 72 respectively have been found at Commentry.

Although the Carboniferous insects of Commentry are placed in new families, some of them come wonderfully near those into which existing insects are classified, and obviously form the precursors of these. This is true

1 Charles Brongniart. - Recherches pour servir à lhistoire des insectes fossiles des temps primaires, précédées d'une Étude sur la nervation des ailes des insectes. 1894.

2 S. H. Scudder, Am. Journ. Sci., vol. xlvii, February, 1894. Art. viii. 
of the Blattidae, Phasmidae, Acridiidae, and Locustidae among the Orthoptera, the Perlidae among the Neuroptera, and the Fulgoridae among the Homoptera. The differences which separate these existing families from their Carboniferous ancestors are most interesting and instructive. Thus the Carboniferous cockroaches possessed ovipositors, and probably laid their eggs one at a time, while ours are either viviparous or lay their eggs in a capsule. The Protophasmidae resemble living species in the form of the head, antennae, legs, and body; but while our species are either wingless or, with the exception of the female Phyllidae, have the anterior pair reduced to tegmina, useless for flight, those of Palaeozoic times possessed four well-developed wings. The forms representing locusts and grasshoppers (Palaeacridiidae) possessed long slender antennae like the green grasshoppers (Locustidae), from which the Acridiidae are now distinguished by their short antennae. The divergence and specialization which is thus shown is amazingly small in amount. In the vast period between the Upper Carboniferous rocks and the present day the cockroaches have gained a rather different wing venation, and have succeeded in laying their eggs in a manner rather more specialized than that of insects in general; the stick insects and leaf insects have lost or reduced their wings, the grasshoppers have shortened their antennae. These, however, are the insects which most closely resemble the existing species; let us turn to the forms which exhibit the greatest differences. Many species have retained in the adult state characters which are now confined to the larval stage of existence, such as the presence of tracheal gills on the sides of the abdomen. In some, the two membranes of the wing were not firmly fixed together, so that the blood could circulate freely between them. On the other hand, they are not very firmly fixed together in existing insects. Another important point was the condition of the three thoracic segments, which were quite distinct and separate, instead of being fused as they are now in the imago stage. This external difference probably also extended to the 
nervous system, so that the thoracic ganglia were separate instead of concentrated. The most interesting distinction, however, was the possession by many species of a pair of prothoracic appendages much resembling miniature wings, and which especially suggest the appearance assumed by the anterior pair (tegmina) in existing Phasmidae. There is some evidence in favour of the view that they were articulated, and they exhibit what appears to be a trace of venation. Brongniart concludes that in still earlier strata, insects with six wings will be discovered, or rather insects with six of the tracheal gills sufficiently developed to serve as parachutes. Of these, the two posterior pair developed into the wings as we know them, while the anterior pair degenerated, some of the Carboniferous insects presenting us with a stage in which degeneration had taken place but was not complete.

One very important character was, as I have already pointed out, the enormous size reached by insects in this distant period. This was true of the whole known fauna as compared with existing species, but it was especially the case with the Protodonata, some of these giant dragon-flies measuring over two feet in the expanse of the wings.

As regards the habits of life and metamorphoses, Brongniart concludes that some species of Protoephemeridae, Protoperlidae, \&c., obtained their food in an aquatic larval stage, and did not require it when mature. He concludes that the Protodonata fed on other animals, like our dragon-flies; that the Palaeacridiidae were herbivorous like our locusts and grasshoppers, the Protolocustidae herbivorous and animal feeders like our green grasshoppers, the Palaeoblattidae omnivorous like our cockroaches. The Homoptera, too, had elongated sucking mouth-parts like the existing species. It is known that in Carboniferous times there was a lake with rivers entering it, at Commentry. From their great resemblance to living forms of known habits, it is probable that the majority of these insects lived near the water and their larvae in it. 
When we look at this most important piece of research as a whole, we cannot fail to be struck with the small advance in insect structure which has taken place since Carboniferous times. All the great questions of metamorphosis, and of the structures peculiar to insects, appear to have been very much in the position in which they are to-day. It is indeed probable enough that the Orders which zoologists have always recognized as comparatively modern and specialized, such as the Lepidoptera, Coleoptera, and Hymenoptera, had not come into existence. But as regards the emergence of the Class from a single primitive group, as regards its approximation towards the Myriapods, which lived at the same time, and of both towards their ancestor Peripatus, we learn absolutely nothing. All we can say is that there is evidence for the evolution of the most modern and specialized members of the Class, and some slight progressive evolution in the rest. Such evolution is of importance as giving us some vague conception of the rate at which the process travels in this division of the Arthropoda. If we look upon development as a series of paths which, by successively uniting, at length meet in a common point, then some conception of the position of that distant centre may be gained by measuring the angle of divergence and finding the number of unions which occur in a given length. In this case, the amount of approximation and union shown in the interval between the Carboniferous Period and the present day is relatively so small that it would require to be multiplied many times before we could expect the lines to meet in the common point, the ancestor of insects, to say nothing of the far more distant past, in which the Tracheate Arthropods met in an ancestor presenting many resemblances to Peripatus. But it must not be forgotten that all this vast undefined period is required for the history of one of the two grades of one of the three branches of the whole Phylum.

Turning now to the brief consideration of the second grade of Arthropods, distinguished from the first grade by the absence of antennae, the Trilobites are probably 
the nearest approach to an ancestral form met with in the fossil state. Now that the possession of true antennae is certain, it is reasonable to suppose that the Trilobites represent an early Class of the Aceratous branch which had not yet become Aceratous. They are thus of the deepest interest in helping us to understand the origin of the antennaless branch, not by the ancestral absence, but by the loss of true antennae which formerly existed in the group. But the Trilobites did not themselves originate the other Classes, at any rate during Palaeozoic times. They represent a large and dominant Class, presenting more of the characters of the common ancestor than the other Classes; but the latter had diverged and had become distinct long before the earliest fossiliferous rocks; for we find well-marked representatives of the Crustacea in Cambrian, and of the Arachnida in Silurian strata. The Trilobites, moreover, appear in the Cambrian with many distinct and very different forms, contained in upwards of forty genera, so that we are clearly very far from the origin of the group.

Of the lower group of Crustacea, the Entomostraca, the Cirripedes are represented by two genera in the Silurian, the Ostracodes by four genera in the Cambrian and over twenty in the Silurian; of these latter, two genera (Cythere and Bairdia) continue right through the fossiliferous series and exist at the present day. Remains of Phyllopods are more scanty, but can be traced in the Devonian and Carboniferous rocks. The early appearance of the Cirripedes is of especial interest, inasmuch as the fixed condition of these forms in the mature state is certainly not primitive, and yet, nevertheless, appears in the earliest representatives.

The higher group, the Malacostraca, are represented by many genera of Phyllocarida in the Silurian and Devonian, and two in the Cambrian. These also afford a good example of the imperfection of the record, inasmuch as no traces of the group are to be found between the Carboniferous and our existing fauna in which it is represented by the genus Nebalia. The Phyllocarida 
are recognized as the ancestors of the higher Malacostraca, and yet these latter already existed-in small numbers, it is true-side by side with the Phyllocarida in the Devonian. The evolution of the one into the other must have been much earlier. Here, as in the Arthropoda, we have evidence of progressive evolution among the highest groups of the Class, as we see in the comparatively late development of the Brachyura as compared with the Macrura. We find no trace of the origin of the Class, or of the larger groups into which it is divided, or, indeed, of the older among the small groupings into families and genera. ${ }^{1}$

Of the Arachnida, although some of the most wonderful examples of persistent types are to be found in this class, but little can be said. Merely to state the bare fact that three kinds of scorpion are found in the Silurian, two Pedipalpi, eight scorpions, and two spiders in the Carboniferous, is sufficient to show that the period computed by geologists must be immensely extended to account for the development of this Class alone, inasmuch as it existed in a highly specialized condition almost at the beginning of the fossiliferous series; while, as regards so extraordinarily complex an animal as a scorpion, nothing apparent in the way of progressive development has happened since. Professor Lankester has, however, pointed out to me that the Silurian scorpion Palaeophonus possessed heavier limbs than those of existing species, and this is a point in favour of an aquatic life like that of its near relation, Limulus. If so, it is probable that it possessed external gills, not yet introverted to form the lung-book. The Merostomata are of course a Palaeozoic group, and reach their highest known development at their first appearance in the Silurian; since then they have done nothing but disappear gradually, leaving the single genus Limulus, unmodified since its first appearance in the Trias, to represent them. It is impossible to find clearer evidence

1 For an account of the evolution of the Crustacea see the Presidential Addresses to the Geological Society in 1895 and 1896 by Dr. Henry Woodward. 
of the decline rather than the rise of a group. No progressive development, but a gradual or rapid extinction, and consequent reduction in the number of genera and species, is a summary of the record of the fossiliferous rocks as regards this group and many others, such as the Trilobites, the Brachiopods, and the Nautilidae. All these groups begin with many forms in the oldest fossiliferous rocks, and three of them have left genera practically unchanged from their first appearance to the present day. "What must have been the time required to carry through the vast amount of structural change implied in the origin of these persistent types and the groups to which they belong-a period so extended that the interval between the oldest Palaeozoic rocks and the present day supplies no measurable unit ?

But I am digressing from the Appendiculate Phylum. We have seen that the fossil record is unusually complete as regards two Classes in each grade of the Arthropod branch, but that these Classes were well developed and flourishing in Palaeozoic times. The only evidence of progressive evolution is in the development of the highest orders and families of the Classes. Of the origin of the Classes nothing is told, and we can hardly escape the conclusion that for the development of the Arthropod branches from a common Chaetopodlike ancestor, and for the further development of the Classes of each branch, a period many times the length of the fossiliferous series is required, judging from the insignificant amount of development which has taken place during the formation of this series.

It is impossible to consider the other Coelomate Phyla as I have done the Appendiculata. I can only briefly state the conclusions to which we are led.

As regards the Molluscan Phylum, the evidence is perhaps even stronger than in the Appendiculata. Representatives of the whole of the Classes are, it is believed, found in the Cambrian or Lower Silurian. The Pteropods are generally admitted to be a recent modification of the Gastropods, and yet, if the fossils 
described in the genera Conularia, Hyolithes, Pterotheca, \&c., are true Pteropods, as they are supposed to be, they occur in the Cambrian and Silurian strata, while the group of Gastropods from which they almost certainly arose, the Bullidae, are not known before the Trias. Furthermore, the forms which are clearly the oldest of the Pteropods-Limacina and Spirialis-are not known before the beginning of the Tertiary Period. Either there is a mistake in the identification of the Palaeozoic fossils at Pteropods, or the record is even more incomplete than usual, and the most specialized of all Molluscan groups had been formed before the date of the earliest fossiliferous rocks. Even if this should hereafter be disproved, there can be no doubt about the early appearance of the Molluscan Classes, and that it is the irony of an incomplete record which places the Cephalopods and Gastropods in the Cambrian and the far more ancestral Chiton no lower than the Silurian. Throughout the fossiliferous series the older families of Gastropods and Lamellibranchs are followed by numerous other families, which were doubtless derived from them; new and higher groups of Cephalopods were developed, and, with the older groups, either persisted until the present time or became extinct. But in all this splitting up of the Classes into groups of not widely different morphological value, there is very little progressive modification, and, taking such changes in such a period as our unit for the determination of the time which was necessary for the origin of the Classes from a form like Chiton, we are led to the same conclusion as that which followed from the consideration of the Appendiculata, viz. that the fossiliferous series would have to be multiplied several times in order to provide it.

Of the Phylum Gephyrea, I will only mention the Brachiopods, which are found in immense profusion in the early Palaeozoic rocks and have occupied the subsequent time in becoming less dominant and important. So far from helping us to clear up the mystery which surrounds the origin of the Class, the earliest forms are 
quite as specialized as those living now, and, some of them (Lingula, Discina), even generically identical. The demand for time to originate the group is quite as grasping as that of the others we have been considering.

All the Classes of Echinoderma, except the Holothurians, which do not possess a structure favourable for fossilization, are found early in the Palaeozoic rocks, and many of them in the Cambrian. Although these early forms are very different from those which succeeded them in the later geological periods, they do not possess a structure which can be recognized as in any way primitive or ancestral. The Echinoderma are the most distinct and separate of all the Coelomate Phyla, and they were apparently equally distinct and separate at the beginning of the fossiliferous series.

In concluding this imperfect attempt to deal with a very vast subject in a very short time, I will remind you that we were led to conclude that the evolution of the ancestor of each of the higher animal Phyla probably occupied a very long period, perhaps as long as that required for the evolution which subsequently occurred within the Phylum. But the consideration of the higher Phyla which occur fossil, except the Vertebrata, leads to the irresistible conclusion that the whole period in which the fossiliferous rocks were laid down must be multiplied several times for this later history alone. The period thus obtained requires to be again increased, and perhaps doubled, for the earlier history.

In the preparation of the latter part of this address I have largely consulted Zittel's great work. I wish also to express my thanks to my friend Professor Lankester, whom I have consulted on many of the details, as well as the general plan which has been adopted.

If the facts and arguments set forth in the address to which you have done me the honour of listening be sound, the naturalist need not fear for the result of this attack upon the great theory which has been a light to his path for nearly half a century. Natural Selection will never be stifled in the Procrustean bed of insufficient geological time. 
Note.-At the time when this address was delivered I felt keenly the gap left in the argument by the absence of any statement concerning the evolution of land-plants. Since r 896 an immense amount of labour has been expended upon fossil floras, and startling conclusions as to the affinities of certain groups have been placed on a solid foundation. Now, after the lapse of ten years, it is far more possible than it was in 1896 to compare safely the evidence yielded by fossil plants with that of fossil animals. Allowing for the important difference in the length of the records - animals appearing in full force in the Cambrian, plants only in the Devonian-the two lines of evidence support precisely the same conclusion.

Professor A. C. Seward, F.R.S., in his Presidential Address to Section K (Botany) of the meeting of the British Association at Southport, in 1903, took as his subject Floras of the Past: their Composition and Distribution. He speaks of the Devonian and Lower Carboniferous plants as 'practically the oldest records of plant-life', and states that they 'lead us away from the present along converging lines of evolution to a remote stage in the history of life': the distribution of their fossil remains over the globe 'shows how widely some of the plants had migrated from an unknown centre far back in a still more remote age. We are, as yet, unable to follow these Devonian plants to an earlier stage in their evolution. We are left in amazement at their specialized structure and extended geographical distribution, without the means of perusing the opening chapters of their history'.'

During the present year my friend Dr. D. H. Scott, F.R.S., has published a valuable and comprehensive memoir on The Present Position of Palaeozoic Botany, ${ }^{2}$ setting forth the results of modern researches upon the structure and evolution of fossil plants.

Dr. Scott has most kindly provided me with the following concise summary of the history of plant evolution as set forth in the fossil record at present known to us:-

1 Report, 1903, p. 831 .

${ }^{2}$ Progressus Rei Botanicae, Jena, 1906, pp. 139-217. 
' Of the main divisions of the Vegetable Kingdom the Angiosperms alone appear to originate within the periods of which we have any adequate fossil record. They do not appear, as at present known, until late in the Mesozoic. Some affinity between them and the much more ancient Cycadophyta is indicated by the latest work.

'The other seed-plants go back certainly to the Devonian-we do not know how much further. During Palaeozoic times there was a great group of seed-plantsthe Pteridospermeae-of a relatively primitive type, showing affinity with Ferns. Most of the so-called Palaeozoic "Ferns" were really seed-bearing plants of this kind.

'But, side by side with them, and going back equally far according to present records, there were the Cordaiteae, a well characterized family of Gymnosperms comparable in many respects to the Coniferae.

'Hence the evolution of seed-plants had already reached a very advanced stage at the period to which our earliest satisfactory records of land-plants belong.

'It is thus only a very small fraction of the whole course of plant-evolution which is revealed in the fossil record.' 


\section{'WHAT IS A SPECIES?'}

The Presidential Address read at the Annual Meeting of the Entomological Society of London, January 20, 1904. Reprinted from the Proceedings of the Society, 1903, p. lxxvii.

Revised and modified: several paragraphs added and several rewrilten: addilional footnotes.

The late Professor Max Müller, in an eloquent speech delivered at Reading in $189 \mathrm{I}$, spoke of the necessity of examining, and, as time passes by, re-examining the meaning of words. He referred as an illustration to the man at the railway station who taps the wheels with his hammer, testing whether each still rings true or has undergone some change that may mean disaster. In almost the same way, the speaker maintained, a word may slowly and unobtrusively change its meaning, becoming, unless critically tested to ascertain whether it still rings true, a danger instead of an aid to clear thinking, a pitfall on the field of controversy. He then went on to say, that Darwin had written a great work upon the Origin of Species, and had never once explained what he meant by the word Species. So decided an utterance-the statement was made emphatically-ought to have involved a careful and critical search through the pages of the work that was attacked. However this may be, it is quite certain that the search was unsuccessful; and yet a few minutes' investigation brought me to a passage in which the meaning attached by the author to the term Species is set down in the clear, calm, and simple language which did so much to convince an unwilling world.

Darwin is speaking of the revolution which the acceptance of his views will bring about. 'Systematists will be able to pursue their labours as at present; but they will not be incessantly haunted by the shadowy doubt whether this or that form be in essence a species. This I feel sure, and I speak after experience, will be no slight 
relief. The endless disputes whether or not some fifty species of British brambles are true species will cease. Systematists will have only to decide (not that this will be easy) whether any form be sufficiently constant and distinct from other forms, to be capable of definition; and if definable, whether the differences be sufficiently important to deserve a specific name. This latter point will become a far more essential consideration than it is at present; for differences, however slight, between any two forms, if not blended by intermediate gradations, are looked at by most naturalists as sufficient to raise both forms to the rank of species. Hereafter we shall be compelled to acknowledge that the only distinction between species and well-marked varieties is, that the latter are known, or believed, to be connected at the present day by intermediate gradations, whereas species were formerly thus connected. Hence, without quite rejecting the consideration of the present existence of intermediate gradations between any two forms, we shall be led to weigh more carefully and to value higher the actual amount of difference between them. It is quite possible that forms now generally acknowledged to be merely varieties may hereafter be thought worthy of specific names, as with the primrose and cowslip; and in this case scientific and common language will come into accordance. In short, we shall have to treat species in the same manner as those naturalists treat genera, who admit that genera are merely artificial combinations made for convenience. This may not be a cheering prospect; but we shall at least be freed from the vain search for the undiscovered and undiscoverable essence of the term species.' I have quoted from pages 484,485 of the original edition (I 859 ), and have italicized the sentences in which Darwin defines a species and distinguishes it from a variety.

Max Müller's special criticism falls to the ground, but his general exhortation remains, and I think we shall do well to be guided by it, and attempt to apply it to this difficult and elusive word sPEciEs.

The passage I have quoted was Darwin's prediction of the meaning which would be attached to the word 'species ' 
by the naturalist of the future. Nearly half a century has passed since those words were written. For more than a generation the central ideas of the Origin have been an essential part of the intellectual equipment, not only of every naturalist, but of every moderately intelligent man. What then is the meaning of the word 'species' to-day, and how does it differ from that of the years before July I, I 858, when the Darwin-Wallace conception of Natural Selection was first launched upon the world ?

The present occasion is specially favourable for this inquiry, because we have just been given two additional volumes of the letters of Charles Darwin. After the three volumes published in 1887 , naturalists were certainly unprepared for the welcome revelation of such a mine of wealth. The work is all the more valuable because it contains many letters from Alfred Russel Wallace and Sir Joseph Hooker, thus giving both sides of a part of their correspondence with Darwin. Then in I900 the Life and Letters of Thomas Henry Huxley appeared, so that we are now admitted 'behind the veil', and can read, as never before, the central thoughts of the great makers of biological history. On the publication of the last-named work, I took occasion to combat the view that the thousand closely-printed pages might have been reduced by omitting and condensing many of the letters. The serious student of those stirring years requires the opportunity of thinking over and comparing all the available thoughts and opinions of the chief actors in the memorable scene; and the very repetition of certain ideas, which proves their persistence and dominance in the writer's mind, is a matter of deep importance and interest. However it may be to the general reader, the student would deprecate the omission or condensation of any of the writings of Darwin or Huxley. The special interest and value in the letters of these men depend on the fact that their inmost convictions on subjects of the deepest scientific importance are to be read, often in the compass of a brief sentence. There we find, as we cannot find in any other way, the real core of the matter, with all accessory and surrounding considerations stripped 


\section{DARWIN'S LETTERS TO HIS FRIENDS}

away from it. ${ }^{1}$ A careful study of the two recent volumes of Darwin's letters, and a re-study of the three earlier volumes, with a view to this Address, have shown how the writer's thoughts were again and again occupied upon subjects bound up with the problem I have ventured to bring before you this evening. The interest reaches its height when we find that strongly marked differences of opinion on fundamental questions are threshed out in the correspondence, when we see, as I shall have occasion to point out in greater detail in the later pages of this Address, Darwin differing sharply from Huxley on the one hand, and with Wallace on the other, as to the significance and history of sterility between species.

In such episodes we are permitted to become the witnesses of a supremely interesting struggle, where the central figure of modern biological inquiry is contending with his chief comrades in the great fight,- - with the co-discoverer of Natural Selection, with the warrior hero who stood in the forefront of the battle.

The correspondence of Charles Darwin has a further deep interest for us. We see the means by which a gentle, sympathetic, intensely human nature overpassed the stern limits imposed by health, and was able to impart and to receive fresh ideas, and a stimulus ever renewedthe impulse to varied and unceasing research. I have lately been studying with keen interest the life of another great Englishman, William John Burchell, ${ }^{2}$ than whom no better equipped or more learned traveller ever explored large areas in two continents. When I state that searching inquiry has only brought to light a dozen of his letters, ${ }^{3}$ and that he was known to few of the great naturalists of his day, we see the reason for the sad, unproductive, brooding close of a career which opened

1 Quarterly Review, January 1901, p. 258.

2 Ann. and Mag. Nat. Hist., January 1904, p. 45.

3 Since these words were written I have through the courtesy of Mr. Francis A. Burchell of the Rhodes University College, Grahamstown, been permitted to see a large number of letters written by the great explorer to members of his family. A number of Burchell's letters to Swainson, of which I was unaware when this Address was written, are preserved in the library of the Linnean Society. 
with almost unexampled brilliancy and promise. The time which we give to Societies such as this-time we are sometimes apt to grudge-is well spent. Here, and in kindred communities, a 'man sharpeneth the countenance of his friend,' and there is born of the influence of mind upon mind, thought,- - not a mere resultant of diverse forces, but a new creation.

The scientific man who shuts himself away from his fellow men, in the belief that he is thereby obtaining conditions the most favourable for research, is grievously mistaken. Man, scientific man perhaps more inevitably than others, is a social animal, and the contrast between the lives of Darwin and Burchell shows us that friendly sympathy with our brother naturalists is an essential element in successful and continued investigation.

\section{Insects, and especially Lepidoptera, pre-eminently fitted to supply examples for a Discussion on Species.}

I do not suppose that it is necessary to justify a discussion of the term 'species' as the subject of the Anniversary Address to the Entomological Society of London. The students of insect form and function hold an exalted place among naturalists. The material of their researches enables them, almost compels them, to take the keenest and most active interest in broad questions affecting the history and course of life on our planet. Naturalists engaged upon other groups may reasonably inquire why insects, above all other animals, should be so especially valuable for the elucidation of the larger problems which deal, not only with the species of a single group, but with every one of the innumerable and infinitely varied forms, vegetable no less than animal, in which life manifests itself. The answer is to be found in the large number of offspring produced by each pair of insects, and the rapidity with which the generations succeed each other, many cycles being completed in a single year in warm countries; in the severity of the struggle for life which prevents this remarkable rate of multiplication from becoming the cause of any progressive increase 


\section{INSECTS AS EXAMPLES OF EVOLUTION 5 I}

in the number of individuals ; and finally, in the character of the struggle itself, which is precisely of that highly specialized kind between the keen senses and activities of enemies, and the means of concealment or other modes of defence of their insect prey, which leads, by action and answering reaction, to a progressive raising of the standard in both pursuer and pursued. This is why it is that insects mean so much to the naturalist or to the philosopher who desires to look beneath the surface for the forces which have moulded existing forms of life out of earlier and very different forms. The wings of butterflies, it has been said, 'serve as a tablet on which Nature writes the story of the modifications of species.' ${ }^{1}$ But the careful study of insects tells us even more than this; for it gives us the clearest insight we as yet possess into the forces by which these changes have been brought about. Light is thrown upon the causes to which organic evolution is due no less than upon the course which organic evolution has pursued. ${ }^{2}$

And I think we shall find that a consideration of the numerous distinct categories of forms presented by the insect world is especially advantageous in an attack upon the difficult question-' What is a species ?', while properly directed observation of insects, and experiments upon insects afford the most hopeful prospect of a final answer.

And here I am compelled to say a word in defence of the Lepidoptera from this point of view. Undoubtedly it is most unfortunate that the obvious attractions of the group have led entomologists to neglect other Orders; for this can be the only explanation why naturalists have so often preferred to do over again what others have done already, apparently oblivious of fields comparatively empty and unexplored. It must further be admitted, that the greater visibility of structure, and the more

${ }^{1}$ H. W. Bates, quoted by A. R. Wallace in Natural Selection, London, 1875, p. 132. The original passage may be found in The Naturalist on the Amazons (London, pp. 347,348 of the 1879 edition).

2 This justification for the study of insects was urged by the present writer in the Hope Reports, vol. iii, r 903, preface, pp. 4, 5. 
urgent necessity for the study of structure in other groups, render them better instruments of zoological education. But although the Lepidoptera are inferior in this respect, although they lack the unique interest of the Hymenoptera and the social Neuroptera, and cannot claim any of the respect due to venerable age like the Aptera, Orthoptera and Neuroptera-in spite of their many demerits they stand at the head, not only of all insects, but of the whole organic world, as the registers of subtle and elusive change-ever going on, yet never seen,-by means of which forms are slowly becoming different from what they have been in the past. It is the existence of a complex pattern composed of several colours, which renders butterflies and to a less extent moths such a remarkably delicate record of change. As we trace the representative individuals of a community of butterflies over any wide range, the trained eye, and often the inexperienced eye, can detect differences which are not seen to anything like the same extent in the individuals of other Orders with corresponding ranges. If the wings of Hymenoptera, Diptera, or Orthoptera possessed the same elaborate patterns as the Lepidoptera, we cannot doubt that they too would exhibit the same differences in various parts of their areas. The continual change which we find as we study the distribution of Lepidopterous forms in space, is undoubtedly a measure of the speed with which evolution has occurred in time. Rapidity of change is essential if it is to keep its adjustment with nicety to the fleeting details of distribution. ${ }^{1}$ - Hence we may confidently

${ }^{2}$ It is to be observed that I speak of the details as fleeting. The general area of distribution is doubtless extremely ancient in most cases. Thus, although a species of Heliconius, \&c., may have originated within the South American tropics, and never have wandered beyond them, the complex shape of its actual area of distribution at any one time cannot be regarded as fixed or ancient. Yet in many a species the variation of the constituent individuals is adjusted with precision to the geographical details of the existing range.

Mr. Roland Trimen, on reading the above footnote, writes to me January 24, 1904:- Your note reminds me of the recent appearance on the Natal coast of several conspicuous East-African butterflies, vid.: Pieris spilleri, Crenis rosa, and Godartia wakefieldii, all of which are shown to have not only extended their range to a point where they were previously 


\section{BUTTERFLIES AS REGISTERS OF CHANGE 53}

believe, that if we could wake up in say a thousand years, we should be able to detect changes in the patterns of some butterflies. Although I am afraid the advance of science is not likely to be sufficiently rapid in our time for me to hold out any prospect of such an experience for any of you, there is every reason why we should afford this opportunity to posterity. A critical examination of the fragments of many species of butterflies captured over ninety years ago by Burchell in South Africa, and gnawed to pieces during his Brazilian travels from 1825 to 1830 , renders it probable, nay, almost certain, that with moderate care, insect pigments will endure for an indefinite period in our museums. One important justification for the great and permanent outlay required to bring together and maintain large collections of insects is, that we are allowing our successors the chance of detecting and measuring the rate of specific change. ${ }^{1}$ And, as I have already said, for this purpose the Lepidoptera stand pre-eminent.

For the purpose of the inquiry this evening, our

quite unknown, but to have also established themselves in the fresh area. 'This is a good case, as Durban has had, for the last twenty-five years at least, a number of keen collectors of Lepidoptera, whom such conspicuous forms could not possibly have escaped had they inhabited the neighbourhood. Besides these species, the last butterfly that my friend and collaborator, the late Colonel Bowker, sent to me $(1898)$ was the large and extremely conspicuous black-and-white Acraea satis, which he took at Malvern, near Durban. This is the only example known to me to have occurred in Natal; but Bowker, who noted the resemblance on the wing to Papilio morania, wrote that he had seen one other for certain, and thought that he might very possibly have passed over more examples for the common Papilio named. This last case is of special interest (should it prove one of extended range like the three mentioned), because the Acraeae are so exceptionally slow-flying and gregarious, that they must spread very slowly indeed into fresh areas.'

${ }^{1}$ Karl Jordan argues with great force in favour of specialization in this direction by our museums. (See Novilates Zoologicae, vol. iii, December 1896, pp. 43I-3.) The Burchell collection from Brazil was made between 1825 and 1830 , and is therefore only seventy-six to eighty-one years old, but the species are numerous, and often represented by long series. Miss Cora B. Sanders' account of the Ithomiine, Danaine and Satyrine butterflies contains evidence that certain species have undergone change of form or of distribution. Sce Annals and Magazine of Natural History, 1904, pp. $305^{-23}, 35^{6-71}$. 
instances will be drawn from the Lepidoptera rather than other Orders of insects, because of the numberless examples of subtle distinction between forms which but yesterday, so to speak, became separate ; because of our knowledge, insufficient but considerable, of their geographical range; because of our experience, excessively imperfect and scanty, but still much larger than in other Orders, of interbreeding and of descent from parent to offspring.

\section{The Linnaean Conception of Species as Separately Created, and Fixed for all time at their Creation.}

First among the attempts to define species must be placed that which we rightly associate with the name of Linnaeus:-'Species tot sunt, quot diversas formas ab initio produxit Infinitum Ens, quae formae, secundum generationis inditas leges produxere plures, at sibi semper similes.'

It is necessary at the outset to point out that the Linnaean definition contains two widely different ideas.

First, species are diversae formae, distinguished from one another by characters which can be studied and defined. Secondly, these specific differences were originally created as we see them, and are for ever permanent and fixed.

I propose to discuss the second idea before the first.

It has been admirably pointed out by the late Rev. Aubrey L. Moore, ${ }^{1}$ that the dogma of the fixity of species is entitled to none of the respect which is due to age. 'It is hardly credible to us,' he wrote, ' that Lord Bacon, "the father of modern science" as he is called, though he was only a schoolman touched with empiricism, believed not only that one species might pass into another, but that it was a matter of chance what the transmutation would be. Sometimes the mediaeval notion of vivification from putrefaction is appealed to, as where he explains the reason why oak boughs put into the earth send forth wild vines, "which, if it be true (no

${ }^{3}$ Science and the Faith, London, 1889, pp. I74 et seq. 
doubt)," he says ", "it is not the oak that turneth into a vine, but the oak bough, putrefying, qualifieth the earth to put forth a vine of itself." "Sometimes he suggests a reason which implies a kind of law, as when he thinks that the stump of a beech tree when cut down will "put forth birch", because it is a "tree of a smaller kind which needeth less nourishment". ${ }^{2}$ Elsewhere he suggests the experiment of polling a willow to see what it will turn into, he himself having seen one which had a bracken fern growing out of it! ${ }^{3}$ And he takes it as probable, though it is inter magnalia naturae, that "whatever creature having life is generated without seed, that creature will change out of one species into another". Bacon looks upon the seed as a restraining power, limiting a variation which, in spontaneous generations, is practically infinite, "for it is the seed, and the nature of it, which locketh and boundeth in the creature that it doth not expatiate."' And the author also shows that much earlier than the date at which Bacon wrote, theologians were by no means unanimous in accepting 'special creation'; that St. Augustine even distinctly rejected it, and propounded an idea which was evidently considered tenable by the greatest of the schoolmen, St. Thomas Aquinas. St. Thomas's words, quoted by Mr. Aubrey Moore, are as follows:- 'As to the production of plants, Augustine holds a different view. For some expositors say that, on this third day (of creation), plants were actually produced each in his kinda view which is favoured by a superficial reading of the letter of Scripture. But Augustine says that the earth is then said to have brought forth grass and trees causaliter-i. e. it then received the power to produce them.' 4

How then did the fixity of species becomean article of belief in later years? Aubrey Moore traces it to the influence of Milton's account of creation in the seventh book

1 Nat. Hist., Cent. vi, 522 , fol. ed.

2 loc. cit. p. 523 .

3 loc. cit. p. 112.

4. St. Thomas Aquinas, Summa Theol., Prima Pars, Quaest. Ixix. Art. 2. 
of Paradise Lost (1. 4 r 4 et seq.), and Professor Huxley had still earlier suggested the same cause in his American Addresses. I cannot help thinking that the belief had even more to do with the spirit of the age which spoke, and spoke for all time, with Milton for its interpreterthe spirit of the Puritan movement, with its insistence on literal interpretation and verbal inspiration.

John Ray was Milton's younger contemporary, and many writers, including Aubrey Moore, have thought that with him began the idea of the fixity of species. Sir William Thiselton-Dyer has, however, recently pointed out, that a conception similar to Ray's may be traced to Kaspar Bauhin (I550-1624), and to Jung (I $587-1657){ }^{1}$

From Ray we pass to Linnaeus with his celebrated definition. Of the Ray-Linnaeus-Cuvier conception of species which found its most precise and authoritative expression in the Latin sentence quoted on p. 54, Dr. F. A. Dixey has well said that it "left order where it had found confusion, but in substituting exactness of definition for the vague conceptions of a former age, it did much to obscure the rudimentary notions of organic evolution which had influenced naturalists and philosophers from Aristotle downwards'. ${ }^{2}$ At the same time it is by no means improbable, as Dixey has suggested, that the Linnaean conception 'of the reality and fixity of species perhaps marks a necessary stage in the progress of scientific inquiry' ${ }^{3}$

The Linnaean idea of special creation has no place in the realm of science; it is a theological dogma. The formation of species, said Darwin in a letter to Lyell, ' has hitherto been viewed as beyond law; in fact, this branch of science is still with most people under its theological phase of development.' 4 And this explains

${ }^{1}$ The Edinburgh Revier, October, 1902, p. 370.

2 Nature, June 19, 1902, p. 169. For the history of these early ideas upon evolution see From the Greeks to Darwin, by H. F. Osborn, New York, 1894 .

${ }^{3}$ Church Quarterly Revizw, October, 1902, Art. II, p. 28.

${ }^{4}$ Letter $\mathbf{r}^{2}$ to C. Lyell, August 21, 186r. More Letters of Charles Darwin, London, 1903, i, p. 194. 
the intense opposition at first encountered by the principles of the Origin. The naturalist whose genius sympathized most fully with the Linnaean conception would feel that he was admitted, like a seer of old, into the thoughts of the Maker of the Universe. His convictions as to species were to him more than the conclusions of the naturalist; they were a revelation, stirring him to 'break forth and prophesy'. Do we not sometimes recognize a lingering trace of this phase of thought in the serious shake of the head and tone of profound inner conviction with which we are sometimes told that the speaker is decidedly of the opinion that so-and-so is a perfectly good species?

We recognize the same sharp antagonism between two irreconcilable sets of ideas when the late W. C. Hewitson expressed such horror at Roland Trimen's remarkable discovery of the polymorphic mimetic females of the Papilio dardanus (merope) group. The wonderfully acute detection of minute but significant resemblance hidden under the widest possible superficial difference, which enabled the great South African naturalist to unravel the tangled relationships, was to Hewitson but one of 'the childish guesses of the ... Darwinian School'. To meet the carefully-thought-out argument, the only objections that could be urged were, that the conclusion stretched too severely the imagination of the writer, and that it shocked his notion of propriety $!^{1}$

1 See an account of the controversy in Trans. Ent. Soc. Lond., 1874, p. 137. The passages $I$ have alluded to are as follows:- 'P. merope, of Madagascar, has a female the exact image of itself; and it would require a stretch of the imagination, of which $I$ am incapable, to believe that the $P$. merope of the mainland, having no specific difference, indulges in a whole harem of females, differing as widely from it as any other species in the genus. .... In the two species of Papilio which have lately been united, Torquatus and Caudius, and Argentus and Torquatinus, though much unlike each other, there is quite sufficient resemblance not to shock one's notions of propriety.' A little later Mr. Hewitson himself received evidence of the truth of the conclusion he so disliked; for he told how his collector Rogers had sent 'Papilio merope and P. hippocoon, taken by him in copulation, another illustration of the saying that "truth is stranger than fiction". I find it very difficult (even with this evidence) to believe 
In leaving the dogma of 'special creation', and the assumption of 'fixity of species' with which it is bound up, it is only right to point out how completely the logical foundations of both were undermined by the great thinker who has just passed away. Years before the appearance of the Darwin-Wallace essay, and of the Origin, Herbert Spencer wrote on The Development Hypothesis. ${ }^{1}$ Although of course wanting the great motive power to evolution supplied by Natural Selection, this essay is a powerful and convincing argument for evolution as against special creation. It is astonishing that it did not produce more effect. I may appropriately conclude this section of the Address by quoting the results of Herbert Spencer's critical examination, from every point of view, of the Linnaean conception of the origin of species. 'Thus, however regarded, the hypothesis of special creations turns out to be worthlessworthless by its derivation; worthless in its intrinsic incoherence; worthless as absolutely without evidence; worthless as not supplying an intellectual need; worthless as not satisfying a moral want.' 2

I now pass to the first idea contained in the Linnaean conception :- that species are different from one another. Stripped of the assumption that the differences were determined by separate creation and of the assumption that they are fixed for all time, this idea is no less than the recognition of specific characters definable by the method of Diagnosis. And it is only fair to remember that if the theology of Linnaeus demanded the acceptance of these assumptions, his life was really devoted to the ceaseless study of animal and vegetable forms as a foundation for the definition and grouping of species. A discussion of the method of Diagnosis, its implications

that a butterfly, which, when a resident in Madagascar, has a female the image of itself, should, in West Africa, have one without any resemblance to it at all' (Entomologist's Monthly Magazine, October, 1874, p. II3).

${ }^{1}$ In the Leader, between January, 1852, and May, 1854, reprinted in Essays Scientific, Political, and Speculative, London, 1868, vol. i, p. 377 .

${ }_{2}^{2}$ The Principles of Biology, London, 1864 , vol. i, p. 345 . 
and limitations, will be attempted in the later pages of this Address.

\section{Various conceptions of Species.}

In a letter to Hooker, Dec. 24, I856, Darwin gave a short account of the various definitions he had met with. 'I have just been comparing definitions of species, and stating briefly how systematic naturalists work out their subjects. ... It is really laughable to see what different ideas are prominent in various naturalists' minds, when they speak of "species"; in some, resemblance is everything, and descent of little weightin some, resemblance seems to go for nothing, and Creation the reigning idea-in some, descent is the key,-in some, sterility an unfailing test, with others it is not worth a farthing. It all comes, I believe, from trying to define the indefinable.' 1

As regards the work done by the systematist, we find that Darwin did not agree with those of his friends who thought that a belief in evolution would entirely alter its character. Thus he wrote to Hooker, Sept. 25, 1853 :'In my own work I have not felt conscious that disbelieving in the mere permanence of species has made much difference one way or the other; in some few cases (if publishing avowedly on the doctrine of non-permanence), I should not have affixed names, and in some few cases should have affixed names to remarkable varieties. Certainly I have felt it humiliating, discussing and doubting, and examining over and over again, when in my own mind the only doubt has been whether the form varied to-day or yesterday (not to put too fine a point on it, as Snagsby would say). After describing a set of forms as distinct species, tearing up my MS., and making them one species, tearing that up and making them separate, and then making them one again (which has happened to me), I have gnashed my teeth, cursed species, and asked what sin I had committed to be so punished. But I must confess that perhaps nearly the

${ }^{1}$ Life and Letters of Charles Darwin, London, 1887 , vol. ii, p. 88. 
same thing would have happened to me on any scheme of work.' 1

The essentially subjective character of the results reached by the systematist stands out with remarkable force in this as in other passages of Darwin's letters.

A few years later, on July 30,1856 , he wrote to the same friend:- 'I differ from him [Lyell] greatly in thinking that those who believe that species are not fixed will multiply specific names: I know in my own case my most frequent source of doubt was whether others would not think this or that was a God-created Barnacle, and surely deserved a name. Otherwise I should only have thought whether the amount of difference and permanence was sufficient to justify a name.' ${ }^{2}$

Disregarding for the moment the term species, it is convenient to consider the various groupings of individual animals and plants.

I. Forms having certain structural characters in common distinguishing them from the forms of other groups. Groups thus defined by the Linnaean method of Diagnosis may be conveniently called Syndiagnostic

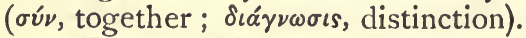

2. Forms which freely interbreed together. These may be conveniently called Syngamic ( $\sigma \dot{v} v$, together; rápos, marriage). Free interbreeding under natural conditions may be termed Syngamy; its cessation or absence, Asyngamy (equivalent to the Amixia of Weismann). ${ }^{3}$

' Life and Letters, vol. ii, p. 40.

2 Ibid. vol. ii, p. 8I.

3 The history of the term Syngamy, although brief, has been remarkable. By a curious coincidence this very word was independently proposed by my friend, Professor Marcus Hartog, of Queen's College, Cork, in order to express that fusion of the essential reproductive elements, or gametes, which has been generally known by the inconvenient and in many ways misleading term fertilization. Prof. Hartog suggested the word (Sept. 14, 1903) in introducing a discussion on fertilization in Section D (Zoology) at the meeting of the British Association at Southport. The Report of the meeting (p. 693) only prints the names of the speakers. I was not at the Southport meeting, and never heard the word until it was suggested as suitable for my purpose by Mr. Arthur Sidgwick. 
3. Forms which have been shown by human observation to be descended from common ancestors or from a common parthenogenetic or self-fertilizing ancestor. Such groups may be called Synepigonic (oúv, together; émíyovos, descendant). Breeding from common parents or from a common parthenogenetic or self-fertilizing parent may be spoken of as Epigony or the production of Epigonic evidence. ${ }^{1}$

I first made use of it in the Presidential Address to the Entomological Society, delivered Jan. $20, \mathrm{I}_{904}$, but it was not published until the sixteenth of the following March, the date of issue, printed upon the cover of Part V of the Transactions for 1903 . Professor Hartog first published Syngamy in the number of the Quarlerly Journal of Microscopical Science for March, 1904. The precise date of publication is not given, but the publishers, Messrs. J. and A. Churchill, have courteously informed me that copies did not leave their office until April 12. Professor Hartog's article is entitled Some Problems of Reproduction.-II, and is to be found in New Ser. vol. xlvii, 1903-4, p. 583, of the Quarterly Journal. The second part B.An Essay on Fertilization (pp. 590-605) begins with an allusion to the discussion at Southport which was opened by the author, on very short notice, by the invitation of Professor Hickson, President of Section D. 'The following pages,' Professor Hartog continues, 'represent far more closely what I would have wished to say than what I actually said.' On p. 595 the word is introduced as follows:"... I venture to propose the term "Sysgasy" to replace "fertilisation," in its modern restricted sense...' I have now given the listory of this strange and unfortunate coincidence, and desire to express my regret that Professor Hartog, who made use of the word at the earlier date, should lose priority because of the later publication. But if such technical rules exist and if they are applicable to scientific terms of this class, I do not sce how it is possible to avoid enforcing them. It would be extremely inconvenient to use the same term for ideas so closely related and yet so utterly different as Professor Hartog's and mine. Furthermore, there is a word as was suggested to me by Professor Lankester, which seems almost to coin itself for Professor Hartog's purpose. When the two gametes have united in 'fertilization' their product is known as the 'zygote'. Thus Professor Hartog in his summary on p. 605 speaks of 'the cell freshly produced by syngamy (the zygote)'. It is obvious

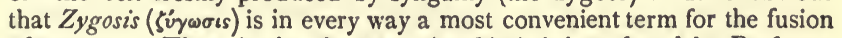
of gametes. There is also the term Amphimixis introduced by Professor Weismann in $189 \mathrm{I}$, but this term really expresses a theory as to the significance of gametic fusion rather than the fact of the fusion itself. (Weismann, Essays upon Heredity, vol. ii, p. 101, Oxford, 1892).

${ }^{1}$ My friend, Mr. Arthur Sidgwick, has kindly helped me by suggesting the appropriate Greek words. The use of ímírovos I owe to my friends Dr. Arthur Evans, F.R.S., and Dr. R. W. Macan. The adjectival ter- 
4. Finally there is geographical distribution, of the utmost importance in the modification and origin of species and sub-species. Forms found together in certain geographical areas may be called Sympatric ( $\sigma \dot{v} v$, together; $\pi \alpha$ r $\rho a$, native country). The occurrence of forms together may be termed Sympatry, and the discontinuous distribution of forms Asympatry.

My friend, Professor E. Ray Lankester, to whom I owe so much, in this as in many other subjects, is inclined to think that we should discard the word species not merely momentarily but altogether. Modern zoology having abandoned Linnaeus's conception of 'species' should, he considers, abandon the use of the word. In his opinion the 'origin' of species was really the abolition of species, and zoologists should now be content to describe, name, draw, and catalogue forms. Furthermore, the various groups of forms briefly defined above should be separately and distinctly treated by the zoologist, without confusion or inference from one to the other. The systematist should say, 'I describe and name certain forms $a, b, \& \mathrm{c}$.'; and then he or another may write a separate chapter, as it were:- 'I now show that the forms $a b, a c, a d$ (form names) are syngamic': at another time he may give reason for regarding any of them as related by Epigony.

I fear that this suggestion is a 'counsel of perfection', impossible of attainment, although there would be many and great advantages in thus making a fresh start and in the abandonment of 'species', or rather the restriction of the word to the only meaning it originally possessed before it was borrowed from logic to become a technical term in zoology. ${ }^{1}$ If the main contention of this Address be accepted, that a species is a syngamic and synepigonic group of individuals, - an objective reality however difficult to establish in practice,-we have an additional powerful reason for the permanent use of the word.

mination is made -ic throughout for the sake of convenience, although Sympatriole or Sympatrid would have been more correct.

1 See F. A. Dixey in Nature, June 19, 1902, p. 169. 


\section{THE IMPORTANCE OF PERSISTENCE 63}

Professor Lankester in former years ${ }^{1}$ published the suggestion that the term species should be limited to a group which includes all the forms derived from common ancestors within human experience, or inferred to be so derived within the possible period of human observation. Thus if the common ancestry of two forms has to be traced back to a period beyond the late prehistoric times (or beyond any other arbitrary line which is agreed upon), then they are not members of the same species. Professor Lankester is the first to admit that the practical application of this as of every other conception of species would very often mean a great deal more than we can prove, in fact, hypothesis.

It is evident that Darwin regarded constancy of form as an important criterion of a species. We recognize this in the definition I have quoted from the Origin (see p. 47), and it is stated with even greater force in the following passage, where persistence is placed beside other distinguishing marks of a species and given the pre-eminence. In a letter to Hooker (October 22, I864) Darwin says:- 'I will fight you to the death that as primrose and cowslip are different in appearance (not to mention odour, habitat and range), and as I can now show that, when they cross, the intermediate offspring are sterile like ordinary hybrids, they must be called as good species as a man and a gorilla. .. . The power of remaining for a good long period constant I look at as the essence of a species, combined with an appreciable amount of difference.' ${ }^{2}$

\section{Introduction to the Discussion 'What is a Species?'}

The preceding pages have been occupied with preliminary considerations necessary for a discussion of the problem stated in the title of this Address. It is now proposed to preface that discussion with a few words

'Neither Professor Lankester nor I have been able at present to lay our hands upon the communication.

${ }^{2}$ More Letters, vol. i, p. 25 , Letter 179. 
of introduction, setting forth the main conclusions which will be defended.

Diagnosis, it will be maintained, is founded upon the conception that there is unbroken transition in the characters of the component individuals of a species. Underlying this idea are the more fundamental conceptions of species as groups of individuals related by Syngamy and Epigony.

In immense numbers of cases it will be shown that the component individuals of a species do not form an unbroken series, but one that is sharply broken at one or more points. At each of these breaks the older systematist made a new species, which the modern systematist has rejected, because in his day the more fundamental criteria have been actually established or by strong indirect evidence have been inferred. When the test of Diagnosis necessarily fails-as it will be shown to do in many large groups of examples-the appeal is made to Syngamy and Epigony.

Syngamy and Epigony are but two sides of the same phenomenon-Reproduction. Although occasional union between individuals of distinct species may occur in nature, sometimes leading to the production of hybrid offspring, this is not the "free interbreeding under natural conditions' which I have called Syngamy. Syngamy, thus defined, implies the production of normal offspring capable of continuing the species-implies Epigony. As a practical criterion, the evidences of Syngamy are generally much easier to collect than those of Epigony. Both Syngamy and Epigony can be established by indirect evidence based on a sufficient number of accurate observations upon the habits and modes of occurrence of individuals. The criterion of Syngamy of course fails in the case of parthenogenetic and self-fertilizing species. In such cases, like that of the Bee Orchis referred to below on p. 92, we are compelled to fall back on Epigony. This latter criterion may lead, although only in rare and exceptional instances, to an erroneous inference, when hybrid are mistaken for normal offspring.

There is a great advantage in the admission that 
Diagnosis is only a provisional criterion, inasmuch as the systematist would then continually seek and continually suggest the search for the more fundamental tests.

It will be argued that the true interspecific barrier is not sterility but Asyngamy-the cessation of interbreeding-but that the first will inevitably follow, sooner or later, as the incidental consequence of the second.

Various causes of the origin of species by Asyngamy will be discussed. One of these, preferential interbreeding, may hereafter appear of the utmost significance in species maintenance and species formation in the higher animal sub-kingdoms. This, of course, would imply that the instincts leading to preference are of dominant importance. We can imagine hardly any operation of Natural Selection more obvious or more effective than that by which these instincts are led to promote a maximum fertility. Any variation of instinct causing an individual to attempt to pair outside the syngamic community to which it belongs could only result in a diminished representation in future generations.

The consideration of a special form of Asyngamy at the close of the Address leads to an unexpected result : suspicion as to the validity of the generally accepted interpretation of the manifold adaptations for crossfertilization.

The conclusions set forth above, if hereafter established, lead to a belief in the reality of species. Unlike and apart from genera, families and other groups employed in our 'little systems' of classification which 'have their day and cease to be', not only do individuals stand out as objective realities, but equally real, though far less evident, are the societies into which individuals are bound together in space and time by Syngamy and Epigony.

\section{The Definition of Species by Diagnosis.}

It is now necessary to examine in some detail the most usual conception of a species, a conception based upon distinguishing structural characters, or Diagnosis. 
This idea of a species is clearly expressed by Sir William Thiselton-Dyer, when he speaks of the older writers who employed 'the word species as a designation for the totality of individuals differing from all others by marks or characters which experience showed to be reasonably constant and trustworthy, as is the practice of modern naturalists'. ${ }^{1}$

This conception of a species is founded upon transition. Whenever a set of individuals can be arranged, according to the characters fixed upon by the systematist, in a series without marked breaks, that set is regarded as a species. The two ends of the series may differ immensely, may diverge far more widely than the series itself does from other series; but the gradual transition proclaims it a single species. If transitions were all equally perfect, of course there would be no difficulty. But transitions are infinite in their variety; while the subjective element is obviously dominant in the selection of gaps just wide enough to constitute interspecific breaks, just narrow enough to fuse the species separated by some other writer,-dominant also in the choice of the specific characters themselves. ${ }^{2}$ Looking back upon the interval between Linnaeus and Darwin, it seems remarkable that the mutability of species was not forced upon systematists as the result of their own labours. It is astonishing that many a naturalist was not driven by his descriptive work to the conclusion which Darwin stated to Asa Gray on July 20, 1856: ' - as an honest man, I must tell you that I have come to the heterodox conclusion, that there are no such things as independently created speciesthat species are only strongly defined varieties.' ${ }^{3}$

For, as I have said above, every describer of species made continuity and transition in characters the test of a variety, discontinuity the test of a separate species.

\section{${ }^{1}$ loc. cit. p. 370.}

${ }^{2}$ How important this choice may be is well shown by Karl Jordan in Novitates Zoologicae, vol. iii, Dec. 1896, pp. 428-30. Characters are subject to independent variation as well as correlated variation. Hence there will often be the widest discrepancy between the transitions constructed by naturalists making use of different characters.

' Life and Letters, vol. ii, p. 79. 
And in difficult cases no two of them agreed in their conclusions. Many passages in Darwin's correspondence convincingly prove how essential an element is this continuity, and how inevitable is the dominance of the subjective element. Thus he writes about his descriptive work on Cirrhipedes to Hooker, October I 2, I849:' I have of late been at work at mere species describing, which is much more difficult than I expected, and has much the same sort of interest as a puzzle has; but I confess I often feel wearied with the work, and cannot help sometimes asking myself what is the good of spending a week or fortnight in ascertaining that certain just perceptible differences blend together and constitute varieties and not species. As long as I am on anatomy I never feel myself in that disgusting, horrid, cui bono, inquiring, humour.' 1

On another occasion, when Darwin was anxious to ascertain the 'close species' in the North American Flora, and wrote for information to Asa Gray, he frankly adopted the subjective criterion in order to explain exactly what he meant. He wrote, June 8 [1855]:- 'The definition I should give of a "close species" was one that you thought specifically distinct, but which you could conceive some other good botanist might think only a race or variety; or, again, a species that you had trouble, though having opportunities of knowing it well, in discriminating from some other species.' ${ }^{2}$

Asa Gray's reply is also very interesting from the same point of view. He wrote, June 30 , I 855 :- ' Those thus connected' [he had bracketed the 'close species' in a list of the Flora], 'some of them, I should in revision unite under one, many more Dr. Hooker would unite, and for the rest it would not be extraordinary if, in any case, the discovery of intermediate forms compelled their union.' 3

Darwin was evidently in high spirits when he wrote the following passage which bears on the same subject. The Origin had been published on November 24, 1859,

1 Life and Letters, vol. i, p. 379.

3 More Letters, vol. i, p. 42 I, Letter 324.

2 Ibid., vol. ii, p. 64 . 
and the whole edition of 1,250 copies sold on the day of issue. On November 29 he wrote to Asa Gray:'You speak of species not having any material base to rest on, but is this any greater hardship than deciding what deserves to be called a variety, and be designated by a Greek letter? When I was at systematic work I know I longed to have no other difficulty (great enough) than deciding whether the form was distinct enough to deserve a name, and not to be haunted with undefined and unanswerable questions whether it was a true species. What a jump it is from a well-marked variety, produced by natural cause, to a species produced by the separate act of the hand of God! But I am running on foolishly. By the way, I met the other day Phillips, the palaeontologist, and he asked me, "How do you define a species ?" I answered, "I cannot." Whereupon he said, "At last I have found out the only true definition,-any form which has ever had a specific name !"'

\section{The idea of Syngamy underlies the gradual transitions} as well as the more uniform resemblances characteristic of Diagnostic Species.

The idea of a species as an interbreeding community, as syngamic, is, I believe, the more or less acknowledged foundation of the importance given to transition. This will become clearer from the consideration of a concrete example. The common black-and-white Danaine butterfly, Amauris niavius of West Africa, is represented on the East and South-East Coasts by a very similar butterfly, distinguished by the greater size of the largest white patch, and of the white spot in the cell of the fore-wing. Both forms are very constant in the areas over which they were known, and on these constant easily recognizable characters the eastern butterfly was described as a distinct species under the name of $A$ : dominicanus. Aurivillius, however, in his valuable Catalogue refuses to recognize this latter as a distinct species, and considers it as the dominicanus variety of niavius. Through the

1 More Letters, vol. i, p. 127 , Letter 79. 
kindness of Mr. C. A. Wiggins and Mr. A. H. Harrison, the Hope Department has recently been presented with an exceedingly fine series of butterflies from both east and west of the northern shores of the Victoria Nyanza. These have been carefully studied by Mr. S. A. Neave, M.A., B.Sc., of Magdalen College, Oxford, who finds that the typical niavius occurs in great abundance to the west of the lake, while on the east he meets, in both collections, with varieties beautifully intermediate between it and dominicanus. These varieties, occurring precisely in the zone where the eastern form meets the western, complete for the systematist the transition which renders dominicanus a variety of niavius and not a distinct species. But it is clear that they do more than this ; they make it almost certain that the two forms freely interbreed, and constitute but a single syngamic community.

This is one of the remarkably clear examples. In many cases we know the transition, but the extremes are not sorted out in different parts of the total area of distribution. Nevertheless, if complete enough, the transition of forms on the same area always raises the strong presumption that we are dealing with a syngamic community.

Probably the most remarkable series of transitional varieties ever depicted is that shown in the eleven quarto plates of the last part of Monsieur Charles Oberthür's great Études d'Entomologie, entitled 'Variation des Heliconia thelxiope et vesta' (Rennes, February, 1902).

\section{The failure of Diagnosis as the sole test of Species.}

The method of Diagnosis, at its clearest and simplest, is always consistent with, and often strongly suggests, an underlying Syngamy. There are, however, numberless examples belonging to various categories in which a rigid adherence to Diagnosis cannot avail. In these cases the systematist frankly appeals to Syngamy or Epigony as decisive ; and if he has not direct proof of the existence of either of these, indirect evidence is, at any rate provision- 
ally, regarded as sufficient. Some of the chief of these categories are briefly set forth under the five heads $a-e$.

a. Dimorphism, Polymorphism:-In an ever increasing number of examples an assemblage of individuals is regarded as a single species, although split up into two or more widely different and sharply separated groups, between which transitional varieties are excessively rare or even unknown. For instance, the extremely abundant, widely distributed butterfly Limnas chrysippus includes among other forms one in which the black-and-white tip is" wanting from the fore-wing, the dorippus (=klugii) form. This variety is sharply cut off from the type form. Although faint traces of a former white bar can be made out in dorippus, I have never seen, among thousands of individuals, the material out of which a good transitional series between it and chrysippus could be constructed. In this case the evidence of Syngamy is strong and complete; for Col. Yerbury has recorded the fact that the two forms certainly occur in copula $\hat{a}^{1}$. But even if this record were wanting there would still be strong presumptive evidence that the forms are associated by Syngamy and Epigony. Thus, so far as our knowledge extends, dorippus occurs as the only form in certain parts of NE. Africa alone. From this, its metropolis, dorippus spreads on all sides, its individuals existing intermingled with those of chrysippus, becoming less and less numerous until they finally die out. Thus if we trace the two forms eastward we find them both abundant at Aden; further east, at Karachi, dorippus is well known, but very scarce as compared with chrysippus; in Southern India it is a great rarity, if indeed it is known at all on the mainland; in Ceylon a single specimen was captured by Col. Yerbury in I89I, and since then others have been taken. ${ }^{2}$ Further east I have never heard

${ }^{1}$ Speaking of his experience at Aden, Col. Yerbury says: 'I have taken them [the forms of chrysippus] "in coitu" in every possible combination' (Journ. Bomb. Nat. Hist. Soc., vii (1 892), p. 209).

${ }^{2}$ See Major N. Manders, F.Z.S., in Journ. Bomb. Nat. Hist. Soc., xiv (1902), p. $716:-$

'The first specimen of this insect [dorippus=klugii] in Ceylon was captured by Lieut.-Colonel Yerbury at Trincomalie, April 15,1891 ...' 


\section{POLYMORPHISM AND DIAGNOSIS}

of a specimen. Similarly when it is traced southward in Africa, dorippus is dominant in the coast strip of British East Africa, where it constitutes about threequarters of the total number of individuals. Further to the south it becomes rarer and rarer, until in Natal and the Cape, if it occurs at all, it is even rarer than in Ceylon. ${ }^{1}$ Such a distribution is consistent with the interpretation that dorippus and chrysippus are two forms in one syngamic community. It is difficult on any other hypothesis to account for the facts which we observe on the outskirts of the range of dorippus - the occasional appearance of single individuals in the swarms of the type form. And if the two are syngamic on the outskirts, the gradual transition in proportions towards the metropolis of dorippus suggests that they are syngamic throughout. Common as the species is-probably the commonest butterfly in the world-the evidence from Epigony has never been obtained, although from the point of view of heredity the investigation promises to be of the deepest interest.

The remarkable forms of the females of the Papilio dardanus (merope) group already alluded to afford another

Of five or six more recent examples Major Manders writes, 'These specimens were captured by Mr. Pole at Puttalam on the east coast and Hambantotte on the south coast in the dryest and perhaps most arid portion of the island. It is evidently widely distributed in the desert portion of the island and is possibly not uncommon.'

'The distribution of this insect in India cannot yet be fully known; it is rare in Canara, but is not yet reported from the plains of the Deccan, or Southern India so far as I am aware though it probably exists.' The occurrence of dorippus at Bombay, Khandalla, Poona, and Karachi had been previously published by Col. C. Swinhoe (P.Z. S. 1884, p. 504; 1885, p. 1 26); and at Campbellpore (Col. Yerbury) by Dr. A. G. Butler (P.Z.S. 1886, p. 356 ).

${ }^{1}$ Mr. Roland Trimen tells me that he knows of only three South African dorippus :- two from Durban and one from Pretoria. The latter and one of the former were taken by Mr. W. L. Distant (Ann. Mag. Nat. Hish. (7), vol. i, 1898, pp. 48, 49). Mr. Geo. F. Leigh, of Durban, Natal, writes March 3, 1904:- 'I have myself captured two or three specimens during the past three years, and one was taken only last September by Mr. Burn who was out collecting with me.' Two specimens captured in 1905 at Salisbury, Rhodesia, have been presented to the Oxford University Collection by Mr. Guy A. K. Marshall. They are, so far as I am aware, the only examples of dorippus hitherto recorded from Rhodesia. 
excellent example, although in this case good transitional series can be constructed. The evidence of Syngamy was first obtained by Hewitson (see p. 57, footnote I), but is now well known. The evidence of Epigony has fortunately been obtained in 1902 and again within the last few weeks by one of our Fellows at Durban, Mr. G. F. Leigh. Eggs laid in 1902 by a female of the commonest South African form, cenea, yielded a synepigonic group, including a large majority of forms like the parent, but also examples of the very different hippocoon form. In the more recent example seven eggs from the rarest of the South African forms, trophonius, produced, in addition to males, two females of the cenea variety, and not one resembling the parent. ${ }^{1}$

These differences, although only of colour and pattern, greatly exceed those between ordinary close species. When we deal with other kinds of dimorphism or polymorphism involving important structural differences, such as those of the social Hymenoptera and Neuroptera, the discriminating characters between nearly related genera are commonly equalled or exceeded.

b. Seasonal Dimorphism:-In certain exceedingly interesting examples of dimorphism the relation between the forms is epigonic and not syngamic; for rare and occasional interbreeding is not Syngamy. I refer to the most strongly-marked cases of seasonal dimorphism in butterflies, especially the wonderful examples proved to be epigonic by Guy A. K. Marshall. ${ }^{2}$ In some of the forms the two seasonal phases were not even regarded as closely related species. In these extraordinary cases,

1 Trans. Ent. Soc. Lond., I 904, pp. 677-88, Plate XXXI. Still later, in $1904, \mathrm{Mr}$. G. F. Leigh bred from the eggs laid by a trophonius female, six males, four females of the cenea form, and one female of the trophonius form (Trans. Ent. Soc. Lond., 1906, pp. 281-3, Plate XVII). Finally, within the last few weeks $I$ have received from the same keen naturalist a splendid synepigonic group of twenty-eight specimens bred from a hippocoon parent-the first time that offspring have been reared from this form of female. Of the twenty-eight, fourteen are males, eight are cenea females, three are hippocoon females, and three are trophonius females [December 2 , $1906]$.

2 Trans. Ent. Soc. Lond., 1902, pp. 414-60. 
where the widest difference in colour and pattern exists, in combination with others which are far more deepseated, I urged upon Mr. Marshall that the few recorded examples of capture or observation in coitu were insufficient evidence of specific identity, and that nothing short of Epigony would suffice.

In seasonal dimorphism, in the dimorphism of social insects, and doubtless in a large proportion of other examples, it is probable, indeed often certain, that the different forms are produced in response to some stimulus which acts at a specially susceptible period of the lifehistory; but from the point of view of the systematist the mature individuals can only be known as forms which, structurally widely different, must nevertheless be placed within the limits of a single species. The investigation of the probable physiological causes of difference is, however, of the utmost importance from other points of view. Altogether apart from its bearing upon dimorphism, the effect of individual susceptibility to stimulus requires treatment in a separate category.

c. Individual Modification ${ }^{1}$ :-One of the most striking developments of recent years has been the growth in the number of these very cases in which an individual animal or plant has been rendered by Natural Selection susceptible to some stimulus associated with each one of its possible normal environments. Every individual of such species comes into the world with two or more very distinct and very different possibilities before it, each of which will be realized only in the appropriate environment-realized as the response to some stimulus provided by the environment itself. We can see clearly that this idea was in Darwin's mind, although there were then but few observations which pointed in its direction. Thus in Schmankewitsch's experiments Crustacea of the species Artemia salina were described as gradually changing in the course of generations, as the result of a progressive

1 'A structural change wrought during the individual's lifetime (or acquired), in contradistinction from variation, which is of germinal origin (or congenital).' Dict. of Phil. and Psych., ed. by J. Mark Baldwin, New York and London, vol. ii, 1902, p. 94. 
freshening of the water in which they were kept, until they took on the characters of the genus Branchipus. On this subject Darwin wrote to Karl Semper, February 6, I 88I :- 'When I read imperfectly some years ago the original paper I could not avoid thinking that some special explanation would hereafter be found for so curious a case. I speculated whether a species, very liable to repeated and great changes of conditions, might not acquire a fluctuating condition ready to be adapted to either conditions.' 1

I venture to express the prediction that this class of cases, already very numerous, will hereafter be immensely enlarged, and will become especially important in the vegetable kingdom. ${ }^{2}$ Although Hooker at one time took the opposite side, and thought that plants were never ' changed materially by external conditions .. . except in such a coarse way as stunting or enlarging,, ${ }^{3}$

1 More Letters, vol. i, p. 391, Letter 303 .

2 See Stimulus and Mechanism as Factors in Organization, by J. Bretland Farmer, F.R.S. (the New Phytologist, vol. ii, Nos. 9 and ro, November and December, 1903). Professor Farmer speaks of the probable prevalence in the plant-world of ' a constant specific mechanism that is able to be actuated in different ways by different kinds of stimuli'. Although for the purpose of his paper Professor Farmer is concerned with the train of physico-chemical sequences which is set going, utility or no utility, whenever the mechanism of an individual is stimulated, he fully admits that the mechanism itself has come to be a character of the species by the operation of Natural Selection. 'Naturally,' he says, 'only those species whose inner character expressed itself in making these "suitable" adjustments to the environment were able to survive.'

Toward the close of his paper Prof. Farmer seems to bring the considerations that have regard to the species into somewhat unnecessary conflict with those that have regard to the individual. Thus he says that 'current literature still teems with teleological explanations that really explain nothing, but rather bar the way of scientific inquiry'.

A properly loaded, well-constructed modern gun goes off, for disadvantage no less than for advantage, when its trigger is pulled; but the very existence of the gun depends upon a long succession of past stages, each of which was more advantageous than its predecessor. The recognition of this history does not bar the way of inquiry, but rather stimulates and suggests a searching and intelligent study of the latest mechanism with all its intricacy.

- See the letter from Hooker to Darwin, March I 7, 1862, in More Letters, vol. i, p. 197, footnote 2. 
Darwin considered that 'physical conditions have a more direct effect on plants than on animals'. ${ }^{1}$ Undoubtedly the view at the time was that of Buffon, the idea of an operation of the environing forces almost as direct as those which produce the weathering of rocks or the whitening of an exposed flint. But it is probable that the more intimately we know the conditions of plantlife, the more fully it will be recognized that all such changes are adaptive. I will mention merely by way of illustration that my attention has been called in recent years to the dwarfing effect of the prevalent southwestern winds on the vegetation of the exposed chalk downs of the Isle of Wight. It has occurred to me as a mere suggestion, but one worth investigating, that the effect of wind upon a tall flower-head might be such as to render less easy and less frequent the visits of insects. If this were so, it would perhaps explain why certain species of entomophilous plants liable to grow in such situations have gained a special susceptibility to the stimulus provided by constant winds during some particular period of growth. The absence of this stimulus would also correspond to a condition in which the plants would gain in the conspicuousness brought about by increased height.

The further growth of a class already proved to be large would play havoc with a definition of species rigidly based upon discriminating structural characters alone.

d. Geographical Races or Sub-Species:-If we depend upon unaided Diagnosis there is no means of discriminating between species and those sub-species of which the whole mass of individuals are distinguished by recognizable characters. Here again the mere beginning of the difficulty is in sight ; for as museums recognize more and more the necessity for long series of specimens with exact geographical data, so will the comparatively simple conception of the single species be replaced again and again by the far more complex but much truer idea of subspecific groups still fused by Syngamy into a single

${ }^{1}$ See the letter from Darwin to Lyell [June I 4, 1860], Life and Letters, vol. ii, p. 319. 
species, but, as it were, trembling on the edge of disruption, ever ready, by the development of pronounced preferential mating or by the accumulated incidental effects of isolation prolonged beyond a certain point, to break up into distinct and separate species.

e. Results of Artificial Selection:-These obvious difficulties encountered by a mechanical adherence to definition by Diagnosis naturally lead to the consideration of the further difficulties presented by domestic races of animals and plants. The wide structural differences between the forms accumulated by human selection greatly impressed Darwin. Thus he wrote to Hooker, September 8, [ 1856$]$ :- ' By the way, I have been astonished at the differences in the skeletons of domestic rabbits. I showed some of the points to Waterhouse, and asked him whether he could pretend that they were not as great as between species, and he answered, "They are a great deal more." How very odd that no zoologist should ever have thought it worth while to look to the real structure of varieties....' I But if the differences between many of our domestic breeds, and between them and the nearest wild species, are, as is well known, generic rather than specific, why do we not consider such races to be of different species and genera? Because of the criterion suggested by Lankester; because we have reason to believe in their descent from common parents within the historic period; because, in spite of their wide differences, they are still syngamic.

\section{Advantages of the admission that conclusions based on Diagnosis are provisional.}

What is the practical bearing of these criticisms upon the definition of species by Diagnosis and Diagnosis alone? The systematist, confronted by his series of specimens in a museum cannot do otherwise than arrange them in groups which he will describe and name as species. But much would be gained if he admitted at the outset that his conclusions are provisional, if he said with Dr. Karl

1 More Letters, vol. ii, p. 2 10, Letter 543. 
Jordan, 'The actual proof of specific distinctness the systematist as such cannot bring; . . . we work, or we ought to work, with the mental reservation that the specific distinctness of our species novae deduced from morphological differences will be corroborated by biology:'

The advantage of this attitude is obvious. Work would go on as at present. Powers of acute observation and good judgement would still furnish descriptions of species to be hereafter confirmed or confirmed at the time by observation and experiment upon the living material. But the systematist would not only receive our gratitude for the performance of these important and necessary duties: he would also be seeking in every direction for the evidence of Syngamy and of Epigony. The museum would become a centre for the inspiration of researches of the highest interest to the investigator himself, of the greatest importance to the whole body of naturalists.

\section{Interspecific Sterility as a test of Species.}

We now turn to the consideration of interspecific sterility, which many have supposed to be an infallible criterion. Huxley himself felt this so strongly that he was, in consequence, never able to give his full assent to Natural Selection. The grounds of his objection were the subject of prolonged correspondence with Darwin. In order to prove that Natural Selection has produced natural species separated rigidly, as he believed, by the barrier of sterility, Huxley maintained that we ought to be able to produce the same sterility between our artificially selected breeds; and until this had been done he could not thoroughly accept the theory of Natural Selection. This objection he expressed, or implied, in many speeches and writings up to within a few months of his death. One of the simplest statements is contained in a letter to the late Charles Kingsley. Huxley wrote, April 30, 1863:-

1 Novitates Zoologicae, vol. iii, December, 1 896, pp. 450, 451. I here desire to express my indebtedness to the author of this learned and valuable paper. 
' Their produce [viz. that of Horse and Ass] is usually a sterile hybrid.

'So if Carrier and Tumbler, e.g., were physiological species equivalent to Horse and Ass, their progeny ought to be sterile or semi-sterile. So far as experience has gone, on the contrary, it is perfectly fertile-as fertile as the progeny of Carrier and Carrier or Tumbler and Tumbler.

'From the first time that I wrote about Darwin's book in the Times and in the Westminster until now, it has been obvious to me that this is the weak point of Darwin's doctrine. He has shown that selective breeding is a vera causa for morphological species; he has not yet shown it a vera causa for physiological species.

' But I entertain little doubt that a carefully devised system of experimentation would produce physiological species by selection-only the feat has not been performed yet.' 1

It was against this same view, as expressed in Huxley's Lectures to Working Men in I863, that Darwin argued with convincing force in many letters. The main facts with which he confronted Huxley again and again were the artificially selected races of certain plants which are sterile inter se. The position is clearly expressed in the following amusing, vehement passages from two letters :-

$$
\text { 'Dec. 18, [1862.] }
$$

'Do you mean to say that Gärtner lied, after experiments by the hundred (and he a hostile witness), when he showed that this was the case with Verbascum and with maize (and here you have selected races) : does Kölreuter lie when he speaks about the varieties of tobacco? My God, is not the case difficult enough, without its being, as I must think, falsely made more difficult? I believe it is my own fault-my $\mathrm{d} \longrightarrow \mathrm{d}$ candour: I ought to have made ten times more fuss about these most careful experiments.' 2

1 Life and Letters of Thomas Henry Huxley, vol. i, p. 239.

2 More Letters, vol. i, p. 230 , Letter 156. 


$$
\text { '[Jan.] 10, [1863.] }
$$

'In plants the test of first cross seems as fair as test of sterility of hybrids. And this latter test applies, I will maintain to the death, to the crossing of varieties of Verbascum, and varieties, selected varieties, of $Z e a$. You will say Go to the Devil and hold your tongue. No, I will not hold my tongue; for I must add that after going, for my present book [Variation under Domestication], all through domestic animals, I have come to the conclusion that there are almost certainly several cases of two or three or more species blended together and now perfectly fertile together. Hence I conclude that there must be something in domestication,- perhaps the less stable conditions, the very cause which induces so much variability,- which eliminates the natural sterility of species when crossed. If so, we can see how unlikely that sterility should arise between domestic races. Now I will hold my tongue.' 1

Darwin made attempts to 'produce physiological species by selection', and thus meet his friend's criticism. He thought out and suggested a plan of experiment to W. B. Tegetmeier, ${ }^{2}$ and gave a brief account of the scheme to Huxley, December 28, [1862]:-'I have... given him [Tegetmeier] the result of my crosses of the birds which he proposes to try, and have told him how alone I think the experiment could be tried with the faintest hope of success-namely, to get, if possible, a case of two birds which when paired were unproductive, yet neither impotent. For instance, I had this morning a letter with a case of a Hereford heifer, which seemed to be, after repeated trials, sterile with one particular and far from impotent bull, but not with another bull. But it is too long a story-it is to attempt to make two strains, both fertile, and yet sterile when one of one strain is crossed with one of the other strain. But the difficulty ... would be beyond calculation.' ${ }^{3}$

The experiment was evidently unsuccessful,-perhaps

1 More Letters, vol. i, pp. 231, 232, Letter 157.

2 Ibid. vol. i, pp. 223,224 , Letter 153, [1862, December] 27.

Ibid. vol. i, pp. 225,226 , Letter 154 . 
was never seriously undertaken,-and a few years later Darwin added the following postscript to a letter to Huxley, January 7, [1867].

'P.S.-Nature never made species mutually sterile by selection, nor will men.' 1

This was probably only an off-hand expression of opinion, not intended to be taken seriously. An altogether hopeless attitude would not be reasonable until the suggested scheme had been applied many times, and in several parts of the animal and vegetable kingdoms.

But the positive results demanded by Huxley, even if obtained, would by no means justify his far-reaching conclusions. If the barrier of sterility were thus artificially produced, we should be very far from the proof that its existence in nature is due to the same kind of cause, viz. selection. If Darwin was right in his controversy with Wallace, if 'Nature never made species mutually sterile by selection', the suggested experiment would merely do by Artificial Selection what is not done by Natural Selection.

\section{Interspecific Sterility an incidental consequence of Asyngamy.}

It is by no means difficult to understand the mutual sterility which is usual between natural species as an incidental result of their separation by Asyngamy for a long period of time. In the process of fertilization a portion of a single cell nucleus from one individual fuses with a portion from another individual, the two combining to form the complete nucleus of the first cell of the offspring, from which all the countless cells of the future individual will arise by division. Each part-nucleus contains the whole of the hereditary qualities received from and through its respective parent, and must therefore be of inconceivable complexity. We can only speak in generalities about processes of which so little is known, but we cannot be wrong in assuming that sterility is sometimes due to the fact that the complex architecture

${ }^{1}$ More Letters, vol. i, p. 277 , Letter 197. 
of one part-nucleus fails in some way to suit the equally complex structure of the other. The individuals of an interbreeding community form a biological whole, in which selection inevitably keeps up a high standard of mutual compatibility between the sexual nuclei. Individuals whose sexual nuclei possess a structure which leads to sterile combinations with those of other individuals are excluded from contributing to the generations of the future. As soon, however, as a group of individuals ceases, from any reason, to breed with the rest of the species, there is no reason why the compatibility of the sexual nuclei of the two sets should be retained. Within each set, selection would work as before and keep up a high standard of compatibility ; between the sets, compatibility would only persist as a heritage of past selection, gradually diminishing as slight changes of structure in either or both of the sets rendered them less and less fitted to produce fertile combinations. ${ }^{1}$

It is probable that of all the nice adjustments required in the living organism, the mutual adjustment of these inconceivably complex part-nuclei is the most delicate and precise. Now, delicately adjusted organs, such as those of sight, rapidly become incapable of performing their functions when in any species they have been withdrawn from the operation of Natural Selection; similarly it is suggested, that the adjustment of sexual nuclei to each other would sooner or later give way when no longer sustained by selection. If, then, mutual fertility be the result of unceasing selection, and mutual sterility the

${ }^{1}$ I must guard against the inference that the only explanation of sterility is here set forth. It is indeed maintained that incompatibility of the sexual part-nuclei is the inevitable outcome of enduring Asyngamy, and is the probable cause of the sterility of hybrids. Thus it may be suggested that sterility is a result of the combination of two incompatible germ-plasms in the sexual cells of the hybrid. When the incompatibility is not strongly marked we can understand how such sexual cells may be capable of fertile fusion with the cells of either parent, but not with those of another hybrid.

But short of these ultimate effects it must not be forgotten that there are many obscure factors of Asyngamy-causes of various kinds which interfere with the fusion under normal conditions or entirely prevent the meeting of the sexual cells. 
inevitable, even if long-postponed, consequence of its cessation, it is obvious that Huxley's difficulty is solved, while his suggested experimental creation of sterility by selection would not reproduce any natural operation: it would afford a picture of a natural result but would be produced in an unnatural way. This criticism of Huxley's contention was advanced by the present writer three years ago, ${ }^{1}$ the final conclusion being stated in the paragraph printed below :-

'If, then, we cannot as yet reproduce by artificial selection all the characteristics of natural species-formation, but can only imitate natural race-formation, we can, nevertheless, appreciate the reasons for this want of success, and are no more compelled to relinquish our full confidence in natural selection than we are compelled to adopt a guarded attitude towards evolution because our historical records are not long enough to register the change of one species into another.' ${ }^{2}$

It was, therefore, with intense interest and pleasure that I read the following sentences in a letter written by Darwin to Huxley, December 28, [1862]-sentences which show that criticism practically identical had been made by the illustrious naturalist nearly forty years earlier.

'We differ so much that it is no use arguing. To get the degree of sterility you expect in recently formed varieties seems to me simply hopeless. It seems to me almost like those naturalists who declare they will never believe that one species turns into another till they see every stage in process.' 3

After reading, in the first volume of More Letters, the often-repeated refutation of Huxley's objection so clearly and strongly expressed in letters received by the objector himself, it is surprising that no effect was produced, and that reference should have been nearly always made to this supposed flaw in the theory of Natural Selection, whenever the great comparative anatomist had occasion

1 The Quarterly Review, No. 385, January, 1901, pp. 368-71.

2 loc. cit. p. 37 .

3 More Letters, vol, i, p. 225 , Letter 154. 
FERTILITY BETWEEN DOMESTIC RACES 83

to speak or write on the broader aspects of biological inquiry. ${ }^{1}$

Darwin also considered that there was something in the very conditions of domestication which tended to promote fertility between races and even between distinct species. Thus he followed Pallas in believing that the domestic dog has been derived from more than one wild species, although he did not trace existing differences to this cause but to Artificial Selection. ${ }^{2}$ However, as regards the origin of the dog, 'the evidence is, and must be, very doubtful,' as he wrote to Lyell, August I I, [1860]. The fact which Darwin 'considered the most remarkable as yet recorded with respect to the fertility of hybrids' was the fertility of the offspring of the Common and Chinese Goose, originally described by Eyton, and confirmed by Goodacre and by Darwin himself. "The two species of goose now shown to be fertile inter se are so distinct that they have been placed by some authorities in distinct genera or sub-genera.' 3

Another interesting and exceedingly difficult experiment in hybridization has been carried through by the Rev. P. St. M. Podmore, F.Z.S., who in September, I 899, after numerous failures, succeeded in rearing a healthy male hybrid between the Ring Dove (Columba palumbus) and the domestic pigeon. On May 27, 1903,

1 For several instances see Poulton's Charles Darwin and the Theory of Natural Selection, Lond. I 896, pp. I 24-41.

2 'Though I believe that our domestic dogs have descended from several wild forms, and though I must think that the sterility, which they would probably have evinced, if crossed before being domesticated, has been eliminated, yet I go but a very little way with Pallas \& Co. in their belief in the importance of the crossing and blending of the aboriginal stocks. .... Although the hound, greyhound, and bull-dog may possibly have descended from three distinct stocks, I am convinced that their present great amount of difference is mainly due to the same causes [Artificial Selection] which have made the breeds of pigeons so different from each other, though these breeds of pigeons have all descended from one wild stock; so that the Pallasian doctrine I look at as but of quite secondary importance.' More Lelters, vol. i, pp. 127, 128, Letter 80, to Lyell, October 31, [1859].

${ }^{3}$ Life and Lellers, vol. iii, p. 240. 
this male was mated with a Blue Homer hen, which produced healthy offspring. ${ }^{1}$

A comparison between the difficulty of producing such a cross and that of obtaining hybrids between the Ring Dove and the Rock Pigeon, the ancestor of the domestic breeds, would probably throw much light on the Pallasian hypothesis.

If the view here proposed be sound-that Syngamy lies behind, and is at least provisionally implied in the transition which means so much to the systematist, and is his only real evidence when the structural test breaks down, the conclusion is suggested that the real interspecific barrier is not sterility but Asyngamy. Nevertheless, as argued on pp. 80, 8I, Asyngamy will infallibly lead to sterility, although the result may be long delayed. This latter view, which was that of Darwin, is the exact opposite of the 'physiological selection' of Romanes, in which sterility is supposed to arise spontaneously, Asyngamy being not the cause, but the consequence.

\section{A syugamy as a consequence of Asympatry.}

Asyngamy may be brought about in various ways, of which the most obvious is geographical separation. But Asyngamy is by no means the necessary result of geographical discontinuity or Asympatry. Thus Darwin considered that there is regular interbreeding between Madeiran and continental birds of the same species. He wrote to Hooker, August 8, [1866]. 'I do not think it a mystery that birds have not been modified in Madeira. Pray look at p. 422 of Origin [ed. iii]. You would not think it a mystery if you had seen the long lists which I have (somewhere) of the birds annually blown, even in flocks, to Madeira. The crossed stock would be the more vigorous.' ${ }^{2}$ An even more striking case is that

1 The Zoologist, November, 1903, p. 401.

- More Letters, vol. i, pp. 487,488 , Letter 370 . Dr. Karl Jordan has maintained ('Der Gegensatz zwischen geographischer und nichtgeographischer Variation', Zeitschr. $f$. Wissenschaft. Zool. Bd. Ixxxiii) that this argument is valueless, inasmuch as more critical study of extensive 
of Pyrameis cardui (the 'Painted Lady' butterfly), which ranges over nearly the whole world. The singular rarity of local geographical races ${ }^{1}$ in this abundant species is almost certainly due to the astonishing powers of dispersal which enable intermittent Syngamy to prevail over the nearly whole vast area of its distribution.

\section{Asyngamy as a consequence of Mechanical Incompati- bility.}

An interesting and curious cause of persistent Asyngamy is the 'Mechanical Selection' so thoroughly explained and abundantly illustrated by Karl Jordan. ${ }^{2}$ The complex genital armature of Lepidoptera is during Syngamy kept constant by unceasing selection. Comparatively brief isolation of a group of individuals may lead to a departure from the specific type of apparatus prevalent in other areas, and may thus mechanically prevent Syngamy if from any cause members of the group became again sympatric with those of the parent species.

\section{Asyngamy as a consequence of Preferential Mating.}

A very different but exceedingly interesting origin of Asyngamy is suggested by observations which support the conclusion that varietal forms may show a tendency towards preferential interbreeding.

H. W. Bates believed that he had strong evidence for the existence of this tendency in the races of certain tropical American butterflies. He stated this in his epoch-making paper on the butterflies of the Amazon valley, ${ }^{3}$ and it is interesting to observe in the published

material in recent years has revealed peculiarities in the Madeiran birds which were unknown when Darwin wrote. But the general argument still holds good, even though our knowledge has been increased and modified. Nadeiran birds have changed but slightly as compared with those of the Galapagos Islands, where interbreeding with the related mainland species has been almost or entirely prevented by local conditions contrasting sharply with those by which Madeira is surrounded.

${ }^{2}$ There is only the small, slightly modified form, kershawi, from the Australian Region.

2 Novilates Zoologicae, vol. iii, Dec. 1896, pp. 518-22.

${ }^{3}$ Trans. Linn. Soc., vol, xxiii (1862), p. 495. 
letters how Darwin instantly fixed upon the point and tried to elicit the data upon which the conclusion was formed. Thus he wrote to Bates, November 20, [1862]: ' No doubt with most people this [viz. the interpretation of Mimicry] will be the cream of the paper ; but I am not sure that all your facts and reasonings on variation, and on the segregation of complete and semi-complete species, is not really more, or at least as valuable, a part. I never conceived the process nearly so clearly before; one feels present at the creation of new forms. I wish, however, you had enlarged a little more on the pairing of similar varieties; a rather more numerous body of facts seems here wanted.' 1

Then a few days later we find Darwin still thinking of the subject, and writing to Hooker [1862, November] 24 :'I have now finished his [Bates'] paper ... ; it seems to me admirable. To my mind the act of segregation of varieties into species was never so plainly brought forward, and there are heaps of capital miscellaneous observations.' $^{2}$

He also again wrote to Bates, probably on the following day, November 25, [1862 ?], asking for the solid facts which are so greatly wanted:-

' Could you find me some place, even a footnote (though these are in nine cases out of ten objectionable), where you could state, as fully as your materials permit, all the facts about similar varieties pairing, - at a guess how many you caught, and how many now in your collection? I look at this fact as very important; if not in your book, put it somewhere else, or let me have cases.' ${ }^{3}$

Remembering that Mr. Roland Trimen, F.R.S., had expressed the same opinion as the result of his wide and long experience of South African butterflies, I asked him if he would kindly furnish me with a statement. His reply, dated December 28, 1903, is as follows:- 'I have noticed the tendency of the sexes of a variety to pair together rather than with other varieties in the numerous

1 Life and Letters, vol. ii, p. 392.

2 More Letters, vol. i, p. 214 , Letter 147.

Ibid. vol. i, p. 2 I 5 , Letter 148. 
cases of captured pairs sent to me by correspondents in South Africa, and sometimes in cases of the same kind which occurred to myself when collecting. The species which particularly attracted my notice in this way during my visit to Natal was Hypanis acheloia (=Götzius, Herbst, part), which is curiously variable on the underside, from pale creamy to deep chocolate. I did not know of its seasonal variation at the time, but I was in Natal just at the change of season from wet to dry, when the intermediate gradations were about, and I was struck with the close resemblance of the sexes in pairs that I caught. I am sorry to have nothing more definite to give on this head; it is a point much requiring exact and prolonged observation.'

Mr. Trimen furthermore entertains no doubt that much, if not all, of the material upon which he based the conclusion that the individuals of the same race tend to interbreed, exists, distinctively labelled, in the South African Museum, at Cape Town. It is greatly to be hoped that collectors will in future carefully label all specimens captured in coitu, and that the fact will be recorded on the labels in museums and in private collections. It is tantalizing to reflect upon the number of interesting and important questions which could be now decided if this practice had prevailed during the past fifty years. The question of the possible origin of species from races by preferential Syngamy is of such high importance that we may confidently hope that the attention here directed to the question, and especially the quotation of Darwin's - letters to Bates, may lead to that 'exact and prolonged observation', accompanied by careful records, without which a safe decision cannot be reached. In the meantime the decided impressions of two such naturalists as H. W. Bates in South America and Roland Trimen in South Africa render it in every way probable that the conclusion will be established on a firm foundation. ${ }^{1}$ It

1 Dr. T. A. Chapman sends me the following interesting and suggestive note :-

'I met lately with a curious instance that deserves following up, of some bearing on the question of selective mating of varieties. 
has been already pointed out on p. 65 that, should preferential Syngamy be established on a large scale, the instincts concerned would assume fundamental significance in the origin of species.

\section{Asyngamy as a consequence of the breaking of a Syngamic Chain.}

It is also possible that Asyngamy may be brought about by the breaking of what we may call 'a Syngamic Chain'. In the case of large and widely-distributed interbreeding communities it is an open question whether Syngamy would freely take place between the most distant of the outlying sections if directly brought into contact, and whether, even if Syngamy prevailed, there would be any diminution in fertility.

Limnas chrysippus, perhaps the commonest butterfly in the world, forms a probably continuous syngamic chain stretching from the Cape of Good Hope at least as far as Southern China. It is even reported from Japan. The far Eastern forms are readily distinguishable by the greater size of a single white spot, giving quite a different appearance to the fore-wing. If pupae or eggs were transferred from Hong-Kong or Macao to South Africa, would the perfect butterflies freely interbreed with the indigenous forms of chrysippus? We do not know ; but it is an experiment well worth trying, and one which

'I saw some broods of $P$. phlaeas lately that differed from each other, but each brood was remarkably uniform. There were three broods, all bred in the same conditions, in a greenhouse (by Mr. Carpenter of Leatherhead). It seems difficult to explain this, unless both parents of each brood were very nearly identical.

'Mr. Frohawk, who has bred the species largely, tells me he has noticed similar facts.

'When I bred Acronycta tridens and psi largely, some fifteen or more years ago, I noticed that each brood had its own facies, and suggested that tridens was now trying to break up into separate species just as some ancestor split into psi, tridens, and cuspis.

'Another fact I observed in Acronycta rather bears on the other side of the question. Of $A$. strigosa I reared a large brood, which paired readily and frequently together, but no eggs were laid. I then got some captured males, which paired with equal readiness with the bred females, and as a result obtained plenty of fertile eggs.' 


\section{THE BREAKING OF A SYNGAMIC CHAIN 89}

would yield results valuable in many ways. If interbreeding did not take place, or if the unions were sterile, then we should have the interesting case of a single species which would instantly become two if through any circumstance a central link dropped out of the chain. Even if chrysippus yielded negative evidence in this respect, it is highly probable that other widely-distributed species would, under these circumstances, fall into two or more groups, each held together by interbreeding, and divided from others by Asyngamy.

Sterility, if present in any degree, would have been brought about quite independently of selection; for in such cases each link of the chain would be freely syngamic with the links on either side, and Asyngamy or sterility would only be revealed by artificially bringing together the widely-separated ends of the chain.

I cannot but think, therefore, that such experiments made upon many carefully-selected species would probably bring important additional evidence to bear upon the controversy as to whether sterility between species is, as Wallace believes, a selected quality, or, as Darwin held, an incidental one. The deep interest of this question is realized when we thus remember that the two discoverers of Natural Selection held widely different opinions about it. We cannot read the letters on both sides, printed in the first volume of More Letters, without realizing how deeply this divergence-one of the principal differences between them-was felt by the two great naturalists.

This is one of the many reasons for which I plead with $\mathrm{Mr}$. Roland Trimen ${ }^{1}$ for the establishment of tropical biological stations where work of the kind could be carried on. Such establishments should be associated with and be under the control of museums at home, where the experiments could be directed and the results studied and made available for all time for the researches

${ }^{1}$ In his two Presidential Addresses to the Entomological Society of London. Proc. Ent. Soc. Lond., 1897, pp. xcvi, xcvii ; 1898, pp. Ixxvii, Ixxviii. See also his remarks from the Chair in the discussion on May 5 , I 897 , loc. cit. pp. xxxi, xxxii. 
of the naturalist. Just as Harvard has her main Observatory at the University, but also maintains an outlying institution in the Peruvian Andes, where certain kinds of research, unsuited to New England, can be carried on under the most favourable conditions, so our chief museums should be provided with the means of establishing temporary stations in the most favourable parts of the tropics. When I say temporary, I do not refer to the means, but to the position of the station, which should be freely movable in response to the call of important problems as they present themselves for solution in other localities.

Another urgent reason for the establishment of biological stations is forced upon us by the inadequacy of Diagnosis for the separation of very variable species, such as many of the African Acraeinae. I cordially agree with the view often expressed to me by my friend Mr. F. A. Heron, of the British Museum of Natural History, that we shall never reach a secure foundation until epigonic series have been obtained on a large scale. To achieve this end a temporary station would be required. In this way our museums could receive, and should keep for permanent study, the whole of the offspring reared from the eggs of a single parent. If several species were thus represented by one or more large epigonic series, we should know what to expect and what to allow for ; and Diagnosis in general would gain the most helpful guidance.

\section{Asyngamy as a consequence of certain Adaptations for Cross-Fertilization.}

Asyngamy, as regards particular lines of union, has also been incidentally brought about by certain adaptations for cross-fertilization in plants, and such Asyngamy has in some cases persisted long enough to have led to sterility in greater or less degree. Of all Darwin's work, that upon the fertilization of heterostyled plants threw most light, he considered, upon sterility between species. As Francis Darwin has stated, ' $\mathrm{He}$ found that a wonder- 
fully close parallelism exists between hybridisation and certain forms of fertilisation among heterostyled plants. So that it is hardly an exaggeration to say that the "illegitimately" reared seedlings are hybrids, although both their parents belong to identically the same species. In a letter to Professor Huxley, given in the second volume [of Life and Letters] (p. 384), my father writes as if his researches on heterostyled plants tended to make him believe that sterility is a selected or acquired quality. But in his later publications, e.g. in the sixth edition of the "Origin", he adheres to the belief that sterility is an incidental rather than a selected quality. The result of his work on heterostyled plants is of importance as showing that sterility is no test of specific distinctness, and that it depends on differentiation of the sexual elements which is independent of any racial difference.' 1

The different forms of a heterostyled plant are adapted for cross-fertilization by insects, and each individual of each form is by the same means excluded more or less completely from fertilization by another of the same form. In the former case the sexual cells and the accessory apparatus have been kept by selection during long generations of Syngamy in a high state of mutual compatibility; in the latter Asyngamy, partial or complete, has produced a large measure of the sterility which is its inevitable even if long-delayed result.

\section{Are the injurious effects of Self-Firtilization the conse-} quence and not the cause of the Adaptations for Cross-Fertilization"

The argument based upon heterostyled plants has, I admit, carried me much further than I originally intended, and it will be a pleasure to me if the following criticism can be overthrown.

If the special adaptation of heterostyled plants for particular lines of Syngamy has incidentally resulted in lessened fertility, when the unions discouraged by these adaptations are artificially secured, and in this case

${ }^{1}$ Life and Letters, vol. iii, p. 296. 
without appeal to the physiologically injurious effects of self-fertilization, why should we not similarly explain these effects whenever manifest in the self-bred ${ }^{1}$ offspring of any plant especially adapted for cross-fertilization?

Darwin tells us in the Autobiography that as soon as his 'attention was thoroughly aroused to the remarkable fact that seedlings of self-fertilised parentage are inferior, even in the first generation, in height and vigour to seedlings of cross-fertilised parentage', ${ }^{2}$ he entered upon a series of experiments which lasted eleven years, appearing in 1876 as Effects of Cross and Self-Fertilisation in the Vegetable Kingdom. Of this work he wrote in I $88 \mathrm{I}$, "the results there arrived at explain, as I believe, the endless and wonderful contrivances for the transportal of pollen from one plant to another of the samespecies.' 3 It is here suggested that these injurious results have been not the cause but the consequence of specialization for cross-fertilization. In such plants fertilization is mainly brought about along the line for which special adaptation is made: self-fertilization is relatively infrequent, often very rare, sometimes perhaps absent altogether. May not the less successful results have followed from a condition in which self-fertilization is but little tried by the fires of selection ? ${ }^{4}$ It would be of much interest to compare a long series of experiments on the cross-fertilization of plants which are habitually self-fertilized and on the self-fertilization of plants in which the adaptations for cross-fertilization are made use of in widely different degrees.

This criticism, should it be sustained, would of course throw much light upon the case of the Bee Orchis and the numbers of tropical Orchidaceae, \&c., which are now known to be regularly self-fertilizing without apparent physiological injury. It would also bear powerfully upon an intrusive set of facts which must often have weighed upon the minds of naturalists as they reflected upon the

${ }^{1}$ See The Knight-Darwin Law, by Francis Darwin in Nature, October 27,1898, p. 630 .

2 Life and Letters, vol. i, p. 96.

s Ibid. vol. i, p. 97.

4 See also A. R. Wallace in Darwinism, London, 1889, pp. $321-6$. 
commonly received hypothesis that assumes the dangers of continued breeding between near of kin. A. R. Wallace speaks of these facts in Darwinism, ${ }^{1}$ and I have drawn attention to them in discussing the meaning of insect migration, although, as will be seen in the following passage, without any serious doubt as to the physiological significance of cross-fertilization. ${ }^{2}$

We may well inquire why it should be necessary for such emigration, with a possible successful issue in colonization, to require the services of countless individuals when the importation of half a dozen rabbits or a few specimens of Pieris rapae will, for the naturalist, change the face of a continent. The results of these unintentional, or intentional but ill-considered, experiments do indeed shake the belief in the paramount necessity for crosses and the dangers of in-and-in breeding; but the end is not yet, and the teeming colonies which have arisen from such small beginnings may in time vanish from the operation of deep-seated causes. The varied adaptations for cross-fertilization and the prevention of in-and-in breeding are so evident in nature, that we are compelled to believe that they meet and counteract serious dangers which sooner or later would menace the very existence of the species.' ${ }^{3}$ But now the considerations set forth in this and the preceding Section throw doubt upon the existence of such serious dangers and the reality of any such compulsion.

It is impossible to do more than mention certain advantages which may have favoured cross-fertilization, if hereafter the generally accepted physiological necessity turn out to be a delusion. Brief reference may, however, be made to the special advantages of community which are possible through Syngamy alone. By interbreeding the favourable variations arising in one direction are combined with others arising in different directions; by the kaleidoscopic changes produced by interbreeding more varied results are presented for selection, and the beneficial qualities arising in one part of the mass may quickly become

${ }^{1}$ p. 326.

2 Trans. Ent. Soc. Lond., 1902, pp. 460-65. ${ }^{3}$ loc. cit. p. 464. 
the heritage of the whole; by interbreeding excessive spontaneous variation is checked, and the whole community of the species advances surely and with stability into adjustment with the progressive changes of the environment.

We all remember Darwin's beautifully elaborated metaphor ${ }^{1}$ by which the past history of evolution is shown forth in the form and branching of a great tree. Darwin represented species by the 'green and budding twigs', and we may suppose that the leaves stand for individuals, and that Syngamy is represented by the contact of leaf with leaf when the branches sway in the wind. And just as contact may run through large and small, irregular and compact masses of leaves, so Syngamy binds together groups of varying size and distribution. So too a mass of foliage breached by a sudden storm pictures for us the splitting of a syngamic chain into two species by the disappearance of an intermediate link.

It has been a pleasure to me that the central idea which I have endeavoured to bring before you should be represented, I trust without violence to the imagery, by means of 'the great Tree of Life, which fills with its dead and broken branches the crust of the earth, and covers the surface with its ever branching and beautiful ramifications'. ${ }^{2}$ 


\section{III}

\section{THEORIES OF EVOLUTION}

An Address delivered to the Boston Society of Natural History, as an Introduction to the Discussion, held on February 7, 1894. Reprinted from the Proceedings of the Society, vol. xxvi, p. $3^{27}$.

Revised: additional footnotes.

IN dealing with theories of evolution, I think that we shall all be agreed that we may leave out of consideration the question of the origin of life, and deal only with what has happened to life after its appearance, however that may have taken place. On this subject we shall probably most of us still agree with the opinion of Darwin ${ }^{1}$, that we are not in a position to even speculate or think upon that question,- - that any speculation about it is almost a waste of time. And this, I think, remains true in spite of the magnificent results of the organic chemists in producing chemical bodies by synthesis, which before had been regarded as capable of being made only in the laboratory of the living body. Many of these can now certainly be produced, but that is very different indeed from creating protoplasm endowed with life; and so far are we from achieving this by any chemical means that I think we may venture to dismiss all consideration of the ultimate origin of life.

But granting the origin of living matter, these theories of evolution which we are considering and hope to discuss to-night can deal with it, and with their help we believe that we can account for what has subsequently happened; namely, the evolution of all forms of life, animal and vegetable, upon the surface of the earth.

The first of these theories which I propose to discuss is the well-known Darwin-Wallace theory of Natural Selection, with its three factors.

First, Individual Variation,- the fact that individuals differ, and that the differences are essential or inherent 
in the organism, so that even if animals were brought up alike, we know they would still be unlike, and so that, however much the offspring may resemble their parents, they are never exactly like their parents or exactly like each other. There is, then, first, individual difference, one of the most essential facts in the organism.

Secondly, the fact of Heredity, - the fact that these inherent differences may be and are inherited. Although the hereditary transmission of acquired differences is disputed, the transmission of those that are inherent is certain. This stands before us as one of the most obvious and certain of conclusions, equally proved by the observation and experience of every one of us.

Thirdly, the fact that there must be a Struggle for Existence; that there are far more individuals born into the world in every species, even the most slowly increasing, than can possibly survive and reproduce.

These three factors must by logical necessity lead to a survival of the fittest among individual variations. It does not require a scientific mind to comprehend that, to infer that some amount of evolution must ensue from the co-operation of those three factors, every one of which stands firm and undisputed. Among all the advocates of rival theories which have been brought forward to explain evolution, no one has ever ventured to attempt to disprove any one of these three factors. They stand unchallenged.

The politician, Henry Fawcett, saw, long before scientific people themselves understood what Darwin meant by Natural Selection, that logically some result must ensue from such co-operation. Fawcett said that Natural Selection must produce evolution as surely as a round stone will roll further than a square one. Some measure of evolution is simply the logical result of the co-opera. tion of these three undisputed, abundantly proved factors.

Now, certain writers have thought to undermine the theory of Natural Selection by arguing that the important and essential factor of individual variation is not explained by the theory which rests upon it. True, it is not; but for the theory of Natural Selection, the explanation does 
not signify. So long as individual variation is present, so long as it is hereditary, it does not signify how it is produced. There are, indeed, many theories professing to account for it; but biologists are not generally agreed as to the manner in which it is produced. But so long as it is there, it is available, and Natural Selection can make use of it.

It is interesting to note that, when Newton discovered the principle of Universal Gravitation, some people maintained that he had discovered nothing because he had not explained what gravity itself was. Now, after over two hundred years, we can safely assert that Universal Gravitation stands out as one of the most triumphant discoveries of the human intellect; and yet we, even now, are just as much in the dark as to what gravitation itself is as when Newton wrote. Exactly so it is with regard to individual variation. So long as it is a fact essential to organic nature, that one individual must be different from another, and so long as these differences are hereditary, so long may Natural Selection have abundant material for its work, even though it does not itself explain how that individual difference is produced. I am very far from undervaluing the interest of such an explanation; on the contrary, I maintain that it forms one of the most interesting of biological problems now before the scientific world, or likely to be before it for many a day.

In fact, every successful attempt at scientific explanation only interprets down to a certain level of causation; and this is just as true of Universal Gravitation and Natural Selection as it is of smaller efforts. Down to a certain level of causation, Natural Selection explains at any rate some part of organic evolution. A more fundamental level would be to explain the factors upon which Natural Selection itself depends; but because we have not yet reached that lower level, we have no reason for doubting, as some would believe, the complete efficiency, at its own level, of the explanation we do happily possess.

The theory which stands in contrast with Natural Selection, and has been supported in the United States more fully than in any other civilized country, with the 
exception of France, is the theory we usually attribute to Lamarck. Erasmus Darwin in England, however, has the priority, in that he first brought forward the principles which Lamarck more effectively supported. But to Herbert Spencer belongs the chief credit, because he has taken that part of the earlier theory which is acceptable to modern biological thought, and upon this basis has formed his great theory of evolution.

Lamarck believed in an innate tendency toward perfection in animals. Now, that is a view which very few zoologists at the present time, if any, would dare to sustain. In fact, an evolution due to an innate principle of perfection is not very far removed from special creation,- - a doctrine which opposes any theory of evolution. Herbert Spencer, therefore, rejecting all those elements of Lamarck, which the scientific world could not possibly accept, has taken that which was likely to commend itself to science, and upon it has formed his great theory of evolution; so that the Lamarckian Theory, as presented to the world to-day, comes before it in Spencerian language, and in the closest relation to Spencerian thought. In saying this, however, I do not by any means intend to be understood as supporting Spencer's theories or the views upon which he bases them.

The Lamarckian Theory, then, upon which Spencer has based his philosophy, is a theory of evolution dependent, not like Natural Selection upon three factors, but upon two. It depends first of all upon the effect wrought on the individual by that which happens during its lifetime. Instead of depending on those innate and essential differences upon which Natural Selection rests, this theory depends on those changes which are caused during the life of the individual,- the action of some external force upon it, the effect of its own will, the changes produced by the use and disuse of its own parts. The Lamarckian Theory depends in fact on all those changes in an individual which we now call its Acquired Characters; that is, characters which the individual has come to possess but which were not potentially present at the very beginning of its development. 
The first factor, therefore, is made up by changes that are wrought in this way. The second factor is Heredity, by which it is supposed that these changes are transmitted; and it is certainly true that if such transmission is possible, some amount of evolution must result. You will all be prepared to admit that if these two factors represent facts, their co-operation must produce some amount of evolution.

It is important to remember, however, that both factors are not undisputed, as are the three factors of Darwinian Evolution. Although we all admit the existence. of acquired characters as the effect of external causes upon the individual during its life, yet biologists are by no means agreed that these effects are hereditary, and, if not, the acquired character ends with the individual in which it arose, and, not being handed on, can never become a character of the species. It is impossible for those who hold the Lamarckian or Spencerian view to escape from this. If it is true that such characters are transmitted, then the foundation of the theory is secure; but the transmission of acquired characters is by no means proved. Herbert Spencer has preferred to occupy himself in building a magnificent edifice upon this foundation, rather than employ his acute intellect in testing its firmness and security in every possible way.

So far as observation goes, all those characters which are believed by many to owe their origin to the Lamarckian principle are present, actually or potentially, in the individual before the beginning of its active life, before the operation of those causes which were believed originally to account for the characters. According to the Lamarckian Theory such characters have already become hereditary; and therefore it is of essential importance to the Lamarckian to prove that acquired modifications can be and are transmitted. Only in this way can he give good grounds for the opinion that such characters, when they occur ready-made in the individual, are to be explained by the action of external causes during the lives of ancestors.

These are the two main theories of evolution. There 
are several others, upon which I will dwell only for a moment because these two alone command any very large amount of attention at the present time.

In the first place, Lamarck's theory of the innate tendency towards progressive perfection in animals is not held in exactly that form, but some zoologists in the United States and other countries believe that they see evidence in the rise and fall of certain groups of fossil animals for the existence of a tendency towards extinction, or a tendency towards sudden growth, which lies within the animal itself and is not determined by any external cause. That is a very close approach to Lamarck's original principle of an innate tendency in one direction or another. I will not discuss it at any length, because I think that this evening if we can get a clear idea and attempt some discussion of the merits of the two main theories of evolution, that will be as much as we can expect. I will only say with regard to the subject that arguments based upon fossil remains are apt to be somewhat dangerous, because we have, at least so far as the conditions of life are concerned, so small an amount of evidence. In certain parts of Africa, for instance, the presence of the tse-tse fly absolutely limits the existence of some of the larger quadrupeds. Wherever that fly is, the animal cannot exist. It is very possible that in future times skeletons will be found in specially large numbers on the borders of districts where the fly abounded, and any attempt to argue, from the appearance of the skeletons themselves, as to the causes of this great extinction will obviously be entirely false and misleading. We have in the skeleton of an animal so small an indication of the events of its life and the conditions of its death, that it is, except in very rare cases, most unsafe to argue as to the causes of its extinction.

Another theory of evolution is one which has been brought forward by Professor Geddes of Edinburgh. He believes that there is an innate tendency towards growth and towards that dissipation of matter which constitutes its reverse,- the anabolic and katabolic tendencies, as he 
calls them. But that view, although he argues it with much eloquence, has not been widely accepted, and I think it will be generally admitted that it does not yet rest on sufficient proof.

In addition to these, there are some who maintain the position that there is an unknown cause of evolution. They believe that these theories, although one or more of them may be of value, are yet insufficient to account for organic evolution. Those who take this line are of course logically bound to bring forward the classes of facts with which no existing theory is, as they maintain, competent to deal.

All we shall have time for to-night is briefly to compare Natural Selection, the Darwinian interpretation of evolution, with the Lamarckian Theory. It is interesting to note that, although they are so essentially distinct one from another, in earlier times these two theories appear to have been entirely confused. Lamarckian Evolution, Spencerian Evolution, appeals to the mind of man far more strongly than Darwinian Evolution. Any one of us, were he to have created the organic world, would certainly have created it according to Lamarck. We should have made evolution by use and disuse of parts, and not by Natural Selection. However, we are not concerned with the sort of world that we should have created. The question before us as scientific men is not what might have happened, but what has happened. Nature, as I have heard Prof. Michael Foster say, has a very queer way of going by roundabout paths and refusing to take the roads we should lay out for her ourselves,-roads which we look upon as the most direct and obvious. The fact that the general aspect of the Lamarckian Theory commends itself to the human mind affords no reason for looking upon it as the correct one, as opposed to the Darwinian Theory.

The Duke of Argyll, who is still strongly antagonistic to Natural Selection, a few years ago wrote an article in The Nineteenth Century called The Power of Loose Analogy: By this title he intended to imply that those who believe in Natural Selection have been led away 
by the specious character of the words themselves. I suppose that the Duke feels himself bound to account in some way or other for the fact that people believe in Natural Selection, while he does not, and accordingly he suggests that the seductive power of the title employed by Darwin has misled the scientific mind into a belief in the process itself,-only rare and subtle intellects like his own being proof against such an allurement. Natural: a word expressive of familiar objects and processes always around us. Selection: a process with which we are all familiar. In this way it seems reasonable to the Duke of Argyll to suppose that men have been misled by the seductive nature of the terms employed by Darwin. The terms apply to processes familiar to every one, and therefore every one accepted them at once, without inquiring what they really meant. This is, of course, an explanation eminently satisfactory to the single writer who was not to be overcome by 'the power of loose analogy'. But when we proceed to test this ingenious suggestion, and look into the history of the times to which it applies, when we read Darwin's letters, we find that he continually complains that people do not understand what he means by Natural Selection, and he almost regrets having used the words. He says more than once that he wishes he had employed Herbert Spencer's term, the Survival of the Fittest, because his own title, Natural Selection, is comprehended with such difficulty.

When we look to another class of evidence we find equally sure ground for the conviction that Natural Selection was driven into men's minds with the very greatest difficulty, and by no means with the ease which the Duke of Argyll assumes. It is very interesting to consult the various skits written between twenty and thirty-five years ago, ${ }^{1}$ in which the writers supposed that they were making fun of Darwin's theory. If you will read them, you will be struck by one very remarkable fact : their authors are all making fun of Lamarck when they believe they are making fun of Darwin.

${ }_{1}$ The discussion at which these words were used took place Feb. 7, 1894 . 


\section{EARLY PARODIES OF DARWINISM 103}

I remember once seeing a picture in Punch, representing the evolution of the power of flight by the human species. It represented a man standing upon the roof of a house and waving his hands, which, in consequence of the use to which they were put during his individual life, grew somewhat in size. Passing down to the next generation, his son was found waving rather larger hands, and the waving made them still larger. In the course of generations the descendants acquired large wings and flew down from the roof of the house. That was supposed to be a parody on evolution according to Darwin. I have called it a skit, but you will see at once that you cannot get a better illustration of Lamarckism. It is Lamarckism. It is not making fun of it; it is a description of the process itself.

Then Lord Neaves wrote a song [May, 186I] in which he attempted to make great fun of Darwin's theory. It was a very long song, many verses of which were skits upon Lamarck, while supposed to be skits upon Darwin.

A deer with a neck that was longer by half

Than the rest of its family's (try not to laugh),

By stretching and stretching, became a Giraffe,

Which nobody can deny.

This is pure Lamarckism. The evolution was supposed to be caused by stretching without any selection at all.

The best example of all, however, is given by Mr. Courthope, in his Paradise of Birds [1870]. I commend his account of the evolution of birds and mammals to those who believe the Lamarckian Theory. He tells us there about the Ornithorhynchus, which he praises as a very prudent beast :-

For he saw in the distance the strife for existence,

That must his grandchildren betide,

And resolved, as he could, for their ultimate good,

A remedy sure to provide.

With that, to prepare each descendant and heir

For a different diet and clime,

He laid, as a test, four eggs in his nest-

But he only laid two at a time. 
On the first he sat still, and kept using his bill, That the head in his chicks might prevail:

Ere he hatched the next young, head downwards be slung From the branches, to lengthen his tail.

Conceive how he watched till his chickens were hatched, With what joy he observed that each brood

Were unlike at the start, had their dwellings apart, And distinct adaptations for food.

From the bill, in brief words, were developed the Birds,

Unless our tame pigeons and ducks lie;

From the tail and hind legs, in the second-laid eggs,

The Apes and-Professor Huxley.

If we now turn to the skits on evolution written at the present day we find they are very different. Miss May Kendall, in writing her Ballad of the Ichthyosaurus, only a few years ago [1887], says :-

E'er Man was developed, our brother,

We swam and we ducked and we dived, And we dined, as a rule, on each other-

What matter, the toughest survived.

This is true Natural Selection. The authoress understood what she was talking about. But, strangely enough, what might well be looked upon as the most incisive parody of Natural Selection was published more than ten years too early! The first part of James Russell Lowell's Biglow Papers appeared between 1846 and 1848 . One of the earlier poems contains the following lines :-

Some flossifers think thet a fakkilty's granted

The minnit it's proved to be thoroughly wanted,

Thet a change o' demand makes a change o' condition,

An' thet everythin' 's nothin' except by position;

$\mathrm{Ez}$, fer instance, thet rubber-trees fust begun bearin'

Wen p'litikle conshunces come into wearin', -

Thet the fears of a monkey, whose holt chanced to fail,

Drawed the vertibry out to a prehensile tail.

If these amusing verses had been written later they would certainly have been accepted as a satire upon the origin as opposed to the survival of the fittest. As it is, we must believe that they were indirectly inspired by the Lamarckian idea of change wrought by the desires of animals. The publication in 1844 of the Vestiges of the 
ELIMINATION VERSUS SELECTION 105

Natural History of Creation was probably the immediate occasion of the parody.

Another interesting question has been raised by Professor Lloyd Morgan as to whether the phrase 'Natural Elimination' would not be a more correct one than 'Natural Selection'. The process is, of course, selection by and through elimination. The survival of the fittest means the elimination of the unfittest.

The relation between selection and elimination has been put in a very striking way by Mr. Samuel Butler, who says that according to Natural Selection we are what we are, not by the successes of our fathers and mothers, but by the failures of our uncles and aunts. The question is, shall we dignify with the title of this important cause of evolution those who have failed in the struggle, and do not happen to be the ancestors of any living species, or those who have succeeded in the struggle and are now abundantly represented by descendants? I think that 'Natural Selection' forms on the whole the best term for the process. It has the advantage, also, of being the historic term proposed by Darwin.

Another important point in favour of 'Natural Selection' as a term is that it suggests a parallelism or comparison with the process of Artificial Selection. Yet another point is the fact that you may find in the words themselves all the three factors obviously suggested; for selection would be impossible without individual difference, and it would be useless unless these differences were hereditary; and, furthermore, selection implies something which selects; that is to say, the conditions of nature. The rate of increase makes a struggle for existence inevitable : natural conditions at the time determine the relationship between the qualities of survivors and the qualities of those that fail. The three factors of Natural Selection are implied by the very words themselves.

Now I want very briefly to bring forward the chief objections that have been urged against Natural Selection. In the first place, if Natural Selection be true, all the varied characters of animals and plants must prove to be 


\section{6 \\ THEORIES OF EVOLUTION}

useful to the possessor in the struggle, or to have been useful at some time in its history.

We are only required, however, to prove utility as regards undoubted characters of the species,- and these are hereditary,- and we must put on one side certain characters which are confined to the individual in which they appear. For instance, if it were proved that the Mollusca of any one river differed from those of the same species in another river, but that the differences were confined to the individuals in which they occurred, so that if these Mollusca were placed when young in the second river, they would come to resemble those which were proper to it, then we should not be concerned with characters of the species at all. The language spoken by a nation similarly is not a character of the human species, for we know that a child of another nation would acquire it perfectly, together with the particular modes of thought and expression, tortuous or direct, which are associated with it. These results of environment are not characters of the human species. The individuals of the human species come into the world with a certain elasticity, a certain power of being developed in various directions. But although the elasticity itself is a character of the species, and is inherent, the particular quality in which it may result when developed by environment is certainly not a specific character.

The more we study the characters of animals in general, even though we at first can see no utility, the more we come to admit this principle, and to believe that either now or in some past time, the characters have been useful. I can certainly say of many characters which I have studied in some of my investigations, that at first they seemed to be meaningless, but afterwards appeared to be of much importance in the struggle for existence. I think we may safely assume with regard to many characters of which we can now see no explanation that ultimately the explanation will be forthcoming.

Being unable to prove utility does not invalidate Natural Selection. If inutility could be proved for any large class of characters, the theory would certainly be 
destroyed as a wide-reaching and significant process. I do not think, however, that any such evidence has been forthcoming. I shall be interested in the discussion which follows this paper to hear whether those who believe in the Lamarckian Theory have such evidence to produce, whether they can prove that any one great class of characters has been useless in the past and remains useless in the present.

Another kind of objection has. been urged long ago, and is still urged to-day. Why do we not find in the palaeontological series the records of individual failures? Now, as regards the individuals of a species we cannot expect to find any such evidence. What is failure? Failure means, according to Natural Selection, the failure to produce offspring. The individual which comes into the world and dies without offspring has failed. The individual which is represented in the generations of the future has succeeded. Natural Selection has set its stamp upon that individual. But it is impossible to decide from the fossil record whether any particular individual of sufficient maturity had failed or succeeded. We have not got the facts before us by which we can form any conclusions.

Furthermore, we know the struggle for existence is excessively complicated. The skeleton alone, though of the highest value in association with the rest of the organism, has been the sole turning-point in the struggle in a comparatively small number of cases. When it has been the turning-point in association with other parts, these latter are absent. We have only a very small part of the problem before us, and never can expect any more.

But while we cannot expect to find evidence of the survival of the fittest among the individuals of a species, we may expect to find it in the supplanting of classes by classes, of groups of species by groups of species. Some of the facts which have been brought forward as evidence in this direction do, to my mind, very strongly support the theory of Natural Selection by palaeontological evidence. Consider especially the case of the large mammals preceding those which gave rise to the quad- 
rupeds now upon the earth. So far as we can judge of these huge forms by their skeletons, they appear to have possessed a bodily structure as well fitted to survive as that of many now living in the world; but they differed from these latter in that they had extremely small brains. We can easily understand that inferiority of intellect would cause them to be worsted by animals which were in other respects no better endowed.

Exactly parallel is the relation of man and the apes. In bodily structure the difference is insignificant. In the brain, however, we meet an important and essential distinction. It would appear here that Natural Selection has taken one particular part of the organism of paramount importance in the struggle, and has developed that rather than made a change along the whole line.

We see the same relationship in the gigantic reptiles of the Secondary Period as compared with the mammals of the Tertiary. The latter with their larger brains and higher intelligence were able to supplant the former, just as they have in turn been supplanted by the still larger brained animals whose descendants now people the earth. All this seems to me to afford very strong support to the theory of Natural Selection.

Passing now to another class of objections: Natural Selection, it is said, can never account for the beginnings of things. Until an organ is raised to a useful level, selection can have nothing to do with it. At first sight that is a serious objection, but it suggests its own answer, viz. that an organ so rarely develops $a b$ initio. Organs are not formed anew in an animal, but they are formed by the modification of pre-existing organs ; so that, instead of having one beginning for each organ, we have to push the beginning further and further back, and find that a single origin accounts for several successive organs, or at any rate several functions instead of one.

The typical vertebrate has four limbs. These in fishes are used for swimming, while in terrestrial forms the same limbs are modified and used for walking. New organs are not introduced, but the old are modified for a new purpose. When the terrestrial form again becomes 
aquatic, the limb that was used for terrestrial progression is modified back into a functional fin; and again, when flight becomes necessary, the same organ is used for the new function. So that whatever the changes in the mode of progression, we need no new organ at all; for the old organ is used for the new purpose. It is very much easier to understand how a useful level can be attained in that way than by organs starting ab initio. But of course we must come down to a true beginning if we push our inquiries far enough. In attempting this, we are carried to those remote times in which the ancestors of vertebrates arose. Upon these forms we can do no more than speculate, but it is at any rate impossible to prove that bud-like projections from the body, probably later reduced to four, may not have been useful, from their very beginning, to a slender worm-like animal for pushing its way through mud or thick weeds, or for the purpose of respiration. Professor E. B. Tylor has told me that he believes that the same thing holds with regard to human weapons. He said that, in examining ancient weapons, he was often struck with the fact that a weapon or implement had ultimately turned out to be so very much more useful for a new purpose rather than that for which it was originally formed. Here, then, one origin apparently accounts for several forms of implement.

Another objection raised against Natural Selection is that a selective cause is never a true cause. Professor Cope means to imply that when he speaks of the 'Origin of the fittest'. But Darwin's argument on this point is perfectly sufficient. He says that when a man drops iron into sulphuric acid, he does not originate the chemical force that operates, but he may be fairly said to make sulphate of iron. So Natural Selection does not itself originate the factors upon which it depends, but it is so essential to the result that it may be fairly looked upon as the true cause (at that level of causation). In Galton's work we have a most complete inquiry into human variation and its inheritance, and he shows us that such variation by itself, unguided by selection, can never advance to anything. Even if you start with ancestors 
who are remarkable for any intellectual or structural feature, their descendants, although some of them may partake of their parents' peculiarities, sometimes even to an increased extent, will ultimately return to the pattern of the race. There is always a 'recession towards mediocrity'. Hence, unguided variation can never explain the 'origin of the fittest'. [Since these last words were written De Vries and others have brought forward many facts which, as they believe, support the hypothesis that sudden large variations lead to a fresh position of organic stability and the origin of a new species by 'Mutation'. Natural Selection is, however, still invoked in order to arbitrate between different mutations, as well as between these and the parent species. A final decision as to whether the course of evolutionary history has been interrupted or continuous will probably be reached by the study of Palaeontology.]

I have briefly touched on some of the chief difficulties which are advanced against Natural Selection. I now propose to devote the remaining part of my time to the difficulties which seem to me to apply to the Lamarckian Theory.

Lamarckian Evolution, as I have mentioned before, depends upon acquired characters. A good deal of misconception has arisen from this use of the word 'acquired'. An acquired character has sometimes been interpreted to mean any character that an animal has come to possess; hence, inherent and acquired characters have been confused. The word 'acquired', as used by biologists, must be understood to have a limited and special application, meaning only those characters which have been produced in the organism by the incidence of external forces, or by the action of its own forces, use and disuse of parts, and so on, during its life. Weismann has suggested the term 'Blastogenic' for characters potentially present in the germ at the very beginning of life, and 'Somatogenic' for those which appear afterwards and are not potentially present in the germ. Here blastogenic is the equivalent of inherent, and somatogenic of acquired.

Some years ago I suggested that the terms 'Centri- 
petal' and 'Centrifugal' might be employed to express this acquired difference. ${ }^{1}$ Acquired characters are centripetal, because they are impressed upon the body or one of its parts from without ; inherent characters are centrifugal, because, arising from within due to the essential nature of the organism itself, in the course of development they come to appear, as it were, on the surface as visible features.

When we now consider the transmission of acquired characters, upon which the Lamarckian Theory certainly depends, we are led first of all to inquire whether it is possible to frame a theory of heredity within which such transmission can be included. If, for instance, there is a change in the brain of an animal, owing to the exercise of some part of it, how can such a change in the braincell be transferred to the germ-cells of the animal, so as to be transmitted to its offspring? It may be objected, if you can prove that such transmission does take place, it is no matter how it takes place. Quite true, if the evidence is sufficient and indisputable. But we must remember that the amount of evidence required, in order that there may be sufficient, depends upon the probability or improbability of the thing to be proved. This view is extremely well put by Professor Huxley in his memoir of Hume, where he says that if any one came to him and stated that he had seen a piebald horse in Piccadilly he would be prepared to believe it; that he might require confirmatory evidence if the statement were that a zebra had been seen; but that if even the friend in whom he trusted told him he had seen a centaur trotting down that eminent thoroughfare, he should emphatically disbelieve it, and that nothing short of a monograph on the anatomy of the centaur by a comparative anatomist of the stamp of Johannes Müller would convince him that the observation was correct. We are compelled to admit that the amount of evidence we require does to a great extent depend upon the inherent probability or improbability of the conclusion to be sustained. If it appears to us to be almost impossible to conceive of a mechanism whereby 
an acquired character can be transmitted from the outlying parts of the organism to its germ-cells, then we have every reason for scrutinizing most carefully any evidence that is alleged to prove such transmission.

Let me first of all give you a concrete example which is frequently brought forward by those in this country ${ }^{1}$ who believe in the Lamarckian Theory, and have chiefly studied the skeletons of Mammalia. They say the joint of an animal possesses just the sort of shape that would be produced by the motion of the joint itself, and they urge that the joint as we see it has arisen from the hereditary effects of that motion. They look upon this as a very satisfactory explanation, because they consider it to be so obvious and fundamental. You do not require anything further, selection is unnecessary, and even the individual variation-so mysterious a factor of the Darwinian Theory-is here entirely explained.

But is the interpretation valid? In the first place, it is clear that such an hypothesis can never afford a wide or general explanation. There are a great many parts of the animal body which are not modified by their use. You cannot thus explain the growth of hair, or the colour upon the surface of the organism. For these and other useful but passive structures the Lamarckian interpretation will not hold at all. Hence we may divide the organism into two sections, to one of which the Lamarckian Theory might be held to apply, and to the other the Darwinian alone.

But upholders of the Darwinian Theory consider that it applies to the other section as well. They point out, that while the form of the joint is the sort of form that would be produced by the motion, it is also necessarily one which admits of convenient motion, that motion has been essential to the life of the organism, that alert and rapid movements have been a necessity in the struggle for existence, and that any form which would prevent or clog the movements would be at once destroyed by the operation of Natural Selection. Natural Selection they hold to be competent to explain those parts which the

$$
1 \text { The United States. }
$$




\section{PASSIVE AND ACTIVE STRUCTURES II 3}

Lamarckians also claim to explain, while it offers the only explanation of the other parts.

If we suppose that Lamarckian Evolution in part explains the actively used organs, and Darwinian Evolution in part, we should expect that modification would take place more quickly in that section of the organism where the two principles were at work than in the other section where only one principle-the Darwinian-can play a part. But there is no evidence of such especially rapid evolution. It seems to me that we are in a position to use the old principle of cutting off superfluous causes. No unnecessary cause should ever be introduced into an explanation, and if Lamarckism, untenable in the one section, is superfluous in the other, it should be removed, unless there is very clear evidence proving that it has been at work.

Furthermore, in certain cases, such as the protective attitudes and appearances assumed by many animals, we meet with clear evidence that the two kinds of partsthose that are affected by their use and those that are not affected-have undergone development together, suggesting strongly that their evolution has been under the direction of one set of forces, and not of two sets which have little in common.

Having now brought forward certain general objections to the Lamarckian position, let me take exception to one or two special cases.

Certain animals, such as lobsters and crabs, have the power of very readily parting with some of the most important of their members. The large claws are easily thrown off, and this may be of great advantage in the struggle for life, because when an individual is attacked, and has seized the enemy with its claw, it has a chance of escaping. In the case of the lobster, the dismembered claw may not let go of the enemy although the enemy may wish to let go of the claw. The claw may take charge of the enemy while the lobster escapes.

Now that is a very interesting adaptation. We find the claw so constituted that it can be thrown off, but even when thrown off it continues to be of much use to the 
organism. Its nervous and muscular mechanism is so arranged that mutilation actually stimulates it to contract, and it continues to hold the enemy. In the case of certain crabs, the dismembered claws keep snapping and jumping about. The same is true of the tails of many lizards, which, when thrown off, will jump about in the most active way, distracting the attention of the enemy, while the lizard makes its escape. Here, too, mutilation stimulates the nervous and muscular mechanism in claw and tail.

In these cases of actively used parts of the organism the Lamarckian interpretation is absolutely at fault. You cannot apply it. It is impossible to explain upon the theory of the transmitted effects of use and disuse. No activity manifested by the tail after it has ceased to be part of the lizard can ever be transmitted. Not only that, but it is difficult to see how the development undergone by the tail from the effects of use and disuse, \&c., up to the time of its severance, can be hereditary. And so with the claw. The large claws are the most important appendages of the lobster, and yet it is certain that many a lobster loses one of these organs and grows a new one, several times in the course of its life. We have here a very specialized organ with definite functions which continue in even an increased degree after severance from the animal: all this is readily explained by the Darwinian Theory, but cannot be explained by the Lamarckian.

The same inadequacy of the Lamarckian Theory is forced upon us when we examine a little more deeply into the nature of the process which is supposed to occur. The Lamarckians attempt to explain joints and some other structures by the effects of stress and pressure, but when we look into the matter we find that the explanation is not so complete as it is supposed to be.

For instance, it has been believed in the United States by many distinguished biologists that the complex shape of mammalian teeth is due to pressure produced by mastication. As the pressure has been applied to the tooth, so has the tooth grown. But would pressure produce such an effect upon a tooth? That is certainly 


\section{FORMS. OF JOINTS AND TEETH II5}

not our experience. Pressure and friction have an unfortunate way of wearing a hole in the tooth, rather than causing it to grow an elevation. As a matter of fact we know that the shape of teeth is predetermined, long before they are cut, in the soft dental matrix beneath the gum. It is not a question of the transmission of acquired characters, but the supposed transmission of a character which the parent cannot by any means acquire. Teeth, so far as they react to pressure or friction, can only react by wearing away.

With regard to the joint, we are told by some Lamarckian writers that pressure and friction produce the reverse effect and wear away cavities rather than stimulate growth. I was reading the other day a most interesting paper by Dr. Wortman of New York, in which the author attempted to explain the occurrence of a furrow in a joint owing to the pressure of a corresponding ridge. The pressure of the ridge, he said, produces a furrow in the opposite side of the joint. It seems to me that in this we are going a little beyond what physiology and histology teach us and making a blind appeal to mechanical forces unsupported by any adequate investigation of the tissues concerned. Is it likely that a bone would react to intermittent pressure by producing a furrow? It is far more probable that the reverse effect would tend to be caused.

I will only ask one more question with regard to this subject of use and disuse, and that is, why, if you are going to explain any of these parts by pressure and friction, should the process be stopped when a useful level is reached? If the pressure does cause such effects and they are hereditary, how are they prevented from increasing beyond all bounds in the course of generations? Why should pressure on teeth cease to produce further growth, when the tubercle has reached its proper height? The fact that all these shapes of bones and teeth just reach and stay at an adaptive level is the strongest evidence that they are not produced by the operation of mechanical forces, but by Natural Selection.

We now pass to the consideration of indirect evidence: 
that it would be impossible to explain evolution without the Lamarckian Theory.

Time will permit me to deal with only one class of characters, a class associated with the nervous system and manifested as instinct. These instinctive actions are generally thought to be the strongest evidence in favour of Lamarckian Evolution. It has been argued that we cannot explain the instinctive action of animalsthe wonderful instincts which are due, as we know, to modifications of the nervous system,--except by supposing that animals have intelligently modified their actions in consequence of experience and observation, and that the result has then been transmitted and has become the non-intelligent instinct of their offspring. If we had no other explanation of instinctive action, such an interpretation would constitute a strong support to the Lamarckian Theory.

I do not, however, believe that this is the only, or, indeed, the correct explanation of instinct. In considering this question, we must distinguish between the instinct manifested by many of the higher invertebrate animals and much that we are apt to call the instinct of the vertebrates. A great many actions which are put down to instinct in the higher vertebrates, such as birds and mammals, are not instinctive at all, but the result of intelligence. We see an example of this in the altered behaviour of the seal which, as Nansen tells us, took up a position on the outer ice-floes to escape the dangers of the polar bear, and afterwards incurred this very danger on the inner floes to avoid the greater peril from the hunter. This is a clear case of intelligent association, and no instinctive avoidance of danger. So also with a bird which flies away if you have a gun in your hand, but allows you to come near when you have a walkingstick. This is the result of intelligence and not merely instinct; and we must carefully distinguish between a lesson learned by the individual, however well learned and easily repeated it may be, and a true instinctive action which is never learned at all but springs fully formed into existence. Such true instincts certainly occur in the 
higher vertebrates, such as the act of sucking performed so perfectly without any education or practice by the newly-born mammal. But in the lower animals true instincts are relatively far more numerous and play a most prominent part in the life of the individual. In these cases of true instinct I would suggest that we are dealing with actions which have never been intelligent at any time in the past history of the species, but have arisen through the operation of Natural Selection upon the nervous system. Certain activities which are most strongly held to be the outcome of the transmission of experience and the acquired results of practice obviously cannot be explained in this way.

For instance, how upon any such hypothesis can you explain the wonderful structure of the cocoon spun by the larva of an insect? The view would be, I suppose, that the ancestral larva spun a cocoon which was not much of a success and was in consequence attacked by enemies; that the larva observed these attacks, and accordingly improved its cocoon. But that is not the way in which the struggle for existence is waged with insects. If the larva failed, it failed, and that would be the end of the matter. It has no chance of improvement; it has no opportunity of learning by experience. Its only chance of survival is to avoid experience of foes altogether; experience is the most dangerous thing in the world to an edible insect. This becomes still more obvious when we remember that failure or success is almost always determined long after the cocoon is made. The caterpillar perhaps spins the cocoon in autumn, but the real stress of competition will come in winter, when insecteating animals are pressed hard with hunger and search high and low for food. But the caterpillar by this time is a chrysalis and of course has no opportunity of improving the cocoon. The selective test is applied long after the operation has been performed, and when there is no possibility of gaining by experience. We are thrown back, then, solely upon Natural Selection, which acts on the nervous system of the caterpillar, and thus compels it to make the cocoon in a certain way. In other words, 
those caterpillars which are impelled by their nervous system to make ill-formed, conspicuous cocoons have no chance of living, and, in the perfect stage, of producing offspring. Hence, the selection caused by the keen sight of foes first raises and then maintains at a high level the standard of cocoon-making.

This contention as to the uselessness and danger of experience applies to the whole of those smaller defenceless animals which, when once they have been detected, have no chance of fighting with their enemies and but little of escaping.

Another special kind of instinct has been greatly relied on by Romanes as evidence for the Lamarckian Theory of transmitted experience. Certain Hymenoptera allied to wasps, the Fossores or sand-wasps, possess an instinct which leads them to sting larvae and store them up in their nests as food for their young. It is generally believed that the larva is stung in the central part of the nervous system so that it can no longer struggle. I say ' generally believed' because it has been pointed out to me by so distinguished an observer as Dr. G. W. Peckham of Milwaukee, that certain facts are opposed to the generally received account. ${ }^{1}$ It is to be hoped that the observations, which are chiefly due to Fabre, will be repeated and tested as minutely as possible. The prey is stored up in the mud-tube or burrow of the Hymenopteron, and keeps perfectly fresh because it is alive, although completely paralysed. Larvae stored up in this way appear to live much longer than those which, in the full possession of their faculties, are deprived of food.

Now this is a very wonderful instinct, which, it has been argued, cannot be explained except on Lamarckian lines. I maintain, on the contrary, that it is a case which cannot by any possibility be explained by the Lamarckian Theory.

${ }^{1} \mathrm{My}$ friends Mr. and Mrs. Peckham have now published their valuable researches upon the habits of the Fossorial Hymenoptera in two works, which are a mine of information on this fascinating subject. George W. Peckham and Elizabeth G. Peckham, On the Instincts and Habits of the Solitary Wasps; Wisconsin Geological and Natural History Survey: Madison, Wis., U.S.A., 1898. Wasps Social and Solitary. Boston and New York, 1905. 
The wasp-like insect has no opportunity of learning by experience, because it can never know whether the larva stored up is a failure or a success. If the larva had not been stung, or, accepting the received accounts, had been stung in the wrong place, it would struggle and perhaps kill the young grub; or, dying of starvation, it might dry up and be useless as food. But the Hymenopteron never goes back to inquire. It makes all the difference to the young grubs whether the food provided for them is in an appropriate condition or not, but it makes no difference whatever to the parent insect. The latter seals up the chamber in which its eggs have been laid and never opens it again; it has no chance of noting the failure or success of the food it has provided. It is clearly a case, like that of the cocoon, which cannot be explained on the Lamarckian Theory and must be explained on the Darwinian. And this latter interpretation is easy: those insects which possessed the nervous mechanism impelling them to provide food in an appropriate condition gave to their offspring the opportunity of surviving and inheriting the same instinct; while others, impelled to perform less efficient actions, were thereby cut off from any representation in the next generation.

If the origin of wonderful and complex examples of instinct such as these cannot be explained by the Lamarckian Theory but readily by the Darwinian, why should not Natural Selection also offer an adequate explanation of all other cases?

I have already taken up a great deal too much of your time. I hope to have the opportunity to-night of hearing stronger arguments in favour of the Lamarckian Theory than it has been my opportunity to meet hitherto.

Note.-In revising the shorthand transcript for publication, I have not made any changes which alter the character of the address. It remains the record of a spoken address, the sequence and continuity of which were maintained by the use of brief notes. I have not verified the quoted opinions and words of others, and there are probably verbal errors. I believe, however, that in every case the true meaning of the author has been preserved.

Oxford, May 21, 1894. 


\section{THEORIES OF HEREDITY}

The Presidential Address read at the Annual Meeting of the Midland Union of Natural History Societies, held at Oxford, September $23,1889$. Reprinted from the Midland Naturalist, November, 1889.

Revised and greatly modified: in large part rewritten.

IN order to understand the problem of heredity, it is necessary to have some general idea of the manner in which the higher organisms are built up. The lowest organisms, both animal and vegetable (Protozoa and Protophyta), consist of single cells, while all higher animals and plants (Metazoa and Metaphyta) are composed of cell aggregates. A single Protozoon does not represent a single Metazoon, but one of the innumerable units of which all except the minutest Metazoa are composed.

The higher animals are, however, something more than aggregates of cells ; they are cell-republics, in which, at any rate in health, the structure and function of the units are subordinated to the good of the whole. Certain diseases are due to the literal insubordination of some of these units, which grow and multiply in defiance of that relationship in proportion, in position, and in the consumption of nutriment, which is necessary for the well-being of the whole. The surest hope of successful treatment lies in an early extirpation of the centre of insurrection. Later on, the centre will not only grow, but will dispatch agents along the channels of communication, setting up other centres of mischief in distant parts of the body. Such a republic is not only liable to destruction from within by the revolt of its own members, but also by the successful attack of enemies from without. Numerous other forms of life are ever seeking to obtain a 


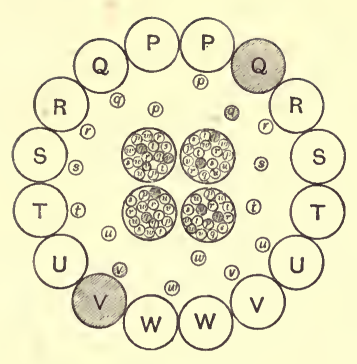

Diagram $I$.

\section{Pangenesis.}
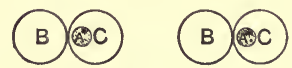

Stage 2.
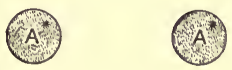

Stage ra

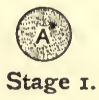

Diagram III.

Devolopment of Identical Twins.
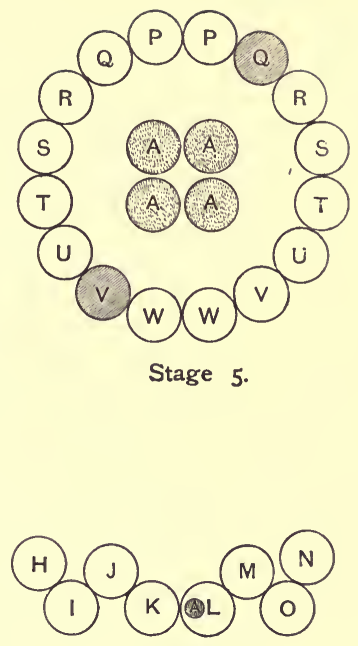

Stage 4 .

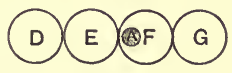

Stage 3.

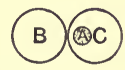

Stage 2.

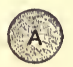

Stage 1.

Diagram $I I$.

Continuity of Germ-Plasm. 

lodgement within it,-and, if successful, discomfort, disease, or death, is almost invariably caused. ${ }^{1}$ The larger enemies, or parasites, have been known for ages; while the smaller, but far more dangerous foes, the germs of disease, have only been appreciated in comparatively recent times. Now, however, they attract a very large amount of attention, and the germ theory of disease has led to the most fruitful advance ever made in the history of medicine and surgery.

The cells, or units, which compose the body of one of the higher animals differ greatly in structure according to the part they play in the economy of the organism. Thus, in man, the upper skin, or epidermis, is composed of layers of cells, becoming horny scales on the surface. The epidermic cells are continuous with those lining the digestive tract and passing up the ducts into the various glandular organs. The connective tissues which bind the various structures together and make up many parts, such as tendons and the lower skin or dermis, are also composed of cells and fibrous elements derived from cells. The supporting tissues, bone and cartilage, are composed of cells and structures derived from cells; and the same is true of the great contractile tissues, striped and unstriped muscular fibre, and of the elements of the nervous system-nerve-cells and nerve-fibres. Out of many of these elements the complex organs are built up, with the addition of peculiar or specific cells of their own.

All the varied units which compose the Metazoan body may be classified under two chief heads. There are the cells which are concerned with maintaining the life of the individual-the body-cells or somatic cells; and there are those concerned with maintaining the life of the species - the reproductive cells or germ-cells.

In the higher animals, the latter are aggregated in

1 An example of benefit rather than injury may be found in the lactic acid bacillus which, according to Metschnikoff, plays a valuable part in digestion. Metschnikoff believes that the custom of drinking sour milk, common to many races, is founded on an empirical knowledge of the beneficial effects wrought by this bacillus. 
a comparatively limited area, the reproductive organs (ovaries or testes). These primary sexual organs can be removed in the operation of castration without essentially affecting any somatic cells except the components of characters indicative of sex. When the influence of the germ-cells is withdrawn such secondary sexual characters, as they are called, tend to be transformed into those indicative of the opposite sex. Although the succession of individuals is of course prevented by the removal of the primary organs, the life of the individual may continue to its normal length.

The problem of heredity may be stated as follows :How is it that a single germ-cell can produce, by repeated division, an organism in which the peculiarities of the somatic units of the parent are reproduced? A single cell separates from a small area in the body of the parent, but it controls the development of the offspring, so that the characters of every part of the parent are repeated with more or less accuracy.

It seems that there are only two possible ways in which this marvellous fact can be explained. First, the whole of the somatic cells may be so intimately connected with the germ-cells that each of the latter bears within itself the influence of the whole of the former-an influence, too, of such a nature as to lead to the reappearance of the corresponding somatic cell in the course of development ; clearly, therefore, an influence of a material nature. Secondly, we may look upon the germ-cells as directly developed from the germ-cell from which the parent arose. Parent and offspring would then resemble each other, because they are developed from the same thing, although at different times.

There is an essential difference between these two theories of heredity. In the first, the germ-cells may bear the impress of every event which happens to the somatic cells during the life of the parent, and such characters may therefore be looked for in the offspring; in the second, offspring and parent can only resemble each other in characters which were predetermined in the germ-cell from which the parent arose. These latter 
characters-peculiarities of any somatic cell which follow from the structure of the original germ-cell-have therefore been called blastogenic by Weismann. They have also been called spontaneous, because they spring up in the individual without reference to the causes which operate during its lifetime; also inherent or centrifugal, because they belong to the essential nature of the individual, and because they may be looked upon as developing from within rather than as impressed from without. Conversely, the characters which appear in the somatic cells as the result of external influences, or as the outcome of their own special or unusual activities, -in fact, any characters appearing in the body which were not predetermined in the original germ-cell, have been called somatogenic, because their origin cannot be traced to the structure of the original germ-cell, but is entirely due to events brought about in somatic cells; they are also called acquired, because the individual comes to possess them, although they do not belong to its essential nature; and centripetal, because they are impressed upon the individual from without, and are not the outcome of internal causes.

It is my object to give a more detailed account of these two theories of heredity, and then to allude very briefly to some of the evidence which has been believed to establish the hereditary transmission of acquired or somatogenic characters.

The first theory, maintaining that a close relationship of a material kind exists throughout life between somatic and germ-cells, was suggested by Darwin, under the name of Pangenesis.

This theory is illustrated by Diagram $I$, in which the large circles, indicated by the capital letters $\mathrm{P}$ to $\mathrm{W}$, represent the body-cells of a Metazoon, which, for the sake of simplicity, is supposed to be composed of only sixteen somatic and four germ-cells, the latter being placed in the centre. The somatic cells are arranged in pairs, $\mathrm{P} P, \mathrm{QQ}, \& \mathrm{c}$., in order to indicate the fact that similar cells are generally found on opposite sides of the body in the higher Metazoa (bilateral symmetry). 
The fact that each germ-cell, placed under appropriate conditions, will develop somatic cells like those of the parent, is explained by the supposition that all the latter cells give off gemmules, which are stored up in the germcells. The gemmules are represented in Diagram $I$ by the small circles marked with the small letters $p$ to $w$. The gemmules are seen to be traversing the space which separates them from the germ-cells, and also stored up in the latter. This double representation is explained on $\mathrm{p} .125$.

The space between the circle of somatic cells and the central germ-cells in Diagram $I$ has been introduced for the sake of clearness. In higher animals the distance which the gemmules would be compelled to travel in order that the change in a brain-cell may be registered in a germ-cell, would be relatively greater than that represented in the diagram.

With this hypothesis every somatic cell is a germ-cell, while the germ-cells proper are merely the meeting-place for the germs of somatic cells. Because every part of the body is thus supposed to reproduce itself, Darwin called his hypothesis Pangenesis. Each germ-cell is supposed to be, as it were, an extract of the whole body; a microcosm, in which every cell that takes part in the composition of the organism is represented.

The first difficulty which this hypothesis encounters is the almost infinite complexity of a germ-cell which contains a material particle, a representative or gemmule, from every somatic cell of one of the higher animals. The countless number of cells in the human body may be imagined from the fact that it would require over ten million red blood corpuscles, lying flat, one deep, to cover an area one inch square. And yet every single blood corpuscle, although not exactly a cell itself, is the product of a single cell.

But this is not all; for we must also suppose that each cell of every stage of development, and of the cellgenerations which succeed each other during maturity, is also represented in each germ-cell, and is the material cause of the reappearance of such stages and such genera- 
tions when the germ-cell itself undergoes development and becomes a mature individual.

Thus the gemmules stored up in the germ-cells of Diagram I represent a previous generation of bodycells, while those crossing the space separating bodyfrom germ-cells represent the existing generation.

Nor is this all; for we are also compelled to believe that gemmules from the cells of large numbers of generations of ancestors are present in many germ-cells, accounting for the facts of atavism or 'throwing back'. When an animal 'throws back' to some remote ancestor, the gemmules must have been handed down in a dormant condition through all intermediate generations.

Furthermore, there are grave practical difficulties in the way of the acceptance of Darwin's hypothesis. If it were true, we should expect that mutilations, especially such as are inflicted early in life, would be transmitted to offspring; for all the cell-generations later than the date of the injury would be absent, and therefore unrepresented by gemmules. But there is no evidence in favour of the transmission of mutilations, however early they may be inflicted. All the evidence, when carefully examined, points in the opposite direction.

Again, in the process of transfusion, when the blood of one individual is replaced by that of another, it seems reasonable to suppose that, if the gemmules exist, many of them would be carried over, and would collect in the germ-cells of the individual which received the blood, and that thus some characters of one individual would afterwards appear in the offspring of another. Careful experiments, conducted by Galton and later by Romanes, prove that such transference of hereditary characters does not accompany the transfusion of blood.

Not only may blood be transfused, but various tissues may be grafted and will thrive on another individual of the same species ${ }^{1}$. In these cases, too, we should expect that such transferred tissues would produce effects upon

${ }^{1}$ Grafted tissues will also thrive on an individual of a very different species; but such an experiment, however interesting from other points of view, would obviously be unsuitable as a test of Pangenesis. 
the offspring, for, according to the hypothesis, they would continue to give off gemmules. No such hereditary influence has ever been traced or even rendered probable.

When we inquire why Darwin was led to frame such a hypothesis, which, in spite of its great merit in connecting together a number of apparently isolated facts, has so much to be said against it, we find the answer in a reply to one of Huxley's letters, in which Pangenesis had evidently been adversely criticized. Thus Darwin says: 'I do not doubt your judgment is perfectly just, and I will try to persuade myself not to publish. The whole affair is much too speculative; yet I think some such view will have to be adopted, when I call to mind such facts as the inherited effects of use and disuse, \&c.' 1

This opinion of Darwin's is as true to-day as when it was written at some uncertain date about the year 1865 . If the effects of use and disuse are transmitted, the explanation must be sought in a hypothesis constructed on the lines of Pangenesis. But if we are mistaken in believing that such transmission occurs, a very different hypothesis will account for the facts.

The manner in which the transmission of such effects can be explained by the hypothesis of Pangenesis is shown in Diagram $I$. Two of the somatic cells, $\mathrm{Q}$ on the right side and $\mathrm{V}$ on the left, are dark coloured. This is to represent some change wrought in their structure by the influence of an external force, or by some unusual exercise or practice of a part. Thus the darkened $Q$ might represent the change which occurs in a bone-cell when a bony growth has been caused by intermittent pressure long-continued; $\mathrm{V}$ on the left side might represent the change which occurs in a nerve-cell when some new habit is acquired by long practice. Such altered cells would produce correspondingly altered gemmules, indicated by the same dark appearance: these ex hypothesi would be stored up in the germ-cells, and would reproduce similarly altered cells in the offspring.

I have given a very brief account of the main features

${ }^{1}$ Life and Letters, first edition, $x 887$, vol. iii, p. 44 . 
of Pangenesis. It is a hypothesis which would explain the hereditary transmission of acquired characters. At the same time it is beset by difficulties which appear well-nigh insuperable.

We will now proceed to examine another theory of heredity, that of Professor Weismann. The hypothesis is called 'The Continuity of the Germ-plasm', the name germ-plasm being applied to the essential part of the germ-cell which determines its development into an individual. The word 'continuity' is employed to express the theory that heredity depends upon the fact that a minute quantity of this germ-plasm is reserved unchanged during the development of the individual, and subsequently grows and gives rise to the germ-cells. Hence the germ-plasm is continuous from one generation to another in unending succession, and from it the germcells of each generation are produced.

The germ-plasm in a germ-cell possesses such a constitution that, placed under appropriate conditions, an individual of a certain species will be produced; but the germ-cells of this individual will also contain the same germ-plasm, and will therefore develop into offspring which resemble the parent. Parent and offspring resemble each other because both arise from the same substance, although it develops later in the case of the offspring. Hence everything which is predetermined in the germcell, every blastogenic character, may be transmitted, while somatogenic characters cannot be transmitted.

The hypothesis will be rendered more intelligible if we refer to Diagram $I I$, in which the development of a Metazoon, like that shown in Diagram $I$, is represented, according to the theory of the continuity of the germplasm. Development is complete in five stages, the number of the somatic cells being doubled in every stage, after their first appearance in the second. The first Stage (Fig. I) is the fertilized ovum, A, the single cell out of which all others are produced. It contains germplasm from two individuals, the combination being the process of fertilization. In the preparation for fertilization and the twofold nature of the fertilized ovum 
Weismann sees the causes of individual difference and the divergence of offspring from parent. Weismann believes that the germ-plasm is in reality only found in the nucleus, but the distinction between this and the cell has been omitted from the diagram for the sake of simplicity. The germ-plasm is supposed to be represented by the dots in the circle $A$.

The second Stage (2) is produced by division of the ovum into two cells ( $B$ and $C$ ), in one of which (C) a small part of the original germ-plasm, represented by the small circle $\mathrm{A}$, is carried on, unchanged.

Roux has demonstrated that, if one of the products of the first division of the egg of a frog ( $B$ or $C$ in Diagram $I I$ ) be destroyed with a hot needle, development is not necessarily arrested, but, when it proceeds, leads to the formation of an embryo from which either the right or the left side is absent. When the first division takes place in another direction, either the hind or front half was absent from the embryo which was afterwards produced. After the next division, when four cells were present, destruction of one produced an embryo from which one-fourth was absent. ${ }^{1}$

The preceding paragraph was written in 1889 before Roux's experiments had been repeated and tested by other workers; but their arresting interest was such that they soon became the foundation of a prolific school of experimental embryology. The ultimate result of numerous researches is to leave no doubt that Roux was mistaken in some of his conclusions. An excellent discussion of the whole question will be found in Professor T. H. Morgan's work. ${ }^{2}$ The general conclusion that there is a necessary correspondence in position between the early embryonic precursors and the organs or parts to which they give rise has been abandoned. On the other hand, the still broader and more fundamental conclusion that definite organ-forming

$1 \mathrm{My}$ attention was first directed to these interesting experiments by Professor Windle's paper in the Journal of Anatomy and Physiology, vol. xxiii, p. 393 .

2 Regeneration, chapter xi, New York, 1901. 
material is present at the beginning of development has been proved at any rate for embryonic organs of many species. Thus pre-formation (in the above sense) in the earliest stages, at least of embryonic organs, is confirmed, although it is not necessarily accompanied by prelocalization.

Turning to the details of Roux's researches upon the frog, briefly mentioned on p. I 28 , the results he claimed to produce by destroying one or both of the anterior or posterior pair of the first four cells (blastomeres) formed by the second cleavage are not now accepted. As regards the injury to one of the first two cells (blastomeres) and the development of a half-embryo from the other, Roux stated that after a time the material of the injured cell is 'reorganized', and the missing half of the embryo restored by 'post-generation'. The reorganization is, according to Roux, of complex origin, in part due to formation of cells from the injured part itself, but chiefly to the influence of the uninjured part. When converted into cells by reorganization, postgeneration begins. 'A few hours or a night is sometimes sufficient to change a hemi-embryo into a whole embryo.' 'The pieces of the old nucleus... may take a part in the formation of the new cells; wandering cells migrate from the yolk mass of the old half into the new, and the cells of the formed germ-layers may be pushed over to the other side.' This brief recapitulation of Roux's account is quoted from T. H. Morgan, who has himself shown that a half-embryo is formed by the uninjured cell when it and the injured cell retain their original position, but that the missing part is regenerated from the uninjured half or from the still living material of the injured cell. Morgan also proved that if the two first ceils do not retain their original position-e.g. if the egg be turned upside down-the uninjured cell forms not a half but a whole embryo, as in Hertwig's experiments. Furthermore, Schulze and Wetzel have proved that the uninjured egg, if kept upside down in the two-celled stage, develops into a double monster, one from each cell (blastomere). We are thus driven to the conclusion 
that the pre-localization in normal development of each half of the frog in one of the two first cells does not warrant the conclusion that such pre-localization is a fundamental or essential phenomenon. For, as shown above, mere change of position will compel each of these two cells to manifest a far wider potentialitythe potentiality of the whole body instead of one of its halves. The most crucial test which could be applied to Roux's conclusion would be not to injure but to remove altogether one of the first two cells of the egg. This is unfortunately impossible in the case of the frog; for the single remaining cell collapses. The experiment has, however, been successfully performed upon the egg of the newt (Triton), ${ }^{1}$ by Herlitzka, who 'found that each blastomere gives rise to a perfect, whole embryo of halfsize'. 'Thus we see', Morgan concludes, 'that whatever the factors may be that determine the development of a single embryo from the egg, still each half, and perhaps each fourth also, has the power of producing a whole embryo.' ${ }^{2}$ When we consider the development of widely different animals we are led to widely different conclusions. Thus, according to Driesch, $\frac{1}{32}$ of the egg of an Echinoderm (Sea-urchin) can undergo at least the preparatory stages of complete development.

It has been shown that the planes of division by which the egg is cut up into cells may bear no relationship whatever to the position of the future embryo. Dr. Jenkinson has even proved that the position of the embryo frog, although predetermined in the egg itself, is nevertheless without relationship to the direction of the furrow which divides the egg into the two first cells. ${ }^{3}$

Returning to Diagram $I I$, the second division produces the four cells of Stage 3, indicated by the letters

${ }^{1}$ Dr. J. W. Jenkinson points out that by a clerical error Professor T. H. Morgan (1. c. p. 226) has spoken of the salamander (Salamandra) instead of the newt (Triton). Herlitzka's two papers (Arch.f. Entrvick.Mech. d. Organism., ii. 1896, p. $35^{2}$; iv. 1897, p. 624 : Leipzig) describe experiments upon Triton (Molge) cristatus.

${ }^{2}$ l. c. p. 226.

${ }^{3}$ Biometrika, vol. v, pts. i and ii, Oct. 1906, On the Relation between the Symmetry of the Egg and the Symmetry of the Embryo in the Frog. 
$\mathrm{D}$ to $\mathrm{G}$. In one of these, $\mathrm{F}$, the unaltered germ-plasm is supposed to be carried on. The third division leads to Stage 4, with eight cells marked $\mathrm{H}$ to $\mathrm{O}, \mathrm{L}$ being the carrier of the germ-plasm. Finally, the fourth and last division leads to the ultimate Stage 5 , with sixteen body-cells indicated by $\mathrm{P}$ to $\mathrm{W}$, the two cells of each pair being marked by the same letter. We must also suppose that the minute mass of germ-plasm, A, grows and separates as a germ-cell or germ-cells from either L or one or more of the somatic cells into which the latter divides. The four germ-cells of the adult Metazoon are then produced by division. These germ-cells are, therefore, similar to that which started development; they are, in fact, a piece of it, which has grown without undergoing any essential alteration. The four germcells will, therefore, tend to produce offspring resembling their parents. It must be borne in mind, however, that in actual development the precursors of future germ-cells become recognizable as a definite group at a far earlier stage than that shown in the diagram. In certain species, e. g. Cyclops and Ascaris, the germ-antecedent has been traced at almost the very beginning of development. In Ascaris megalocephala, Boveri has shown that one of the two cells formed by the first division of the egg contains the germ-antecedents together with many other potentialities. These latter are gradually told off in the succeeding divisions, until, at the sixth, a single cell out of the sixty-four into which the egg is then divided is the precursor of the future germ-cells and germ-duct, but bears no other potentiality. ${ }^{1}$

If, however, some of the somatic cells become modified from that nature which was predetermined in the germplasm of the ovum, there is no way in which the hereditary transmission of such modifications can be explained by the hypothesis of the continuity of the germ-plasm; for it does not include any means by which the effects could be conveyed to the germ-cells, or, if conveyed, could produce in them changes such as would predetermine

' Kupffer's Festschrift, Jena, 1899, p. 383, Die Entwickelung von Ascaris megalocephala. 
similar effects in the corresponding somatic cells of the offspring. The acquired changes in $Q$ on the right side and $\mathrm{V}$ on the left, indicated by their dark colour, would be confined to the organism in which they arose, and would not affect its offspring, at any rate in a corresponding manner.

If the transmission of acquired characters were proved to be an undoubted fact, Weismann's hypothesis of heredity would inevitably collapse. It cannot, however, be maintained that such proof is forthcoming.

The question largely turns upon an exact knowledge of the proportion borne by blastogenic or inherent to somatogenic or acquired characters. We know how dominant a share of our physical and mental qualities is hereditary-so dominant indeed that it would follow, if Weismann's hypothesis be correct, that blastogenic characters are far more important than somatogenic.

There is some evidence that this is the case, and I will here bring forward one line of proof, which also supports the conclusion that the whole organism is predetermined in the ovum.

If this last conclusion be valid, it follows that the differences which characterize individuals are predetermined in the ova from which they arise, and that ova are not in their essential nature alike any more than individuals. We do, however, occasionally meet with individuals so much alike that we (incorrectly) speak of them as 'identical'. The resemblance between certain twins is far closer than that between other members of the same family. If, therefore, we can prove that such 'identical' individuals are derived from 'identical' ova, the above-mentioned arguments and conclusions will receive strong support.

'Identical' twins are invariably of the same sex. When twins are of different sex, the degree of resemblance is no greater than that between brothers and sisters generally. This is also true of many twins of the same sex, and Galton has brought forward evidence to show that they may even differ more widely than is usual with brothers or sisters. 
It has been long known that twins of the same sex are often enclosed in the same embryonic membranes, while twins of opposite sex are always enclosed in separate membranes. The latter would be the product of distinct ova, which had been separately fertilized, as in the ordinary multiple births of animals (cats, dogs, rabbits, \&c.). The former would be the product of a single ovum, which has divided into two ova, in all probability after fertilization. But it is clear that the ova arising from the two halves of a single ovum, at a time when the individual characteristics were already determined, would be very nearly identical : their resemblance would be of a very different order from that of separate ova. We also find that some twins of the same sex present resemblances of a very different order from that of brothers or sisters who are developed from separate ova. It must be admitted, therefore, that there is a very high degree of probability that the 'identical' ova are those which develop into the 'identical' individuals. The interesting conclusion that sex is predetermined in the fertilized ovum also follows from the same facts.

The probable beginning of the development of 'identical' twins is shown in Diagram $I I I . \quad A^{*}$ is a fertilized ovum with the individual characteristics predetermined. At its first division $\mathrm{A}^{*}$ does not, like $\mathrm{A}$ in Diagram $I I$, form the cells of Stage 2, indicated by the letters B and $\mathrm{C}$; but it divides without differentiation into two equivalent cells, like each other and like the ovum. Hence the first division of $\mathrm{A}^{*}$ does not produce Stage 2 , but Stage $\mathrm{I}^{\mathrm{a}}$, consisting of two similar ova. Each of these then divides, as shown in Diagram $I I I$, forming a true Stage 2, comparable to that of Diagram $I I$. After this the other stages succeed as in the latter, and finally two individuals will be formed, which must resemble each other if it be true that individual characteristics are predetermined in the fertilized ovum. And, as a matter of fact, such resemblances are seen in individuals whose development may be considered, with a very high degree of probability, to have followed the lines indicated in Diagram $I I I$. 
The germ-plasm $\mathrm{A}^{*}$ is carried on in $\mathrm{C}$ and $\dot{e x}$ hypothesi would, in the mature offspring, develop into germ-cells with a tendency to divide like those of the parent and to produce 'identical' twins. It is, however, necessary to bear in mind the effects of union in fertilization with a germ bearing different tendencies, as well as the changes introduced by the preparation for fertilization.

The amount of resemblance between 'identical' twins has been shown by Galton, ${ }^{1}$ who traced the after-life of about eighty as far and as completely as possible, obtaining instructive details in thirty-five cases. Of the latter there were no less than seven examples 'in which both twins suffered from some special ailment or had some exceptional peculiarity'; in nine cases it appeared 'that both twins are apt to sicken at the same time'; in eleven cases there was evidence for a remarkable association of ideas; in sixteen cases the tastes and dispositions were described as closely similar. These points of identity are given in addition to the more superficial indications presented by the failure of strangers or even parents to distinguish between the twins.

When the lives of twins were followed in after years ' in some cases the resemblance of body and mind continued up to old age, notwithstanding very different conditions of life'. In other cases 'the parents ascribed such dissimilarity as there was wholly, or almost wholly, to some form of illness'.

The conclusions of the author are as follows:- 'Twins who closely resembled each other in childhood and early youth, and were reared under not very dissimilar conditions, either grow unlike through the development of natural characteristics which had lain dormant at first, or else they continue their lives, keeping time like two watches, hardly to be thrown out of accord except by some physical jar. Nature is far stronger than nurture within the limited range that I have been careful to assign to the latter.' And again, 'where the maladies of twins are continually alike, the clocks of their two lives move regularly on, and at the same rate, governed

${ }^{1}$ Journal of the Anthropological Institute, 1875, pp. $3^{24}$ and 391. 
by their internal mechanism. Necessitarians may derive new arguments from the life histories of twins.'

Mr. Galton furthermore met with twenty cases of twins (also of the same sex) in whom the differences were greater than those which usually distinguish children of the same family. In such twins the conditions of training, \&c., had been as similar as possible, so that the evidence of the power of nature over nurture is strongly confirmed. Mr. Galton writes, 'I have not a single case in which my correspondents speak of originally dissimilar characters having become assimilated through identity of nurture. The impression that all this evidence leaves on the mind is one of wonder whether nurture can do anything at all beyond giving instruction and professional training.'

The argument thus leads to the conclusion that nearly everything which is characteristic of an individual is blastogenic, and therefore can be transmitted by the continuity of the germ-plasm. We can thus appreciate Weismann's contention that Natural Selection, while seeming to decide between successful and unsuccessful individuals, is in reality deciding between successful and unsuccessful germs.

Monstrosities (except such as are produced by external agencies) can be satisfactorily explained, in the same manner as 'identical' twins, by the occurrence, at some stage of development, of an equivalent division instead of a differentiating division of a cell or a substance which is the precursor of the doubled part. During the vast succession of differentiating divisions which take place in the development of one of the higher animals, the cells which represent parts of less and less importance are gradually told off. Thus the divisions which lead to the doubling of a small part of the body would occur far later in development than those which would lead to the doubling of a large and important part. But early or late the occurrence of an equivalent instead of a differentiating division at the critical stage was predetermined in the structure of the fertilized egg. We know that supernumerary digits are in a high 
degree hereditary, as they would be if the germ-plasm were continuous.'

Repair, and the renewal of lost parts in certain animals, is also explained by the persistence of substances or cells of the same kind as those which were the precursors of the injured tissue or lost part;-substances or cells which would be ready to initiate development under the stimulus provided by an injury.

The simplicity and beauty of Professor Weismann's hypothesis of heredity commends it to our favourable attention, and demands a searching inquiry into the evidence for the supposed transmission of acquired or somatogenic characters.

Into this inquiry it is impossible to enter on the present occasion. I will only mention the various lines of evidence which require investigation. The evidence may be either Direct or Indirect. Direct proof would be afforded if an undoubtedly somatogenic character could be shown to have reappeared in the offspring sufficiently often to prevent its explanation as a coincidence. Thus, if mutilations, or the results of training, exercise, or education (as apart from predisposition), or acquired diseases (some diseases are certainly blastogenic) reappeared in the offspring as the result of the operation of heredity, the required proof would be afforded and the hypothesis of the continuity of the germ-plasm would collapse. Many diseases are due to living organisms ('germs'), and when these reappear in the offspring the result is clearly due to inoculation of the embryo or even the germ-cell (as in the silkworm disease), and is not therefore due to the operation of heredity.

The present [in 1889] adverse position of the medical faculty is in part due to want of discrimination between blastogenic and somatogenic characters; in part to the fact that the evidence on which they rely was collected when the transmission of somatogenic characters was

${ }^{1}$ See Professor Windle's interesting papers on Teratology, published during the last few years [previous to the date at which this address was read] in the Journal of Anatomy and Physiology, and the Proceedings of the Birmingham Philosophical Sociely. 
assumed by every one; and in part to real difficulties which, however, require the most careful re-examination before they can be accepted as proofs of the transmission of acquired characters and as the death-blow to Weismann's hypothesis.

If the direct evidence for the transmission of acquired characters fails to stand the ordeal of a thorough investigation, the indirect evidence still remains. If it could be shown that certain phases of evolution would have been impossible without such transmission, we should be compelled to maintain that the latter had taken place.

The chief lines of indirect evidence are:-The fact of individual variation, the effects of use and disuse of parts, the facts presented by the phenomena of instinct.

Individual variation was believed to be due to the hereditary effect of the direct action of environment. It is known that in some cases (e. g. certain plants) variation has been caused by the direct action of environment on the germ-cells while still contained in the body of the parent. Such a change is, of course, blastogenic, and would be transmitted. There is less evidence for the operation of such causes in the case of animals. The consideration of twins and monstrosities pointed to the conclusion that individual variation is predetermined in the fertilized ovum. If it be asked why the germ-cells of an individual should differ among themselves, Weismann has pointed out that there is reason to believe that the changes which ova and spermatozoa undergo, as a preparation for their fusion in fertilization, must lead to individual differences. He, therefore, considers that variation is produced by sexual reproduction, and is, in fact, its raison d'être. The meaning of this form of reproduction is to supply variations upon which Natural Selection can operate.

The apparently hereditary effects of increased use are more probably due to the operation of Natural Selection upon a part which is, ex hypothesi, of especial importance, combined with the admitted strengthening and growth which follow increased use during the life of the individual. The apparently hereditary effects of disuse are 
more probably due to the cessation of Natural Selection, which can no longer maintain the efficiency of a useless part. All functional parts of an organism are kept up to a high standard by the operation of Natural Selection; withdraw selection and sooner or later degeneration will begin. It is very interesting to find that both Galton and Weismann independently arrived at the conclusion that the cessation of Natural Selection offered a better explanation of the gradual dwindling of useless parts, than that afforded by the supposed transmission of the admitted dwindling which follows from disuse during an individual life.

Finally, the phenomena of instinct seem capable of explanation by the operation of Natural Selection upon blastogenic variations of the nervous system, rather than by the supposed transmission of acquired habit. In many cases we are compelled to adopt the former theory, and it is open to us in all.

The time at our disposal has made it impossible to attempt any real discussion of the transmission of acquired characters. I have only indicated the lines along which it is likely that discussion will be directed.

NotE.-Mr. Francis Galton kindly writes to me (Feb. 12, 1907) on the subject of the first paragraph on p. 134:-'There is plenty of evidence that twin-bearing runs in families, but I know of no inquiry as to whether the tendency to produce identical twins does so. It would be a hard task to collect and to sift adequate evidence on this point.' 


\section{THE BEARING OF THE STUDY OF INSECTS UPON THE QUESTION 'ARE ACQUIRED CHARACTERS HEREDITARY?'}

The Presidential Address read at the Annual Meeting of the Entomological Society of London, January 18, 1905. Reprinted from the Proceedings of the Society, I904, p. civ.

Revised: addition to footnote 2 on $p p .167-8$.

To those who incline to criticize the subject of this Address as a raking of the embers of a dead and almost forgotten fire, I would reply that the controversy which sprang into sudden flame-in this country in the year 1887 -is still a great memory. I trust that it will ever remain as a great memory. Of August Weismann it has been well said that 'he awoke us from our dogmatic sleep'. He made us realize that cherished convictions upon fundamental questions were based on nothing more solid than assumptions, and thus administered the most stimulating shock that has been received by the biological world since the appearance of the Origin of Species.

It was impossible that a controversy of this magnitude could be conducted without frequent appeals to the Insecta. Their structures, functions, and instincts offered evidence so striking in character, and upon a scale so vast, that discussion was inevitably attracted again and again towards this centre. Indeed, the controversy would have been but one-sided, the conclusion unconvincing, had it been otherwise. At the same time discussion is and must be free and, being free, is almost necessarily scattered. To attempt therefore to disentangle from the mass and to present as a whole the evidence offered by the study 
of insects is of value in two ways. First, we are made to realize the importance of our study: by the contemplation of its relation to one majestic example we are prepared for the belief that our subject is essential for the solution of all the widest and deepest problems concerned with organic nature as a whole. Secondly, the attempt for the first time to marshal the whole of the evidence supplied by the study of insects will make it possible to strengthen and amplify certain parts, and thus render the whole fabric better balanced and more stable.

I should wish at the outset to express my indebtedness to the columns of Nature by means of which nearly the whole of the controversy has been followed. We are happy in the possession of a single journal in which discussions on general scientific questions are, by common consent, carried on.

\section{'Acquired Characters' defined.}

Before beginning a discussion it is important to remove any possibility of doubt or uncertainty as to the precise meaning of the terms which are employed. The word 'acquired' as used in this controversy has been the source of as much confusion as the word 'mimicry'. Just as almost every one who hears of 'mimicry' for the first time assumes that the word means a power of intentional imitation, so the inexperienced think that an acquired character is any new structure which a species has gained in the course of its history. "Why should we not consider every character acquired as an "acquired character"?' they not unnaturally ask. And the answer is the same in both cases. Because these ordinary and untechnical words were given a special and technical meaning by the writers of memoirs which have become classical. In spite of all inconvenience both words are, in their scientific use, historic, and we must reckon with the fact that they have a special meaning which differs from their ordinary meaning.

Erasmus Darwin was, I believe, the first to use 'acquired' in this restricted sense. 'Fifthly,' he says, 'all animals undergo transformations which are in part 
produced by their own exertions, in response to pleasures and pains, and many of these acquired forms or propensities are transmitted to their posterity.' ${ }^{1}$ Although Lamarck made a preliminary statement of his views on evolution in 1802 , the celebrated Philosophie Zoologique was not published until I 809, fifteen years after the appearance of Darwin's Zoonomia, and it is uncertain whether the author of the later work had ever seen the earlier treatise. Professor Osborn concludes upon the whole that he had not (1. c., pp. I 52-5). However this may be, the technical use of the words 'acquired characters' is chiefly due to his memoir. The essential passages are the two following Laws of Lamarck :-

'Première Loi.-Dans tout animal qui n'a point dépassé le terme de ses développemens, l'emploi plus fréquent et soutenu d'un organe quelconque, fortifie peu à peu cet organe, le développe, l'agrandit, et lui donne une puissance proportionnée à la durée de cet emploi ; tandis que le défaut constant d'usage de tel organe, l'affoiblit insensiblement, le détériore, diminue progressivement ses facultés, et finit par le faire disparoître.'

'Deuxième Loi.-Tout ce que la nature a fait acquérir ou perdre aux individus par l'influence des circonstances où leur race se trouve depuis long-temps exposée, et, par conséquent, par l'influence de l'emploi prédominant de tel organe, ou par celle d'un défaut constant d'usage de telle partie; elle le conserve par la génération aux nouveaux individus qui en proviennent, pourvu que les changemens acquis soient communs aux deux sexes, ou à ceux qui ont produit ces nouveaux individus.' ${ }^{2}$

Opposite to the characters which Lamarck spoke of as 'acquired' are the characters which may be called constitutional, congenital, genetic, inborn, innate or inherent.

'Zoonomia, 1794. Quoted by Professor H. F. Osborn, From the Greeks to Darwin. New York, 1894, p. 145 .

${ }_{2}^{2}$ Philosophie Zoologique, tome i. p. 235, Nouv. Ed., 1830 : quoted by Professor E. R. Lankester in Nature, vol. xli. 1890, p. 415. There had been a tendency in the discussion on this subject to protest against the restricted application of the word 'acquired', and it was assumed that the use was quite recent, and in fact due to Professor Weismann himself. Professor Lankester shows the error of this assumption. 
Other names have been specially proposed in order to render apparent the distinction between these two classes of characters. Weismann employed terms which set forth their different origin. The inherent characters he called blastogenic, expressing an origin that lay far back in the germ-cell from which the individual arose. Acquired characters he called somatogenic, to express a later origin due to circumstances which had affected the body-cells. The word centrifugal suggests characters developing from within rather than as impressed from without: centripetal conversely suggests characters impressed upon the individual from without, characters which are not the outcome of internal causes. ${ }^{1}$ Acquired structural changes have also been spoken of as modifications, the term variation being restricted to characters of germinal origin. ${ }^{2}$

All the terms suggested for these two classes of characters convey something of a definition. Thus the brief convenient definition of acquired characters as 'those modifications of bodily structure or habit which are impressed on the organism in the course of individual life' 3 is obviously suggested more or less completely by one set of terms, and 'those characters or properties with which the organism is originally endowed' 4 by the other set. Another attempted definition of an acquired character is as follows:- Whenever an organism reacts under an external force, that part of the reaction which is directly due to the force is an acquired character.' ${ }^{5}$ And although it may be impossible entirely to unravel the one part from the other, certain elements may easily be discriminated. For instance, the starting of the reaction as contrasted with the sequence of events which make up the reaction itself is obviously an acquired element, and those who maintain the hereditary transmission of

1 Theories of Heredity, in the Midland Naturalist, Nov. 1889. Reprinted in the present volume, see p. 120.

${ }^{2}$ Prof. J. Mark Baldwin, A New Factor in Evolution, in the American Naturalist for June and July, 1896 .

s Prof. C. Lloyd Morgan in Baldwin's Dictionary of Philosophy and Psychology, New York, 1901, vol. i, p. 10.

4 E. S. Goodrich, l. c., p. 10.

- Nature, vol. li, 1894, p. 55. 
acquired characters are required to prove that a reaction, which can only be started by an external force in the parent, starts without this stimulus in the offspring.

We owe another definition to Mr. Francis Galton: ' Characters are said to be acquired, when they are regularly found in those individuals only, who have been subjected to certain special and abnormal conditions.' ${ }^{1}$

Professor Lloyd Morgan's definition conveys nearly the same idea :-'When the complex of stimuli, which constitute the normal environment, are sufficiently altered (to upset that balance established between environment and innate qualities resulting in the production of a normal individual) to produce an appreciable change, such a modification or 'difference' may be called an acquired character.' ${ }^{2}$

Such results of abnormal conditions undoubtedly supply extremely striking examples of acquired characters, but it is, I submit, a mistake to make too much of abnormality, or to import it into a definition. Some of the most marked and certainly the most easily studied and tested of acquired characters are the differences between the effects of alternative environments, all of which are normal, upon the individuals of a single species. The green colour of a larva of Amphidasys betularia, if fed upon broom, is an acquired character, as is the dark colour it would assume upon oak, \&c. I think therefore that a more satisfactory definition of, at any rate, a large class of acquired characters may be framed as follows :'Whenever change in the environment regularly produces appreciable change in an organism, such difference may be called an acquired character.'

Sir Edward Fry has objected to Mr. Galton's definition - and his objection would equally apply to that which I have suggested above-that 'the possibility of inheritance is excluded by the definition, and the inquiry whether acquired characters are inherited is impossible '. ${ }^{3}$

1 Nature, vol. li, 1894 , p. 56 .

2 Baldwin's Dictionary of Philosophy and Psychology, vol. i, p. Iо.

${ }^{3}$ Nature, vol. li, 1 894 , p. 198. See also Professor Lankester's reply to the criticism, on p. 245 . 
This appears to me to be only a verbal difficulty. Before attempting to prove whether a certain class of characters can be inherited, it is essential to be able to decide whether a given character which it is proposed to test belongs to the class. If a satisfactory criterion can be reached we can proceed with the test even though the name 'acquired' be by our definition denied to the character after transmission by inheritance. The interest of the result would remain all the same. If the character were there-appreciable, measurable,-the effects would be incalculable in their importance, and would not be diminished one iota by the consideration that the name would no longer apply. Sir Edward Fry's criticism does indeed suggest a change-and I think a desirable changein the statement of the problem. For the question "Are acquired characters hereditary?' it would be more accurate to substitute 'Can the acquired characters of the parent be handed down as inherent characters in the offspring ?'

It is in no way necessary that the acquired elements of a character should be disentangled from the inherent elements, if only we can prove that the character as a whole is dependent upon a controllable external cause, and is therefore itself controllable. In fact we speak of a character as 'acquired' just as we speak of an article as 'manufactured', although the result itself is a complex of the properties of natural substances and of changes introduced by art. ${ }^{1}$

\section{Lamarck's Second Law a contradiction of his First Law.}

Before leaving these general introductory considerations and proceeding to weigh the evidence offered by the insect world, it is of importance to demonstrate that there is an inconsistency in the teaching of Lamarck and his followers which, startling as it is, was never noticed until pointed out by Professor E. R. Lankester in $1894{ }^{2}$

' Normal conditions of environment have for many

1 For an interesting discussion on the relation between 'acquired' and ' genetic' characters see Adam Sedgwick's Presidential Address to Section D of the British Association at Dover (Report 1899, pp. 759-66).

2 Nature, vol. li, 1894, p. 102. 
thousands of generations moulded the individuals of a given species of organism, and determined as each individual developed and grew "responsive" quantities in its parts (characters); yet, as Lamarck tells us, and as we know, there is in every individual born a potentiality which has not been extinguished. Change the normal conditions of the species in the case of a young individual taken to-day from the site where for thousands of generations its ancestors have responded in a perfectly defined way to the normal and defined conditions of environment; reduce the daily or the seasonal amount of solar radiation to which the individual is exposed; or remove the aqueous vapour from the atmosphere ; or alter the chemical composition of the pabulum accessible; or force the individual to previously unaccustomed muscular effort or to new pressures and strains ; and (as Lamarck bids us observe), in spite of all the long-continued response to the earlier normal specific conditions, the innate congenital potentiality shows itself. The individual under the new quantities of environing agencies shows nerw responsive quantities in those parts of its structure concerned, new or acquired characters.

'So far, so good. What Lamarck next asks us to accept, as his "second law", seems not only to lack the support of experimental proof, but to be inconsistent with what has just preceded it. The new character, which is ex hypothesi, as was the old character (length, breadth, weight of a part) which it has replaced-a response to environment, a particular moulding or manipulation by incident forces of the potential congenital quality of the race-is, according to Lamarck, all of a sudden raised to extraordinary powers. The new or freshly acquired character is declared by Lamarck and his adherents to be capable of transmission by generation; that is to say, it alters the potential character of the species. It is no longer a merely responsive or reactive character, determined quantitatively by quantitative conditions of the environment, but becomes fixed and incorporated in the potential of the race, so as to persist when other quantitative external conditions are substituted for those which 
originally determined it. In opposition to Lamarck, one must urge, in the first place, that this thing has never been shown experimentally to occur; and in the second place, there is no ground for holding its occurrence to be probable, but, on the contrary, strong reason for holding it to be improbable. Since the old character (length, breadth, weight) had not become fixed and congenital after many thousands of successive generations of individuals had developed it in response to environment, but gave place to a new character when new conditions operated on an individual (Lamarck's first law), why should we suppose that the new character is likely to become fixed after a much shorter time of responsive existence, or to escape the operation of the first law ? Clearly there is no reason (so far as Lamarck's statement goes) for any such supposition, and the two so-called laws of Lamarck are at variance with one another.'

These passages have been quoted at length because they apply not only to the thoughts of Lamarck but to those of many modern naturalists as well, and because, so far as I am aware, no attempt has been made to meet the objection. In its most condensed form the argument may be stated thus :-Lamarck's 'first law assumes that a past history of indefinite duration is powerless to create a bias by which the present can be controlled; while the second assumes that the brief history of the present can readily raise a bias to control the future '.

I now pass to the discussion of evidence derived from the study of the insect world.

I do not propose to multiply examples, but shall be content with a few of those which seem sufficiently well adapted to illustrate the main lines of evidence. They have been chiefly, but by no means invariably, selected from the Lepidoptera. This is merely due to the accident that my experience has been chiefly gained in this Order, and not because the examples are in any way more suitable or convincing than those of other Orders. As regards the most interesting part of the discussion, that 
relating to instinct, the most striking examples have of course been chosen from the Hymenoptera.

\section{The Origin of the Pupal Groove which receives the Silken Loop in Pierinae, Ec.}

If we examine the dorsal surface of such a Pierine butterfly as Pieris brassicae (the 'Large Garden White') or P.rapae (the 'Small Garden White') it is at once seen that the first abdominal segment is traversed by a strongly marked line parallel with its posterior boundary. This character is so well marked that it presents all the appearance of a morphological feature.

A study of the living suspended pupa shows that the line is formed by the approximated lips of a groove which receives the silken loop or 'girdle' as it is often called. Longitudinal vertical sections of the dorsal cuticle are of course transverse to the line, and reveal the fact that the bottom of the groove is specially thickened. Here was a feature at first sight strongly suggestive of the mechanical effects of linear pressure, pointing to an origin in a kind of mutilation performed by the silken cord upon the soft freshly-exposed surface of the pupa. When I found that removal of the loop before pupation, but after the period at which the larva could spin another, did not alter the normal appearance of line and groove in the resulting pupa, I was for the moment convinced that acquired characters are hereditary. But fortunately the inquiry did not come to an end at this point. It was observed that the Pierine pupae which furnished the material for experiment ( $P$. brassicae or $P$. rapae) invariably suspended themselves either horizontally or vertically with the head upward,-never vertically with the head downward. Several larvae of $P$. brassicae had fixed themselves in the normal vertical position preparatory to pupation, upon a sheet of glass. Before pupation, but after the period at which the larvae could fix themselves afresh or indeed make any attempt to spin, the glass sheet was rotated through half a circle, so that all the larvae came to be suspended head downward. In this 
position they were compelled to pupate. The condition of the resulting pupae clearly refuted the hypothesis of a mechanically-created groove and thickening, caused by the cutting into and pressure upon the soft yielding cuticle. For in the vertical position with head downward the pupa slips through the silken loop beyond the position of the groove, so that the pressure has to be borne by an unprepared part of the cuticular surface. Upon the mechanical hypothesis, we should expect that the fresh surface would gain some measure of resistance from the strain ; but on the contrary the pupae were all hopelessly deformed and the imagines-if indeed they could have emerged at all-would have been incapable of flight. ${ }^{1} \quad$ It is evident that from the very beginning the loop has been accompanied by a sufficient strengthening of the part of the surface exposed to its pressure as soon as the larval skin is thrown off.

The silken loop together with the attachment of the posterior extremity of the pupa is in all probability the persistent trace of a vanished cocoon, and we may imagine the selective process which made good each step on the road of gradual transformation. A cocoon is one form of passive defence, cryptic colouring is another, although the two are commonly combined, especially in cocoons built to endure for comparatively long periods, including the times of special stress-the winter of the northern belt, the dry season of more southern latitudes. The original decline of the cocoon was probably favoured by a short pupal period falling wholly within the time of least stress-summer or the wet season. When the cryptic colouring of the bare pupal surface is as effective for concealment as that of the cocoon, it presents certain advantages over the latter. The secretion of a large quantity of material is unnecessary and tell-tale movements in the period before pupation are greatly reduced. These benefits are conferred when the concealment

1 This experiment has not been published hitherto. It was, however, described and the pupae exhibited in the discussion in Section D of the British Association at Manchester, on Monday, Sept. 5, 1887. See Reporl, p. 755 . 
afforded is equal; but the pupal cuticle lends itself to certain forms of cryptic defence much more freely and completely than the walls of the cocoon:- to the production of angular shapes and of smooth or polished surfaces, to the attainment of varied colours and the perfect gradation of tints, above all to the power of individual colour-adjustment. This latter culminating effort of adaptation - so commonly possessed by larvae and exposed pupae-is apparently extremely rare in the cocoon. Indeed the only positive evidence of its existence is supplied by Hylophila (Halias) prasinana, ${ }^{1}$ and even in this case it would be satisfactory to repeat the experiments on a far larger scale than has been as yet attempted. The transition is easy from a loose and open cocoon with apertures through which the cryptic colours of the enclosed pupa could play their part in defence, through stages in which the latter element becomes more and more important as the cocoon progressively diminishes, to the climax when the almost invisible remnants of the silken covering are retained as supporting structures merely. In all except small and light pupae a point would be reached, at a greater or less distance from the climax, when some special strengthening of the cuticle exposed to the strain became the indispensable condition of further advance. Thenceforth further reduction and further strengthening would proceed together, the existing groove and thickening being but the concentration of the broader band of pupal tissue specially prepared to meet the pressure when it first became a danger.

Comparison with the pupae of some of our common British Geometrae supports the hypothesis set forth above; for it is seen that very similar changes have independently occurred, and occurred so recently that the essential stages are still preserved. Furthermore, they are invariably met with in species which have a short pupal period passed in the warmer months of the northern year. Eugonia quercinaria (the 'August Thorn Moth') spins a loose and open cocoon, within which the chrysalis, as well as the larva before pupation, develops an effective cryptic

$$
1 \text { Trans. Ent. Soc. Lond., I 892, pp. 448-51. }
$$


colouring. ${ }^{1}$ Both larva and pupa are freely exposed to view through chinks in the scanty network and between the imperfectly united leaves. Uropteryx sambucaria (the 'Swallow-tailed Moth') constructs a slight hanging cocoon, affording very little concealment. The enclosed pupa bears a marked cryptic appearance, while the only experiment which has been made indicates the possibility of a well-developed power of individual colour adjustment. ${ }^{2}$ Both these species, and especially the last, have long since reached the stage at which the reduction of the cocoon became advantageous. In the genus Zonosoma (Ephyra) we independently arrive at the same climax of reduction attained in the Pierinae, \&c., the cocoon being represented by a supporting loop and the means of fixation of the posterior extremity. ${ }^{3}$ No search has been made, so far as I am aware, for a special strengthening of the cuticle upon which the loop presses, but it is probable that nothing of the kind is required by these small light pupae. The exposed Ephyrid chrysalis is fully as cryptic as that of the average butterfly, but it lacks the power of colour adjustment. When the Ephyrid larva is dimorphic, green or brown, the colour of the pupa corresponds to that of the larva from which it developed.4 Such correspondence has not been observed in any other Lepidopterous insect.

If we take into account the fact that Zonosoma (Ephyra) is a characteristic Geometrid genus, although its method of pupal suspension is unique in a family whose species make cocoons or bury, we may feel confident that it has been descended from cocoon-making ancestors, and that Eugonia quercinaria and Uropteryx sambucaria give us a clear idea of the steps by which the reduction was effected.

1 Trans. Ent. Soc. Lond., I885, p. 319.

2 See Colours of Animals, London, 1890, pp.' II I, I1 2. Only one example was placed on white paper before pupation. Although the resulting chrysalis was very pale and strikingly different from the ordinary appearance, the evidence is quite insufficient, and it is much to be hoped that the experiment will be repeated upon a large scale.

3 Trans. Ent. Soc. Lond., 1884, p. 57.

4 Trans. Ent. Soc. Lond., 1884, p. 51 ; Phil. Trans. Roy. Soc., vol. 178 (1887), B., pp. $437,43^{8}$. 


\section{The effect of Gravity upon the shape of Suspended Pupae such as those of the Nymphalinae.}

Every naturalist who has watched the pupation of a Vanessid must have observed the extraordinary mobility of the abdominal region of the freshly-exposed chrysalis. Movements of remarkable amplitude take place in every direction, and especially in the dorso-ventral plane, these latter being essential for the withdrawal of the posterior segments from the larval skin and the remarkable feat of attachment to the silken boss close to the point from which the skin itself is hanging. Success is only rendered possible by the remarkable contractile power of the intersegmental muscles along the median ventral area. These, by their contraction, keep the rigid hook-armed apex of the abdomen firmly pressed to the outside of the larval skin up which it is being forced, and enable it to press down or push aside any of the stiff spines which oppose the movement: these finally bring it to the small silken boss which alone provides a secure basis of attachment for the terminal hooks. For this purpose the ventral muscles require to be far stronger than those of any other region, and we invariably find that they entirely overbalance the dorsal intersegmental muscles in pupae which have been produced on the floor of the breedingcage. In such pupae the abdominal segments are curved round towards the ventral side, so that the long axis of the apical part forms at least a right angle with that of the thoracic region, and this attitude becomes stereotyped with the hardening of the pupal cuticle and the consequent loss of all power of dorso-ventral movement. These free pupae form a striking contrast with the normal attached individuals in which the long axis of the abdominal segments is nearly in the same line with that of the thoracic. Suspension by the posterior apical hooks and the assumption of a form in which the long axis of the body is nearly in one line, is very ancient, dating back to the common ancestor of a number of closely-related species. For a countless number of generations the soft and yielding Vanessid pupa has 
been subjected to the strain of gravity and has responded by the production of a definite shape, viz. one in which the long axis is parallel with the line of force. And yet not a trace of any hereditary effect is manifest. Remove the strain and the individual is free, unbiased by the forces exerted upon unnumbered ancestors, to assume an entirely different shape.

Vanessid pupae alone, so far as I am aware, have been studied from this point of view. Figures of other suspended Nymphaline pupae, however, indicate that all do not yield equally to the strain, although I believe that all are to some extent affected. The pupae of the Argynnidae (the 'Fritillaries') contrast in an interesting manner with those of the Vanessidae in this respect. The strongly-curved pupa of Argynnis aglaia figured by W. Buckler ${ }^{1}$ was probably supported wholly or in part by a leaf, as is suggested not only by the shape but the plane of the surface of attachment, as shown in the figure, and to some extent by the description.

\section{Variable Protective Resemblance in Insects.}

The power which it is now known that many larvae and pupae possess of changing their colour into correspondence with the tints of each one of several possible environments has been thought to favour the Lamarckian interpretation of the origin of variation. Thus the late George J. Romanes said of the evidence which had been brought forward to prove the power in question: 'It has always appeared to me that the experiments themselves are among the most valuable which have hitherto been made regarding the causes of variation' $;{ }^{2}$ an opinion due, as the writer states, to his acceptance of the 'Lamarckian conception'.

On the other hand, I have never doubted that the results are in the nature of a climax rather than a foundation, that they represent the highest achievement of Natural Selection in the protective colours of insects.

1 Ray Society, Larvae of British Butterflies and Moths, vol. i, Plate X, fig. $3 b, \mathbf{1} 886$.

${ }_{2}$ Nature, vol. xxxviii, 1888 , p. 364 . 
If these variable colours represented the beginnings of ordinary fixed colour variations the species would lose and not gain by the change. The essence of the protective value is the power of being concealed in each of several different environments, and hereditary transmission of the results would only injure the individuals of the next generation. The intricacy of the processes by which the stimulus gives rise to each appropriate colour-effect is no difficulty to the interpretation based on Natural Selection - an agency capable of dealing with complex physiological relationships in precisely the same way that it deals with all other kinds of variations '. ${ }^{1}$

The barren conception of 'self-adaptation'-the hypothesis that organisms possess a constitution which compels them to react adaptively, breaks down when we find the adaptation is only possible by means of a specialized and complex train of physiological sequences.

We must remember that the species we investigate are 'heirs of all the ages', thoroughly inured to experimental research, past masters in the art of meeting by adaptive response the infinite variety of stimulus provided by the environment. If we remember this we shall always be on our guard against a too hasty interpretation based on the fundamental properties of protoplasm. ${ }^{2}$

The hypothesis that organisms are so built that they must produce useful variations seems to be little more than the old 'internal developmental force', or 'innate tendency towards perfection', in a modern dress. Furthermore, a consideration of the essential meaning of adaptation proves the futility of any such attempt at explanation. The ultimate object of adaptation is to obtain food, to escape enemies, or to subserve reproduction. The most conspicuous adaptations manifested by

${ }^{1}$ Professor Meldola in Nature, vol. xxxviii, 1888, p. 389. See also Professor Meldola's Presidential Address in Proc. Ent. Soc. Lond., 1896, pp. Ixx, lxxi; and the first scientific paper published by him, viz. Proc. Zool. Soc., i 873 , p. I 53 .

2 Nature, vol. Ixxi, 1905, p. 244. 
an individual are relative to the condition of the organic environment with which its contact is in many respects irregular, uncertain, or even wanting. Caterpillars are provided with beautiful protective adaptations, but the successful individual never comes into contact with an enemy. But there is an environment which the organism cannot avoid-the physico-chemical stimuli of climate and food; and it is presumably here, in the inorganic conditions of life, that the influences which bear a preeminent part in evoking useful variations are supposed to reside. So that stimuli provided by one form of environment are looked upon as the direct causes of adaptations which are essentially related to another and very different environment. ${ }^{1}$

\section{The Instincts of Insects.}

Those who advocate the hereditary transmission of acquired characters have made great use of the argument that the wonderfully complex and precise adaptive instincts of insects require for their production the accumulation of experience and of effort through many generations. Only by such transmission, they maintain, is it possible to understand such development.

It is safest to begin with a definition, and I accept the brief, convenient, and in my opinion entirely accurate, statement of Lloyd Morgan: 'Instinct depends on how the nervous system is built through heredity; while intelligence depends upon how the nervous system is developed through use.' 2

We observe in the first place that the Lamarckian interpretation places the more difficult phases of the evolution of instinct-the phases when it was not instinct at all but something much higher-in some remote epoch of the past, and at a lower level of progress. In such times, ex hypothesi, the less developed and presumably less efficient brains of insects did by the intelligent use of experience what they now do

1 The substance of the argument set forth in this paragraph was published by the writer in Nature, vol. 1, 1894, p. 445 .

Animal Behaviour, London, 1900, p. I 20. 
mechanically by instinct. This is an inversion of the probable course of evolution: the less efficient instrument has assigned to it by far the more difficult task.

A part from this prima facie objection there are solid grounds for the belief that the exquisitely perfect operations of insects with which we are familiar arose as instincts, as instincts were gradually perfected, and that intelligence never came into the history at all.

It is not from the insects which have had the most varied experience of enemies, most opportunity of learning by contact with danger how to avoid them, and thus of developing their nervous systems through use-it is not from these that existing forms have been descended, but from precisely those which have had the least experience. Even for ourselves experience is spoken of as 'the stern guide'. To an insect she is apt to be so stern as to lose all her educational value. The less an insect sees of her the better the chance of existence and of representation in the generations of the future. The prime necessity for an insect, as for all animals which cannot in any real sense contend with their foes, is to avoid experience of them altogether. ${ }^{1}$

This is an argument with the broadest possible application to all Orders of insects. To the adaptive movements of a beetle which when disturbed falls to the ground, draws in its limbs and antennae, and looks exactly like a little lump of earth; to the alertness of a fly to take wing before an enemy is within striking distance; to the perfection of all such means of defence in insects, and they are numberless, we may apply the words of Browning :-

Oh, the little more, and how much it is!

And the little less, and what worlds away!

1 This argument was brought forward by the present writer in the discussion on Are Acquired Characlers Hereditary? at the meeting of Section D of the British Association, at Manchester, Sept. 5, 1887 (Reporl, p. 755). No part of the discussion is published. The argument is, however, briefly stated in Proc. Boston Society of Nat. History, vol. xxvi, 1895 , p. 391 (reprinted in the present volume: see pp. 117, 118), and also quoted in The Zoologisl, Dec. 1900, pp. $55 \mathrm{I}, 55^{2}$. 
It is all the difference in fact between success and failure, between life and death. Comparatively rarely are the conditions of the struggle such as to admit of partial failure or of improvement by experience.

One special reason for the passive means of defence adopted by the vast majority of insects is to be found in the peculiar dangers of their structure. Especially is this true of larvae, with their haemolymph contained in freely communicating cavities, and subject to the pressure of muscular body-walls. Hence an insignificant injury may often cause death or imperfect development from the quantity of fluid which is lost. "It is, I believe, in consequence of these facts that the various means of protection in larvae are almost always of a passive kind. ... Nearly all the means of defence against... enemies [other than ichneumons, \&c.] are such as tend to prevent the larva from being seen or touched, rarely such as to be of any avail when actually attacked. There may be various changes in the mode of defence, but the object is always the same,- to leave the larva untouched, a touch being practically fatal.' 1

Let us consider for a moment the mental operations involved in the act of profiting by experience. Consider, for instance, Mr. A. H. Hamm's interesting observation - since abundantly confirmed by the testimony of many naturalists - that the vast majority of the individuals of Hybernia leucophaearia (one of the common 'Winter Moths') rest with the body horizontal, thus bringing the lines of the wings into parallelism with the dark shadows in the vertical cracks of the oak-bark. ${ }^{2}$ An individual which adopted a different attitude and rested so as to cause the main lines of its pattern to cut the main lines of its environment might indeed escape by flight; but can any one really believe that a moth, or any of the ancestors of moths, could associate the special disturbance and danger to which it had been exposed with the special attitude it had assumed, and would as a result of that association begin to make changes in its attitude? It is

1 Trans. Ent. Soc. Lond., $188_{5}$, pp. $3^{21-3}$.

${ }^{2}$ Proc. Ent. Soc. Lond, for March 19, 1902, p. xv. 
easy to speak of improvement by experience, perhaps easy to think of the progress of an insect's education under the sternest of teachers:- -easy so long as we confine ourselves to generalities. Attempt to picture the process in a definite case, and apply it, as I have done, to account for the growth of some special protective adaptation, and it is instantly borne in upon us that we are placing on insect psychology a load it is altogether unable to bear.

\section{The Cocoon-making Instinct.}

There are, however, numberless examples in which it is impossible that improvement could be thus effected, even if insects did possess the requisite brains, that is unless we also accord to them the gift of prophecy. These are the cases in which instinct prepares for the dangers of a struggle at some future time, when the organism which manifested the instinct will have changed its form, and become incapable of making further changes in the means of protection, and indeed as a rule entirely incapable of making any defence.

Consider, for example, another observation made by Mr. Hamm in July, I900, upon the cocoons of Malacosoma neustria (the common 'Lackey Moth') spun within the leaves of black-currant and apple in his garden at Oxford. These he found to be opened by birds, probably sparrows, which had pecked a hole in the leaf, thus breaking through the cocoon at its thinnest point, ${ }^{1}$ and abstracted the chrysalis.

${ }_{1}$ The cocoons were exhibited to the Entomological Society on March 19, 1902. See Proc. Ent. Soc. Lond., 1902, p. xv.

Mr. W. Holland many years ago showed that birds attack in this particular way, but his observation was upon larvae spun between leaves, and not pupae; and the latter are specially suited for enforcing the present argument. Mr. Holland's observation is as follows:-

' On the 6th of this month [June, 1890, near Reading] Capt. Robertson and I went to get some larvae of populeti from some low trees of Populus tremula which were covered with that species. Capt. Robertson had picked off about roo larvae the night before; but this morning when we arrived at the trees, we found some starlings had also discovered the caterpillars, and had gone over the trees systematically from branch to branch, pecking a hole in one side of the spun together leaves, and drawing out the caterpillar, and so nearly had they cleared 
A still more convincing example is to be found in the origin and maintenance of the instincts involved in the construction of a freely exposed yet admirably concealed cocoon on bark. Think of the natural cracks just filled up, of tunnels closed flush with the surfaces around, of the resemblance to excrescences or ridges which appear perfectly natural upon bark. Considering not only the forms but the colours and texture of the external surface, we recognize at once that such structures are the product of a highly perfected group of instincts. At first sight indeed the case seems to prove too much; for it may be thought that such cocoons are so completely hidden as to defy the sharpness of any enemy however acute, and believers in Natural Selection may properly be asked to bring evidence of the existence of a struggle in which the high elaboration of the instincts in question is a defence. There is no difficulty in meeting the challenge, for specially directed observation at once reveals the existence of a keen struggle in which the concealment of the cocoon is the criterion of life or death.

$\mathrm{My}$ attention was first directed to this particular aspect of the struggle for existence in insects, on April I 2, I 893, when I found on the bark of Populus nigra near Yoxford, Suffolk, a cocoon of Dicranura bifida (the 'Poplar Kitten Moth') which had been opened by some enemy, and the pupa removed. The observation is, I believe, a common one, in fact Commander Walker and Mr. Holland inform me that it is usually difficult to find cocoons of this species which have not been thus attacked. Nevertheless, for the sake of those who have not had the experience, I think it is worth while to re-describe the evidence which certainly justifies us in inferring that 'an enemy hath done this'.

'The edges of the opening were still brown and fresh, as was the interior of the cocoon; and the larval skin remained fresh and untouched inside. The opening was

them all off, that we had much trouble to find a dozen. We caught the birds in the act, and although they had so nearly finished their feast they were very unwilling to go, and loudly objected to our disturbing them.'Entomologist's. Monthly Magazine, 1890, p. 216. 
in the middle of the exposed surface and not at one end, as it is when the moth emerges. Besides, the cocoon had been opened and cracked by a blow from some hard object such as a bird's beak, and the sharp irregular margins were quite different from those of the natural opening made by the moth, doubtless by means of a corrosive fluid, as in the allied species, Dicranura vimula (the "Puss Moth"), which Mr. O. H. Latter has recently shown to secrete caustic potash for this purpose. Furthermore, the moth emerges far later in the year, and, had it emerged at an exceptional time, the empty pupal skin would have been left behind in the cocoon. We may therefore safely assume that the opening was the work of an enemy, and, as the cocoon was five feet from the ground, it was probably due to some tree-creeping, barkexploring species of bird.... It is probable that the attention of the enemy is directed to any cocoon-like object by the sense of sight and that the object is then tapped, and, if found to be hollow, opened and the pupa devoured.' 1

The cocoons of bifida are spun in the autumn, but the attack did not take place for several months. The example is probably typical in this respect. The procryptic preparation of the autumn is the adaptation by which the average numbers of the species are kept up in spite of ceaseless bark-hunting during the months when the trees are leafless and food is scarce. The Lamarckian interpretation fails to account for the cocoon-making instinct for two very sufficient reasons : first, a chrysalis is incapable of learning by experience how to improve anything,--even more obviously incapable of learning concerning a structure which it never makes. Secondly, however intelligent a chrysalis may be, the experience itself is of such a nature that its stores of learning cannot be handed down to posterity. ${ }^{2}$

1 The enemies of Lepidopterous pupae enclosed in bark-formed cocoons. -Science, xxiii, 1894, p. 62. The date of the observation is erroneously given as the year of issue instead of 1893 . Some of the later sentences of the same communication are also quoted with slight modification on the present occasion.

2 This argument also is briefly stated in the Proc. Boslon Soc. Nal. 
If the Lamarckian interpretation of the cocoon-making instinct must inevitably fail, as I think we shall agree it must, what is there to put in its place? Those who believe in the efficiency of Natural Selection in evolution will probably regard the instinct of building these beautifully-adapted structures as the outcome of countless generations during which the attacks of enemies have been, on the whole, more successful against the products of less perfected instincts and less so against those of the more perfected. They will further suppose that the increasing perfection in instinct has acted selectively on enemies, sharpening their faculties, until, by action and reaction, the present high level of constructive skill has been reached, and is maintained.

\section{The Instincts of the Hymenoplera.}

No discussion of instinct would be in any way complete without a consideration of the most wonderful examples of all, viz. those manifested by the Hymenoptera. The instincts of the Fossorial Aculeates in providing for their larvae-studied with all the sympathy of a born naturalist and described by a master of style-have formed the foundation of a gigantic speculative edifice. The controversy has in reality been a three-sided one.

I. First, we have Fabre disbelieving in evolution altogether, and adducing evidence that his favourite insects have not gained their wonderful instincts by progressive change, pointing out that they perform their duties under some stimulus which to them is imperative, whether the object of their pains be achieved or not: arguing, for example, that in those that feed their larvae from time to time, the stimulus to enter and deposit the insect food is not the young larva itself but the door of the tunnel.

II. Secondly, Lord Avebury and the late George J. Romanes have argued in favour of evolution by a gradual education, finally inherited as instinct. There is reason to believe that Darwin accepted the same view. $\mathrm{He}$ certainly never opposed it. Lord Avebury alludes to the Hist., vol. xxvi, 1895, p. 39 I (reprinted on pp. I I 7 , I 8 of this volume), and quoted in The Zoologist, Dec. 1900 , pp. 551, $55^{2}$. 
letter written to Fabre, in which Darwin 'refers to the great skill of the Gauchos in killing cattle, and suggests that each young Gaucho sees how the others do it, and with a very little practice learns the art'. ${ }^{1}$

Lord Avebury identifies himself with this view, which, indeed, he had himself set forth in the Contemporary Review, in I 885. Concerning the instinct of the Ammophila to sting the ganglionic centres of its caterpillar prey, he suggests that 'during these long ages they may have gradually learnt the spots where their sting would be most effective, and . . . so have gradually acquired their present habits'. ${ }^{2}$ He finally concludes that 'these remarkable instincts' are 'the result of innumerable repetitions of similar actions carried on by a long series of ancestors'. ${ }^{3}$

George J. Romanes, in reviewing Lord Avebury's book, goes much further:- 'Here, by the way, we have an excellent instance of the difficulty which we so often encounter in the domain of instinct, when we relinquish the so-called Lamarckian principle of the inheritance of acquired characters. The hypothesis in question goes upon the supposition that some of the ancestors of the Sphex were intelligent enough to notice the peculiar effects which followed upon stinging insects or caterpillars in the particular regions occupied by nerve-centres, and that, in consequence of being habitually guided by their intelligence to sting in these particular regions, their action became hereditary, i.e. instinctive. But if, in accordance with post-Darwinian theory, we relinquish this possible guidance by intelligence, and suppose that the whole of this wonderful instinct was built up by natural selection waiting for congenital (i.e. fortuitous) variations in the direction of a propensity to sting, say, the nine nerve-centres of a caterpillar-then it surely becomes inconceivable that such an instinct should ever have been developed at all.' ${ }^{4}$

1 Sir J. Lubbock, On the Senses, Instincts, and Intelligence of Animals, with Special Reference to Insects. London, 1888. Internat. Sci. Ser., p. 248 .

2 Ib. p. 248.

${ }^{3}$ Ib. p. $25^{2}$.

4 Nature, vol. xxxix, 1888, p. 77.

POULTON 
Eimer is even more rash in his statements :- This is one of the most marvellous instincts that exist; since the wasp operates on various larvae with nervous systems of various forms, she must effect the paralysis in various ways, and even apart from this, she makes a physiological experiment which is far in advance of the knowledge of man. . . It may be suggested that the wasp only paralysed the larvae in order to carry them more easily; but even if this were the case, she must, since she now invariably acts in this way, have drawn a conclusion by deductive reasoning. In this case it is absolutely impossible that the animal has arrived at its habit otherwise than by reflection upon the facts of experience.'

Mr. and Mrs. Peckham make the following comment upon this wild passage from Eimer:-'One can hardly be expected to take such statements seriously, since it is certain that the writer has no knowledge of the life histories of these insects.' 1

III. Thirdly, there are those who believe that the instincts in question are to be explained by the operation of Natural Selection upon hereditary nervous mechanisms, who believe that the Lamarckian principle of the hereditary transmission of education has never come into the history at any stage. Fabre's observations are quite consistent with this view; in fact it would almost appear that Darwinian evolution as apart from Lamarckian evolution is really unknown to this great naturalist. $\mathrm{He}$ seems invariably to strike Lamarck when he aims at Darwin. In this, however, he is only acting in the same manner as the majority of the early critics of the Origin. ${ }^{2}$

In attempting to decide upon the past history of these insects the first necessity is to be sure of the facts. Fortunately the ground has been re-traversed by $\mathrm{Mr}$. and Mrs. Peckham, so that we can compare the observations of great and keen naturalists in two hemispheres.

1 The Instincts and Habits of the Solitary Wasps, by George W. and Elizabeth G. Peckham, Madison, Wis., r 898, p. 221 .

2 Proc. Bosion Soc. Nal. Hist., vol. xxvi, 1895, pp. 377-9 (pp. 102-4 of this volume). See also Poulton, Charles Darwin and the Theory of Natural Selection. London, r896, chapters xix, xx, pp. I44-60. 


\section{INSTINCTS ARISE BY SELECTION I63}

We find that by the study of nine wasps of an American species, $A$. urnaria, of the very genus $A$ mmophila, which, as previously described, chiefly furnished the basis of speculation, the American naturalists have shown that the immense superstructure is in large part due to a fertile imagination. So far from the assumed perfection and accuracy with which every detail is supposed to be repeated, the instinct is shown to be excessively variable. The frequently-quoted conclusions that the object of the sting is to reduce the larvae to helplessness and yet keep it in a fresh condition, that a dead larva would be unsuitable food and an active one a danger to the offspring of the wasp-all these conclusions are entirely disposed of by a few careful specially directed observations. These show that the larva rapidly dies in a large proportion of cases and yet affords excellent food, and that it may remain sufficiently uninjured to wriggle continuously without stimulation, and to move violently when bitten by the larva of the wasp. ${ }^{2}$

The following activities or performances are regarded as truly instinctive, viz. as due to the compulsion of hereditary nervous mechanism:- Stinging, the methods of attack, capture and carriage of prey peculiar to each species, the kind of prey selected, the general style and situation of the nest, the form of cocoon. ${ }^{2}$

The American naturalists finally conclude their volume with these words :- 'The general impression that remains with us as a result of our study of these activities is that their complexity and perfection have been greatly overestimated. We have found them in all stages of development and are convinced that they have passed through many degrees, from the simple to the complex, by the action of natural selection. Indeed, we find in them beautiful examples of the survival of the fittest.' 3

As long ago as 1889 the present writer had argued that the Lamarckian interpretation of the instincts of Ammophila or Sphex introduced the same difficulty as

1 Instincls and Habits of Solitary Wasps, pp. 30, 31. 2 1. c. p. 234.

s See the review of Dr. and Mrs. Peckham's work in Nature, vol. lix, 3899, pp. 466-8. 
that alluded to in the discussion of the cocoon-making instinct. It implied a gift of prophecy, a knowledge of what would happen to offspring after the burrow had been sealed and the inmate left to its fate. ${ }^{1}$

Another powerful argument is derived from the comparison between the instincts which are performed but once and those which are performed many times in a single life. Various elaborate performances are undertaken but once in an insect's lifetime, and thus are always 'prior to individual experience'. ${ }^{2}$ The behaviour which leads to the production of an elaborate cocoon or the burial of a larva in its earthen cell is clearly instinctive, and the most convincing evidence would be requiredevidence which it is needless to say is entirely lackingin order to prove that certain insects which perform an act no more elaborate many times in their lives are guided by anything except the compulsion of a 'nervous system built through heredity' ${ }^{3}$ If the cocoon-making instinct has evolved through selection, the comb-making instinct of the social Hymenoptera has surely arisen in the same way and not through the operation of an entirely different set of causes.

As a matter of fact, I have witnessed the perfection of comb-building 'prior to individual experience' and under conditions which prevented the worker from profiting by the experience of others. I have seen 'the worker of a species of $V e s p a$ freshly emerged from the pupa, and

1 The argument was used in the Discussion on Acquired Characters in Section D of the British Association at Newcastle, Friday, September I 3 , 1889. See Report, p. 620, where, however, only the title of the paper is printed. The following sentences are quoted from the abstract in Nature, vol. xl, r 889, p. 6ro:-

- With regard to instinct, Dr. Romanes had suggested a difficulty-that was, the instinct of certain wasps to sting and paralyze the nerve centres of their prey. But it must be remembered that the benefits arising from this instinct were felt not by the wasps themselves, but by their progeny.'

In Proc. Boston Soc. Nat. Hist., vol. xxvi, 1895, p. 392 (pp. I 18 , I 19 of the present volume), the argument is stated in greater detail.

${ }^{2}$ For instance, the cocoon-making instinct, already alluded to (see pp. 157-60). Weismann has directed particular attention to this argument against a Lamarckian interpretation (The Evolution Theory, London, I 904 , vol. i, pp. I 55 et sqq.).

${ }^{3}$ Nature, vol. Ixv, r90 r, p. 51. The passage has been slightly modified. 
the sole perfect insect upon the young comb (the queenmother having been previously killed) immediately seize upon the broken material of the comb and begin accurately and with exact precision to build up the thin and delicate sides of injured cells containing the living larvae'.'

The strongest of all arguments against Lamarckian evolution was advanced nearly fifty years ago by Darwin in the first edition of the Origin of Species; and here too we see that demonstrative evidence was supplied to the greatest of all naturalists by reflection upon the insect world, and of the part of it which we are now considering. 'No amount of exercise, or habit, or volition,' he says, speaking of ants, 'in the utterly sterile members of a community could possibly have affected the structure or instincts of the fertile members, which alone leave descendants. I am surprised that no one has advanced this demonstrative case of neuter insects against the wellknown doctrine of Lamarck.' ${ }^{2}$

It is indeed surprising that Darwin himself, after his own crushing argument against the hypothesis of evolution by inherited experience, should have been willing to admit some tincture of the same principle in other parts of the wide field. If we are perforce thrown upon unaided Natural Selection for the origin and growth of the most complex and specialized societies of the Hymenoptera, what need have we for co-operating causes of evolution elsewhere?

I conclude this section of my Address dealing with the most remarkable of all nerve-mechanisms of instinct known to us, with the following impressive comparison, made by Professor Lankester, after contemplating the higher forms in which instincts have been replaced by the power of educability:- 'The character which we describe as "educability" can be transmitted; it is a congenital character. But the results of education can not be transmitted. In each generation they have to be acquired afresh. With increased "educability" they are more readily acquired and a larger variety of them. On the other hand, the

${ }^{1}$ Nature, vol. lxv, 1901, p. 50.

2 The Origin of Species, London, 1859, p. 242. 
nerve-mechanisms of instinct are transmitted, and owe their inferiority as compared with the results of education to the very fact that they are not acquired by the individual in relation to his particular needs, but have arisen by selection of congenital variation in a long series of preceding generations.

"To a large extent the two series of brain-mechanisms, the "instinctive" and the "individually acquired", are in opposition to one another. Congenital brain-mechanisms may prevent the education of the brain and the development of new mechanisms specially fitted to the special conditions of life. To the educable animal - the less there is of specialised mechanism transmitted by heredity, the better. The loss of instinct is what permits and necessitates the education of the receptive brain.

'We are thus led to [the] view that it is hardly possible for a theory to be further from the truth than that espoused by George H. Lewes and adopted by George Romanes, namely that instincts are due to "lapsed" intelligence. The fact is that there is no community between the mechanisms of instinct and the mechanisms of intelligence, and that the latter are later in the history of the development of the brain than the former, and can only develop in proportion as the former become feeble and defective.' 1

The bearing of Insect Warning and Mimetic Colours upon the supposed Hereditary Transmission of Experience by their Vertebrate Enemies.

Adaptations which facilitate the education of entomophagous vertebrates are so perfect and so wide-spread in insects that they constitute a large body of indirect evidence in favour of the non-transmission by heredity of the results of experience. Fritz Müller, in his celebrated theory of mimicry, suggested that the object of the likeness between the warning colours of specially-protected species was to reduce the danger from the attacks of young and inexperienced enemies. This is all the more interesting

${ }^{1}$ From the Jubilee Volume of the Soc. de Biol, Paris, 1899. Reprinted in Nature, vol. lxi, 1900, pp. 624-5. 
because, as Professor Meldola has pointed out, 'in 1879 the question of the non-transmission of acquired characters had not been brought into prominence. It was tacitly assumed in the theory of Bates that a knowledge of edible and inedible types could be transmitted by heredity. It is remarkable that Müller, by virtue of his hypothesis, should have unconsciously challenged this tacit assumption by suggesting that young birds had to learn by experience, and did not derive their knowledge of eatable and distasteful forms by heredity. The whole tendency of Professor Lloyd Morgan's work of late years has been to confirm this suggestion by actual observation and experiment; and Mr. Finn, also, in summing up his results, states that "each bird has to separately acquire its experience, and well remembers what it has learned." Thus the Muillerian theory of 1879 has now been placed on a psychological basis of well-ascertained facts.' ${ }^{1}$

The problem has been attacked from both sides with concordant results. In contemplating the vast scale upon which these aids to memory and education are developed, it is necessary to take into account the pressure of the struggle for existence upon the enemies themselves. ' This pressure is chiefly felt by the young, and it is so excessive that comparatively few individuals in the fresh wave sent forth at each breeding season, survive to become mature and experienced. It follows from this fact that the amount of selective pressure exerted by inexperienced enemies of insects is many times as great as that which is due to the educational period of the mature enemies existing at any moment.' ${ }^{2}$ We also realize

1 Nalure, vol. 1x, 1899, p. 57 .

2 Proc. Ent. Soc., Lond., 1903 , p. lxv. The form of the passage has been slightly modified.

My kind friend Dr. A. R. Wallace, D.C.L., F.R.S., wrote (April 3, 1905) concerning these quoted sentences-' There is one short passage ... which I had to read two or three times to see the point, which is quite sound but too condensed. ... It wants much amplifying to make it clear. ...'

The argument may be stated in another and I hope clearer form, as follows :-

The numbers of the species keeping approximately constant over a long period of time, we are compelled to suppose that each pair of 
the fact that insects as food are of far greater importance than might be at first sight supposed; for they supply not only the insectivorous species but those other forms which in turn prey upon them.

Thus, when we bring together the evidence supplied by the study of insects it is seen that it nowhere supports the assumption upon which Lamarckian evolution is founded, the assumption that acquired characters are transmissible by heredity.

Before leaving the Chair at the conclusion of my second year of office I desire warmly to thank the Officers, Members of Council, and Fellows of the Society, who by their kindness have made my task so easy and altogether pleasurable. You will, I know full well, accord the same generous sympathy to my successor, and under his guidance I feel confident that the prosperity of recent years will be continued, I hope in even larger measure.

Before taking leave of the Fellows in my official capacity I desire to direct their attention to two thoughts,

insect-eating birds of one generation is on the average replaced in the next generation by a pair and only a pair of its offspring. Consequently, each pair produces relatively enormous numbers of young which are destined to destruction. If, merely as an illustration, we suppose that the duration of the natural individual life in a given species of small bird is ten years, and that five young are produced each year, then the pressure upon insect life of a single family during one generation is that exerted by two adult birds, the parents, by the two offspring which will survive and take their place, and by forty-eight offspring which will themselves succumb in the struggle for existence at various ages. Special attention is here directed to the pressure of these forty-eight, of which a large proportion will not survive for more than a very small fraction of the natural term of life. Every season will bring forth its fresh supply of five young uneducated enemies of insects. Any of these which live long enough to feed themselves will enter upon an educational career during which they will exert that very kind of selection which tends towards Müllerian (Synaposematic) mimicry. After exerting this pressure for a variable time they will themselves succumb; and there is no doubt that only a very small proportion will survive until their education is complete.

Extending these considerations to the whole community of insect-eating birds in any country, we realize at once that the selective pressure of the inexperienced enemies is, as has been maintained above, many times as great as that exerted by the experienced and educated. 
both of which I have endeavoured to keep prominently before the Society, thoughts which I trust will always inspire our meetings.

First, ever to remember the high significance of the material we study; to realize its priceless value for the elucidation and the solution of problems the most intricate, difficult and important; to feel that this unrivalled opportunity is a serious personal responsibility.

Secondly, always to bear in mind that London is a great deal more than the capital of England, and that the Entomological Society of London can do much to help the work of naturalists all over the world-men in some conditions better off than we are, in other conditions less well provided; - with new and inspiring problems at hand calling for study, but without the stimulus and the continual aid of our vast stores of literature and our easy intercourse with kindred minds. We can do much to help such men, not only by means of our publications but even more by establishing contact with them, by showing them that their work is of value and interest to the naturalists of a distant land. And although I know full well that such encouragement will be offered freely to every naturalist who may approach us, whatever be his nationality, yet the wide extent of the British Empire and the roving spirit of her sons, ensure that it will be our own people in many lands whom we shall chiefly benefit, who will benefit us in turn. And thus we may hope to aid in no small measure the forces that make for sympathy and friendship and true union between men whose communication is thwarted by both time and space. And this happy result will be achieved by and will itself promote the advancement of that branch of learning for which this great Society came into being, grew into strength and beneficence, and awaits I doubt not a yet more glorious future. 
Note. - The following statement formed part of the general introduction to the Anniversary Address. The importance of the subject, and the very insufficient attention as yet directed to it, are my excuse for reproducing it in the present volume.

Before I proceed to the subject of my address there is one important point upon which I feel bound to warn not only this Society, but other Scientific Societies as well. I refer to the enduring qualities of the paper on which scientific publications are often printed, and still more emphatically the 'paper' on which they are often illustrated. I allude especially to the so-called 'art papers', assuredly named on the principle 'ut lucus a non lucendo'. The opaque, white, polished surface, which yields the most successful 'half-tone' and 'three-colour' printings, is at present only possible by means of a veneer of chinaclay. Dust it is, and we are assured by experts that not many years will pass by before it succumbs to the fate which the highest authority tells us is in store for dust. For the purposes of advertisement, this is no disadvantage: the cynic may even maintain that the writings of the present day are, to the great benefit of the human race, recorded upon a fitting medium. But cynicism has no part in science, and every Fellow of this Society will agree that an age producing scientific records which cannot be made to endure, is an age to be rightly scorned by the generations of the future,-scorned as one that sunk to the lowest level of production, that, intellectually, owing its very existence to the noble standard reached by days yet earlier, took the benefits, and deliberately or carelessly neglected in like manner to assist its successors.

We have only to reflect upon the paramount importance of tradition in order to realize the weight of our responsibilities. Lloyd Morgan, discussing the trend of human development, speaks of a 'transference of evolution from the individual to the environment', which ' may leave the faculty of the race at a standstill, while the achievements of the race are progressing by leaps and bounds.' ${ }^{1}$ Or, again, he contrasts the progressive evolution of the intellectual and moral edifice of society with the cessation

1 Habil and Instinct, London, 1896, p. 340. 
of evolution, perhaps even the declining level of 'the human builders that contribute in each generation a few more stones to take a permanent place in its fabric'.1

This great edifice was founded on oral tradition. Later on written tradition, and still later printed tradition took its place. When Society comes to depend upon the one it in large part ceases to depend upon the others, and in changing its methods it is itself changed. Contrast, for instance, the period in the life of each one of us when we ceased to remember the affairs of daily life and gave our memory into the keeping of ink and paper. Although much was gained in the inevitable change, something was lost. Until recently there have been many people in this country, there are probably a few now, who, unable to read or write, can remember the details of complicated accounts in a manner astonishing and impossible to those who possess these accomplishments. We see that when society in any age has come to depend upon printing it will be through printing and not in other ways that it will contribute its chief share to the social edifice; and this is not a mere truism, for that age will have lost in large measure other powers which would have developed in earlier times, powers which would still develop if printing did not exist.

Our American friends, who enter so thoroughly into the essentials of a subject whenever they direct their attention to it, have not, so far as I am aware, made any determined attack upon this problem. Indeed, the majority of the scientific works, which they so freely and generously place at the disposal of students in other lands, are printed upon material-I cannot call it paper-constructed of the felted fragments of wood, or of a thin paper backing overlaid and loaded with china-clay. The latter class are abnormally heavy, the former abnormally light.

This is a matter so important that it ought not to be left to the President of your Society to sound the warning. It is a matter which it would have been well if the Royal Society or the British Association had taken up years 1. c. p. 345 . 
ago. It is not creditable to have left to our artist brethren a subject of such paramount importance to ourselves; for to them belongs the honour of having made the only serious attempts to improve our practice and to call attention to the evil.

To the trades concerned I would say that it is strange want of enterprise to continue methods and use materials which only require to be thoroughly understood to ensure a swift and sudden collapse for all but the most ephemeral purposes. I know no producer, scientific or other, whose self-respect would suffer the employment of materials, however good the effect, however low the cost, which would not last over so brief a period as five-and-twenty years.

I desire to thank Mr. Horace Hart, Controller of the Oxford University Press, and Mr. J. W. North, A.R.A., for the kind manner in which they have freely given information on this most important matter. 


\section{A REMARKABLE ANTICIPATION OF MODERN VIEWS ON EVOLUTION} I 897.

Reprinted from Science Progress, New Series, vol. i, no. 3, April, Revised: additional footnotes.

THE great pioneer of modern anthropological and ethnological research-James Cowles Prichard, was born at Ross, in Herefordshire, February I I, I786. The following brief account of his life is taken from an article by Professor E. B. Tylor, F.R.S. ${ }^{1}$ Prichard was brought up as a member of the Society of Friends, to which body his parents belonged. He joined the medical profession, taking his Doctor's degree at Edinburgh, 'afterwards reading for a year at Trinity College, Cambridge, whence, joining the Church of England, he migrated to St. John's College, Oxford, afterwards entering as a gentleman commoner at Trinity College, Oxford, but seeking no degree in either university. In 1810 he settled at Bristol as a physician.' Among his many great achievements in anthropology was the proof 'that the Celtic nations are allied by language with the Slavonian, German, and Pelasgian (Greek and Latin), thus forming a fourth European branch of the Asiatic stock (which would now be called Indo-European or Aryan)' ${ }^{\prime}$. His treatise on the subject, entitled Eastern Origin of the Celtic Nations, appeared in $183 \mathrm{I}$. "It is remarkable that the essay by Adolphe Pictet, De l'Affinite des Langues Celtiques avec le Sanscrit, which was crowned by the French Academy and made its author's reputation, should have been published in 1837 in evident ignorance of the earlier and in some respects stricter investigations of Prichard.'

1 Encyclopaedia Britannica, 1885, vol. xix, pp. 722, 723 . 


\section{I74 A REMARKABLE ANTICIPATION OF}

Although Prichard's memory is much honoured, it appears that in one important respect he has not hitherto received his due. My friend Professor Meldola, F.R.S., lately drew my attention to a section of the second volume of Prichard's Researches into the Physical History of Mankind ${ }^{1}$ which, as he pointed out, anticipated in the clearest manner the arguments which have been recently advanced by Professor Weismann in favour of the non-transmission of acquired characters. The deep significance of the passages in question had been observed by Dr. Maurice Davis, J.P., who brought them under the notice of his son-in-law, Professor Meldola.

In response to Professor Meldola's invitation to prepare an account of this most interesting contribution to the history of evolution, I read the work carefully and soon found that other important ideas are anticipated in it.

Thus, Prichard apprehended with perfect clearness that domesticated races of animals and plants have been produced by the selection of man and not by favourable surroundings, careful training or cultivation. He believed in the possibility of organic evolution and supported it by excellent arguments which still have the strongest weight to-day. He even recognized the operation of Natural Selection, although he assigned to it a subordinate rôle. ${ }^{2}$ The most important anticipation is, however, the masterly discussion on the transmission of acquired

1 and edition, 1826 .

${ }^{2}$ Mr. Francis Darwin, F.R.S., and Professor A. C. Seward, F.R.S., consider that the present essay exaggerates ' the degree to which Prichard believed in evolution' (More Letters of Charles Darwin, vol. i, p. 43, London, 1903), and, while admitting the tendency of passages here brought forward, believe that they are entirely neutralized by other passages. I had endeavoured to make it evident that this antagonism exists in Prichard's writings, not only as regards the evolutionary passages, but also in those dealing with the non-transmission of acquired characters. My object was and is to show that certain of Prichard's thoughts, as expressed in his published works, were a remarkable anticipation of modern views on evolution. The historic and human interest of these thoughts remain, notwithstanding the fact that they were abandoned by their author in later years, and were even inconsistent with other thoughts to be fcund in the same work. 
characters, a discussion in which the distinction between acquired and inherent or congenital characters is clearly drawn, and many of the most difficult cases are fully argued out, the conclusions reached being those independently arrived at by Professor Weismann over half a century later.

It is very remarkable that all this should have passed, as I believe, unnoticed. The neglect can only be explained by supposing that this particular edition was never consulted, but that Darwin and others always went to later editions of the same work. I shall be able to show that Prichard was not very confident in the strength of his own conclusions and, so far as I have consulted his later editions and works, I find reason for the belief that his convictions weakened still further. Indeed, strong indications of uncertainty are to be found in the second edition itself, although they are confined to the later sections, and do not appear in close proximity to the important conclusions which they nevertheless affect.

It is certain that if Darwin had read this second edition he would have given Prichard a high place in the account of the history of evolution which appears in the introduction to all later editions of the Origin. ${ }^{1}$ So too would my friend Professor Osborn have given high honour to Prichard in his interesting work, From the Greeks to Darwin. It is an anomaly that such works as the Vestiges should attract attention, while Prichard's keen insight, sound judgement, and balanced reasoning on many aspects of organic evolution, and especially on the scope of heredity, should remain unknown.

I am very far from maintaining that these most interesting anticipations in any way diminish the credit of those recent writers who have treated the same subjects in greater detail and of course independently. The interest evoked by Dr. Davis's discovery in the literature of evolution is mainly due to the work of those recent

${ }^{1}$ F. Darwin and Seward state that Charles Darwin only possessed the third and fourth editions (1. c. p. 44); they also agree that 'in the historical sketch prefixed to the Origin of Species writers are named as precursors whose claims are less strong than Prichard's' (1.c. p. 45). 


\section{I76 A REMARKABLE ANTICIPATION OF}

authors by whom the whole subject has been brought into the light of day, and the attention of every intellectual man and woman has been compelled.

The limits of space oblige me immediately to proceed, after this too brief introduction, with a detailed statement of Prichard's arguments and conclusions, which will be found to justify, in the fullest manner, all that I have said in his praise.

It has already been said that the arguments referred to are found in the Researches into the Physical History of Mankind. ${ }^{1}$ They are included in the seven sections of the first chapter of Book ix (p. 525), which is entitled a General Survey of the Causes which have Produced Varieties in. the Human Species, with Remarks on the Origin of Nations and on the Diversity of Languages. The first chapter treats of the Causes which have given rise to Varieties in the Human Species. In the first Section of the first chapter the author admits that it is fruitless to seek for a complete explanation of the causes which have produced the varieties which are witnessed in the human species. 'The origin of the varieties in the breed is enveloped in the same obscurity which still hangs over every question relating to the theory of propagation.'

The opinion that the different shades of colour met with in various races are caused by climatic changes and by varying intensity in the rays of the sun, is then considered, and a great many ancient and modern exponents of this view are quoted. After reproducing a long passage from Buffon, the hypotheses of the Rev. Dr.S.S. Smith of New Jersey are described. These deal not only with the 'gradation in the complexion, nearly in proportion to the latitude. ... but also with the influence which heat exerts upon the secretion of bile. In consequence of heat 'the bile . . . is augmented. ... This liquor tinges the complexion. ...' 'Bile, exposed to the sun and air, is known to change its colour to blackblack is, therefore, the tropical hue.' This latter and the very similar views of Blumenbach are, however, ${ }^{1}$ Vol. ii, London, and edition, 1826 . 
dismissed by Prichard as 'without foundation'; while as to the suggestion of Dr. Smith, together with that of Buffon and the older writers upon the effect of latitude, he observes that the principal observations on which it is based are correct. 'It is certain that the majority of black races of men are inhabitants of the intertropical regions, and that most of the light-coloured nations, . . . are to be found in cold or temperate climates.' But although he admits the fact, he maintains that it is capable of ' a different interpretation from that which modern writers have in general adopted'. He similarly admits that the skin of a European is darkened by the sun, and continues: 'It seems, at first, not very improbable, that individuals, darkened by exposure to heat in southern climates, may have an offspring of deeper colour in consequence, and if this effect increases in every generation, it may be thought sufficient, in a long course of ages, to produce a black colour of the deepest tint.' But this view does not by any means commend itself to him; for he continues, 'that this notion, however, is altogether incorrect I venture to conclude from the following considerations.

' 1 . The progeny of individuals, embrowned by exposure to the sun, is born with the original complexion, and not with the acquired hue of the parents.' Furthermore, he points out that white and black races moved respectively to tropical and temperate climates have retained their original colour for ages. The second consideration which leads him to reject the abovementioned conclusion is very significant, and I give it in his own words (p. 532):-

' 2 . The supposition is contrary to a general law of the animal economy, according to which, acquired varieties are not transmitted from parents to their offspring, but terminate in the generation in which they have taken their rise.'

The succeeding two Sections are allotted to the considerations contained in paragraphs $I$ and 2.

Section ii (p. 532) is headed, Instances showing the Permanency of Complexion in different Races. The 


\section{A REMARKABLE ANTICIPATION OF}

cases in which races have completely changed in colour after removal to a different climate he explains by a mixture of breed; and points out that 'it is easy to find examples of an opposite tendency, and to show that the original hue has been preserved. ...' Thus he brings forward the instances of the descendants of English colonists in the West Indies and Spanish in South America who 'remain as fair as their European ancestors', when there has been no intermarriage with other races. 'That this assertion is correct, I am convinced,' he says, 'by the result of repeated inquiries.' In the East the same results are found, although the migration of white races into hot climates took place at far earlier dates. Thus amongst other examples he mentions that of the 'white or Jerusalem Jews' who are believed to have migrated to the Malabar coast in the year 490 A.D., and whose living descendants are 'said to resemble the European Jews in features and in complexion'.

The converse 'experiment of transplanting black races into northern climates' has not been carried on for so long a period, but Dr. Prichard points out that 'several generations have produced little or no alteration in the complexion of Negroes in the United States and in other temperate climates'. It is indeed stated that 'the domestic Negroes who are protected from the heat of the sun by more clothing, and who pass their time in sheltered houses, are of a darker complexion than the slaves who labour half naked in the fields'.

Section iii. This most significant and remarkable part of the work is headed (p. 536), Laws of the Animal Economy in regard to the Hereditary Transmission of peculiarities of Structure: the brief title at the head of the pages runs, Lawes of Nature in Hereditary Transmission. This discussion, which forestalls by more than half a century the considerations and conclusions of recent writers and especially of Professor Weismann, is opened by the statement that physiological writers have often inquired 'what peculiarities of structure are liable to be transmitted by parents to their offspring, 
and what terminate with the individual without affecting the race. Perhaps the following remark, the author goes on to say, 'may afford the solution of this inquiry.'

I must now quote without any omission the succeeding two paragraphs in which the two classes of characters-inherent and acquired-are defined, as fully and clearly as they have ever been, and where the opinion is strongly expressed that the former are transmissible, the latter non-transmissible by heredity :-

'It appears to be a general fact, that all connate varieties of structure, or peculiarities which are congenital, or which form a part of the natural constitution impressed on an individual from his birth, or rather from the commencement of his organization, whether they happen to descend to him from a long inheritance, or to spring up for the first time in his own person-for this is perhaps altogether indifferent-are apt to re-appear in his offspring. It may be said in other words, that the organization of the offspring is always modelled according to the type of the original structure of the parent.

' On the other hand, changes produced by external causes in the appearance or constitution of the individual are temporary, and, in general, acquired characters are transient; they terminate with the individual, and have no influence on the progeny.'

At this point the author adds a most interesting footnote, in which he tells us (p. 537) that 'this distinction, which has not been pointed out by any former writer on physiological subjects, was first suggested to me in conversation many years ago by $\mathrm{Mr}$. Benjamin Grainger, of Derby'. It would be of high interest to ascertain something more about Mr. Grainger and to find out whether he ever published on his own account. It is however probable, from the other pregnant ideas contained in Dr. Prichard's work, that the clear expression, apt illustration, and admirable discussion of these principles are entirely original.

He then proceeds to illustrate the first proposition 'that all original or connate peculiarities of body are 
hereditary'; first instancing the well-known 'porcupine family, in which a remarkable peculiarity of the [human] skin was transmitted through three successive generations,' and the facts which prove the hereditary nature of complexion, as shown in Section ii. Supernumerary and abnormally thickened digits are then brought forward and proved by many examples to be markedly hereditary; as also 'a singular thickness of the upper lip, in the Imperial house of Austria', introduced it is believed 'many centuries ago, ... by an intermarriage with the ancient house of Jagellon'.

The last examples of such connate characters are especially significant. 'The same observation equally applies to those minute varieties of organization, which give rise to peculiarities of habit or temperament, and predispose to a variety of morbid affections, as deafness, scrofulous complaints, and the whole catalogue of disorders in the nervous system. Even those singular peculiarities termed idiosyncrasies are often hereditary, as in the instance of a remarkable susceptibility of the action of particular medicines, such as mercury.'

With regard to the second proposition 'that acquired peculiarities, or characters impressed by adventitious circumstances, and not arising in the spontaneous deve. lopement of the bodily structure, are never transmitted...' he remarks, as it has often been insisted upon since, that the conclusion 'is more difficult to establish than the foregoing ...., since the proofs must needs be of a negative kind. But,' he continues, 'there is no want of evidence of this description.' And he again insists, as if he could not put it too clearly and emphatically: 'It seems to be the law of the animal economy, that the organization of the offspring, which as we have seen follows the type given by the natural and original structure of the parent, is unaffected by any change the latter may have undergone, and uninfluenced by any new state it may have acquired.'

He then discusses the examples which are supposed to support the opposite conclusion, first mentioning the statement 'that dogs and cats, the tails of which had 
been cut off, sometimes produce young ones which have a natural defect of the same part. It is taken for granted that these appearances are connected together in the relation of cause and effect, and therefore afford a proof that acquired peculiarities are hereditary.' The author argues that cases of this kind are accidental, and he points out that such defect of parts is apt to occur in every species; - in man as well as in animals. He points to the vast experiment due to 'our caprice' in mutilating the ears and tails of domestic animals, and to the effects of surgical operations upon man. What remarkable results would be witnessed if such changes were hereditary!

Professor Weismann was first led to the same conclusion as Dr. Prichard by constructing a theory of heredity which seemed to him to explain the facts and observations better than any which had been previously proposed. But the theory did not include any mechanism by which the transmission of acquired characters could take place. Professor Weismann, believing that his theory was in the main right, began to inquire for the evidence on which the belief in such transmission is based, and as soon as he commenced his inquiries the evidence broke down in every direction.

With Prichard it was otherwise, for the existing theories seem to have been against him. Thus he argues that his opponents 'seem to have derived their opinion rather from some conjectural theory of generation, than from any facts which have appeared well established '; and he goes on to contend that we know so little 'that we are not authorized to reason from any hypothesis on this subject'.

He next deals with the statement 'that after any mutilation or other artificial change has been repeated through many generations, a sort of habit may be acquired, by which the new state becomes as it were natural, and may thus modify the race'. To this he replies that the evidence of such habit could only be obtained by diminishing the mutilation in progressive generations and comparing the result; whereas in all such cases the violence committed 
and the resulting injuries are continued unabated. 'If, however, an experiment be wanting to prove that repetition effects no difference in the results,' he points to the practice of circumcision which has gone on for some thousands of years without producing any hereditary change.

Prichard argues that such non-transmission is beneficial, in fact he contends 'that all the laws of nature, or the general plans which we trace through the organized world, tend uniformly to produce beneficial effects, though particular evils are sometimes contingent upon their operation'. With regard to this instance he points out that, if such transmission took place, both man and animals would practically become more and more 'mutilated and defective'.

The author next proceeds to consider the effects of disease, introducing the subject in the following paragraph : 'We cannot discern any essential circumstance, in which changes produced by art, or by casual injury, differ from those which are effected by other external causes. We should therefore suppose from analogy that the latter are not more communicable to posterity than the former, and this presumption is confirmed when we inquire into facts.'

He points out that the constitutional effects of many diseases ('small-pox, measles, scarlatina, hooping-cough'), rendering those who have suffered from them more or less immune, are never hereditary. Without attempting to explain in what the change consists, he rightly claims it as a 'permanent state of the constitution, which lasts as long as the individual. . . . Those imperceptible modifications in the bodily structure which render the constitution incapable of being acted upon by certain morbid poisons are governed by the same law, as far as regards hereditary descent, as the observable changes of form which are induced by art or accident'.

At this point the writer intercalates another clear statement of the essential distinction between inherent hereditary and acquired non-hereditary characters. The statement is so admirable that I quote it in full.

'We may remark in general that each individual being, 


\section{MODERN VIEWS ON EVOLUTION I 83}

through the animal and vegetable worlds, has certain laws of organization impressed upon its original germ ; according to which the future developement of its structure is destined to take place. These inbred or spontaneous tendencies, governing the future evolution of the bodily fabric, cause it to assume certain qualities of form and texture at different periods of growth. From these predispositions are derived the characteristic differences, and the peculiarities of individual beings. Now it appears that such spontaneous tendencies are alone hereditary, and that whatever changes of organization are superinduced by external circumstances, and are foreign to the character of structure impressed upon the original stamina, cease with the individual, and have no influence on the race.

'Yet this law of hereditary conformation exists with a certain latitude or sphere of variety, but whatever varieties are produced in the race, have their beginning in the original structure of some particular ovum or germ, and not in any qualities superinduced by external causes in the progress of its developement.'

These sentences might well have been written to-day, to sum up the results of all our observations on such subjects. They have been summed up at greater length and in more technical language, but I venture to think that Dr. Prichard's statement contains everything that is valuable and essential in every later attempt. It will be observed that Weismann's conception of inherent characters as blastogenic, acquired as somatogenic, stands out clear and distinct; furthermore, that the source of individual difference is traced to the germ.

After these general statements he returns to the question of disease, and discusses predisposition. He points out that medical writers have generally believed that any predisposition to disease may arise in any constitution if subjected to the appropriate causes; ' that ... the gouty diathesis, for example, may be acquired by long habits of intemperance, and transmitted to posterity,' and so also with other ill effects witnessed in the children of dissolute parents. If this be so, Prichard admits that 'we have 


\section{A REMARKABLE ANTICIPATION OF}

a clear proof of the hereditary nature of acquired states of the constitution'.

Against such a view he contends that any particular disease can only follow when there exists 'a preparation, laid in the first place by nature, in the original stamina and habit of the body'; and he points out that the same hurtful cause may produce quite distinct diseases. Thus ' intemperate living . . . is commonly said to bring on, in one person, a predisposition to gout, in another to diseases of the liver, or of the stomach, or of the brain. Now, since the difference is not in the external causes, it must be in the natural peculiarities of the constitutions on which they act. These, therefore, are previously fitted by original organization to take on them one form of morbid affection rather than another. It is then clear that the predisposition is laid by natural or congenital structure, in the first instance'. Individuals differ in particular organs; the exciting causes of disease bring out the weaknesses which previously existed and might otherwise have remained unknown. Such defects 'being a part of the original bodily structure' are hereditary. 'The first individual who exposes himself to the morbid causes, first betrays the peculiar defect of the race, and is thus erroneously supposed to lay the foundation for it.'

Syphilis, which appears to be an exception, he explains by 'a peculiar mode of infection. . . . This is evidently a phænomenon of a very different kind from the similarity of structure which the laws of nature have ordained between parents and their offspring'.

Hence he infers ' that the phænomena of predisposition to diseases rather confirms than invalidates the general observations before laid down, and we may be allowed to conclude, that no acquired varieties of constitution become hereditary, or in any manner affect the race'.

The preservation of complexion after a race has migrated to a very different climate conforms to the general law. Although the parents may alter greatly, 'the adventitious colour has no influence on the offspring'.

Hence in looking for the causes of varieties of mankind we must not 'direct our attention to the class of external 
powers which produce changes on individuals in their own persons, but to those more important causes, which, acting on the parents, so influence them that they produce an offspring endowed with certain peculiar characters, which characters, according to the law of nature, become hereditary, and thus modify the race'.

The sentence I have last quoted concludes the Section and very naturally introduces Section iv, entitled, Theory of the Origin of Varieties (p. 548).

This Section opens with a sentence which might well have been written by Darwin: 'Varieties of form or colour, as they spring up in any race, are commonly called accidental, a term only expressive of our ignorance as to the causes which give rise to them.' On the other hand'how, by what infuence, and in what manner' they are produced, 'we shall perhaps never be able to ascertain.'

Examples of new varieties which have sprung up within the experience of man are then given: the 'porcupine' and six-fingered man, albinos, and variations in colour. He next describes the sudden origin of the ancon or otter breed of sheep, quoting from Colonel Humphries in the Philosophical Transactions for 18 I 3 (part i).

Prichard favours the view that when the offspring does not exhibit a new variety but follows the main lines of its race or breed it is apt to be influenced by the father rather than the mother; and he quotes a number of statements and opinions believed to favour this view; and finally alludes to the celebrated cross between the mare and the male quagga, in which it was confidently believed that so great an effect was produced on the former that her later offspring, although begotten by a stallion, were influenced in the direction of the quagga (telegony).

The mother, on the other hand, was believed to be in the main responsible for the new varieties which arise from time to time. This opinion Prichard considered to be probably well grounded; and the conclusion that size and stature chiefly depend on the mother he also thought to be well established. Hence we see that his judgement and penetration were not always proof against popular convictions insufficiently sustained by evidence. These 
strange views about the relative importance of the two parents seem to have disappeared, and only traces of them are to be found in the popular beliefs of the day.

The author dismisses the extreme cases of the supposed effect of the mother's imagination upon the unborn child as manifestly absurd; but looks with some favour upon the opinion, also held by Erasmus Darwin, whom he quotes, that the future offspring may be affected by the imagination of the parent at the moment of conception. In proof of the ancient origin of this belief he alludes to Jacob's experiments upon the flocks of Laban.

When, however, Prichard comes to reconsider all his suggested causes of variation he is dissatisfied with them and admits that 'the circumstances ... . are of a more permanent nature', and that it is often 'impossible to discover any peculiar circumstance in the condition of the mother'. This leads him to consider the similar instances among domestic animals and among plants, and at this point he anticipates in a truly remarkable manner Darwin's general conclusions as to the origin of our domestic breeds.

'It is generally supposed,' he says on page 557 , ' that cultivation is the most productive cause of varieties in the kind, both in the animal and vegetable kingdom. But it may be questioned, does cultivation actually give rise to entirely new varieties, or does it only foster and propagate those which have sprung up naturally, or as it is termed accidentally?

'In this latter way the influence of art is very important in constituting breeds, as of cattle, dogs, horses. The artificial process consists in a careful selection of those individual animals which happen to be possessed, in a greater degree than the generality, of any particular characters which it is desirable to perpetuate. These are kept for the propagation of the stock, and a repeated attention is paid to the same circumstances, till, the effect continually increasing, a particular figure, colour, proportion of limbs, or any other attainable quality, is established in the race, and the uniformity of the breed is afterwards maintained by removing from it any new variety which may casually spring up in it.' 
The main result of Darwin's indefatigable labours on the formation of domestic races could not be more accurately summarized than in these words published in 1826 .

Prichard expresses himself as uncertain whether domestic animals are more prone to vary than others, but considers that the artificial conditions may in all probability 'occasion deviations in their progeny'.

The influence of climate seemed to him the most important of all causes of race-formation-so important in fact that he discusses its examples under a separate Section, while the adaptation of races, animal and human, to their climates form the subjects of the concluding Sections vi and vii.

The examples of the effect of climate are brought forward in Section v (p. 558), entitled, Instances of variety in the Breed, arising from the operation of external, chiefly of local causes. The first instance is that of the swine of Cuba, which are said to be twice the size of the parent breed. He then instances the peculiar and uniform colour of the cattle and horses 'descended from the variegated domestic breeds' which have become wild in South America, and the common bear, which differs in colour in various European localities.

When the races of several distinct species resemble each other in a single locality it is fairly maintained that some special local influence may be strongly inferred. Thus it is stated that the Angora breeds of rabbits, goats, and cats are remarkable for their long, fine, silky hair, and white colour. 'These characters ... indicate a common cause, which must be some peculiarity in the circumstances under which these animals exist in the climate and situation occupied by them.'

Then follow many other examples - the blackness which characterizes both men and animals in Malabar and Guinea, the whiteness of Polar animals, the height of Patagonian man, the differences which separate the English race in America and the West Indian Islands from that in the parent country, and the negroes of America from those of Africa. 
The Section concludes in a significant paragraph in which the author suggests that perhaps some of these local varieties may be specially adapted to 'the circumstances of the countries in which the deviation has taken rise', and he finally concludes by introducing the succeeding Section in these words: "It may indeed be inquired, whether the deviations in general, which appear to follow a change of climate, are not founded on a law of the animal economy, which gives rise to an alteration in the breed calculated to fit the race for its new abode' (page 566).

The sixth Section (p. 567) is headed Adaptation of certain Breeds to particular local circumstances. In this Section we are provided with numerous instances of the adaptation of races to their environments. Blumenbach's opinion in favour of the multiple origin of the dog is quoted at some length. Considering the undoubted adaptation of many breeds for certain ends, this naturalist concludes: 'I can scarcely persuade myself to look upon this as a mere accidental consequence of degeneration, and not rather as an intentional contrivance of the wise Creator.' To this Prichard replies that such a remark 'suggests the inquiry whether the degeneration or variation of animals is in fact a mere accidental phænomenon ... We should note that degeneration is here used in the sense of departure from ancestral type, and not implying, as it does in our time, any degradation or simplification of structure.

Then follows a paragraph most significant of modern views of organic evolution and the kind of evidence on which the modern naturalist relies. The remarkable 'double relation' which individual species bear on the one hand to their special localities, and on the other to the group to which they belong, is first pointed out, and maintained to be characteristic of the vegetable kingdom as well as the animal. Thus the species of a family or genus are often distributed round a centre 'which seems to be the principal focus or favourite seat of the tribe', from which the branches diverge in various directions. The particular species, when compared, can be referred 
to 'one type of organization'. The slighter differences between them 'seem to lose themselves in the sameness of form belonging to the genus, and even suggest a suspicion that they all proceeded from one original. The phænomena of resemblance must have had their sufficient reason as well as those of diversity'. He then inquires whether the explanation is to be found in the action of 'some slight modification in the productive causes' which stamped the genus at its first appearance 'with all these specific diversities'; or whether, on the other hand, a uniform genus was first created which 'afterwards became diversified by the influence of external agents'. He concludes that the former of these alternatives is more strongly indicated by the knowledge of his time.

'Whichever of these suppositions may be true in point of fact, the separation of families and genera into particular species, and the distribution of these species to particular habitations, according to their physical properties, is evidently a part of the provision of nature for replenishing the earth with organized inhabitants, placed everywhere according to the congruity of soils and temperatures, with their structure and habitudes.

' But why is it to be supposed that the influence of this law of adaptation has stopped here? Is it not probable that the varieties which spring up within the limits of particular species, are further adaptations of structure to the circumstances under which the tribe is destined to exist [?] Varieties branch out from the common form of a species, just as the forms of species deviate from the common type of a genus. Why should the one class of phænomena be without end or utility, a mere effect of contingency or chance, more than the other ?

'There are indeed many instances in which we can perceive an advantage in the varieties of form, and an adaptation of particular breeds to external circumstances.' He then gives numerous examples- the small, active cattle and horses which are found in mountainous countries, the larger forms which flourish on fertile plains; the various breeds of the hog which are believed to hold 


\section{A REMARKABLE ANTICIPATION OF}

'a particular relation to the localities in which they are placed'; the change of a thick fleece into a thin coat when certain breeds of sheep are transported to the tropics. 'On considering these and analogous phænomena, we can scarcely avoid concluding that the variation of animals proceeds according to certain laws, by which the structure is adapted to the necessity of local circumstances.'

This statement looks at first sight very much like Natural Selection. It is clear, however, that the writer held a view similar to that which has been termed 'selfadaptation' by some modern writers, viz., that external influences act on the organism in such a manner as to evoke directly a favourable response.

Examples of similar adaptation are then found among the races of man. The skin of black races is considered to be a protection against the effect of heat; the native African races can multiply in localities where a white population cannot maintain its numbers, while negroes are unable to establish themselves in northern latitudes. From these and many other instances, it appears that 'in mankind, as in some other races, particular varieties are adapted by constitution and physical peculiarities to particular local situations'.

The Section finally concludes with the following paragraph : 'These remarks, if they are well founded, serve to illustrate the doctrine of variation, or deviation, in the races of animals in general, and they seem to lead us to the conclusion, that this is not merely an accidental phænomenon, but a part of the provision of nature for furnishing to each region an appropriate stock of inhabitants, or for modifying the structure and constitution of species, in such a way as to produce races fitted for each mode and condition of existence. A great part of this plan of local adaptation appears to have been accomplished by the original modification of a genus into a variety of species. It has been further continued, and the same end promoted, by the ramification of a species into several varieties.'

The seventh and last Section (p. 575) of this part of 
the work treats of the Relation of particular Varieties of the Human Species to Climates.

Prichard evidently thought that adaptation of races to climate is especially characteristic of the human species, and must be admitted to hold in certain instances, whatever be thought of his hypothesis that 'the varieties in the species of animals proceed from a principle in nature, modifying the structure and constitution of races, and adapting them to the physical circumstances under which these races may be destined to exist .... He considers that the distribution of the races of men bears 'a certain relation to climates', and gives a broad sketch of the geographical arrangement of races in support of this opinion. At the conclusion, after inquiring how it is that 'these varieties are developed and preserved in connexion with particular climates and differences of local situation', he gives the following very significant answer : ' One cause which tends to maintain this relation is obvious. Individuals and families, and even whole colonies, perish and disappear in climates for which they are, by peculiarity of constitution, not adapted. Of this fact proofs have been already mentioned.' We have here the undoubted recognition of Natural Selection, and it is remarkable that a man of such penetration who recognized fully that domestic breeds are due to man's selection, should not have seen in this principle a larger importance and have extended it to the relations of species to each other as well as to their physical environment. Great as Prichard was, he did not appreciate the most pressing part of the 'struggle for existence'.

Prichard furthermore considers it probable that there are local influences which 'promote the appearance of those varieties which are best suited to them, or tend to give rise to their production in the breed'. He freely admits that this conclusion conflicts with his contention in Section ii, that the colour of a race is not permanently affected by a change of climate, and, he might have added, conflicts equally strongly with his argument in Section iii, that acquired characters are not transmitted. However, he is so fascinated by the view of a local influence directly 


\section{A REMARKABLE ANTICIPATION, ETC.}

producing adaptation that he throws over much that he had previously argued for in a most convincing manner. Thus he suggests that races of men when removed into another climate may not change because they are defended from the local influences by living in houses, adhering to their old foods, \&c., also that the facts about the black and white Jews of Cochin, from which he argued in Section ii that climate produces no permanent effect on the race, may be insufficiently known.

It is strange that one who reasoned so acutely in Section iii did not seem to see that the following view, if proved to be true, would undermine the whole of the argument: 'It may however be true, that particular varieties, once established in the stock, and transmitted for many generations, though originally resulting in a certain degree from the influence of local causes, will nevertheless continue permanent, even long after the race has been removed from the climate in which they originated.'

In spite of this logical flaw, which is in itself of much interest, inasmuch as it probably explains the suppression of Prichard's original views in later works, sufficient has been said to prove that the author was one of the most remarkable and clear-sighted of the predecessors of Darwin and Wallace. 


\section{THOMAS HENRY HUXLEY AND THE THEORY OF NATURAL SELECTION}

The Huxley Lecture for 1905 , delivered before the University of Birmingham, March 23.

Hither to unpublished.

THE relation of a great man to a great theory which arose in his time is always a deeply interesting subject of contemplation. A great theory, like Gravitation or Natural Selection, is an all-powerful weapon of inquirystrong enough to effect a reclassification of workersinexorable sometimes in making the first last and the last first, according to the prejudice or the sympathy with which the new instrument is received. A theory of the highest rank compels attention and can be no more passed by with indifference than the discovery of iron or of gunpowder.

The attitude of Huxley towards Natural Selection was, I shall endeavour to show, remarkable and unusual. Although no one strove so nobly and against such odds in its defence from unfair attack, although no one ever fought the battle of science with more complete success, Huxley was at no time a convinced believer in the theory he protected.

The origin and growth of the theory and the circumstances under which it was made public have often been told, but no lecture of this kind would be complete without a brief recapitulation of the main points.

Darwin, convinced of evolution by reflection upon his observations in South America, during the voyage of the Beagle $(1831-6)$ began in July, 1837 , systematically to collect facts bearing upon the modification of species 


\section{HUXLEY AND NATURAL SELECTION}

and its causes. In October of the following year, when a few months under thirty, he read Malthus On Population, and the idea of Natural Selection at once dawned on his mind. In June, 1842, he wrote a brief account of the theory in thirty-five pages, expanded two years later into an essay of 23 I pages, folio; but he could not bring himself to publish until, on June $18,185^{8}$, almost exactly twenty years after the conception first came to him, he received a manuscript essay written by Alfred Russel Wallace at Ternate, in the Moluccas, On the Tendency of $V$ arieties to depart indefinitely from the Original Type. In the accompanying letter Wallace asked him if he thought well of the essay to send it to Sir Charles Lyell. In the paper which had reached him from the other side of the world Darwin was astounded to find a clear, concise statement of his own theory of Natural Selection. He sent it on to Lyell that very day and shortly afterwards asked him to forward it to Sir Joseph Hooker. Thus appealed to, Lyell and Hooker requested Darwin to give them an abstract of his own work, and presented this, together with Wallace's paper, as a joint communication to the Linnean Society. They explained the circumstances of the case in an introductory note to the DarwinWallace memoir, which was read at the meeting held on July I, I $85^{8.1}$

That, of two naturalists on opposite sides of the globe, one should seek the other for advice upon the theory at which they had independently arrived, is a sufficiently remarkable fact in the history of discovery; but now that we know the circumstances under which Wallace wrote his essay, the coincidence is far more striking. He also was convinced of Evolution before he thought of a motive cause, and had in 1855 defended it in a powerful paper, written in Borneo, On the Law which has regulated the Introduction of New Species. In February, 1858, lying ill of intermittent fever in Ternate, he, too, began to think of Malthus On Population, which he had read some

'In addition to the specially prepared abstract, Darwin's section of the joint memoir includes a copy of a letter he had written Sept. 5, 1857, explaining his theory to Asa Gray, the great American botanist. 
years before, and the idea of Natural Selection instantly flashed across his mind. But he did not wait for twenty years of thought for repeated observation and experimental test. In two hours of ague he had thought out almost the whole of the theory, in three evenings he had completed his account, and it was posted to Darwin by the next mail.

Thus on July Ist, I 858 , when Darwin was nearly fifty, and Huxley just over thirty-three, the great theory was before the world; and the striking thing about the relation of the younger man to this crisis in the history of science, is that he knew really nothing about it. Darwin and Huxley had corresponded for some years prior to $185^{8}$; but even had this not been so, Darwin was a great central power in biological science, and his writings would naturally be received with the widest interest. Huxley did not become a Fellow of the Linnean Society until December, 1858 , but the publications of scientific societies are readily accessible to all. Huxley certainly knew that Wallace had in some way acted as a stimulus to Darwin ; for he wrote to Hooker on September 5, I 858, 'Wallace's impetus seems to have set Darwin going in earnest, and I am rejoiced to hear we shall learn his views in full, at last. I look forward to a great revolution being effected.' 1 But Huxley clearly knew nothing of the contents of the joint memoir; for on June 25, 1859, almost exactly a year after it had appeared, he wrote to Lyell $^{2}$ in favour of transmutation of species but against the idea of transition between species. The letter contains no reference to Natural Selection, but only to the direct action of external conditions and to laws analogous to those of chemical change, where one substance passes into another without intermediate stages, e.g. by the substitution of one element for another. 'I have a sort of notion that similar laws of definite combination rule over the modifications of organic bodies, and that in passing from species to species "Natura fecit saltum".' And yet, in October, $1859,{ }^{3}$ Canon H. B. Tristram, writing

1 Life and Letters of Thomas Henry Huxley, London, 1900, vol. i, p. 159.

2 Ibid. p. I 73 , ${ }^{3}$ In The Ibis, vol, i. 


\section{I96 HUXLEY AND NATURAL SELECTION}

upon the larks of the Sahara, made use of the DarwinWallace theory in the interpretation of the colours of desert animals.

The Origin of Species was published, and the whole of the I,250 copies sold, on November 24, 1859. An advance copy had been sent by Darwin to the friend whose opinion he was so extremely anxious to learn. 'I shall be intensely curious to hear what effect the book produces on you,' he wrote on October I $5 .^{1}$ Huxley replied on November 23 that he had finished the Origin on the previous day. He wrote of 'the great store of new views you have given $\mathrm{me}^{\prime} ;{ }^{2}$ and in his chapter On the Reception of the Origin of Species, he says, 'my reflection, when I first made myself master of the central idea of the "Origin" was, "How extremely stupid not to have thought of that !" '3 - further evidence that he knew nothing of the subject of the Linnean Society memoir, where this central idea is admirably, although of course briefly, set forth and illustrated by its two great discoverers.

Huxley's ignorance of Natural Selection between July I, I858, and the end of November, I859, suggests certain interesting conclusions. Great and original workers rarely have the time for wide reading in their subject away from the lines of their special investigations. But want of time is not the only cause. They are, perhaps unconsciously, led by an instinct which warns them that the attempt to be encyclopaedic, though within the limits of but a single science, is itself destructive of originality. And yet there is nothing so inspiring to a young worker as the fact that his attempts have interested a great leader in his own subject. To a Darwin at the age of fifty, it may be a small thing that his younger friend is too engrossed to read his paper, and yet many years before we know that even Darwin keenly felt the neglect, as it appeared to be, of his early geological work. Thus he wrote in 1844 or 1845 : "I have long discovered that geologists never read each other's works, and that the

1 Life and Letters of Charles Darwin, London, 1887 , vol. ii, pp. 172, 3 .

2 Ibid. p. 23 I.

s Ibid. p. 197. 
only object in writing a book is a proof of earnestness, and that you do not form your opinions without undergoing labour of some kind.' ${ }^{1}$

The first research which has tempted a young man over the Rubicon of his life is and ought to be everything to him. It is a crisis in his life when, in spite of all the inspiration of the work itself, he needs every encouragement, and yet is apt to find disappointment and neglect as an incidental result of the devotion of other workers to other work. The position looks like a dilemma, but fortunately for scientific students the escape is easy. The conditions of science are daily becoming more favourable at our Universities. Here the older worker has a parental interest in the younger, and will by no means quench the smoking flax by unintended neglect. Science is also rich in numerous societies where old and young can meet, and where through personal contact, far better than by endless hours of reading, the deepest inspiration and the highest encouragement can be given and received.

If however the antagonism between the excessive cultivation of the memory and the development of originality is seen in the lives of older men whose capacity for the highest work is proved and certain, surely conclusions of value may be learned by those whose duty it is to watch over and direct the developing mind of the young. A little knowledge, we are told, is a dangerous thing, but as regards the awakening and the growth of the most indispensable part of our intellectual equipment - the imagination-it may be more truly said that excessive knowledge is a dangerous thing. Owing to the deadly grip of the examination system upon our country, we develop the memory far too exclusively, and a poor sort of memory at that, valuable for the purposes of the barrister but of little use for any other career. The imagination is not only neglected but actually stunted and atrophied by forcing into disproportionate growth an antagonistic intellectual faculty of a rather low order. Not unintentionally, Kingsley chose the turnip, beet, and ${ }^{1}$ Life and Letters of Charles Darwin, vol. i, pp. 334-5. 


\section{HUXLEY AND NATURAL SELECTION}

radish as symbols of the unfortunate victims of the 'Examiner of all Examiners'. With the very best intentions, but with the very worst effects, the idea has taken root in this country that the imagination must not be allowed free play until some arbitrary amount of knowledge has been absorbed, with the result that too often all original faculty is water-logged and drowned in a sea of facts. We lose sight of the educational value of research, and the fact that the imagination needs exercise and grows by performance. We frequently hear of the danger of encouraging crude work. The real danger is the other way: it is only too easy to discourage and dishearten, forgetting the great truth that a first research, poor and immature though it be, means a rich intellectual growth-forgetting that to chill the divine spark is often to quench it for ever.

The home of information is in this country too often the grave of the imagination. The mind of man appeals to the known for instruction, to the unknown for inspiration; and the teacher who understands education, which means development, will continually bring his pupils, however young, with a stimulating shock right up against the boundaries of knowledge.

Huxley, in his essay on $A$ Liberal Education, spoke of one ' whose mind is stored with a knowledge of the great and fundamental truths of Nature and of the laws of her operations '; ${ }^{1}$ but the emphasis is here laid on quality rather than quantity. He knew full well that no training of any man worth calling a man is complete without research. Thus we find that on December 31,1856 , at the age of thirty-one, he made this entry in his journal, ${ }^{2}$ "1 856-7-8 must still be "Lehrjahre" to complete training in principles of Histology, Morphology, Physiology, Zoology, and Geology by Monographic Work in each Department.' It must not be concluded that Huxley waited until he was thirty-one before beginning original work. In 1845, when he was twenty, he published an account of what has since been known as 'Huxley's layer'

1 Lay Sermons, \&c., London, 1877, pp. 34-5.

'Life and Letters of T. H. Huxley, vol. i, p. 151. 
in the 'root-sheath' of the hair, ${ }^{1}$ and at the end of the following year his four years' voyage in the Rattlesnake began - a record of a ceaseless energy in research.

The commonly received British doctrine teaches that research may only be attempted after the most heroic preparation. Existing knowledge of any important educational subject may be likened to a vast plain dipping beyond the horizon in every direction, and the student is supposed to explore it all in a superficial kind of way before proceeding to climb the height which he would fain make his own. In a true system of education, developing the higher as well as the lower faculties, he would be shown the main roadstraversing the plain, but his search for unconquered peaks would be aided from the first, in the full knowledge that a wide extent of country round the mountain base would be gladly explored and learnt with a zest and a thoroughness attainable in no other way. And if the appetite for discovery be not acquired early in life it is hardly ever acquired at all. For, as regards research, it is not so much in the old age of which Matthew Arnold wrote, as in the tantalizing consciousness of strength unfit for highest exercise that -

- long the way appears, which seem'd so short

To the less practised eye of sanguine youth ;

And high the mountain-tops, in cloudy air,

The mountain-tops where is the throne of Truth, Tops in life's morning-sun so bright and bare!

Once reached in youth they will be seen ever more clearly in after life, and if the pathos of its close should be deepened by a time of failing power, it will be illumined by the bright and unquenchable memory of the heights.

To return to Huxley's views on Evolution. Before November, I 859, these were what we should expect of a great student of animal structure rather than of animal life, who was at the same time a profound and cautious thinker. Huxley states that before the appearance of the Origin he took his stand upon two grounds, 'firstly, that ${ }^{1}$ Life and Letters of T. H. Huxley, vol. i, p. $2 \mathrm{I}$. 


\section{HUXLEY AND NATURAL SELECTION}

up to that time, the evidence in favour of transmutation was wholly insufficient; and, secondly, that no suggestion respecting the causes of the transmutation assumed, which had been made, was in any way adequate to explain the phenomena.' ${ }^{1}$ 'So,' he tells us, 'I usually defended the tenability of the received doctrines, when I had to do with the transmutationists; and stood up for the possibility of transmutation among the orthodox-thereby, no doubt, increasing an already current, but quite undeserved, reputation for needless combativeness.' ${ }^{2}$ And yet all along there was alive in him 'a sort of pious conviction that Evolution, after all, would turn out true'. ${ }^{3}$ And the kind of evolution he imagined was, so far as we are able to judge, a conception which would arise in the mind of one who studied and compared animal structures with the eye and brain of the artist or engineer rather than of the naturalist. At the age of twenty-six, only seven years before the appearance of the Darwin-Wallace essay, we find him writing to W. S. Macleay, 'I am every day becoming more and more certain that you were on the right track thirty years ago in your views of the order and symmetry to be traced in the true natural system.' Macleay's views of the grouping of the animal kingdom are about as regular and symmetrical as the figures seen in a kaleidoscope. Such a conception of sharply separated mathematically grouped forms would naturally lead to the idea of evolution by abrupt steps, whereby a new form would appear from the sudden transformation of the old, just as a chemical compound changes when one element in it is replaced by another-the metaphor employed by Huxley in his letter to Lyell, already referred to on p. 195.

The evidence at our disposal leads to the belief that this was the state of Huxley's opinion when, towards the end of November, 1859 , he read the Origin. The book is planned so as precisely to meet his two-fold difficulty. In place of insufficient evidence in favour of evolution, he here met with convincing and weighty proofs; and these

1 Life and Letters of C. Darwin, vol. ii, p. 188.

2 Ibid. p. 196.

Ibid. p. 190. Life and Letters of T. H. Huxley, vol. i, p. 92. 
he accepted at once, unreservedly, and permanently. He furthermore encountered what was to him the entirely new idea of Natural Selection, and he instantly recognized that it disposed of his second objection that no suggestion in any way adequate to explain the phenomena had been made. But to the end of his life he never went beyond this. He never committed himself to a full belief in Natural Selection, and even contemplated the possibility of its ultimate disappearance.

But Natural Selection appeared to him so reasonable, so well worth consideration, that he could no longer feel any force in an adverse argument depending on the want of a cause. If we were so dense as not to think of such a reasonable idea founded upon the most familiar of facts, what right have we to make use of any such argument? To the Transmutationists and the non-Transmutationists he had said, with Mercutio, 'a plague on both your houses,' and he might have expressed his opinion of Natural Selection by another quotation from the same character. It may not be 'so deep as a well, nor so wide as a churchdoor, but 'tis enough, 'twill serve'.

But while Natural Selection thus enabled Huxley freely to accept evolution, it is evident, as I have said, that he was by no means fully satisfied with it. The difficulty which he felt early and late, and about which he had a prolonged discussion with Darwin, was the fact that the breeds created by the artificial selection of man are mutually fertile, while the species created ex hypothesi by Natural Selection are mutually sterile. Without going into the controversy, ${ }^{1}$ it may be said briefly, that, according to Darwin, Huxley's objection merely meant that the results of an experiment prolonged for an immense period were not in every respect the same as those attained when it endured for a time comparatively short.

The reason why other students have felt a confidence in Natural Selection not shared by this great leader is to be found in his own words. Speaking of 'every great advance in natural knowledge', Huxley says: 'The

1 A fairly complete account of the controversy will be found on pp. $77-83$ of the present volume. 
most ardent votary of science holds his firmest convictions ... because his experience teaches him that whenever he chooses to bring these convictions into contact with their primary source, Nature-whenever he thinks fit to test them by appealing to experiment and to observationNature will confirm them.' But with respect to Natural Selection, as it required the student of living nature to discover the principle itself, so the experience which brings confidence in it is that mainly of the naturalist. The strongest confidence in the abiding truth of a theory is gained by those whose imagination has been inspired by it. Every verified prediction made in the light of Natural Selection places the theory upon a more secure foundation. That foundation has been growing firmer for nearly half a century; but, as I hope to show by illustration in the remaining section of this address, the increasing confidence is not so much due to the facts which are the province of the anatomist as those which form the everyday experience of the naturalist, of the man who studies animal form and change and instinct, not in relation to the single individual or the single species, but in relation to the whole environment, and especially the world of living organisms. Huxley's researches, determined by the bent of his mind, were not of this kind, they were physiological, anatomical, and palaeontological. To use his son's words, 'It was the engineering side of nature, the unity of plan of animal construction, worked out in infinitely varying detail which engrossed him.' 1 Again, 'walking once with Hooker in the Rhone valley, where the grass was alive with red and green grasshoppers, he said, "I would give anything to be as interested in them as you are."' 2

It is no wonder, therefore, that, as Huxley's experience was not that of the naturalist, the confidence in Natural Selection of which I have spoken was not for him.

I now propose to draw your attention to a few examples of that adaptation which more than anything else kept Darwin orthodox, but in the end furnished him with the

'Life and Lelters of T. H. Huxley, vol. ii, p. 443.

2 Ibid. p. 443 . 


\section{THE STUDY OF LIVING NATURE 203}

strongest evidence in favour of his theory. The illustrations will be chiefly selected from old subjects in which something new may still be found. The examples must be limited, and therefore I propose to select them from a single Order of insects-the Lepidoptera, or butterflies and moths.

\section{Some points in the Resemblance of Butterflies to Dead Leaves.}

One of the finest and best-known examples of concealment for the purposes of defence is found in the underside coloration of butterflies of the genus Kallima, so graphically described by Wallace. ${ }^{1}$ Among the most interesting details of the resemblance is an oval transparent patch on each fore-wing, which allows the light to pass through and produces the effect of a hole in the apparent dead leaf. In another part of the fore-wing of Kallima the appearance of a hole is produced as an artist would paint it, by the use of white body-colour. Of these two methods found on the same wing, the former is undoubtedly the more recent and more highly-specialized method; for when the transparent 'window' is examined under the microscope, scattered opaque white scales can still be seen in abundance over its surface, not thickly placed so as to prevent the passage of light, but witnesses to an earlier and less perfect representation of light shining through a hole.

In many species a hole is suggested by means of the more primitive method alone. One of the most remarkable markings possessed by any British insect is the white ' C' or 'comma' on the under surface of the hind-wing of the 'Comma' butterfly, Polygonia (Grapta) C-album. Many years ago I came to the conclusion that it represents, in bright, strongly-reflecting 'body-colour', the light shining through a semi-circular rent in a fragment of dead leaf-the rent produced when a little segment of leaf has broken away along a curved line, but still remains connected with the rest across the chord of the arc. Unless such a segment remains precisely in the plane

1 Essays on Natural Selection, London, 1875, pp. 59-62. 


\section{HUXLEY AND NATURAL SELECTION}

of the leaf, light may pass through a curved and often a semi-circular slit-like window. Such curved cracks are extremely common in old weather-beaten dead leaves. They are probably produced by drying and shrinkage after much wetting and sonie decay.

On April 23, I903, I had the opportunity of testing how far the whole attitude of Polygonia C-album, during profound repose, is consistent with the interpretation suggested above. By a curious coincidence, I had been speaking of the differences between temporary and prolonged resting attitudes in butterflies, at the meeting of the Entomological Society of France on the evening of April 22, and the very next morning saw for the first time in my life the position of this species during complete repose. The day was excessively cold for this time of the year, and the butterfly was hanging perfectly torpid from the horizontal rail of a wood fence in a street at Passy. Several excellent but very small photographs were taken with my daughter's camera: enlargements have been made, and from these the actual specimen has been set and photographs taken of the natural size. ${ }^{1}$ These show that the two anterior wings are held so far forward that a deep wedge-shaped notch appears between them and the hind-wings. On each side of this notch the wellknown ragged outline of the wings is extremely distinct. The two posterior pairs of legs by which the butterfly clings to the supporting surface are light-brown in colour and unexpectedly conspicuous. 'The antennae are concealed, and the contour of the head does not break that of the costal margin of the anterior wings so as to interfere in any way with the general effect. The whole appearance is consistent with a single interpretation-concealment effected by resemblance to a weather-beaten fragment of dead leaf, deeply notched and ragged, and hanging by two denuded fibro-vascular 'veins' standing out far beyond one of the edges. The kind of injury suggested by the 'comma' only adds another convincing detail to a perfectly harmonious cryptic effect.

It is interesting to compare this mode of concealment

\footnotetext{
${ }^{1}$ Exhibited upon the screen.
} 
with that which is common in other Nymphaline butterflies (Kallima, Doleschallia, Anaea, Precis, \&c.), viz. the resemblance not to a fragment but an entire dead leaf, with midrib and suggestion of lateral oblique venation.

Holes may not only be suggested by opaque 'bodycolour' and by transparent windows, but also by actual discontinuity, as is probably the case in certain species of Anaea in which the deeply-cut bay in the inner margin of the fore-wing may be converted into the likeness of a hole by closure along its open side by the costal margin of the hind-wing. The holes represented in these apparent entire dead leaves seem to have been produced by gnawing, e.g. of insect larvae. ${ }^{1}$ They are surrounded very conspicuously with a marginal zone of modified colour varying greatly in different individuals as regards both tint and breadth. This border of altered colour may represent the effect of the attacks of fungi entering along the freshly exposed tissues of the edge. On the other hand, in the leaf-fragment suggested by $C$-album the forces of the inorganic environment, which by their prolonged action have produced the wear and tear of the margin, have also been responsible for the more centrally-placed discontinuity. Comparing various species of the genus Polygonia (Grapta), it is seen that the curved C-like window occurs in several; in some the suggested rent is V-like, while occasionally the mark appears to represent a hole of a reniform shape. ${ }^{2}$

Another interesting point in the likeness to a dead leaf is the appearance of fungus-growth, finely described by

${ }^{1} \mathrm{Mr}$. W. B. Grove, of Handsworth, Birmingham, who was present at the Huxley Lecture, afterwards sent me leaves of several plants attacked by minute fungi, species of Phyllosticta and Cercospora. The attack was local and followed by the death and disappearance of the central portion of the leaf-tissue of each patch, leaving a roundish or oval window outlined with brown, sometimes in the form of a narrow line, sometimes spreading centrifugally into the leaf for a greater or less distance. I have no doubt that Mr. Grove is right in believing that the 'windows' of Kallima resemble perforations made in this way, and not, as I supposed, by the gnawing of larvae followed by fungus attack along the raw edge of the aperture. See Proc. Ent. Soc., Lond., June 7, 1905 .

${ }^{2}$ See Ibid. May 6, 1903 , for the account from which the foregoing description has been adapted. 


\section{HUXLEY AND NATURAL SELECTION}

Wallace, on the wings of a large proportion of the individuals of Kallima. Here, too, further investigation has shown greater detail in the resemblance. The markings which represent the largest patches of cryptogamic growth bear a black central column composed of tall, upstanding scales. When the patch is photographed slightly magnified, under oblique illumination, the character of the scales is well shown, together with the pronounced shadow cast by the column. ${ }^{1}$ These tall, black scales doubtless represent, in form as well as in colour, the fructification in the centre of a patch of leaf-attacking fungus, perhaps the very kind which at a later stage of development produces the holes suggested by the 'windows' on another part of the wing surface. ${ }^{2}$

Hence it is seen that recent research into this longknown resemblance to dead leaves has brought out many new details, but only such as add to and strengthen the old descriptions and support the old interpretation. The likeness to leaves is shown to be even more remarkable and more detailed than was at first supposed, but not a single new fact suggests that the appearance serves any purpose except protection from enemies in the struggle for life, or hints at any cause of evolution except accumulation by the survival of the best-concealed individuals through innumerable generations.

\section{Some Seasonal Changes in Butterflies and their Significance.}

The fact that there are well-marked differences between the wet season and the dry season broods of certain butterflies has been known for many years. Among the most characteristic of these is the tendency of the apex of the fore-wing to be much elongated and bent, or sometimes even hooked, in the dry season. Almost equally marked is the greatly produced anal angle of the hindwing at the same season of the year. These characters have been recently observed to be conspicuous in the Indian Kallimas of the dry season, which are also larger

1 Exhibited upon the screen.

2 Proc, Ent. Soc., Lond., June 7, 1905. 


\section{SEASONAL FORMS OF BUTTERFLIES 207}

than those of the wet, and possess paler tints. ${ }^{1}$ In attempting to understand the difference in outline which is characteristic of so many butterflies in the dry season, it must be borne in mind that the apex of the fore-wing represents the tip and the anal angle of the hind-wing the base of a leaf, and that the two are commonly joined by a streak representing the mid-rib, with more or less distinct lateral marks suggesting traces of the oblique veins. All are peculiarly well marked in Kallima. Now the dry season outline certainly cannot be explained by affinity between the butterflies possessing it, inasmuch as it is found independently in Satyrinae, Nymphalinae, and Pierinae. Its explanation is rather to be sought for in the independent protective resemblance to some feature which is characteristic of the surroundings in the dry season, as contrasted with the wet. Such a feature may probably be found in the forms assumed by dead leaves: curled and warped in the dry season, flat-like damp blotting-paper-in the wet. $^{2}$

The differences here described are not invariably characteristic of the season. Thus in Kallima paralekta, of the Malay archipelago, the species rendered classical by Wallace's description, the dry season appearance is borne by the females, the wet by the males. The interpretation may perhaps be found in the different habits of the two sexes, or it may be an advantage to the species that one set of individuals should resemble leaves of one form, another set those of another form, thus increasing the categories of objects in the surroundings for which they might be mistaken by their enemies.

Both seasonal forms of the Indian Kallimas tend strongly towards concealment, although the individuals of the dry season are probably more perfectly hidden than the others. In Africa the two seasons are more sharply contrasted than in India, and the differences between the forms of butterflies with seasonal phases may also be far greater. Some of the African species of the genus

${ }^{1}$ See Observations on Indian Butterfies, by T. R. Bell ; Ent. Month. Mag., 1906, pp. I 2 I-8.

2 Proc. Ent. Soc., Lond., Oct. 2 I, 1903 ; see also Ent. Month. Mag., I 906 , p. 126. 
Precis, allied to Kallima, possess seasonal forms closely resembling those of the latter. In other species, however, the phases are more distinct than those of any known butterfly. Naturalists were fairly astounded when, in 1898, Mr. Guy A. K. Marshall first bred the black and blue dry season Precis sesamus from the black and red wet season $P$. natalensis. ${ }^{1}$ The two butterflies differ in size, form, pattern, colours, relation of upper to under surface, and habits. But for the fact that very rare intermediate examples were known, they would not have been looked upon as closely allied. The under side of the dry form is very dark and well-adapted to hide the insect in the sheltered places it frequents; the under side of the wet form resembles the upper side, save that it is even more conspicuous, and the individuals of this phase furthermore seek exposed and open ground. The same alternation between a dry form with under side strongly adapted for concealment, and a wet form in which it is highly conspicuous, has been established in other species by Mr. Marshall, by the same incontrovertible evidence. Of these Precis antilope and P. actia are almost, if not quite, as remarkable as $P$. sesamus. In Precis archesia, which he has not yet succeeded in breeding from one form to the other, the difference is particularly instructive. A mid-rib-like stripe is, perhaps, the most effective detail in the dead-leaf-like appearance of the dry phase under side, and this very feature is emphasized-broadened, lightened in tint, and with sharp outlines-into the most conspicuous character of the wet form. The very character which chiefly promotes the concealment of one phase is the principal element in the conspicuousness of the other. In attempting to understand these astonishing alternations it is necessary to study the relationship between the seasons and the struggle for existence which goes on in them. The dry season is a time of far greater pressure than the wet; for although enemies of insects are fewer, the insects themselves are proportionatelyeven more reduced. Large groups of insects bury themselves in the ground, and so disappear altogether. Hence the struggle ${ }^{1}$ Ann. Mag. Nat. Hist., ser. 7, vol. ii, July 1898, p. 30. 
falls with especial severityon those still to be seen. Furthermore, the dry season forms are much less upon the wing than the wet forms of the same species, and are apt to pass long periods in a state of hybernation. Although drought rather than cold is the probable cause of these periods of torpor, the term hybernation is not inappropriate; for almost everywhere in southern Africa the dry season correspondswith the winter,the wet with summer. Althoughless upon the wing, the dry forms are commonly more alert and active, and thus more difficult to catch than the wet. The succession of broods is also nearly or quite at a standstill in the dry season, so that the individual insects must endure the repeated risks of a much longer life than those of the other season, when the numbers are suddenly multiplied again and again by a series of brief generations. Hence each individual of the dry phase is worth far more to the species, and its loss is a much greater loss than that of a short-lived individual of the other phase. The risks during the periods of repose form a much larger proportion of the total risks in the dry season than in the wet. During these periods the insects are sought by enemies different from those which pursue them upon the wing and in the brief rests between short flights. It is probable that the former enemies-insectivorous mammals, reptiles, and birds which explore crevices for their food-are less scrupulous in their tastes than those which hunt alert and active butterflies. In the wet season, on the other hand, butterflies are upon the wing in every gleam of sunshine throughout their comparatively short life ; and the enemies which they chiefly have to encounter are those which pursue them on the wing or stalk them in the brief intervals of rest. It has already been pointed out that insectivorous forms generally are living in a time of comparative plenty in the wet season. From these considerations we can understand how it may be an advantage to a somewhat distasteful species to be represented by individuals with conspicuous warning (aposematic) colours at a time when there is abundance of more palatable food, and by well-concealed individuals at a time when food is scarce and the struggle for life severe. 
Similar considerations encourage the hope that we may understand another feature which has been long known to be characteristic of wet season forms, especially in the Satyrinae, the group which includes our well-known 'Meadow-brown', 'Heath,' and 'Ringlet' butterflies. I refer to the development of eye-spots on the under side of the wings in wet season broods and their disappearance in those of the dry. An observation made in 1887 by Professor Meldola and the present writer throws light upon the problem. I had introduced a 'Small Heath Butterfly' (Coenonympha pamphilus) into the cage of a lizard. It was at once obvious that the reptile was greatly interested in the large eye-spot on the under side of the fore wing; it examined the mark intently, and several times attempted to bite it. ${ }^{1} \mathrm{Mr}$. Marshall has also observed that a South African kestrel pecked out the eye-spots from the hind-wing of a 'Swallow-tail' butterfly before eating any other part. ${ }^{2}$ Furthermore, captured butterflies are especially liable to exhibit injuries in the vicinity of such marks. Some of these tears or snips out of the wing afford very strong indirect evidence that they were made by an enemy. ${ }^{3}$ It is probable, therefore, that such eye-spots as those of the Satyrinae, which are placed on parts of the wing surface remote from the body, are adapted to divert the attention of an enemy from the vital parts, thus giving the insect another chance of escape. Such directive marks will render the butterflies more conspicuous during the periods of complete repose, and we can readily understand that they would be a great danger, and why they should be withheld in the dry season. The fact that these markings are of value in a period of activity and a danger in complete repose, is also rendered probable by movements of the fore wing which have been observed in many Satyrines, changes in the attitude such as to reveal the eye-spot during a brief rest when the insect is alert, but to conceal it when the rest becomes prolonged. ${ }^{4}$ It is probable,

1 Colours of Animals, London, 1890, pp. 206, $20 \%$.

3 Trans. Ent. Soc., Lond., 1902, p. $34 \mathrm{r}$.

${ }^{3}$ l.c. pp. 366-75. 1.c. pp. $372,440$. 
therefore, that the eye-spots tend to be developed in the active wet season individuals of many Satyrinae and a few Nymphalinae as a special adaptation to meet the attacks that are made upon them in the alert condition; and that eye-spots are withheld in the dry season brood because they would be a danger in the periods of repose, which are far more pronounced in this as compared with the wet phase. ${ }^{1}$

The light thrown by recent investigations leads us confidently to believe that the differences between the seasonal forms - hitherto devoid of interpretation-have a meaning and a value in the struggle for existence, and came into being under the sway of Natural Selection.

\section{A new Interpretation of an old example of Mimicry in Butterfies.}

In the short time that remains I can only say a few words about the recent growth of the theory of mimicry which we owe to Fritz Müller, and its gradual encroachment upon the area formerly held by the theory of H. W. Bates. This latter was not, as has been generally supposed, originated by Bates during his years of observation in the valley of the Amazon. It arose in his mind after his return home, when he came to examine his collection and to reflect upon his experiences. His theory, published in $1862,{ }^{2}$ is so well known that it is unnecessary to do more than direct attention to the essential point, that the mimics are supposed to be hard-pressed and palatable insects which gain advantage from their close resemblance to abundant, distasteful, conspicuous species. Bates did not fail to see that these common, unpalatable models certainly mimic each other, but the fact could not be explained on his hypothesis; and although he mentioned the fact, no example finds a place in the beautiful coloured figures of his historic memoir. Had they been thus illustrated, I venture to think that his theory would never have received the general support which has been accorded to it; for it would have been at once

${ }^{1}$ See Ann. Soc. Ent. France, vol. Ixxii, 1903, p. 407.

2 Trans. Linn. Soc., Lond., vol. xxiii, p. 495. 
recognized that the resemblance between his mimic and his model was a very poor thing as compared with the astonishing likeness of one model to another. And there is no question of affinity in the resemblance of models any more than in that of mimic and model. In 1879 , when Fritz Müller offered an explanation of these mysterious resemblances, ${ }^{1}$ the Batesian theory had been before the world for seventeen years, and had attracted a great deal of attention. Furthermore, the examples selected by Müller were not very striking, and were illustrated without the use of colour. He made the illuminating suggestion that the resemblance between the dominant models was mutually advantageous, inasmuch as it facilitated the education of their inexperienced foes, reducing the amount of destruction which must be wrought during the time in which young birds and other insect-eating animals are learning what to eat and what to avoid. If $A$ and $B$ be two distasteful species closely resembling each other, and if they be equally common, an individual of $A$ will be seized before $B$ by an inexperienced enemy as often as an individual of $B$ before $A$. In the first case $B$ benefits from the unpleasant effects produced by $A$, in the second $A$ benefits from the effects of $B$. Professor Lloyd Morgan's observations upon the activities and instincts of young birds of many species ${ }^{2}$ prove that their education is actually of the kind presupposed by the Müllerian theory. He shows that they have no instinctive knowledge of things which are good for food, but examine and test everything. On the other hand, they have very good memories, and retain a firm impression of the appearance of objects which have given them an unpleasant experience. Furthermore, there is evidence that they are influenced in their behaviour towards objects resembling the one which has proved objectionable to them.

Fritz Müller's paper was translated by Professor R. Meldola, and published in this countryalmost immediatelyafter its appearance, ${ }^{3}$ with the result that the theory has been

1 In Kosmos, for May, 1879, p. 100.

${ }^{2}$ Habit and Instinct, London, 1896.

${ }^{3}$ Proc. Ent. Soc., Lond., 1879, p. xx. 
more widely understood and has gained a larger number of supporters in this country than in any other. Nevertheless, in spite of the powerful defence always accorded to it by Professor Meldola, the progress of opinion in the direction of Müller's hypothesis has been until quite lately slow and gradual; and this is probably due to the fact that the minds of naturalists were already occupied by the older and, in many respects, antagonistic theory. It is impossible on this occasion to give any general account of the evidence which has been gradually accumulating in support of the Müllerian theory; but the name of Dr. F. A. Dixey will always stand out as one of its chief defenders, and one who, more than any other, is responsible for the recent rapid growth of opinion in its favour. ${ }^{1}$

Ever since the appearance of Bates's original paper textbooks have copied from it and from one another the wonderful examples of palatable Pierine butterflies (belonging to the group which contains our own ' Garden Whites') living upon the evil reputation of their models belonging to the tropical American 'Heliconidae' (a composite group in Bates's memoir). But Dr. Dixey has even dared to lay his hand, so to speak, upon the Ark of Batesian Mimicry itself, when, in I 894, he argued that the Heliconid models in certain respects mimic their Pierine imitators : that the resemblance has been attained by means of reciprocal approach.

It has been shown on page I0 3 that the columns of Punch afforded an excellent reflection of the state of contemporary thought and criticism on Darwinian and Lamarckian Evolution. It is precisely the same with Batesian and Müllerian Mimicry, as is clearly shown in the following passages : ${ }^{2}-$

"The same [museum] case contains an object-lesson illustrating what is described as "Reciprocal Advantage". So far as I can follow it, the situation is something like this:

${ }^{1}$ See especially the following memoirs by Dr. Dixey : Rep. Bril. Ass., 1894 , p. 692 (abstract); Trans. Ent. Soc., Lond., 1894, p. 249 ; ibid., 1896 , p. 65 ; ibid., 1897, p. 317 ; see also the discussion which followed this latter paper, in Proceedings, $1897, \mathrm{pp}$. $\mathrm{xx}$-xxxii and $\mathrm{xxxiv}-\mathrm{xlvii}$.

${ }^{2}$ Punch, May 2, 1906, pp. 312, 3r3, Moral Reflections at the Natural History Museum, I. 


\section{HUXLEY AND NATURAL SELECTION}

'There is a Nice Butterfly (whom we will call $A$.) who is uncomfortably conscious of being regarded as a delicious titbit by every bird or lizard with any pretensions to a palate.

- There is also a Nasty Butterfly (hereinafter referred to as $B$.) whom even the least particular lizard or bird will, after a single experience of his peculiar flavour, take uncommonly good care never to touch again.

'So says $A$. to himself (or else Nature says it for himI am too unscientific to know which): "If I could only make myself look as nasty as $B$. is, all the birds and lizards would let me alone!" Which, by patience and perseverance, $A$. gradually contrives to do.

'Well, I will admit that this idea of $A$.'s is not without a showy ingenuity, even if it is wanting in true reciprocity and consideration for $B$.'s interests. What I fail to see is that, from $A$.'s point of view, it is really such a very masterly stratagem.'

The writer then goes on to point out that when the enemy comes across $A$ before $B$ all the advantages as he conceives them would be lost, while $B$ itself would be endangered in spite of its nauseous qualities.

Omitting the allusions to conscious imitation, which, although expressing a common popular error, are clearly not intended to be taken seriously, the whole argument is a fair presentation and criticism of Batesian mimicry. It only fails to do justice to this hypothesis in one respect, - the minics are represented as relatively common, so common indeed that it is assumed to be a matter of indifference whether $A$ or $B$ be met with first. But Bates assumed that the nauseous models are hundreds or even thousands of times as abundant as their palatable mimics. It is true, however, that the mimics are often extremely abundant, but then it is probable that such cases are to be explained by the alternative theory of Fritz Müller. As a matter of fact, the title of the exhibit, 'Reciprocal Advantage', is conclusive evidence that it was this theory, and not that of Bates, which was being illustrated. In fact both $A$ and $B$ are supposed to be nauseous : then if an enemy eats $B$ first it will be warned against the appearance of $A$ as well as $B$; if it eats $A$. 
first, against $B$ as well as $A$. A certain number of lives must be sacrificed in the period during which inexperienced enemies are being educated to avoid the appearance which $A$ and $B$ bear in common. If we assume that the individuals of the two species are equally abundant and occur intermixed, it follows that these necessary losses will be shared between them, instead of being contributed by each independently, as would be the case if their colours and patterns were different. Each loses only fifty per cent. of what it would lose but for the resemblance-surely an ample measure of 'Reciprocal Advantage'.

The writer in Punch criticized an illustration of the Muillerian theory, believing it to be an illustration of Batesian mimicry.

I propose, in conclusion, to draw your attention to one of the oldest and best-known, as well as one of the most beautiful, examples of mimicry-one upon which new light has been thrown by increase of knowledge. The example will serve as an illustration of the reasons which have led to the gradual transference of confidence from the Batesian to the Müllerian theory.

The Danaine butterfly Limnas chrysippus is, perhaps, the commonest species on the earth, ranging over nearly the whole of the Old World tropics. Its conspicuous colouring and simple pattern are everywhere mimicked; but especially in Africa. In fact, we may confidently conclude that Africa is the ancestral home of the species, because of the intensity of the effect which has been wrought by it upon the butterfly and moth fauna of this part of the world. ${ }^{1}$ One of its mimics accompanies chrysippus in all parts of the range:-Hypolimnas misippus, a Nymphaline butterfly of powerful flight. The mimetic likeness is, as in so many other species, borne by the female alone, but in this sex it is singularly perfect, and in earlier years it has always been regarded as one of the best-known and commonest illustrations of Bates's theory. But it is far more likely that $H$. misippus belongs to a genus which is in some way unpalatable, and that it ${ }^{1}$ Proc. Amer. Ass. Adv. Sci, 1897, vol, xlvi, p. 244. 
enters into Müllerian association with a Danaine butterfly even more distasteful to insect-eating animals. Bates supposed that his mimics were hard-pressed forms which managed to survive by their deceptive likeness to some well-known, specially-protected, conspicuous, abundant model. But misippus is an extraordinarily dominant species : it may often be met with more abundantly than its model. ${ }^{1}$ Furthermore, the mimic has now succeeded in establishing itself and lives without its model in several places in the New World-Florida, certain West Indian islands, Demerara, Brazil. This remarkable extension of range is mainly due to its wonderful power of flight, ${ }^{2}$ but also to the possession of qualities the very reverse of those commonly supposed to be characteristic of a Batesian mimic. The tropics of the New World are inhabited by a community in which a feeble intruder is by no means likely to hold its own.

Furthermore, Hypolimnas misippus belongs to a genus of which nearly all the species mimic Danaine butterflies and yet none appear to be hard pressed in the struggle for life. This is readily explicable if the whole genus possesses distasteful qualities. The males when nonmimetic, as in many of the forms, bear a marked likeness to one another, whereas the mimetic females have been modified in all kinds of directions by the mimicry of diverse models. The remarkable species from Madagascar, Hypolimnas dexithea, mimetic in neither sex, possesses a pattern of the same general type as that of the nonmimetic males of other species. There can be little doubt that this is the ancestral appearance of the genus, and that the females at one time possessed the pattern of their non-mimetic males, to which indeed in many species they commonly tend to revert in a greater or less degree. Now this ancestral non-mimetic pattern is about as conspicuous as that of any known butterfly,-a black groundcolour, with a large white patch in the centre of each wing,

\footnotetext{
${ }^{1}$ See Mr. C. A. Wiggins's and Mr. H. A. Byatt's observations in Africa, Proc. Ent. Soc., Lond., May 6, 1903, p. xxix.

${ }^{2}$ See Ent. Record, xii, Dec. 1900, p. 315 , for the account of a swarm encountered on the Atlantic 580 miles from the nearest South American land, and 960 from the nearest African.
} 
and an additional smaller patch at the apex of the fore-wing. The under side, although different from the upper, is also conspicuous, and evidently belongs to a very different category from, e.g., the leaf-like under sides of Kallima.

If the remarkable cryptic coloration and attitude of this latter is held to be indirect evidence that the species is palatable to insect-eating animals, it follows that such an under side as that of the male H. misippus constitutes indirect evidence of unpalatability, in other words that it is a warning (aposematic) appearance.

If the argument set forth above be sound, it is obvious that the mimetic females of Hypolimnas have, in their past history, merely exchanged a conspicuous warning pattern characteristic of the genus for conspicuous patterns borne by distasteful forms inhabiting the same country. In other words, the evolution has been of the kind we should expect upon the Miillerian theory. ${ }^{1}$

And now in recent years astonishing evidence in support of the same conclusion has been forthcoming. The non-mimetic male of Hypolimnas misippus is itself beautifully mimicked on both upper and under sides by two Nymphaline butterflies in Western China-Limenitis albomaculata and Athyma punctata.

The model is abundant in the tropics far away to the south, but becomes much rarer in Northern India, and has never been known in Western China, where its mimics are found. We are driven to suggest two alternative hypotheses: (I) The model, with its immense powers of flight, has visited Western China sufficiently often and for long enough periods to render the mimetic resemblance advantageous. Against this it may be urged that H. misippus is a tropical butterfly, and it is most improbable that it would reach, or at any rate establish itself, in such a latitude and elevation as, e.g., Ta-tsien-lu; (2) A more probable hypothesis is afforded by the lines of migratory birds, applying in the temperate zone, where they nest, the experience learnt in the tropics. If a bird's experience of $H$. misippus be an unpleasant one, it follows

${ }^{1}$ See Proc. Amer. Ass. Adv. Sci, r 897 , vol. xlvi, p. 242 ; also Trans. Ent. Soc., Lond., 1902, pp. 500-2. 


\section{I8 HUXLEY AND NATURAL SELECTION}

that a modification in the pattern of any other conspicuous butterfly which suggests the same experience and leads to a cautious attack, or perhaps averts attack altogether, will be advantageous. Both the genera to which the mimics belong are certainly conspicuous, and it is probable that they, too, are distasteful. It is, of course, necessary that the same enemy should see both model and mimic; but, if this be achieved, it matters not how many hundreds of miles may intervene between the two. The northern mimics belong to genera of black, white-marked butterflies which have much in common with the black, whitemarked male of $H$. misippus; so that it is not difficult to understand why the latter species, rather than any other distasteful resident of the tropical areas to the south, has been imitated. There was, in fact, from the very first, sufficient likeness for Natural Selection to work upon. ${ }^{1}$

The hypothesis here suggested demands inquiry into the habits of the migratory birds of Western China, the routes followed, and dates of arrival and departure.

The consideration of Hypolimnas misippus as an example of mimicry, and especially the striking fact that its male is a model, while its female is a mimic, serves as an illustration of the changes in interpretation wrought by the accumulation of new observations. But the outcome of such modifications-and they are taking place everywhere in the field of natural history - is that Natural Selection rests on an ever-broadening foundation. If it were an erroneous or a merely inadequate theory of evolution, would not the astonishing increase of knowledge again and again bring to light facts which are absolutely irreconcilable with it?

The examples brought forward on the present occasion are but a selection from a vast body of observations which receive an intelligible interpretation under this theory, but not under any other. ${ }^{2}$ When accumulated facts, not

1 See Report of the Delegates of the Oxford University Museum for 1904 in the Oxford University Gazette, 1905.

${ }^{2}$ For a detailed statement of the facts of mimicry in relation to Natural Selection see Linn. Soc. Journ. Zool., vol. xxvi, pp. 558-612, reprinted as Essay viii, p. 220. 
only of the class here referred to, but of the most diverse kinds, receive an intelligible explanation upon any theory, they finally become a solid foundation for the theory itself. Many theories of transcendent importance are held upon indirect evidence of precisely this kind. We believe in evolution, not because we see it taking place, but because of the immense number of observed facts which it renders intelligible, and the same is true of our confidence in the Newtonian Theory.

Whenever a naturalist approaches a problem in the light of Natural Selection, and is able, by its aid, to predict a conclusion which subsequent investigation proves to be correct, he is helping in the production of evidence in favour of the theory. When a naturalist has found the formula 'if Natural Selection be true, so-and-so ought to happen', the safest of all guides into the Unknown, when it has brought him success many times and in very different directions, when he knows that many other workers in other fields of biological inquiry have had a similar experience, he gradually comes to feel a profound confidence in the permanent truth and the far-reaching importance of the great theory which has served him so well. ${ }^{1}$

The experiences of the naturalist, the student of living nature, did not appeal to Huxley, and therefore it is not remarkable that he was unable to feel much confidence in Natural Selection. But those who are inspired by it will never forget how much they owe to Huxley for the leading part he took in the great battles which had to be fought before Evolution, and Natural Selection, too, were accorded a fair hearing; and his success went far beyond even these issues. Whatever stirring and subversive ideas the future may bring forth, we may be sure that they will never suffer from the treatment accorded to the Origin of Species; and, far more than to any other single man, the world owes this immense gain to Thomas Henry Huxley.

'Poulton, Charles Darwin and the Theory of Natural Selection, London, $1896, \mathrm{pp} . \mathrm{I}_{4} 2, \mathrm{I} 43$. 


\section{NATURAL SELECTION THE CAUSE OF MIMETIC RESEMBLANCE AND COMMON WARNING COLOURS}

A Paper read before the Linnean Society of London, March $\mathbf{~} 7, \mathbf{1} 898$. Reprinted from the Linnean Society's Journal-Zoology, vol. xxvi, p. $55^{8}$.

Revised: greatly modified: many additions to text and footnotes.

\section{Historical Introduction.}

SUPERFICIAL resemblances between animals, especially numerous in Insecta, were known long before $\mathrm{H}$. W. Bates's paper, Contributions to an Insect Fauna of the Amazon Valley, was read before the Linnean Society on November 21, 1861, and published in the Transactions the following year. ${ }^{1}$ Some of the principal records of these earlier observations are to be found in the Transactions of the same learned Society.

W. S. Macleay, in his Horae Entomologicae, ${ }^{2}$ alluded to certain cases which are now included under Mimicry, viz. the likeness of some Diptera to Hymenoptera, and interpreted them, together with many other resemblances of structure and life-history, by the principle of Analogy as distinct from Affinity in Nature. ${ }^{3}$ These views were adopted by Macleay's immediate successors.

The Rev. William Kirby read $A$ Description of some Insects which appear to exemplify Mr. William S. MacLeay's Doctrine of Affinity and Analogy, before the Linnean Society on December 17,1822 , and the paper was published in the Transactions. ${ }^{4}$
1 Vol. xxiii, p. 495 .
${ }^{3}$ Pt. II, p. 365 .
2 London, 1819 and $182 \mathrm{r}$.
${ }^{4}$ Vol. xiv, p. 93. 
Boisduval, in 1836 , remarked on the resemblance between certain West African butterflies belonging to very different groups. ${ }^{1}$

Professor Westwood read Illustrations of the Relationships existing amongst Natural Objects, usually termed Affinity and Analogy, selected from the Class of Insects before the Linnean Society, on January I 7 and May 2, 1837, the paper appearing in the Transactions. ${ }^{2}$ In the memoir many new examples were published and figured, while Macleay's views were criticized and expanded in an interesting manner.

The same recognition of Mimicry is equally well seen in the names with the termination -formis given to so many of our moths, indicating their resemblance to wasps, bees, and other insects. In spite, however, of the knowledge of a large number of instances, the subject made no real progress until the appearance of H.W. Bates's paper. The view then set forth that the resemblances are in themselves beneficial to the possessor was, as far as I am aware, only once suggested before-in the well-known Introduction by Kirby and Spence. These authors write as follows :- 'Some singular larvae, with a radiated anus, live in the nests of humble-bees, and are the offspring of a particular genus of flies (Volucella, Geoffr., Pterocera, Meigen), many of the species of which strikingly resemble those bees in shape, clothing, and colour. Thus has the Author of nature provided that they may enter those nests and deposit their eggs undiscovered. Did these intruders venture themselves amongst the humble-bees in a less kindred form, their lives would probably pay the forfeit of their presumption.' 3 This interesting paragraph, although fully recognizing the utility of Mimetic Resemblance in species which were then believed to have been separately created and to have come into existence fully formed and complete, sustains a position which is the very antithesis of that taken up by Bates. The contention that the utility of the resemblance has been the

1 Species Général des Lépidoptères, pp. 372, 373.

Vol. xviii, p. 409.

${ }^{3}$ Kirby and Spence, vol. ii, 1817 , p. 223. 
cause of its persistence, and, by the selection of variations going further in the same direction, of its improvement, would have been rejected, probably with indignation, by the distinguished authors of the Introduction.

Bates's great paper dealt with the fauna of tropical America, and the generalization was manifestly incomplete until it had been extended to other parts of the world. This confirmation was not long in coming, being supplied for the tropical East by A. R. Wallace's paper published in the Transactions of the Linnean Society, ${ }^{1}$ and for Africa by Roland Trimen's paper, also to be found in the Transactions of the same Society. ${ }^{2}$

It is remarkable how completely the Linnean Society has been the medium for the publication of classical memoirs upon Mimicry. Up to the year I870 it contained them all; while in $185^{8}$ it served as the channel through which the parent theory of Natural Selection was first given to the scientific world. The next great advance did not take place until I879, and was published elsewhere.

Bates had called attention to certain resemblances which could not be interpreted under his Theory of Mimicry, viz. the frequent similarity between the specially defended forms themselves. Species which are themselves the models for Mimicry nevertheless mimic or at least resemble other models. For such cases Bates could only suggest the direct action of some unknown local force or forces, and in this interpretation he was at first followed by Wallace.

In May, 1879, Fritz Müller published a paper in $K_{o s m o s^{3}}$ which for the first time offered an explanation, based on the theory of Natural Selection, of these mysterious resemblances. He suggested that such likeness between dominant forms was advantageous, inasmuch as it facilitated the education of their enemies, reducing the amount of destruction which must be wrought during the time in which young birds and other animals are learning what to eat with impunity and what to reject.

\footnotetext{
1 I 866, vol. xxv, p. I.

3 Ituna and Thyridia; a remarkable case of Mimicry in Butterfies.
} 


\section{ADVANCE OF MÜLLER'S THEORY 223}

The paper was translated by Professor R. Meldola and published in this country almost immediately after its appearance. ${ }^{1}$ The new hypothesis was at once accepted by Wallace as well as by Meldola, but, to the end of his life, Bates could never bring himself to believe it. In I882 Meldola published an important paper ${ }^{2}$ containing new facts and arguments in favour of Müller's hypothesis and further support was afforded by the present writer in $1887 .^{3}$

During the past thirteen years the Müllerian theory has gradually absorbed more and more of the ground that was formerly believed to be covered by the theory of Bates-an advance due in chief part to the researches of Dr. F. A. Dixey. ${ }^{4}$

The facts which the Müllerian theory sought to explain concerned the fauna of tropical America; the naturalist who explained them was living in the same part of the world. A few years later, however, F. Moore showed that there is the same resemblance between the dominant butterflies of the tropical East ${ }^{5}$; and in 1897 it was pointed out by the present writer that the same facts hold in Africa. ${ }^{6}$

In I 897 I pointed out that Muillerian Resemblance is not true Mimicry at all, but rather an example of Common Warning Colour, ${ }^{7}$ and with the assistance of Mr. Arthur Sidgwick the term Synaposematic was proposed as descriptive of it; the term Aposematic having been previously suggested for ordinary Warning Colours. ${ }^{8}$

I have now given a brief account of the leading phases in the history of Mimicry. Even before the appearance

1 Proc. Ent. Soc., Lond., 1879, p. xx.

2 Ann. and Mag. Nat. Hist., 5th ser., vol. x, Dec. 1882 , p. 417.

${ }^{3}$ Proc. Zool. Soc., Lond., March 1887, p. 19r. See p. 2 13, n. ${ }^{3}$.

${ }^{5}$ Proc. Zool. Soc., Lond., 1883, p. 201.

${ }^{6}$ Report of the British Association at Toronto, 1897, pp. 689-91. See also Roland Trimen's Presidential Address to the Entomological Society, Jan. 19, 1898 (Proceedings, 1897, p. lxxxv).

7 Proc. Ent. Soc., Lond., 1897 , p. xxix; Report Brit. Assoc., 1897, p. 691.

Poulton, Colours of Animals, Internat. Sci. Ser., London, 1890, p. 337 . 
of Fritz Müller's paper a great effect had been produced. The immediate stimulus to the investigation of new examples and fresh aspects of Mimicry which followed Bates's memoir, must be ascribed to the fact that then for the first time was offered a good working hypothesisa hypothesis which seemed to afford an adequate explanation of one class of known facts, and challenged its critics to find insuperable difficulties among facts as yet unknown. In the forty-five years which have elapsed since the appearance of this great memoir an immense number of facts bearing upon the subject have been discovered, and many naturalists consider that the Theories of Mimicry, associated with the names of $\mathrm{H}$. W. Bates and Fritz Müller, have stood the test with complete success, and that an interpretation based on the theory of Natural Selection is in a far stronger position than in 1861. It is, I believe, true that this opinion is more generally held among the students of other groups of the animal kingdom than among those who are specially devoted to entomology.

2. The various Hypotheses which have been proposed as Substitutes for Natural Selection as the Explanation of Mimicry and Common Warning Colours.

All the various suggestions which have been proposed as substitutes for Natural Selection, may be included under three heads:-

i. The direct effect of some physical or chemical cause or causes connected with locality, such as climate, food, \&c. This may be called the Theory of External Causes.

ii. The independent evolution of a similar appearance in distinct species. Mimetic Resemblance, according to this hypothesis, is due to internal developmental causes, compelling different species to pass through similar phases. My friend Professor Patrick Geddes has told me that he is in favour of this view, and it is the central idea of Professor G. H. Eimer's work. ${ }^{1}$ The hypothesis that 'Laws of Growth' may cause these resemblances also falls into this category. The suggestion that such laws ${ }^{1}$ Orthogenesis der Schmetterlinge, Leipzig, 1898. 
may account for certain phenomena which are usually explained by the theories of Natural and Sexual Selection was made by Professor D'Arcy Thompson at the Oxford meeting of the British Association in $1894 .^{1}$

The conceptions briefly set forth under this head may be grouped as the Theory of Internal Causes.

iii. The operation of Sexual Selection. Fritz Müller proposed this idea in a letter to Darwin, who wrote not unfavourably of it to Professor Meldola, on January 23, 1872. 'You will also see in this letter a strange speculation, which I should not dare to publish, about the appreciation of certain colours being developed in those species which frequently behold other forms similarly ornamented. I do not feel at all sure that this view is as incredible as it may at first appear. Similar ideas have passed through my mind when considering the dull colours of all the organisms which inhabit dull-coloured regions, such as Patagonia and the Galapagos Is.' ${ }^{2}$

In the present paper the attempt will be made to show that many of the known facts of Mimetic Resemblance do not admit of interpretation by any of the three theories mentioned above, while they do receive a ready explanation on the supposition that the resemblances are useful and have been produced by Natural Selection. Certain new observations upon the details of the resemblances in a large group of insects, undertaken specially to test these rival theories, will be found to point strongly in the same direction. ${ }^{3}$

\section{The Relation of the Resemblances under Discussion to other Resemblances in Organic Nature.}

To those who accept Natural Selection as the explanation of Mimicry, the facts under discussion fall into their place as part of the much wider group of Protective

1 Only the title-On some Difficulties of Darwinism-is printed in the Report of the meeting, p. 689 .

2 Charles Darwin and the Theory of Natural Selection, Poulton, London, 1896, p. 202.

3 See Section I 2, p. 26 r.

POULTON 
Resemblances in general. Mimicry becomes, as A. R. Wallace expresses it, merely 'an exceptional form of protective resemblance'.1 The following classification was suggested by the present writer, with the assistance of Mr. Arthur Sidgwick, in $1890:^{2}-$

\begin{tabular}{|c|c|c|c|}
\hline \multicolumn{2}{|c|}{$\begin{array}{l}\text { I. Apatetic colours.-Colours re- } \\
\text { sembling some part of the environ- } \\
\text { ment or the appearance of another } \\
\text { species. }\end{array}$} & \multirow[t]{2}{*}{$\begin{array}{l}\text { II. Sematic co- } \\
\text { lours.-Warning } \\
\text { and Signalling } \\
\text { Colours. }\end{array}$} & \multirow{4}{*}{$\begin{array}{l}\text { III. Epi- } \\
\text { gamic colours. } \\
\text { - Colours } \\
\text { displayed in } \\
\text { courtship. }\end{array}$} \\
\hline $\begin{array}{l}\text { A. Cryptic co- } \\
\text { lours. - Protec- } \\
\text { tive and Aggres- } \\
\text { sive Resem- } \\
\text { blances. }\end{array}$ & $\begin{array}{l}\quad \text { B. Pseudo- } \\
\text { sematic colours.- } \\
\text { False Warning } \\
\text { and Signalling } \\
\text { Colours. }\end{array}$ & & \\
\hline $\begin{array}{l}\text { I. Procryptic } \\
\text { colours. - Pro- } \\
\text { tective Resem- } \\
\text { blances. }\end{array}$ & $\begin{array}{l}\text { 1. Pseudapose- } \\
\text { matic colours.- } \\
\text { Protective Mimi- } \\
\text { cry. }\end{array}$ & $\begin{array}{l}\text { 1. Aposematic } \\
\text { colours. - Warn- } \\
\text { ing Colours. }\end{array}$ & \\
\hline $\begin{array}{l}\text { 2. Anticryptic } \\
\text { colours. - } \mathrm{Ag}- \\
\text { gressive Resem- } \\
\text { blances. }\end{array}$ & $\begin{array}{l}\text { 2. Pseudepise- } \\
\text { matic colours. - } \\
\text { Aggressive Mimi- } \\
\text { cry and Alluring } \\
\text { Coloration. }\end{array}$ & $\begin{array}{l}\text { 2. Episematic } \\
\text { colours.-Recog- } \\
\text { nition Markings. }\end{array}$ & \\
\hline
\end{tabular}

Thus the facts of Mimicry fit into a broad system which includes many other resemblances in organic nature. The relation between Protective Resemblance (I. A. I) and Protective Mimicry (I. B. I) is as follows :In the former an animal resembles some object which is of no interest to its enemy, and in doing so is concealed; in the latter an animal resembles an object which is well known and avoided by its enemy, and in doing so becomes conspicuous. Thus Mimicry as interpreted by H.W. Bates finds its place in I. B. I, while the resemblance between protected conspicuous forms (sometimes, but, as I think, erroneously, called Mimicry), as interpreted by Fritz Müller, ${ }^{3}$ falls into II. I. Such cases only differ

1 Darwinism, London, 1889 , p. 265.

2 The Colours of Animals, Internat. Sci. Ser., London, 1890, p. 338.

s Kosmos, May 1879 , p. 100, translated by Meldola in Proc. Ent. Soc., Lond., 1879 , p. $\mathrm{xx}$. 
from ordinary Warning Colours in that they are common to two or more species: hence, as has been already pointed out, the term Synaposematic Colours, or Common Warning Colours, may be conveniently applied to them.

The arguments in favour of Natural Selection as the explanation of Protective Resemblance run entirely parallel with those which favour it as the interpretation of Mimetic Resemblance and Common Warning Colours. By modifying the examples and, in some cases, the form of the argument, nearly every section of this paper might be converted into a defence of the former, and the arguments which are strongest in support of the one are the strongest in support of the other, viz. those contained in Sections 4, 5, 6, 7, I I, and I 2.

Under the theory of Natural Selection all the resemblances among animals, mimetic and other, show the clearest relationship, and (with the exception of the debated Epigamic Colours) are to be explained by the working of a common principle, viz., the selection of variations which are useful in the struggle for existence. Under the other theories mentioned above no such grouping can be readily brought about, and Mimetic Resemblance becomes due to one set of principles and the other resemblances to another set. The majority of those who look on Mimicry as due to External or to Internal Causes, or to Sexual Selection, would probably agree in explaining Protective Resemblance by Natural Selection. And yet these latter cases, while far more common, are often as detailed and as remarkable as those of Mimicry. Those who adopt the most extreme form of the theory of External Causes might perhaps maintain that the resemblance to twigs, leaves, and bark is to be explained in the same manner, and would thus bring Protective and Mimetic Resemblance under the operation of the same set of forces; but few will be prepared to carry the theory so far. Under the theory of Internal Causes it is impossible to bring the two kinds of resemblance together; for while it is held by some that two or more animals may independently and without 
selection arrive at corresponding points in their evolutionary history, which are such as to involve Mimetic Resemblance, no one could believe that the similarity to bark or earth has been produced in the same manner. Those who are inclined to accept Sexual Selection as the explanation can only bring the two classes of facts together by supposing that the appearance of some minute portion of the total vegetable or mineral environment has acted as a stimulus and has led one sex to select the other according as it resembled the object in question; just as Fritz Miuller suggested in his letter to Darwin ${ }^{1}$ that mimicry might be due to Sexual Selection stimulated by the appearance of another species. Probably no one is prepared to adopt this view as regards the former class of facts, although Darwin had, as he states in his letter to Meldola ${ }^{2}$, considered the possibility of the general tints of the environment influencing the trend of Sexual Selection in this way.

A fatal objection to any explanation based on the theory of Sexual Selection is the fact that Protective Resemblances are so extremely common and perfect in the immature stages of insects. The same objection holds, although with less force, against its use as an explanation of Mimetic Resemblance.

The conclusion appears inevitable that under no theory except Natural Selection do the various resemblances of animals to their organic and inorganic environments fall together into a natural arrangement and receive a common explanation. On any theory except Natural Selection this can only be brought about by the adoption of extreme views as to the area over which the alternative theory is to be applied-views which, at any rate, the great majority of those who are disposed thus to explain Mimetic Resemblance are not prepared to adopt. 
4. Mimetic Resemblance and Common Warning Colours between different Arthropod Classes and between various Insect Orders, and their Relation to Similar Resemblances within the Limits of a Single Order.

The various criticisms of Natural Selection as the motive cause of Mimicry have been based almost exclusively upon the phenomena presented by Mimetic Resemblance and Common Warning Colours among the species of a single Order of insects (Lepidoptera), and generally the species of one Family (Nymphalidae), and one Sub-Family (Pierinae). I cannot but think that this limitation of the survey to one small part of the field over which the resemblances commonly occur is, in large part, the cause of the rejection of Natural Selection and the substitution of alternative suggestions. There is something attractive and plausible in the idea that the strong mutual resemblances within a group of butterflies of different genera and Sub-Families, inhabiting a single locality, are due to the direct action of peculiar local physical or chemical influences; but the suggestion loses all its attractiveness when it is applied to the resemblance between a spider and an ant, or a moth and a wasp. And yet few could bring themselves to believe that the resemblances which are here contrasted have been built up by two entirely different sets of forces.

The majority of naturalists will probably agree with this argument, and, realizing that the theories of External Causes and of Internal Causes are useless to explain the mimetic likeness between a wasp and an insect of a different Order, will reject these theories as unnecessary to explain the resemblance between one butterfly and another. But an attempt may be made, in fact has been made, to discriminate between the relative powers of the Batesian and Müllerian Theories 'respectively in these two spheres of Mimetic Resemblance-that which includes forms of remote affinity and that which includes those more nearly akin. It has been supposed that the Müllerian Theory does not explain Mimetic Resemblances between remote forms, however adequate it may be for 
those between forms closely allied. To the former examples of Mimicry it has been contended that the Batesian Theory alone applies. It may be urged on the contrary that the resemblances between remote forms have not been as yet sufficiently examined from the Müllerian standpoint; and that there are, nevertheless, and have been for many years, the strongest indications that here also much of the ground formerly believed to be covered by the older theory will be found to be occupied by the newer.

The Müllerian Theory by no means demands that the methods of defence in the members of a convergent group should be uniform.

So long ago as $1887^{1}$ the present writer tabulated the colours and markings of all insects which up to that time had been experimentally proved to be specially defended, and was enabled to apply to the whole group of conspicuous species which had been tested the explanation offered by Fritz Müller. ${ }^{2}$ This general conclusion will be found to be supported by many facts and considerations in the paper referred to.

A good example is to be found in the resemblance which the black-and-yellow-ringed unpalatable larva of Euchelia jacobaeae (the Cinnabar Moth) bears to a wasp. It is in this case 'more than probable (as has been previously suggested by other observers) that the species rendered conspicuous by alternate rings of black and yellow gain great advantages from the justly respected appearance of Hornets and Wasps. It must not be forgotten, however, that the latter forms also probably gain to some extent by the greater publicity which follows from the resemblance.' ${ }^{3}$

The attention of those who dwell on the excessive amount of assumption in the theories of Mimicry may be invited to the numerous tables in the paper quoted above. In these will be found recorded the whole of the results

1 Proc. Zool. Soc., Lond., 1887, pp. 191-274, The Experimental Proof of the Protective Value of Colour and Markings in Insects in reference to their Vertebrate Enemies.

2 1.c. p. 227.

3 1.c. pp. $235,23^{8}$. 
of actual experiments made, up to 1887 , upon the palatability and unpalatability of conspicuous and inconspicuous insects. It may be safely asserted that the theories in question are not nearly so devoid of support from the results of experiment and observation as has been represented.

Since 1887 further evidence has been forthcoming in support of the Müllerian explanation; for it has been shown in many cases that insects which resemble specially defended members of another Order, themselves belong to a specially defended group within their own Order. Thus Haase ${ }^{1}$ points out that the South-American moths which resemble 'immune' Coleoptera-the Lycinae, 'belong to the immune families of the Glaucopidae (Mimica, Lycomorpha) and Arctiidae (Pionia),' and also that the South-American Glaucopidae furnish numerous cases of resemblance to Aculeate Hymenoptera. ${ }^{2}$

In the year 1897 Dr. L. O. Howard, of Washington, kindly presented to the Hope Department, Oxford University Museum, a pair of specimens which prove that the specially protected moth Lycomorpha latercula (Edw.) occurs in the same locality and at the same time of the year as the protected beetle Lygistopterus rubripennis (Lec.), which it closely resembles, the former having been captured on June 18 , the latter on June 5 , 1897 , in the Chiricahua Mountains, Arizona, by H. G. Hubbard.

Furthermore, the resemblance between the species of the two great sections of the Order Lepidopterathe Rhopalocera and Heterocera-is frequently of the Mullerian rather than the Batesian kind. Thus Sir George Hampson has pointed out that the moth Abraxas etridoides, resembling the butterfy Teracolus etrida, belongs to a specially protected genus, and that similarly three genera of the Chalcosid group of Zygaenidae, which are said to resemble Danaine and Papilionine butterflies, are also

${ }^{1}$ Researches on Mimicry, part ii, Stuttgart, 1896 , English translation by C. M. Child, p. 70.

"1. c. p. 73. In a note to the same page Haase adduces some little direct evidence for the inedibility of a Glaucopid moth. 
extremely distasteful to insect-eating animals. ${ }^{1}$ Similarly, Mr. Roland Trimen, F.R.S., in his Presidential Address to the Entomological Society, ${ }^{2}$ points out that the ' abundant and extremely conspicuous slow-flying diurnal Lithosiid [Geometrid] moth, Aletis helcita', together with its 'apparently protected analogues ... the closely similar Lithosiid [Hypsid] Phaagarista helcitoides, and Agaristid Eusemia falkensteinii', show great similarity to the group which is headed by Danais (Limnas) chrysippus - 'so that from the aspect of warning of distastefulness to enemies the two sets may be regarded as practically but one.' Similar facts will probably be found in numerous other examples of moths which resemble butterflies.

It may be safely asserted that, even with our present limited knowledge, Müllerian Resemblance, no less than Batesian Mimicry, can be found in the species of groups with all degrees of affinity, and that there is no ground for the contention that the latter theory alone derives support from the facts presented by the groups which include species from different Orders.

Under Natural Selection the interpretation of the whole series of facts is perfectly valid. The dominant forms which in each locality move towards each other and towards which less dominant forms also move, are in some way specially defended. The principles are the same when the approximation is between the species of different Orders or Sub-Orders, or between those which are much more closely related. The Müllerian Theory explains the resemblance of immense numbers of stinging insects to each other and of other specially defended forms to them, whether they be closely or distantly related: it also explains the resemblance of the dominant Heliconinae and Ithomiinae in each locality in South and Central America and of other forms to them. Batesian Mimicry explains the cases in which the attracted forms are not specially defended.

The conclusion which emerges most clearly is the entire independence of zoological affinity exhibited by

Nature, ז 898 , Feb. 7, p. 364 .

2 Delivered Jan. 19, 1898 : Proc. Enl. Soc., Lond., 1897, p. lxxxv. 
these resemblances; and one of the rare cases in which Darwin's insight into a biological problem did not lead him right was when he suggested that a former closer relationship may help us to a general understanding of the origin of mimicry. 1 The preservation of an original likeness due to affinity undoubtedly explains certain cases of Mimicry, but we cannot appeal to this principle in the most remarkable instances. Further confirmation of this independence of affinity will be found in the additional details supplied in the succeeding Section.

When we look at the phenomena of Mimicry and Common Warning Colours as a whole, it is found that the theory of Natural Selection is equally applicable throughout; while the theories of External Causes and Internal Causes cannot be applied to some of the most striking resemblances, those of moths, beetles, and flies to the stinging Hymenoptera. The theory of Sexual Selection is less logically assailable on these grounds; but with the other two suggested substitutes for Natural Selection, it entirely fails to account for the attractive force exercised by specially protected forms. Under any of these three theories it is a mere coincidence that the insects which are resembled by species of all kinds happen to possess stings-that the central types in the groups of butterflies belong to Sub-Families which are more abundant and even more unpalatable than the generality of their Order. It is, furthermore, a mere coincidence that such groups are formed round the Danainae and Acraeinae, wherever they occur in all the warmer regions of the world, and in tropical America also round the Ithomiinae (Neotropinae), which are closely related to the former, and the Heliconinae, which are closely related to the latter.

1 See Darwin's letter to Meldola, dated Jan. 23, 1872 ; Poulton, Charles Darwin and the Theory of Natural Selection, London, 1896, pp. $201-2$ : also Charles Darwin, The Descent of Man, \&c., roth ed., London, 1874, p. 324. The passage runs as follows:- 'As some writers have felt much difficulty in understanding how the first step in the process of mimicry could have been effected through natural selection, it may be well to remark that the process probably commenced long ago between forms not widely dissimilar in colour.' See also Origin of Species, 6th ed., p. 377. 
No theory except Natural Selection explains why the number of colours and patterns in the dominant groups of butterflies mentioned above are so few in relation to the number of species, as was pointed out by Professor Meldola, F.R.S., in his paper Mimicry between Butterflies of Protected Genera. ${ }^{1}$ These colours and patterns have been recently studied very carefully, especially in the Ithomiinae, by A. G. Mayer," who shows that 'the 200 species of Papilio in South America display 36 distinct colors, while the 450 species of Danaoid Heliconidae [Ithomiinae] exhibit only I 5. Hence the numbers of the species and of the colors are almost in inverse ratio in the two groups. This may be explained by the fact, that the Danaoid Heliconidae mimic one another, while the Papilios do not. . . . There is no lack of individual variability among the species of the Danaoid Heliconidae; yet the species as a whole vary but little from the two great types of color-pattern represented by Melinaea and Ithomia. In order to account for this remarkable fact I am forced to resort to Fritz Müller's theory of mimicry.' ${ }^{3}$ Again, on page 225 Mayer remarks : 'It is difficult to account for the remarkable conservatism in respect to color-variations among the Heliconidae [here used, as in Bates's original paper, to include Danainae, Ithomiinae, and Heliconinae?, unless we resort to the explanation afforded by the theory of mimicry; for, while there is such remarkable simplicity and uniformity of colorpattern throughout the whole group of the Heliconidae individual variations are very common.'

It is not from any predisposition or bias in favour of Natural Selection that these conclusions are reached, but simply because this theory offers an explanation of so many remarkable facts which are utterly meaningless under any other theory yet brought forward.

1 Ann. and Mag. Nat. Hist., 5th ser., vol. x, Dec. 1882, p. 417.

${ }^{2}$ Bulletin of the Mus. of Comp. Zool. at Harvard Coll., Feb. I897, p. 167.

1.c. p. 229. 


\section{MIMICRY INDEPENDENT OF AFFINITY 235}

\section{Resemblances cven within the Limits of an Order are entively independent of Affinity.}

The entire independence of affinity is specially well seen in the groups of convergent moths and butterflies which are found in different localities in South America. Although the resemblance is clear enough throughout all the members of a large group, it is far closer between certain species than others. When these are examined they are found to be not more nearly related than other members of the group, but frequently the reverse. Thus it is very common for a species of Heliconius ${ }^{1}$ to resem. ble with the most remarkable precision a species of Melinaea or some other Ithomiine genus in its locality. Such resemblance is in these cases far closer than that of the former to the species of the other genus (Eucides) in its Sub-Family, and than that of the latter to any species of the numerous related Ithomiine genera. Thus, to illustrate this conclusion from some examples in the Hope Collection, in Honduras by far the strongest resemblance is to be found between a Heliconius and a Melinaea; and this is also the case (both species being different) in Surinam. In Trinidad the resemblance is closest between a Heliconius and a Tithorea, another Ithomiine.

Under the theory of Natural Selection this association is readily explicable. The pairs which thus form the centres of local groups are probably the dominant forms, relying more completely than the other members upon the defence afforded by their warning colours and the associated unpalatability. As a matter of fact there is some evidence for their exceptional abundance as compared with the other members of their groups. Again, they are usually more nearly of the same size than the other members, so that the perfection of the resemblance in colour and pattern is aided by resemblance in another quality.

The theory of External Causes entirely fails to account

${ }^{1}$ Although united by Bates in the Family Heliconidae, the Heliconinae and the Ithomiinae are Sub-Families lying at the very opposite ends of the great group of Nymphalid butterflies. 
for these facts. Uniform local conditions, if they can produce any effect at all, must be expected to produce the closest likeness where there is the closest constitutional similarity-in other words, in the more nearly related forms, in preference to the less nearly related, in each locality. With the theory of Internal Causes we should also expect the facts to be the reverse of those which exist. At the best it is unable to account for the observed phenomena.

Any theory of Selection (Natural, Artificial, or Sexual) affords a logical explanation of the facts, in the sense that it is quite conceivable that the observed results might be thus obtained. Hence the objection to Sexual Selection as a suggested cause is not as strong as the objection to the other causes which have been brought forward. Nevertheless, I believe that very few will be found to support the hypothesis that Sexual Selection supplies the interpretation we are seeking.

The conclusions here arrived at by a consideration of the facts presented by the Lepidoptera are entirely confirmed by those already known in the Coleoptera; although as yet but little attention has been paid to the latter Order in this respect. C. J. Gahan, in an interesting paper,' clearly shows that the Phytophagous genus Diabrotica is in the same position as the large protected groups of butterflies already mentioned (Danainae, Ithomiinae, Heliconinae, Acraeinae). The individuals of its species swarm in the localities where they occur; they are conspicuously coloured, and many of them are known to feign death when captured and to discharge a yellow fluid from various parts. The facts at present ascertained justify the conclusion that these Coleoptera form centres of Müllerian Resemblance, in that 'some of the species belonging to one section in this genus are, in colour and marking, extremely like certain species of the other section which come from the same localities '.2 Mr. Jacoby has also 'recorded that many of the species of his genus $N e o-$ brotica exhibit most striking resemblances to species of the

1 Trans. Ent. Soc., Lond., 1891, pp. 367-74.

2.c. p. 372. 
closely-related genus Diabrotica' (1. c. p. 370). The latter species are also mimicked by those of the allied genus Dircema. Mr. Gahan shows, furthermore, that eighteen species of the genus Lema, belonging to a different SubFamily, closely resemble the species of Diabrotica (in one case the allied genus Cerotoma) found in the same localities in tropical America. In three cases species of Neobrotica, and in one a species of Dircema, fall into the groups thus formed.

Mr. Gahan is disposed to regard the resemblance of the species of Lema, together with that of the Longicorn, Oxylymma gibbicollis, for a species of Diabrotica, as an example of Batesian Mimicry. Future observation and experiment must decide upon this as upon so many other cases concerning which we are uncertain whether to adopt the Batesian or the Mullerian interpretation. The tendency of recent observation, however, strongly favours the opinion that the latter theory will explain a much larger number of resemblances than the former.

But whichever interpretation be ultimately adopted, the fact remains the same-that the resemblances in the Coleoptera are of the same character as those in the Lepidoptera, and are, like the latter, independent of affinity. They are readily to be explained by the operation of a theory of selection, but present the same difficulties as those presented by the Lepidoptera to an interpretation by any other theory as yet brought forward.

6. The Resemblances in question are not accompanied by any changes in the direction of the Mimicked Species except such as assist in the production or strengthening of a Superficial Likeness.

This argument is fatal to any theory as yet advanced except one based upon the principle of selection directed to a definite end, viz. the production of resemblance. It is impossible to explain why external forces or internal forces should thus act upon a certain set of characters whose only relationship is that they tend to produce a superficial likeness to another species-that they should 
act upon these alone to the exclusion of all other sets. No assistance can be obtained from the conclusion that the results are recent and therefore superficial, and that a resemblance in deeper characters will follow in time. In the first place, the examples of more perfect (and presumably older) resemblance show no more tendency towards approximation in characters which do not help to produce likeness, than the examples in which the resemblance is comparatively rude (and presumably recent in origin). In the second place, deep-seated parts of the organism are affected when the superficial resemblance is thereby increased, but not otherwise. To take a single example, the common British Longicorn, Clytus arietis, strongly suggests the appearance of a wasp, partly because of its black and yellow banding, but even more because of its alert and wasp-like movements. This implies, of course, appropriate changes in its nervous and muscular systems. Although Clytus arietis is a rough and imperfect example of Mimicry, the resemblance, such as it is, chiefly depends upon deep-seated structures. We are, in fact, led to infer in Clytus and in an immense number of other mimics that the deep-seated modifications were the origin of the resemblance, and that the superficial modifications of colour, \&c., followed later.

The subject is, perhaps, of sufficient interest to warrant the production of another example, in which the changes in deep-seated structures are of more importance than anything else in determining the resemblance. I know of no more striking instance than the movements and attitudes of the young (Lepidopterous) larvae of Endromis versicolor, the 'Kentish Glory' moth, rendering them extremely like the larvae of saw-flies (Phytophagous Hymenoptera). Numerous experiments have convinced me that the latter are almost invariably distasteful. During the early stages of their growth the moth larvae 'arrange themselves in small groups upon the leaves and leaf-stalks of the birch, and when disturbed they raise the anterior part, bending the head over the dorsal surface of the posterior part of the body. In this attitude they strongly remind the observer of those Tenthredo larvae 
which, when irritated, bend the tail forwards over the anterior part of the body. The fact that the head is raised in the one, and the tail in the other, does not cause any conspicuous difference when the larvae are seen from a little distance. The common Tenthredo larva, Croesus septentrionalis, is about the same size as these small Lepidopterous larvae, feeds in similar small groups when large (when small the groups contain far more individuals), and also frequents the birch.' ${ }^{1}$ Furthermore, the conspicuous orange-coloured true legs of the caterpillar suggest the appearance of the orange ventral glands of the Croesus, which are everted when the larva is irritated. In my experience, however, the Croesus feeds much later in the year.

Thus the sources of the resemblances we are discussing may be deep-seated or may be superficial : the likeness is however generally due to several kinds of causes in each category. It is in the latter extremely complex cases, and these are far the commonest, that the argument for Natural Selection becomes irresistible. This will be more thoroughly dealt with in the succeeding Section; but even in the case of the simplest element in the resemblance, viz. the similarity in colour and pattern taken alone, the theories of External and Internal Causes are unable to offer an adequate explanation of certain facts which are clearly explicable by Natural Selection.

In the males of the South-American Pierine group Dismorphina, the long-and-narrow-winged appearance of an Ithomiine butterfly is largely produced by the excessive overlap of the upper upon the under wings. This results in the concealment of a large part of the upper side of the under and of the under side of the upper wing; and it will be found that the mimetic patterns are withheld from these hidden surfaces, which often retain some distinct trace of the old Pierine character, viz. an opaque

${ }^{1}$ Poulton, in Proc. Ent. Soc., Lond., I891, p. xv. W. Holland also noted the same resemblance in the Entomologist's Record for Oct. I5, r 89 r (see vol. ii, p. 228). His manuscript notes, made at the time and kindly lent to me, prove that he also observed the saw-fly-larva-like movements which follow disturbance. 
white appearance. This fact holds true even for such a specialized and perfect mimic as Dismorphita orise.

F. D. Godman, F.R.S., and O. Salvin, F.R.S., ${ }^{1}$ speak of these hidden chalky patches, surrounded by a silky area covered by peculiarscales, as a character of the Dismorphina. The interpretation of the patch as a sexual brand, perhaps with the nature of a scent-producing organ, does not in any way disprove the suggestion here adopted-that the white pigment in the scales is a survival from an ancestral condition still found over the greater part of the wingsurface in so many non-mimetic Pierinae, as well as in the males of many mimetic species (e. g. in the genus Mylothris). It should be noted, however, that the patch is not white in all species of the Dismorphina. Mr. Belt ${ }^{2}$ states that the white patch is usually concealed by the males, as indeed may be inferred from the change in character of the surface, which indicates the normal amount of overlap of the fore upon the hind wing. The same author, believing that the white patch is ancestral and has been retained by the operation of Sexual Selection, makes the daring suggestion that it may be 'an attraction in courtship, to exhibit to the females, and thus gratify a deep-seated preference for the normal colour of the order to which the Leptalides [Dismorphina] belong'.

The rigid restriction of mimetic effects to those parts of the surface which can be seen tells very strongly against any theory which is not based on the principle of Selection.

\section{Essential Nature of these Resemblances: their Analysis into the several kinds of Effect produced.}

The resemblances under discussion are made up of elements of very different kinds combined in single individuals; but the essentially composite nature of the effect easily yields to analysis. Some of these complex combinations only require to be stated in order to show the inadequacy of the theory which is most usually

1 In the Biologia Centrali-Americana (Rhopalocera, vol. ii, p. 173).

Naturalist in Nicaragua, 2nd ed., London, 1888, pp. $384,3^{85}$. 


\section{COMPOSITE NATURE OF MIMICRY 24I}

substituted for Natural Selection, viz. the theory of External Causes.

A mimetic appearance is commonly made up of (I) colour, including $(a)$ structural as well as (b) pigment colours; (2) pattern; (3) form ; (4) attitude ; (5) movement.

It may be plausible to hold that direct local influences determine colour, but the case becomes much more difficult when structural tints are included, as they frequently are. Thus it might well be held that the dark pigment of a female Hypolimnas and of the Euploea which it resembles are alike the direct effect of the locality they both inhabit. But the most convinced advocate of direct local causes would probably hesitate to explain, by the operation of the same forces, the structurally caused blue sheen which overspreads the dark pigment in some of these mimetic pairs. Similarly with pattern, it is much more difficult to understand the appropriate arrangement of the colours by direct forces than the production of the tints themselves; still more difficult to understand how such forces could modify shape, and, again, more difficult to see how they could mould the nervous and muscular systems so as to produce appropriate attitudes and movements. Most difficult of all to understand, except on a theory of Selection, how the several elements in the complex set of changes could be kept in their proper relationship and guided to a definite end, viz. the production of a superficial resemblance to another species.

The objection to the theory of Internal Causes is not that it is inadequate to produce each of the effects, but that it is in the highest degree improbable that so complete and harmonious an effect could be frequently produced accidentally by the combination of such diverse elements.

It is useless to maintain that these resemblances are the uniform result of uniform forces peculiar to the locality; for investigation proves that the results are very far from uniform. They appear at almost any point in the structure of the body, superficial or deep-seated, generally at many points in a single individual both 
superficial and deep-seated, and the only common bond which can be established between the various elements which make up the common effect is that they all cooperate in producing superficial resemblance to some other species.

It is here shown that the changes wrought in a single species are far from uniform. It will be shown later on (see Sections I I and I 2, pages 250 and 26I) that there is frequently no uniformity in the methods made use of by mimic and model, nor any uniformity between the various mimics of the same model, nor between the different members of a synaposematic group. These, too, often have only one thing in common, and that inexplicable except on a theory of Selection, viz. the subordination of all these divergent methods to a single end-the attainment of a superficial resemblance.

The arguments in this and the preceding Section are equally powerful in support of the interpretation of Protective Resemblances as due to Natural Selection.

Again, Mimetic Resemblances are comparatively rarely seen in more than one stage of insect life, and are, in the great majority of cases, restricted to the final stage. In all such species the total appearance presented by the final stage, including mimetic resemblance, is prepared for in the earlier stages, especially the larval. Not only are the changes in question confined, as has been already pointed out in this Section, to the parts, tissues, and organs which influence the superficial appearance, but they are also generally confined to the final stage of insect life. During larval life the foods peculiar to the locality are devoured and the material for the mimetic stage is stored up. The larval and pupal stages are together, in the great majority of cases, far longer than the imaginal stage, and are no less, and, as regards food, far more, subject to the direct action of the forces peculiar to the locality. On what theory except Natural Selection is it possible to explain the rigid limitation of these changes, in so large a proportion of cases, to the final stage, and their entire exclusion from the stages during which they are, in the history of the individual, predetermined? 


\section{Conditions of a Species in any locality are chiefly determined by its Habits and Life-history.}

In the last Section it was shown that there is no uniformity in the effects produced in any locality. In this Section it will be made clear that there is no uniformity in the forces which, by their uniformity, are supposed to produce the effects. When we are told that common food, common climate, \&c., produce a common effect, we have the means for proof or disproof in, at any rate, some striking examples; for we know the food and conditions of certain species which exhibit mimetic or common warning associations. There are many examples of Longicorn beetles mimicking Lycidae (Malacoderm beetles) in the same locality; but during the earlier stages, in which the appearance of the final stage is determined, the former lives in a burrow, feeding upon wood or the tissue of plant-stems, and sheltered from many of the climatic influences and changes, while the other lives in the open, freely exposed to them all, and sustained by an exclusively carnivorous diet. I owe this suggestive comparison and the Section which arose out of it to a conversation with Mr. C. J. Gahan, of the British Museum. Similarly in the case of South-American moths belonging to the Castniidae, which resemble Ithomiine butterflies (see Section I2, page $26 \mathrm{I}$ ), the larvae of the former burrow in plants, while the latter are freely exposed on the leaves which form their food.

It is hardly necessary to insist on the importance of the larval stages in this respect. When the imago emerges from the pupa and its expanded wings have dried, it has assumed its permanent appearance, and nothing that it will eat or endure henceforward, produces any further effect upon its colours or patterns, \&c. Hence identity of food and conditions during the final stage cannot be of any assistance in the interpretation of Mimicry. It is necessary to point this out clearly, inasmuch as Beddard has said, speaking of the resemblance between Eristalis, the drone-fly, and the hive-bee, 'It is an interesting fact, in connection with the resemblance between this fly and 
a hive-bee, that it feeds upon pollen and honey. This fact may have some significance in relation to the effects of food upon form and coloration.' 1 But the larva of Eristalis stores up nutriment, out of which the final form is built, by feeding on putrefying animal matter, a food as different as possible from that provided for the larval bee. The peculiar conditions under which the larvae of stinging Hymenoptera obtain their food invariably contrast strongly with the larval condition of their numerous mimics. We find in this Section, as in the others, that the suggested interpretation of these resemblances as the common effect of a common cause or set of causes breaks down the moment it is analysed. The view is a superficial one, and cannot be sustained when the slightest attempt is made to understand the nature of the phenomena it professes to explain.

\section{Mimetic Resemblance and Common Warning Colours more characteristic of the Female than the Male Sex.}

These resemblances are far commoner in females than males, and when the two sexes differ in the closeness with which a likeness to some other form is brought about, it is the female which always attains the greater perfection. Examples of mimetic females with non-mimetic males are extremely abundant, being in fact a high proportion of all the cases which occur; examples of the converse relationship are very nearly unknown. These general statements hold with Common Warning Colours as well as with truly mimetic species; they are equally true in all the warmer parts of the world where examples of Mimicry are well known and abundant.

In the numberless cases in which a non-mimetic male is accompanied by a mimetic female, the male bears the ancestral appearance, so that when we pass to a land where both sexes of the representative species are nonmimetic, both resemble the non-mimetic male of the former species. In a long series of related species, moreover, the males are found to be nearly alike, while the females

\footnotetext{
'Animal Coloration, London, 1892, p. 232, n.
} 
diverge in all directions after the species which serve them for models. Furthermore, the females, by reversion, are in rare instances brought back towards the ancestral type represented by the males.

It is hardly necessary to point to examples, for these general principles will probably be at once conceded by any who have made a study of the subject. I may, however, allude to the non-mimetic Papilio meriones of Madagascar and the related forms with similar males but widely different mimetic females on various parts of the mainland of Africa; to the general resemblance between the males of so many forms of Hypolimnas of the bolina group to each other and to those of H. misippus, \&c. ; to the varying degrees of reversion towards the appearance of the male presented by occasional females of Hypolimnas bolina.

These relationships are the reverse of those which usually obtain. Outside the category of Mimetic Resem. blances it is the rule, when any difference between the sexes exists, for the female to show us the ancestral type, the male the more modern development; and the male in growth from youth to maturity generally passes through the condition permanently retained by the female.

No probable interpretation of the unusual relationship has been offered by any theory except Natural Selection. The theory of External Causes demands the improbable hypothesis, for which no evidence can be found, that the female of certain mimetic species (but not of others) is constitutionally more ready to respond to the direct action of external forces than the male, and that the difference is commonly great enough for the female to have given a complete and detailed response, when the male, subject to the same direct forces, does not exhibit the faintest trace of the operation of any such influence.

The facts are equally inexplicable by the theory of Internal Causes-and not inexplicable only, but the reverse of what we should expect; for, as I have already stated, it is the female which, outside these resemblances, tends to retain the ancestral form.

The theory of Sexual Selection also fails to account 
for the facts. If it were valid, the selection would be exerted by the male, for these recent developments are specially characteristic of the other sex. In other cases in which male rather than female selection is supposed to have acted in the production of colour or patterns in butterflies, there is some direct evidence derived from the observation of courtship; but here no such support is forthcoming.

Under the theory of Natural Selection the facts at once receive an explanation. Wallace suggested long ago that the slower flight of the females 'when laden with eggs, and their exposure to attack while in the act of depositing their eggs upon leaves, render it especially advantageous for them to have some additional protection'. I In animals which are hidden by Protective Resemblance, similar causes explain why the female is so often better concealed than the male. In birds the dangers of incubation balance the dangers of egg-laying in insects. But Protective Resemblances are less special than cases of Mimicry in the sense that the models (bark, twigs, leaves, \&c.) are more generally alike throughout all countries, and less rapidly change their distribution than the models of Mimicry and the dominant types of Common Warning Colours. These and other reasons, such as the great number and wide geographical range of species belonging to the same genus and adopting a single method of concealment, compel the belief that examples of Protective Resemblance are extremely ancient in the past history of the species as compared with examples of Mimicry, so that we can well understand how it is that in the former, when the female differs it is ancestral as compared with its male, while in the latter the converse relationship obtains, and the appearance presented by the male is comparatively ancestral.

The main conclusion which emerges is that the advantageous is the thing that is attained. If an ancestral appearance is advantageous it is retained, especially in the sex that needs it most; if a new appearance is

${ }^{3}$ Trans. Linn. Soc., Lond., vol. xxv, I866, p. 22. 
advantageous it is attained, especially by the sex that needs it most. The female sex becomes conservative or progressive according to the needs of the species, and Natural Selection is limited by no bounds of constitutional difference between the sexes as regards the preservation of the old or the initiation of the new.

\section{Io. The Space and Time Relationships of the Resemblance in Question.}

A mimetic group is found in the same locality, or at least the mimic (Batesian) is not found beyond the range of its model. The types of Common Warning Colours are remarkably local, although probably certain members of the group (being ex hypothesi all specially protected) may sometimes have a wider range than others. When such a mimic as Hypolimnas misippus can invade and thrive in South America and the Antilles in the absence of its model (Limnas chrysippus), we probably have to do with a Müllerian rather than a Batesian association. ${ }^{1}$

Looking at the examples broadly, the phenomena are characteristically local. This, although harmonizing with the other suggested explanations, is quite unintelligible if the theory of Internal Causes be adopted. Why should these results if attained independently in the evolution of various forms be attained in the same locality? The number of patterns and the number of forms is so vast that we must expect a certain amount of accidental resemblance due to internal causes, as has been suggested by Beddard, ${ }^{2}$ but such resemblances will differ from those under discussion in this among other things-that they will not be characteristically local. The theory of Internal Causes offers us a valid interpretation of such cases, which are, as a rule, readily distinguishable in other ways from those which are here considered.

There is another aspect of locality which only receives

1 See also a paper by the present writer on Mimicry in Butterfies of the Genus Hypolimnas in Proc. Amer. Assoc. for Adv. of Sci., Delroit Meeting, $\mathbf{1 8 9 7}$, vol. xlvi, p. 242, where other arguments in support of this conclusion are urged.

2 Animal Coloration, London, 1892, p. 252. 
an explanation on the theory of Natural Selection. Why should examples of Mimicry and Common Warning Colours be so much more abundant and perfect in one country than another? The physico-chemical influences, the effects of luxuriant vegetation, as Wallace has pointed out, are very similar in tropical South America, Malaya, and West Africa, and yet the first-named country is pre-eminent in affording examples of the resemblances under consideration. This is not only true of likenesses within the Order of Lepidoptera, it appears to be equally true within the Coleoptera; it is true of the resemblances of moths to wasps. It is even more marked in Müllerian Resemblance between protected forms than in the examples of Batesian Mimicry. If the direct action of forces connected with locality cannot explain the immense predominance of tropical South America in this respect, we are driven to inquire whether insect life is especially luxuriant and remarkable in this part of the world, and whether it is not probable that the struggle for existence is especially keen. There is no doubt about the answer to these questions: the variety, peculiarity, and abundance of insect life is far greater than in any other part of the world, and it is a fair inference that the conditions are in an equally marked degree favourable for rapid and complete modifications under the operation of Natural Selection.

We have not as yet sufficient evidence that mimetic groups and groups with a Common Warning coloration appear at the same time of the year. Such evidence as we have points in this direction. The rarity of the mimetic species is usually stated to be due to their being lost in the swarms of the abundant model. There are, however, a large number of cases in which the forms have been caught together by a collector who has passed a limited time in a given locality.

I am bringing together in the Hope Department of the Oxford University Museum as many examples as possible of mimetic species, captured upon the same day and in the same place as their models. This series, which is kept separate, even now affords very valuable evidence 


\section{TIME RELATIONSHIPS OF MIMICRY 249}

on the point. Already it proves that the members of the groups which converge round Limnas chrysippus, Amauris echeria, and the black and white species of Amauris in Natal are upon the wing together. This evidence has been very kindly supplied me by Mr. Guy A. K. Marshall. I have similar, but less complete, evidence as regards some of the Central and SouthAmerican groups.

It will probably be conceded that the phenomena generally are likely to exhibit the same relationship in time which has been already proved to exist for many of them. This conclusion, however, is a considerable difficulty in the way of the theory of External Causes as well as a further difficulty to the theory of Internal Causes. As regards the latter, the time relationship is an entirely unexplained coincidence; as regards the former, it is a coincidence which leaves much to be explained. It is difficult enough to believe that local forces could produce local resemblance; it is a further difficulty that the resemblances are contemporaneous. If, as is probable, the forces are supposed to act during larval life, they must include in their effects an influence on the rate of growth and development, an adjustment of the duration of stages delicate enough to bring the various species into the phases in which the resemblance is shown at similar times of the year. But such effects are entirely different from those which are manifest in the resemblance itself, and add a further complexity to a result already shown to be so complex that the theory of External Causes fails to supply an interpretation (see Section 7, p. 240).

But it has been shown in many cases, and is probably true in all, that the time relationships between the species which exhibit these resemblances are not confined to their appearance at the same season of the year. They are such that they fly together under those conditions of light which render the resemblance visible to enemies. When moths resemble butterflies, they are mostly species which are as truly day-flying as the butterflies themselves; in other cases they are species which fly readily by day 
when disturbed. Similarly with the species of various Orders which resemble Hymenoptera. The case of Coleoptera recently suggested to me by Mr. Gahan is peculiarly interesting. It is known in so many cases that beetles which are about by day possess finely facetted eyes as compared with the larger fewer facets of the nocturnal species, that it is possible to infer the habits from the structure of the eyes. Thus the species of the Longicorn genus Doliops (Family Lamiidae), which closely resemble weevils (see p. $26 \mathrm{I}$ ), are, judged by this standard, diurnal in their habits. The case is all the more interesting, inasmuch as such an eye-structure, such habits, and such mimicry are quite exceptional in the Longicorn group, the Niphoninae, to which the genus belongs.

The facts recorded above imply such a relationship between the nervous systems and sense-organs of the various species as will make them, like their models, diurnal (or in some cases semi-diurnal) in their habits. This constitutes a further grave difficulty in the way of any explanation based on External or Internal Causes. If the diurnal habits are supposed to be due to such causes, the greatly increased complexity of the result is the difficulty. If the resemblances are supposed to be thus produced only in the species which are already diurnal, it is impossible to explain why the external or internal forces are thus restricted in their operation.

It is hardly necessary to point out that the time and space relationships, which are such a difficulty in the way of the other two theories, are entirely necessary to the explanation based on the theory of Natural Selection. If they did not exist it would be overthrown.

\section{I. The Resemblances which Insects of various Orders} bear to those of another Order are produced in the most Diverse Ways.

The most common types for mimetic resemblance are those of the wasp and ant. These aggressive, abundant, and successful forms are resembled by insects of various Orders. Still more interesting is the fact that the resemblance is produced in the most varied ways. 
A superficial resemblance to stinging Hymenoptera is probably more general and is brought about by smaller changes in Diptera than in any other Order of insects. A fly which gains alternate black and yellow rings on its body is at once suggestive of an appearance presented by many common wasps. In more extreme cases, the body gains a constriction presenting a strong likeness to the slender petiole of the wasp's abdomen, there are changes in the manner of folding and sometimes in the colour of the wings, in the buzz, in the movements of the body (the latter being such as to suggest the power of stinging), and (when the humble-bees are mimicked) in the acquisition of an abundant hairy covering.

A Hemipterous insect or bug requires the most profound modification in the shape of its flattened un-wasplike body, and in the display and characteristics of its wings. Corresponding to these much greater initial differences, the resemblance is rarer than in Diptera.

A Lepidopterous insect requires above all to gain transparent wings, and this in the most striking cases that have been studied is produced by the loose attachment of the scales, so that they easily and rapidly fall off and leave the wing bare except for a marginal line and along the veins (Hemaris, Trochilium). In other cases again (certain Sesiidae) the scales may remain on the wing, but themselves become transparent. In the numerous more perfect instances the body is banded, and may gain a marked 'waist', while the scales upon it may be lost or modified, so that the appearance of the hard shining body of the model is suggested with extraordinary exactness.

The means adopted among Coleoptera, even in closely related genera, are so curiously different that a longer description is necessary.

The following examples are all selected from the Longicorns. The simplest resemblance to a wasp is that attained by the common beetles of the genus Clytus, such as the British $C$. arietis, the 'Wasp-beetle'. In these cases there is nothing visible to represent the wings of a wasp; but the elytra and thorax are black banded with yellow, there is a far more pronounced 'waist' than is 
usual in Coleoptera, the legs are slender and wasp-like, and are moved with wasp-like activity and jerkiness. In spite of the apparent want of wings, the effect produced is very considerable, and the majority of persons would hesitate to touch the insect. This, then, is the method adopted in the group of Clytinae; but in various other allied tribes, such as the Nccydalinae, the Rhinotraginae, the Esthesinac, the Callichrominae, and others, the elytra, which form by far the largest part of the visible dorsal surface in the Clytinae, become greatly reduced so as to show the under wings, which, folded over the back or expanded in flight, in either case strongly suggest the wings of a wasp, or in some cases an ichneumon. Furthermore, the elytra are reduced in two different ways-in some genera to linear rudiments more or less broadened at their bases; in others to small subquadrate or oval structures representing the bases alone.

We thus find that wasps and allied forms are resembled by species of many groups of insects, and the resemblance is attained in all kinds of different ways.

The numerous mimetic resemblances to the aggressive, abundant, and well-defended ants supply an even better illustration. In the majority of mimics the whole body of the mimetic form is moulded from the ancestral shapestill exhibited by non-mimetic allies-into that which is characteristic of an ant. In some groups this means a large amount of alteration, in others less. In this case, too, the resemblance extends to forms which are altogether outside the Insecta; for many small species of spiders closely mimic ants. In the family of Attidae alone-and such resemblances occur in other families of spiders-George W. and Elizabeth G. Peckham state that about a hundred ant-like species are known from various parts of the world, and that they are 'very much more numerous in South America and in the Malay Archipelago than in any other countries', 1 viz. in the very countries in which other examples of Mimicry are especially abundant. The spider with its two-fold division

'Occasional Papers of the Natural History Sociely of Wisconsin, vol. ii, 1892, Milwaukee; see also a paper by the same authors in vol. $\mathrm{i}, 1889$. 
of body is often made to assume the appearance of an ant, with its three-fold division, by a constriction which sometimes crosses the cephalothorax, sometimes the abdomen. The absence of antennae in the spider is known to be compensated in some of the species, which have been studied in the living state, by the habit of holding up one pair of legs, while the walking legs are thus reduced to the ant-like number of six. Of two wellknown North-American species, Synageles picata holds up the second pair, and Synemosyna formica the first. The habits of seizing and dealing with prey, and the move.

FIG. I.

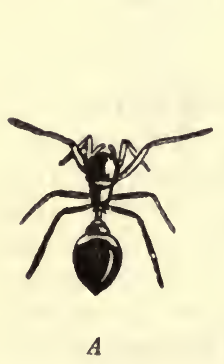

FIG. 2 .

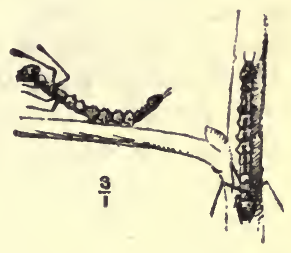

FIG. 1.-Two North-American Attid spiders which resemble ants. $A$ is Synageles picata; B. Synemosyna formica. (From G. W. and E. G. Peckham, Occasional l'apers of the Nat. Hist. Soc. of Wisconsin, vol. i, 1889, pp. 110 \& 112.)

FIG. 2 ( $\times 3$ ). - The young larva of Slauropus fagi seen from above and from the left side.

ments generally are extremely un-spider-like and most suggestive of ants; so that the nervous and muscular systems, as well as the body-form, have been modified. The remarkably ant-like appearance of these two species is shown in the adjoining Fig. I $(A$ and $B)$.

Among the Insecta, too, there are many examples of an ant-like appearance brought about by changes of the same kind as those mentioned above, although less marked because the forms to be approximated are less essentially different. Among the Lepidoptera the young larvae of a British moth, Stauropus fagi, the 'Lobster', have often been described as resembling ants. The likeness has 
recently been analysed in much detail by Portschinski: ${ }^{1}$ This acute observer considers that the head of the larva represents the globular abdomen of the ant, while the head and antennae of the latter are suggested by the larval caudal shield with its two appendages. He believes that the disturbed larva represents an ant which has seized and is endeavouring to carry off some object on the branch which it is exploring. Under these circumstances the head of the ant, with its mandibles fixed in the object, would be held low and remain motionless, while the abdomen would be elevated and the legs in constant activity, moving the posterior part of the body from side to side. Such an appearance and such movements, he maintains, are strongly suggested by the disturbed larva if we only identify the posterior end of the mimic with the anterior end of the model. I have to thank Professor W. R. Morfill for very kindly translating the memoir of the Russian naturalist. During the summer of 1898 I had the opportunity of studying these larvae. The young caterpillars were thought to be ants by all the friends to whom they were shown. One lady considered that they were 'double ants'-an interpretation evidently due to their disproportionate length and to the head-like appearance of the caudal shield. Drawings of the larvae at this stage were made by Mr. P. J. Bayzand and are reproduced in Fig. 2 (p.253), but they fail to convey the ant-like appearance which depends so largely on movement. I did not, however, observe any attitudes which support the details of Portschinski's interpretation, nor did I witness the appearances which he figures. ${ }^{2} \mathrm{His}$ comparison of the caudal appendage with a head was, on the other hand, entirely confirmed.

Turning to other Orders which supply examples of the mimicry of ants, the Hemiptera have perhaps the farthest distance to travel in the modification of their flattened bodies. A beautiful example from East Africa, viz. that of Myrmoplasta mira (Gerstaecker), is shown in Fig. 3. Gerstaecker states that a single specimen of this insect

1 Coloration marquante et Taches ocellées, V.: St. Petersburg, 1897, p. 44. 2 .1. c. p. 45 , fig. 21 . 
was sent from Rosako, Usaramo, August, 1888 , as 'an ant', together with two undoubted species of these Hymenoptera (Polyrrhachis gagates and Ponera tarsata). The resemblance between the former species of ant and the Hemipteron, Gerstaecker describes as strong enough to be deceptive. ${ }^{1}$ It is principally brought about by the short

FIG. 3 .
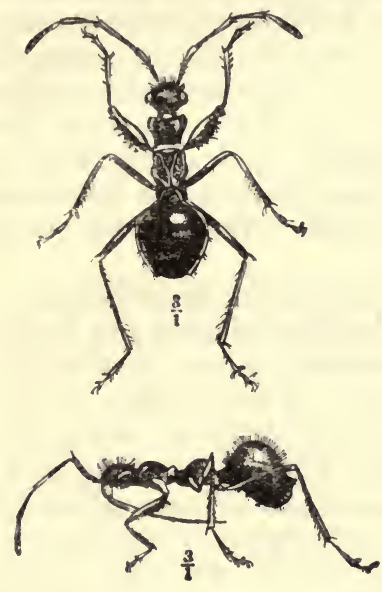

FIG. $3(\times 3)$.-An aut-like East-African Hemipterous insect, Myrmoplasla mira (Gerst.), seen from above and from the left side. (From Gerstaecker, Article 6, Hemiptera, p. 9, in Fr. Stuhlmann's Zool. Ergeb. 1888-1890, Bd. I. Berlin, I893.)

F1G. 4.-An ant-like N.-American beetle, Euderces picipes, Fab., seen from above and from the right side.

globular abdomen, united to the thorax by a constricted portion, well seen in the side view represented in Fig. 3 .

Among Coleoptera the resemblance to ants is very common. I select as an example a little Longicorn (Euderces picipes, Fab.), which I found very abundantly upon the heads of U mbelliferous plants at Pine Lake, Hart-

1 Zool. Ergeb. einer Reise in Ost-Afrika, Fr. Stuhlmann, Bd. I; Article 6, Hemiplera, p. 9: Dietrich Reimer, Bsrlin, 1893. 
land, Wisconsin, in July and August, I 897, when visiting Dr. C. A. Leuthstrom. Ants were also very common on the same flower-heads. The appearance and movements of the beetles were extremely ant-like, the suggestion of a stalked abdomen being conveyed by an oblique white line crossing the elytra in a very shallow depression in which the dark ground-colour of the insect appeared to be of a more intense black than elsewhere. The increased darkness was in reality due to the shadow in the depression combined with the effect of a difference in the texture of the surface. This combination of characters produced a strong superficial resemblance between the elytra of the beetle and the abdomen and thorax of the ant, while the head of the latter was represented by the beetle's head and thorax together. These resemblances are indicated in Fig. 4 (p. 255); but the living insect is required in order fully to appreciate them.

In all the cases alluded to above, the resemblance is attained by a modification in the form of body and limbs, accompanied by changes in those more deep-seated structures which affect the habits and movements.

There are, however, other very different means by which the same end is attained. One of the most interesting of these is the case of a Locustid (Phaneropterides), Myrmecophana fallax from the Sudan, described by Brunner von Wattenwyl. ${ }^{1}$ Brunner's two figures are reproduced as Fig. 5 on p. 258 . Upon the stout body of this insect the slender-waisted form of an ant is represented in black pigment, the remainder of the body being light in colour and presumably invisible against a similar background. Of the habits of the insect nothing is known, but the method is of great interest, being so entirely different from that by which mimetic likeness is usually effected. In a more recent work ${ }^{2}$ Brunner von Wattenwyl again alludes to this example, and states that the form of the species "leads to the conclusion that it lives on the ground', viz. in the position which gives a meaning to the

1 Verhandl. der k.-k. zool.-botan. Ges. in Wien, 1883, p. 247.

${ }^{2}$ Observations on the Coloration of Insects, English translation by E. J. Bles, Leipsic, 1897, p. 11 . 
resemblance. In spite of this he asks, "Is this imitation an accidental freak of nature?' If Myrmecophana were the only example of such resemblance the question might fairly be asked, but in view of the numerous other equally close resemblances to ants, produced in various ways, it is quite unnecessary. The suggestion of an 'accidental freak' can never explain such close likeness, in appearance, in movements and habits (so far as they are known), in locality - a likeness, furthermore, to particular insects in the environment, members of a specially successful and aggressive group-a likeness not produced in one way but in many different ways. To suggest an 'accidental freak' as the explanation shows an amazing credulity, only to be explained by the bias which is ready to accept any interpretation except that afforded by the theory of Natural Selection. ${ }^{x}$

1 Several examples of the kind are now known, although some doubt has been thrown upon the details of Brunner's interpretation in the case of Myrmecophana itself, an insect of which the habits were entirely unknown. Guy A. K. Marshall has captured a Locustid of the same genus in company with ants upon a small bushy vetch, near Salisbury, Rhodesia (Trans. Ent. Soc. Lond., 1902, p. 535, Plate xix, fig. 59). The un-ant-like parts of the body were green and thus invisible against the leaves; but in the dead specimen they have faded to a pale yellowish tint much like that described by Brunner on the corresponding parts of $M$. fallax. In fact, Malcolm Burr is inclined to think that the Rhodesian example is $M$. fallax and that Brunner was misled by a faded specimen. But even if this particular example is to be explained in a slightly different mannerobliteration by harmony with a green background instead of a glaring one, several other instances have now come to light, and these are to be explained precisely in the manner suggested by Brunner. Thus Colonel J. W. Yerbury has shown me an Asilid fly-Promiachus iopterus (Wied.), from Pará, with white patches on the sides of the basal abdominal segments, leaving the appearance of a slender black stalk like that of so many Hymenoptera. Again, R. Shelford describes four Bornean Longicorn beetles of the genera Scytasis and Oberea as 'marked with a large white patch of pubescence on the sides of the first and second abdominal segments, which patches, when the beetle is seen in profile, give an impression of a wasp-like waist, from the posterior end of which the abdomen appears gradually to swell in size' (Proc. Zool. Soc. Lond., 1902, vol. ii, p. 238, Pl. xix, figs. 1 3-15). The most interesting case, however, is that of a common British Reduviid bug, Nabis lativentris, which in its immature stages bears an ant-like appearance produced exactly in the manner described by Brunner. It is remarkable that so interesting a form of mimicry in such a common insect should have been undescribed 
Another and equally interesting method is adopted by certain tropical American Rhynchota Homoptera belonging to the family Membracidae. In this remarkable group the dorsal region of the first thoracic segment (the pronotum) is of enormous size, extending upwards and backwards so as completely to cover the insect with the exception of the head, limbs, and wings. What Natural

\section{Fig. 6.}

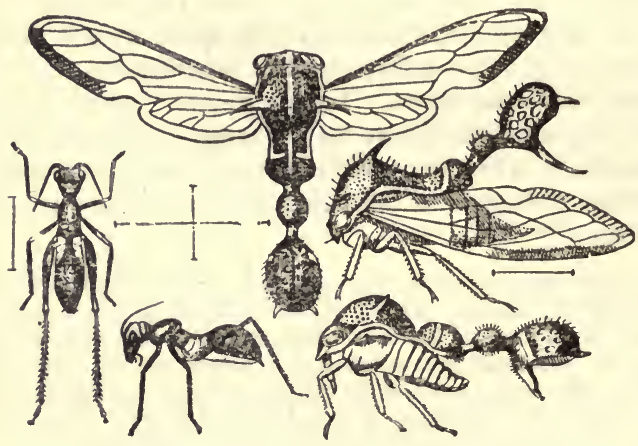

FIG. 5 .

Fig. 5.-A Locustid from the Sudan, Myrmecophana fallax (Brunner), seen from above and from the left side. On this insect the appearance of an ant is represented in black pigment, all other parts being light in colour and presumably concealed. (From Brunner von Wattenwyl, Verhandl. d. k.-k. zool.-botan, Ges. in Wien, Bd. xxxiii, 1883 , pl. xv, figs. I $a$ \& I b.)

Fig. 6.-A Central American Membracid (Rhynchota Homoptera) in which the prothoracic shield resembles an ant. Thus the body of the insect which is not like an ant is concealed by an ant-like shield. The species is Heteronotus trinodosus as seen from above and the left side. The upper of the two figures seen from the side represents a female, the two other figures, males. (From W. W. Fowler, Biol. Centr.-Am., Rynch. Homopt., vol. ii, pl. 6, figs. 16, I6 A, \& I 7.)

Selection effects in the general body-form of other insects must here be effected, if it is to be of any value, in the shield, which is seen, and not in the body, which is concealed. This change has been brought about, and certain species of the group have their un-ant-like bodies concealed under an ant-like shield. In other species the

until so late as 1899 (David Sharp, F.R.S., Insecla, vol. ii, Lond., 1899, pp. 556, 557, Fig. 269).-E. B. P., Oct. 1906. 
prothoracic shield is modified into a resemblance to various objects, such as seeds, thorns, \&c.-an excellent example of the parallelism between Mimetic and Protective Resemblance pointed out in Section 3, p. 225. The effects produced in the shield are at least as exact and detailed as those which in other cases are wrought in the form of the whole body. Thus, as Mr. W. F. H. Blandford has pointed out to me, a peculiar characteristic of certain tropical American ants (viz. the bead-like dilatation in the stalk of the abdomen) is reproduced in the shield of the Membracid. This is well seen in Heteronotus trinodosics, shown in Fig. 6, copied from Canon W. W. Fowler's Monograph of the group in the Biologia Centrali-Americana.

Finally, in the same group of Membracidae we meet

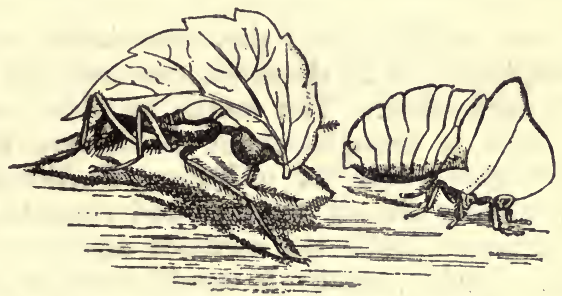

FIG. 7.-About three times the natural size. On the right is represented an immature Membracid (Rhynchota Homoptera) from British Guiana, which resembles an ant together with the leaf it is carrying. The latter is seen on the left, and represents the species Atta (Oecodoma) cephalotes from the same locality. The English leaf shown in the drawing is unlike the semi-circular fragments gnawed by the ant. (From Poulton, Proc. Zool. Soc. Lond., 1891, pl. xxxvi, fig. 2.)

with another example which is also incapable of interpretation by any theory as yet brought forward except Natural Selection. An immature form of Membracid, with the prothoracic shield not yet formed, found by W. L. Sclater in British Guiana, strongly resembles one of the leaf-carrying ants which are so common in that part of the world; but the resemblance includes the leaf as well as the ant! The dorsal region of the Membracid is flat and compressed, so that it is as thin as a leaf; its border (the dorsal surface, which forms a sharp edge) is irregularly jagged as if gnawed, and during life it is green in colour. Beneath this leaf-like expanse the brown head 
and legs of the insect are visible just as, in the case of the ant, they appear beneath the piece of leaf which is carried vertically between the mandibles and thrown over the back. ${ }^{1} \quad$ The appearance of the Membracid and leafcarrying ant is shown in Fig. 7 (p. 259). It is probable that certain species of the Orthopterous genus Tettix (Acridiidae) also resemble ants carrying leaves.

It would of course be ridiculous to ascribe this last resemblance to any direct external forces connected with locality, or to any internal forces, independently producing a like result, and, as the resemblance appears at an immature stage, it is equally impossible to invoke the aid of Sexual Selection.

Natural Selection remains as the only feasible interpretation.

Even more striking than this remarkable example is the contemplation of all these various methods and their relation to each other. The means by which the resemblance to ants is brought about are diverse, the endthe resemblance itself-is uniform. Furthermore, the likeness is almost always detailed and remarkable, however it is attained, while the methods made use of differ absolutely. Such a result, it would seem, is the most complete proof of the operation of Natural Selection that can be attained, short of the actual demonstration of its action by observation and statistics. If this argument be confirmed by a study and comparison of the foregoing Figs. I to 7 , I venture to think that it will meet with general acceptance.

When one insect resembles an ant by the superficial alteration of its whole body-form, another by the modification of a shield-like structure which conceals its unaltered body, another by having the shape of an ant painted, as it were, in black pigment upon its body while all other parts are rendered invisible; another by a further modification of the body, so that it represents not an ant only, but the object which the ant is almost always carrying,when the effect of all these results is heightened by appropriate habits and movements, we are compelled to believe ${ }^{1}$ Proc. Zool. Soc. Lond., 189 i, p. 462. 
DIVERSE CAUSES OF RESEMBLANCE 26 I

that there is something advantageous in the resemblance to an ant, and that Natural Selection has been at work. The phenomena do not merely disprove all other suggested causes of change; they constitute the most powerful indirect proof of the operation of Natural Selection.

\section{The Resemblances within the Limits of the Order are also produced in the most Diverse Ways.}

Illogical as I believe the position to be, it is quite possible that many observers may concede the force of the argument concluded above, and yet continue to hold that the resemblances within the Order are produced by External or perhaps by Internal Causes. It can, however, be shown that the very same conditions which were true in the wider group are also found in the narrower. Even within the Order itself resemblances are produced in very diverse ways, although minute examination is sometimes necessary before the essential difference which separates them can be revealed.

Certain Longicorn beetles resemble weevils, the Curculionidae being, so it is believed, specially defended by their extremely hard chitinous covering. The weevils closely resembled by such Longicorns as Doliops curculionoides and D.geometrica have short antennae ending in a knob. The antennae of the Doliops are nearly three times as long; the resemblance to the weevil being produced by a dilatation of the third joint, which represents the knob, while all the joints beyond are of such excessive fineness that they are almost invisible. The strong resemblance of the Longicorn Estigmenida variabilis to Estigmena chinensis, belonging to the Hispidae (Phytophaga), is brought about in a similar manner, as was pointed out by C. J. Gahan. In this case about onethird of the length of the Longicorn's antenna is concealed by its extreme fineness, while the apparent terminal thickening is produced by hairs at the end of the stouter basal section.

In these examples, kindly shown me by Mr. Gahan, neither the theory of External nor that of Internal Causes is of any avail. It is impossible to believe that the 
resemblance is a direct effect of climatic or other forces connected with locality, when the results are in reality so utterly different and yet superficially so entirely alike. It is obvious that the methods by which the appearance of a terminal thickening is produced in the two mimics are as essentially different as are those by which the appearance of short antennae is produced in the model on the one hand, and its two mimics on the other. The fact which requires explanation is the extraordinary likeness in spite of the essential difference, and this, when it is repeated again and again, cannot be interpreted by any theory unless based upon the principle of selection.

Many other examples of the same kind could easily be brought forward: in fact, it may be admitted as a general principle that in Protective Mimicry and Common Warning Colours the resemblance is never attained by precisely similar methods, and generally by methods which are extremely unlike. I propose, in concluding this Section, to discuss a few examples from the Lepidoptera, inasmuch as the resemblances in question have been chiefly studied in this group, and because an explanation based on the theory of External or on that of Internal Causes has been sought more often and pressed more strongly in the Mimetic Lepidoptera than in any other Order.

The Pierinae are specially liable to take on these Resemblances. In tropical America they chiefly resemble the Ithomiinae, Heliconinae, and Papilioninae, affording some of the best and earliest recorded examples of Mimicry (although Dr. F. A. Dixey has now shown that they are more probably to be interpreted as Common Warning Colours). The chemical nature of the wingpigments of the Pierinae has recently formed the subject of an interesting paper by F. Gowland Hopkins. ${ }^{1}$ The author shows that the white pigment so common in the group is an impure uric acid probably uncombined, that the yellow and orange pigment is a derivative of uric acid to which he gives the name 'lepidotic acid', while a much rarer red pigment, less fully investigated, is probably of

1 Proc. Ro:. Soc., lvii, 1894, p. 5, and Phil. Trans., 1895, B. p. 661. 
a closely similar constitution. These three pigments, with black, which is apparently intimately associated with the cuticle of the scales, with a pigment placed between the two laminae of the wing and with superadded optical effects due to structure, account for the whole of the colouring of Pierine butterflies. No pigment of similar constitution to the Pierine white, yellow, and red, was found by Mr. Hopkins in any other butterfly-not even in the allied Papilioninae. The Pierine butterflies which resemble the Ithomiinae or other butterflies were found by $\mathrm{Mr}$. Hopkins to achieve this end, not by gaining the true pigments of their models, but by means of the characteristic Pierine pigments. The bands of warm redbrown, the spots of white and yellow, which so closely resemble the same tints in the Ithomiinae, are in reality caused by pigments of an entirely different nature,- the resemblance, even between the pigments themselves, is wholly superficial.

The argument that the resemblances we are discussing are a common result of common forces is simply an improbable assumption. It has been proved again and again that the results are not common, the resemblance merely deceptive. And now this has even been shown for the colours themselves, in some of the best known and most striking examples of Mimicry.

The last example of similarity in appearance produced through diversity of method is one which occurred to me a few years ago when lecturing on Mimicry in the Hope Department at Oxford. It was worked out in detail during the summer of 1897 , and the general results were communicated to Section D of the British Association at Toronto. ${ }^{\mathrm{l}}$

Although the Lepidoptera are characterized as an Order by the clothing of scales upon the wings, examples are very frequent in which this covering has been in part, or almost wholly, lost. By comparison with kindred unmodified forms, as well as by microscopic examination of the transparent areas themselves, it is possible to show

${ }^{1}$ August 23, 1897. A brief abstract is printed in the Report of the Neeting, pp. 692-4. 
that this loss is recent, and to trace the steps by which it has been reached from a condition in which normal scales were present.

In the very large convergent group of tropical American Lepidoptera which has sprung up round the best known species of the Ithomiine genera Methona and Thyridia, transparency of a large part of the wings is a characteristic feature. Throughout the group the ground-colour of the wings is transparent, with a black border which generally passes inwards as two transverse bands in the fore-wing, separating the transparent part into three areas, and as one band in the hind-wing, separating it into two areas. The group consists of Ithomiinae (Neotropinae) of many genera, of Danainae, of Pierinae, and of moths of the genera Anthomyza and Hyelosia, belonging to the Pericopidae (Hypsidae), and the widely separated genus Castnia (Castniidae).

Under the theory of External Causes we should expect that the transparency would be attained in a similar manner throughout, by the reduction of scales to hairs, by the complete loss of scales, or by some other uniform method. Under the theory of Natural Selection we should expect the methods would be different in the different groups. There are many ways in which transparency can be attained, and we should expect that one group would submit one set of variations making towards the resemblance, another a different set, to the operation of Natural Selection. It will be shown that this prediction is abundantly justified.

Microscopic examination of the Ithomiinae ( $N$ cotropinae) showed that the scales on the wings are of two kinds, broad and narrow, which alternate more or less regularly. In the transparent parts both kinds of scale can still be detected, the narrow being frequently reduced to fine simple hairs, and, in the most extreme cases, the broad scales being reduced to $Y$-shaped hairs.

The two commonest species of the whole group, probably forming the centre towards which the others have converged, are the Ithomiine butterflies Methona 
confusa and Thyridia psidii. These species, belonging to very different genera, afford a good example of the closeness of resemblance which may be attained by Common Warning Colours. The two forms are constantly found intermixed in collections, and superficially are almost exactly alike. Nevertheless, a study of the transparent part of the wing under the microscope reveals the fact that the degeneration of the scales has reached a very different level in the two species. The broad scales, reduced to small bifid structures, exhibit a distinctly different form in the two species; while the narrow scales are reduced to long extremely fine hairs in the Methona, and to much broader ones in the Thyridia. The comparison between the almost identical appearance of the two insects to the naked eye, and their real differences when seen by means of the microscope, affords another good example of the principle which has been already so abundantly illustrated-that when a close superficial resemblance has been attained no further similarity in the details of structure is produced. This is apparent enough even in these two genera belonging to the same sub-family. It is of course illustrated in a far more striking manner when the affinity is more remote.

We now pass to the Danainae which fall into the group. This Sub-Family supplies it with two species, both belonging to the genus Ituna. The Ithomiinae were formerly classed with the Danainae, and in any case form the sub-family which stands next to them. But, nevertheless, transparency is attained in an entirely different manner, the scales being neither greatly lessened in size nor much altered in appearance. It is the great reduction in numbers which is here the cause of the transparency. The scales retain their dark pigment and produce the effect of a grey dusting over the transparent areas.

Finally, there is a single species belonging to the distant Family Papilionidae and Sub-Family PierinaeDismorphia orise. In certain parts of Ecuador the black borders and bands of the Methona model, distin- 
guished as M. psamathe, Godm. and Salv., are much narrower than in the type form, and we find that the Dismorphia from the same locality has followed in the same direction. Microscopic examination reveals that in Lismorphia the transparency is attained, unlike Ituna, by a reduction in size of the scales; while, unlike the Ithomiinae, the normal shape and outline are preserved almost unchanged.

It is a little remarkable that in this large, dominant, and widely distributed group, no member of the Heliconinae has yet been shown to find a place.

We now pass to the Heterocerous members of the group. Microscopic examination proves that the moths become transparent in two ways, which differ entirely from each other, and from any of the methods already described in the butterflies. The scales of Castnia are not reduced in size, but they have lost their pigment and are transparent; they are furthermore set up on edge so that the light freely passes between them. The scales towards the centre of the transparent patches are much more upright than those of the margin, where they are transitional into the opaque border. The arrangement in Hyelosia is closely similar to that of Castnia, save that the scales are much reduced in number. The scales of Anthomyza, on the other hand, are normal in arrangement as well as in size. They lie flat on the wing-membrane with the usual overlap, but are so devoid of pigment that the light passes through them. Although transparent, they retain a more or less faint yellow or greenish-yellow tinge, but this is also to be noticed in the transparent part of the wings of Methona, Dismorphia, \&c.

The comparison of these details is almost a demonstration of the operation of the Darwinian theory. We cannot conceive of Natural Selection acting other than along some such lines as those which have here been shown to exist; for it is impossible to believe that very different species with very different natures would present anything but very different variations for its action. On the other hand, we cannot conceive of any 


\section{MIMICRY AND NATURAL SELECTION 267}

theory, not dependent upon the principle of Selection, which could explain such extraordinary superficial resemblances among numbers of species by methods which are entirely unlike in their details.

\section{The supposed Direct Effect of Local Forces implies} the Hereditary Transmission of Acquired Characters.

Finally, the hypothesis which is more commonly than any other substituted for Natural Selection, has the further disadvantage that it implies the unproved improbable hypothesis of the hereditary transmission of acquired characters.

A discussion of this latter hypothesis cannot be attempted here. ${ }^{1}$ It will be sufficient to observe that after years of search no particle of evidence in its favour, which can stand the test of investigation, has been forthcoming.

14. General Conclusions: Natural Selection as the Cause of Mimclic Rescmblance and Common Warning Colours.

I think it is not too much to claim that, even if the theories which have been proposed as substitutes for Natural Selection have not been destroyed in single Sections of this essay, - and I confidently believe that they have been thus destroyed over and over again,their most convinced supporter will admit that they must yield to the accumulated pressure of all the arguments here brought forward.

The resemblances of Mimicry and Common Warning Colours have certain salient features in common, certain peculiarities which are apt to manifest themselves repeatedly; they also bear certain general relationships to other resemblances in organic nature. In this paper I have attempted to set down all the general statements which can be made as to the phenomena under discussion. These general statements represent an

1 The hypothesis in question has been discussed in Essays iii and v, pages 95 and 139 . 
enormous number of facts observed in many very different parts of the world. I believe that the generalizations will be admitted to be sound and to be well warranted by the facts. Under any theory which is not based upon selection, the whole of the facts on which the generalizations rest become mere coincidences and receive no explanation of any kind. Under Natural Selection this vast body of facts becomes at once intelligible. Here the accumulated facts of the most diverse kind, which receive an intelligible explanation by the theory in question, yield a firm support to the theory. There are many theories which are held upon indirect evidence of precisely the same nature. We believe in evolution, not because we see it taking place, but because of the immense number of observed facts which it renders intelligible.

In the case of Natural Selection in relation to Mimicry and Common Warning Colours it is to be confidently hoped that direct evidence may yet be added; indeed, a considerable amount is even now forthcoming. Professor Lloyd Morgan's work " upon the activities and instincts of young birds of many species, proves that their education is actually of the kind which is presupposed in the theories of H. W. Bates and Fritz Müller. He shows that they have no instinctive knowledge of things which are good for food, but that they examine and test everything. On the other hand, they have excellent memories, and retain a firm impression of the appearance of objects which have given them an unpleasant experience. Furthermore, there was evidence that they are influenced in their behaviour towards other objects resembling the one which has proved objectionable to them. As to the aggressive Hymenoptera, the evidence of their special methods of defence is obvious to every one. With regard to specially protected groups of butterflies there is a large amount of evidence from observation and experiment, but more is to be desired. For positive results I may refer to Guy

1 Habit and Instinct, London, 1896. 


\section{FINN'S EXPERIMENTS ON BIRDS 269}

A. K. Marshall's memoir already often quoted, ${ }^{1}$ and to Frank Finn's interesting and important set of papers especially devoted to this question. ${ }^{2}$ After a long series of experiments begun and conducted with a perfectly open mind, upon Indian insect-eating vertebrates, $\mathrm{Mr}$. Finn supports the theories based upon Natural Selection in the following words : ${ }^{3}-$

'I conclude from these experiments-

' 1 . That there is a general appetite for butterflies among insectivorous birds, even though they are rarely seen when wild to attack them.

'2. That many, probably most species, dislike, if not intensely, at any rate in comparison with other butterflies, the "warningly-coloured" Danaince, Acraea viola, Delias eucharis, and Papilio aristolochia ; of these the last being the most distasteful, and the Danaina the least so.

'3. That the mimics of these are at any rate relatively palateable, and that the mimicry is commonly effectual under natural conditions.

'4. That each bird has to separately acquire its experience, and well remembers what it has learned.

' That therefore on the whole, the theory of Wallace and Bates is supported by the facts detailed in this and my former papers, so far as they deal with Birds (and with the one Mammal used). Professor Poulton's suggestion that animals may be forced by hunger to eat unpalateable forms is also more than confirmed, as the unpalateable forms were commonly eaten without the stimulus of actual hunger-generally, also, I may add, without signs of dislike.'

Mr. Finn concludes with some valuable suggestions as to the conduct of future experiments.

The chief objection that has been raised against the theories of Bates and Fritz Müller, is the want of evidence that birds are in any important degree the enemies of butterflies. Many excellent observers have rarely

1 Trans. Ent. Soc. Lond., 1902, p. 287.

2 Journal, A siatic Sociely of Bengal, lxiv, pt. ii, 1895 , p. 344 ; lxv, pt. ii, 1 896 , p. 42 ; lxvi, pt. ii, 1897 , p. 528 , and p. 613 .

sbed., lxvi, pt. ii, 1 897, pp. 667-8. 
seen butterflies attacked by birds. On the other hand, the Müllerian theory presupposes that only young birds test the palatability of a few members of each convergent group in their locality, and henceforward, except when driven by hunger, avoid all the members, so that the recent tendency to explain so many of these resemblances on Müllerian rather than on Batesian lines is in harmony with the conclusion that the members of such groups are not greatly attacked by adult birds.

As regards butterflies which do not exhibit these resemblances, I may point out that it is impossible to exhaust the details of the struggle for existence, even as regards a single species, in the intervals of the time devoted to collecting. Such an investigation would demand the whole time of a first-rate observer, and, so far as I am aware, the inquiry has never been approached in so thorough a manner. Even if collectors would pay attention to the worst specimens instead of the best, some evidence of the nature and amount of attack would be forthcoming. During the visit of the British Association to Canada in $1897 \mathrm{I}$ made a point of capturing butterflies which had evidently been pecked by birds. In this way, although I did not witness a single attack, I obtained indirect proof that butterflies are not nearly so immune as has been asserted. Similar observations were made at a much earlier date by Fritz Mïller. ${ }^{1}$

The review of the whole subject during the past forty-five years increases our confidence in the theories of Bates and Fritz Müller, while. it disposes of all alternative hypotheses. Even more than this,-it will, I believe, be claimed by all who take a broad view over the whole field of evidence, that the explanation of these deeply interesting facts, which form so fascinating and important a department of natural history in the tropics, is one of the most notable triumphs ever won by the great theory of Natural Selection.

1 See Trans. Ent. Soc. Lond., 1902, pp. 353-75, where a large body of evidence, direct as well as indirect, is published. The direct evidence is reprinted, p. 282, as an Appendix to the following Essay. 


\section{MIMICRY AND NATURAL SELECTION}

The English Address to the Fifth International Zoological Congress held at Berlin. Read at the 'Allgemeine Sitzung', August I5, I901. Reprinted from Verhandl. d. V. Internat. Zool. Congr. z. Berlin, Jena, 1902, p. I7 I.

Revised; an Appendix added.

I FEEL it to be a great honour and pleasure to be called on to deliver the address on behalf of the English-speaking nations to the Fifth International Zoological Congress, at Berlin. At the same time I am sensible of the great difficulty of the task, in the attempt to say anything adequate on so wide a subject in the narrow compass of five and forty minutes.

In attempting to arrive at a decision upon the origin and cause of Mimetic Resemblance we have no direct evidence to assist us. We are driven to base our opinion upon the same ground as that upon which the belief in the theory of Gravitation is founded. This theory finds acceptance, not because of direct evidence in its favour, but because the facts of the Cosmos, so far as we know them, are consistent with the theory and none of them inconsistent with it.

It is necessary therefore first to give a brief account of the theories which have been advanced to explain the origin of Mimicry, secondly to inquire how far each one of them is consistent with the main facts of Mimicry.

1. The Theory of Natural Selection as an explanation, assumes that these resemblances have been produced because they are or have been useful in the struggle for existence. There has been, according to this interpretation, a greater average survival in successive generations of the forms in which these useful likenesses were more 
strongly developed as compared with those in which they were less strongly developed, and thus in process of time a very high degree of resemblance has been attained.

2. The Theory of External Causes assumes that Mimicry has been produced by the direct action upon the organism of some one or more of the various influences which exist in the locality, such as food, moisture, dryness, heat, cold, \&c.

3. The Theory of Intirnal Causes assumes that Mimetic Resemblances are due to the independent arrival of different species at the same evolutionary stage, as regards the characters in which such resemblances are manifest.

4. The Theory of Sexual Selection has occasionally been invoked to account for Mimicry, the assumption being that the selection of mates has been influenced by the colours and patterns of other species living in the same country.

The last-mentioned theory is held by comparatively few naturalists, although it was deemed to be worthy of consideration by Charles Darwin and Fritz Muiller. ${ }^{1}$ The theory of External Causes is probably more commonly received as an explanation than any of the others except Natural Selection itself.

I now propose to bring before you several examples, ${ }^{2}$ setting forth the main aspects of Mimetic Resemblance, and to inquire how far each of them is consistent with these four theories.

The too-exclusive study of Mimicry in Lepidoptera (butterflies and moths) alone is probably responsible for a common belief in the theory of External Causes. Thus when we contemplate a group of many species of Ithomiine, Danaine $\lambda y$ mphaline, Heliconine, Erycinid, and Pierine butterflies from British Guiana and Surinam, and find that all tend to develop dark hind-wings, it is plausible to suggest as an interpretation that we are

'See a letter from Charles Darwin describing Fritz Müller's thoughts on this subject. Charles Darwin and the Theory of Natural Selection. Poulton, London, 1896, p. 202.

2 These examples were illustrated by projections of three-colour illustrations prepared by Mr. Sanger-Shepherd from the actual specimens in the Hope Department of the Oxford University Museum. 
witnessing the common effect of local influences. But this and every other explanation, except Natural Selection, leave as a mere coincidence the fact that the first-named three groups contribute the vast majority of the species, and undoubtedly provide the models for the others. Under Natural Selection the interpretation is easy; the groups in question are specially defended by unpalatable qualities, and it is to their advantage to warn their enemies by a common advertisement. The Nymphaline, Erycinid, and Pierine species may also be unpalatable and fall into the same Müllerian (Synaposematic) ${ }^{1}$ combination, or $^{2}$ they may be edible and gain advantage by living on the reputation of the three nauseous sub-families (Batesian Mimicry or Pseudaposematic Resemblance). Taking all available facts into consideration the former is the more probable view. Not in Guiana alone, but wherever we may travel in tropical America, groups of species of the three Sub-Families tend to resemble each other and to act as models for butterflies of other Families and SubFamilies. In Venezuela, for example, they are reddishbrown black-barred insects as in Guiana, but without the tendency towards preponderant black in the hind-wings; in South Eastern Brazil they all possess an especially light stripe, frequently bright yellow, along the hindwings, and a light spot, frequently white, at the apex of the fore-wings ; at Ega, on the Upper Amazon, they all gain a rich chestnut-brown ground colour; still further west, the brown ground colour is much less dark than at Ega, and of a very characteristic shade. Why should these three Sub-Families be so conspicuously subject to the common influence of locality? Why should they more than all other butterflies arrive independently at the same evolutionary stage as regards visible characters? Why should Sexual Selection operate so exclusively upon them in the direction of producing a common likeness? None of these questions can be answered. The facts remain mere coincidences under all theories except Natural Selection. In other words, Natural Selection is the only satisfactory interpretation.

$$
1 \text { Proc. Ent. Soc. Lond., 1897, p. xxix, n. }
$$




\section{MIMICRY AND NATURAL SELECTION}

Mimicry among Rhopalocera (butterflies) is much less common as we pass into northern regions, but there is one excellent example in temperate North America which serves to show how superficial an interpretation is that offered by the theory of External Causes, and how completely it breaks down when examined with a little care. With comparatively few exceptions the insect fauna of North America is that of the great northern circumpolar land-belt. These exceptions are intruders from the tropical South, and among them is the large Danaine butterfly Anosia plexippus which now ranges over the United States and a large part of Canada. In tropical America closelysimilar representative species, sub-species, or forms still persist. This abundant Danaine butterfly affords the model which is closely resembled by an indigenous Nymphaline butterfly which we should place in the genus Limenitis, although some American naturalists prefer to put the Nearctic species in a separate genus, Basilarchia. There are also other mimics among the species of the North American Limenitis (Basilarchia), but two of them are non-mimetic and enable us to reconstruct the appearance of their close ally before the intrusion of the great Danaine model. In the New World the genus Limenitis is confined to the Nearctic Region with the exception of a single species, a form of the mimetic $L$. astyanax (Fabr.), which just enters the borders of Mexico. If butterfly colours and patterns are the expression of the direct influences of the environment, then it is clear that the indigenous non-mimetic species of Limenitis (Basilarchia) are an expression of Nearctic (temperate North American) conditions, and according to the theory of External Causes, the invader from the South should have come to resemble them, instead of drawing an ancient Nearctic species far away from its ancestral colours and patterns into a close superficial likeness to itself. The fact that certain species of a single genus should thus be entirely mimetic, while others are entirely non-mimetic and preserve the ancestral appearance, has been sometimes urged, for example by the late Professor J. O. Westwood, against the interpretation 
afforded by the theory of Natural Selection. It is a real difficulty to the theories of External and Internal Causes ; for, as regards the first, we should expect the closely related species of a genus to react similarly to the local conditions, rather than that certain of them should react quite differently from the others but quite similarly to the species of distantly related Sub-Families; and, as regards the second, we should expect such species to reach nearly the same evolutionary stage together, rather than that some should reach one stage and others another entirely different one, but the same as that reached by certain species of remote affinity. With Natural Selection for our explanation such differences are at once intelligible. The variation which formed the foundation for selection to build upon may well have been present in certain species of a genus but not in others; or slight differences in life-history or the methods of adaptation, or the attacks of enemies, may have rendered Mimicry advantageous for this species but not for that.

When we pass from Mimicry among butterflies to Mimicry between butterflies and moths, the difficulties encountered by all theories except Natural Selection become greater because of the wider structural difference between model and mimic. To take an example, certain species of day-flying Chalcosid moths of Borneo mimic Danaine butterflies while others mimic Pierinae: another mimics an Agaristid moth. ${ }^{1}$ Why should part of the Heteroceran group be acted on by external conditions so as to cause a superficial resemblance to Danainae, the others so as to cause a resemblance to Pierinae? Why out of the same closely related set of species should some reach the evolutional stage of Danainae, the others of Pierinae? Why should the models happen to differ from butterflies in general in their slow flight and conspicuous appearance, in the similarity of the patterns on the under side of the wings to those on the upper side, in the fact that they are distasteful to the generality of insect-eating

${ }^{1}$ See the beautiful plate (xxi) illustrating these resemblances in R. Shelford's paper in Proc. Zool. Soc. Lond., 1902 : also pp. 256, 257 , and 259,260 of the text. 
animals? Why should the mimics happen to belong to a day-flying group, although moths are as a rule nocturnal? All these questions receive an obvious answer when the theory of Natural Selection is adopted as the explanation of Mimicry: they cannot be answered by any other existing theory. Under any other theory the facts are gratuitous, devoid of meaning.

When the model belongs to one insect Order and the mimic to another, difficulties of interpretation, except on the theory of Natural Selection, become even greater. Why should the models in the vast majority of cases happen to belong to the Hymenoptera and to possess stings or other special modes of defence? Why under the totally different conditions of Borneo and South Africa should a local Xylocopid bee be mimicked by a local Asilid fly (Hyperechia) ? 1 Many moths come to resemble transparent-winged Hymenoptera by losing, probably during their first flight, scales which were present on their wings when they emerged from the pupa. Is any one bold enough to maintain that a resemblance thus caused is due to External or Internal Causes or to Sexual Selection?

The assumption that local influences act uniformly on different species is by no means justified except in the case of species with similar habits and life-histories : Mr. Guy A. K. Marshall has sent me a wonderful group of reddish brown or ochreous insects with the posterior part of the visible dorsal surface black. It contains many species of the Lycid models, and also Coleoptera belonging to the Telephoridae, Melyridae, Phytophaga, Cantharidae, and Longicorns, several species of aculeate Hymenoptera, a few Hemipterous insects, two species of moths and one of Diptera. ${ }^{2}$ We have here all kinds of habits and all kinds of life-histories, larvae living in the open, larvae burrowing in plant-stems, carnivorous larvae, leaf-eating larvae, larvae with special food stored in cells. It is

1 R. Shelford in Proc. Zool. Soc. Lond., 1902, pp. 261, 262 ; plate xxii, figs. 1, 2. G. A. K. Marshall in Trans. Ent. Soc. Lond., 1902, pp. 533, 534 ; plate xxii, figs. $19,20$.

${ }^{2}$ G. A. K. Marshall in Trans. Ent. Soc. Lond., 1902, pp. 515-18; plate $\mathrm{xviii}$. 
simply childish to appeal vaguely to the direct action of like forces as the explanation of the remarkable resem. blance which runs through the group. The environing forces are not like but extremely unlike, because of the very diverse conditions under which various members of the group live and grow.

All the butterfly Sub-Families which furnish the chief models for Mimicry are remarkable for the uniformity of colour and pattern throughout groups of species in each of the countries they inhabit. These Sub-Families are the Danainae, found all over the tropics, and the allied Ithomiinae (Neotropinae) of tropical America, the Acraeinae, almost confined to Africa and tropical America, and the allied Heliconinae, practically restricted to the latter. A very strong family likeness runs through long series of species, as any one may see by a glance at the successive drawers of a collection of African Acracinae or Oriental Euploeini and comparing them with an equal number of species in any Sub-Family which does not provide numerous models for Mimicry. Compare, for instance, our European Vanessidae with sets of local species belonging to any of the four above-named Sub-Families. The species of Vanessa do indeed possess homologous markings, ${ }^{1}$ and many of the gaps between them can be filled up, but we have to hunt the world in order to do it, and even then we only obtain a partial continuity between extreme differences, whereas in the specially protected SubFamilies there is not only continuity but uniformity in large groups of species. $\mathrm{Mr}$. A. G. Mayer ${ }^{2}$ has found that among 450 species of Neotropical Ithomiinae and Heliconinae there are only fifteen shades of colour, whereas among 200 species of Neotropical Papilioninae there are thirty-six shades. And this is not by any means due to the scarcity of variation in the former, for individual differences in each locality, and geographical differences, as we pass from one district to another, are very prevalent. Combined with the uniformity within these Sub-Families is a marked tendency to resemble other protected Sub-

1 See F. A. Dixey in Trans. Ent. Soc. Lond., 18yo. p. 89.

2 Bull. Mus. Comp. Zool. at Harvard Coll., Feb. 1897 , p. 167. 
Families inhabiting the same region, a tendency which is so pronounced in the case of the Ithomiinae and Heliconinae that they were long regarded as a single group, although the structural differences between them, as larva, pupa, and imago, are strongly marked and indicate that the first Sub-Family belongs to one side of the great Nymphalid family and the second to the opposite side. This remarkable uniformity in the species of certain butterfly Sub-Families was first explained by Professor Meldola $^{1}$ on the lines suggested by Dr. Fritz Müller ${ }^{2}$ in 1879 , viz. as an adaptation in order to reduce the amount of life sacrificed during the period when young and inexperienced insect-eating animals are learning to distinguish between palatable and unpalatable (and perhaps unwholesome) food. If two species living intermingled and equally numerous are superficially exactly alike, and both nauseous, each will lose only half the number of individuals which would have been required in order to educate their enemies if they had been dissimilar. The sacrifice of life is also reduced by the strong general resemblance running through the species of each specially protected Sub-Family in one country. Such resemblance is by no means confined to the Rhopalocera (butterflies) or the Lepidoptera. It is found abundantly in all specially defended insect Orders, principally the Hymenoptera. If we look at the Australian Aculeata we notice a large group of species in which the orange ground colour is deeper and browner than in banded Aculeata generally, while the black zones are broader and fewer, being in fact usually reduced to two, one crossing the thorax, another the abdomen. This very characteristic appearance is to be found in Abispa, Eumenes, Alastor, Odynerus, Bembex and probably many other genera : it also occurs in mimetic Diptera (Asilidae), and Longicorn Coleoptera. Here is a broad fact which receives an intelligible explanation by Natural Selection, but by no other theory which has been suggested. We can well understand, on the theory of Natural Selection, why the members of specially defended

1 Ann. Mag. Nat. Hist., Dec. 1882, p. 417.

2 Kosmos, May 1879, p. 100; also Kosmos, v, I881. 
groups should be far more alike than those of others, why they should resemble members of other such groups in the same region, why they should have conspicuous patterns and contrasted colours which in Lepidoptera tend to be the same upon the under as on the upper side of the wings, why their flight should be slow and flaunting, why they should be remarkably tenacious of life. Here are a number of important characters associated together, and true of all such groups wherever they may occur in any part of the world. One theory alone explains all the numerous observations which are here condensed into a brief statement. It is by no means an assumption to maintain that the groups in question are specially defended. This is admitted to be the case with the Hymenoptera, and there is now a very large mass of experimental evidence in the Lepidoptera. ${ }^{1}$

Another admitted fact of wide application is the tendency of Mimetic Resemblance to appear in the female rather than the male. Thus mimetic female butterflies of many species are associated with non-mimetic males, while the converse relationship is almost unknown. Such nonmimetic males maintain the ancestral appearance which has been lost in the mimetic females. It is interesting to observe, however, that more or less distinct traces of the original pattern can generally be recovered by the careful study of individual variation in the females. This is a remarkable reversal of the ordinary rule that when male and female differ the latter is the more ancestral. This striking exception is quite unintelligible except under the theory of Natural Selection, which offers the convincing explanation, long ago suggested by Alfred Russel Wallace, that the slower flight of the heavier females and their exposure to attack during oviposition render it especially advantageous for them to resemble conspicuous distasteful species in the same locality. ${ }^{2}$

Another aspect of Mimicry affords, in my opinion,

1 See especially Frank Finn in Journ. Asial. Soc. Bengal, lxiv, pt. ii, 1895 , p. 344 ; lxv, pt. ii, 1896 , p. $4^{2}$; lxvi, pt. ii, 1897, p. $5^{28}$, and p. 613 .

¿ Trans. Linn. Soc. Lond., vol. xxv, 1866, p. 22. 
perhaps the most powerful argument of all in favour of an interpretation based on the theory of Natural Selection. If these resemblances are attained by selection because they are advantageous in the struggle for life, we should expect to find that they are produced in a great variety of ways; for one species would reach the beneficial end by one path pointed out to it by the structure it possessed at the beginning and by the trend of its variation, while another species with a very different initial structure would reach the same end by a widely different path. Thus many Diptera, for example species of Ceria, gain a superficial resemblance to wasps by a narrowing in the anterior abdominal region which suggests the characteristic peduncle of a Hymenopterous insect. On the other hand, Longicorn beetles of the genus Oberea gain the same effect by a patch of white which obliterates the anterior abdominal region with the exception of a small linear remnant representing the peduncle. ${ }^{1}$ In brilliant illumination the white marking is not seen as part of the insect. The resemblance of the Locustid Myrmecophana fallax to an ant is produced in the same manner. ${ }^{2}$ The Homopterous family Membracidae are characterized by an enormous growth of the dorsal region of the pro-thorax, which spreads backwards and in many species covers the insect like a shield. In the American species which mimic ants, this shield, and not the insect beneath it, becomes ant-like. Some of the larval Membracidae are laterally compressed, becoming in the dorsal region as thin as a leaf, and the body is green like a leaf, while the head and legs are brown. The whole appearance is singularly like that of the tropical American ant Atta (Oecodoma) cephalotes, carrying its leaf vertically in its mandibles, and thrown over its back, so that the brown head, legs, and part of the body are seen beneath the green burden. ${ }^{3}$ It is manifestly absurd to attempt to

'See R. Shelford in Proc. Zool. Soc. Lond., 1902, pp. 238-40, plate xix, figs. $13,14,15$.

${ }^{2}$ See pp. ${ }^{256-7}$ of the present volume, together with Fig. 5, p. 258.

${ }^{3}$ See description and figure of a specimen found by Mr. W. L. Sclater in British Guiana. Poulton, in Proc. Zool. Soc. Lond., 1891, p. 462, pl. $x \times x$ vi. See also pp. ${ }^{258-60}$ of the present volume and Fig. 7, p. 259 . 


\section{MIMICRY OF ANTS AND WASPS 28I}

account for this series of Mimetic Resemblances by an appeal to the operation of External or Internal Causes or of Sexual Selection. There remains Natural Selection, which at once offers a convincing interpretation. Ants and wasps are known to be aggressive dominant insects avoided by the majority of insect-eating animals, although certain species are adapted to feed almost exclusively upon them. It is in every way probable that a superficial resemblance to ants and wasps would be beneficial in the struggle for existence. There is, indeed, some experimental evidence to prove that real advantage is conferred. ${ }^{1}$ We find that species of many groups mimic ants and wasps in a variety of entirely different ways. The results are exactly what might have been predicted to occur if Natural Selection be the efficient cause of Mimetic Resemblance.

The attempt has been made, in recent years, to cut away the foundation of an interpretation based on the theory of Natural Selection, by calling in question the conclusion that butterflies are, as a matter of fact, attacked by insect-eating animals such as birds. I have recently collected together a great mass of evidence bearing on this point, most of it obtained in Mashonaland, South Africa, by the admirable naturalist, Mr. Guy A. K. Marshall. This material conclusively proves that the wings of fresh unworn specimens of butterflies are constantly notched, as if by the attacks of birds and lizards, and that in a considerable proportion of the examples the notches on opposite sides fit together, proving that the insect was seized when its wings were in contact. The attacks are most frequently directed to the posterior angle of the hind-wing, less frequently to the tip of the fore-wing, still less frequently to the intermediate borders and angles. The points of attack are those where special marks and structures, probably having a directive function, are commonly developed. Thus the tip of the fore-wing is often rendered specially conspicuous and the posterior angle of the hind-wing is continually produced into so-called 'tails'

1 Poulton, Colours of Animals, London, 1890, p. 247 : Lloyd Morgan, Animal Behaviour, London, 1900, pp. 164-5. 
(Papilio, Charaxes, \&c.), which in many Lycaenidae are antenna-like and associated with eye-spots, suggesting the appearance of a head. The resemblance is further intensified in the resting position by movements of the hindwings, which cause the apparent antennae to pass and repass each other. Such structures and marks are constantly injured or entirely bitten away in fresh specimens. Direct observation of actual attack by birds and lizards has also been made by Mr. Marshall and others, ${ }^{1}$ so that it may be safely assumed that the doubts thrown upon the reality of the struggle for life in butterflies have their origin in the want of observation specially directed to this end. The majority of naturalist-travellers are chiefly concerned with collecting, and it is not surprising that many of them have not seen what they never looked for.

If time had permitted, many other aspects of Mimetic Resemblance night have been dwelt upon, and it would have been found, as it has been found with those which I have had the honour to bring to your notice, that all are readily explicable by the theory of Natural Selection, but remain mere coincidences under any other alternative theory as yet suggested. ${ }^{2}$

\section{APPENDIX}

The evidence collected by Mr. Guy A. K. Marshall, alluded to on pp. $28 \mathrm{I}-2$, is now published in his great memoir on The Bionomics of South African Insects. ${ }^{3}$ The

1 Two members of the Fifth International Congress who were present at my lecture informed me afterwards that they had witnessed such attacks. Professor E. Pénard of Geneva saw a bird, probably a sparrow, persistently pursue and at the third attempt capture a white butterfly (probably a species of Pieris). The incident happened in the early summer of 1900 , in a park near Geneva. Mr. F. Muir, of Ipswich, England, expressed surprise that any doubts should have been raised. $\mathrm{He}$ had frequently observed such attacks at Delagoa Bay and other places on the East coast of Africa, and had seen birds waiting in trees or bushes and darting out at butterflies as they approached.

2 Further evidence is discussed in the writer's paper in the Journ. Linn. Soc. Zool., vol. xxvi, p. 558, reprinted as Essay viii in the present volume (p. 220$)$.

${ }_{3}$ Trans. Ent. Soc. Lond., 1902, pp. 287-584. 
indirect evidence supplied by injured specimens of freshly emerged butterflies is illustrated in Plates ix, x, and xi, and described on pages $366-75$ of the paper. The direct evidence (pp. 357-66) is so important that, with the kind consent of Mr. Marshall, Colonel Yerbury, Colonel Bingham, and the Council of the Entomological Society of London, it is reprinted below :-

12. Records of Attacks on Lepidoptera, especially Butterflies, by wild Soutil African Birds, by G. A. K. Marshall.

1897. March 28. While out collecting at Malvern, Durban, Natal, I saw a Paradise flycatcher (Terpsiphone perspicillata) catch a specimen of Eronia cleodora. The butterfly was hovering over a flower when the bird swooped down, seized it with its feet, and carried it off.

1898. Salisbury, February 27. Saw a Marico woodshrike (Bradyornis mariquensis) dart down from a tree and catch a Sarangesa eliminata (Holl.), which was sitting with outspread wings on a small plant.

March 6. Saw a flycatcher (Pachyprora molitor) make several futile attempts to catch a Tarucus plinius which was circling round the bush on which it sat.

November 23. Saw a bush kingfisher (Halcyon chelicutensis) catch and eat two butterflies, viz. Funonia cebrene and Catopsilia florella, both of which were captured when feeding.

December I. C. F. M. Swynnerton saw a drongo (Buchanga assimilis) fly past him with a white butterfly in its beak, probably $C$. florella.

December 15. Remains of Papilio dcmodocus found in the stomach of a cuckoo (Coccystes caffer).

1899. Salisbury, Fanuary I. - While watching an Atella phalantha hovering over a bush of its food-plant, a Paradise flycatcher (Terpsiphone perspicillata) darted past, and with a loud snap of its beak tried to catch the butterfly in its swoop. The latter escaped, however, and on following it up I found that the tip of one hind-wing had been cut 
clean off; unfortunately I had no net and failed to capture the insect.

Swynnerton shot a hobby (Falco subbuteo), which had in its stomach an almost complete Terias. The thorax and abdomen were quite uninjured, but the tips of the fore-wings were gone.

April 26. I was watching a drongo hawking insects from the top of a dead tree; there were many Pierinae about, chiefly Teracolus and Belenois, but the bird paid not the least attention to them. At last a Belenois came by which had its wings very much shattered, so that its flight was weak and erratic; the drongo observed it at once, and swooped down on it, but I saw the butterfly drop into the long grass. Whether it was injured by the bird I could not say, as I was unable to find it, and I did not see it rise again. This episode would point to the conclusion that the fact that birds refrain from pursuing butterflies may be due rather to the difficulty in catching them, than to any widespread distastefulness on the part of these insects.

1900. C. F. M. Swynnerton wrote from Gazaland: 'In March [1900] I saw a Pratincola torquata [South African stonechat] in chase of Tarucus plinius. Had it not been frightened off by coming face to face with me, it would undoubtedly have caught it. I think I told you long ago of having found the wings of a lot of butterflies, chiefly $P$. corinneus, below the branch of a tree on which some swallows were constantly settling.'

May' I 3. Salisbury. Saw a drongo (Buchanga assimilis) swoop from a tree and catch what I took to be an injured Belenois, which it dropped almost at once. I marked the insect down, and found it to be a common white moth of the distasteful genus Diacrisia (D. maculosa).

1901. December 17. Melsetter, 5,500 feet, Gazaland. A specimen of the large, conspicuous Hypsid moth Callioratis bellatrix was seized and rejected by a drongo, undoubtedly a young bird, judging by its plumage. [The moth, which is now in the Hope Department, has lost most of the head, but is otherwise uninjured.-E. B. P.] 
13. Records of Attacks on Butterflies by wild Birds in India and Ceylon, by Colonel J.W. Yerbury, R.A.

[Colonel Yerbury has kindly extracted from his notes all the observations he has made bearing on this interesting question.-E. B. P.]

About the year 1884 a discussion arose in the Bombay papers as to whether birds preyed on butterflies, and the general opinion expressed was that it was comparatively rare for them to do so. In common with some other members of the Bombay Natural History Society, I determined to watch and note the results. My records taken from old diaries are as follows :-

1884. Neighbourhood of Poona and Aden. None.

1885. September 23. Aden, Campbellpore, and Murree Hills. Road up Thundiani, near the Kala Pani Bungalow. Saw a young king-crow, Dicrurus ater, stoop at a big blue Papilio, either $P$. polyctor or $P$. arcturus, and miss it. The bird did not repeat the attempt.

1886. September 2. Campbellpore, Thundiani, \&c. Road up Thundiani, near top of the hill. Saw a young king-crow stoop at a specimen of Vanessa kaschmirensis, and after missing it once take it at the second attempt. Did not notice whether the insect was eaten.

1887. Rawul Pindi and home, via Japan and America. None.

1888-9. At home.

1890. Fune. Ceylon, Trinkomali. No record.

1891. November 14. On the Kandy Road between Trinkomali and Kanthalai; butterflies in great numbers sitting on the wet mud by the roadside; chiefly Pierinae (Catophaga), but a few $P$. nomius with them. These butterflies rose in clouds as one drove past. A bee-eater, Merops philippinus, kept flying in front of my carriage and taking specimens of these butterflies as they rose. The bird seemed to select the yellow females, which are rare, the white females being to them probably in the proportion of IOO to I. These flocks of butterflies often unite and form what are known as snowstorms in Ceylon; they then migrate right across the island. 
These bee-eaters were often seen catching Pievinae; in fact, it seems to have occurred so often that I ceased to record the fact, for I can only find this one reference. Probably the attacks were always witnessed at the beginning of the N.E. monsoons during the time of the heavy rains, i.e. September to December.

I am not certain as to the date on which I saw the Ashy swallow-shrike (Artamus fuscus) catching specimens of the Euploea, Crastia core. The fact is associated in my mind with a particular place, and with the capture of Charaxes psaphon $q$ there. This is recorded for April I 2, I89I, so this may be the correct date on which I watched the bird. At least six specimens of the Crastia were captured by the shrike, all of which it carried away to a branch high up in a big tree, but I could not see whether they were eaten.

As regards my experience of birds catching butterflies, it appears to have occurred more frequently in damp than in dry districts; e.g. it was frequent in Ceylon, rare in places with moderate or small rainfall, such as Campbellpore, Poona, and Aden.

In my opinion an all-sufficient reason for the rarity of the occurrence exists in the fact that in butterflies the edible matter is a minimum, while the inedible wings, \&c., are a maximum.

[See Proc. Zool. Soc. I 887 , p. 2 10, where Lepidoptera and especially butterflies are spoken of in almost exactly these terms, as a suggested explanation of the fact that lizards, although they eat them, greatly prefer flies or cryptic larvae.-E. B. P.]

\section{Records of Attacks on Butterflies, \&C., by wild Burmese Birds, by Colonel C. T. Bingham.}

[Colonel Bingham has kindly sent me the following extracts from his 1878 diaries, for incorporation in the present memoir.-E. B. P.]

- April 23. Marched from Kawkaraik to Thinganyinaung, fourteen miles. Started about 7.45 , rather late as there was some difficulty in collecting the elephants this morning. . . The road, a mere jungle path, followed 
the course of the Akya Chaung, a feeder of the Haundraw River, and crossed the little stream some twenty or more times in the first six or seven miles before turning up the hill to the Taungyah Pass in the Dawnat Range. From the outskirts of Kawkaraik right up to Thinganyinaung on the other side of the Pass, the road goes through dense evergreen forest, and consequently the collecting is very good on this road, both for insects and birds. To-day, the day being hot, butterflies, bees, and dragon-flies swarmed, and at every opening of the Chaung I found crowds seated on the damp sand apparently sucking up the moisture. Collecting as I went, it was past eleven o'clock before I got to the foot of the Pass. I was hot and a bit tired, so I sat down on a fallen tree to rest, just before crossing the Akya Chaung for the last time. I had not been seated many minutes, looking at the swarms of butterflies, bees, and dragon-flies, which were flitting about or sitting on the sands, when my attention was attracted by a bird, a bee-eater (Merops swinhoei), which, swooping down from a tree overhead, caught a butterfly, a Cyrestis, within a few paces of me. The bee-eater seemed to catch the butterfly with ease, and I distinctly heard the snap of its bill. Then, holding the butterfly crossways, the bird flew back to the tree, and sat still for a minute or so, then came a little jerk of the head, and the wings of the butterfly came fluttering to the ground, while the body was gulped. On the same branch some four or five more bee-eaters of the same species were seated, and as I sat very still, one after another these birds swooped close to me, sometimes after a butterfly, sometimes at a bee or a dragon-fly. More than once I saw a bird miss a butterfly, when the latter would dodge and try to get away among the bushes of the dense undergrowth around, but only very seldom was this successful, for the bird would hover and twist and turn in hot pursuit, and generally managed to catch the insect. I was greatly interested, for though I had seen both bee-eaters and king-crows (Dicrurus) go for butterflies and moths, this was the first time I had witnessed a continuous hawking of butterflies on the part of birds. I sat for nearly half-an-hour 
watching. The birds seemed to swoop only for the insects flying about, never at those on the ground. A drove of pack bullocks, with their shouting Shan drivers, coming down the road frightened the bee-eaters, and they flew off. I got up and prepared to start uphill, when it struck me that it would be interesting to see what species of butterfly had been taken by the bee-eaters, so I set to work and collected all the loose wings I could find. I did not get many, for the undergrowth was very dense, and the wings dropped in it were difficult to find. Also the place swarmed with ants; I could see them on all sides carrying off whole wings, or portions bitten out of them. Again, I was pressed for time, so that I managed to get together only nineteen wings, most of them odd ones, luckily. . . I have just sorted out and put away my collections of the day. The butterflies hawked and eaten by the bee-eaters belong to the following species-Papilio erithonius, $P$. sarpedon, Charaxes athamas, Cyrestis thyodamis, and Terias hecabe. A meagre list, for I am certain I saw the bee-eaters swoop for and catch Prioneris, Hebomoia, Funonia, and Precis. I also particularly noticed that the birds never went for a Danais or Euploea, or for Papilio macareus, and $P$.xenocles, which are mimics of Danais, though two or three species of Danais, four or five of Euploea, and the two above-mentioned mimicking Papilios simply swarmed along the whole road.' 1

Looking through my diaries I find more scattered notes of my having witnessed birds swoop for and catch butterflies and moths, but these were solitary incidents, and only slight mention is made of them in the diaries, with one exception, which is given below :-

'Camp Wabosakhan, December 3, r891. . . . Going through some fairly open jungle close to the main road I put up a Melanitis zitenius, which fluttered across the road and was swooped at by a king-crow (Dicrurus), but missed; the butterfly dodged, got to the other side of the road

${ }^{1}$ I did not then realize the importance of my find, or I should have spared more time for the collection of the fallen wings of the butterflies, and taken more care of them.-C. T. B. 
and dropped to the ground among the herbage and fallen leaves, as is the habit of Melanitis. The king-crow hovered for a minute not three feet from the ground over the exact spot where I had noticed the butterfly drop, failed to see it, flew off, but returned and again hovered over the spot, but was again unsuccessful, and flew up to a tree. I went forward very cautiously, and having carefully noted the spot where the butterfly had dropped, was enabled to make it out, but not till after fully ten minutes of patient and very cautious looking. The Melanitis was there among dead leaves, its wings folded, and looking for all the world a dead dry leaf itself. With regard to Melanitis, I have not seen it recorded anywhere that the species of this genus when disturbed fly a little way, drop suddenly into the undergrowth with closed wings, and invariably lie a little askew and slanting, which still more increases their likeness to a dead leaf casually fallen to the ground.

' Only once again did I see the systematic hawking of butterflies by birds. The second occurrence was also by bee-eaters; this time it was the large Merops philippinus. I had been up in the Salween forests beyond the great rapids, and had managed to get a bad bout of fever, which necessitated my returning to Moulmein, my headquarters. It was a hot steamy day in October, and I was lying with the hot fever fit on me in the boat on the Salween below Shwègon, when I noticed clouds of butterflies, chiefly Catopsilia, migrating, crossing the Salween from east to west in a continuous stream. These were being persistently hawked by the Merops, mixed with which were some king-crows.'

With regard to Microhierax coevulescens catching butterflies, I find the following note:-

'March 20, 1881. . . Passing through a taungyah on my way back to camp, I noticed a number of butterflies, some seated, some hovering round a spot where some Karens had been eating their food, and had left some rice and gnapi scattered on the ground. I was approaching. the butterflies cautiously to see what species were there, when a small black-and-white bird came down from a tree 
close by and perched on the ground close to one little mob of butterflies busy feeding away on the gnapi. I recognized the bird at once as the pigmy hawk (Microhierax coerulescens). His coming flop down close to the butterflies disturbed some, but not all. A few were too intent on their meal. The hawk sat for fully two minutes looking at the butterflies, then he crouched as birds do when they are about to rise, and next moment, with a quick snatch, he had taken a butterfly in his claws, and was flying to the nearest tree. Though I was watching intently I am quite unable to say whether he took one of the sitting butterflies or one that was flying about. I watched him eat the insect, which he held with his claw against the branch on which he was seated, and he tore at it just as the larger hawks do with their prey. I wanted a specimen of the bird, so shot it, and afterwards picked up the wings of the butterfly he had eaten ; it was a Papilio sarpedon.'

N.B.-That same specimen of Microhierax is now, I believe, in a small case by itself in the bird gallery of the British Museum.

[Colonel C. T. Bingham has also made some interesting observations on the use of insects' wings as a pad at the bottom of a hole in a tree, forming the nest of this same species of bird, the falconet Microhierax coerulescens, Linn. (M. eutolmus, Hodgs.). The following account is quoted from Stray Feathers (vol. v, no. 2, June, 1877, pp. 7981 ). The observations were made in the 'Government Teak Reserve on the Sinzaway Chaung, a feeder of the Yoonzaleen River, which it enters about two days' march below our frontier station of Pahpoon in 'Tenasserim.' The nest was found on April 14, 'in a hole on the under side of a decayed bough of a mighty Pymma tree (Lagersiroemia Flos Reginae).' - The four eggs were found to be 'stained by resting on the broken leaves, wings of dragonflies, and bits of wood which composed the nest'. The editor appends to this account a note of Davidson's which had been in his possession for years. On March 25 the nest of Microhierax fringillarius, Drap., was examined. It had been made in a hole in a dry tree in an old taungyah (clearing) 'near Bankasoon at the extreme south of Tenas- 
serim'. 'At the bottom of the hole, which was about eighteen inches deep, was a soft pad composed of flies and butterflies' wings, mixed with small pieces of rotten wood.'

In March, I 878, Colonel Bingham found a second nest of the same species $(M$. coerulescens) which he sent to the late Mr. de Nicéville in order to ascertain the species of insects which had been made use of. Mr. de Nicéville wrote as follows:-

'The fragments of butterfly wings you send are as follows :-

No. I. Portion of fore-wing of Papilio caunus.

"2. Fore- and hind-wing of Mycalesis perseus.

" 3. Hind-wing of Papilio erithonius.

" 5. Portion of fore-wing of Funonia orithyia.

, $4,6,7,8,9$, too fragmentary to make out, but seem to belong to some species of the Lycaenidae.

" IO. Half of fore-wing of Charaxes sp. (?)

"I I. Portion of hind-wing of Symphaedra dirtea 9 .

" 12 to I 7 are the wings of dragon-flies.' 1

A" passage from another letter of Mr. de Nicéville to Colonel Bingham indicates in a different manner the severity of the nearly unseen struggle for existence which butterflies of certain genera pass through. The wings

${ }^{1}$ In the Zoologist (4th Series, vol. v, 1901, pp. 224, 225) Colonel Bingham states that he found, on April 23, 1899, a nest of the same species of pigmy falcon in a hole on the under side of a branch of a dead tree 'in a deserted taungya alongside the high road leading from Thabeitkyin, on the banks of the Irrawaddy above Mandalay, to Mogok, the site of the famous ruby mines of Upper Burma'. The hole had evidently been made by a Barbet. It was $\mathrm{I} 5$ inches long, and at the end was slightly enlarged into an oval chamber containing 'a fairly firm pad of chips of wood, a few leaves, with an upper stratum quite two inches thick composed almost entirely of the wings of Cicadas, with a few butterfly and moth wings interspersed therein.' There were no eggs or nestlings. ' Further south, in Tenasserim,' Colonel Bingham continues (1. c. p. 225), 'I found the eggs of this Falcon in a precisely similar situation early in April, as well as I can remember. That nest was composed almost entirely of butterfly wings.' Colonel Bingham informs me that the last-named nest was the one, described above in the text, which was found in March 1878, and furnished the wings named by de Nicéville.' 


\section{MIMICRY AND NATURAL SELECTION}

sent by Colonel Bingham were found by him in 1888 . Mr. de Nicéville wrote concerning them :-

'See p. 275 of vol. ii. of my Butterfies. Ferguson found a single wing of Charaxes schreiber $i$ in Travancore on the ground. It is curious that the only record so far of the same species from Burma should be the three wings you send me, which you say you found on the ground.' E. B. P.] 


\section{$\mathrm{X}$}

\section{THE PLACE OF MIMICRY IN A SCHEME OF DEFENSIVE COLORATION}

THE title of this essay formed the subject of a lecture on Mimicry, delivered September 5, 1890, before the British Association at Leeds, and published in abstract in Nature, October 2, 1890, p. 557. The attempt has now been made to bring this lecture up to date by including a brief account of the most important results which have been published since its delivery, such as those contained in the writer's article on Colours of Animals I, Bionomics in the Encyclopaedia Brilannica, vol. xxvii, 1902 , pp. 1 46-50, and in numerous memoirs and short communications by Dr. F. A. Dixey, Mr. G. A. K. Marshall, Mr. R. Shelford, Mr. F. Merrifield, Mr. A. H. Thayer, Mr. W. J. Kaye, Mr. S. A. Neave, Mr. F. Finn, Dr. G. B. Longstaff, Mr. W. Holland, Mr. A. H. Hamm, the author, and others. The examples brought forward as illustrations at Leeds are, except when otherwise indicated, marked by asterisks.

In this essay the word 'group' is employed to express an arrangement based on affinity, the word 'combination' or 'association' to express an arrangement founded on bionomic relationship. Thus a genus or family is spoken of as a group, a set of Müllerian models and mimics as an association or combination.

\section{CONTENTS}

I. CRYPTIC COLOURING OR PROTECTIVE AND AGGRESSIVE RESEMBLANCES ; - PROCRYPTIC AND ANTICRYPTIC COLOURS . . • $\quad 297$

A. Procryptic, or Protective Resemblance . . 297

a. General Protective Resemblance . . . . 297

b. Special Protective Resemblance . . . . 298 I. The Neutralization of Shadow . . . . . 299

2. Adjustable Neutralization of Shadorv . . . . 300

3. The Reduction of Shadow by Attitude. . . . 300

4. The Choice of Appropriate Surfaces upon which to Rest $30 \mathrm{I}$ 
5. The All-Importance of Instinct in bringing about Protec- PAGE tive Resemblance. . . . . . . 301

6. The Hypertely of Brunner von Wattenwyl . . . 302

7. Hours during which the Struggle for Life is most Severe 303

8. The Value of Brightly-coloured Surfaces Concealed during Rest . . . . . . . . 303

c. The Gregarious Habit may assist Concealment . $\quad 304$

г. Adjustable Protective Resemblance. . . 304

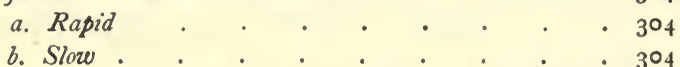

11. Coincidence between the Colours of Organisms and those

of their Peculiar Environments may be probably

Caused by the Local Operation of Natural Selection .

12. The Recent Progressive Darkening of many Species of

Moths in the Lancashire and Yorkshire District 308

13. Dimorphism and Polymorphism in Procryptic Defence . 310

14. Seasonal Changes in the Individual . . . . 3ro

15. Seasonal Dimorphism in Procryplic Defence. . . 310

16. Syncryptic or Common Protective Resemblance . . 312

B. Anticryptic or Aggressive Resemblance. • . . 312

C. Allocryptic or Adventitious Protective (And AggresSive) Resemblance • . • . . . . . 3 I 3

II SEMATIC COLOURS, OR WARNING AND SIGNALLING (RECOGNITION) COLOURS;-APOSEMATIC AND FPISEMATIC CHARACTERS

A. Aposematic or Warning Characters . . . . $3^{\mathbf{I}} 5$

I. Experimental Evidence of Special Protection in Forms with Warning Colours . . . . . . 316

2. Species with Warning Colours depend for their Existence upon the Co-Existence of Palatable Species . .

3. Erroneous Assumption that Warning Colours imply Complete Immunity from Attack . . . . . 317

4. Transition from Cryptic to Aposematic Defence . - $3^{18}$

5. Seasonal Transition from Cryptic to Aposematic Defence. $3^{20}$

6. Geographical Transition from Aposematic to Cryptic Defence . . . . . . . . 
7. A. H. Thayer's Criticism of the Statement that Animals are Conspicuous

8. The All-Importance of Instinctive Attitudes and Movements in the Display of Warning Colours . . 323

9. Warning or Intimidating Sounds. . . . . 324

10. Intimidating Attitudes . . . . . . . . 324

II. Directive Marks and Structures . . . . . 325

12. The Seasonal Development of Directive Marks . . 326

*. Synaposematic or Common Warning Colours (Múllerian MIMICRY)

I. The Mathematical Statement of the Advantage Conferred by Perfected Müllerian Resemblance . . .

2. The Advantage Conferred during the Growth of Miillerian Resemblance. . . . . . . 329

3. Striking Examples of Millerian Resemblance . . $33^{1}$

a. The New World . . . . . . ‘33I

b. The Old World . . . . . . . 333

4. The Limit to Mullerian Unification of Warning Colours in any Country . . . . . . . $33^{6}$

5. Seasonal Transition from Cryptic to Synaposematic Defence

6. Seasonal Transition in degrees of Synaposematic Defence, or from Aposematic to Synaposematic Defence . $\quad 34 \mathrm{I}$

7. The Gradual Predominance of the Millerian Hypothesis. 342

8. Diaposematic Resemblance; Reciprocal Warning Colours. 344

9. Primary and Secondary Milllerian Resemblance; Protoand Deuterosynaposematic Resemblance . . .

10. Further Indirect Evidence Supporting a Millerian or - Synaposematic Interpretation . . . . 346

I1. Mullerian Resemblance Associated with Warning Colours; Batesian Mimicry Associated with Cryptic Colours .

12. Mimetic Patterns in Stations or Localities different from those of the Model. . . . . . .

13. Classes of Facts which have Recently been Urged in Support of the Batesian Hypothesis . . . $35^{\circ}$

a. Butterfies Exhibiting Mimetic Resemblance on the Upper Surface of the Wings and Procryptic Defence on the Under Surface . . . . . . $35^{\circ}$

b. Dimorphic or Polymorphic Mimetic Butterflies with Forms Resembling Different Models . . 
14. A Possible Instance of Observable Change in a Member of a Millerian Group since 1825 • • 356

B. Allaposematic Colours, or Adventitious Warning Colours . • • • • • • • . 356

C. Episematic or Recognition Characters . . • $\quad 357$

III. PSEUDOSEMATIC RESEMBLANCE, OR PROTECTIVE (BATESIAN) AND AGGRESSIVE MIMICRY; -PSEUDAPOSEMATIC AND PSEUDEPISEMATIC RESEMBLANCES * . . . . . .

I. Various Uses of the Term Mimicry: The Essential Element in Mimicry . . . . .

A. Pseudaposematic Resemblance, or Protective (Batesian) Mimicry . . . . . . . . . $36 \mathrm{I}$

I. Wallace's Statement of the Conditions under which Protective Mimicry Occurs. . . . . . 36r

2. The Chief Characteristics of Mimetic Resemblance and the Attempt to Explain their Evolution . . . $3^{62}$

3. The All-Importance of Instinctive Attitudes and Movements in the Attainment of Mimetic Resemblance . . $3^{63}$

4. History and Migration may be inferred from Mimicry $\cdot 3^{6} 3$

5. A History Inferred from Mimicry may be Confirmed by other Evidence . . . . . . . 365

6. Mimetic Resemblance between Species of very Different Size . . . . . . . . . 366 7. Remarkable Examples of Mimicry . . . . $3^{67}$

8. Mimetic Resemblance to Cryptic Models . . . . 369

9. Butterfies and Moths, chiefly Oriental, selected in 1890 , to Illustrate Various Aspects of Mimicry - . 370

a. Both Sexes Mimetic: Both Sexes of Model and Mimic Superficially Alike . . . . .

b. Sexes readily Distinguishable: Male mimics Male, Female mimics Female. . . . . . $37 \mathrm{r}$

c. Male and Female mimicking Different Species - 372

d. Female Mimetic: Male Non-Mimetic . . . 372

c. Female Mimicking two or more Different Species: Male perhaps Non-Mimetic, or Mimicking still another Species . . . . . . . 373 
f. Non-Mimetic Ancestor preserved on Islands, \&c.; on Adjacent Continent Mimicry developed in one or both Sexes: Remarkable case of Papilio dardanus (merope)

g. Imperfect Resemblance, not to any Particular Species, but to the General Appearance of an Unpalatable Group

B. Pseudallaposematic Resemblance: Mimetic Representation of some Adventitious Object Associated with THE Model

C. Pseldepisematic Resemblance or Aggressive Mimicry, including Alluring Colours

IV. EPIGAMIC COLOURS . NOTE

I. CRYPTIC COLOURING, OR PROTECTIVE AND AGGRESSIVE RESEMBLANCES; -PROCRYPTIC AND ANTICRYPTIC COLOURS.

The commonest use of colour is for concealment (Cryptic), enabling an animal to escape its enemies, or to approach its prey. In these Protective (Procryptic) or Aggressive (Anticryptic) resemblances, animals are concealed by a likeness to some object which is of no interest to enemies or prey respectively. Similar effects may be produced by the use of foreign objects with which the animal covers itself to a greater or lesser extent (Allocryptic).

A. Procryptic, or Protective Resemblance.

a. General Protective Resemblance.-In this form of concealment the animal, in consequence of its colouring, produces the same effect as its environment, but the conditions do not require any great or special modification of shape and outline. This method of concealment is chiefly found among the animals inhabiting some uniformly coloured expanse of the terrestrial surface, such as an ocean or a desert. 
On the surface of the ocean it is common for animals of all shapes to be protected by their transparency and often by a blue colour: on the desert equally diverse forms are defended by their likeness to the sand. Modification of shape in the direction of flattening occurs in some species. The elimination of shadow, to be described below, is of the utmost importance on such a strongly lighted surface as the desert.

The effect of a uniform appearance may be produced by. a combination of tints in startling contrast. Thus the dark and light stripes of the zebra blend together at a little distance, and 'their proportion is such as exactly to match the pale tint which arid ground possesses when seen by moonlight '.

b. Special Protective Resemblance is far commoner than general, and is the form usually met with on the diversified surface of the earth, on the shores, and in shallow water, as well as in the masses of Algae floating on the ocean, such as those of the Sargasso Sea.

In these environments the Cryptic Colouring of animals is usually aided by special modifications of shape, and by the instinct which leads them to assume particular attitudes. Complete stillness, and the assumption of a certain attitude also play an essential part in General Resemblance on land; but in Special Resemblance the attitude is often highly elaborated, and perhaps more important than any other element in the complex method by which concealment is effected. In Special Resemblance the combination of colouring, shape, and attitude is such as to produce a more or less exact resemblance to some of the objects in the environment, such as a lump of earth, a stone, a leaf or twig, a patch of lichen, or flake of bark. The animal is not merely hidden from view by becoming indistinguishable from its background, as in the case of General Resemblance, but it is mistaken for some wellknown object of no interest to its enemy.

A good example in the shallow seas round our coasts

${ }^{1}$ F. Galton, South Africa, London, 1889, p. 187. 
is seen in the green pipe-fish (Siphonostoma typhle $\left.{ }^{*}\right)^{1}$ conspicuous in the weedless water, but well concealed among the leaves of Zostera. The brown Lappet moth (Gastropacha quercifolia*) conspicuous on a smooth deal board, but well concealed among dead leaves, serves to show that colour and shape cannot be correctly interpreted except by reference to the natural environment. Many examples of the Protective Resemblance to dead leaves are given on pp. 203-6. Mr. Abbott $\mathrm{H}$. Thayer has pointed out ${ }^{2}$ that many species bear upon the under surface of the wings the representation of shadows as they are cast by such thin objects as dead leaves lying one over the other on the ground.

1. The Nentralization of Shadow.-The colours of large numbers of animals are darkest on the back, becoming gradually lighter on the sides, and passing into white on the belly. Abbott $\mathrm{H}$. Thayer ${ }^{3}$ has suggested that this gradation obliterates the appearance of solidity, which is due to shadow. A colour-harmony, which is also essential to concealment, is produced because the back is of the same tint as the environment (viz. earth), bathed in the cold blue-white of the sky, while the belly, being cold blue-white bathed in shadow and yellow earth reflections, produces the same effect. Thayer has made and presented models to the Natural History Museums of Oxford, Cambridge, and London, which support his interpretation in a very convincing manner.

Special resemblances to twigs, upright stems, \&c., are, $\mathrm{Mr}$. Thayer considers, represented upon a background in which the shadow is neutralized as described above. Hence the background, viz. the animal's body, disappears, while the markings upon it are alone distinctly seen.

For ages the artist has known how to produce the appearance of solid objects standing out on his canvas, by painting in the likeness of the shadows. It has remained for this great artist-naturalist to realize the

1 The asterisk added to this and the following examples indicates that they were employed as lecture illustrations at Leeds in 1890 .

2 Trans. Ent. Soc., Lond., 1903, p. 557.

3 The $A u k$, vol. xiii, 1896, pp. I 24 and 318. 
logical antithesis, and show how solid objects may be made to fade away and become ghost-like, or even invisible, by painting out the shadows.

Twenty years ago the present writer recognized the importance of the neutralization of shadow by a compensating lightness of tint, for the purpose of concealment. But this was only in particular examples, a certain Geometrid larva, ${ }^{1}$ and a chrysalis ${ }^{2}$ - and the far-reaching significance of the principle was unseen until A. H. Thayer's great discovery in 1896 .

2. Adjustable Neutralization of Shadow.-An adjustable form of Thayer's principle was discovered in the chameleon in 1905, when Dr. G. B. Longstaff, Professor C. V. Boys, and the present writer observed that the illuminated side of the South African Chamaeleo pumilus is darkened, the side in shadow brightened in tint.

These pigmentary changes neutralize the effects of differing illumination on the two sides, and thus remove the appearance of solidity. ${ }^{3}$

3. The Reduction of Shadow by Attitude.-It has been shown, especially by Dr. G. B. Longstaff, ${ }^{4}$ that many butterflies, when they come to rest, turn the axis of the body so that the head is away from the sun. In this position, when the wings are raised, the shadow cast is a mere line and inconspicuous. In other positions the broad wings of a butterfly cast a shadow which, when the axis of the body approaches a right angle to the sun, may be far more conspicuous than the insect itself. Many Satyrine butterflies, when they come to rest, have a pronounced tilt to one side or 'list' ${ }^{.}$. It is probable that this attitude also is valuable in reducing the

1 Trans. Ent. Soc., Lond., 1887, pp. 292-4.

2 Trans. Ent. Soc., Lond., 1888, pp. 595-7.

3 An account of the observations was read before The Linnean Sociely of London, March, 1907. See Zool. Journ. Linn. Soc., vol. xxx, p. 45.

- Trans. Ent. Soc., Lond., 1905, p. 135 ; 1906, p. 97.

- See Dr. Longstaff's papers referred to in the above note: also Colonel Bingham's observations on Melanitis quoted on p. 289 of the present volume. Confirmatory observations on the same genus have been made by Mr. E. E. Green (Spolia Zeylanica, vol. ii, Pt. vi, August 1904, p. 76), and Mr. T. R. Bell (Ent. Mo. Mag., 1906, p. 1 26). 
shadow. Many years ago I observed a Green Hairstreak Butterfly (Thecla rubi), which, when it settled on a leaf, let itself down on one side so completely that it seemed to lie flat on the surface. The obliteration of shadow was very marked, and forced itself upon me at the time as the significance of the attitude. ${ }^{1}$

4. The Choice of Appropriate Surfaces upon which to Rest.-Dr. F. A. Dixey ${ }^{2}$ and Mr. A. H. Hamm ${ }^{3}$ have produced evidence which suggests that the Small Garden White, Pieris rapae, tends to select white surfaces upon which to rest for the night. An observation made by Dr. T. A. Chapman ${ }^{4}$ upon Colias edusa supports this conclusion. Dr. Dixey and Dr. Longstaff have observed an analogous instinct in Evonia cleodora ${ }^{5}$ in South Africa, and have published many records of similar observations on other species. ${ }^{6}$ Mr. Hamm's records $^{7}$ and photographs of British moths in their natural attitudes of rest on bark or stone also show the same co-operation of appropriate instinct with a Procryptic colouring and form. The manner in which one of the moths observed by this keen naturalist brings the main lines of its pattern into parallelism with the main lines of shadow in its immediate environment has already been described on p. 156.

5. The All-Importance of Instinct in Bringing About Protective Resemblance.-The appropriate instincts form probably the most important and essential element in Procryptic Defence. Several examples have been given in the two preceding paragraphs, and many others will be found on pp. 154-66 of the present work, where it is shown that the appropriate actions are performed

1 Proc. Ent. Soc., Lond., 1 906, p. xxviii.

2 Trans. Ent. Soc., Lond., 1906, pp. I 16-1 7 .

s Proc. Ent. Soc., Lond., 1904, p. Ixxv; Proc. Ent. Soc., Lond., 1905, p. Ixxiii ; Proc. Ent. Soc., Lond., I906, pp. c, ci.

1. c. 1905 , p. Ixxv.

- Trans. Ent. Soc., Lond., 1906, pp. 113-14; 1907; pl. xxv.

- See Longstaff in Trans. Ent. Soc., Lond., 1906, pp. 113-17. A large number of Dr. Dixey's observations are recorded in this paper. See Dixey in Proc. Ent. Soc., Lond., 1906, p. xxix.

?Trans. Ent. Soc., Lond., 1906, p. 483, pl. xxix. 
without intelligence, under the compulsion of hereditary mechanisms forming part of the nervous system.

6. The Hypertely of Brunner von Wattenwyl.-The very perfection and minute detail of certain Cryptic Resemblances have been used as an argument that they cannot have been produced by the operation of Natural Selection. Thus in the likeness of butterflies to dead leaves, described on pp. $203-6$, or in that of the South American moth, Draconia rusina, ${ }^{1}$ to a leaf attacked by a fungus which has 'skeletonized' certain parts, and is still at work upon others-in cases such as these it is sometimes objected that the detail goes beyond what can be conceived of as advantageous in the struggle for life. The particular examples which led Brunner von Wattenwyl ${ }^{2}$ to suggest the term 'Hypertely', were the South American Locustids of the genus Pterochroza. $\mathrm{He}$ considered that the exposed anterior wings of certain species resembled leaves bearing the tracks and marks of leaf-mining larvae. The same argument is sometimes employed in relation to the remarkably detailed resemblances of mimicry. All such criticism is founded on our imperfect knowledge of the struggle for existence. The impressions and judgements of man are immensely influenced by the 'corroborative detail', giving 'artistic verisimilitude to a bald and unconvincing narrative'. Indeed, the laughter which is invariably raised by this passage from The Mikado is, I have always thought, not only or chiefly due to the humour of the application, but to the way in which a great and familiar truth breaks in upon the listener with all the pleasing surprise which belongs to epigram. Birds, the chief enemies of insects, are known to have powers of sight far superior to those of man, and, from our experience of them in captivity, it may be safely asserted that their attention is attracted by excessively minute detail. Until our knowledge of the struggle for life is far more extensive than at present, the argument founded on Hypertely may be left to

1 Proc. Ent. Soc., Lond., 1906, p. Ixxviii. Trans. Ent. Soc., Lond., 1906, p. 533, pl. xxxii.

2Verh. zool.-bot. Ges. Wien, xxxiii, I883, p. 248. 
contend with another argument often employed against the explanation of Cryptic and Mimetic Resemblance by Natural Selection. Hypertely assumes that there are unnecessary details in the resemblance, that the resemblance is perfect beyond the requirements of the insect : the second argument maintains that birds are so supremely sharp-sighted that no resemblance, however perfect, is of any avail against them. In the meantime the majority of naturalists will probably reject both extremes and believe that the enemies are certainly sharp-sighted and successful in pursuit, but that perfection in detail makes their task a harder one, and gives to the individuals possessing it in a higher degree than others, increased chances of escape, and of becoming the parents of future generations.

7. Hours duiring which the Struggle for Life is most Severe.-In any attempt to understand the details of the struggle, it is essential to ascertain its relative severity during the various periods of the day and night. Mr. N. Annandale ${ }^{1}$ has observed that certain Siamese insects were active during the hottest hours of the day, a time when the birds did not hunt for food, and that conversely the same insects were rarely either seen in motion or found at rest during the cooler hours of daylight, when enemies were busily at work. Dr. G. B. Longstaff ${ }^{2}$ has also suggested as a result of his experience in South Africa, that the Cryptic colouring, attitudes, and instincts of butterflies must be considered in relation to the large number of hours of daylight during which they are in the condition of complete rest.

8. The Value of Brightly-coloured Surfaces Concealed during Rest.-The brightly coloured hind wings of many moths (Catocala, Tryphaena, \&c.) and grasshoppers (Oedipoda, \&c.) which flash out conspicuously when the insect becomes active, and disappear equally suddenly when it alights, probably serve, as Lord Walsingham ${ }^{3}$ has suggested, to confuse a pursuing enemy. The same

1 Proc. Roy. Phys. Soc., Edinb., 1900, No. xxix, pp. 439-44.

2 Trans. Ent. Soc., Lond., 1 906, p. 118.

3 Proc. Ent. Soc., Lond., 1890, pp. 1-lii. 
interpretation was offered by the late Mr. J. Jenner Weir, ${ }^{1}$ who brought forward evidence that the bright colours are also of value in diverting the attention of an enemy. Hence the insect is likely to be seized by the fragile hind wing, and to gain an additional chance of escape. The hind wings of recently emerged moths are often found chipped and torn as though they had been seized in this manner. Protection afforded in this latter way perhaps belongs more properly to a section of the succeeding division of the subject-Warning or Aposematic Colours (see p. 325).

9. The Gregarious Habit may assist Concealment.Although the gregarious habit is more commonly associated with, and tends to intensify the effects of Warning Colours, examples are known where cryptic larvae packed closely side by side produce the appearance of a brown patch on a leaf. While some of the details of the resemblance of a group of African Flatidae (Homoptera), as described and figured by Professor J. W. Gregory, ${ }^{2}$ have not been supported by later observations, yet the main conclusion that they represent together a cluster of flowers and unopened buds has been entirely confirmed. ${ }^{3}$

10. Adjustable Protective Resemblance.-In this, the highest and most perfect form of concealment as an aid in the struggle for life, an individual can change its colour into any tint which would be appropriate in any environment normal to the species. Such changes are of two kinds :-

a. Rapid, a response to Dynamic Conditions, in which owing to the rapid movements of the organism one environment is exchanged for another with speed, and any number of times. In such forms the adjustment is effected rapidly, and can be effected any number of times. b. Slow, a response to the Static Conditions of

1 Trans. Ent. Soc., Lond., 1869, pp. 22-3.

2 The Great Rift Valley, London, 1896, pp. 273-5, and Frontispiece.

3 S. L. Hinde in Trans. Ent. Soc., Lond., 1902, p. 695: see also the reproduction in Pl. xxvi of Mrs. Hinde's drawings of a cluster of living insects. 
sedentary organisms, a response nevertheless necessary when the individual may find itself placed in any one out of several differently coloured environments. In such cases the adjustment is comparatively slow and the result long-continued, so that the individual can only adapt its colours once, or at most a few times in the course of its life.

Rapid Adjustable Protective Resemblance is suited to wandering forms which must in the course of their lives continually pass and repass over environments of different colours. It is widely found in fish, and also in Amphibia and Reptilia, the chameleon affording the classical example. It is also well known to exist in Crustacea and Cephalopoda (Cuttlefish). All these rapid changes of colour are due to modifications in shape or position of superficial pigment cells controlled by the nervous system. That this control is itself regulated by the stimulus of reflected light, through the medium of the eye and optic nerve, has been proved in many cases.

Slow Adjustable Protective Resemblance is found in sedentary animals passing their life in a single environment which, however, may be very different in the case of different individuals. Thus, in many a species of moth the eggs are deposited now on trees with twigs of one colour now of another, on young trees or on those with old lichen-encrusted branches. One caterpillar will wander on to a surface of one colour, another on to a surface of a very different colour, in order to become a chrysalis. In all such cases the power of colour-adjustment is only needed once, or at most, in certain wandering larvae, two or three times.

Such changes, so far as they have been studied, appear to be produced through the nervous system, although the stimulus of light probably acts on the skin, and not through the eyes. Parti-coloured surfaces do not produce parti-coloured chrysalises, probably because the antagonistic stimuli neutralize each other in the central nervous system, which then disposes the superficial pigments so that a neutral or intermediate effect is produced over the whole surface. 
It has been contended by Mr. W. Bateson ${ }^{1}$ that there is no struggle for existence during the pupal stage of Vanessa urticae (the Small Tortoiseshell Butterfly), and that, therefore, its power of colour-adjustment is not related to any danger, and cannot have been evolved by Natural Selection. An attempt has been made by Miss C. B. Sanders, Miss M. E. Notley, Miss F. A. Wright, and the author to test this conclusion by exposing the pupae of urticae and allied species upon environments of various kinds, and keeping a careful watch upon them. The results, of which only a preliminary statement has been published, ${ }^{2}$ prove that there is immense destruction during the pupal period, short as it is, and that these angular chrysalises fixed to flat surfaces were in far greater danger than when suspended against a rough background. On the other hand, the evidence of protection afforded by colour-harmony with the environment was far less clear in these experiments.

The power of individual colour adaptation known to exist in many larvae and exposed pupae of Lepidoptera received a striking and novel illustration in some experiments conducted at Oxford in $1893-4 .^{3}$ The larvae of the Geometrid moth Odontopera bidentata were found to be extremely sensitive to the various shades of brown and grey, colouring the bark of their natural food-plants. The green of the leaves, on the other hand, did not produce green but extremely pale brown caterpillars. It is to be noted, furthermore, that the larvae do not rest on the leaves by day, but only on the twigs and branches. So far, the experiment was conducted along the same lines as the earlier investigations, and yielded similar results. The exposure of the larvae to lichencovered branches produced effects unseen in previous experiments, viz., brown, bark-like larvae, bearing green, lichen-like markings. The contrast between the effect of the continuous green surfaces of the leaves and the scattered green of the lichen was remarkable and striking.

1 Trans. Ent. Soc., Lond., 1892 , pp. 2 i2-1 3.

2 Report of the British Association, Bristol Meeting, 1 898, pp. 906-9.

8 Fully described in Trans. Ent. Soc., Lond., 1903, p. $3^{11}$, plates xvi-xviii. 
The experiment was then tried, with equally successful results, upon the young larvae of Gastropacha quercifolia (the Lappet Moth). In this case the change was produced before hybernation, and no subsequent change in the conditions availed to effect any modification. The appearance of bark densely covered by masses of grey lichen was beautifully reproduced on some of the larvae, and considerable effects were wrought in all exposed to the above-named conditions.

In these experiments, as in all others of the kind, the effects produced are those with which the field naturalist is perfectly familiar. The advance in our knowledge consists in the proof that such familiar effects are controllable, and in ascertaining the conditions under which they are evoked.

Adjustable Protective Resemblance, probably of an analogous kind, is known in Coleoptera. Thus Mr. W. Holland ${ }^{1}$ has observed that the specimens of a wellknown British weevil, Cleonus sulcirostris, are reddishbrown upon the sands of Boar's Hill, near Oxford, dark grey on Shotover Hill, also near Oxford, and a pale grey on the Deal sand-hills. I also observed in I90 I that the very abundant individuals of a species of grasshopper in Heligoland were.invariably dark reddish brown like the earth, while on the flat sandy Düne, threequarters of a mile away by sea, they were sandcoloured, or, more rarely, green like the grass. It is probable that experiment would prove that many such Coleoptera and Orthoptera, as well as the flower-haunting spiders, possess a power of individual colour-adjustment similar to that proved to exist in many Lepidopterous larvae and pupae. The alternative interpretation suggested in the next Section is probably inapplicable here.

II. Coincidence between the Colours of Organisms and those of their Peculiar Environments may be probably Caused by the Local Operation of Natural Selection.It is well known that individuals of the Geometrid moth Gnophos obscurata are light-coloured when found upon 1 Trans. Ent. Soc., Lond., 1899, p. 430. 
chalk, dark when found upon peat. Naturalists who have had much experience of the species in its native haunts assert that its habits are such as to render these tints highly protective. Careful experiments ${ }^{1}$ have proved that when nearly full-fed larvae are transferred from chalk to a very dark background, and kept there during the whole of the pupal period, the tints of the resulting moths are in no way affected. Unless the imaginal colours are determined by stimuli applied still earlier in the larval life-upon the whole an improbable conclusion-we can only suppose that the local colourharmony has been produced by the gradual destruction through many generations of the darker forms on chalk and the paler ones upon peat, \&c.

12. The Recent Progressive Darkening of many Species of Moths in the Lancashire and Yorkshire District.-A great deal of evidence has been brought forward to show that many moths in the neighbourhood of great centres of population, and also in distant areas affected by their smoke, have become very different in appearance from what they were during the lives of the last generation of naturalists and even within the memory of many still living. The latest records on the subject are those of Mr. G. T. Porritt, ${ }^{2}$ who does not himself accept the conclusion that the change has been caused by Natural Selection. The smoke from the manufacturing districts of Yorkshire, driven by the prevalent S.W. wind, has killed the lichen and rendered the tree trunks and branches uniformly dark over a wide strip of country. Their appearance has become utterly different, and the pale variegated tints formerly borne by the moths in question would now stand out with startling distinctness upon them. It is of the utmost importance to gain the fullest knowledge of the character of the struggle for existence in these species, and to test the interpretation founded on Natural Selection in every possible way; but the facts as they stand seem to raise an overwhelming probability in favour of this explanation, which

1 Trans. Ent. Soc., Lond., 1892, pp. 453-8.

${ }^{2}$ British Association, York, 1906, Report, p. 316. 
was suggested many years ago by Mr. J. W. Tutt. ${ }^{1}$ Under any circumstances the colour-harmony is not to be explained, like that of many larvae and pupae, by susceptibility of the individual at any time in its life to the darkened tints of its environment. Eggs sent from the smoky districts and reared in other parts of the country produce the same dark moths. Furthermore, the smoky districts act as centres, from which, by interbreeding, hereditary influence radiates into the surrounding areas; and even so far off as Oxford, black forms of some of the species are believed to be more prevalent than formerly. It is of interest to note that the changes which have occurred offer little support to the hypothesis of evolution by mutation. Owing entirely to artificial conditions, a sudden and rapid change has occurred in the tints of the environment. In nature we should rarely meet with such rapid and sudden changes. In one species, Amphidasy's betularia, a black 'mutation', the form doubledayaria, existed as a rarity before the darkening of the environment. Doubledayaria has now replaced the typical form in the districts we are considering. But Mr. Porritt tells me that such a sudden change is quite the exception among the numerous species which have darkened. In the great majority, a long series of intermediate varieties can still be found,

1 Entomologist's Record, vol. i, 1890-I. The following passage is quoted from p. 56 :- 'The vast quantity of smoke, gases, fumes, \&c., in manufacturing towns, brought down by rain, is scarcely credible, and it is from these impurities I consider the permanent darkening comes. When the water evaporates, the solid matter is left behind, and as a result the impurities are left to darken the surfaces to which they have been carried by the rain-water. The theories of "natural selection" and "protection" now apply in their fullest sense, the insects become darkened, "hereditary tendency" perpetuating and intensifying the melanism. I believe from this (and it appears to be a fair deduction), that Lancashire and Yorkshire melanism is the result of the combined action of the "smoke," \&c., plus humidity, and that the intensity of Yorkshire and Lancashire melanism produced by humidity and smoke, is intensified by " natural selection " and "hereditary tendency".' The only words I should criticize in this passage are those which suggest that the humidity and smoke have had any effect apart from that due to Natural Selection. 
and the transformation appears to be going on very gradually. ${ }^{1}$

13. Dimorphism and Polymorphism in Procryptic Defence.-It is common for different individuals of a species to adopt two or more different appearances, each of which resembles some special object that is of no interest to an enemy. Thus the Oriental "leaf-butterflies' (Kallima) represent many of the well-known appearances borne by dead leaves. Caterpillars and chrysalises are also frequently dimorphic-green and brown,- the two dominant colours of the normal environment. Such differences extend the area over which an enemy must search in order to obtain its food. It has been shown that green forms predominate in the offspring of green parents, and similarly with the brown. We are, therefore, led to the conclusion that the two forms intermixed are more advantageous than either alone, and that otherwise one would quickly replace the other altogether.

14. Seasonal Changes in the Individual.-Seasonal changes may occur in the course of the individual life, as in the Alpine Hare, Ptarmigan, \&c. In many cases it is known that the change is brought about by moulting, but if an observation by Captain James Ross can be depended on, the whitening may begin in an existing coat in the course of a single night. The animal experimented upon was the Hudson's Bay Lemming, which was suddenly exposed to intense cold. The results were so surprising that it would be most desirable to repeat the experiment.

1 5. Seasonal Dimorphism in Procryptic Defence.-This mode of protection is seen in many forms with more than one brood in the course of the year. Concealment is effected by different colours and even shapes, corresponding to the different environments provided by the two seasons. Thus it has already been pointed out on pp. 206-7 that the hooked apex of the fore wing and

${ }^{1}$ See also Handbuch der paläarktischen Gross-Schmetterlinge, M. Standfuss, Jena, 1896. This author's observations on Melanism are stated in a condensed form by Dr. F. A. Dixey in Science Progress, vol. vii (vol. ii of New Series); No. 7, April 1898, pp. 196-202. 
produced angle of the hind wing in certain Satyrine and Nymphaline butterflies are characteristic of the brood of the dry season, when dead leaves are bent and twisted and warped, and that the absence of these characters in the wet season corresponds to a time when such leaves are sodden and lie flat on the ground. Dr. Dixey has shown that analogous seasonal changes occur in certain South American and African Pierinae. ${ }^{1}$ In cases where the character and intensity of the struggle for existence vary greatly with the seasons, procryptic defence may be developed in the time of greater stress, the dry season, and very different methods employed by the broods of the other season (see pp. 208-11, 320, 339-41). Seasonal changes of procryptic significance also take place in certain northern species, such as Selenia illunaria, \&c. These have been the subject of exhaustive investigation prolonged over many years by F. Merrifield, who finds that heat applied to the pupal stage is the stimulus under which the changes are set on foot. Much excellent work has also been done on the same subject by Standfuss of Zürich, earlier by Weismann, and first of all by Dorfmeister.

The laborious experiments of G. A. K. Marshall in South Africa have led to a knowledge of interesting differences in the reactions of different species. Thus, in the Pierine butterflies Teracolus omphale and $T$. achine, a warm, moist atmosphere applied to the larvae produced wet season butterflies: on the other hand, very little additional effect was produced when the pupae also were similarly treated, and hardly any effect at all when damp heat was applied to the pupae alone. On the other hand, in another Pierine, Belenois severina, damp heat applied during the larval stage produced no result, but when the pupae as well as the larvae were thus treated great effects were manifest. In this species, too, there were interesting differences in the character of the effect, according as heat alone or heat with moisture was applied. It seems quite clear from these experiments that the larva is the sensitive stage in Tevacolus and the pupa

1 Trans. Ent. Soc., Lond., 1903, p. I57, plate vii. 
in Belenois.' Further investigations into the stimuli under which the seasonal forms develop are briefly mentioned on pp. 340, 34I.

16. Syncryptic or Common Protective Resemblances.Colouring for concealment in similar environments may incidentally produce superficial resemblances between species. Thus, desert forms of the most varied kinds are coloured in the same way, while a Special Protective Resemblance to lichen, bark, grasses, pine-needles, \&c., may often lead to a tolerably close similarity between the species which are thus concealed. Such Syncryptic Resemblance is to be distinguished from Mimicry and Common Warning Colours, in which the superficial likeness is not incidental but an end in itself.

Syncryptic Resemblance has much in common with the superficial likeness incidentally produced by similar functional adaptations. Thus mole-like forms adapted for a burrowing life have been independently evolved in Insectivora (true moles), Rodentia, and Marsupialia. Such resemblances, which have been called Analogical or Adaptive, may be termed Syntechnic, because they follow from similar modes of life. Syntechnic Resemblance is an incidental result of similarity in the dynamic conditions of life, just as Syncryptic Resemblance is incidentally produced by similarity in its static conditions. ${ }^{2}$

\section{B. Anticryptic or Aggressive Resemblance.}

It is unnecessary to speak in detail about concealment for the purpose of attack, inasmuch as all the principles encountered are the same as those upon which Procryptic or Protective Resemblance depends. The colouring of the lion harmonizing with the desert is a good example of General Resemblance, a huge constricting serpent lying in wait for prey and hanging like a broken branch from a forest tree serves equally to illustrate Special Resem-

${ }^{1}$ See Dr. F. A. Dixey's interesting account of these most valuable experiments in Proc. Ent. Soc, Lond., 1906, p. civ ; 1907, p. xii.

2 See the article Mimicry, in Dict. philos. and psychol., J. M. Baldwin, New York and London, 1902, vol. ii, pp. 79-80. In this article the present writer, with the kind help of Mr. Arthur Sidgwick, introduced the terms Syncryptic and Syntechnic. 
blance. The neutralization of shadow is well seen in the predaceous Carnivora, and, in many of them, characteristic details are depicted on the shadowless and ghost-like surface of their general ground-colour; vistas of upright stems on the tiger, effects of light and shade, even, it is said, pin-hole images of the sun as cast by minute interstices between leaves, on arboreal species. Adjustable Resemblance in aggressive species, such as the Chameleon, Cuttlefish, and many Crustacea, is probably chiefly protective in function, but there can be little doubt that it is aggressive as well. Chamaeleo pumilus, slowly moving to within striking distance of its alert and active prey, is probably aided by colour adjustment and the neutralization of shadow. The Seasonal Changes of northern forms are just as characteristic of the predaceous Arctic Fox and Ermine as of the Alpine Hare, Lemming, and Ptarmigan.

\section{Allocryptic or Adventitious Protective and Aggressive Resemblance.}

Concealment is often effected by means of a covering of foreign objects. Such forms are of course hidden in any environment. When sedentary they are covered with local materials, when wandering they have the instinct to reclothe. The great majority of examples are Alloprocryptic, such as the little English crab Stenorrhynchus phalangium*, which decks itself with pieces of seaweed; but examples of Allanticryptic Resemblance are well known. It will be sufficient to mention two species :

I. The large Brazilian frog Ceratophrys cormuta* which squats in a hole in the ground and covers its back with earth, the exposed parts harmonizing with the surroundings. The frog remains thus motionless and concealed, waiting until some small animal approaches or even walks over it.

2. The ant-lion (Myrmeleon) larva, buried in fine sand or dust, at the bottom of its crater-like pit.

Allocryptic Resemblance may be both protective and aggressive at one and the same time. 
A good example is to be found in the little British crab Hyas coarctata*, which covers itself very completely with Algae, exposing only the pearly pink large claws. It then climbs into a mass of Alga, to which it imparts a gentle swaying motion. The attention of small fish is probably first attracted by the movement, and their interest excited by the brightly coloured claws which alone can be seen. They approach to within striking distance, are seized and devoured by the crab. All this has been observed in the aquarium by Prof. A. F. Dixon, of Dublin, to whom I am indebted for the information. ${ }^{1}$ The Hyas itself is greedily devoured by larger fish, and it cannot be doubted that the adventitious covering acts as a defence against these enemies. This crab affords a good example of the complexity of the uses of colour. The covering of Algae is an alloprocryptic defence against enemies, an allanticryptic assistance in the capture of prey, a capture also aided by the alluring or pseudepisematic colouring of the claws.

A subtle form of allocryptic defence is found in the use of the colour of the food in the digestive organs showing through a transparent body, or the still more remarkable cases in which it is dissolved in the blood and secreted in the superficial cells of the body. In one case it has even been shown that the different shades of green produced by modified chlorophyll from the leaves of different plants, is preserved in the pupa, collected into the eggs of the perfect insect, and can still be detected in the larvae of the next generation when first hatched from those eggs. ${ }^{2}$

True or Batesian Mimicry is closely related to the Cryptic Colours described and illustrated above, but differs in that the mimetic animal resembles an object

${ }^{1}$ On the Marine Invertebrate Fauna near Dublin, by G. Y. and A. F. Dixon. Proc. Roy. Irish Acad., 3rd ser., vol. ii, no. 1, r 891 , p. $3^{\circ}$.

2 Smerinthus ocellatus. See Proc. Physiol. Soc. in Journ. Physiol., vol. viii, $1887, \mathrm{pp}$. xxv, xxvi. The fact that modified chlorophyll derived from food forms an important element in the colouring of certain larvae has been clearly proved in the case of Tryphaena pronuba. See Proc. Roy. Soc., vol. liv, 1893, p. 417 , pl. 3,4 . 
which positively repels its enemies or positively attracts its prey, rather than one which is of no interest to either. It is more convenient, therefore, to defer its consideration until after the description of the Warning Colours which form the models for Mimicry.

\section{SEMATIC COLOURS, OR WARNING AND SIGNALLING (RECOGNITION) COLOURS ; APOSEMATIC AND EPISEMATIC CHA- RACTERS.}

The second great use of colour is to act as a warning or signal (Sematic Colours), repelling enemies by the indication of some unpleasant or dangerous quality (Aposematic or Warning Colours), or signalling to other individuals of the same species, and thus assisting them to escape from danger (Episematic or Recognition Colours). In a very interesting group of cases (Allaposematic), the animal warns off its enemies by associating with itself some other animal with unpleasant qualities and Warning Colours.

\section{A. Aposematic or Warning Characters.}

The use of colour for the purpose of warning is the exact opposite of the one which has been described on p. 297, its object being to render the animal so conspicuous to its enemies that it can be easily seen, well remembered, and avoided in future. Warning Colours are associated with some quality or weapon which renders the possessor unpleasant or dangerous, such as unpalatability, an evil odour, a sting, the poison-fang, \&c. The object being to warn off an enemy, these colours are called Aposematic.

Good examples are to be found in the American skunks (Mephitis mephitica*, Mephitis suffocans*, Conepatus mapurito*, \&c.), which possess the power of emitting an intolerable stench, and are, under ordinary conditions, slow-moving, conspicuous black and white mammals.

An element of Mimicry exists in the appearance of the remarkable chrysalis of Limenitis populi* as interpreted 
by Portschinski. ${ }^{1}$ The Russian naturalist considers that this pupa, which he found to be rejected by birds, bears the most detailed resemblance to a chrysalis which has been pecked and seriously injured, but finally abandoned.

It has been objected that in the case of small unpalatable animals the individual with Warning Colours is often injured or destroyed by an enemy before it becomes aware of the unpleasant quality or other special defence. But the species benefits by the experience thus gained by an enemy, even though the individual suffers. It is the species which is preserved and advanced by Natural Selection, and when this involves danger to the individual-as it continually does, the individual must incur the risk. An insect-eating animal does not come into the world with knowledge; it has to be educated by experience, and Warning Colours ensure that this education is conferred by a small instead of a large waste of life. Nevertheless, the necessary risk to the individual is reduced to the lowest possible level. Great tenacity of life is usually possessed by animals with Warning Colours. The tissues of insects with an Aposematic appearance often possess great elasticity, toughness, and power of resistance, so that large numbers of individuals can recover after very severe treatment.

1. Experimental Evidence of Special Protection in Forms with Warning Colours.-Apart from the species armed with the sting or poison fang, a large number of conspicuous species have been proved to possess an unpleasant smell. Dr. Dixey and Dr. Longstaff have made a special point of investigating the scents of living African butterflies, and they find that while the scents confined to the male and presumably employed in courtship are pleasant to the human sense, those found in both sexes (and when there is a difference more thoroughly developed in the female) are unpleasant to man. Such disagreeable scents were detected in conspicuous butterflies belonging to the Danainae, Nymphatinae, Acraeinae, and Papilioninae. Dr. Dixey has published several inter-

${ }^{1}$ Lepidopterorum Rossiae Biologia, St. Petersburg, 1890. 
esting notes on the subject. ${ }^{1}$ Fritz Müller has also shown in S. America that the scents of male butterflies are agreeable. ${ }^{2}$ Far stronger evidence is of course afforded by offering forms with Warning Colours to their natural enemies, and stronger still by watching the behaviour of enemies in the wild state and by keeping a precise record of the food found in their stomachs. Although an immense amount of such evidence is still required, a great deal has been done. The summary of Mr. Frank Finn's striking experiments in India has been quoted on p. $269 .^{3}$

2. Species with Warning Colours depend for their Existence upon the Co-Existence of Palatable Species.-Aposematic Colours, together with the qualities they indicate, depend for their very existence upon the relative abundance of palatable food supplied by animals with Cryptic Colouring. Unpalatability or even the possession of a sting is not sufficient defence unless there is enough food of another kind to be obtained at the same place and time. ${ }^{4}$ Hence insects with Warning Colours are not seen in temperate countries except during the months when insect life as a whole is most abundant; and in warmer countries, with well-marked wet and dry seasons, it is found that Warning Colours are less developed in the latter season, which is the time of greater stress. Examples will be given in later Sections.

3. Erroneous Assumption that Warning Colours imply Complete Immunity from Attack.-Although animals with Warning Colours are probably but little attacked by educated enemies of their class, they have special foes which keep the numbers down. Thus the cuckoo appears to be an insectivorous bird which will freely devour conspicuously coloured larvae unpalatable

${ }^{3}$ Proc. Ent. Soc., Lond., 1904, p. lvi ; 1905 , pp. xxxvii, liv ; 1906, p. ii. See also G. B. Longstaff in Proc. Ent. Soc., Lond., 1905, p. xxxv, and Trans. Ent. Soc., Lond., 1905, p. 136.

${ }^{2}$ Jen. Zeit., vol. xi, p. 99 ; Trans. Ent. Soc., Lond., 1878, p. 21 I.

3 See also Proc. Zool. Soc., Lond., 1887, p. I91, for an account of all the work done up to that date, and Trans. Ent. Soc., Lond., 1902, p. 287, for the most important of recent researches on the subject.

- Proc. Zool. Soc., Lond., 1887, p. 191 ; confirmed also by F. Finn : see p. 269 of the present volume. 
to other birds. Nothing can be further from the truth than Haase's contention that the species with Warning or Aposematic Colours are absolutely 'immune' from the attacks of all enemies, including parasites. ${ }^{1}$ There is indeed much evidence to show that such species are especially liable to destruction by these latter foes. ${ }^{2}$ Many groups of predaceous insects also appear especially to attack the conspicuous, easily-captured prey provided by the groups with Warning Colours. This has been observed in the case of the predaceous Asilid flies, Dragonflies, Hemiptera, Mantidae and Locustidae. ${ }^{3}$

4. Transition from Cryptic to Aposematic Defence.Although these two methods of protection are as a rule sharply contrasted, intermediate examples are common, and even more numerous are the cases in which an individual in the course of its life-history or by an instantaneous change of attitude passes from the one category into the other.

The larvae of Cucullia verbasci (the Mullein Shark Moth) are good intermediate examples. Their colouring harmonizes well with the flowering spike of the Mullein, and when disturbed their instant fall and active wriggling movements, tending to concealment among lumps of earth, roots of grasses, \&c., belong to the category of Cryptic defence. On the other hand, they are rendered conspicuous by gregarious habits, while the large larvae are very visible upon the broad leaves of the foodplant. Furthermore, experiment shows the existence of distasteful qualities. ${ }^{4}$ There is also a considerable element of concealment in the resemblance of the orange bands of the larva of Euchelia jacobaeae (the Cinnabar Moth) to the flowers of its food-plant. I was formerly disposed to regard these two species as examples of recent transition from a Cryptic to an Aposematic mode of defence. ${ }^{5}$ I should now be more inclined to explain the Cryptic

1 Researches on Mimicry, part ii, Stuttgart, 1896, English translation.

- Trans. Ent Soc., Lond., 1902, p. 337.

3 Trans. Ent. Soc., Lond., I906, p. 323.

Proc. Zool. Soc., Lond., 1887, pp. 202, 203, 238.

- Proc. Zool. Soc., Lond., 1887, p. 238. 
element as a protection against the special enemies which attack the species in spite of their unpalatability. The more completely the larva is concealed from special enemies, and the more visible it is to enemies which respect the defence of unpalatability, the greater its chance of survival. The compromise is effected in these species by concealment at a distance, passing into conspicuousness on a near approach, combined with further defensive methods when an actual attack is made.

Abrupt changes in the method of protection in the course of the life-history are very common. Thus the caterpillar of Cucullia verbasci produces a moth possessing a beautiful Cryptic colouring, the resemblance being to a splinter of wood. Euchelia jacobaeae, on the other hand, becomes even more Aposematic in the perfect than in the larval state. One of the most beautiful instances of change is afforded by the larva of the rare British species Acronycta alni. In its young stage the caterpillar bears the closest likeness to the excrement of a bird: at a change of skin it suddenly emerges with a startling black and yellow pattern which has all the appearance of a Warning character.

Even more interesting are the species which by some significant movement pass at once from the Cryptic to the Aposematic category. The change thus undergone by certain larvae was described in $1887^{1}$ by the present writer:- 'Such larvae are apt to pass unnoticed because of the harmony between their colours and markings and the artistic effect of their surroundings; but, if discovered, or even if an enemy approach so that there is danger of their being discovered, the protective [cryptic] attitude is instantly changed for one which renders the larva conspicuous, and warns the enemy of the presence of unpleasant attributes (taste or smell), or alarms it by the resemblance of the new appearance to some object of terror [the reference is here to C.elpenor as described on pp. 367,368$]$. These facts may even be true of gregarious larvae. Thus a group of phytophagous Hymenopterous

${ }^{1}$ Proc. Zool. Soc., Lond., 1887, pp. 197, 204. See also pp. 206, 207 of the same memoir, where experiments on four species are recorded. 
larvae may remain inconspicuous while undisturbed, but nevertheless the approach of an enemy determines united movements in the colony which render the whole strikingly conspicuous, and ... may be attended later by the emission of an offensive smell from the numerous ventral glands of all the individuals simultaneously (e. g. Croesus septentrionalis).'

\section{Seasonal Transition from Cryptic to Aposematic} Defence.-It has been pointed out on P. 3I 7 that in latitudes like our own the insects with Aposematic colouring are compelled to hide during the periods when the food of insect-eating animals is scarce. An analogous alternation may be produced by the wet and dry season broods of certain species. In some African butterflies of the Nymphaline Genus Precis, the wet season broods are distinguished by the more or less conspicuous under sides of the wings, while those of the dry season are highly Cryptic. The South and East African species Precis archesia was the one which most impressed the present writer, and led him to seek for an interpretation in the conditions of life peculiar to the two seasons.

It appeared, on comparing a series of specimens, ${ }^{1}$ that, as described on p. 208 , the feature which chiefly renders the wet season form conspicuous is derived from the very marking which is the principal element in the concealment of the other! This led directly to the conclusion that there must be some great difference in the conditions of the two seasons which made a certain measure of conspicuousness an advantage in the wet, and concealment a necessity in the dry. Some account of these differing conditions and the manner in which such an astonishing alternation in this and many other species may have arisen is given on pp. 206-1 I.

6. Geographical Transition from Aposematic to Cryptic Defence. - The much-mimicked, conspicuous Limnas chrysippus-perhaps the commonest butterfly in the world-tends to be replaced on desert areas, and

${ }^{1}$ For such a transitional series see Trans. Ent. Soc., Lond., 1902, plate xiii, figs. 5-8. Consult also pp. $428-9$ of the same memoir. 
in the Somali Desert appears to be completely replaced, by a form (dorippus =klugii) without the black and white tip to the wing (see pp. 70-1). Furthermore, in some of the specimens the tawny colour is replaced by a tint far more adapted for concealment against a sandy background. It is probable that under the stress of desert conditions-constituting, as it were, a permanent dry season-this highly distasteful form has been compelled to adopt a measure of Cryptic Defence. Conversely, in the luxuriant life and abundant food of the tropical west coast of Africa, a form (the white-hind-winged alcippus) even more conspicuous than the type, has become dominant, and, from the mouths of the Niger to the southern edge of the Sahara, is now apparently the only form ${ }^{3}$.

7. A. H. Thayer's Criticism of the Statement that Animals are Conspicuous.-Mr. Abbott H. Thayer has criticized, from the artist's point of view, the use of the term 'conspicuous' by the naturalist. ${ }^{2}$ In the first place he states that ' Only unshiny, bright ${ }^{3}$ monochrome is intrinsically a revealing coloration. As soon as patterns begin, obliteration of the wearer begins, ... Nature does not blunder, and Natural Selection would evolve the monochrome, instead of a patterned surface, were simple conspicuousness her aim'. But naturalists, in using the word 'conspicuous', have not meant to imply a conspicuousness as great as the artist could make it; and reasons have been given in the preceding Sections why

${ }^{1}$ I should have carried the southern limit of the exclusive occurrence of alcippus considerably further had I not recently seen in the Stockholm Natural History Museum a male and a female specimen of the type form captured respectively December 26 and $2 \mathrm{I}, 1890$, in the Cameroons, by my friend Professor Yngve Sjöstedt. They were, he told me, excessively rare as compared with alcippus. In a large amount of material at Tring and Oxford from far inland and considerably further south-Luebo, on a southern branch of the Congo-the type form alone is represented. For the suggested interpretation of the dorippus and alcippus forms, and for the evidence that chrysippus is the ancestral form, consult Trans. Ent. Soc., Lond., 1902, p. 473 .

2 Trans. Ent. Soc., Lond., 1903, p. 556.

${ }^{3} \mathrm{Mr}$. Thayer tells me that he would now omit the words 'unshiny, bright'. 
the aim of nature could not be 'simple conspicuousness' alone. There is the danger of special enemies, and the danger of specially hungry enemies; and it must be freely admitted that conspicuousness beyond what is necessary for warning an attacking enemy would be a danger. Mr. Thayer states that iridescence tends to render colours less conspicuous, and we certainly observe that a uniform black appearance unrelieved by pattern is continually accompanied by iridescence or structural surface colours of some kind. In view of Mr. Thayer's suggestion, it becomes probable that dead black would be too conspicuous for many a well-armed Aculeate or nauseous Euploea, and that it is therefore modified so that it obtrudes less upon the distant view of enemies that 'mean business'.'

Naturalists have used the term 'conspicuous' relatively, and furthermore, in using it, have taken into account the habits, movements, modes of display, \&c., which may be of even more importance than the colouring itself. The Ithomiine and convergent Heliconine butterflies of tropical America are no doubt far from possessing an 'intrinsically revealing coloration' such as Mr. Thayer describes; but it is equally true that they fall into an entirely different category from that which includes the Cryptic species, with undersides resembling leaves, bark, \&c. Mr. Thayer suggests that they resemble flowers, and the surroundings of flowers, and that their extraordinary likeness to each other may be incidentally due to their resembling the same kind of flower-in other words may be Syncryptic. The British Guiana association of Ithomiinae, Heliconinae, \&c. (see pp. $33^{1-3}$ ) has been studied in its native haunts far more completely than any other. Mr. W. J. Kaye, who has devoted special and prolonged attention to them, states that these black, 'cow-red, and chrome-yellow' butterflies, as they are precisely described by Mr. Thayer, frequent 'the white flowers of the plant Eupatorium macrophyllum'. ${ }^{2}$ There is no evidence of Cryptic Resemblance to flowers

1 Trans. Ent. Soc., Lond., 1903, p. 575.

2 Trans. Ent. Soc., Lond., 1906, p. 4 I 2. 
in any of the representative combinations in other parts of the tropical New World, while a careful study of the exact changes which they undergo as we pass from one district to another enables us to dismiss any such hypothesis.

$\mathrm{Mr}$. Thayer's criticism is considered in this place because the preceding five Sections show how subtle is the relationship between two sharply contrasted methods of defence, and how easily and frequently the barrier between them is traversed. The determining factors in each case are to be found in the complex conditions of the struggle for existence. It is these that have decided the degree of conspicuousness attained by Warning Colours, and have kept them far short of an 'intrinsically revealing coloration' as defined by the artist.

8. The All-Importance of Instinctive Attitudes and Movements in the Display of Warning Colours.Warning Colours are, like Cryptic, assisted by special adaptations of the body-form, and especially by movements which aid in rendering the appearance as conspicuous as possible. On this account forms with Warning Colours generally move or fly slowly, and it is the rule in the wings of butterflies that the warning patterns are similar on both upper and under surfaces, and so far as there is a difference, that the colours of the under surface exposed during prolonged rest should be even more conspicuous than those of the upper surface. The flight of certain American Danaine butterflies appears to be especially adapted to display the conspicuous under surface of the wings. ${ }^{1}$

Other instincts also assist in Aposematic display. Thus the effect of the Warning Colours of caterpillars is often intensified by gregarious habits. Furthermore, many animals (spiders, beetles, caterpillars, \&c.) when attacked or disturbed, 'sham death' (as it is commonly but wrongly described), falling motionless to the ground. Well-concealed animals, when once detected, are thus given a second chance of escape among little fragments of earth, dead leaves, or the roots of grasses. Animals with Warning Colours are, on the other hand, enabled

1 Ann. Mag. Nat. Hist, ser. 7, vol. xiii, April, 1904, pp. 358-9. 
to assume a position in which their characters are displayed to the full. Thus Portschinski has shown that the two unpalatable English moths Spilosoma urticae* and $S$. mendica*, female, when disturbed, assume attitudes which serve to display their conspicuous yellow and black colours.' In both types of so-called 'sham death'Cryptic and Aposematic - a definite attitude is assumed, which is not that of death.

9. Warning or Intimidating Sounds. - Sound may be employed as an Aposematic Character, as in the hiss of snakes and some lizards. Certain poisonous snakes when disturbed produce by an entirely different method a farreaching sound not unlike the hiss. Thus the Rattle Snake (Crotalus) of America rapidly vibrates the series of dry, horny, cuticular cells, movably articulated to each other and to the end of the tail. The stage through which the character probably arose is witnessed in another genus which vibrates its tail among dry leaves and thus produces a warning sound. The deadly little Indian snake, Echis carinata (the 'Kuppa') makes a penetrating swishing sound by writhing the coils of its body one over the other. Special rows of the lateral scales are provided with serrated keels which cause the sound when they are rubbed against each other. Large birds, when attacked, often adopt a threatening attitude accompanied by an intimidating sound which usually suggests more or less closely the hiss of a serpent, and thus includes an element of Mimicry.

Io. Intimidating Attitudes.-The Cobra warns an intruder chiefly by attitude and by the broadening of its flattened neck, the effect being heightened in some species by the 'spectacles'. In such cases we often witness a combination of Cryptic and Aposematic methods, the animal being concealed until disturbed, when it instantly assumes a Warning attitude.

The benefit of such intimidating characters is clear: a venomous snake gains far more advantage by terrifying than by killing an animal it cannot eat. By striking, the serpent temporarily loses its poison and with this

${ }^{1}$ Lepidopterorum Rossiae Biologia, St. Petersburg, 1890. 
a reserve of defence. Furthermore, the poison does not cause immediate death, and the enemy would have time to injure or destroy the snake.

II. Directive Marks and Structures.-Another Aposematic use is of a different kind, viz. to divert attention from the vital parts and thus give the animal attacked an extra chance of escape. The large, conspicuous, easilytorn wings of butterflies and moths act in this way, as is shown by the numbers of individuals which may be captured with notches bitten symmetrically out of both wings when they were in contact. The eye-spots and 'tails' so common on the hinder part of the hind wing, and the conspicuous apex so frequently seen on the fore wing, probably have this meaning. Their position corresponds to the parts which are most often found to be notched in fresh specimens. In some cases (e. g. many Lycaenidae) the 'tail' and eye-spot combine to suggest the appearance of a head with antennae at the posterior end of the butterfly, the deception being aided by movements of the hind wings. ${ }^{1}$ It has already been pointed out on p. 303, that the brightly coloured hind wings of certain moths and grasshoppers are of benefit in the manner here described.

The flat-topped 'tussocks' of hair on many caterpillars look like conspicuous fleshy projections of the body, and they are held prominently when the larva is attacked. If seized, the 'tussock' comes out, and the enemy is greatly inconvenienced by the fine branched hairs. The tails of lizards, which easily break off, are to be similarly explained, the attention of the pursuer being probably still further diverted by the extremely active movements of the amputated member. Certain crabs similarly throw off their claws when attacked, and the claws continue to snap most actively. The tail of the dormouse, which easily comes off, and the extremely bushy tail of the squirrel, are probably of use in the same manner.

The classification of Directive Characters is a matter of

1 This deeply-interesting adaptation has been independently recognized by many naturalists in many countries. For a list of records see Proc. Ent. Soc., Lond., 1906, p. lii ; also Ent. Mo. Mag., 1906, p. 128. 
great difficulty. I have here provisionally retained them in the position originally assigned in The Colours of Animals. The 'tussocks' of hair, themselves providing distasteful qualities, will probably always be looked upon as a form of Aposeme. On the other hand, as my friend Mr. Marshall has pointed out to me, deception and not unpalatability is the essential element in the protection generally afforded by eye-spots, and, when this is the case, they should be regarded as a form of Pseudoseme, and probably of Pseudepiseme. Huge, terrifying, eye-like marks, such as those of the Brassolinae, fall into their place beside the more perfect and specialized Pseudaposemes of certain snake-like larvae (see p. ${ }^{667}$ ). Mr. Marshall observes that there is a marked absence of eyespots in the great distasteful groups of butterflies, the Ithomiinae, Danainae, Heliconinae, and Acraeinae. On the other hand they form a most characteristic Aposematic feature in the much-mimicked Morphine (Amathusiine) genus Tenaris, and are often found in Papilios with a conspicuous pattern on the under surface.

12. The Seasonal Development of Directive Marks.It has been explained on Pp. 2 IO-I I that the eye-spots developed, especially on the under surface of the wings, in the wet season broods of many Satyrinae and certain Nymphalinae are probably adapted to meet the kind of attack which is chiefly made at this time of plenty, and that such markings would be too great a danger in the stress of the dry season; furthermore, that the eye-spots are a defence during times of activity, but would be the reverse in the longer periods of repose of the dry season. It was the recognition of the same phenomena in such distantly related butterflies as Satyrinae and Nymphalinae that impelled the present writer to seek an interpretation in conditions of life which are common to the two groups. ${ }^{1}$

${ }^{1}$ Ann. Soc. Ent., France, vol. Ixxii, 1903, p. 407. 


\section{A*. Synaposematic or Common Warning Colours}

\section{(MÜlleRian Mimicry).}

This subject, though logically but a section of Aposematic Colours, is of such vast importance that it is here converted into a separate heading equivalent to A. Aposematic, and marked with an $A^{*}$.

Animals with Warning Colours often tend to resemble each other superficially, as was pointed out by H.W. Bates in his paper on the Theory of Mimicry. ${ }^{1} \mathrm{He}$ showed that the conspicuous, presumably unpalatable, tropical American butterflies, belonging to very different groups, which are mimicked by other species, also tend to resemble each other, the likeness being often remark. ably exact. The resemblances were not explained by Bates's Theory of Mimicry, and he could only suppose that they had been produced by the influence of a common environment, a suggestion at first adopted by Wallace but abandoned by him as soon as Fritz Müller's hypothesis appeared in $18790^{2}$

It seems probable that Bates was misled by a failure to realize the remoteness of the affinity borne by the Heliconinae to the Ithomiinae, and that consequently the mimicry between them did not appeal strongly to him. He indeed saw and described the important structural differences, but still left them united as Heliconidae, calling the Heliconinae, Acraeoid, and the Ithomiinae (including the Danaine genera Lycorea and Ituna) Danaoid. The superficial resemblances were so close in shape as well as pattern of wing that he was driven to accept an arrangement which gave too little weight to characters of greater importance.

As a solution of the difficulty Fritz Müller suggested that life is saved by a resemblance between the Warning Colours in any area, inasmuch as the education of young

1 Trans. Linn. Soc., Lond., vol. xxiii, 1862, p. 495. The fact that these examples were not figured in the accompanying plates probably explains the long delay in the appearance of the Muillerian hypothesis. See pp. 21 1-1 2 of the present work.

2 Kosmos, May, 1879. 
inexperienced enemies is facilitated, and insect life saved in the process. Each species which falls into a group with Common Warning or Synaposematic Colours ${ }^{1}$ contributes to diminish the destruction of the other members. It is obvious that the amount of learning and remembering, and consequently of injury and loss of life involved in these processes, are reduced when many species in one place possess the same A posematic colouring, instead of each exhibiting a different 'danger-signal'.

It has been pointed out that this struggle is in reality far more severe than has been supposed. At each breeding season a fresh wave of young enemies is sent forth, takes its toll of insect life, and, except for an insignificant fraction, perishes in the struggle with its own foes. ${ }^{2}$

Before proceeding to discuss Synaposematic Resemblance in some detail, adducing many examples, I desire to state as prominently as possible that a Müllerian, as opposed to a Batesian, interpretation is suggested in no positive or dogmatic spirit. Detailed researches into the subject are very recent, while new material and the record of fresh observations are continually appearing. Hence the explanation of special examples must in many cases be regarded as provisional. My friend, Mr. G. A. K. Marshall, would consider that a Batesian or Pseudaposematic interpretation is more probable for many of the examples. On the other hand, so far as I can judge from existing evidence, I believe-and at any rate for the most part Dr. Dixey agrees with me-that all of them fall under the Müllerian Hypothesis of Common Warning Colours.

I. The Mathematical Statement of the Advantage Conferred by Perfected Muillerian Resemblance.-The precise statement of advantage was made by Mr. Blakiston and $\mathrm{Mr}$. Alexander, of Tokio. 'Let there be two

1 These terms were introduced in a note, dated June 14,1897 , to the report of the discussion on Dr. Dixey's paper on Mimetic Attraction in Trans. Ent. Soc., Lond., 1897, p. 317. See Proc. Ent. Soc., Lond., 1897, p. xxix, n.

2 Proc.Ent.Soc., Lond., 1903, p. lxv ; see also pp. $167-8$ of the present work. 
species of insects equally distasteful to young birds, and let it be supposed that the birds would destroy the same number of individuals of each before they were educated to avoid them. Then if these insects are thoroughly mixed and become undistinguishable to the birds, a proportionate advantage accrues to each over its former state of existence. These proportionate advantages are inversely in the duplicate ratio of their respective original numbers compounded with the ratio of the respective percentages that would have survived without the mimicry.' The difference between this hypothesis and the Mimicry of Bates is well shown in the following passage, in which it is supposed that $B$ exists in smaller numbers than $A$ :- 'It must be remembered, however, that $B$ does no harm to $A$ by mimicking it; on the contrary, the act of mimicry is of advantage to $A$ over its former state of existence as well as to $B$; but $A$ being the more numerous the advantage is less. Still, after the assimilation neither has an advantage over the other. Proportionally they suffer from the ravages of birds equally; the percentage of losses is the same; they are on equal terms. No matter how long they continue the association, neither gains nor loses on the other; though through one being more numerous it loses more individuals, yet equally in proportion with the other. So that, if one is twice as numerous as the other at the time of assimilation, it must always-other conditions being equal-remain twice as numerous.' 1

2. The Advantage Conferred during the Growth of Miillerian Resemblance.-The above statement is concerned with a Müllerian Resemblance which has reached the climax of evolution, when the constituent species cannot be distinguished by their enemies. It is very doubtful whether this climax is ever attained except when affinity comes to the aid of mimicry. At the same time it is useful to assume indistinguishability in a hypothetical example, if by this means the advantages of resemblance

1 The full statement here quoted was published by the authors in Nature, vol. xxix, 1884, pp. 405-6: a preliminary statement had been published in Nature, vol. xxvii, 1883 , pp. 481-2. 
can be made clear-if we are thus led to realize how it is that a higher degree of resemblance is more advantageous than a lower degree. For this reason I have set forth below, by means of a hypothetical case, the principles which, in my opinion, have led to the gradual growth of Synaposematic likeness.

If we suppose ( 1 ) that two species of butterfly, $A$ and $B$, living in the same locality are equally distasteful to birds, and that young birds have to learn their qualities by the test of experience before avoiding them for the future; (2) that during this education each young insectivorous bird destroys or prevents the reproduction of one example of each pattern; (3) that the numbers of $A$ and $B$ are equal, but that half the individuals of $B$ possess a pattern $A^{\prime}$, indistinguishable from $A$, and the other half, a pattern $B^{\prime}$ sufficiently distinct to require learning by a separate set of tasting experiments,-it follows that, if the inexperienced insectivorous birds of a given area be estimated at 20,000 and the two butterflies at 1,000,000 each, then 20,000 losses will be suffered by the $1,500,000$ individuals of pattern $A+A^{\prime}$ and an equal number by the 500,000 of pattern $B^{\prime}$. In other words, pattern $A^{\prime}$ will lose $1 \frac{1}{3} \%$ and $B^{\prime} 4 \%$.

In the vast majority of cases, however, the two species are not equal in numbers, but those of the mimicking species very much smaller. If, for the sake of illustration, we suppose the numbers of $A$ to be $1,750,000$ and those of $B 250,000$ divided as before into $A^{\prime}$ and $B^{\prime}$, it follows that $A+A^{\prime}$ would lose 20,000 out of $1,875,000$ or a little over $1 \%$ (about 1.07 ), and $B^{\prime} 20,000$ out of 125,000 or $16 \%$ It is thus possible at once to see why, when the numbers become very disproportionate, the only appreciable approach is from the side with the smaller number of individuals.

The advantages of Diaposematic or Reciprocal Resemblance may be illustrated in the same manner. Taking the numbers of the first illustration, let us suppose that half the individuals of $A$, viz. $A^{*}$, advance to meet an equal advance of half the individuals of $B$, viz. $B^{*}$, so that the two form a single pattern $A^{*}+B^{*}$ separate 
from $A$ and also from $B$. It follows that $A^{*}+B^{*}$ will incur 20,000 losses out of $1,000,000$, or $2 \%$; while the two different patterns $A$ and $B$ will each lose 20,000 out of 500,000 , or $4 \%$.

The examples are of course unnatural in a high degree, especially in the sharp separation of the patterns into distinguishable and indistinguishable. But they enable us to understand the advantage of a close over a rough resemblance and thus to realize the causes which have encouraged the growth of a Muillerian likeness through a long series of generations.

3. Striking Examples of Miillerian Resemblance.a. The Neru World.-The statements in Section I on pp. 328-9 apply to the finished product, - the cases of perfect resemblance wh:ch are supposed to be indistinguishable to the inexperienced enemies. Although the mode of flight certainly facilitates discrimination, ${ }^{1}$ we must admit that the patterns of Melinaea mneme and Heliconius mumata figured by Mr. W. J. Kaye ${ }^{2}$ are almost exactly alike. Their likeness reaches the climax of perfection as nearly as it is ever reached by these superficial resemblances between members of distantly related groups. The plate shows seven examples of the Ithomiine and seven of the Heliconine. Each set is arranged to exhibit the gradual transition from a barred to a black hind wing. Each of the seven varieties of the Ithomiine is matched by a corresponding variety of the Heliconine. When the two patterns are compared it is at once clear that the Melinaea (Ithomiinae) has acted as the model. It still presents an entirely characteristic Melinaea pattern which the Heliconius has adopted. There is no reason for believing that the latter is more palatable than its model. In addition to their mimicry of the Ithomiinae the Helico-

${ }^{1} \mathrm{H}$. W. Bates pointed out in the original memoir on Mimicry that the Heliconines 'move along in a sailing manner, often circling round for a considerable time, with their wings horizontally extended'. The Ithomiines, on the other hand, 'for the most part, keep near the ground, and have a very slow irregular flight, settling frequently.' Trans. Linn. Soc., Lond., vol. xxiii (1862), p. 499. A small but distinct means of discrimination between the patterns is mentioned on p. $35^{\circ}$ of the present work.

${ }_{2}$ Trans. Ent. Soc., Lond., 1 906, pl. xxv1. 
ninae extensively mimic each other, and are extensively mimicked by other Lepidoptera. The Heliconinae which resemble the Ithomiinae belong to the same group as those which resemble other Heliconinae. The likeness is even closer in some pairs made up of Heliconines than in any made up of an Ithomiine and a Heliconine. There is no good example of Procryptic colouring in the whole Sub-Family, and the Heliconine types of Aposematic colouring are far more glaring than those of the Ithomiinae. When, however, we inquire into the relative numbers, it is seen at once that the Melinaea as an advertisement is hundreds of times as efficient as the Heliconius, because it is hundreds of times as numerous in the perfect state. With Mr. Kaye's kind help I obtained two days' captures of butterflies from the locality near the Potaro River, British Guiana, where this wonderful Müllerian combination has been chiefly studied. It was arranged that butterflies were to be taken as they came, without any selection. On the first day, August 28, 1903, just 323 butterflies were captured, of which 253 were Melinaea mneme, while 2 were Heliconinae-I Heliconius vetustus, and I Eueides nigrofulva. Of these, the first-named very perfectly resembles the dark-hind-winged forms of the Melinaea, while the Eucides is a far more outlying member of the combination. On the second day, February 23, 1904, out of a total of 325 butterflies, 220 Melinaea mneme were taken, but not a single Heliconine. ${ }^{1}$ Mr. Kaye's experience, extending over many years, quite confirms the extraordinary difference in numbers which was shown by the results of these two days' captures. It may be argued that the very numbers of the Melinaea imply a higher degree of unpalatability, but this is by no means necessarily the case. Relative numbers are determined by many other causes, such as fecundity, attacks (chiefly parasitic) in the earlier stages, \&c.

We are led to conclude that during the period of gradual approach the varieties of $H$. numata which were most conspicuously different from the pattern of Melinaea mneme suffered most, upon the whole, from experimental ${ }^{1}$ Proc. Ent. Soc., Lond., 1906, p. Ixi. 
attacks, and that thus gradually the existing resemblance was reached and is by the same process maintained. The immense difference in numbers explains why it is that this approach appears to have been entirely from the side of the Heliconius, and why the Melinaea was not appreciably affected.

It is interesting to note that the same relationship obtains between the Heliconinae of the special group which provides the Müllerian mimics, and their models, whether Ithomiine or Heliconine. In both cases the models exist in immensely greater numbers. It has been argued on p. 332 that the Ithomiine models are not more unpalatable than their Heliconine mimics. There is obviously even less reason for supposing increased unpalatability when the models are themselves Heliconinae.

b. The Old World.-We find precisely the same phenomena in the Old World. The distasteful muchmimicked Sub-Family, the Danainae, contains in addition to smaller aggregates two main groups, the Danaini and the Euploeini. Although the two are closely related, the last-named make up a homogeneous set of species with a very characteristic appearance, and it is convenient to separate them from the far less uniform Danaini. The Danaini range all over the tropics of the Old World, are everywhere mimicked, and everywhere enter into synaposematic combinations within the group itself, and with distasteful groups outside. A very few of them enter the New World, where they are mimicked in North (see p. 274) but apparently not in South America. The Euploeini, on the other hand, are almost absolutely restricted to the Oriental and Australian Regions (including Southern China, Malaya, and Polynesia). Within that area they are predominant, and abound in species. They are much mimicked, and enter largely into synaposematic combinations; but the colours and patterns are almost invariably those of the Euploeini themselves. The wide difference between the superficial appearance of the Euploeini and that of other Lepidoptera in their area of distribution, together with the uniform colouring and pattern of their abundant species and genera (if, 
indeed, these have been rightly made), have doubtless led to the development of combinations within the limits of the group, and the necessity imposed upon species of other groups to adopt the same Warning Colours. Once begun, such a process would of course tend still further to increase the uniformity within each combination. ${ }^{1}$

Now, are there any grounds in the above-mentioned facts for considering the Danaini more distasteful than the Euploeini, or vice versa? As regards the power of ranging the world and drawing towards them a variety of mimics of all kinds, the Danaini must be considered the superior; as regards predominance on the one area where they both meet, the Euploeini take the higher place. But in respect to unpalatability there is no reason for considering one more highly protected than the other. Yet in the few cases where representatives of the two groups enter the same synaposematic combination, it is, so far as we know at present, nearly always a Danaine that is attracted, and assumes the characteristic, superficial appearance of the Euploeine type. This is readily explicable, for the reasons given in discussing the case of Melinaea and Heliconius. The Euploeine type is far better known and far more valuable as a warning character than that of the comparatively isolated Danaine which enters the combination. The same association contains not one but several species of Euploea, all superficially alike, and between them producing enormous multitudes of individuals. ${ }^{2}$ Euploeini of the Trepsichrois

${ }^{1}$ See also p. $35^{8}$, where the possible rôle of the male scent brands of the Euploeini is suggested.

2 The same explanation probably holds in a curious example from South America. A species of the Nymphaline genus Colaenis, $-C$.telesiphe, is a beautiful mimic of a Heliconius with the same specific name, both being black insects with a broad red bar across the fore wing and a pale narrow stripe along the hind wing. There is no doubt about the identification of model and mimic, for the pattern of the Colaenis is isolated, while the Heliconius is in this respect related to many other species of its Sub-Family. I was therefore much surprised to see the mimic put down in a dealer's list at a shilling apiece, while the model was eighteen pence. I wrote for an explanation, and was informed, as I expected, that the prices represented the relative numbers of the specimens sent by collectors. It is probable that here, too, the effect 
mulciber group form an exception which supports the same conclusion; for their females, although acting as models for the Elymniinae (see p. 372), are undoubtedly themselves mimetic of the principal Danaine combination in their localities.

The same argument holds, and is even more convincing, in the synaposematic approach between species of the same genus, where there is even less ground for considering that the relation of model and mimic is determined by degrees of unpalatability. Mr. S. A. Neave has shown, in an interesting paper, ${ }^{1}$ that two of the dominant Danaini on the east and south of Africa, Amauris echeria and A. albimaculata,- - themselves so alike that they have been only recently separated on solid grounds,-come on the borders of their range under the influence of western species of the same genus with a different pattern. He shows conclusively, by measuring the diameters of a certain spot of the fore wing, that the eastern forms exhibit a more and more considerable synaposematic approach as they invade the districts where the western forms are more and more dominant (see also p. 337). Here, too, there is no reason whatever for regarding the effect as due to degrees of unpalatability.

We may summarize the above facts, and many more which are excluded by the exigencies of space, in the conclusion that in any given area the more evidence we possess that certain widely different groups of butterflies are all specially protected in a high degree, the more certainly will it be found that ( $\mathrm{r}$ ) within each group there will be Mimicry between the species of the same genus, and also between the species of genera both allied and widely separated, and that (2) there will be Mimicry between the species of the different groups. Furthermore, the most perfect

of the model is increased by the co-existence of other Heliconinae with somewhat similar patterns. Whether this interpretation be correct or not, the facts are opposed to the application of the Batesian Hypothesis. Mr. Marshall has also pointed out to me that Fritz Müller in 1878 demonstrated the existence of stink-glands in the genus Colaenis (Zeit. Wiss. Zool., xxx, p. 168).

3 Trans. Ent. Soc., Lond., 1906, p. 208. 
resemblances to models will generally be found among mimics with the highest degree of special protection.

It must be again pointed out, as it has been before (see pp. 235-7), that these mimetic resemblances are independent of affinity. In large numbers, even of closely related species, it can be shown that mimetic likeness is not ancestral, but has been superposed upon an earlier pattern which was entirely different.

4. The Limit to Mullerian Unification of Warning Colours in any Country.-The Müllerian principle of unification of Warning Colours, as an aid in the education of enemies, would seem to carry with it the implication that the process will continue almost indefinitely until the utmost possible simplification is attained. The facts brought forward in the last Section might also be considered to support this conclusion. Nevertheless, there can be little doubt that a limit is quickly reached, and that henceforward the main change consists in detaching the mimics or even the central models, when by migration, or spreading through increase of numbers, they extend beyond the influence of the original combination to which they belonged and come within that of another. The transference would be, of course, more easily effected if the pattern of the new combination resembled that of the old. The Muillerian principle is reciprocal in its action, and the crowd of mimics in a given combination-the less perfect as well as the more perfect-all tend to keep the central member or members stable.

The tendencies of Müllerian Mimicry are best studied in Africa, where the problem is far simpler than in South America. The chief Ethiopian models, the Danaini, are represented by comparatively few species, and of these a high proportion form the centres of strong Müllerian combinations. Thus on the East Coast, the common conspicuous Danaines are Limnas chrysippus, Amauris niavius (form dominicanus), $A$. ochlea, $A$. echeria and A. albimaculata. The two last, entering into the closest synaposematic relationship, form the centre of one strong combination, the first forms the centre of another, the second of another, the third of a smaller and less well- 
defined association. Some species like Papilio dardanus (merope) have forms entering two or more of the combinations (see below and pp. 373-5). The condition reached is probably stable: all the central patterns are clear, well defined, and very distinct from one another, and there is no reason for anticipating any tendency towards further unification. When, however, we pass westwards along the equatorial belt, it has already been pointed out (see p. 335) that A.echeria and its ally, the central models of perhaps the most important eastern combination, come within the sphere of western species of Amauris and show evident traces of influence. Why should the echeria-albimaculata type be influenced here and not along the East Coast? The answer is clear; because the pattern of the western Amauris is much nearer to that of the intruders than any of the eastern species of the same Danaine genus. This consideration suggests the probably sound conclusion that it would be impossible for these particular models from the East and West to form and keep distinct important combinations on the same area.

When we turn to the West Coast the same phenomena are met with. The Danaine models, when possessed of the same general pattern, tend to approach one another, or if the patterns be bold and isolated, to stand singly-in either case forming the centres of Müllerian combinations. In an extremely interesting example from the Cameroons, an abundant and dominant type of Amauris has drawn to it a species of a very different Danaine genus, Tirumala (or Melinda), $-T$. morgeni. The resemblance is extraordinarily close and deceptive.

Having given examples of the changes that occur in the central members of Müllerian groups, it is now necessary briefly to describe the changes that occur in a few of the outlying members. This can be well illustrated from the eastern combinations which have been mentioned above. One of the female forms of Papilio dardanus (merope), the cenea form, is a beautiful mimic of the echeria-albimaculata-centred combination. As we pass westward, another bold and conspicuous model, belonging to the Acraeinae, makes its appearance, 
Planema poggei. This black butterfly with a broad orange bar across the fore wing, and a white bar across the hind wing, appears to the east of the Victoria Nyanza, but has become far more dominant on the west shore, and thence extends to the west coast of the continent. The models overlap for some distance on both sides of the lake, and as far as Toro in Western Uganda. A new female form of $P$. dardanus, planemoides, beautifully mimetic of the Planema, appears on the east side, becomes common on the west, and extends to the coast. I have specimens of the cenea female up to the north-eastern shore of the lake, but not beyond. If they occur at all, they probably quickly cease westward, and the form has never been seen anywhere near the West Coast. In the case just described, one very different model replaces the other, leading to an equally wide divergence between a mimetic form and its substitute. It is more usual for the changes to be less abrupt, both models and mimics being replaced by closely allied representative species or sub-species. Thus we find the eastern Amauris niavius (form dominicanus), with an immense white patch, replaced on the west by $A$. viavius, with a considerably smaller white patch. The two sub-species meet, as described on pp. 68-9, on the eastern shores of the Victoria Nyanza, and there interbreed, if we may so conclude from the number of intermediate examples. Another of the mimetic females of Papilio dardanus (merope), the black and white hippocoon form, undergoes corresponding changes in pattern, and here, too, intermediate varieties are found in the neighbourhood of the lake. The equally beautiful Nymphaline mimic Hypolimnas (Euralia) wahlbergi of the east is similarly replaced at about the same point by the closely allied $H$. anthedon with a smaller white patch. Such examples might be multiplied almost indefinitely. Those here brought forward are, however, especially striking, being large insects with a bold and simple pattern. A succession of such replacements in an outlying member of a Müllerian combination, in correspondence with the successive changes in its other members, is described in the tropical American genus Protogonius, on pp. 350-2. 
It will be admitted that the above account may be taken as typical of the way in which Müllerian associations are scattered over a country, and of the changes which are witnessed as we follow them from one area into another. There is nothing to lead us to believe that progressive unification will occur on any given area. Each tract has developed its own set of important combinations. The recognition of these, and a memory of the implied qualities, is the climax of one important side of the education of an insect-eating animal.

5. Seasonal Transition from Cryptic to Synaposematic Defence.-The astonishing discovery by the irrefutable evidence of breeding, that Precis natalensis is the wet season form of $P$. sesamus, is briefly described on p. 208. The latter forms, with a highly procryptic under surface, were bred by Mr. Marshall from wet season individuals, in which the conspicuous colours and pattern of the upper surface are reproduced, considerably heightened in effect, upon the under surface. It is particularly interesting that upon both surfaces this wet season form should bear a general likeness to some of the larger red and black Acraeas found in various parts of its wide range. ${ }^{1}$ Although the shape of these broad-winged butterflies is very different from that of an Acraea, I do not doubt that Mr. Marshall is correct in considering the resemblance roughly mimetic. If we take different habits and modes of flight into account, it is difficult to believe that the resemblance would deceive a bird at any distance. It might well, however, put the bird on its guard and lead to a cautious attack during which a special defence would be recognized by the enemy. Hence it appears to be more reasonable to regard natalensis as a Müllerian than as

1 The present writer was in error in drawing a distinction between the basal white-marked black patch of the under side in natalensis, and the black-marked light-coloured patch which occupies the same position in Acraeinae. Although the foregoing is true of the great majority of African Acraeas possessing the marking, the particular large species (e.g., A. acara and A. anemosa), to which we must suppose that natalensis bears a general resemblance, exhibit a white-marked black basal patch. Compare Trans. Ent. Soc., Lond., 1902, pp. 424-8, where the upper and under surfaces of natalensis are contrasted in detail. 
a Batesian mimic. The same argument holds with greater force for the allied Precis antilope in which the resemblance to an Acraea is still more imperfect.

It will be of interest at this point to exhibit in a tabular form some of the remarkable series of appearances which the wet forms may display in relation to the dry in the great genus Precis (including Funonia).

\section{S. African habitat Species of the of Species.}

Character of Under Surface of Wings:

Dry season. Procryptic Procryptic

Wet season.

\section{Forest}

[Oriental]

Woodland

Woodland and Open Open, Swampy (in Mashonaland)

Woodland

Woodland and Open
Precis tugela

" elgiva

, natalica

, almana

, artaxia

archesia

, ' ceryne

" ${ }^{2}$ actia

" ${ }^{3}$ antilope

", "sesamus

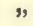

,

9

,

,

9)

9)

,

,
9

Directive marks (eyespots) developed.

Far less well concealed than the dry forms. Archesia I believe to be Aposematic.

Very conspicuous; roughly mimetic of an Acraea type.

The types of country alluded to in the table are as follows:-Forest, with heavy timber affording deep shade; Woodland, without timber, trees small, affording light shade; Open, nothing higher than small scrub. ${ }^{5}$

The discovery of the nature of the physiological stimulus determining the two forms of Precis is a most interesting problem, to which Mr. Marshall has devoted an immense amount of labour. The outcome of his splendid investigations under most difficult conditions is not yet published, and therefore I will only say that the results exhibit much that is puzzling and contradictory. As bearing upon the problem, it may be stated that the wet

1 Dry form bred from wet by Marshall in 1905 : Proc. Ent. Soc., Lond., 1906, p. lvii.

2 Dry form bred from wet by Marshall in $1903:$ Proc. Ent. Soc., Lond., 1903, p. xxxii.

3 Dry form bred from wet by Marshall in 1902: Trans. Ent. Soc., Lond., 1902, pp. 418-20.

4 Dry form bred from wet by Marshall in 1898: Ann. Mag. Nat. Hist., ser. 7, vol. ii, July 1898 , p. 30.

- Trans. Ent. Soc., Lond., 1902, pp. 422-3. 
season ocellated phase of Precis almana, the asterie form, is the only one found in the permanently damp forests of Siam. The wide experience of Mr. T. R. Bell in North Kanara has led him to the belief that a larval food consisting of young succulent leaves containing abundant moisture, is the condition determining the wet season forms of the dimorphic butterflies that have come under his observation. ${ }^{1}$ (See also pp. 3 I I , 3 I 2.)

Mr. Marshall also considers that the under surface of the wet season Nymphaline butterfly, Byblia götzius is mimetic of the Acraea serena type of pattern, while the under surface of the dry forms of it and B. ilithyia is Procryptic. ${ }^{2}$ An intermediate ilithyia and a dry götzius bred by him from the eggs laid by wet season females are figured, together with the respective parents, by Dr. Dixey. ${ }^{3}$ In order to realize the general resemblance of these latter to an Acraea it is necessary to imagine the fore wings almost entirely covered by the hind, as in the attitude of repose. The application in the early wet season of dry warmth to the pupae of ilithyia caused a butterfly to approach the dry season type. ${ }^{*}$

Dr. Dixey has stated that, while the under surface in both sexes of Teracolus regina is clearly Procryptic in the dry season, it is in mimetic association with certain undescribed forms of Belenois in the wet. ${ }^{5}$

6. Seasonal Transition in degrees of Synaposematic Defence, or from Aposematic to Synaposematic Defence.Dr. F. A. Dixey has recently described the following interesting seasonal changes of Ethiopian Pierinae. ${ }^{6}$ The dry season male of Belenois thysa is a much better mimic of the male of Mylothris agathina than is the wet season male; while the female thysa is an excellent mimic of the female agathina in the dry season, but does not mimic it at all in the wet. The Mylothris model shows no seasonal

1 Ent. Mo. Mag., I 906, p. 122.

2 Ent. Mo. Mag., I902, p. 49.

3 Trans. Ent. Soc., Lond., 1902, p. 189, pl. iv.

4 Trans. Ent. Soc., Lond., 1902, pp. 202, 203.

- Proc. Ent. Soc., Lond., I 906, pp. xcvi, xcvii.

- Proc. Ent. Soc., Lond., 1906, pp. xxxvi, xxxvii; 1907, pp. xxiii, xxiv. 
change. Furthermore, the males of four species of Teracolus (achine, omphale, evenina, antigone) are often nearly indistinguishable in the dry season but can be separated at a glance in the wet. The same comparison holds, but to a less extent, with the females of the dry and wet broods. A similar relationship obtains in two Indian species of the Oriental and Austro-Malayan Pierine genus Huphina, $H$. nadina and $H$. phryne.

It is impossible to leave this part of the subject without alluding to the European Nymphaline butterfly, Araschnia levana and its later form prorsa, investigated by Weismann, and proved by him to be susceptible to the stimulus of temperature in the pupal stage. It has been suggested that the black white-marked form prorsa is mimetic of the species of Limenitis (White Admirals), which, although larger, possess a pattern of the same general type on both upper and under surfaces. The earlier brood levana has been similarly compared to a small Fritillary. If these suggestions be confirmed we should witness a seasonal transition in the kinds rather than the degrees of Minetic and probably Synaposematic Defence.

7. The Gradual Predominance of the Miillerian Hypothesis.-A brief history of the discovery of Müllerian Resemblances among the butterflies of South America, the East, and finally of Africa, has been given on pp. 222-3; their extension to explain the uniformity in the species of distasteful groups, and the resemblances between the Warning Colours of all kinds of forms in the same country, is referred to on pp. 230-4. A fuller statement of the essential differences between the rival hypotheses will be found on pp. $211-15$.

Reasoning, based on the investigations of the last I 3 years, has tended more and more to remove examples from the category of Batesian (Pseudaposematic) Mimicry and transfer them to that of Müllerian (Synaposematic) Resemblance. Thus almost the whole of the butterflies and moths shown in the lecture before the British Association ( 1890 ) as examples of Batesian Mimicry would now be looked upon as instances. of 
Common Warning Colours (Müllerian Resemblance). Some of the reasons for this change of view are briefly indicated on pp. 370-6, where a nearly complete list ${ }^{1}$ of the examples intended to illustrate Protective Mimicry is quoted.

The recent sudden growth in the importance of the Müllerian Hypothesis in Lepidoptera dates from two papers $^{2}$ published by Dr. F. A. Dixey in 1894 . In these it was shown that both Pierines and Papilios enter Müllerian associations. Two years later Dr. Dixey wrote, ${ }^{3}$ after again discussing the Müllerian relations between Heliconines and Pierines:- 'The same argument will apply to features similar to the above which may be seen in certain Papilioninae, Nymphalinae, Erycinidae, and even in some moths. And I may say in passing that Fritz Müller's principle here referred to appears to me to be of much wider application than has been hitherto supposed. There exist several large groups more or less uniform in their scheme of coloration, though heterogeneous in their affinities, which it seems almost certain will in the main turn out to be cases of "inedible associations", each one possibly including a few instances of true mimicry within its borders.'

The wonderful sets of South American butterflies selected by Mr. W. F. H. Blandford from the GodmanSalvin Collection, and exhibited at the Entomological Society of London ${ }^{4}$ in 1896 and 1897 , also had a marked effect in stimulating interest in the Müllerian Hypothesis. It was at once obvious that the most remarkable resemblances were those between species belonging to the most highly protected groups, and especially between the Ithomiinae and Heliconinae.

The change of opinion is not only due to a re-study of the old examples, but to entirely new material which

${ }^{1}$ The list is complete except for the examples illustrating the history of the transparent-winged mimics of Hymenoptera. These are quoted on pp. $3^{6} 5-6$.

${ }_{2}$ Brit. Assoc. Report, 1894, p. 692. Abstract. Trans. Ent. Soc., Lond., 1894, p. 298.

8 Trans. Ent. Soc., Lond., 1896, p. 75.

4 Proc. Ent. Soc., Lond., 1896, p. xxxviii ; 1897 , p. xxii. 
seemed at once to call for the Müllerian rather than the Batesian interpretation. A fine instance is to be found in the wonderful African group shown by Mr. G. A. K. Marshall to converge towards the distasteful Lycid beetles. It is briefly described on p. 276 .

The chief lines of indirect evidence in favour of the Muillerian interpretation are due to the investigations of Dr. F. A. Dixey. They are briefly set forth in the two following Sections. These will be succeeded by three further Sections in which additional lines of indirect evidence will be considered. The sixth Section from the present point, Section I 3, will be devoted to the discussion of counterbalancing evidence which is believed to support the Batesian interpretation.

8. Diaposematic Resemblance; Reciprocal Warning Colours.-Dr. F. A. Dixey first recognized the fact that in certain cases of superficial resemblance the butterfly, hitherto regarded solely as the model, has itself advanced to meet the very different species regarded as its mimic. For this attainment of a resemblance by mutual approach he suggested the name 'Reciprocal Mimicry'.' Dr. Dixey also argued with great clearness and force 'that reciprocal mimicry can only take place in Müllerian associations, not in Batesian; and that it is therefore . . . "good evidence of the distastefulness of all the forms between which it can be shown to occur" ' ${ }^{2}$ The present writer has urged $^{3}$ that the name 'Reciprocal Warning Colours' is more appropriate than 'Reciprocal Mimicry', inasmuch as Mimicry, as first explained by H. W. Bates, is invariably a deceptive or Pseudaposematic Resemblance. In order to include Dr. Dixey's principle in the terminology proposed in $1890,{ }^{4}$ the name 'Diaposematic Resemblance' was, with Mr. Arthur Sidgwick's assistance, suggested for it. ${ }^{5}$

1 Trans. Ent. Soc., Lond., 1894, p. 298.

2 Trans. Ent. Soc., Lond., 1897, p. 328 . In the above passage Dr. Dixey is quoting from his earlier paper in Trans. Ent. Soc., Lond., 1896, p. 75 .

\footnotetext{
Proc. Ent. Soc., Lond., 1897 , pp. xxviii, xxix.

- Colours of Animals, 1890, pp. 336 et sqq.

"Proc. Ent. Soc., Lond., 1897 , p. xxix, n.
} 
Further examples of Diaposematic Resemblance have been suggested and considered in recent years by Mr. S. A. Neave ${ }^{1}$ and the present writer. $^{2}$

9. Primary and Secondary Milllerian Resemblance; Proto- and Deuterosynaposematic Resemblance.-The principles discovered by Dr. Dixey and briefly described in the preceding Section are further set forth in the following passage :- Every conspicuous and distasteful form is a centre of attraction for other forms, whether edible or inedible; but in the former case (Batesian Mimicry) the mimetic attraction is limited in operation, and acts only in one direction, influencing nothing but the mimic; while in the latter case (Müllerian Mimicry) the mimetic attraction is unlimited and mutual, acting reciprocally in both directions, and influencing each member of the group.' ${ }^{3}$ This and other passages in Dr. Dixey's important series of papers on the Müllerian principle,${ }^{4}$ have prepared beforehand for the discovery of many cases, especially in Ethiopian butterflies, where the species of a single combination, in addition to their primary resemblance to some central model (almost invariably a Danaine) have undoubtedly been modified into a Secondary Resemblance to each other. ${ }^{5}$ Such Deuterosynaposematic approach is quite independent of affinity ; for the blood-relationship of a species to the primary model may be far closer than it is to a co-mimic towards which it is drawn by Secondary Resemblance. It is obvious that the existence of these complex resemblances supports the interpretation of the group within which they are manifested as Synaposematic (Müllerian) rather than Pseudaposematic (Batesian). ${ }^{6}$ It is interesting to note that in certain cases the Secondary Resemblance is

1 Trans. Ent. Soc., Lond., 1906, pp. 21 6-18.

2 Trans. Ent. Soc., Lond., 1902, pp. 488-90.

3 Trans. Ent. Soc., Lond., I 897, pp. 324-5.

4 See p. 213, n. I.

- Trans. Ent. Soc., Lond., 1902, pp. 470-2, 485-7. The same phenomenon has been observed in African Coleoptera, l.c.pp. $5^{1} I_{-1} 5$.

- Hence it was probably erroneous to suggest the existence of Secondary Batesian Mimicry (Deuteropseudaposematic Resemblance): l.c. p. $5^{15}$. 
closer between the species exhibiting a strong Primary Mimicry than between those exhibiting a weaker resemblance to the central model. This suggests that the Secondary Resemblance is of permanent value, and not a mere phase which will ultimately be lost in the Primary Resemblance. ${ }^{1}$

The very best example of Secondary Mimicry I have ever seen was shown to me, when a young man, by the late Professor Westwood. He asked what I thought of two small transparent-winged, black-marked South American Lepidoptera with hind wings margined in red and black. Did I think they were the same species? To my inexperienced eyes, attracted by the pattern, they looked absolutely alike. Did I think they were the same genus or family, and finally was it possible that one was a butterfly and the other a moth? And so it proved to be! The model was a small Erycinid butterfly, itself a mimic of an Ithomiine; the mimic a day-flying moth of the same size. In this remarkable case, the Secondary Mimicry was far closer than the Primary. Not only is the Erycinid shown to be specially protected by acting as a model, but the moth itself was a member of a conspicuous distasteful group.

ro. Further Indirect Evidence Supporting a Miillerian or Synaposematic Interpretation. - The following generalizations, first published in $1902,{ }^{2}$ support the Müllerian interpretation of a large number of examples previously explained upon the Batesian Hypothesis.

(a) The fact that mimetic likeness tends to run in genera or larger groups and is rarely seen in single isolated species. It is more reasonable to explain this fact by the hypothesis of some special defence common to the group in question, than by supposing that all or almost all of its members are compelled to shelter themselves under a deceptive likeness to other dominant and specially defended forms.

(b) In many cases it is known that the mimetic groups are large and dominant, and the individuals of many of

1 Trans. Ent. Soc., Lond., 1 902, p. 485.

2 Trans. Ent. Soc., Lond., 1902, pp. 500-2. 
the species excessively abundant. Some mimetic species have an immense range, in the case of Hypolimnas misippus far exceeding that of the model. ${ }^{1}$

(c) The marked tendency towards Mimicry in the species of a single group cannot be explained by hereditary transmission of the mimetic form attained by a single ancestral species, or from the tendency of closely related species to vary along nearly the same lines. As a matter of fact, the species of such groups, mimicking various different models, have been led to diverge in all kinds of directions.

(d) The non-mimetic species of mimetic groups and the non-mimetic males of mimetic females are, as a rule, distinguished by a conspicuous and apparently Aposematic colouring. Such Aposematic patterns are especially developed on the under surface of the wings, where Procryptic colouring is found in other butterflies.

(e) The converse of this last argument is also true, viz., some of the species in a group, which is as a whole markedly conspicuous and itself mimicked, are often mimetic of quite other groups. Forms closely related to Mimetic species tend to be Aposematic; Forms closely related to Aposematic species tend to be Mimetic.

$(f)$ The non-mimetic species of mimetic groups and the non-mimetic males ${ }^{2}$ of mimetic females are sometimes themselves mimicked.

(g) Species which mimic the best known and presumably the most unpalatable models are often in certain points even more conspicuous than their models. They appear to have retained some traces of Warning Characters which they possessed before the mimetic likeness was assumed. ${ }^{3}$

(h) The fact that the resemblance between species belonging to the admittedly distasteful groups is far closer and more perfect than that between these and the species of groups believed to be palatable.

1 See p. 216.

2 A good example is described on pp. $217-18$.

${ }^{3}$ For examples see pp. $37 \mathrm{I}, 375$. Another very good instance is seen in the great Ethiopian Aletis-Euphaedra combination mentioned on p. 232. 
II. Miillerian Resemblance Associated with Warning Colours; Batesian Mimicry Associated with Cryptic Colours.-Protective Mimicry is, as Wallace has stated, merely 'an exceptional form of protective resemblance (see p. 226). On the other hand, Müllerian Resemblance only differs from ordinary Warning Colours in that it is common to two or more species. When, therefore, we desire to obtain a general indication of the probable interpretation of a certain resemblance it is reasonable to consider as a whole the group to which the species exhibiting it belongs. Tested in this way, the vast majority of the superficial resemblances of the Lepidoptera and Coleoptera-for the two Orders supply wonderfully concordant evidence ${ }^{1}$-are Müllerian and not Batesian. They are chiefly manifested in groups with distinct Warning Colours, and, furthermore, the principal Aposematic sections always seem to include examples of these resemblances. In the Cryptic groups, on the other hand, they either do not occur or else they form welldefined subordinate groups, of which all the members are Mimetic, or Mimetic and Aposematic. The further the study of Mimetic Resemblance is carried the more clear it becomes that the affinity is with Warning and not with Cryptic Colours. We meet with striking exceptions, however, in the species with a Mimetic pattern on the upper and a Procryptic pattern on the under surface (see pp. 350-4), as well as in the seasonal transitions of certain species (see pp. 320, 339-4I).

Equally significant is the ever-increasing evidence that groups which contain imitators also include other species which are imitated. The same species may even act in both capacities, as has been described on pp. 215-18. A very striking example was discovered by Mr. R. Shelford in Borneo. Longicorn beetles belonging to the Clytinae tend, nearly all over the world, to resemble wasps or other specially defended Hymenoptera. This is the case with our own Wasp-beetle (Clytus arietis) as described on pp. 25I-2. Well, Mr. Shelford has 
shown ${ }^{1}$ that in Borneo many non-mimetic Clytinae are themselves resembled by entirely different Longicorn beetles, and as soon as attention was directed to the case Mr. C. J. Gahan found the same thing happening in Ceylon. ${ }^{2}$

12. Mimelic Patterns in Stations or Localities Different from those of the Model.-Many examples are already known in which the mimic inhabits a station where the model is rare, or even unknown. Thus the Geometrid moth Abraxas etridoides is found on the hills and its model Teracolus etrida in the plains of Southern India. Only recently I have heard from Mr. S. A. Neave that several of the African mimics of chrysippus, belonging to the Nymphalinae, Acraeinae, and Lycaenidae prefer the woodland while their model is chiefly found in open grassy places. Still more striking butmuch rarer are the instances in which the mimic is found in a very different locality from its model (see pp. 2I 7, 218). The spreading of a mimic beyond the range of the model is probably by no means rare: a remarkable example is quoted on p. 216.

All these curious relationships are difficult to understand on the Batesian Hypothesis, easy on the Müllerian. It is impossible to believe that sharp-sighted enemies would remain deceived by the likeness of a palatable mimic in one station or locality to a distasteful model in another. But if we suppose that the mimic also is distasteful and possessed a warning pattern of its own before the mimicry began, the interpretation is clear. Its mimetic pattern still remains a warning of distastefulness, more easily learnt, that is learnt with less waste of life, because it is similar to that of a still more abundant distasteful form well known to the enemy. In this way, too, it is possible to understand why the growth of a very perfect resemblance often leaves untouched some small but distinct discriminating feature. Thus differences in habits and modes of flight often persist and would be recognized by an observant enemy as they are by the naturalist.

${ }^{1}$ Proc. Zool. Soc., Lond., 1902, vol. ii, pp. $250-1$. See also the corresponding illustrations on $\mathrm{pl} . \mathrm{xx}$.

l. c., p. 252. 
Thus, too, traces of the scalloped border are almost invariably retained by the mimetic species of Hypolimnas, and a Heliconine can nearly always be distinguished at a glance by the short radiate white lines on the black border of the hind wing under side. These take the place of roundish white spots which occupy the same position in the Ithomiine model.

It is possible that simple and easy means of discrimination such as those described in the last paragraph may facilitate recognition between the sexes (see p. 358). But whatever be the value to the species, their persistence is a far greater difficulty on the Batesian than on the Müllerian Hypothesis.

13. Classes of Facts which have Recently been Urged in Support of the Batesian Hypothesis.-Many arguments have been given in favour of the Müllerian as opposed to the Batesian interpretation of Mimicry, and now two counterbalancing considerations remain to be discussed.

a. Butterfies Exhibiting Mimetic Resemblance on the Upper Surface of the Wings and Procryptic Defence on the Under Surface.

Instances of this interesting combination of methods are rather rare, the chief examples being found in a single Sub-Family in the Old World and a single genus in the New. Other instances belonging to the Nymphalinae are however, not uncommon. Dr. Dixey considers that the same combination is to be found in several Pierinae, e.g. in the genera Teracolus and Eronia. ${ }^{1}$

In the tropical American Nymphaline genus Protogonius the whole of the species or sub-species are imperfect but undoubted members (as regards the upper surface) of the principal Ithomiine-centred Synaposematic combinations of their respective localities. They reproduce roughly but clearly the characteristic elements of the pattern whatever they may be: the barred black and tawny pattern of Central America and Venezuela, the overspreading yellow of Trinidad, the darkened hind wing of the Guianas, the yellow hind wing stripe and white fore

${ }^{1}$ For Mimicry in the latter genus see Prof. Ent. Soc., Lond., 1906, pp. $x x x, x_{x x i}$ 


\section{IN DEFENSIVE COLORATION}

wing apical spot of Eastern Brazil, the chestnut groundcolour of the Upper Amazon at Ega, the bold black and tawny of Ecuador, Bolivia, and Peru. The Procryptic colouring of the under surface differs from the mimetic pattern of the upper in its perfection. The resemblance, invariably to a dead leaf, is remarkably detailed and beautiful. The general colouring of the upper surface does indeed influence the under, but never in such a manner as to interfere in any way with the cryptic effect. Thus, the under surface of the dark forms from Ega and Peru is mottled with rich dark shades of brown, while in the pale and yellowish Protogonius from Trinidad the shades are light in tint and include prominent greys and yellows. Similarly in every locality a correspondence between upper and under surface is at once evident, but nevertheless the first always remains roughly mimetic, the second beautifully cryptic. The hind wing in this genus possesses a well-developed 'tail', somewhat expanded at the end, and this is probably Directive during the active condition, serving to divert attacks from the body, while during profound rest it may resemble a leafstalk and thus aid in the cryptic effect. This suggestion requires for its confirmation the careful observation of the living insect.

The interpretation of the facts presented by this deeply interesting genus is by no means easy. It has been brought forward by Mr. R. Shelford ${ }^{1}$ as an instance of Pseudaposematic or Batesian Mimicry, and I have always thought that it afforded some of the strongest, probably the very strongest, evidence in support of the existence of such resemblances among butterflies. The colouring of the upper surface is undoubtedly displayed during flight, and has been developed in relation to attacks made when the butterfly is upon the wing. ${ }^{2}$ The mimicked Aposematic pattern would of course make the butterfly extremely conspicuous, while at the same time the roughness of the resemblance and different mode of flight would render it easily distinguishable among the crowd of Ithomiines,

1 At the Entomological Society, June 5, 1907. Unpublished.

2 See W. J. Kaye in Trans. Ent. Soc., Lond., 1906, p. 431. 
Heliconines, \&c. Again, the fact that every form in the genus is mimetic leads us back to a mimetic common ancestor. Now there is no difficulty in understanding such an evolutionary history in a group of closely related Müllerian mimics. The common ancestor possessed some special protection in the way of unpalatability, \&c., and adopted the Warning Colours of other more powerful combinations, also specially defended. The species or forms to which the common ancestor gave rise inherited the defensive quality, spread into various districts, and joined the local Synaposematic combinations. It is very different when we attempt to reconstruct this history on the hypothesis of H.W. Bates, and try to imagine qualities in an ancestor which would determine universal Pseudaposematic Resemblance among the descendant species. Upon the whole, therefore, it is probable that Protogonius is specially protected like so many other Nymphaline genera, and that the defence holds against the majority of enemies that attack butterflies upon the wing. Against these all the advantages of Müllerian Resemblance would be gained. Such enemies, put on their guard by the well-known Warning Colours, would learn to avoid this member of the group with a lessened waste of life from experimental tasting. Against special enemies that would devour them in spite of their special defence, the cryptic colouring would be a valuable safeguard, making the insects extremely difficult to mark down when they came to rest. The concealed under surface is also of importance-probably of supreme importance-as a protection against the class of enemies that hunt for insects in a state of complete repose.

Before passing to the consideration of the next group, I desire to state that the interpretation of these two difficult cases is put forward in no confident or dogmatic spirit. The balance of evidence appears to me to suggest the conclusion here stated. It is impossible to predict whether the further knowledge, so greatly needed, will bring with it confirmation or revision.

The chief Old World examples which manifest the same interesting combination are to be found in the little 
Nymphalid Sub-Family the Elymniinae, closely related and, by many systematists, united to the Satyrinae. With a very. few possible exceptions the whole of the Elymniinae are mimetic. Both sexes of the few Ethiopian forms resemble Acraeinae-closely upon the upper surface, more roughly but still distinctly on the under. The Oriental and Austro-Malayan forms mimic Euploeini, Danaini, Pierinae, and Morphinae (or Amathusiinae, as the Old World representatives of the group are sometimes called). Of all these the Euploeini, forming the dominant distasteful group of the Regions, are by far the most important as the models of this Sub-Family. The females are in many of the species far more striking mimics than the males, and often mimic different models. The Mimetic Resemblance on the under surface is in some species very perfect, in others imperfect, while in a considerable proportion it is replaced by a . Procryptic Resemblance to dead leaves which, although wanting the perfection and detail of Protogonius, is doubtless very efficient in promoting concealment. A small number of species which do not fall into the above categories apparently possess Warning Colours peculiar to themselves, or patterns which, without further evidence, we cannot as yet interpret.

Mr. Shelford, who has had an intimate experience of the male of the Bornean species, Elymnias (Melynias) lais, describes it as closely resembling, upon the wing, the abundant Danaines of the genera Caduga, Parantica, \&c., but disappearing the moment it comes to rest on the ground among dead leaves, when the procryptic under surface is alone visible. ${ }^{1}$ From this he infers, as in Protogonius, that the butterfly is palatable to birds which would reject the Danaine model as unpalatable, but that these enemies do not distinguish the one from the other when upon the wing: in other words, he considers the resemblance to be Pseudaposematic, or an example of Batesian Mimicry. This conclusion may be sound, both for Protogonius, Elymniinae, and other forms with the same methods of colouring. It must in any

$$
1 \text { Proc. Zool. Soc., Lond., 1902, vol. ii, p. } 259 .
$$


case be admitted that the Batesian interpretation is more probable here than in other butterflies. But, for the reasons given in the discussion upon Protogonius, it appears to me that the balance of probability is the other way. The Elymniinae being, almost without exception, a mimetic Sub-Family, we must certainly assume a mimetic ancestor with qualities determining mimetic descendants. It has been already shown that such a history is consistent with the Müllerian interpretation, but with our present knowledge difficult or perhaps impossible to reconcile with the Batesian Hypothesis (see p. 352).

b. Dimorphic or Polymorphic Mimetic Butterflies with Forms Resembling Different Models. - The phenomenon described in the title of this Sub-Section is quite common among mimetic species. Examples will be given in a later part of this Essay (see pp. 372-5) showing that the male and female of a mimetic species may resemble different models; that the male may resemble one model, and two kinds of female two others; that a non-mimetic male may be accompanied by two, three, or even four forms of female mimicking different models. The great example of this latter complex form of mimicry is of course the Ethiopian Papilio dardanus (merope), described on pp. 373-5.

At first sight such cases appear strongly to support the Batesian interpretation. His hypothesis assumes that the resemblances are a fraud which, if detected, would lead to the destruction of the mimic. It may be admitted that great increase in numbers would multiply the chances of detection, and hence, upon the Batesian Hypothesis, the advantage to a mimic of dividing its individuals among two, three, or four models instead of concentrating all of them upon a single one. Accepting this conclusion, I was much startled in $1902,^{1}$ when considering the African Acraeine butterfly, Acraea esebria, to observe that this protected and distasteful species possessed two forms of mimetic female, both resembling Danainae-one Limnas chrysippus and the other the black and white species of $A$ mauris.

3 Trans. Ent. Soc., Lond., I 902, p. 469. 
'When an abundant well-protected Acraea thus approximates to two very different Danaine patterns, it is obvious that we are not necessarily driven to a Batesian interpretation of the forms of the female Papilio cenea [the southern and south-eastern sub-species of $P$. dardanus (merope)], which approximate to the appearance of Amauris echeria as well as to ... two other Danaine types.... The enemies of chrysippus and the species of Amauris are certainly not precisely the same, and it may well be an advantage to a Müllerian mimic to secure that increased protection from [the experimental attacks of ] insect-eating enemies, which is conferred by belonging to two or more groups. ... It is probably of advantage to the whole group that the Danaine which set the pattern should still be the dominant member of the assemblage of which it is the centre. This dominance is favoured by the individuals of an abundant species joining two or more groups, instead of throwing the whole of their number into a single one.' 1 We may add to these considerations the advantages that would be gained from differences in the distribution or local predominance of the various models, and from any overlap they may exhibit in time. A Müllerian mimic belonging to two or three combinations is far more likely to be surrounded by models and co-mimics in any given place, or at any given time, than a nimic which belongs to a single one. Indeed, when we consider it, there is no essential difference between a mimetic species such as Hypolimnas misippus, or Acraea encedon, presenting three forms resembling respectively the three forms of the single species, Limnas chrysippus, which serves as a model, and the cases under discussion where models of two or three very distinct species are mimicked. The advantages conferred are probably nearly the same, and a specific identity, or remote affinity, between a set of models in any area would not in itself affect the selective process by which they became mimicked by the forms of a single species.

It is thus seen that the polymorphism of a mimetic 1 Trans. Ent. Soc., Lond., 1902, p. 469.

A 22 
species, leading it to resemble two or more models, although at first sight suggesting only a Batesian interpretation, does not by any means exclude the Müllerian. The facts presented by a dominant well-protected Acraeine mimic prove that a resemblance to more than one model cannot serve as a criterion between the two rival theories.

14. A Possible Instance of Observable Change in a Member of a Miullerian Group since $1825-7 .-$ A powerful combination ${ }^{1}$ of distasteful butterflies in Eastern Brazil has developed a characteristic pattern of which the most marked feature is a bright yellow horizontal band running along the hind wing. The central members are Ithominae and Heliconinae. An outlying member is the Danaine butterfly Lycorea halia, with a pale band instead of a bright yellow one. In the Hope Collection at Oxford there are eight examples, captured by W. J. Burchell, in Brazil, between Nov. IO, I825, and Dec. 24, I827. There can be no doubt that these specimens, which are in very good condition, are on the whole further removed from the combination than captures of recent date, 'inasmuch as the band is but slightly paler than the tawny ground colour of the wing.' Unless, therefore, there has been a darkening of tint with age, we have here an example of approach towards the combination since $1825-7$. The case is precisely of the kind in which some observable change might be looked for. That a butterfly which is outlying to-day should have been even more outlying seventy-five years ago, is not surprising. But many further observations must be made before the evidence can be accepted as in any way satisfactory. ${ }^{2}$

\section{B. Allaposematic Colours, or Adventitious Warning Colours.}

Certain palatable animals make use of the Special Defence and Warning Colours of other forms. Thus, the common English hermit-crab, Pagurus bernhardus*,

${ }^{1}$ Blandford's Series iv, Group 3, Division (a): see Proc. Ent. Soc., Lond., r897, p. xxiv.

${ }^{2}$ See Ann. Mag. Nat. Hist., ser. 7, vol. xiii, May 1904, pp. 359-60. 
commonly carries on its borrowed shell the conspicuous stinging sea-anemone Sagartia parasitica; while another English species, Pagurus prideauxii*, inhabits a shell which is invariably clothed by the flattened Adamsia palliata. Two crabs (Polydectus cupulifer* and Melia tessellata*), from Mauritius, described by Möbius, invariably held a sea-anemone in each claw.

Two other groups of animals, sponges and Ascidians, in addition to sea-anemones, are avoided by enemies of the Crustacea, and these are also employed by the latter. Thus the British hermit-crab Pagurus cuanensis* is found in shells which are covered with a (generally) brightly-coloured sponge (Suberites domuncula). Möbius also describes a Mauritian hermit-crab (Ascidiophilus caphyraeformis*) which lives in a case formed by an Ascidian.

\section{Episematic or Recognition Characters.}

Episematic Colours are the logical antithesis of Aposematic, their object being to assist in keeping friends together instead of keeping enemies at a distance. Episematic markings help the individuals of the same species to keep together when their safety depends upon numbers, or to follow each other to a place of safety, thus enabling the young and inexperienced to profit by the example of the older. Episematic characters are far less common than A posematic, and these than Cryptic ; although, as regards the latter comparison, the opposite impression is generally produced from the very fact that concealment is so successfully effected.

The white patch near the tail which is frequently seen in the gregarious Ungulates, such as the Red Deer*, and is often rendered conspicuous by adjacent black markings, probably assists the individuals in keeping together; and appearances with perhaps the same interpretation are found in many birds. The white, upturned tail of the Rabbit* is probably of use in enabling the individuals to follow each other readily. Many of the sounds made by animals probably have the same meaning, as also the characteristic flicking movements with which 
the individuals of certain burrowing species disappear into their tunnels.

Episematic markings afford a very good illustration of the subordination of the individual to the community or species which is so evident in nature whenever we look beneath the surface. It is only the superficial observer who sees the triumph of individualism in the sway of Natural Selection. Nevertheless, the danger of Recognition Characters is reduced to the lowest possible level.

The difference between a typical Aposematic Character appealing to enemies, and an Episematic Character intended to assist other individuals of the same species, is well seen when we compare such examples as (I) the large, banner-like white tail, conspicuously contrasted with the black or black and white body, by which the slow-moving skunk warns enemies of its power of emitting an intolerable odour; (2) the small, upturned white tail of the rabbit, only conspicuous when it is likely to be of use, and when its owner is moving, and, if pursued, very rapidly moving towards safety in the burrow.

It is by no means improbable that the wonderfully exact likeness between closely allied butterflies with Common Warning Colours would tend to confuse the sexes, and that the remarkable differences in the scentpatches of males in certain groups (Euploeini, certain Danaini, Heliconinae ${ }^{1}$ ) have been developed in order to facilitate recognition by females of the same species. ${ }^{2}$

\section{PSEUDOSEMATIC RESEMBLANCE, OR} PROTECTIVE (BATESIAN) AND AGGRESSIVE MIMICRY: PSEUDAPOSEMATIC AND PSEUDEPISEMATIC RESEMBLANCES.

Protective and Aggressive Mimicry may be defined as False Warning and Signalling Colours (Pseudosematic), repelling enemies by the deceptive suggestion of some unpleasant or dangerous quality (Pseudaposematic), or

${ }^{1}$ W. J. Kaye in Proc. Ent. Soc., Lond., I 907, p. xiv. The margin of glistening scales which by its breadth in the males divides the Heliconinae into two sub-groups, is in all probability a scent-producing area.

"Poulton in Proc. Ent. Soc., Lond., June 5, 1907, p. xl. 
alluring prey by the deceptive appearance of something attractive to them (Pseudepisematic). Even foreign objects commonly associated with some well-defended and aggressive species may be mimicked by a comparatively defenceless form (Pseudallaposematic).

I. Various Uses of the Term 'Mimicry': The Essential Element in Batesian Mimicry.-Mimicry is often extended to include all the superficial resemblances between animals and any part of their environment. It was thus employed by Bates, although the characteristic and original part of his memoir deals exclusively with Protective Mimicry. Wallace separated the Cryptic Resemblances already described, and the majority of naturalists have followed this convenient arrangement. In Cryptic Resemblance an animal gains a likeness to some object of no interest to its enemy or prey, and in so doing is concealed. In Protective Mimicry an animal resembles some other animal (almost invariably with Warning. Colours) which is especially disliked by its enemy; in Aggressive Mimicry an animal or some part of it resembles an object which is especially attractive to its prey. In either case conspicuousness to enemy or prey respectively is the usual incidental result.

Excluding Cryptic Resemblances, the term 'Mimicry' is generally used to express a resemblance, independent of affinity, between certain species inhabiting the same country-a resemblance which appeals to the senses of enemies, especially to the sense of sight, not uncommonly to hearing, occasionally to smell and touch. Even this definition is, however, far too wide, and includes at least five distinct kinds of resemblance, to only one of which the term 'Mimicry' as explained by Bates's wellknown hypothesis is strictly applicable.

$a$. The resemblance of a mollusc to the coral on which it lives, or an external parasite to the hair or skin of its host, would be Procryptic.

b. That between moths which resemble lichen, Syncryptic (see p. 312).

c. That between the Insectivor mole and the Rodent mole, Syntechnic (see p. 312). 
d. That between distasteful insects, Synaposematic (see p. 327).

e. That between a palatable mimic and its unpalatable model, Pseudaposematic or Mimetic in the Batesian sense. ${ }^{1}$

The essential element in Protective Mimicry is that it is a False Warning (Pseud-Aposematic); in Aggressive Mimicry that it is a False Attraction (Pseud-Episematic).

Some have considered that Mimicry implies resemblance to a moving object, but apart from the various other likenesses between animals shown in the above classification, there are common Cryptic Resemblances to drifting leaves, swaying bits of twig, \&c., while true Mimetic Resemblances are often specially adapted for the attitude of prolonged rest.

The term 'Mimicry' is generally used to include Synaposematic as well as Pseudaposematic Resemblances, the former being spoken of as 'Müllerian', the latter as 'Batesian' Mimicry. It must be borne in mind, however, that in Synaposematic colouring the warning is genuine, while in Pseudaposematic it is a sham. These Greek terms, or their respective English equivalents, 'Common Warning Colours ' and 'Protective Mimicry', make the essential distinction sufficiently clear. Nevertheless, it is impossible to avoid using the term 'Mimicry' in connexion with a Müllerian association, because the relationship between Model and Mimic requires even more consideration in Synaposematic than in Pseudaposematic Resemblance. Furthermore, the ultimate position of vast numbers of examples is still under discussion. It is certain that they are mimics in the sense of resembling a model, but opinions differ upon the question whether they are Batesian or Müllerian. In speaking of the origin and growth of these resemblances the unqualified term 'Mimicry' may. be conveniently employed, whether the likeness be Pseudaposematic or Synaposematic. In speaking of their bionomic value the unqualified term should never be used.

${ }^{1}$ For a further account of each of the heads $a .-\ell$., and more numerous illustrations, consult the writer's article, Mimicry, in Dict. Philos. and Psychol., J. M. Baldwin, New York and London, I902, vol. ii, pp. 79, 80. 
The term 'Mimicry' has led to much misunderstanding from the fact that in ordinary speech it implies deliberate imitation. The production of Mimicry in an individual animal has no more to do with consciousness, or taking thought, than any of the other processes of growth in the individual or evolution in the species.

The example described on pp. 217-18, should it be hereafter confirmed, would provide a striking demonstration of the production of Mimicry by the selective action of enemies alone: model and mimic being, as it is believed, permanently and widely separated by areas and barriers over which the enemies are supposed to pass.

Protective Mimicry is here defined as an advantageous superficial resemblance of a palatable defenceless form to another that is specially defended so as to be disliked or feared by the majority of enemies of the groups to which both mimic and model belong-a resemblance which appeals to the senses of enemies in the manner described on p. 359, but does not extend to deepseated characters, except when the superficial likeness is affected thereby. Mutatis mutandis, this definition applies to Aggressive (Pseudepisematic) Mimicry.

A. Pseudaposematic Resemblance, or Protective (Batesian) Mimicry.

A brief historical account of Protective Mimicry has been given on pp. 220-3.

$\mathrm{H}$. W. Bates's historic theory is of especial interest because it was one of the first attempts made by naturalists to employ the great weapon put into their hands by the Origin of Species. Natural Selection was here invoked to offer an intelligible explanation of a large class of phenomena, up to that time well known but unexplained.

1. Wallace's Statement of the Conditions under which Protective Mimicry Occurs. - The five conditions are as follows:-' I. That the imitative species occur in the same area and occupy the same station as the imitated. 2. That the imitators are always the more defenceless. 3. That the imitators are always less numerous in indi- 
viduals. 4. That the imitators differ from the bulk of their allies. 5. That the imitation, however minute, is external and visible only, never extending to internal characters or to such as do not affect the external appearance.' 1

The wide difference between the Mimicry of Bates and the resemblances explained by Fritz Müller is well seen when we attempt to apply these conditions to the latter. A striking exception to the first condition is given on pp. $217-18$, and many instances of divergence in station could be quoted (see p. 349). It is still more obvious that the second condition does not apply to such examples. There is no reason for supposing that a Chalcosid moth is any more palatable to an insectivorous bird than the Danaine it mimics (see p. 275). But the Danaine is far commoner, and its pattern is consequently a far more effective advertisement of unpalatability than that of the moth. The third condition also does not appear to be an invariable rule in cases of Müllerian Resemblance (see pp. 216 and 334, n.). A good example to the contrary is brought forward by Dr. F. A. Dixey in Trans. Ent. Soc., Lond., 1894 , p. $298, \mathrm{n}$.

2. The Chief Characteristics of Mimetic Resemblance and the Attempt to Explain their Evolution.-In the two preceding Essays the principal general statements that can be made about Mimetic Resemblance, both Batesian and Müllerian, ${ }^{2}$ have been brought together and discussed in relation to the various hypotheses which have been proposed as to their evolutionary origin. It was argued that statements based on a very broad foundation of fact receive an adequate explanation on

1 Darwinism, London, 1889 , pp. 264-5.

2 The rival interpretations are rarely discriminated, as the discussion of Bates v. Muller was not the object of Essays VIII and IX. It may be safely affirmed that not one of the general statements necessarily supports the hypothesis of Bates. Dr. F. A. Dixey showed in 1894 that the special tendency towards mimicry exhibited by the female sex (see pp. 244-7) is witnessed in Mullerian Resemblance, and is in no way to be accepted as evidence supporting the alternative hypothesis. The Papilio-Euterpe association defies interpretation on Batesian lines (Trans. Ent. Soc., Lond., 1902, p. 467 , and the references there given). 
the hypothesis of Natural Selection, but on no alternative hypothesis that has been proposed. It is not necessary to refer further to the origin of Mimicry by means of Natural Selection, but before proceeding to the discussion of examples certain additional aspects of the subject may be considered.

It is of the utmost importance to realize that in the aspects of the subject discussed in the following five Sections, and probably even in the sixth, there is nothing necessarily characteristic of Batesian as opposed to Muillerian Mimicry. The dominant importance of instinct-inferences as to past history and migration-the confirmation of a history inferred from Mimicry by the study of structure-Mimetic Resemblance independent of size; all these are just as applicable to examples of one kind of Mimicry as of the other. The remarkable examples mentioned in Sections 7 and 8 require consideration on their own merits, and oftentimes the accumulation of further evidence, before they can be allotted their final place in either category.

3. The All-Importance of Instinctive Attitudes and Movements in the Attainment of Mimetic Resemblance.The necessity of studying Mimetic Resemblance during life and under entirely natural conditions, is convincingly shown by the well-known Indian Longicorn beetle Glenea pulchella. In the cabinet this insect appears as an obvious Longicorn, but Mr. Leslie Andrewes found that in the field it bears a striking resemblance to an Ichneumonid. ${ }^{1}$ A similar observation was made upon the South African Longicorn Nitocris nigricornis by Mr. C. N. Barker. ${ }^{2}$ It is also true of our British Wasp-beetle, Clytus arietis, and of a very large proportion of the examples of Mimicry generally. ${ }^{3}$ It is as true of Müllerian Resemblance as it is of Batesian Mimicry.

4. History and Migration may be Inferred from Mimicry.-Batesian Mimicry and Müllerian Resemblance may supply evidence of the former migrations and history

1 Proc. Ent. Soc., Lond., 1904, p. vi.

2 Ibid., p. xxxiv.

${ }^{3}$ See also pp. $23^{8}, 239,252,253,256$ of the present volume. 
of species. The large Danaine butterfly, Anosia plexippus (archippus) alluded to on p. 274, has now travelled from its home in the New World to many parts of the Old, but the effect it has produced upon the butterfly fauna of North America would always show, even if we had no further evidence, the position of its ancestral home. ${ }^{1}$ So, too, the commonest Danaine in the Old World, Limnas chrysippus, although ranging through and beyond the Oriental Region, is clearly shown by the same kind of evidence to have been an inhabitant of Africa for a far longer period. Not only is this inference justified, but it can also be stated that the exclusive predominance of the white-hind-winged alcippus form of chrysippus on the west coast of Africa, from the Niger Mouths to the Sahara (see p. 32I), is a result of modern changes in distribution. It has not affected any of the West Coast mimics, except perhaps Acraea encedon, in which case there is some evidence, from one locality in Sierra Leone, to show that the presence of alcippus has encouraged the white-hind-winged alcippina form. ${ }^{2}$ Furthermore, a study of mimetic forms may enable us to reconstruct the past stages through which the older model has passed. When a geologist finds a recognizable fragment of one rock included in a stratum of another, he infers with confidence that the latter is the younger. With equal certainty the zoologist may conclude that the mimicking species is younger than the model it has come to resemble. In certain cases the species acting as a model is di- or trimorphic. Thus the individuals of Limnas chrysippus fall into three groups, of which two, as described on pp. 70, 7I, are sharply marked off and unconnected by gradual transition. The individuals of the two commonest mimics of chrysippus also fall into three corresponding groups. In both species of mimic, however, all the groups are connected by abundant transitional forms. We are led to believe that the mimics, being younger, present us with a picture of the former condition of the older model, when transitional

1 Proc. Amer. Ass. Adv. Sci., vol. xlvi, 1897, p. 244.

2 Trans. Ent. Soc., Lond., 1902, p. 480. 
forms between the groups now sharply separated had not been obliterated. ${ }^{1}$

5. A History Inferred from Mimicry may be Confirmed by other Evidence.

[The following facts and arguments were first brought forward in the Leeds lecture, and published in Nature for October 2, 1890. They have been revised for the present work.]

Evidence for the evolution of Mimetic Resemblance has been forthcoming as the result of recent [in 1890] work, of which the general results are set forth below, but the details still remain unpublished.

Many moths have lost the scales which are characteristic of the Order of insects to which they belong, so that their wings become transparent, and they mimic stinging insects such as humble-bees, wasps, and hornets. This is the case with two British Hawk Moths (Haemorrhagia fuciformis* and $H$. tityus* ${ }^{*}$ bombyliformis). It is known that when these moths emerge from the chrysalis, the transparent parts of their wings are thinly covered with scales which are shaken off during their first flight. The loss of the scales is due to the rudimentary nature of the stalk at the base of the scale and of the socket in which the stalk is inserted. A closely allied Eastern andEthiopian moth (Cephonodes hylas*) is still more completely denuded of scales, but in it also the rudimentary sockets are found to be thinly scattered over the transparent wings. These facts suggested that other moths with transparent wings would be found to repeat, in the course of their own individual lives, the history of the change by which transparency has been attained by the species. Investigation has supported this suggestion. The examination of two British Sesiid moths which resemble hornets or wasps was especially instructive. In one of these, Trochilium (Sesia) apiforme*, the mimicry is not so perfect as in the other, and is therefore presumably of more recent date; in this moth the rudimentary scales which fall off are comparatively perfect, while in the

1 Trans. Ent. Soc., Lond., 1902, pp. 482-4. The mimics alluded to are Hypolimnas misippus, female, and Acraea encedon. 
better mimic, Trochilium (Sesia) crabroniforme* (bembeciforme), they are far more degenerate, in accordance with the presumption that they have been useless to the species for a longer period of time. It is interesting to note that these degenerate scales have not been reduced in size in either species, but are, on the contrary, much larger than the scales which are retained for the whole life of the moth. It is probable that the increase of size renders it even more difficult for the degenerate stalks to retain the scales during flight. In certain allied 'Clearwings' of the genus Sesia (Trochilium) the transparency of the fore wing has been attained by the transparency of scales which are retained, as well as by the loss of scales. ${ }^{1}$

6. Mimetic Resemblance between Species of very Different Size.-It has been observed for many years that close mimetic likeness may be found between species of very different size. One of the most striking examples is to be seen in Papilio (Drurya) antimachus, an immense West African swallow-tail butterfly with an obvious Acraeoid appearance. The Papilio appears to form one of a complex mimetic group of which the centre is composed of many comparatively small but dominant species of Acraea. ${ }^{2}$ When the members of this mimetic combination were exhibited, Mr. F. A. Heron suggested ${ }^{3}$ an interpretation of such remarkable cases of the want of accord between size and the other elements which go to make up a likeness. Size, as correlated with the idea of distance, was, he pointed out, extremely difficult of estimation. In fact the huge antimachus, seen far off, may well appear to be smaller than the comparatively insignificant Acraeas at a much less distance: Especially is this likely to be true of young and inexperienced enemies, and it is precisely these which Müllerian Resemblances are in large part adapted to meet. This interest-

See also pp. 264-6 for other examples of transparency attained in a variety of ways. Consult also W. J. Kaye in Ent. Record, vol. xvii, nos. 4 \& 5, and Mark L. Sykes in Trans. Manch. Microsc. Soc. I901, p. 82.

\footnotetext{
2 Proc. Ent. Soc., Lond., 1903, Nov. 18, pp. Ixiii-lxv.

Ibid., p. lxv.
} 
ing and convincing suggestion would, however, apply to Batesian Mimicry as well as to Synaposematic Resemblance.

7. Remarkable Examples of Mimicry.-Many instances of Mimetic Resemblance between forms of all degrees of affinity have been given in Essays VIII and IX. They have been drawn from the Arthropoda and almost exclusively from the Insecta, the group in which these superficial likenesses are developed far more extensively than in all the others put together.

Mimicry is known, although instances are relatively rare, among the Vertebrata. Thus the venomous South American snakes of the genus Elaps are mimicked by harmless species inhabiting the same areas; defenceless birds such as the cuckoos and orioles mimic powerful aggressive species living in the same countries, and, in Malaya, tree-shrews mimic the more powerful squirrels. ${ }^{1}$

The terrifying appearance assumed by certain large caterpillars, e.g. the British Choerocampa elpenor (the Elephant Hawk Moth), is founded upon the mimicry, or rather the caricature of a cobra-like serpent. Many observations prove that terror is undoubtedly inspired by the appearance, in man no less than in insect-eating animals. It is probable that these are examples of true Batesian Mimicry-Pseudaposematic Resemblance. In an experiment made by the present writer in 1887 , a large lizard, Lacerta viridis, was for some time immensely terrified by the larva of elpenor. When, however, the lizard eventually succeeded in overcoming its fright, it devoured the caterpillar with apparent relish. ${ }^{2}$ It is

1 For details consult A. R. Wallace, On Natural Selection, London, 1875, pp. ror -7 . Mr. Shelford informs me that the tree-shrews certainly possess distasteful qualities and yet that they are undoubtedly the mimics. It is not improbable that the resemblance is Mullerian. The interpretation of the likeness as aggressive-the shrews being enabled under the disguise of squirrels to approach their insect prey - has broken down in somewhat analogous cases (see p. 378), and would require a great deal of confirmatory evidence before it can be accepted as probable.

${ }^{2}$ Colours of Animals, London, 1890, p. 261. For other earlier observations on the same species consult the same work, pp. 258-60, also Proc. Zool. Soc., Lond., 1887, pp. 204, 206-7, together with the 
interesting to note that this terrifying appearance has been shown in certain cases to be combined with a highly cryptic appearance. The larva of elpenor is well concealed until disturbed, when it instantly assumes an entirely different method of defence. The suddenness of the transformation undoubtedly adds to the effect.

Another remarkable group of examples includes the cases in which the tail of the mimic is so modified and so held as to resemble the head of its model. An instance has already been described on p. 254, and Mr. R. Shelford has described two beautiful instances discovered at Singapore by Mr. H. N. Ridley, F.R.S. In one of these the effect is mainly produced by two black eye-like spots on the abdomen of an ant-like spider. ${ }^{1}$ The form of the abdomen assists in the resemblance. In the second example, the appearance of an ant of the genus Oecophylla is strongly suggested by the form, markings, and movements of the posterior end of a caterpillar. Mr. Shelford speaks of "the resemblance as positively startling' ${ }^{2}$ In the same manner, the posterior end of a large Oriental chafer (Lepidiota bimaculata) appears to resemble the head of a shrew-like mammal. ${ }^{3}$ Dr. Longstaff also describes and figures the third pair of legs of an African beetle (Heterochelus) projecting like formidable jaws from a flower, in which the beetle itself is buried head downwards. ${ }^{4}$

Even more remarkable are the cases in which the mimicry is of a composite kind, suggesting the appearance of two entirely different objects. A good example has been described and figured on pp. 259-60, and an even

references there given. For the snake-like appearance of a Bornean Choerocampa, see R. Shelford in Proc. Zool. Soc., Lond., 1902, vol. ii, p. 253 ; of an African species of the same genus and the terrifying effect produced on monkeys, see Marshall, Trans. Ent. Soc., Lond., 1902, p. 397. For the effect of an African Choerocampa larva on man, see S. A. Neave, Proc. Ent. Soc., Lond., 1905 , pp. xxii, xxiii; for the superstitious dread with which elpenor is regarded in Ireland, see Trans. Ent. Soc., Lond., 1902, p. 399 , and the references there given.

\footnotetext{
Proc. Zool. Soc., Lond., 1902, vol ii, p. 266. $\quad 2$ Ibid., pp. 254-5.

3 Proc. Ent. Soc., Lond., 1906, p. xxi.

- Trans. Ent. Soc., Lond., 1906, p. 94.
} 
more remarkable one has been provided by the acute observation of Portschinski. ${ }^{1}$ The great Russian naturalist has suggested that the mature and semi-mature larva of Stauropus fagi (the Lobster Moth) resembles a caterpillar attacked by a Pentatomid bug. The bug itself is represented by the flattened caudal shield, of which the terminal processes resemble antennae. In its usual position, this shield is bent forward over the back of the larva, so that the flattened ventral surface becomes dorsal, the convex dorsal surface ventral, the antenna-like processes anterior. It thus resembles very closely the appearance of a bug seated on the back of the caterpillar and engaged in sucking its juices.

The extraordinary mimetic resemblance of the $\mathrm{Mem}$ bracidae, in which the appearance is wrought in the visible shield, and not in the insect which it conceals, has been described and figured on pp. 258-9. Other remarkable instances to be found in the same Essay need not be further mentioned.

8. Mimetic Resemblance to Cryptic Models.-A set of examples, very rare in Mimicry, is to be found in the numerous Longicorn beetles which resemble Rhynchophora. Mr. Shelford ${ }^{2}$ has shown that in Borneo all three groups of Rhynchophorous beetles, the Curculionidae (weevils), the Anthribidae and the Brenthidae are thus mimicked; in South Africa, Mr. Marshall ${ }^{3}$ has shown that the first-named group provides models for Longicorns. Wallace ${ }^{4}$ suggested long ago that the weevils and Anthribidae are protected by their excessive hardness, and are on this account mimicked by less well-protected Longicorns. Although in some cases the Rhynchophorous models possess a conspicuous warning pattern, the great majority appear to bear a Procryptic colouring. This appearance is, however, often deceptive, inasmuch as the habits of the insect may render it conspicuous.

${ }^{1}$ Coloration Marquanle et Taches ocellées, V., St. Pétersbourg, 1897, p. 5 I, fig. 25 .

${ }_{2}$ Proc. Zool. Soc., Lond., 1902 , vol. ii, pp. $245-7$.

3 Trans. Ent. Soc., Lond., I902, p. 523 . Consult also the whole section on pp. 522-5.

- On Natural Selection, London, 1875, p. 94.

poutros

B b 
Thus the dark, stick-like Brenthidae seem to possess a marked Procryptic appearance when examined in the cabinet, but Mr. Shelford tells me that they are very commonly found on flowers where they are most conspicuous. Mr. Marshall also states that the large black African weevils move slowly, and are freely exposed, so that they, too, must be visible from a great distance. The examples in which the models appear to be undoubtedly Procryptic are probably to be explained by the peculiar character of the defence. Hardness would not avail 'against an enemy large enough to swallow the beetle whole, so that it could be ground down in the gizzard, or the interior slowly extracted by digestive fluids gaining access by the joints and other apertures. Defence by a sting, a nauseous taste or smell, or unwholesome qualities, is effective against enemies of all sizes and all degrees of strength, although failing against occasional specially adapted foes. It is possible that these considerations may enable us to understand why it is that certain Rhynchophora are remarkable among Coleoptera for combining a cryptic colouring with sufficient immunity to render them feasible models for mimicry '. ${ }^{1}$

9. Butterflies and Moths, chiefly Oriental, Selected in 1890 to Illustrate Various Aspects of Mimicry.-Almost all of the following species, shown as examples of Mimicry at the Lecture to the British Association in I 890 , would now be looked upon as instances of Müllerian (Synaposematic) Resemblance. The entire list is, however, reprinted in this place in order to direct attention to the recent change in interpretation. The examples were selected-except in one important series of related forms, viz. Papilio dardanus (merope), its sub-species and allies-from Oriental Lepidoptera. The examples of Mimicry hitherto brought forward in this work are principally South American and Ethiopian, so that it may be useful to direct attention to a brief list of mimetic species from the East, especially when they have been chosen in order to illustrate the various degrees of complexity with which these superficial resemblances are attained.

1 Trans. Ent. Soc., Lond., 1902, p. 523. 
With the exception of some of the forms of Papilio dardanus, the whole of the species arranged under the following heads, $a .-g$., were shown in 1890 , and it has not been thought necessary to indicate these particular illustrations by asterisks. The first paragraphs under each of the heads $a .-g$. were published in $1890,{ }^{1}$ but the synonyms, \&c., have been as far as possible brought up to date. The paragraphs in square brackets give a brief account of the reasons why nearly all the examples employed in 1890 to illustrate Bates's Hypothesis, would at the present day be looked upon as illustrations of the Hypothesis of Fritz Müller. Repeated evidence will thus make it clear that fifteen years have brought a fundamental change in the point of view.

a. Both Sexes Mimetic: Both Sexes of Model and Mimic Superficially Alike.-Both sexes of the North Indian Papilio agestor closely resemble the Danaine butterfly Caduga tytia.

[The large white spots on the body of the Papilio render it in this respect more conspicuous than the Danaine. Furthermore, it is an abundant species, and other members of the same group tend to approach it in certain points more closely than the primary Danaine model, so that there can be hardly any doubt that we are dealing with an example of Müllerian Resemblance.]

b. Sexes readily Distinguishable: Male Mimics Male, Female Mimics Female.-An Indian moth (Epicopeia philenora) similarly mimics an unpalatable butterfly (Papilio protenor), but in this case the male moth mimics the appearance of the male butterfly, and the female moth that of the female.

[The moths belong to the Family Uraniidae, and are probably specially protected. In another still more wonderful example of likeness between species froni the same groups in New Guinea, although the resemblance is probably to a certain extent reciprocal (Diaposematic), the approach is chiefly from the side of the Papilio ( $P$. laglaizei), rather than from that of the Uraniid moth (Alcidis aurora).]

${ }^{1}$ Nature, 1890, October 2, p. 557 .

$\mathrm{B}$ b 2 
c. Male and Female Mimicking Different Species.If the mimicking species became common relatively to the mimicked, the deception would be liable to be detected. We therefore find that two or more models are often mimicked by the same species. Thus the male of the Indian Melynias malelas (Elymnias leucocyma) mimics Stictoploea harrisi, while the female mimics the female Trepsichrois mulciber. Both these Euploeas are also imperfectly mimicked by day-flying moths (Callamesia midama). So also the male of the Indian Papilio castor mimics Papilio chaon, while the female mimics Crastia core: in Southern India, Papilio chaon is absent, and both sexes of the species (Papilio dravidarum) which represents $P$. caslor mimic $C$. core.

[There is more reason for believing that the Elymniinae are Batesian mimics than almost any other butterflies. ${ }^{1}$ The case has been discussed on pp. 353-4, and the inferences to be drawn from a resemblance to two or more models on pp. 354-6. The resemblance of Callamesia, belonging to the highly distasteful Family Zygaenidae, SubFamily Chalcosiinae, is certainly Müllerian, and the same is doubtless true of the Papilios, which are themselves often mimicked by other species. $P$. aristolochiae has been shown (see p. 269) to be extremely distasteful to birds.]

d. Female Mimetic: Male Non-Mimetic.-Female butterflies are exposed to more dangers than the swiftlyflying males, and we find many instances in which the former are mimetic, although the latter are not. Thus the female of the Indian Hypolimnas bolina mimics Crastia core, while the male is non-mimetic. The same is true of Hypolimnas misippus, the female of which mimics Limnas chrysippus. The last-named Danaine model is trimorphic, and all three forms are mimicked by the female Hypolimnas.

[Recent evidence renders it probable that the whole Nymphaline genus Hypolimnas is distasteful, and that the resemblance is Mullerian : see pp. 2 I 5-I 8.]

1 As argued by Mr. R. Shelford, at the meeting of the Entomological Society of London, on June 5,1907 . The discussion is not reported in the Proceedings. 
e. Female Mimicking two or more Different Species: Male perhaps Non-Mimetic, or Mimicking still another Species.-The mimetic females also often resemble two or more different species of nauseous butterflies. Thus the female of Papilio polytes (pammon) appears in two forms, mimicking respectively Papilio hector and $P$. aristolochiae; while the females of Euripus halitherses (the male of which is probably also mimetic) mimic Danisepa diocletianus (rhadamanthus) and Penoa deione.

[The conspicuous under side of the non-mimetic male of Papilio polytes (pammon) suggests special protection, and renders it probable that the resemblance of the female is Müllerian. The genus Euripus is also probably distasteful, like many other mimetic Nymphaline genera. ${ }^{1}$ For dimorphism in mimicry, see pp. 354-6.]

$f_{:}$Non-Mimetic Ancestor preserved on Islands, \&c.: on Adjacent Continent Mimicry developed in one or both Sexes: Remarkable case of Papilio dardanus (merope).There are also striking examples in which the nonmimetic ancestor of a mimetic species has been preserved, e. g. in an adjacent island. Thus the female of Elymnias undularis mimics Salatura plexippus (genutia) in Sikkim and North-East India; in Burma there is a common form of the latter with white hind wings ( $S$. hegesippus), and the Burmese female of $E$. undularis is apparently beginning to mimic this variety; in South India $E$. undularis is represented by $E$. caudata, in which the male is also beginning to mimic Salatura plexippus, and the female is a more perfect mimic than in the other localities; in the Andaman Islands Elymnias cottonis represents $E$. undularis, and both sexes appear to be non-mimetic."

A still more wonderful example is found in Africa and adjacent islands. Papilio meriones of Madagascar is non-mimetic and the sexes are nearly alike; the same is true of a closely-allied species, $P$. humbloti, in Grand Comoro, and of an Abyssinian sub-species

1 Trans. Ent. Soc, Lond., 1902, pp. 500-2.

${ }^{2}$ It is not unlikely that $E$. cottonis bears a general resemblance to a Euploeine. 


\section{(antinorii ${ }^{1}$ ) of the African $P$. dardanus (merope).} Wherever it occurs in other parts of the continent dardanus is represented by sub-species with mimetic females $^{2}$ and non-mimetic males. The sub-species merope, from the West Coast to the Victoria Nyanza, possesses three forms of female, hippocoon and trophonius resembling the Danaines-Amauris niavius and Limnas chrysippus; planemoides ${ }^{3}$ resembling the Acraeine Planema poggei. The sub-species polytrophus from the Kikuyu Escarpment, tibullus from the East Coast, and cenea from the south and south-east have the additional female form cenea, mimicking Amauris echeria and albimaculata. The planemoides form is wanting from the sub-species cenea, but exists in polytrophus and may probably be found in tibullus. The hippocoon form of the eastern and south-eastern sub-species resembles the form of Amauris niavius, viz. dominicanus, which is found in the same district. Ancestral females, the trimeni form, intermediate between the non-mimetic Abyssinian females and hippocoon, the most primitive of the mimetic forms, have been found in polytrophus and tibullus. All the

${ }^{1}$ A single mimetic female corresponding to the hippocoon form of merope, \&c., and a single mimetic female corresponding to trophonius, but both tailed, have now been found.

${ }^{2}$ Even the primitive trimeni form is a rough mimic of Amauris niavius, sub-species dominicanus.

3 The planemoides form is a recent addition of the highest interest to our knowledge of this classical example of Mimicry. While the other mimetic female forms all resemble Danaine butterflies, this newly discovered female bears a beautiful likeness to Planema poggei, one of the Acraeinae (see also pp. 337-8). The Mimetic Resemblance was first recognized by Mr. S. A. Neave, M.A., B.Sc., of Magdalen College, Oxford (Proc. Ent. Soc., Lond., 1903, p. xli), while Mr. Roland Trimen, F.R.S., has described the female form, conferring upon it the appropriate name planemoides (Proc. Ent. Soc., Lond., 1903 , pp. xxxix, xl). This new form has not yet been proved by breeding to be one of the females of the merope-group; but a curious accident has supplied the missing evidence. Among some examples captured in 1902-3 by Captain T. T. Behrens, R.E., on the west shore of the Victoria Nyanza, near Entebbe, is a partial hermaphrodite, in which, upon the left wings, traces of the nonmimetic male colours and markings are intermingled with the utterly different mimetic pattern of the female. This interesting individual may be studied in the Hope Department. (See also Trans. Ent. Soc., Lond., 1906, p. $28 \mathrm{r}$, plate xviii, fig. 4.) 
above were shown as illustrations in 1890 , except the sub-species antinorii, polytrophus, and tibullus, and the female forms planemoides and trimeni. ${ }^{1}$

[The grey; black-spotted body of these Papilios renders it probable, as in Papilio agestor, that the resemblance is Müllerian. The examples in which Papilios are models for mimicry, and the proved unpalatability of $P$. aristolochiae should also be taken into account (see $b$. and $e$. on pp. 371,373 ; also p. 269). Concerning the remarkable division of females into forms mimicking different models see pp. 354-6.]

[In Professor Weismann's recent important work ${ }^{2}$ the forms of Papilio dardanus (merope) and their models are for the most part unfortunately represented incorrectly. Plate I, Fig. I, described as 'Papilio merope, male, Africa', is an Abyssinian female: Fig. 5, 'Amauris niavius, South Africa, immune model of Fig. 4,' is the western sub-species ; the eastern and southern sub-species, dominicanus, has a much larger white patch like its mimic from the same area, correctly shown in Fig. 4: Fig. 6, 'Papilio merope, third form of mimetic female, South Africa,' is the female of Papilio echerioides, a comimic with this third form of the same models, Amauris echeria and A. albimaculata: Fig. 7, 'A mauris echeria, South Africa, immune model of Fig. 6,' is not the model but the mimic named in the description of Fig. 6, viz. the third or cenea form of mimetic female of P.dardanus (merope), from the east and south of Africa. The figures are copied, unfortunately incorrectly, from Haase, ${ }^{3}$ the unqualified term 'immune', to which exception has been taken on p. 3 I 8 , being also quoted from the same author. Professor Weismann's prolific labours and great discoveries give an authority and influence to these unlucky copyist's errors, and therefore it is of the utmost importance to set them right in detail. Already, indeed, they

1 The above account of $P$. dardanus has been re-written and much amplified in accordance with existing knowledge.

2 The Evolution Theory, English transl., London, 1904, vol. i, pl. i.

3 Untersuchungen über die Mimicry, plates i and ii, in Bibliolheca Zoo. logica, Stuttgart, Bd. iii, Heft 8, r 891-3. 
have been copied in two books published in the United States, and one in Germany. On the second plate, exhibiting in Figs. I 2-1 5 a Synaposematic combination from Eastern Brazil (called a 'Mimicry-Ring' by Professor Weismann), the descriptions of Figs. I 2 and I 3 as well as of 14 and 15 have been transposed.]

g. Imperfect Resemblance, not to any Particular Species, but to the General Appearance of an Unpalatable Group.There are also examples which show us the origin of mimicry-examples in which the resemblance is very imperfect, but, nevertheless, sufficient to afford some protection. The blue Euploeas of India, \&c. (such as Stictoploea harrisi, Trepsichrois mulciber, and Isamia splendens, including irawada) form a very characteristic group, while their general type of appearance is imperfectly mimicked by several day-flying moths belonging to the Chalcosiinae (Callamesia midama, Amesia aliris, A. sanguifua). It is extremely probable that the wonderfully close likeness of many mimetic species arose by gradual stages from a general resemblance to a type of colour or pattern possessed by a large group of unpalatable insects.

[In this case the moths belong to a group admitted to be distasteful, and the resemblance is clearly Müllerian : see also $c$. on p. 372.]

[Considering the great change in the point of view that has occurred since I 890 , when the above-mentioned examples were shown at Leeds, the question naturally arises as to whether anything will remain of the hypothesis originated by Bates. The clearest examples known to me are the cases of close likeness to a poisonous serpent borne by harmless species, and also by large caterpillars (see pp. 367-8). It is also likely that many of the resemblances to stinging insects and ants are Batesian. Examples to the contrary are mentioned on pp. 230-1. It must also be mentioned that Müllerian Resemblance is very extensively developed among the stinging Hymenoptera themselves, see p. 278 . Numbers of other cases might be quoted.] 
[From this point onwards, asterisks are again employed to indicate the lecture illustrations. $\left.{ }^{1}\right]$

B. Pseudallaposematic Resemblance : Mimetic Representation of some Adventitious Object Associated WITH THE MODEL.

[The examples hitherto observed fall under the head of Protective Mimicry (Pseudaposematic Resemblance) and are therefore given this position. It is not unlikely that hereafter Pseudallepisematic likeness may be found in certain cases of Aggressive Mimicry.]

${ }^{2}$ A very striking instance was discovered by Mr. W. L. Sclater in tropical South America. The well-defended and abundant leaf-carrying ants of the genus Atta* (Oecodoma) are mimicked by an immature Homopterous insect* (a Membracid) possessing a shape and colour which closely resemble the ant together with the piece of leaf it is carrying. [For other probable instances and figure see pp. 259-60.]

\section{Pseudepisematic Resemblance or Aggressive Mimicry, including Alluring Colours.}

This division not only includes the examples of Aggressive Mimicry, in which an animal resembles another, and so is enabled to approach and injure it in some way, but also the cases of Alluring Colouring, in which an animal possesses a lure which is attractive to its prey. These latter are often regarded as examples of Aggressive (Anticryptic) Resemblance, but their logical position is here.

It has been believed that examples of Aggressive

1 The paragraph on the attainment of transparency by certain Sphingid and Sesiid moths which appeared in this place has now been transferred to pp. $3^{6} 5^{-6}$.

${ }^{2}$ With the exception of the paragraphs in square brackets, the following statements, as far as the end of the fourth sentence under 'IV. Epigamic Colours', are reproduced from the lecture-notes published in Nature, $\mathbf{1 8 9 0}$, p. 557. They have been revised for the present work. The Section on Pseudallaposematic Resemblance was originally placed after that upon Pseudepisematic Resemblance. 
Mimicry are seen in the flies of the genus Volucella*, which are enabled to lay their eggs in the nests of Humble-bees, \&c., because of their close resemblance to the latter. The larvae of the fly have been supposed to feed upon those of the bee.

[The larvae of Volucella are probably scavengers, and it is now known that the presence of the flies is not resented. The resemblance is an example of ordinary mimetic likeness to a formidable model, and is rendered all the more effective from the fact that fly and bee are specially associated. ${ }^{1}$ Even in cases where Asilid flies are beautiful mimics of their Hymenopterous victims ${ }^{2}$ it is improbable that the resemblance is aggressive. The explanation is probably similar to that offered in the case of Volucella. There is little doubt, however, that the following examples are truly Pseudepisematic.]

Examples of Alluring Colouring. An Asiatic lizard (Phrynocephalus mystaceus*) possesses pink flower-like structures at the corners of its mouth, and it is probable that flies, \&c. are thus allured. A Terrapin (Macroclemmys temminckii*) from the Southern States of America, when hungry, opens its mouth and actively moves the filaments below the anterior end of its tongue. These look like worms moving in a crevice in the rocks, and attract prey. The animal is otherwise perfectly motionless, and resembles a conferva-covered rock. The fish Lophius piscatorius* (the Angler or Fishing-Frog) attracts its prey by a brightly coloured lure placed over its large mouth, the rest of the body being concealed. Certain deep-sea fishes allied to Lophius, (Ceratias bispinosus*, C. uranoscopus*, \&c.) have a phosphorescent lure attractive to the other fish on which they feed.

[Examples are found among insects, in the flower-like species of Mantidae which attract the other insects forming their prey. The flower-like appearance is undoubtedly Procryptic as well as Pseudepisematic. $\left.{ }^{3}\right]$

1 See Trans. Ent. Soc., Lond., 1904, pp. 663-5.

2 See ibid., pp. 66r-5; 1906, p. 378 .

see N. Annandale, in Proc. Zool. Soc., Lond., 1900, p. 837, for an 


\section{EPIGAMIC COLOURS.}

Epigamic Colours are the bright tints and patterns displayed during courtship. As in other classes of colours the same effects may be produced by the use of foreign objects (Allepigamic). Examples of this latter are found in the various beautiful or curious objects collected by bower-birds for the decoration of their bowers. Especially interesting in this respect is the Amblyornis inornata* of New Guinea. Although, strictly speaking, the subject does not fall into the sphere defined by the title of this Essay, the Epigamic is so closely related to the other bionomic uses of animal colours that some brief account appears to be necessary.

The interpretation of these Secondary Sexual Characters was first suggested by Darwin in the joint memoir contributed by him and Wallace to the Linnean Society of London, July 1, I858. It was further expounded in the Origin of Species, ${ }^{1}$ and published in a complete form in I 87 I. $^{2}$ The rivalry between males for the possession of the female was, Darwin believed, decided by the preference of the latter for those individuals with especially bright colours, highly developed plumes, beautiful song, \&c. Wallace does not accept this theory, but believes that the direct or indirect action of Natural Selection accounts for all the facts. Probably the majority of naturalists follow Darwin in this respect.

The subject is most difficult, and the interpretation of a great proportion of the examples in a high degree uncertain, so that a very brief account is here expedient. That selection of some kind has been operative is indicated by the diversity of the elements into which the effects can be analysed.

The most complete set of observations on Epigamic

excellent account of the flower-like Mantis, Hymenopus, and an allied species, in the living state. R. Shelford has shown that the newlyhatched larvae of Hymenopus bicornis mimic a Reduviid bug; see Proc. Zool. Soc., Lond., 1902, vol. ii, pp. 231-2, pl. xix, figs. 16-19.

${ }^{1}$ London, 1859 , pp. 87-90.

2 Part II of The Descent of Man, and Selection in Relation to Sex. 
display was made by George W. and Elizabeth G. Peckham upon spiders of the family Attidae. ${ }^{1}$ These observations afforded the authors 'conclusive evidence that the females pay close attention to the love dances of the males, and also that they have not only the power, but the will, to exercise a choice among the suitors for their favor'. Observations on the courtship of grasshoppers have also yielded some support to the Darwinian hypothesis of Sexual Selection. ${ }^{2}$

Epigamic characters are often concealed except during courtship : they are found almost exclusively in species which are diurnal or semi-diurnal in their habits, and are excluded from those parts of the body which move too rapidly to be seen. They are very commonly closely associated with the nervous system; and in certain fish, and probably in other animals, an analogous heightening of effect accompanies nervous excitement other than sexual, such as that due to fighting or feeding.

Although there is Epigamic display in species with sexes alike, it is usually most marked in those with Secondary Sexual Characters specially developed in the male. These characters are an exception to the rule in heredity, in that their appearance is normally restricted to a single sex, although in many of the higher animals they have been proved to be latent in the other sex, and may appear after the essential organs of sex have been removed or rendered functionless. The 'higher animals' must in this respect be held to include the insects, inasmuch as a development of these latent characters occurs in bees when the essential reproductive glands have been destroyed by the parasitic Stylops. Wallace suggests that Epigamic Characters are in part to be explained as Recognition Marks, in part as an indication of surplus vital activity in the male. ${ }^{3}$

1 Occasional Papers of the Natural History Society of Wisconsin, vol. i, 1889, Milwaukee: Observations on Sexual Selection in Spiders of the Family Attidae.

2 Trans. Ent. Soc., Lond., 1896, p. 233.

${ }^{3}$ See especially Darwinism, London, 1889, pp. 268-300. 
The mutual relationship of the above-mentioned classes of colours is shown in tabular form on p. 226.

My kind friend, Mr. Arthur Sidgwick, suggested the whole of the convenient Greek terminology which has been employed in this brief statement of the bionomic value of colour and marking in animals, especially insects.

Note on the Resemblance of a Western Chinese species of Athyma and of Limenitis to the male of Hypolimnas misippus. - This remarkable resemblance has been described on pp. 217-18. Athyma punctata is the better and probably the older mimic, and it is likely that Limenitis albomaculata has been brought into the combination by a secondary mimetic approach. This conclusion, however, requires a careful study of the related species for its establishment.

Not until comparatively recently has it been known that the interesting and puzzling relationship of Athyma and Limenitis to Hypolimnas misippus only holds in the male sex of all three species. The Leech Collection contains no female of either Limenitis or Athyma, and Monsieur C. Oberthür, of Rennes, only obtained the latter in 1902, the former about ten years earlier. ${ }^{1}$ Among hundreds of the male Limenitis he received only eight females; of the Athyma no more than two. In pattern the females are quite unlike their males, but resemble each other as closely as do these latter. We have therefore an undoubted association between the Limenitis and the Athyma extending to both sexes, while the two males also possess the pattern of the male of $H$. misippus.

Although it seems certain that the primary model has never been an inhabitant of the localities from which the mimics have been received, it is possible, as Mr. R. Shelford has pointed out to me, that these latter may extend, or may formerly have extended, southward, so as to overlap the northern boundary of the range of $H$. misippus. Although more investigations into the distribution of the

${ }^{1}$ Bull. Soc. Ent. Fr. 1902, pp. 161-2. See also Études d'Ent., xviiie. livraison, p. 15 , pl. 6, fig. 82, Nov. 1893, Renmes. 
species concerned would be very welcome for the solution of this difficult problem, it must be remembered that two great collections have come from this very district. The Leech Collection of Palaearctic Butterflies in the British Museum of Natural History gives the following localities : -H. misippus: Syria, Sultanpore, Kulu, Kashmir, Loochoo; Athyma punctata: Chang-yang, Central China ; Limenitis albomaculata: Moupin, Western China. ${ }^{1}$ Monsieur Charles Oberthür, with a much longer and larger experience than any other naturalist, adds Western China to the range of the Athyma, summing up the distribution of both it and the Limenitis in the statement that they inhabit the frontiers of Western China and Eastern Thibet, especially Moupin, Siao-Lou, Tien-Tsuen, and Tse-Kow. ${ }^{2}$ Monsieur Oberthür also kindly informs me that he has never received $H$. misippus from the district in which the two mimetic males occur.

It is to be hoped that specially directed observations on the migratory birds of Western China may yield further evidence bearing upon the provisional hypothesis proposed on pp. $217-18$. It has also been suggested on p. 2 I 8 that the mimicry was favoured by an initial resemblance. This probably holds good for the iridescent blue margins of the principal white markings as well as for the other elements of the pattern. Thus it is not difficult to understand how the Athyma may have arisen from a species like Athyma (Pantoporia) cama from the Himalayas, Assam, and Upper Burma. The white markings of this species are surrounded by a bluish margin, while the pattern is not very widely different.

The interest and peculiar difficulty of this example of mimicry have led me to add the above note. The fact that the females of the Athyma and Limenitis differ from the males had escaped me, and I owe the opportunity of now rectifying the omission to my friend Mr. G. A. K. Marshall.

${ }^{1}$ Catalogue of the Leech Collection, by R. South, London, 1902, pp. 56,63 .

\& Bull. Soc. Ent. Fr. 1902, pp. 161-2. 


\section{APPENDIX}

\section{A Classification and Index of The Examples OF MIMICRY QUOTED IN THE TEXT}

THE various sub-families, ${ }^{1} \&$ c., of Butterflies are, allowing for omissions, arranged in the order followed in most museums and private collections. In other cases no attempt has been made to adopt sub-groups of equivalent systematic value, and the succession is alphabetical.

Groups from which very few examples were selected (e. g. Hemiptera) are not classified separately, but appear as models or mimics in the classification of those which have been more freely quoted in the text. The mimetic species alone, without models, are given under the mimetic sections of the classification. Under the sections which are made up of models the mimetic species are given with their models, except in the few cases (e. g. ants) where the species or genera of these latter have not been quoted. Models (with their mimics) are placed before mimics in groups which primarily act as models, mimics before models in those which are primarily mimetic.

\section{LEPIDOPTERA}

\section{A. RHOPALOCERA (BUTTERFLIES)}

For Danainae

$$
\text { 1. Ithominae as models }
$$

Models

Mimic

$\left.\begin{array}{l}\text { Methona confusa } \\ \text { Thyridia psidii }\end{array}\right\}$. . . Ituna, 264-6

For Nymphalinae, 272, 273

Model

Mimic

Melinaea, \&c. .... . . Protogonius, 338, 350-2

For Heliconinae, 232, 235, 322, 327, 33 r, 33 I n. I, 343, $35^{\circ}$

Models

Mimics

Melinaea . . . . Heliconius, 235

Melinaea mneme. . . . $\left\{\begin{array}{l}\text { Eueides nigrofulva, } 33^{2} \\ \text { Heliconius numata, 331-3 } \\ \text { Heliconius vetustus, } 33^{2}\end{array}\right.$

Tithorea . . . . Heliconius, 235

For Erycinidae, 272, 273

1 Three sub-sections of the Danaine sub-family are numbered 2, 3, and 4 in the series of butterflies. All other numbers in this series imply sub-family rank. 


\section{CLASSIFICATION AND INDEX OF}

For Pierinae, 272, 273

\section{Models Mimics}

Methona psamathe . . . Dismorphia orise (Ecuador f.), 265, 266

$\left.\begin{array}{l}\text { Methona confusa } \\ \text { Thyridia psidii }\end{array}\right\}$. . . Dismorphia orise, 240, 265, 266

For Moths

Models

$\left.\begin{array}{l}\text { Methona confusa } \\ \text { Thyridia psidii }\end{array}\right\} \cdot \cdot \cdot\left\{\begin{array}{c}\text { Castniidae, 243, 264, } 266 \\ \text { Hypsidae (Anthomyza, Hyelosia), } 264 \text {, } \\ 266\end{array}\right.$

2. LyCORAEINI as mimics

Of IтHоMinae

Ituna, 264-6

3. Danaini as models

For other DanainI

Models

Mimics

Amauris, Western sp. of . . Amauris albimaculata and echeria, 335,337

" " . . . Tirumala morgeni, 337

For Euploeini

Models

\section{Mimics}

Danaini . . . . . . Trepsichrois mulciber (female),

334,335

For Elymninae, 353

Models

Mimics

$\left.\begin{array}{l}\text { Caduga } \\ \text { Parantica }\end{array}\right\}$. . . . Elymnias lais (male), 353

Salatura hegesippus. . . . Elymnias undularis (female), 373

Salatura plexippus (genutia). Elymnias undularis (female), 373

$$
" \quad " \quad \text {. Elyminias caudata, } 373
$$

For Nymphalinar, 349

\section{Models}

Mimics

Amauris niavius . . . Hypolimnas anthedon, $33^{8}$

Amauris niavius f. domini- Hypolimnas wahlbergi, $33^{8}$ canus

Anosia plexippus (archippus). Limenitis, 274, 364

Limnas chrysippus . . . Euphaedra, 347 n. 3

Limnas chrysippus . . . . Hypolimnas misippus (female), 215 , $216,247,347,355,361,365$

n. 1,372

For Acraeinae, 349

Models

\section{Mimios}

Amauris . . . . . Acraea esebria (female f. A), 354, 
Limnas chrysippus . . . Acraea esebria (female f. B), 354, 355

$" \quad " \quad \dot{\quad}$ alcippus Acraea encedon, $355,364,365$ n. I

For Lycaenidae, 349

For PapiLIONINAE

Models

\section{Mimics}

Amauris albimaculata and $P$.dardanus (female f. cenea), 337, echeria

Amauris niavius . . . . P. dardanus (female f. hippocoon),

Amauris niavius, sub-sp. P. dardanus (female forms hippo. dominicanus coon and trimeni), 338, 374, 374 n. 2

Caduga tytia . . . . . P. agestor, $37 \mathrm{I}$

Danaini . . . . . P. macareus, 288

" . . . . . . P. xenocles, 288

Limnas chrysippus . . . P. dardanus (female f. trophonius),

For Mотнs

$$
374,374 \text { n. I }
$$

\section{Models}

Mimics

Danaini . . . . . . Chalcosiinae, 275,362

Limnas chrysippus . . . . Aletis helcita, 232, 347 n. 3

" " . . . Eusemia falkensteinii, 232

" $"$. . . . Phaeagarista helcitoides, 232

Danarni as mimics

Of Euploeisi, 334

For Danaini, 334

4. Euplozini as models

For Elymninae, 335, 353

Models

Mimics

Euploea . . . . . Elymnias cottonis? 373,373 n. 2

Stictoploea harrisi . . . Elymnias malelas (leucocyma) (male), 372

Trepsichrois mulciber (female) Elymnias malelas (leucocyma)

For Nymphalinae, $24 \mathrm{I}$

(female), 372

Models

Crastia core . . . . Hypolimnas bolina (female), 372

Danisepa diocletianus . . . Euripus halitherses (female f. A), 373

Penoa deione. . . . . Euripus halitherses (female f. B), 373

For Papilioninae

Models

Crastia core . . . . Papilio castor (female), 372

C C 


\section{For Moths (Chalcosinak)}

Blue species of Euploea.$\cdot\left\{\begin{array}{l}\text { Mmesia aliris, } 376 \\ \text { Amesia sanguiflua, } 376 \\ \text { Callamesia midama, } 372,376\end{array}\right.$

Of Danaini

Trepsichrois mulciber (female), 334, 335

5. Elymninae as mimics

Of Morphinae (Amathusiinae), 353

Of Danaini, 353

Elymnias caudata, 373

E. lais (male), 353

E. undularis (female), 373

Of Euploeisi, 335, 353

E. cottonis? 373,373 n. 2

E. malelas (leucocyma), 372

Of Acraeinae, 353

Of Pierinae, 353

6. Nymphalinae as mimics

Of Ithominae

Protogonius, 338, 350-2

Of Danaini, 349

Euphaedra, 347 n. 3

Hypolimnas anthedon, $33^{8}$

Hypolimnas misippus (female), $215,216,247,347$

Hypolimnas wahlbergi, $33^{8}$

Limenitis, 274, $3^{64}$

Of Euploeini, $24 \mathrm{I}$

Euripus halitherses, 373

Hypolimnas bolina (female), 373

Of Acraejnae

Byblia götzius (wet season f.), 34 I

Precis antilope ( " ", ), 340

Precis sesamus ( " " = natalensis), 339, 339 n. I, 340

Of Heliconinae

Colaenis telesiphe, 334 n. 2

Nymphalinae as models

For other NymphalinaE

Models Mimics

Athyma punctata (female). . Limenitis albomaculata (female), $3^{8} \mathrm{r}$

Fritillary. . . . . A raschnia levana f. levana, $34^{2}$ 
Hypolimnas misippus (male) . $\left\{\begin{array}{c}\text { Athyma punctata (male), } 217,218, \\ 3^{61}, 3^{81}, 3^{82} \\ \text { Limenitis albomaculata } \\ 217,218,3^{61}, 3^{81}, 3^{82}\end{array}\right.$ (male). Limenitis . . . . . Araschnia levana f. prorsa, $34^{2}$

7. Heliconinae as models

For Nymphalinae

Model

Mimic

Heliconius telesiphe . . . Colaenis telesiphe, $334 \mathrm{n}$.

Heliconinae as mimics

Of IthominaE, $232,235,322,327,331,33^{1}$ n. I, 343,350

Eueides nigrofulva, $33^{2}$

Heliconius, 235

Heliconius numata, 331-3

Heliconius vetustus, $33^{2}$

8. Acraeinae as models

For Elyunilnae, 353

For Nymphalinae

Models

Mimics

Acraea acara . . . . . $\begin{gathered}\text { Precis antilope (wet season f. very } \\ \text { rough mimic), } 340\end{gathered}$ Acraea anemosa . . . . $\{$ Precis sesamus (wet season $\mathrm{f}$. rough mimic), 339, 339 n. I, 340

Acraea serena, type of . . . Byblia götzius (wet season f.), 34 I

For Papilioninae

Models

Acraeas, large . . . . Papilio antimachus, 366

Planema poggei . . . . P.dardanus (female f.planemoides), $33^{8}, 374,374$ n. 3,375

ACraeinae as mimics

Of Danaini, 349

Acraea encedon (type f., alcippina f., \&c.), $355,364,3^{6} 5 \mathrm{n}$. I Acraea esebria, 354, 355

See also

Acraea satis (female). If the resemblance be mimetic, the Papilio acts as the model, $5^{2} \mathrm{n}$. I

9. Pierinąe as mimics

Of Ithominae, 272,273

Dismorphia orise, $240,265,266$

For other Pierinae

Pierinae as models

Models

Belenois . . . . . . Teracolus regina (wet season f.), 


\section{8 \\ CLASSIFICATION AND INDEX OF}

Mylothris agathina . . . . Belenois thysa (female in dry season only, male especially in dry season), 34 I

Huphina, mimicry between 2 species of in dry season chiefly, 342 Teracolus, " " 4 " " $\quad 342$

For Elymninae, 353

For Mотнs, 275

Model

Mimic

Teracolus etrida . . . . . Abraxas etridoides, 231, 349

10. Papilioninae as mimics

Of Danaini

Papilio agestor, 371

P. dardanus (except planemoides, all mimetic females of), 336-8,

$355,374,374$ n. I, 374 n. 2

P. echerioides, 375

$P$. macareus, 288

P. xenocles, 288

Of Euploeini

P. castor (female), 372

P. dravidarum, $37^{2}$

Of Acraeinar

P. antimachus, 366

$P$. dardanus (female f. planemoides), $33^{8}, 374,374$ n. 3,375

Of Мотнs

P. laglaizei, $37 \mathrm{I}$

Papilioninae as models

For other Papilioninae

Models Mimics

P. aristolochiae . . . . Papilio polytes (pammon), female

P. chaon . . . . . . . P. castor (male), 372

$P$. hector . . . . . . P. polytes (pammon), female f., 373

For Acraeinae

$P$. morania and its allies (if mimicry exists between any of these species and Acraea satis female, the latter is the mimic), $5^{2} \mathrm{n}$. I

For Moths, 231, 232

Model

Mimic

P.protenor . . . . . Epicopeia philenora, 371

B. HETEROCERA (MOTHS)

Of Ithominae

Moths as mimics

Castniidae, 243, 264, 266

Hypsidae (Anthomyza, Hyelosia), 264, 266 


\section{EXAMPLES OF MIMICRY}

Of Danaini

Aletis helcita, 232, 347 n. 3

Chalcosiinae, 275, 362

Eusemia falkensteinii, $23^{2}$

Phaeagarista helcitoides, 232

Of Euplokini

Amesia aliris, 376

Amesia sanguiflua, 376

Callamesia midama, 372, 376

Of Pierinae

Abraxas etridoides, 23 r, 349

Chalcosiinae, 275

Of Papilioninae, $23 \mathbf{r}, 232$

Epicopeia philenora, 37 I

Of Lxcid Beetles, 276

Lycomorpha, $23^{\mathbf{I}}$

Lycomorpha latercula, $23^{\mathbf{I}}$

Mimica, $23^{\text {I }}$

Pionia, $23^{I}$

Of Humble-Bees (Bombus), Xylocopidae, and other Hairy Bees, 25 I

Cephonodes (Hemaris) hylas, 365

Haemorrhagia fuciformis, $36_{5}$

Haemorrhagia tityus (bombyliformis), $36_{5}$

Of Wasps, Hornets, Fossors, \&c., $25 \mathrm{I}$

Glaucopidae, 23 I

Sesia (Trochilium), 251,366

Trochilium apiforme, 365

Trochilium crabroniforme (bembeciforme), $3^{66}$

Larvae of Mотнs as mimics

Of ANTs, 368

Stauropus fagi, 253, 253 (Fig. 2), 254

Of HeMiptera

Stauropus fagi, 369

Of Cobra-Like and other SNAKES

Choerocampa elpenor, \&c., 319, 326, 367,367 n. 2, 368, 376

Moths as models

For Papilionine Butterfly

Model

Mimic

Aurora alcidis . . . . Papilio laglaizei, $37 \mathrm{I}$

For other Moths

Model

Mimic

Agaristidae . . . . Chalcosiinae, 275 


\section{COLEOPTERA (BEETLES)}

1. Longicornia as mimics of Hymenoptera

Of Ants

Euderces picipes, 255, 255 (Fig. 4), 256

Of IChNeumonids (in the wide sense)

Glenea pulchella, $3^{6} 3$

Nitocris nigricornis, $3^{6} 3$

Oberea, 257 n. I, 280

Scytasis, 257 n. I

Of Wasps, Hornets, Fossors, \&c.

Callichrominae, 252

Clytus arietis, 238, 251, 252, 348, 363

Esthesinae, 252

Necydalinae, 252

Rhinotraginae, $25^{2}$

Longicornia as mimics of other BeETLES

Of ANThribidae, 369

Of Brenthidae, 369

Of Curculionidae (weevils), 369

Doliops curculionoides, $26 \mathrm{I}$

Doliops geometrica, 26 I

Doliops (Niphoninae), 250

Of Lycidar, 276

Of Phytophaga

Estigmenida variabilis, $26 \mathbf{r}$

Oxylymma gibbicollis, 237

Longicornia (Clytinae) as models

For other Longiconnia, 348,349

2. Lycidae (Lycinae) as models

For Diptera, Hemiptera, and Hymenoptera, 276

For Moths, 276

Models

\section{Mimics}

Lygistopterus rubripennis . . Lycomorpha latercula, $23 \mathrm{I}$

Lycinae . . . . . $\left\{\begin{array}{l}\text { Lycomorpha, 23 } \mathbf{I} \\ \text { Mimica, 23 } 1 \\ \text { Pionia, 23 }\end{array}\right.$

For other BeEtLes

\section{Mimics}

Cantharidae, 276

Longicornia, 276

Melyridae, 276

Phytophaga, 276

Telephoridae, 276 


\section{EXAMPLES OF MIMICRY}

For Longicorn Beetles

Models

Diabrotica . . . . . . Oxylymma gibbicollis, 237

Estigmena chinensis . . . Estigmenida variabilis, 261

For other Phytophagous Beetles

\section{Models}

Cerotoma . Lema, 237

Diabrotica . . . $\cdot\left\{\begin{array}{l}\text { Dircema, 237 } \\ \text { Lema, 237 } \\ \text { Neobrotica, 236, } 237\end{array}\right.$

Phytophaga as mimics

Of Lycid Bretles, 276

4. RHYNCHOPHORA

a. ANTHRIBIDAe as models

For Longicorn Beetles, 369

b. Brenthidae as models

For Longicorn Beetles, 369

c. Curculionidae (weevils) as models

For Longicorn BeEtLes, 369

\section{Mimics}

Doliops curculionoides, $26 \mathbf{I}$

Doliops geometrica, 261

Doliops (Niphoninae), 250

\section{DIPTERA (FLIES, \&c.)}

Diptera as mimics

Of Lycid BeEtles, 276

Of BeE (Apis mellifica)

$$
\text { Eristalis, 243, } 244
$$

Of Humble-Bees (Bombus), Xylocopidae, and other Hairy Bees, 251

Hyperechia, 276

Volucella, 221,378

Of Wasps, Fossors, \&c.

Asilidae, 257 n. 1, 278,378

Ceria, 280

Promachus iopterus, 257 n. I

\section{HYMENOPTERA}

I. ANTs as models

For Caterpillars, 253,253 (Fig. 2), 254, 368

For Longicorn BeEtle

Euderces picipes, 255, 255 (Fig. 4), 256 


\section{CLASSIFICATION AND INDEX OF}

For HeMiptera

Myrmoplasta mira, 254, 255 (Fig. 3)

Nabis lativentris (larva), 257 n. I

For Homoptera

Heleronotus trinodosus, 258, 258 (Fig. 6), 259, 280, 369

Membracid (larva), 259, 259 (Fig. 7), 260, 280, 377

For ORTHOPTERA

Myrmecophana fallax, 256, 257,257 n. I, $25^{8}$ (Fig. 5), 280 Teltix, 260

For SPIDERS, 252, 368

Synageles picata, 253, 253 (Fig. I A)

Synemosyna formica, 253, 253 (Fig. I B)

2. BEE (Apis mellifica) as model

For Eristalis (Diptera), 243, 244

3. Humble-Bees (Bombus), Xylocopidae, and other Hairy Bees

For MотнS, $25^{1}$ as models

Mimics
Cephonodes (Hemaris) hylas, 251, $3^{6} 5$
Haemorrhagia fuciformis, 365
Haemorrhagia tityus (bombyliformis), $3^{65}$

For Diptera, $25 \mathrm{I}$

Models

Mimics

Humble-bees . . . . . Volucella, 221, 378

Xylocopidae . . . . Hyperechia, 276

4. Ichneumonids (in the broad sense) as models

For Longicorn BeEtLes

\section{Mimics}

Glenea pulchella, 363

Nitocris nigricornis, 363

Oberea, 257 n. 1, 280

Scytasis, 257 n. I

5. WASps, Hornets, Fossors, \&c., as models

For Mотнs, ${ }^{2} 5^{\mathbf{I}}$

\section{Mimics}

Glaucopidae, $23 \mathbf{I}$

Sesia (Trochilium), 251, 366

Trochilium apiforme, 365

Trochilium crabroniforme (bembeciforme), 366 


\section{EXAMPLES OF MIMICRY}

For Longicorn Beetles

\section{Mimics}

Callichrominae, $\mathbf{2} 5^{2}$

Clytus arietis, $23^{8}, 25 \mathrm{I}, 252,34^{8}, 3^{6} 3$

Esthesinae, 252

Necydalinae, $35^{2}$

Rhinotraginae, $35^{2}$

For Diptera

\section{Mimics}

Asilidae, 257 n. $1,278,378$

Ceria, 280

Promachus iopterus, 257 n. I

For other WASPS, Fossons, \&c.

$$
\begin{aligned}
& \text { Abispa. } \\
& \text { Alastor . . . . . Internal mimicry between genera } \\
& \text { Eumenes. . . . . . . . }\} \text { of Australian Wasps, \&c., } 278 \\
& \text { Odynerus, \&c. }
\end{aligned}
$$

For Hemiptera, $25^{\mathbf{I}}$

$$
\text { WASPS, \&c., as mimics }
$$

Of Lycid Beetles, 276

\section{VERTEBRATA}

Vertebrates as models and mimics

Birds, 324, $3^{67}$

Mammals, $3^{67}, 3^{67}$ n. 1,368

Snakes, 319, 324, 326, 367, 367 n. 2, 368, 376

\section{AGGRESSIVE MIMICRY AND ALLURING COLOURS}

Examples:-

Ceratias bispinosus, 378

Ceratias uranoscopus, 378

Hyas coarctata, $3^{1} 4$

Hymenopus bicornis, 378 n. 3

Lophius piscatorius, 378

Macroclemmys temminckii, 378

Mantidae, 378

Phrynocephalus mystaceus, $37^{8}$ 



\section{ANALYTICAL INDEX}

NAMES of quoted books, memoirs, journals, and publications of learned societies are printed in thick (Clarendon) type, and the latter are indexed under the name of the society.

The substance of the titles of the text is printed in small capitals, and is followed by the word 'introduction', or 'essay', with its number. The substance of the sectional headings of the text is followed by the contraction 'introd.', or the number, omitting the word 'essay'.

Quoted titles, beginning with the same word as titles or headings of the text, precede these latter, and are themselves arranged in the alphabetical order of the second word. Titles, \&c., of the text, beginning with the same word, are not thus arranged, but are placed in the order of pagination before the list of references under the same word.

References under one word are generally given in the order of pagination. In certain cases, however, they are grouped more or less completely according to subject.

Footnotes, containing references only, are rarely indexed.

Species are indexed under generic as well as specific names, but the analysis of text is given under the specific name alone. The generic name is distinguished by a capital initial letter.

Popular terms with a definite connotation such as 'beetles', 'butterflies', 'caterpillars', and 'weevils', are fully indexed, in preference to their more technical equivalents 'Coleoptera', 'Rhopalocera ', 'Lepidopterous larvae', and 'Curculionidae', respectively.' When the connotation is less definite, e.g. in 'flies' and 'bugs', full references are given under the scientific equivalents, 'Diptera' and 'Hemiptera' respectively.

'f.' indicates 'form '; 'sub-sp.' indicates 'sub-species'; 'sp.' indicates 'species.'

Abispa, species of, resemble other Hymenoptera in Australia, 278.

Abnormal conditions unnecessary for production of Acquired Characters, 143.

Abraxas etridoides, 231, 349.

Abundance of butterflies, various causes of, 332 .

Abyssinia, antinorii, an ancestral sub-sp. of the Pap. dardanus group, 373-5; female of Abyssinian antinorii figured by Weismann in place of male of another sub-sp. with different distribution, 375 .

acara, Acraea, a model of wet $\mathrm{f}$. of Precis sesamus, 339 n. I.

Accidental likeness, an inadequate explanation of mimicry, xxiii, 257.

'Accidental', Prichard's use of term similar to Darwin's, 185.
Acerata, place in classification of, 33 ; relation of Trilobites to, 39 .

acheloia (götzius), Hypanis (Byblia), mating of similar seasonal forms of, 87 ; dry $f$. of bred from wet, $34 \mathrm{I}$; wet $\mathrm{f}$. of a mimic of $A$. serena type, dry f. procryptic, 341 .

Achievement, contrasted with faculty in man, 170, 171 .

achine, Teracolus, experiments on seasonal forms of, 311 ; Müllerian mimicry chiefly in dry f. of, 342.

ACQUIRED CHARACTERS, THE STUDY OF INSECTS AND QUESTION of Transmission OF, Essay V, 139-72.

'ACQUIRED ChaRACTERS' DEFINED, V. 140-4; see also $73 \mathrm{n} .1$.

ACQUIRED CHARACTERS (EXPERIENCE), BEARING OF INSECT 
MIMICRY, \&C. UPON SUPPOSED

TRANSMISSION OF, V. I66-8.

ACQUIRED CHARACTERS, TRANSMISSION OF, IMPLIED BY THE Theory of External CaUses, VIII. 267.

Acquired Characters, transmission of, disputed, 96 ; a factor of Lamarck's theory, 98; meaning of term, IIo; transmission of, discussed, 110-15; Lamarckism and, 110-15 ; theoretical difficulty of transmission of, III, I12; definition of somatogenic, centripetal or, 122, 123; pangenesis and inheritance of, 123-7 ; continuity of the germ-plasm and, I 3I-2; relation to germ-plasm of, shown in Diagram II, 132; 'identical' twins and relation of inherent characters to, 132-5; discussion of transmission of, $136-8$; direct and indirect evidence of transmission of, 136-8; mutilation, education, disease, \&c., 136; position of medical faculty [in I889] with regard to transmission of, 136, 137; origin of individual variation and, 137 ; instinct and, I16-19, 138, 154-66; use-inheritance and, 137,138 ; confusion caused by term, I40; erroneous assumption that use of term is only recent, $14 \mathrm{I}$ n. 2; use of term by Erasmus Darwin (I794), I40-I; by Lamarck (I809), I4I ; by J. C. Prichard (1826), 177, 179; Sir Ray Lankester on use of, I4I n. 2 ; Prof. Weismann on, 142 ; Prof. J. Mark Baldwin on, 73, 73 n. I, 142, 142 n. 2 ; Prof. C. Lloyd Morgan on, 142, 143; Francis Galton on, 143; Sir Edward Fry on, 143, 144; E. B. Poulton on, 143, 144; interpenetrated by inherent elements, 144; parental acquired characters if hereditary would not be acquired but inherent in offspring, 144 ; inconsistency of Lamarck's Laws with regard to, 144-6; due to gravity not inherited in pupae, $15 \mathrm{I}-2$; insect colours and supposed transmission of, 166-8 ; inherent (congenital or connate) characters clearly distinguished from by J. C. Prichard, 175, 179; non-transmission of, clearly apprehended and ably discussed by Prichard (1826), 174-85; 'acquired varieties are not transmitted,' Prichard (1826), 177; 'acquired characters are transient ; they terminate with the individual, and have no influence on the progeny,' Prichard (1826), 179; non-transmission of considered beneficial by Prichard, 182.

Acraea acara, 339 n. 1 ; - anemosa, $339 \mathrm{n}$. I ; - encedon, $355,364,365 \mathrm{n}$. I ; - esebria, 354 ; - satis, 52 n. I ; serena, 341 ; - violae, 269.

Acraeinae (see also classification of examples of mimicry, 384-8), slow-flying and gregarious, $52 \mathrm{n}$. 1 ; need for breeding epigonic series of, 90 ; as models paralleled by Diabrotica, 236 ; always tend to be mimicked, 233 ; an Indian species of proved to be unpalateable, 269; uniformity throughout many species of, 277; unpleasant scent in African, 316; absence of ' eye-spots' in, 326 ; preferring station different from that of model, $L$. chrysippus, 349.

Acraeoid Heliconidae of Bates = Heliconinae, 327.

Acridiidae of Commentry Carboniferous (Palaeacridiidae), 36, 37 ; mimicry of leaf-carrying ant by, 260 ; value of bright hind wings of, 303,304 , 325 ; colour adjustment of, 307 ; observations on the courtship of, 380 .

Acronycta alni, 319; - cuspis, 87 n. I; - psi, 87 n. I; - strigosa, 87 n. 1 ; -tridens, 87 n. 1 .

actia, Precis, seasonal forms of, 208 ; dry f. bred from wet (1903), 340 n. 2 ; under side more conspicuous in wet than dry seasonal form of, $34^{\circ}$; S. African habitat of, 340 .

Aculeata Hymenoptera, see Hymenoptera, and all the groups there referred to except Ichneumonids, and saw-flies.

Adamsia palliata, 357.

Adaptive or Syntechnic Resemblance, 312, 312 n. 2, 359, 360 n. 1 .

Adaptation of certain Breeds to particular local circumstances, J. C. Prichard, 188-90.

Adaptation, Study of, StimuLATES AND DOES NOT BAR INQUIRY, Introd. xliv-xlvii.

ADAPTATION FOR CROSS-FERTILIZATION A CAUSE OF ASYNGAMY, II. 90,91 ; see also 65 .

ADAPTATION FOR CROSS-FERTILIZATION THE CAUSE AND NOT 
THE CONSEQUENCE OF INJURIOUS EFFECTS OF SELF-FERTILIZATION, II. $91-94$.

Adaptation, Darwin's case against mutation that it cannot explain, xix ; rigid self-criticism required in the study of, xlvii; effect of conditions and, 75; for Cross-Fertilization, Darwin's explanation of, 92 ; specialized mechanisms for, 153 ; essential meaning of, 153, 154; in Lepidoptera as evidence for Natural Selection, 203-18 ; in caterpillars, I 54 ; to one environment, but continual contact of organism with another, I 53, I 54 ; J. C. Prichard on locality and, I88; on the 'double relation' of affinity and, 188 , I89; on the laws of variation resulting in, I90; species and varieties compared by Prichard as regards, 189, 190; on locality and climate of human races and, 190, 191.

Aden, Limnas chrysippus at, 70 n. I.

Adjustable Aggressive Resemblance, 3 I3.

ADJUSTABLE NeUTRALIZATION OF SHADOW, X. 300.

Adjustable Protective ReSEMBLANCE, X. 304-7 ; RAPID, 304, 305; SLOW, 304-7.

Adjustable Protective Resemblance, G. J. Romanes on, I52; R. Meldola on, I53; Natural Selection and, I 52, I 53 ; Lamarckism and, I 524 ; non-transmission of acquired characters and, I53; rapid in fish, Reptilia, \&c., 305; slow in caterpillars, 305-7; chrysalises, I49, I 50, I50 n. 2, 305, 306; cocoons, I49; weevils, 307; grasshoppers, 307 ; spiders, 307.

ADVANTAGES OF ADMISSION THAT DIAGNOSIS IS PROVISIONAL, II. 76,77 .

ADVANTAGE CONFERRED BY PERfECTEd Müllerian ResemBLANCE, X. 328, 329.

ADVANTAGE CONFERRED DURING GROWTH OF MÜLLERIAN RESEMBLANCE, X. 329-3I.

Advantage conferred by mimicry, evidence of, 288 ; conferred by concealment, direct evidence of, 288 , 289.

ADVENTITIOUS OR ALLOCRYPTIC
Protective (AND AgGRESSIVE)

RESEMBLANCE, X. 3I3, 314 .

ADVENTITIOUS WARNING OR Allaposematic Colours, X. 356, 357 ; see also 315.

ADVENTITIOUS OBJECT AsSOCIATED WITH MODEL, MIMICKED : Pseudallaposematic ResemBLANCE, X. 377 ; see also 359.

AFFINITY, MIMICRY, \&C., INDEPENDENT OF, VIII. Two sections, 229-34 and 235-7; see also 345 .

Affinity and adaptation, J. C. Prichard on the 'double relation' of, 188, I 89.

Affinity and analogy, W. S. Macleay on, 220 ; Rev. W. Kirby on, 220 ; Professor J. O. Westwood on, 221 .

AFrICA AND ADJACENT IsLANDS, THE PAPILIO DARDANUS (MEROPE) GrouP OF, X. $373^{-6}$; see also dardanus.

Africa, xxvi, 70, 71, 100, 187, 190, $215,222,223,276,277,304,31$, $316,320,336,339$ n. I, 340, 34I, $342,344,345,345$ n. $5,353,364,365$, $367 \mathrm{n.2}, 368,370,373,374,375$; see also Ethiopian, xxv, xxvi, 336, 365 ; Grand Comoro, 373 ; Madagascar, 57 n. 1, 216, 245, 373; Sahara, 321, 364; Sudan, 256, 258 ; Victoria Nyanza, xxxv, 69, 338, 374, 374 n. 3 .

Africa, East, $254,255,282$ n. I, $320,335-8,374,375$; see also Abyssinia, 373-5; Delagoa Bay, 282 n. I; Kikuyu, 374 ; Rosako, Usaramo, 255 ; Somali, 32 I.

Africa, South, 53, 87, 276, 281, 284, $300,301,303$, 31 I, 31 3, 320, 326, 335, $340,363,369,374,375$; see also Cape, 87, 88; Durban, 52 n. I, 7 I n. I, 72,283; Gazaland, 284; Malvern, 52 n. 1, 283; Melsetter, 284 ; Natal, 52 n. I, 71 n. I, 87, 249, 283; Pretoria, 7 I n. I; Rhodesia, 7 I n. I, 257 n. I ; Salisbury, 71 n. I, 257 n. $1,283,284$.

Africa, West, 248, 321, 335, 337, $338,364,366,374$; see also Congo, 321 n. I ; Entebbe, 374 n. 3 ; Guinea, 187; Luebo, 321 n. I ; Niger, 321 , 364 ; Toro, 338 ; Uganda, 338.

After-lives of twins, I 34,135 .

Agaristed moth mimicked by Chalcosid moth in Borneo, 275. agathina, Mylothris as model of 
Belenois, 341 ; no seasonal change in, 341, 342 .

Age of stratified rocks, I6, I 7.

AgE OF THE EARTH, A NaturaLIST ON THE, Essay I. I-45.

Age of the Earth, argument from tidal retardation and length of day, 7-9; from cooling of earth, 9-13; from life of sun, 13-15; radium and, 15 n. 2 ; geological argument on, 16, 17.

agestor, Papilio, in some respects more conspicuous than model, Caduga tytia, $37 \mathrm{I}$.

AGGRESSIVE MIMICRV INCLUDING ALluring Colours: PSEUdePISEMATIC RESEMBLANCE, X. 377,378 : see also Mimicry Aggressive, \&c.

AGGRESSIVE OR ANTICRYPTIC RESEMBLANCE, X. 312, 313.

AgGRESSIVE RESEMBLANCE ADVENTITIOUS OR ALLOCRYPTIC, $X$. 3I3, 314 .

Aggressive or Anticryptic Resemblance, place of in bionomic uses of colour, 226; defined, 297 ; general and special, 312 ; elimination of shadow in, 313; seasonal change in, 3I 3 ; adjustable resemblance in, 31 3 ; to upright stems and their shadows, 313 ; to supposed images of sun, 313 . aglaia, Argynnis, probable effect of gravity on pupal shape of, 152 .

Akya Chaung (branch of Haundraw R.), Burma, bee-eaters capturing butterflies at, 287,288 .

Alastor, species of, resemble other Hymenoptera in Australia, 278.

albimaculata andecheria, Amauris, western Amauris mimicked by, 335, 337 ; dominant models in E. Africa, 336 ; mimicked by the cenea female f. of three sub-sp. of Pap. dardanus, $337,338,355,374$; by female of $P a p$. echerioides, 375 . 185 .

Albinos, sudden origin of in man, albomaculata, Limenitis of W. China mimetic of male $H$. misippus, 217 ; male only mimics misippus, 381; male probably a secondary mimic of male $A$. punctata, $38 \mathrm{I}$; female resembles female of this species, 381 ; distribution of, 382 .

alcippina f. of Acraea encedon, relation to alcippus f. of $L$. chrysippus of, 364 . alcippus f. of Limnas chrysippus, increased conspicuousness suggested as interpretation of, 321 ; distribution of, 321, $32 \mathrm{I} \mathrm{n.} \mathrm{I} \mathrm{;} \mathrm{predominance} \mathrm{of} \mathrm{on}$ W. coast of Africa recent, 364 .

Alcyonaria, resemblance between Palaeozoic and living forms of, 28 .

Aletis.Euphaedra, Müllerian combination, 232; in certain characters more conspicuous than primary model, L. chrysippus, 347 n. 3.

Aletis helcita, 232.

Algae, special resemblance to floating, 298; as covering of Stenorrhynchus, 313; allopro- and allanticryptic use of by Hyas, 314.

A Liberal Education, T. H. Huxley, I98.

aliris, Amesia, with allied Chalcosiine moths, rough Müllerian mimics of blue Oriental Euploeas, 376.

Allanticryptic colours of Ceratophrys, 313; of Myrmeleon larva, 313; of Hyas, 314.

Allaposematic OR AdventiTIOUS WARNING COLOURS, X. 356, 357 ; see also 315.

Allelomorphs or germinal precursors of Mendelian characters, inferences as to the, xxxi-xxxiii.

Allepigamic collections of bowerbirds, 379.

Allier, fossil insects of Department of, 35-8.

AlL-IMPortance OF INSTINCT FoR Protective Resemblance, $X$. 3OI, 302.

ALL - Importance of InstincTIVE ATTITUDES AND MOVEMENTS IN THE DISPlay OF WARNING Colours, X. 323, 324 .

ALL-IMPORTANCE OF INSTINCTIVE ATTITUDES AND MOVEMENTS IN THE AtTainment OF Mimetic RESEMBLANCE, X. 363 .

ALLOCRYPTIC OR ADVENTITIOUS PROTECTIVE (AND AgGRESSIVE) RESEMBLANCE, X. 3I3, 314.

Allocryptic resemblance defined, 297 ; examples of, 313, 314.

Alloprocryptic colouring of Stenorrhynchus, 313; of Hyas, 314.

ALLURING COLOURS AND AGGRESSIVE MIMICRY : PSEUDEPISEMATIC RESEMBLANCE, X. 377, 378; see Mimicry Aggressive, \&c. 
almana, Precis, under side ocellated in wet, procryptic in dry season, 340 ; wet ocellated f. of (asterie) permanent in damp Siamese forests, 34 I.

alni, Acronycta, transition from cryptic to aposematic defence in larva of, 3 I9.

Alpine Hare, seasonal changes of, 310, 3 I3.

Alternation from cryptic to aposematic defence in dry and wet seasons respectively, 208, 209, 320, $339,340$.

\section{Amathusiinae, see Morphinae.}

Amauris, probable importance of Mendelian principle in the splitting of species of, $\mathrm{xxxv}$; see also 68,69 ; black and white species of and Natal mimics in Hope Department, 249; Eastern sp. of influenced by Western at overlap, 335, 337 ; Eastern sp. of and mimics replaced at V. Nyanza by Western sp. and mimics, 336-8; Western sp. of mimicked by $T$. morgeni, 337 ; mimicked by one f. of female, $A$. esebria, 354,355 ; advantage of resemblance to chrysippus as well as to, 355 .

Amauris albimaculata, 335-7, 374,375 ; - echeria, 249, 335-7, 355, 374,375 ; - niavius, 68, 69, 336, $338,374,375$; - niavius, sub-sp. dominicanus, $68,69,336,338,374$, 374 n. 2, 375 ; -ochlea, 336.

Amazon, segregation and preferential mating in butterflies of the, 85 , 86.

Amazon, Upper, character of chief mimetic butterflies at Ega on the, 273, 35 I.

Amblyornis inornata, 379.

America, 187, 315, 323, 324.

America, Central, 232, 249, 258, 350 ; see also Antilles, 247 ; Honduras, 235 ; Mexico, 274 ; Neo-tropical, xxvi; West Indies, 178, 187, 216. America, North, 253, 255, 274, 333 ; see also Arizona, 231 ; Canada, 270, 274; Florida, 216; Hartland, 255, 256; Pine Lake, 255, 256; Toronto, 263; United States, 97, 100, 178; 274, 378; Wisconsin, I1 8 n. $1,252,253,256,380$.

America, South,or Tropical, 87, 178, $187,222,223,231,233,235,237,239$, $243,247,249,252,258,259,264,273$,
$277,280,302,311,317,322,323,327$, 333,334 n. $2,336,346,350,367,370$, 377 ; see also Amazon, 85, 273, 351 ; Andes, 90 ; Bolivia, 351 ; Brazil, 53 n. I, 216, 273, 31 3, 35 I, 356, 376; British Guiana, 259, 259 (Fig. 7), 272, 273, 322, 332, 350; Demerara, 216 ; Ecuador, 265, 35I ; Ega, 273, 351 ; Guianas, 350; Neo-tropical, xxvi ; Pará, 257 n. I ; Patagonia, 187, 225 ; Peru, 351 ; Potaro, 332; Surinam, 235,272 ; Trinidad, 235, 350, 351 ; Venezuela, 273, 350 .

American Addresses, $T$. $H$. Huxley, 56.

American Association for the Advancement of Science, Proceedings of, $215,217,247$ n. 1, 364 . American Journal of Science, 35.

American Naturalist, I 42 n. 2.

Amesia aliris, 376; - sanguiflua, 376.

Amixia of Weismann, 60 .

Ammophila, stinging ganglia of prey, I6I.

Ammophila urnaria, 163.

Amphibia, 26 ; rapid colour adjustment in, 305.

Amphidasys betularia, 143, 309.

Amphimixis of Weismann, 60 n. 3 .

Amphioxus, 26, 30.

Anaea, resemblance to dead leaf of, 205.

Analogical or Syntechnic Resemblance, 312, 359.

Analogy, W.S. Macleay on affinity and, 220; Rev. W. Kirby and Prof. J. O. Westwood on affinity and, 220, 221.

Analysis of Mimetic ResemBLANCE, VIII. 240-2.

Anatomy and Physiology, Journal of, 128 n. I, 136 n. 1 .

ANCESTOR, NON-MIMETIC OF MIMETIC SPECIES PRESERVED ON ISLANDS, \&c., X. 373-6.

Ancestor, Müllerian mimicry best explains origin of divergent mimicry in descendants of a common mimetic, 352,354 .

Ancestral forms of higher branches of animals, 26, 27.

Ancestral pattern, effect on origin of mimicry of, 218,382 ; persistence in non-mimetic males of mimetic females of, $244-7,279$; occasional 
varieties of a mimetic female may show traces of, 279.

Ancon or otter sheep, sudden origin of, 185 .

Andalusian fowl, the blue a heterozygote, xxxvi; Bateson on natural selection and the, xxxvi; suggests variations useless for evolution, $\mathrm{xxxix}$, $x \mathrm{l}$.

Andaman Islands, Elymnias cottonis in, 373, 373 n. 2.

Andes, Peruvian, Harvard branch observatory in, 90 .

Andrewes, Leslie, on mimicry of Glenea pulchella, 363 .

anemosa, Acraea, a model of Precis natalensis, 339 n. 1.

An Essay on Fertilization, Prof. M. Hartog, 60 n. 3 .

Angiosperms, appearance in late Mesozoic of, 45 ; relation to Cycadophyta of, 45 .

Angler or Fishing-Frog, bright lure of, 378 . 187.

Angora breeds, J. C. Prichard on,

Animal Behaviour, Prof. C. Lloyd Morgan, 154, 28I n. I.

Animal classification, 25.

Animal Coloration, F. E. Beddard, $244,247$.

Animals limited by tse-tse fiy, 100 .

Annales de la Société Entomologique de France, 21 1, 326.

Annals and Magazine of Natural History, 49, 53 n. I, 71 n. I, 208, 223, 234, 278, 323, 340, 356.

Annandale, N., on hour swhen insect enemies are inactive, 303 ; on flower-like species of Mantids,Hymenopus, \&c., 378 n. 3. 364 .

Anosia plexippus (archippus), 274,

Ant, see Ants.

ANTAGonism Promoted BeTWEEN STUDIES ALL NEEDED FOR ATTACKING PROBLEM OF EVOLUTION, Introd. xli-xliv.

Antennae, presence or absence of, important in classification, 33; absence in Crustacea of true, $33 \mathrm{n}$. I ; possessed by trilobites, 17,39 ; simulated by legs of mimetic spiders, 253 ; modification in weevils and mimetic Longicorn, 26I ; simulated by 'tails' of Lycaenids, 282, 325, 325 n. I ; mimicked by posterior processes of S. fagi larva, 369.

anthedon, Hypolimnas (Euralia) replaced by eastern $H$. wahlbergi near V. Nyanza in accordance with corresponding geographical replacement of Danaine models, $33^{8}$.

Anthomyza, sp. of, as mimics of Ithomiinae, 264 ; method of obtaining transparency in moths of the genus, 266.

Anthribidae, see classification of examples of mimicry, 390-I.

Anthropological Institute, Journal of, 134 .

Anthropology, discoveries of $\mathrm{J}$. C. Prichard in, 173 .

ANTICIPATION OF MODERN ViEWS on Evolution, Essay VI, 173-92.

ANTICRYPTIC OR AGGRESSIVE Resemblance, X. 312, 313 .

Anticryptic Resemblance, see Aggressive, \&c.

antigone, Teracolus, Müllerian mimicry chiefly in dry f. of, 342.

Antilles, $H$. misippus extends into, 247.

antilope, Precis, seasonal forms of, 208 ; dry f. bred from wet (1902), 340 n. 3 ; reason for considering wet f. a Müllerian mimic, 340 ; under side conspicuous and roughly mimetic in wet, procryptic in dry season, 340 ; S. African habitat of, 340 .

antimachus, Papilio (Drurya), a mimic of far smaller Acraeas, 366.

antinorii, Papilio, an Abyssinian non-mimetic (with exceptions, 374 n. I) member of the dardanus group, 3745 ; see also dardanus.

Ant-lion larva, allanticryptic resemblance of, 313 .

Ants, see also classification of examples of mimicry, 389-92 ; Lamarckism and instincts of worker, 165 ; mimicked in various ways, $252-61$; peculiarities of, reproduced by mimics, 259; advantage of resemblance to, 281; many examples of mimicry of, Batesian, 376; resemblance of covering shield of Membracidae to, 258 (Fig. 6), 258$60,280,369$; mimicry by immature Membracid (Homoptera) of leaf as well as of, 259 (Fig. 7), 260, 280, 377 ; carrying off wings of butterflies, 288.

Apatetic colours, position of, in 


\section{ANALYTICAL INDEX}

a scheme of the bionomic uses of colour, 226.

apiforme, Trochilium (Sesia), nature of lost scales of, 365 .

Apes, brain in man and, 108.

APOSEMATIC AND EPISEMATIC Characters, $\mathrm{X}$. 315-58. For divisions, sections, and sub-sections, see 294-6.

APOSEMATIC OR WARNING CHARACTERS, X. 315-26. For sections see 294-5.

Aposematic colours, see Warning Colours.

Aposeme, 'tussocks' a form of, 326.

Appendiculata, 25, 27, 28; of early Palaeozoic, 30; classification of, 33 ; evolution of, 33-4I ; imperfect record in the stratified rocks of evolution of, $4 \mathrm{I}, 42$.

APPROPRIATE SURFACES FOR RESTING ON, CHOICE OF, X. 301 .

Aptera, great age of, 52 .

Aquinas, St. Thomas, on St. Augustine's views on creation, 55 .

Arachnida: see also spiders and scorpions; place in classification of, 33 ; highly specialized in early Palaeozoic, 39-4I.

Araschnia levana, and its later f. prorsa, 342.

Arch. f. Entwick.-Mech. d. Organism., $130 \mathrm{n} . \mathrm{I}$.

Archaediscus, occurrence in Carboniferous of, 27 .

Archaeopteryx, ancestral features of, 32.

Archdall Reid, xl n. 2.

archesia, Precis, transition from cryptic dry to conspicuous wet phase of, $208,320,320 \mathrm{n}$. I ; under side probably aposematic in wet, procryptic in dry season, $340 ; \mathrm{S}$. African habitat of, 340.

Archipolypoda of Palaeozoic, 34 . archippus, Anosia, see plexippus, 274,364 .

Arctic Fox, aggressive seasonal change of, 313 .

Arctiidae, mimicking Lycinae, 231. arcturus or polyctor, Papilio, attacked by King-crow, 285.

Are Acquired Characters Hereditary? discussion at Brit. Assoc. (1887), 155 n. 1 .

argentus, Papilio, W. C. Hewitson on, $57 \mathrm{n}$. I.

POULTON

D d
Argyll, Duke of, on Natural Selection, IOI-2.

Argynnidae, pupae of, affected by gravity, 152.

Argynnis aglaia, 152.

arietis, Clytus, mimicry of wasp by, $238,251,252,348,363$.

aristolochiae, Papilio, shown to be distasteful, 269, 372, 375; mimicked by female f. of $P$. polytes, 373 .

Aristotle and organic evolution, 56.

Arizona, examples of mimicry from, 231.

Arnold, Matthew, on discovery and youth, 199.

'Art papers', so-called, 170.

Artamus fuscus, 286.

artaxia, Precis, under side ocellated in wet, procryptic in dry season, 340 ; S. African habitat of, 340 .

Artemia transformed into Branchipus, 73,74 .

Artemia salina, 73 .

Arthropoda, classification of, 33; of the Palaeozoic, 34-4I.

ARTIFICIAL SELECTION, DiagNOSIS TRAVERSED BY RESULTS OF, II. 76 .

Artificial selection, probable immense importance of Mendelism in, $\mathbf{x x x v}$; compared with natural selection by Darwin: erroneous statement of Darwin's opinion on, $\mathrm{xl}$, xl n. 2, n. 3, xli ; results of, 76 ; does not produce sterility, 77-80 ; physiological species and, 79, 80; domestic breeds and, 83 n. 2 ; J. C. Prichard on, 186; T. H. Huxley on, 201 .

Asa Gray, letters from C. Darwin to, xxvi, 66, 67, 68; copy of letter from Darwin to, included in Darwin's section of the joint essay (1858), I94 n. 1 .

Ascaris, early appearance of germantecedent in, $\mathbf{I} 3 \mathbf{I}$.

Ascaris megalocephala, 131.

Ascidians, 30; sea-anemones, sponges and, carried by hermitcrabs, sea-anemones by crabs, 356 , 357.

Ascidiophilus caphyraeformis, 357. Ashy swallow-shrike capturing Euploea, 286.

Asiatic lizard with flower-like lures, 378.

Asiatic Society of Bengal, Journal of, 269, 279 n. I. 
Asilidue, mimicry of Hymenoptera by, 257 n. I, 276, 278, 378 ; mimicry of Hymenoptera by, probably not aggressive, 378 ; attacking specially defended insects, 318.

ASPECTS, VARIOUS, OF MIMICRY, ILLUSTRATED BY ORIENTAL AND OTHER LEPIDOPTERA, X. 370-6. 78.

Ass and horse, sterile progeny of, assimilis, Buchanga, capturing probably Catopsilia florella, 283; chasing a Belenois; capturing and rejecting distasteful moths, 284 .

'Association' or 'Combination', use of, contrasted with 'group', 293. asterie, Precis, the wet $\mathrm{f}$. of $P$. almana, 340, 341.

Asteroidea, 30.

astyanax, Limenitis (Basilarchia), extends into Mexico, 274.

ASYMPATRY AS CAUSE OF ASYNGAMY, II. 84,85 .

Asympatry, definition of, 62 .

Asyngamy, definition of, 60 ; the true interspecific barrier, 65,84 ; sections dealing with various causes of, 84-9I ; caused without selection, 89. I25.

Atavism, relation to pangenesis of, Atella phalantha, 283.

ater, Dicrurus, attacking Papilio and capturing Vanessa, 285.

athamas, Charaxes, eaten by beeeater, 288.

Athyma AND Limenitis, ResemBLANCE of Males to Male HypoLIMNAS MISIPPUS, X. 381, 382: see also $217,218$.

Athyma, conspicuous and probably distasteful, 2 I8.

Athyma (Pantoporia) cama, 382 ; punctata, $217,381,382$.

Atlantic, swarm of $H$. misippus in mid-, 216 n. 2.

Atmosphere, energy of sun may have been conserved by, 14 .

Atta (Oecodoma) cephalotes, 259, 259 (Fig. 7), 260, $280,377$.

Attidae, mimicking ants, 252, 253; courtship of spiders belonging to, 380.

Attitude, Reduction of SHADOW BY, X. 300, 301.

ATtITUDES AND MOVEMENTS, IMPORTANCE OF INSTINCTIVE, FOR
Protective Resemblance, X. 301 , 302 : see also 289, 298, 300, 301, 318.

ATtitudes AND MOVEMENTS, IMPORTANCE OF INSTINCTIVE, IN DISPLAY OF WARNING COLOURS, X. 323,324 : see also $319,320$.

AtTitudes, INTimidating, $\mathrm{X}$. $324,325$.

ATtitudes AND MOVEMENTS, IMPORTANCE OF INSTINCTIVE, FOR MIMICRY, X. 363: see also 241, 319, 341 .

August Thorn Moth, 149, I 50.

Augustine, St., on the method of creation, 55 .

Auk, 299.

Aurivillus, Prof. Chr., on Amauris niavius and its form dominicanus, 68 . aurora, Alcidis, mimicked by $P a p$. laglaizei, 371.

Australia, form of $P$. cardui of, 85 n. I; uniformity among wasps and Fossores of, 278.

Australian and Oriental Regions, Euploeini nearly restricted to, 333, 353; mimicry in the Elymniinae of, 353.

Australian Region, see Australia, Austro-Malayan, New Guinea, 371, 379: Polynesia, 333; Ternate, I94.

Austria, hereditary transmission of inherent peculiarity of lip in Royal House of, I 80 .

Austro-Malayan sub-Region, mimicry in the Elymniinae of, 353.

Autobiography, Charles Darwin, xxix, 92.

Avebury, Lord, on instincts of Fossorial Hymenoptera, I60, I61.

\section{B}

Bacon, Francis, on transmutation of species, 54, 55; on 'vivification from putrefaction', 54,55 ; on restraining power of seed, 55 .

Bairdia, persistence through geological time of, 39.

Balanoglossus, 26, 30 ; conclusions of Bateson from study of, xliii.

Baldwin, Professor J. Mark, 312 n. 2 ; on modification and variation, 73, $73 \mathrm{n} . \mathrm{I}, \mathrm{I} 42$.

Balfour, F. M., on Peripatus, 33.

Ballad of the Ichthyosaurus, May Kendall, I04. 
Bankasoon, S. Tenasserim, nest of Microhierax at, 290, 291.

Barbet, Microhierax nesting in hole made by, $291 \mathrm{n}$. $\mathrm{I}$.

Bark, cocoons formed of, 158,159 ; protective resemblance of moths to, 298,301 : see also 322 ; colour adjustment of larvae to, 306, 307 ; syncryptic resemblance to, 312 .

Barker, C. N., on mimicry of Nitocris nigricornis, 363.

Barnacles (Cirrhipedes), C. Darwin on systematic work on, xv, 59, 60, 67 .

Basilarchia, see Limenitis.

Bates, H. W., on the wings of butterflies as registers of evolution, $5 \mathrm{I}$, $5 \mathrm{I} \mathrm{n}$. I; on preferential mating of butterflies, $85-7$; letters from Darwin to, 86 ; theory of mimicry of and transmission of acquired characters, 167 ; theory of mimicry of, 21 1-1 5 : see also 85,86 ; publication of theory of mimicry by (1862), 220-2 ; interpretation of mimicry between models by, 222, 327, $327 \mathrm{n}$. 1; rejection of Müllerian mimicry by, 223; stimulus to investigation due to theory of, 224 ; place in scheme of bionomic uses of colour of theory of (Pseudaposematic colours), 226; use of term Heliconidae by, 213, 234, $235 \mathrm{n} .1$; theory of, consistent with facts, 268 ; objections to theory of, 269,270 ; probably misled by mimicry of Ithomiinae by Heliconinae, 327 ; on different flight of Ithomiines and Heliconines, 33I n. I ; theory of, one of the first great results of Natural Selection, 361 .

Batesian (OR PROTECTIVE) MIMICRY, 36I-76. For sections and sub-sections included under, see 296 , 297: see also 348-56.

Batesian Mimicry, see Mimicry, Protective, \&c.

Bateson, W., exaggerated estimate of importance for evolution of On Variation by, xiii, xiv, $\mathrm{xl}$; on Continuity and Discontinuity, xiv ; on the dominance of Discontinuity, $\mathbf{x v}, \mathbf{x v}$ $\mathrm{n} . \mathrm{I}$; on the sole chance of progress in evolution, xvi $\mathrm{n} . \mathrm{I}$; on the imminent completion of systematic work, xvi $\mathrm{n.I}$; on variation as evolution, $\mathbf{x v i}$; on Natural Selection necessary, but its investigation unnecessary, xviii, xviii n. 1 , xix ; on phenomena of hybridiza- tion perhaps exhibited by Oenothera lamarckiana, $\mathbf{x x}$; on Natural Selection not creative, xxii, xxii n. 3 ; Darwin's work on the primrose compared with that of Gregory and, xxvii-xxxiv ; on the thrum-eyed primrose, xxix n. 4 ; statement of the problem of evolution by, xxxiii, xxxiv ; on Panmixia, xxxvii n. 2 ; exaggerated estimate of effect of Mendelism by, xxxvii n. 2 ; erroneous statement of Darwin's teaching by, $\mathrm{xl}$; unreasonable disparagement of Embryology by, xlii, xliii ; on per saltum evolution, 4; on absence of struggle during pupal stage of V. urticae, 306.

Bauhin, Kaspar, and fixity of species, 56.

Bayzand, P. J., drawings of larvae by, 254 .

Beagle, Darwin's experiences on the voyage of, 193.

Beddard, F. E., on Eristalis and hive-bee, 243,244 ; on accidental resemblances between insects, 247 .

Bees (see also classification of examples of mimicry, $389,391-2$ : see also humble-bees, $221,251,365,378$ ), attacked by bee-eaters, 287 ; larvae of mimic contrasted as regards food, \&c., with larvae of, 244 ; effects of castration by Stylops of, 380 .

Bee-eaters capturing Pierinae in Ceylon, 285, 286; systematically capturing butterflies, $287,288$.

Bee Orchis, self-fertilization of the, $64,92$.

Beetles (see also Anthribidae, Brenthidae, Longicorn, Lycidae, Phytophagous, weevils: see also classification of examples of mimicry, 389-93), often wingless in Madeira, 18; late evolution of, 38 ; protective instincts of, 155 ; 'sham death' of, 323 ; colour adjustment probable in, 307 ; mimicked by distasteful moths, \&c., 231, 276; predominant mimicry in S. American, 248; diurnal groups of, mimicked by diurnal members of nocturnal groups, 250 ; mimetic likeness attained in various ways by, 25I, $252,255,256,257$ n. I, 261, 262 ; mimicry in, independent of affinity, 237; mimicry in Lepidoptera parallel with that in, 236, 237 ; hardness as a special protection in, 369 ; head of shrew-like animal resembled by, 
368; jaw-like legs of S. African, 368; majority of resemblances Müllerian and not Batesian, 348.

Behrens, T. T., capture of hermaphrodite planemoides, female f. of Pap. dardanus, by, 374 n. 3.

Belenois, attack of drongo on injured specimen of, 284 ; the model of wet $\mathrm{f}$. of Teracolus regina, 341 .

Belenois severina, 311 ; - thysa, 341 .

Bell, T. R., on tilt of Melanitis, 300 n. 5 ; on succulent larval food as the cause of wet season forms of butterflies, $34 \mathrm{I}$.

bellatrix, Callioratis, a distasteful moth seized and dropped by young drongo, 284.

Belt, T., on epigamic display of white patch by male Dismorphina, 240.

bembeciformis, see crabroniformis, 366.

Bembex, species of, resemble other Hymenoptera in Australia, 278.

Berlin, Fifth Internat. Zool. Congr. at (IgOI), 271.

bernhardus, Pagurus, carrying Sagartia parasitica, 356, 357.

betularia, Amphidasis, colour of larva as example of acquired character, 143; darkening of in Lancashire and Yorkshire district, 309.

Bibliotheca Zoologica, Stuttgart, 375.

bicornis, Hymenopus, a flowerlike Mantis : mimicry of bug by larva of, 378 n. 3 .

bidentata, Odontopera, colour adjustment to lichen, \&c., by larva of, 306.

bifida, Dicranura, cocoon of attacked by birds, 158, 159.

Biglow Papers, J. R. Lowell, I04.

bimaculata, Lepidiota, posterior end of, with eye-like spots resembling head of shrew-like mammal, 368.

Bingham, T. C., direct evidence of birds capturing butterflies obtained by, $283,286-92$; on wings of butterflies, \&c., as pad in nests of Microhierax, 290, 291, 291 n. I ; on tilt of Melanitis, 289,300 n. 5 .

Biologia Centrali-Americana, F. D. Godman and O. Salvin; Rhopalocera, F. D. Godman and
O. Salvin, 240; Rhynchota-Homoptera, Canon W. W. Fowler, 258 (Fig. 6), 259.

Biological stations needed in tropics, $89,90$.

Biometrika, I30 n. 3 .

Bionomics of Bouth African Insects, G. A. K. Marshall, 282.

Bionomics I, in Colours of Animals, Encycl. Brit., E. B. Poulton, 293.

Birds (see also evidence and enemies), evolution of from reptiles, 32 : see also 26 ; attempt to select sterility between, 79,80 ; little modified in Madeira, 84, 84 n. 2 ; greatly modified in Galapagos Islands, 84 n. 2 ; intelligence of, 116 ; the enemies of pupae in cocoons, 157-9; education of young, 166-8; bearing on mimicry of struggle for existence in young of, 167,167 n. 2,168 ; no instinctive knowledge of qualities of food possessed by young, 212; northern mimics of the male $H$. misippus may have been caused by migratory, 217 , 218,382 ; experiments on instincts and education of, 268, 269 ; indirect evidence of attacks on butterflies by, 270, 270 n. 1, 28I-3, 290-2, 325, 325 n. I ; insufficient, but considerable, direct evidence of attacks on butterflies by, 269, 270 n. I, 282 n. 1, 283-90; distasteful moths seized and rejected by, 284 ; evidence of difficulty in capturing butterfiles, 284 ; attacks of on butterflies influenced by climate, 286 ; powers of sight of, 302, 303; pupa of $L$. populi rejected by, 31 5-16; cryptic resemblance to excrement of, 319 ; intimidating attitude of large, 324 ; Müllerian mimicry in relation to, 329-3I; probably not deceived by mimicry of Precis natalensis, 339 ; Pap. aristolochiae proved to be distasteful to, 269, 372; powerful species mimicked by weak (cuckoos, orioles), 367 ; mimetic sounds made by, 324 .

Birmingham Philosophioal Society, Proceedings of, 136 n. 1 ;

Birmingham University, Author's Huxley Lecture before, the original form of Essay VII, I 93.

bispinosus, Ceratias, phosphorescent lure of, 378 .

Blackness, J. C. Prichard on strong local development of, 187; J. C. 
Prichard on protection against heat by, 190.

Blakiston and Alexander on advantage of Müllerian mimicry, 328, $329,329 \mathrm{n}$. I.

Blandford, W. F. H., on mimicry of ants by Membracidae, 259; examples of Müllerian mimicry exhibited by $(1896,1897), 343,356 \mathrm{n}$. 1.

Blastogenic, see inherent characters.

Blastoids in the early Palaeozoic, 30.

Blastomeres of frog's egg, effect of destruction of certain, 128, 129.

Blattidae (Palaeoblattidae) of Commentry Carboniferous, 36,37 .

Blood, transfusion of, 125 ; coloured by chlorophyll of food, 314 .

Blue Andalusian fowl, a heterozygote, xxxvi; Bateson on Natural Selection and the, xxxvi; suggests variations useless for evolution, xxxix, xl.

Blue Homer, fertile pairing between hybrid pigeon and, 83,84 .

'Blues', see Lycaenidae.

Blumenbach on bile as the cause of dark skin pigments in man, 176 ; on multiple origin of dog, 188.

Body or somatic cells distinguished from germ-cells, I21, 122.

Boisduval on resemblances beween W. African butterflies, 221.

bolina, Hypolimnas, reversion of mimetic female towards non-mimetic male, 245 ; female of, mimics $C$. core, male non-mimetic, 372.

Bolivia, Ecuador, and Peru, colours of the chief Ithomiine-centred combination in, 351 .

Bombay, dorippus f. of $L$. chrysippus at, 70 n. 2.

Bombay Natural Society, observations by members of, on butterflies attacked by birds, 285; Journal of, 70 n. I, n. 2.

Bombus, see humble-bees.

bombyliformis, see tityus, 365 .

Borneo, 257 n. 1, 27.5, 276, 348, $349,353,367$ n. 2,369 .

Boston Society of Natural History, Author's Address to, original form of Essay III, 95 ; Proceedinge of, 95, 155 n. 1, 159 n. 2, 162,164 n. I.

Botany, Journal of, xix n. 5, xxi.
Boulenger, G. A., on Oenothera lamarckiana not a natural species, and De Vries's conclusions founded thereupon, unsound, $x x i, x x i i$.

Boveri, on egg of Ascaris, 131.

Bower-birds, allepigamic collections of the, 379 .

Bowers of bower-birds allepigamic, 379.

Bowker, Colonel, on recent butterfly immigrants into Natal, $52 \mathrm{n}$. 1 .

Boys, Prof. C. V., on concealment of C. pumilus, 300 .

Brachiopoda, of early Palaeozoic, 30 ; rapid decline of, $4 \mathrm{I}, 42$; evolution in, 42, 43; specialization of earliest fossils, 42, 43 ; imperfect record in stratified rocks of, 42,43 .

Brachyura, late evolution of, 40.

Bradyornis mariquensis, 283.

Brain (see also instinct and intelligence), rapid evolution of, in higher animals, 29; evolution in Mammalian, 108; evolution in man's, 108; instinctive mechanisms of the, versus the individually acquired, 166.

Brambles, number of British species of, 47 .

Branch, aggressive resemblance of serpent to, 312 .

Branchipus, Artemia transformed into, 73, 74 .

brassicae, Pieris, pupal groove of, $147,148$.

Brassolinae, the 'eye-spots' of pseudaposematic, 326.

Brazil, 53 n. 1, 216, 273, 313, 351, $356,376$.

Breeding between near of kin, 93 .

Brenthidae (see also classification of examples of mimicry, 390, 391), though stick-like, commonly found in flowers, 370 .

BRIGHTLY-COLOURED SURFACES CONCEALED DURING REST, VALUE OF, 303, 304: see also 325 .

Bristol, J. C. Prichard a physician at, 173.

British Association for the Advancement of Science, Reports of, xvi n. 1, xviii n. 1, xix n. 2, xxii, xxii n. 3, xxix n. 4, xxxiii, xxxvi, xxxvii n. $2, x l$, xliv, xliv n. 1, xlv, xlvi, I, 15, 44, I 44 n. I, 148, 155 n. I, 164 n. I, 213 n. 1, $223,225,263$, 306, 308, 343 ; Prof. Huxley's Presi. 
dential Address (1870), I; Prof. Rolleston's Presidential Address to Zoological Section (1870), I ; Discussion on Acquired Characters at Zoological Section (1887), 148 n. I, 155 n. I; Discussion on Acquired Characters at Zoological Section (1889), I64 n. I ; Author's Evening Lecture on Mimicry (1890), the foundation of Essay X, 293, 365, 370, 376; Sir Archibald Geikie's Presidential Address (1892), 16, 19; Lord Salisbury's Presidential Address (1894), 2-4, 9, 10 ; Author's Presidential Address to Zoological Section (1896), the original form of Essay I, I ; Prof. Adam Sedgwick's Presidential Address to ZooJogical Section (I899), I44 n. I ; Discussion of Fertilization at Zoological Section (1903), 60 n. 3; Prof. A. C. Seward's Presidential Address to Botanical Section (1903), 44 ; Prof. J. B. Farmer's Presidential Address to Botanical Section (1907), xliv-xlvi.

British Guiana, 259, 272, 273, 322, 332, 350.

British : beetle (Clytus), moths (Trochilium, Haemorrhagia), and caterpillar (Euchelia) mimicking wasp, 230, 238, 251, 252, 348, 363, 365,366 ; bug larva (Nabis) mimicking ant, 257 n. I ; caterpillar (Choerocampa) mimicking cobra-like snake, $319,367,367$ n. $2,368,376$; caterpillar (Endromis) mimicking saw-fly (Croesus) larva, 238, 239, 239 n. I ; caterpillar (Stauropus) mimicking ant and bug, 253, 253 (Fig. 2), 254, 369 ; fly (Volucella) mimicking humble-bees, 221, 378, and (Eristalis) bee, 243,244 ; moths and butterflies, choice of resting sites and procryptic attitudes of, 156, 301 ; insects, slow adjustable Protective Resemblance in, 306, 307 ; northern moths, darkening of, 308-10; moths, seasonal dimorphism of, 311 ; crabs, allocryptic defence of, 313,314 ; hermit crabs carrying sea-anemones and sponges, 356, 357 ; hawk moths, \&c., attainment of transparency by, 365,366 .

British species referred to:-aglaia, A., I52 ; alni, A., 319 ; apiforme, T., 365 ; archippus (plexippus), A., 274, 364 ; arietis, C., $238,251,252,348$,
363 ; bee, 243,244 ; bee orchis, 64 , 92 ; bembeciforme (crabroniforme), T., 366 ; bernhardus, $\mathrm{P}$., 356 ; betularia, A., 143, 309; bidentata, O., 306; bifida, D., 158, 159 ; bombyliformis, H., 365 ; brambles, 47 ; brassicae, P., 147, I 48 ; C-album, G., 203-5 ; cardui, P., 85 ; Catocala, 303, 325 ; coarctata, H., 314 ; cowslip, xxviii, 47,63 ; crabroniforme (bembeciforme), T., 366 ; cristatus, T., I 30 ; cuanensis, P., 357 ; cuckoo, 317, 318 ; cuspis, A., 87 n. I ; edusa, C., 301 ; elpenor, C., $319,367,367$ n. 2, 368 ; Eristalis, 243, 244 ; fagi, S., 253, 253 (Fig. 2), 254, 369; fuciformis, H., 365 ; hare, Alpine, 310,313 ; heath butterflies, 210 ; humble-bees, 221, 251, 365, 378 ; illunaria, S., 311 ; jacobaeae, E., 230; 318, 319; lamarckiana, O., xixxxii, xxxv n. I ; lativentris, N., 257 n. I ; leucophaearia, H., 156; meadow brown butterfly, 210; megalocephala, A., 131; mendica, S., 324 ; misseltoe, xix; neustria, M., 157; nigra, P., 158; obscurata, G., 307, 308 ; ocellatus, S., 314, 314 n. 2 ; oxlip, Bardfield, xxviii ; oxlip,common, xxviii ; palliata, A., 357 ; palumbus, C., 83,84 ; pamphilus, C., 2 Io ; parasitica, S., 357 ; phalangium, S., 313; phlaeas, P., 87 n. 1 ; piscatorius, L., 378 ; plexippus (archippus), A., 274,364 ; populeti, T., I 57 n. I ; prasinana, H., I49; prideauxii, P., 357 ; primrose, xxvii-xxxiv, 47,63 ; pronuba, T., 314 n. 2 ; psi, A., 87 n. I; quercifolia, G., 299, 307 ; quercinaria, E., I49, I 50 ; rabbit, 93, 357,358 ; rapae, P., 93, 147, 301 ; red deer, 357; ringlet butterflies, 210 ; Rock pigeon, 84 ; rubi, T., 301 ; sambucaria, U., I 50, I 50 n. 2 ; septentrionalis, C., 239, 320 ; sphex, 161; starling, 157 n. I ; strigosa, A., 87 n. I ; sulcirostris, C., 307 ; tremula, P., I 57 n. I ; tridens, A., 87 n. I ; typhle, S., 299 ; urticae, S., 324 ; urticae, V., 306 ; verbasci, C., 318, 319; Verbascum, 78, 79; versicolor, E., 238, 239, 239 n. I ; vinula, D., 159; Volucella, 221, 378; white admiral, 342 ; woodpecker, xix ; Zonosoma (Ephyra), 150 ; Zostera, 299.

British (Natural History) Museum, Microhierax in, 290 ; A. H. Thayer's model in, 299; Palaearctic localities 


\section{ANALYTICAL INDEX}

of H. misippus, and Athyma and Limenitis mimics of male in, 382 .

Brittany, G. A. Boulenger's study of O. lamarckiana in, xxi.

Brongniart, Charles, on fossil insects of Commentry, $35-8$; on the evolution of insects' wings, 37 ; on the life-history of carboniferous insects, 37.

Browning, Robert, 155.

BRUNNER VON WATTENWYL, HYPERTELY OF, X. 302, 303.

Brunner von Wattenwyl on antlike Locustid, 256, 257, 257 n. I, 258 (Fig. 5).

Buchanga assimilis, 283, 284.

Buckler, W., figure of $A$. aglaia pupa by, 152.

Buds and flowers resembled by Flatidae, 304,304 n. 3 .

Buffon on direct effect of conditions, 75 ; on origin of colours of human races, and effect of latitude, I76, 177 .

Bugs, see Hemiptera.

Bull sterile with one particular heifer, 79 .

Bull-dog, origin of, 83 n. 2 .

Bull. Mus. Comp.Zool. Harvard, $234,277$.

Bull. Soc. Ent. Fr., 381, 382.

Bullidae originate in Trias, 42.

Bumble-bees, see humble-bees.

Burchell, Francis A., discovery of letters of W. J. Burchell by, 49 n. 3.

Burchell, W. J., letters of, 49,49 n. 3 ; isolation of, 49,50 ; Brazilian and South African butterflies of, 53, $53 \mathrm{n}$. I ; possible change since I8257 indicated by specimens of $L$. halia captured by, 356 .

Burma, 286-92, 373.

Burn, G. H., dorippus, f. of L. chrysippas, captured in Natal by, 7I n. 1 .

Burr, Malcolm, on Rhodesian antlike Locustid, $257 \mathrm{n}$. I.

Bush kingfisher capturing butterflies, 283 .

Butler, A. G., on dorippus, f. of L. chrysippus, in India, 70 n. 2.

Butler, Samuel, on Natural Selection, 105.

Butterflies, L. de Nicéville, 292.

BUTTERFLIES, POINTS IN THE RESEMBLANCE TO DEAD Leaves of, VII. 203-6: see also 206-8, 289, 299-302, 310, 311, 322, 351, 353.
Butterflies, SOME Seasonal Changes OF, VII. 206-II : see also Seasonal.

BUTTERFLIES, NEW INTERPRETATION OF AN OLD EXAMPLE OF MIMICRY IN, VII. 21 I-I8.

BUTTERFLIES AND MOTHS, CHIEFLY ORIENTAL, ILLUSTRATING Mimicry, X. 370-376.

Butterflies (see also Lepidoptera, Acraeinae, Danainae, Elymniinae, Erycinidae, Heliconinae, Ithomiinae, Lycaenidae, Morphinae, Nymphalinae, Papilioninae, Pierinae, Satyrinae: see also classification of examples of mimicry, 383-9): seasonal changes in, see seasonal; attacks by birds on, see birds; pigments of, more stable than those of moths, xlv: see also 53 ; recent immigration into Natal of species of, $52 \mathrm{n}$. I ; changes of form or distribution, in about eighty years of, $53 \mathrm{n}$. I, 356; preferential mating of, $85-8$; importance of recording captures in coitu of, 87 ; resemblance to leaves of, 203-8, 289 , 299, 300, 300 n. I, 30I, 310, 31I, $322,351,353$; Boisduval on resemblance between W. African, 221 ; too exclusive study of mimicry in, 229 , 272,273 ; mimicry of, by moths frequently Müllerian, 231, 232 ; fewness of patterns in protected groups of, 234 , 277 ; mimicry in, independent of affinity, 229-37, 345; moths which mimic are day-flying, 249, 250, 275, $276,372,376$; evidence of special defence of, required, 268 ; the chief mimetic combinations of, in Guiana, $272,273,322,331-3,350$; Venezuela, 273, 350; S.E. Brazil, 273, 350, 351, 356; Ega, Upper Amazon, 273 , $35 \mathrm{I}$; Ecuador, Bolivia, and Peru, 351 ; females chiefly mimetic, $215-$ 17 ; 244-7, 279, 347, 353, 372, 373-4 ; characteristics of distasteful groups of, 279 ; evidence of distastefulness in models, 269, 279, $279 \mathrm{n}$. I, 316,317; migration of, in Ceylon, 285; in Burma, 289; crowds of, on damp sand, 287 ; evidence of advantage conferred by cryptic defence of, 288, 289; wings of, in nest of Microhierax, 29o, 291 291 n. I ; reduction of shadow by attitude, $3 \mathrm{co}, 300 \mathrm{n}$. 5, 301 : see also 289 ; daylight hours in relation to cryptic colours and instincts of, 303 ; 
mutual approach between model and mimic in, 344,345 .

Byatt, H. A., on $H$. misippus and its model, $216 \mathrm{n}$. 1 .

Byblia (Hypanis) acheloia (götzius), 87 ; - götzius, 341; ilithyia, 341.

\section{C}

Caduga, the model of E. lais upper side, 353 .

Caduga tytia, 371.

caffer, Coccystes, Papilio demodocus found in stomach of, 283.

C-album,Polygonia(Grapta), meaning of ' comma' of, 203-5.

Calcispongiae in the Palaeozoic, 28.

Callamesia of the Chalcosiinae (Zygaenidae), Müllerian mimics of Euploeinae, 372, 376.

Callamesia midama, 372, 376.

Callichrominae, mimicry of $\mathrm{Hy}$ menoptera by, 252.

Callioratis bellatrix, 284.

cama, Athyma (Pantoporia), probable ancestor of $A$. punctata, 382 ; Oriental localities of, 382 .

Cambrian, origin of Vertebrates in pre-Cambrian or, xliii, 26, 30, 31 ; life long antecedent to, 6 ; thickness of deposits from, 16; Coelomate phyla in, 30 ; specialized forms in, 30,31 ; Crustacea of the, 39, 40; dominance of Trilobites in, 39; Ostracodes in, 39; Mollusca in, 4I, 42; Gastropoda in, 42 ; Cephalopoda in, 42 ; Echinoderma in, 43.

Cameroons, type $\mathrm{f}$. of L.chrysippus occurs very rarely in, $321 \mathrm{n}$. 1 .

Campbellpore, dorippus f. of $L$. chrysippus at, 70 n. 2.

Cambridge, Trinity College, J. C. Prichard a member of, 173 .

Cambridge Zoological Museum, A. H. Thayer's model in, 299.

Canada, 270, 274.

Canara, dorippus f. of $L$. chrysippus rare in, 70 n. 2. 276.

Cantharidae mimicking Lycidae,

Cape, $L$. chrysippus at, 88.

Cape Town Museum, 87.

caphyraeformis, Ascidiophilus, living in an Ascidian case, 357.

Carboniferous, size of dragon-fly of the, 18; Foraminifera of, 27 ; sponges of, 28; Myriapoda of, 34 ; insects of upper, 35-8; Arachnida of, 40; Pedipalpi of, 40 ; scorpions of, 40 ; spiders of, 40 ; land-plants of lower, 44.

cardui, Pyrameis, wide range and great uniformity of, 85 .

carinata, Echis, swishing sound made by, 324.

Carmegie Institution of Wash. ington, xix n. 5, xxii.

Carnivora,aggressive resemblances of, 312,313 .

Carpenter, $P$. phlaeas bred by, 87 n. 1 .

Carrier and tumbler pigeons, fertile progeny of, 78 .

Carus, Victor, letter from C. Darwin to, $x I$ n. 3 .

Castniidae mimicking Ithomiinae, 243,264 ; method of attaining transparency in, 266.

castor, Papilio, male of mimics Pap. chaon, female mimics Crastia core, 372.

Castration, effect of,upon secondary sexual characters, 122, 380 .

Catalogue of the Leech Collection, R. South, 382 .

Caterpillars (for other than Lepidopterous larvae see larvae : see also larval stage): reasons for passive defence of, I 56.

- Procryptic adaptations of :variable protective resemblance in, $152-4$; value of slow colour adjustment to, 305 ; colour adjustment to various backgrounds, including lichencovered bark, 306, 307; gregarious habits in concealment of, 304 ; value of dimorphism in, 310 ; movements essential to cryptic defence of certain, 318,323 ; value of 'sham death' in concealment of, 323.

- Transition between procryptic and aposematic defence in:-double protection of $C$. verbasci, 318 ; transition from cryptic to aposenatic defence caused by movements of, $319,320$.

- Aposematic adaptations of :value of "sham death" in aposematic defence of, 323,324 ; gregarious habits of certain aposematic, 323; movements essential to aposematic defence of certain, 319, 323, 324; value of 'tussocks' of, 325, 326.

- Mimetic adaptations of (see also 
classification of examples of mimicry, 389,391 ):- head of ant mimicked by tail of, 254, 368; clear examples of Batesian mimicry afforded by, 376 ; movements essential to mimetic resemblance of certain, 238,239 , 239 n. I, 253 (Fig. 2), 254, 319, 368.

- Struggle for existence in :- danger of experience to, $117,118,155-60$; stored up in cells of Fossores, 118 , 119; ganglia of, stung by Ammophila, 160-4; starlings attacking T. populeti, 157 n. I ; cryptic larvae preferred to butterflies and moths by lizards, 286; cuckoo devouring aposematic, $317,318$.

Catocala, value of bright hind wings of, 303-4, 325.

Catophaga, captured by bee-eaters, 285.

Catopsilin, migration of, in Burma, 289 ; persistently captured by Merops philippimus and king-crows, 289.

Catopsilia florella, 283. 187.

Cats, Angora, J. C. Prichard on,

Cattle, J. C. Prichard on the production of breeds of, by selection, 186.

Cattle and horses of plains and mountains compared by J.C. Prichard, 189.

Caudal shield of $S$. fagi larva resembles bug, 369 .

caudata, Elymnias, female of, mimics $S$. plexippus (genutia), and male incipient mimic of same model, 373.

caudius, Papilio, W. C. Hewitson on, $57 \mathrm{n}$. 1 .

caunus, Papilio, wing of, in nest of Microhierax, 291.

cebrene, Junonia, captured by $\mathrm{Hal}$ cyon chelicutensis, 283.

Cell-divisions equivalent or differentiating, 133,135 .

Cell-republics of the higher animals, $120,121$.

Cells, division of labour among, 121.

Celtic, shown by J. C. Prichard to be an Aryan language, 173.

cenea, a female f. of three E. and S.E. sub-sp. (polytrophus, tibullus, cenea) of Papilio dardanus (q.v.), 72, 72 n. 1, $337,338,355,374,375$.

cenea, the S. and S.E. sub-sp. of
Papilio dardanus (merope), 355, 374, 375 : see also dardanus.

Centipedes, 27.

Centrifugal or inherent characters, 111, 123, 142: see also inherent characters.

Centripetal or acquired characters, 110, I11, 123, 142: see also acquired characters.

Cephalopoda appear in Cambrian, 42 ; evolution in, 42 ; rapid colour adjustment in, 305; colour adjustment of, both aggressive and protective, 313.

cephalotes, Atta (Oecodoma), mimicked with its leaf by Membracid larva, 259, 259 (Fig. 7), 260, 280, 377.

Cephonodes hylas, 365 .

Ceratias bispinosus, 378 ; - urano. scopus, 378.

Ceratophora, place in classification of, 33 .

Ceratophry's cornuta, 313.

Cercospora, attacking leaves, 205

n. $\mathbf{I}$.

Ceria, method of attainment of mimicry by, 280 .

Cerotoma, mimicked by Lema, 237. ceryne, Precis, dry f. bred from wet (1905), 340 n. I ; under side far more conspicuous in wet than dry season, 340 ; S. African habitat of, 340.

Ceylon, 70, 70 n. 2, 71, 285, 286, 349.

Chaetopoda, relation to ancestry of Appendiculata and Arthropoda of, $27,33,41$.

Chafer, posterior end of, mimicking shrew-like mammal, 368.

Chalcosiinae (Zygaenidae), highlyprotected diurnal moths, mimicking Danainae and Papilioninae, 231; Danainae and Pierinae, 275; Danainae, 362 ; Euploeini, 372, 376; Agaristid moths, 275; mimicry of Müllerian, 231, 232, 362, 372, 376 .

Chalk, procryptic colouring of G. obscurata on, $307,308$.

Challenger, investigations on ocean basins of, 20-2.

Chamaeleo pumilus, adjustable neutralization of shadow in, 300,313 .

Chameleon, rapid colour adjustment in, 305; aggressive resemblance of, 313 .

ChaNGE POSSIBLE IN MÜlleRIAN MiMiC SINCE $1825, \mathrm{X} .356$. 
Changes Seasonal in the INDIVIDUAL, X. 3 IO.

Changes in mode of defence at different stages of life-history, 319.

chaon, Papilio, mimicked by male of Pap. castor, 372.

Chapman, T. A., on evidence of preferential mating, 87 n. 1 ; on choice of resting-sites by butterflies, 30I.

Charaxes, value of 'tails' of hind wings of, 281, 282; wing of, in nest of Microhierax, 291.

Charaxes athamas, 288 ; - psaphon, 286; - scheiberi, 292.

Charles Darwin and the Theory of Natural Selection, E. B. Poulton, 83 n. I, 162 n. 2, 219, 225, 233 n. I, 272 n. 1 .

chelicutensis, Halcyon, capturing Junonia cebrene and Catopsilia florella, 283.

CHIEF CHARACTERISTICS OF MIMETIC RESEMBLANCE AND ATTEMPT TO EXPLAIN THEIR Evolution, X. 362,363 : see also Essay VIII, 220-70.

China, 88, $217,333,382$.

chinensis, Estigmena, mimicked by Estigmenida variabilis, $26 \mathrm{I}$.

Chinese goose fertile with Common, 83.

Chiricahua Mountains, Arizona, examples of mimicry from, 231 .

Chiton, in early Palaeozoic, 30, 42 ; an ancestral form, 42 .

Chlorophyll derived from food, use of by insects, 314 ; by larva of $T$. pronuba, 314 n. 2 ; passing through egg into larva of next generation, 314 n. 2.

Choerocampa, snake-like Bornean species of, 367 n. 2; terror inspired by snake-like African species of, and the British C.elpenor, 367 n. 2 .

Choerocampa elpenor, 319, 326, 367,367 n. $2,368,376$.

CHOICE OF APPROPRIATE SURFACES FOR RESTING ON, X. 301.

Chrysalis, see pupa.

chrysippus, Limnas, forms of, with theirgeographical distribution:-distribution of dorippus and type forms of, 70,71 ; peculiarity of far eastern forms of, 88; 'Syngamic chain' probably formed by, 88,89 ; type f. of ancestral, $321 \mathrm{n}$. I ; type f. of, very rare in Camaroons as compared with alcippus f., 321 n. I; geographical transition from aposematic to cryptic defence of, 320, 321 ; desert form of, 321 ; two of three forms of sharply marked off, 364; corresponding forms of mimics transitional into one another, $364,365 \mathrm{n}$. 1 .

- Mimics of :-as model for mimicry, 215 ; Müllerian mimicry of by Aletis helcita and its mimics, 232 ; Natal mimics of with model, in Hope Department, 249; a dominant model in E. Africa, 336 ; preferring station different from that of certain of its African mimics, 349; mimicked by one f. of female $A$. esebria, 354,355 ; advantage of resemblance to, as well as to Amauris, 355; three forms of, mimicked respectively by three forms of $A$. encedon, 355, 364, 365, $365 \mathrm{n}$. I; also by three forms of female $H$. misippus, $355,364,365$, 365 n. I, 372 ; alcippus f. of, shown by mimics to be only recently dominant in W. Africa, 364 ; shown by mimicry to be ancient inhabitant of Africa, but a recent intruder into Oriental Region, 364 ; mimicked by trophonius, female $f$. of four subspecies of Papilio dardanus, 374.

Church Quarterly Review, 56 n. 3.

Cicada, wings of, in nest of Microhierax, $29 \mathrm{I}$ n. 1 .

Cinnabar moth, 230; larva of, 318.

Circumcision, results of, not hereditary in spite of antiquity, 182 .

Cirrhipedes, continuity the diffculty in Darwin's systematic work on, $x v, 59,60,67$; in Silurian, 39.

Classification of animals, 25 ; of bionomic uses of animal colours, 226; of examples of mimicry, 383-93.

Claws of Crustacea, Lamarckism and, 113,114 ; value of the power of throwing off, I13, I1 4, 325 ; pseudepisematic or alluring use by Hyas of, 314.

'Clearwings', transparency of scales in, 366.

Cleavage, position of future embryo and planes of, 130.

cleodora, Eronia, captured by flycatcher, 283; choice of resting-site by, 301 . 
Cleonus sulcirostris, 307.

Climate (see also external causes) : J. C. Prichard on adaptation of human races to, 19I ; an explanation why human races may not be changed by, 192 ; on the influence of, 187-92 ; hypothesis that mimicry is caused by food, \&c., and, 224; influence of, on attacks of birds on butterflies, 286.

Close, Rev. M. H., on the age of the earth, $12 \mathrm{n}$. I.

Clytinae, as mimics of Hymenoptera, $238,25 \mathrm{I}, 252,-348,363$; as models for other Longicorns in Borneo and Ceylon, 348,349 . 363.

Clytus arietis, 238, 251, 252, 348,

Coal, insects of, 35-8.

coarctata, Hyas, combined alloprocryptic, allanticryptic, and pseudepisematic colouring of, 314.

Cobra, cryptic and aposematic defence of, 324 ; intimidating attitude of, 324,325 ; advantage of intimidation of, $324,325$.

Cobra-like and other snakes mimicked by caterpillars, 319,326 , 367,367 n. 2, 368, 376 .

Coccystes caffer, 283.

Cockroaches, in early Palaeozoic, 30 ; of Commentry Carboniferous, 36,37 .

COCOON, INSTINCT OF FORMING, V. 157-60.

Cocoon, formed prior to experience, and Lamarckian interpretation therefore excluded, $117,118,157-60,164$, $164 \mathrm{n} .2$; probably reasons for decline of, I48; advantage of decline of, 148 , I 49 ; cryptic colouring of, in times of stress, 148 ; colour adjustment of, in Halias prasinana, 149; concealed on bark, 158, 159 .

Coelentera, in relation to classification and evolution, 25, 26, 28, 30, 31 .

Coelomata, in relation to classification and evolution, 25-8, 30, 3I, 4I, 43.

Coenonympha pamphilus, 210.

coerulescens, Microhierax, capturing Papilio sarpedon, 290 ; butterflies' wings, \&c., in nests of, $290,291$.

Co-Existence of Palatable FOOD IMPLIED BY APOSEMATIC DEFENCE, X. 317.

COINCIDENCE BETWEEN COLOURS
AND ENVIRONMENT PROBABLY CAUSED BY LOCAL NATURAL SELECTION, X. 307, 308: see also 308,309 , 309 n. I, 310 n. I.

Colaenis, 'stink glands' of, 334 n. 2. Colaenis telesiphe, 334 n. 2.

Cold, see external causes; effect of, on Hudson's Bay Lemming, 310.

Coleoptera, see beetles.

Colias edusa, 30I.

Coloration marquante et Taches ocellées, 1897, C. Portschinski, 254, 369.

Colour adjustment, see Adjustable Protective Resemblance.

Colour, danger of inferring discontinuity from changes in, xvii.

Colours of animals classified, 226 ; sexual selection of bright, 379 .

Colours of Animals, E. B. Poulton, 4,150 n. 2, 210, 223, 226, 281, $326,344,367$ n. 2.

Colours of Animals : I, Bionomics, Encycl. Brit., E. B. Poulton, 293.

COLOURS PROBABLy ADJUSTED TO ENVIRONMENT BY LOCAL NATURAL SElection, X. 307, 308 : see also 308, 309, 309 n. I, 310, 3 IO n. 1 .

Colours, Value of Bright, CONCEALED DURING REST, X. 303 , 304 : see also 325.

Columba palumbus, 83,84 .

Comb-making instinct, 164 .

Combination of procryptic and mimetic colouring, chief examples of, in butterflies (Protogonius and Elymniinae), $350-4$ : see also 324,368 .

'Combination' or 'association', use of, contrasted with 'group', 293.

Comma butterfly, 203-5.

Commentry, fossil insects of, 35-8.

Common goose fertile with Chinese, 83.

COMMON OR SYNCRYPTIC PROTECTIVE RESEMBLANCE, $\mathrm{X}$. 312 : see also 359.

COMMON WARNING COLOURS, Natural Selection the Cause OF MIMICRY AND (THEORIES OF MimiCRY), Essay VIII, 220-70. See also Essay IX, Mrmicry AND Natural SElection, 271-92.

COMMON WARNING OR SYNAPOSEMATIC COLOURS (MÜLlerian 
MimicRY), X. 327-56. See Mimicry Müllerian. For sections and subsections of this heading see pp. 295, 296.

Comoro, see Grand Comoro, 373.

COMPLETE IMMUNITY NOT IMPLIED BY WARNING COLOURS, X. 317,318 .

Composite mimicry of two models, 368,369 .

Composite nature of Mimicry, 240-2.

Concealment, aposematic forms protected in time of stress by, 317 , 320.

Concealment Assisted By GREGARIOUS HABIT, X. 304 .

Conception, J. C. Prichard on effect of imagination at the moment of, 186.

Conclusions ON NATURAL Selection as THE CaUse of MIMICRY, \&c., VIII. 267-70.

Conclusions supporting Müllerian Mimicry, 346, 347.

CONDITIONS CHIEFLY DETERMINED BY HABITS AND LIFEHISTORY, VIII. 243, 244.

Conditions, see environment, external causes, and uniformity.

Conductivity in interior of earth, 10-13; and radium, 15 n. 2.

Conepatus mapurito, 315.

CONFIRMATION OF HISTORY INFERRED FROM MIMICRY, X. 365,366 . confusa, Methona, mimics of, 2646 ; method of attaining transparency in, 265; Ecuador form of, 265, 266.

Congenital, see inherent characters, 141.

Congo, type f. of L. chrysippus at Luebo on S. branch of, $321 \mathrm{n}$. I.

Coniferae related to Cordaiteae, 45.

Connate varieties of structure ... are apt to re-appear in... offspring ', J. C. Prichard (1826), 179.

Connate, see inherent characters.

CONSPICUOUSNESS IMPUTED TO ANimals CRITICIZED BY THAYER, X. 32I-3.

Conspicuousness only not the aim of nature, 321,322 ; danger of unnecessary, 322 ; relative use of term, 322.

Constitutional, see inherent
Constricting serpent, aggressive resemblance of, 312 .

Contemporary Review, 161.

Contents, Essay X. 293-7.

Continental AREas, Mimetic SPECIES ON, WITH NON-MIMETIC ANCESTOR IN ISLAND, X. 373-6.

Continental areas, stability of, 21 .

Continuity and Discontinuity defined, xiv.

Continuity of the germ-plasm, diagram of, described, 127-8, 130-1; heredity and, $127-36$; blastogenic or inherent characters and, 127 ; somatogenic or acquired characters and, 127, 131, 132; relation between transmission of acquired characters and, illustrated in Diagram II, 13 I, 132.

Continuity the systematist's difficulty, xv.

Continuous or Discontinuous Evolution, Introd., xiv-xvi.

Continuous evolution cannot be claimed as Mutation, xxxviii, xxxviii n. I, xxxix.

Contributions to an Insect Fauna of the Amazon Valley, H. W. Bates, 220.

Conularia in Palaeozoic, 42.

Conviction, the basis of scientific, 201, 202.

Cooling of the earth, 9-13.

Cope, E. D., on Natural Selection not creative, xxii ; on origin of fittest, I09.

Coral, protective resemblance to, 359.

Corals, place in classification of, 25 ; slow evolution in, 28.

Cordaiteae, a group of Palaeozoic Gymnosperms, 45 ; comparable to Coniferae, 45.

core, Crastia, captured by Artamus fuscus, 286 ; mimicked by female of $H$. bolina, 372 ; mimicked by female of Pap. castor and by both sexes of its S. representative, Pap. dravidarum, 372.

corinneus, Papilio, evidence of capture by swallow of, 284 .

Cork, Prof. J. B. Farmer on utility as no explanation of, xlv, xlvi.

cornuta, Ceratophrys, allanticryptic resemblance of, 313 .

Correns, rediscovery of Mendel's principle by, xxix ; on limitation of 
Mendel's principle to crosses between varieties, $\operatorname{xxxv} \mathrm{n} .2$.

Corticata, no fossil records of, 25. Cosmos, facts of the, consistent with gravitation, xxvi, $27 \mathrm{r}$.

cottonis, Elymnias, non-mimetic or with general likeness to a Euploea, 373,373 n. 2.

Courthope, W. J., parody of Darwinism by, 103-4.

Courtship, Colours Displayed IN, X. 379, 380 ; see also 226.

Courtship, for colours, \&c., displayed in, see Epigamic Characters and Sexual Selection.

Cowslip, C. Darwin on specific distinctness of, xxviii, 47,63 . crabroniforme (bembeciforme), Trochilium (Sesia), nature of scales lost by, 366 .

Crabs throwing off claws, 113 , I14 ; value of amputated claws of certain species, 325 ; alloprocryptic, \&c., defence of, 313,314 ; sea-anemones, sponges, and Ascidians carried by hermit-crabs, 356, 357 ; seaanemones by crabs, 357 .

Crastia core, 286, 372 .

Creation, Linnaeus's views on, 549; St. Augustine's views on, 55.

Creation special, a theological dogma, 56, 57; influence of Milton on belief in, 55,56 .

Creative power of Natural Selection, xxiii.

\section{Crenis rosa, 52 n. 1 .}

Crinoids in early Palaeozoic, 30. cristatus, Triton (Molge), Herlitzka's experiments on egg of, 130 .

CRITICISM BY THAYER OF CONSPICUOUSNESS IMPUTED TO ANIMALS, X. $321-3$.

Croesus septentrionalis, 239, 320. Cross and Self-Fertilisation in the Vegetable Kingdom, Charles Darwin, 92.

Cross-Fertilization, AsYNGAMY CAUSED BY ADAPTATIONS FOR, II. 90, 91 : see also 65.

Cross-Fertilization, possible benefits of, 93-4.

CROSS-Fertilization, THE INJURIOUS EFFECTS OF SELF-FERTILIZATION THE CONSEQUENCE AND NOT THE CAUSE OF ADAPTATIONS FOR, II. 91-4.

Crotalus, rattle of, 324 . cruciata, Oenothera, hybrid between O. lamarckiana and, does not follow Mendelian principle, $x x x v n$. I.

Crustacea in classification, 27,33 ; in Cambrian, 39: see also 30 ; experiments on Artemia, 73, 74; rapid colour adjustment in, 305 ; aggressive resemblance of, 313 ; alloprocryptic resemblance of, 313 ; allanticryptic, \&c., resemblance of, 314 ; allaposematic defence of, 356,357 .

Cryptic Colouring, ProtecTIVE AND AGGRESSIVE RESEMBLANCES: PROCRYPTIC AND ANTICRYPTIC COLOURS, X. 297-315. For sections, sub-sections, \&c., of, see Contents, pp. 293, 294.

Cryptic colours (see also Protective Resemblance and Aggressive Resemblance): place of in a scheme of the bionomic uses of colour, 226; defined, 297.

cuanensis, Pagurus, carrying brightly-coloured sponge, 357 .

Cuban swine, J. C. Prichard on, 187.

Cuckoo, indifference to unpalatability of, 317, 318; mimicking aggressive birds, 367 .

Cuckoo ( $C$. caffer), butterfly found in stomach of, 283 .

Cucullia verbasci, 318, 319.

cupulifer, Polydectus, carrying seaanemones, 357.

Curculionidae (see also classification of examples of mimicry, 390-1) : colour adjustment probable in Cleonus, 307; conspicuousness of certain large African, 370; hardness as the defence of, $26 \mathrm{r}, 369,370$.

curculionoides, Doliops, mimicking weevil, 26I.

Curiosity the only true incentive to inquiry, xliv, xlvii, xlviii.

cuspis, Acronycta, Dr. T. A. Chapman on, 87 n. 1 .

Cuttlefish, rapid colour adjustment in, 305 ; colour adjustment of, both aggressive and protective, 313 .

Cuvier, W. Whewell on, xlvi n. I ; on species, 56.

Cycadophyta, relation to Angiosperms of, 45.

Cyclops, early appearance of germantecedent in, 131 .

Cyrestis, captured by Merops swinhoei, 287. 
Cyrestis thyodamas, 288.

Cystoids, in early Palaeozoic, 30.

Cythere, persistence through geological time of, 39 .

\section{D}

Damp, effect on Teracolus and Belenois of, 311, 312.

Danainae (see also Danaini, Danais, and Euploeini; see also classification of examples of mimicry, 383-9): Lycorea and Ituna, included in Ithomiinae by Bates, belong to, 327; absence of 'eye-spots' in, 326 ; unpleasant scent in African, 316; Indian proved to be unpalatable, 269; uniformity throughout many species of, 277 ; as models paralleled by Diabrotica, 236 ; always tend to be mimicked, 233 ; the chief distasteful group of the Old World, 333-5 ; as primary models in Africa, 345 ; as models and mimics (viz. genera Lycorea and Ituna) everywhere in tropical America, 273, 356; probably not more unpalatable than a far rarer Chalcosid mimic, 362; as mimics of Ithomiinae, 264, 265 ; method of attaining transparency in, 265 ; darkening of mimetic in the Guianas, 272, 273 ; Lycorea an outlying member of a chief Ithomiine centred combination in $\mathbf{E}$. Brazil, 356 ; possible change in colour of since $1825-7,356$ : see also $53 \mathrm{n}$. I.

Danaini (see also classification of examples of mimicry, 384-9) : comparison as models of two chief subgroups ofDanainae, the Euploeiniand, 333-5 ; range of Euploeini compared with, 333, 334; mutual mimetic influence of Euploeini and Danaini compared, 334, 335; flight of certain American species of, adapted to display under surface, 323; few in Africa, but much mimicked, 336 ; the chief models in E. Africa belonging to, 336; probable meaning of male scentbrands of certain, 358 .

Danais, species of, not attacked by bee-eaters, 288.

Danaoid Heliconidae (see Ithomiinae) of $\mathrm{H}$. W. Bates include the Ithomiinae, together with the Danaine genera Ituna and Lycorea, 327.

Dances of male Attid spiders, 380.
Dangers of the dry season, 208-I I ; of 'eye-spots' in dry season, 210,211 , 326.

'Danger-signals', advantage of resemblance between, 328 .

Danisepa diocletianus (rhadamanthus), 373.

DARDANUS (MEROPE), PAPILIO, REMARKABLE EXAMPLE OF MiMiCRY, X. 373-6.

dardanus (merope), Papilio, 57, 57 n. I, $71,72,72$ n. I, 337, 338, $354,355,370,371,373-5$.

- sub-sp. 1, antinorii, Abyssinia, $373,374,374$ n. I, 375 .

- sub-sp. 2, polytrophus, Kikuyu, 374,375 ; female f. trimeni, 374, 374 n. 2, 375; female f. hippocoon, 374, 374 n. I ; female f. trophonius, 374,374 n. I; female f. cenea, 374 ; female f. planemoides, 374 .

- sub-sp. 3, merope, Western, 374 ; female f. hippocoon, 57 n. 1, 338, 374, 374 n. I; female f. trophonius, 374 , 374 n. I ; female f. planemoides, 338, 374,374 n. 3,375 .

- sub-sp. 4, tibullus, E. Coast, 337, $338,374,375$; female f. trimeni, 374, 374 n. 2, 375; female f. hippocoon, 338, $374,374 \mathrm{n} .1$; female f. trophonius, 374,374 n. 1 ; female f́. cenea, 337,338 , 374.

- sub-sp. 5, cenea, S. and S.E., 72, 72 n. 1, 355, 374; female f. hippocoon, 72,72 n. I, 374, 374 n. I ; female f. trophonius, 72, 72 n. 1, 374, 374 n. I ; female f. cenea, 72,72 n. 1,374 .

- See also meriones, Papilio, Madagascar; humbloti, Papilio, Comoro I.

- Discovery by Trimen of mimetic females of, 57 ; all three female forms bred by $G$. F. Leigh from one of them, 72 n. I: see also 72 ; three chief Danaine models of E. Africa mimicked by female forms of, 337 ; geographical replacement of models of at the V. Nyanza, and corresponding changes in mimetic female forms of dardanus, 337, 338; the great example of polymorphism in mimicry, 354,355 ; brief account of range and mimetic relationships of all subsp. of, 373-5; probable Müllerian mimicry of, 375 ; female forms of, and their models erroneously figured by Professor Weismann, 375, 376. 
Darkening of hind wing in Guiana mimetic butterfies, $272,273,331$, 332.

DARKENING, RECENT, OF N. ENGLISH MoTHS, X. 308, 309, 309 n. I, 310, 310 n. I.

Darwin, Charles (see also Descent of Man, \&c., Different Forms of Flowers, Further Letters of, Life and Letters of, Origin of Species, Variation under Domestication): continuity the difficulty in the systematic work of, $\mathbf{x v}$; on Mutation as expressed in the Vestiges, xviii, xix; on the creative power of Natural Selection, xxiii ; Bateson's and Gregory's work on the primrose compared with that of, xxvii-xxxiv ; researches upon heterostyled plants by, xxvii-xxix; on the value of the heterostyled condition, xxvii-xxix ; the importance of minute variations assumed by, xxxix; individual differences considered of far greater importance than large single variations by, $x l$, xl n. 3, xli ; letter to Wallace abandoning evolution by large single variations, 3 ; on pre-Cambrian time, 5, 6; troubled by Lord Kelvin's views, 6 , II ; on persistence of oceanic and continental areas, 21,22 ; influence of, upon biological reasoning, 32, 33 ; definition of species by, 46,47 ; on species and varieties, 47 ; on primrose and cowslip as true species, xxviii, 47,63 ; on constancy as a criterion of species, 47,63 ; natural selection as conceived by Wallace and, 48 ; special value of letters of, 48 ; life of Burchell compared with that of, 49 , 50 ; on theological aspect of species, 56 ; the joint essay (1858) of Wallace and, 58,95-7, 194-6: see also DarwinWallace theory; on various definitions of species, 59 ; on evolution and systematic work, 59 ; on subjective side of systematic work, 59,60 ; definition of 'close species' by, 67 ; on describing species, 67 ; on susceptibility to different conditions, 73-4; on effect of conditions on plants, 74,75 ; on interspecific sterility, 77-80, 201 ; on sterility between selected races, 78-80; suggestion to W. B. Tegetmeier by, 79 ; on domestic animals derived from two or three species, 79 ; con- troversy on interspecific sterility between Wallace and, 80,89 ; on fertile pairing of two species of goose, 83 ; on fertility promoted by domestication, 83,84 ; on sterility caused by asyngamy, 84 ; on preferential mating, 86,87 ; on sterility not due to selection, 89 ; on heterostyled plants and interspecific sterility, $\mathrm{sO}, 91$; on injurious effects of self-fertilization, 92 ; metaphor of tree by, 94 ; on origin of life, 95 ; on failure to understand Selection, 102: see also 96 ; term 'Natural Selection' proposed by, 105 ; on Selection a true cause, I09; theory of pangenesis of, 123-7; chief reason for adoption of pangenesis by, 126; unaware of the important second edition of Prichard's work, 175, $175 \mathrm{n}$. I ; views of, on formation of domestic breeds essentially similar to those of Prichard, 186,187 ; J.C. Prichard as a remarkable predecessor of Wallace and, 192; on instincts of Fossorial Hymenoptera, I60, I6I ; and of worker ants, 165 ; discovery of Natural Selection by, 193, 194; consults Lyell and Hooker about publication of Natural Selection (1858), I94; disappointed at reception of early geological writings (1844 or 1845), I96, I97 ; on mimicry and affinity, 233, $233 \mathrm{n}$. I ; on sexual selection as cause of mimicry, 225, 228, 272, $272 \mathrm{n} . \mathrm{I}$; theory of sexual selection of, 379 ; sexual selection set forth in the joint essay (1858) by, 379.

- Letters of, referred to in present work : to H. W. Bates, 86 ; Victor Carus, xl n. 3 ; Asa Gray, xxvi, 66, $67,68,194$ n. I ; J. D. Hooker, 59, $60,63,67,76,84,86$; T. H. Huxley, 78, 79, 80, 82, 91, 126, 196; C. Lyell, $56,75,83,83$ n. 2 ; R. Meldola, 225, 228, 233, 272 n. I (although Meldola's name is not mentioned in this footnote); Carl Semper, 74; W. B. Tegetmeier, $79 ;$ A. R. Wallace, xl n. $3,3,6$; from Hooker to, 74,74 n. 3 ; from Huxley to, 4 n. 2, 196.

Darwin, Erasmus, theory of evolu tion of, 98 ; use of term ' acquired ' by (1794), 140, 14I ; on effect of parental imagination on offspring, 186.

Darwin, Francis, on influence of Fleming Jenkin upon Charles Darwin, 
xl n. 3; on Charles Darwin's work on heterostyled plants, 90,91 ; on the Knight-Darwin Law, 92 ; J. C. Prichard as an evolutionist, considered by A. C. Seward and, 174 n. 2, 175 n. 1 .

Darwin, Sir George, on the life of the sun, 15; on trunks of fossil trees, I8, 19.

Darwin-Wallace theory and the joint essay (1858), 95-7, 194-6: see also xxxvii n. 2, 48, 58, 200, 222, 379.

Darwinian Theory, see Natural Selection.

Darwinians and Mutationists, essential difference between, xxxviii.

Darwinism, A. R. Wallace, 92, $93,226,362,380$.

Darwinism, parodies of, $102-4$.

Davidson, note of, on nest of Microhierax containing insects' wings, 290, 291.

Davis, Dr. Maurice, J.P., first perception of significance of Prichard's writings on heredity by, 174 .

Dawnat Range, Burma, 287.

Dawson, Sir William, on Eozoon, 28.

Day, change in length of, 7,8 .

Day-flying moths mimicking butterflies, 249, 250, 275, 276, 372, 376 .

Daylight and cryptic colours, instincts, \&c., 303.

Dead leaves of wet and dry seasons respectively resembled by seasonal phases of butterflies, 206, 207, 310, 31 I.

DEAD LEAVES, POINTS IN THE RESEMBLANCE OF BUTTERFLIES TO, VII. 203-6: see also 206-8, 289, 299, 300, 300 n. 5, 310, 311, 322, $35 \mathrm{I}, 353$.

Dead leaves, protective (procryptic) resemblance of moths to, 299, 302 ; of Locustid to, 302.

Deal, colour of Cleonus on sandhills near, 307 .

Deccan, dorippus f. of L. chrysippus unknown in, 70 n. 2.

Deductive Biology, Sir W. Thiselton-Dyer, xlvii, xlvii n. I.

Deep-sea fishes, phosphorescent lures of, 378 . 357.

Deer, Red, recognition marking of,

DEFINITION OF SPECIES BY
DEFINITION OF 'ACQUIRED

CHARACTERS', V. I40-4

Definition of instinct, 154.

Definition of Mimicry, 358-61.

Definition of Mutation, xvii, xvii n. 2.

Degenerate scales of moths, great size of an element in the loss of, 366 .

Degeneration, an older use of, equivalent to variation, 188 .

Degeneration following cessation of selection, 138; of lost scales greatest in best moth mimics of wasps, \&c., $365,366$.

deione, Penoa, mimicked by female f. of $E$. halitherses, 373 .

De l'Affinité des Langues Celtiques avec le Sansorit, Adolphe Pictet, 173.

Delagoa Bay, attacks of birds on butterflies witnessed at, $282 \mathrm{n}$. I.

Delias eucharis, 269.

Demerara, $H$. misippus ranges to, 216.

demodocus, Papilio, in stomach of Coccytes caffer, 283.

de Nicéville, L., on insects found in nest of Microhierax, \&c., 29I, 29I n. I, 292.

Dentalina in Carboniferous, 27.

Dentalium in early Palaeozoic, 30.

Denudation, rate of, 16 .

Deposition of rock, rate of, 16 .

Der Gegensatz zwischen geographischer und nichtgeographischer Variation, KarlJordan, 84 n. 2.

Descent of Man, \&c., Charles Darwin, 233 n. 1, 379.

Desoription of some Insects whioh appear to exemplify, \&c., Rev. W. Kirby, 220.

Desert, general protective resemblance to, 297, 298 ; syncryptic resemblance to, 312; aggressive resemblance to, 312 ; stress of life on, 321 ; a measure of cryptic resemblance to, in L. chrysippus, 321 .

Development Hypothesis The, Herbert Spencer, 58.

Devonian Foraminifera, 27; sponges, 28; Myriapoda, 34 ; land. plants appear in, 44 ; appearance of seed-plants in, 45 .

DE VRIES, Hugo, EVIDENCE IN FAVOUR of MUTATION BY, Introd. xvii-xxii ; on the necessity of Natural 


\section{ANALYTICAL INDEX}

Selection, xviii; on Oenothera lamarckiana and Mutation, xix, $\mathrm{xx}, 4$; on intermittent periods of Mutation, $\mathrm{xx}$; rediscovery of Mendel's principle by, xxix ; on minute variations incapable of permanently raising the mean of the species, xxxix; on Mutation, IIO.

dexithea, Hypolimnas, probably ancestral, 216.

Diabrotica, mimicked by Neobro. tica, Lema, and Dircema, 236, 237.

Diacrisia maculosa, 284.

DIAGNOSIS, DEFINITION OF SPECIES BY, II. 65-8; see also sections and sub-sections, $68-77$.

Diagnosis, Linnaean method of, 58,60 ; conclusions of provisional, $65,76,77$; transition and, $64,66,67$, inadequacy of, 90 .

Diagram I, illustrating Pangenesis, I 26.

Diagram II, illustrating Continuity of Germ-plasm, 127, 128, $130-2$.

Diagram III, showing development of 'identical' twins, 133,134 .

DIAPOSEMATIC RESEMBLANCE, Reciprocal Warning Colours, X. 344,345 .

Diaposematic Resemblance, introduction of term, 344 ; illustration showing advantage of, 330,331 ; characteristic of Müllerian mimicry, 344 ; probable between Papilio and Uraniid moth, 371 .

Dicranura bifida, 158, 159;vinula, 159.

Dicrurus attacking Lepidoptera, 285, 287; unable to find Melanitis, 288, 289.

\section{Dicrurus ater, 285.}

Dictionary of Philosophy and Psychology, J. Mark Baldwin, 73 n. I, 142 n. 3, I 43 n. 2, 312 n. 2, $360 \mathrm{n}$. I.

Different Forms of Flowers, Charles Darwin, xxvii.

DIFFERENT MODELS MIMICKED by Male and Female, X. 372.

Different methods of attaining mimetic resemblance, $250-67,280$.

Differentiating cell-divisions, 133, 135 .

Digits, supernumerary, hereditary, 135, 136, 180.

DIMORPHISM, DIAGNOSIS TRAVERSED BY SEASONAL, II. 72-4.
Dimorphism, unique form of, in larvae and pupae of Zonosoma (Ephyra), I 50; value of, 310 ; heredity in, 310.

DIMORPHISM AND POLYMORPHISM TRAVERSE DIAGNOSIS, II. 70-2.

DIMORPHISM AND POLYMORPHISM IN PROCRYPTIC DEFENCE, $X$. 310.

DIMORPHISM AND POLYMORPHISM IN MiMiCRY, X. 354-6.

Dimorphism and Polymorphism, common in mimetic species, 354; apparent strong support to Batesian mimicry of, 354 ; facts of, also consistent with Müllerian interpretation, $354,355,356$; advantages of, in mimicry, 372 ; examples of, 372-5.

Dimorphism and trimorphism in both model and mimic, $355,364,365$ n. 1 .

DIMORPHISM, SEASONAL IN PROCRYPTIC DEFENCE, X. 3IO-12.

Dimorphism seasonal in butterflies, 206-I I, 339-42.

diocletianus

(rhadamanthus), Danisepa, mimicked by female f. of E. halitherses, 373.

Dipnoi, 26.

Diptera (see also classification of examples of mimicry, 390-3): minute changes more evident in Lepidoptera than, 52 ; W. S. Macleay on resemblance to Hymenoptera of, 220; Kirby and Spence on mimicry of bees by Volucella, 22I ; preferred to butterflies by lizards, 286; wings of, in nest of Microhierax, 291 ; probably not aggressive mimics of Hymenoptera, 378; probably attracted by flower-like lures of lizard, 378.

Dircena mimicking Diabrotica, 237.

DIRECTIVE MARKS AND STRUCTURES, X. 325,326; SeAsonal DEVELOPMENT OF, X. 326.

Directive marks and structures evidence of value of, $210,28 \mathrm{I}, 282$; value of movements to, $2 \delta 2$; frequently injured as if by enemy, $28 \mathrm{r}, 282$; difficulty in the classification of: may be aposemes or pseudosemes (pseudaposemes or pseudepisenes), $325,325 \mathrm{n} . \mathrm{I}, 326$; in hind wing of Protogonius, $35 \mathrm{I}$. 
dirtea, Symphaedra, wing of, in nest of Microhierax, 291.

Discina, persistence of, in time, 43.

Discontinuity, definition of continuity and, xiv; the origin of specific, $\mathrm{xv}, \mathrm{xvi}$; importance of geographical distribution for the study of, xvi ; judgement of subjective, xvii ; colour and, xvii ; as a test of species, 66, 67 .

DISCONTINUOUS OR CONTINUOUS Evolution, Introd. xiv-xvi.

Discriminating features even in closest mimicry, 349, 350; possible meaning of, 350,358 .

Discussion on Acquired Characters (1889), 164 n. 1 .

DISCUSSION ON SPECIES, INSECTS ESPECIALLY FITTED FOR, II. 50-4.

DISCUSSION ON SPECIES, INTRODUCTION TO, II. 63-5.

Disease, germs of, 120,121 ; when germ-caused, not hereditary, I 36,184 ; acquired, not hereditary, 136; blastogenic origin of certain, 136; nontransmission of constitutional effects of, $182-4$.

Dismorphia orise, 240, 265, 266.

Dismorphina (Pierinae), mimicry of Ithomiinae by, 239, 240, 265, 266; retention of old Pierine character by males of, 239, 240; sexual brands of males of, 240 ; T. Belt on epigamic use of white patches in males of, 240 .

Distance, importance of, in mode of defence, 319; effect of, on apparent size, 366 .

Distant, W. L., on dorippus f. of L. chrysippus in S. Africa, 71 n. 1.

Distasteful, see unpalatable.

Disuse, apparent inherited effects of, due to cessation of Natural Selection, $137,138$.

DIVERSE WAYS OF PRODUCTION OF MIMICRY, \&C., BETWEEN INSECTS OF VARIOUS ORDERS, VIII. 250-6I ; BETWEEN INSECTS OF THE SAME ORDER, VIII. 26I -7 : see also 280 .

Diurnal models mimicked by diurnal members, even of nocturnal groups, 249, 250; moths mimicking butterflies, 249, 250, 275, 276, 372, 376 ; hours of procryptic defence, 303 .

Dixey, Dr. F. A., on mutation and continuous evolution, xxxviii, xxxix; on species, 56 ; on word 'species', $62 \mathrm{n} .1$; support to Müllerian theory by, $213,223,328,343-5$; on Reciprocal Mimicry (Diaposematism), $213,344,345$; memoirs in support of Müllerian theory by, $213 \mathrm{n}$. 1; on Müllerian mimicry in Pierinae, 262 : on homologous markings of the Vanessidae, 277 ; results obtained by, quoted in Essay X, 293: see also viii ; on choice of resting-sites by butterflies, 301 , 301 n. 6 ; on Melanism, $310 \mathrm{n} . \mathrm{I}$; on seasonal changes in the Pierinae, $311,312,312 \mathrm{n} .1$; on epigamic and aposematic smell in African butterfiies, 316, 317, 317 n. I; on Mimetic Attraction, $328 \mathrm{n} .1$; on wet and dry forms of Byblia götzius and $B$. ilithyia, 341 ; on seasonal forms of Teracolus regina, 341 ; on Müllerian mimicry in its relationship to the seasonal changes of Pierinae, $34 \mathrm{I}, 342$; on secondary Müllerian mimicry, 345 ; on combination of procryptic and mimetic colouring in Pierinae, 350; general applicability of Wallace's third condition to Muillerian mimicry controverted by, 362 ; on female mimicry Müllerian no less than Batesian, 362 n. 2 ; on the Papilio-Euterpe Müllerian association, 362 n. 2.

Dixon, Professor A. F., and G. Y., on habits of Hyas coarctata, 314, $314 \mathrm{n}$. 1 .

Dog, origin of, $8_{3}, 8_{3}$ n. 2 ; Prichard on the production of breeds of by selection, 186; Blumenbach on multiple origin of, 188 .

Doleschallia, resemblance to dead leaf of, 205.

Doliops curculionoides, 261 ; - geometrica, 261.

Doliops (Lamiidae) mimicking weevils, 250, 261 .

Domestic races, probable immense importance of Mendelism in, xxxv; widely different, 76; Darwin's view of two or three species combined in, 79; artificial selection and, 83 n. 2 ; suggested origin from two or more wild species, $83-4$; recognition by J. C. Prichard that artificial selection has produced, 174, 186; fertility between, 20I : see also 77-80.

Domestication, reduction of sterility by, $79,83,83$ n. 2 .

Dominant and recessive characters, $\mathrm{xxx}-\mathrm{xxxiii}$. 


\section{ANALYTICAL INDEX}

dominicanus, f. of Amaurisniavius, a dominant model in E. Africa, 336 ; replaced by type $f$. of niavius at V. Nyanza, 68, 69, 338; corresponding changes in Papilionine and Nymphaline mimics, 338 ; mimicked by hippocoon female f. of E. and S. Pap. dardanus, 374, 375; and roughly by the trimeni female $f$. of two sub-sp. of Pap. dardanus, 374 n. 2.

domuncula, Suberites, carried by Pagurus cuanensis, 357.

Dorfmeister on seasonal changes of Lepidoptera, 31 I.

dorippus (= klugii), f. of Limnas chrysippus, distribution of, 70, 71; suggested interpretation of, as procryptic adaptation to desert, 321 , $321 \mathrm{n}$. I.

Dormouse, value of tail of, 325 .

doubledayaria, a black mutation of $A$. betularia, 309 .

Draconia rusina, 302.

Dragon-flies, great size of Carboniferous, 18, 37 ; attacked by beeeaters, 287 ; wings of, in nest of Microhierax, 290, 29I ; attacking specially defended insects, 318 .

dravidarum, Papilio, mimicking Crastia core, 372.

Driesch, experiments of, on egg of Sea-urchin, 130.

Drone-fly, see Eristalis, 243-4.

Drongo capturing butterflies, 283 , 284 ; capturing and rejecting distasteful moths, 284 .

Drurya, see Papilio, 366.

Dry season a time of special stress, 148, 208-I I, 31 I, 31 7, 320, 326 ; form of butterflies' wings in, 206, 207, 310 , 311 ; butterflies of, especially well concealed, 207-11; cryptic forms of Precis in, 208, 320, 339-41 ; butterflies of, prone to hybernate, 209 ; more alert and active, 209; life of the, 209 ; eye-spots withheld in, 210 , 211,326 ; warning colours less developed in, 317; concealment necessary in the, 320 ; the desert a permanent, 321 .

Dryness, see External Causes.

Düne, near Heligoland, colour of grasshopper in, 307.

Durban, Natal, 52 n. I, 7 I n. I, 72, 72 n. I, 283.

Dynamic Conditions, rapid colour adjustment a response to, 304, 305 ; syntechnic resemblance caused by similarity in, 312.

\section{$\mathrm{E}$}

Ears and tails, mutilations of, not hereditary, 180, I81.

EARTH, AGE OF THE, Essay I, I -45 .

Earth, changing shape of, 8 ; rotation and shape of, 8, 9; cooling of, 9-13 ; conductivity in interior of, 10-1 3 ; higher density of interior of, II ; protective (procryptic) resemblance to colour of, $155,298,307,318$, 323 ; allanticryptic use of, by Ceratophrys, 313.

Earthworms, 27.

East Africa, see Africa East.

East Brazil, see Brazil East.

Eastern Origin of the Celtic Nations, J. C. Prichard, 173.

echeria and albimaculata, Amauris, Natal mimics of, in Hope Department, 249; Western Amauris mimicked by, 335, 337; dominant models in E. Africa, 336 ; mimicked by cenea female $f$. of three sub-sp. of $P$. dardanus (merope), 337, 338, 355, 374; by female of Pap.echerioides, 375.

echerioides, Papilio, female of, mimicking Amauris albimaculata and echeria, 375.

Echinoderm (Echinus), Driesch's experiments on egg of, 130 .

Echinoderma, 25; small advance in geological time of, 28 ; of early Palaeozoic, 30 ; early records of all except Holothurians, 43; earliest forms of, not primitive, 43 ; classes of, in Cambrian, 43.

Echinoids in early Palaeozoic, 30.

Echis carinata, 324 .

Ecuador, Bolivia, and Peru, colours of the chief Ithomiine-centred combination in, 351 .

Ecuador, form of Methona confusa and Pierine mimic in, 265, 266.

Edinburgh, J. C. Prichard an M.D. of, 173 .

Edinburgh Review, 56, 66.

'Educability' a hereditary congeni. tal character, 165 ; as opposed to instinct, $165,166$.

Education, results of, not hereditary, 136, 165, 166-7; value of 
research in, 198, 199; of enemies facilitated by warning colours and Müllerian mimicry, 166-8, 212-15, 222, 278, 327-31, 339.

edusa, Colias, choice of restingsite by, 301 .

Ega, Upper Amazon, colour of the chief Ithomiine-centred mimetic combination at, 273, $35 \mathrm{I}$.

$\mathrm{Egg}$, individual characteristics predetermined in the, xxxvi, xxxvii, xxxvii n. I, 132-5, 183.

- Experiments, \&c., on, by Roux, 128-30; T. H. Morgan, 129; Hertwig, 129; Schulze and Wetzel, 129; Herlitzka, 130; Driesch, I30; J. W. Jenkinson, I 30 ; Boveri, I3I.

- Diagrams of development of, described, 123-8, 130-4.

Eggs of $S$. ocellatus, derived chlorophyll in, 314, 314 n. 2.

Eimer, Prof. G. H., on Natural Selection not creative, xxii ; on instincts of Fossorial Hymenoptera, 162 ; on internal causes of mimicry, 224.

Elaps mimicked by harmless snakes, 367 .

Elephant Hawk moth, see elpenor, Choerocampa, 319, 326, 367-8, 376.

elgiva, Precis, under side procryptic in both wet and dry seasons, 340 ; S. African habitat of, 340.

eliminata, Sarangesa, captured by Bradyornis mariquensis, 283.

Elimination of shadow, Thayer's discovery of the, 299, 300 ; adjustable form of, 300; in aggressive resemblance, 313 .

elpenor, Choerocampa, transition from cryptic to pseudaposematic defence in larva of, 319,368 ; proof of terror inspired by snake-like larva of : superstitious fear of, 367,367 n. 2 : see also 326 ; lizard terrified by, but ultimately devoured larva of, 367 ; mimetic resemblance of Batesian, $367,376$.

Elymnias caudata, 373; - cottonis, 373, 373 n. 2 ; - (Melynias) lais, 353; -leucocyma (Melynias malelas), 372 ; - undularis, 373.

Elymniinae (see also Elymnias: see also classification of examples of mimicry, 284-8): often united with Satyrinae, 353; almost every species of, mimetic, 353 ; females, except in
Africa, often bettermimics than males, 353; under surface sometimesmimetic, sometimes procryptic, 353; a few species of, a posematic or doubtful, 353 ; R. Shelford on habits of Bornean E. lais, 353; compared with Protogonius, 353, 354; mimetic common ancestor of genus suggests Müllerian interpretation, 354 ; latter interpretation merely tentative, 352 .

Elytra, reduction of, in mimetic Longicorns, 252.

Embryo, inoculated by disease germs, 136.

Embryology, unreasonable disparagement of, by Bateson, xlii, xliii ; experimental, 128-30.

Empire and science, 169.

encedon, Acraea, three forms of, mimicking three forms of $L$. chrysippus, 355; three forms of mimic transitional, while two out of three corresponding forms of model are sharply marked off, 364,365 n. I ; alcippina f. of, perhaps developed in W. Africa as mimic of alcippus $\mathrm{f}$. of L. chrysippus, 364 .

Encyclopaedia Britannica, 173, 293.

Endromis versicolor, 238.

Enemies of Lepidopterous Pupae enclosed in bark-formed Cocoons, E. B. Poulton, I 59, I 59 n. I.

Enemies (see also birds and evidence): of pupae in cocoons, 158, 159 ; education of, helped by insect warning colours and Müllerian mimicry, 166-8, 21 2-15, 222, 278, 327-31, 339, 366 ; effect upon insects of struggle for life in young, 167, 167 n. 2, 168, 328 ; of insects in the dry season, 209; confused and attention diverted by bright hind wings, 303, 304; animals with warning colours attacked by special, 317, 318; not deceived when model and mimic occupy different stations, 349 ; judgement of relative size by young, 366 ; hardness compared with other defences against, 370.

English colonists unchanged after many generations in the tropics, 178.

Entebbe, V. Nyanza, hermaphrodite planemoides, female f. of Pap. dardanus, taken at, 374 n. 3.

Enterozoa (Metazoa), place of, in classification, 25 . 


\section{ANALYTICAL INDEX}

Entomological Society of London, Proceedings of, 46, 89, 89 n. I, I39, I 53 n. I, 1 56, 157 n. I, I67, 205, 206, 207, 212, 213 n. 1, 216 n. 1, 223, $232,239,273,301,302,303,312 \mathrm{n}$. I, 317,325 n. I, 328, 328 n. I, 332, 340, $34 \mathrm{I}, 343,344,350 \mathrm{n}$. 1, 356, 358, 358 n. 1 and n. 2, 363, 366, 367 n. 2 , 368,372 n. 1,374 n. 3 .

Entomological Society of London, Transactions of, $57 \mathrm{n}$. I, 72, 93, 149, I 50, 156, 210, 213 n. I, 217 , $236,269,270,270$ n. I, 276, 277 , $282,299,300,301,302,303,304,304$ n. $3,306,307,308,31$ I , 31 7,3 I 8,320 , 321 , 321 n. I, 322, 328 n. I, 331, 335, 339 n. I, 340, 34I, 343, 344, 345, $346,348,351$ n. $2,354,355,362,362$ n. $2,364,365$ n. I, 367 n. $2,368-70$, 373,374 n. $3,378,380$.

Entomological Society of London: Author's Presidential Addresses, 1903, 1904 (read 1904, 1905), the original forms of Essays II and V respectively, 46, I39; Roland Trimen's Presidential Addresses, I 897, I 898 (read 1 898, 1 899), 89,89 n. 1, 90, 232; the Empire and, 169 ; consent of Council for republishing direct evidence of attacks of birds on butterflies, 283 ; examples of Müllerian Mimicry exhibited by W. H. Blandford at, $343,356 \mathrm{n}$. I ; argument that Protogonius and Elymniinae are Batesian mimics at, $35 \mathrm{I}, 372 \mathrm{n}$. I.

Entomologist's Monthly Magazine, 57 n. I, 157 n. I, 207 n. I and n. 2, 300, 325 n. I, 341 .

Entomologist's Record, 216 n. 2, 239 n. I, 309 n. I, 366 n. I.

Entomostraca in Silurian and Cambrian, 39.

Entwickelung von Ascaris megalocephala, Boveri, I 3 I.

ENVIRONMENT, ORGANISM PROBABLY ADJUSTED TO, BY LOCAL NATURAL SElection, X. 307, 308 : see also 308-10.

- Environment (see also External Causes and uniformity): effect of, on organisms, 73-5; susceptibility to, 106, 145; effect of, on germ-cells, 137 ; influence of, 145 ; organic and inorganic, 153,154 ; lines of pattern parallel to shadow lines of, 156, 301 ; evolution transferred from man to,
170, 171; incidence of conditions of, determined by life-history, 243, 244, 276, 277; effects of colour of, on insects, \&c., 305-10; mimicry between models interpreted by $\mathrm{H}$. W. Bates as the effect of a common, 327 .

Eozoon, 27.

Ephemeridae (Protoephemeridae) of Commentry Carboniferous, 37.

Ephyra, see Zonosoma, I 50.

Epicopeia philenora, $37 \mathrm{I}$.

EPIGAMIC ColouRS, X. 379, 380.

Epigamic characters (see also Sexual Selection): place of, in a scheme of the bionomic uses of colour, 226, 227 ; pleasant smell of male butterflies as, 316, 317 ; of Attid spiders, 380 ; of grasshoppers, 380 ; often concealed except in courtship : only exist under conditions of visibility: commonly closely associated with nervous system: display most marked when sexes unlike, 380 ; Wallace's interpretation of, 380 ; exceptional in heredity, 380 ; of one sex latent in the other, 380 ; effect of castration on latent, $122,380$.

Epigonic evidence, need of, 90.

Epigony, definition of, 6I, 6I n. I ; the appeal to, 62, 64; as test of species when diagnosis fails, 69 ; in Limnas chrysippus, 70, 7I ; in $P$. dardanus, $72,72 \mathrm{n}$. I ; in seasonal dimorphism, 72-3; the test of specific identity when differences are great, 76 ; importance of, to the systematist, 77.

EPISEMATIC AND APOSEMATIC Characters, X. 3I 5-58. For divisions, sections, and sub-sections, see 294-6 : see Sematic characters.

EPISEMATIC OR RECOGNITION Characters, X. 357, 358: see Recognition characters.

Equivalent cell divisions, I33, 135 .

Eristalis, a mimic of hive-bee, 243-4; food of larva of, contrasted with that of bee, 244 .

erithonius, Papilio, eaten by beeeater, 288; wing of, in nest of Microhierax, 291.

Ermine, aggressive seasonal change of, 3 I 3 .

Eronia, combination of procryptic and mimetic colouring in, 350,350 n. I.

Eronia cleodora, 283, 301 . 
ERRONEOUS ASSUMPTION THAT WARNING COLOURS IMPLY COMPLETE IMMUNITY FROM ATTACK, X. 317,318 .

Erycinidae, darkening of mimetic in the Guianas, 272 ; mimics belonging to, are probably Müllerian, 273: see also 346; Dixey's discussion of entrance into Müllerian combinations of, 343 ; mimicking Ithomiinae and mimicked by diurnal moths, 346.

esebria, Acraea, two forms of female mimicking Danainae, 354, 355; advantages of this dimorphism in, 355 .

Essay on Fertilization, Prof. Marcus Hartog, 60 n. 3.

Essays on Natural Selection, A. R. Wallace, 5 I n. I, 203, 367 n. I, 369.

Essays, Scientific, Political, and Speculative, Herbert Spencer, 7 n. I, 58 n. 1 .

Essays upon Heredity, August Weismann, xxxvi, xxxvii, xxxvii n. I, 60 n. 3.

ESSENTIAL NatURE OF MiMicRY, \&c., AS SHOWN BY ANALYSIS, VIII. 240-2.

Essential Element in MimicRY, X. 359-6I.

Esthesinae, mimicry of Hymenoptera by, 252.

Estigmena chinensis, 261.

Estigmenida variabilis, $26 \mathrm{I}$.

Ethiopian Region (see Africa) : the study of mimicry should commence in, xxv, xxvi, 336 .

Ethiopian and Eastern hawk-moth, attainment of transparency by, 365 .

etrida, Teracolus, mimicked by Abraxas etridoides, 231 ; inhabits station different from that of its mimic, 349.

etridoides, Abraxas, mimicking Teracolus etrida, 23I ; inhabits station different from that of its model Teracolus, 349.

Études d'Entomologie, Monsieur Charles Oberthür, $69,3^{81}$.

eucharis, Delias, proved to be unpalatable, 269.

Euchelia jacobaeae, 230, 318.

Euderces picipes, 255 (Fig. 4), 256. Eueides, 235.

Eueides nigrof ulva, 332.

Eugonia quercinaria, 149, 150.
Eumenes, species of, resemble other Hymenoptera in Australia, 278.

Eupatorium macrophyllum, 322.

Euploea captured by Ashy swallowshrike, 286 ; not attacked by beeeaters, 288 ; mimicked by female Hypolimnas, 241, 372; limit to conspicuousness of, 322 .

Euploeini (see also Euploea: see also classification of examples of mimicry, 384-6, 388-9): Danaini compared as models with, 333-5; range of Danaini compared with, 333 , 334; mutual mimetic influence of Danaini and Euploeini compared, 334, 335 ; dominance over Danaini in areas where both meet, 333-5 ; homogeneity of, compared with Danaini, 333; abundance of, 334 ; probably not more unpalatable than Danaini, 334 ; uniformity throughout many species of, $277,333-4$; the chief models of the Eastern Elymniinae, 353 ; possible rôle of male scentbrands of the, 334 n. 1, 358 .

Euralia, see Hypolimnas.

Euripus probably a distasteful genus, 373 ; mimicry in, 373 .

Euripus halitherses, 373.

Europe, mimicry in Araschnia of, 342.

Eusemia falkensteinii, 232.

eutolmus (coerulescens), Microhierax, 289-91.

Evans, Dr. Arthur J., assistance in terminology rendered by, 6I n. I. evenina, Teracolus, Müllerian mimicry in dry f. chiefly, 342 .

Evening Primroses, as the evidence for mutation in nature, xix-xxii.

Evidence of SPECIAL ProtecTION IN APOSEMATIC FORMS, X. $316,317$.

EVIDENCE, INDIRECT, SUPPORTING MÜLLERIAN MIMICRY, X. 346, 347.

EVIDENCE, RECENT, IN SUPPORT of BATESian MimicRY, X. 350-6.

EVIDENCE, CONFIRMING HISTORY INFERRED FROM MIMICRY, X. 365, 366.

Evidence adduced by De Vries in favour of mutation, xvii-xxii ; indirect for mimicry, 271 ; of distastefulness in mimicked butterflies, 269, 279, 279 n. I; of advantage conferred by 
mimicry, 269, 281, 288: see also Finn, $\mathrm{F}$.; of distastefulness in larva of $C$. verbasci, 318.

Evidence of attacks on butterflies by birds, insufficient, 268-70; reasons for insufficiency, 270, 282.

- Of actual attack by G. A. K. Marshall, $282-4$; by E. Pénard, 282 n. I; by F. Muir, 282 n. I; by Col. J. W. Yerbury, 283, 285 , 286 ; by Col. Bingham, 283, 28690 ; by C. F. M. Swynnerton, 283 , 284. Indirect evidence obtained by Davidson, 290, 291 ; by Ferguson, 292.

- From following localities : S. Africa, 28I-4; Geneva, 282 n. I ; E. Africa, 282 n. I ; Malvern, Durban, Natal, 283; Salisbury, Rhodesia, 283, 284 ; Gazaland, 284 ; Melsetter, Gazaland, SE. Rhodesia, 284 ; India : Thundiani, Kala Pani, 285; Ceylon, Kandy Road (Trinkomali to Kanthalai), 285, 286; Burma, 286-92; Akya Chaung (branch of Haundraw R.), Kawkaraik to Thinganyinaung, 286-8; Wabosakhan Camp, 288, 289; Salween R., below Shwègon, 289; Sinzaway Chaung (branch entering Yoonzaleen R., below Pahpoon, Tenasserim), 290; Bankasoon, S. Tenasserim, 290; Thabeitkyin to Mogok, Upper Burma, 291 n. I ; Travancore, 292 ; direct evidence only obtained at the firstnamed Burmese localities : excellent indirect evidence at the others: for indirect evidence see also 270,270 n. I, 281-3, 304, 325, 325 n. I.

Evolution Theory, A. Weismann, I64 n. 2, 375 .

EVOLUTION CONTINUOUS OR DISCONTINUOUS, Introd. xiv-xvi.

Evolution, ANTAGonism ProMOTED BETWEEN STUDIES ALL NeEded for AtTacking Problem OF, Introd. xli-xliv.

EVolution, THEORIES of, Essay III, 95-II9.

EVOLUTION, REMARKABLE ANTICIPATION OF MODERN VIEWS ON, Essay VI, 173-92.

Evolution of Chief CharacTERISTICS OF MIMICRY, X. 362, 363: see also Essays VIII and IX.

Evolution (see also Natural Selection).
- Bateson's statement of the problem of, xxxiii, xxxiv ; little help afforded by Mendelism in solving the problem of, xxxiii-xxxv; by minute variation is not Mutation, xxxviii, xxxix ; uselessness of teratological phenomena for, xxxix, xl; slowest in lower branches of animals, 27-3I ; most rapid in highest, 29 ; of nervous system rapid in higher animals, 29; evidence of trend of in pre-Cambrian time, 3I-3; within higher animal phyla, $33-42$; of insects' wings, 36 , 37 ; of Appendiculata, 33-4I ; Arthropoda, 33-4I ; Myriapoda, 34; Insects, 34-8 ; Crustacea, 39, 40; Arachnida, 39-4I ; Mollusca, 4I, 42 ; Gastropoda, 42 ; Cephalopoda, 42 ; Lamellibranchiata, 42; Gephyrea, 42, 43; in land-plants, 44,45 ; evidence of will be furnished by museum collections, 53; ancient writers on, 54-6; influence of Milton on, 55, 56; Aubrey L. Moore on, 54-6; Huxley on belief in special creation, 56 ; Aristotle and, 56 ; contrasted with special creation, 58; effect on systematic work of belief in, 59; Asyngamy and, 65, 81-91 ; Asympatry and, 84, 85; Mechanical Selection and, 85 ; Preferential Mating and, $85-8$ : see also 65 ; breaking of Syngamic chain and, 88-90; Darwin's metaphor of tree for, 94; Darwin-Wallace theory of, 95-7; necessarily follows from factors of selection, 96; Lamarck, Erasmus Darwin, H. Spencer, theory of, $97-9$; belief in innate tendency towards, 100; belief in unknown cause of, IOI ; Lamarck's theory of, apprehended easily, Darwin's with great difficulty, 10I-4; parodies of, 103 , 104; utility and, 105-9; in brain, 107, 108; Palaeontology and, 107, 108; selection a true cause of, 109, I10; Mutation and, IIO: see also INTRODUCTION, especially xiv-xvi, xvii-xxvi ; of actively used structures, I12; of passive structures, 112 ; of joints, 112, 113, 115; of combined active and passive structures, 113 ; of cocoon-making instincts, $117-19$, I60; of social Hymenoptera, 165 ; Lloyd Morgan on the trend of human, 170 , I 7 I ; J. C. Prichard on, I74; Huxley's views on before the Origin, 199, 200 ; Huxley's defence of, 219 ; 
belief in, because of consistency with facts, 268; of Müllerian resemblance, 329-31.

Examinations, injurious results of, 197-8.

EXAMPLES, STRIKING, OF MÜLLERIAN MIMICRY IN NEW AND OLD WORLD, X. 33I-6.

EXAMPLES, REMARKABLE, OF MIMICRY, X. 367-9.

EXAMPLE, REMARKABLE, OF MIMICRY IN PAPILIO DARDANUS (MEROPE), X. 373-6.

Excrement of bird, protective resemblance to, 319 .

Exercise, results of, not hereditary, 136.

Existence, struggle for, and selection, 96 .

EXPERIENCE, BEARING OF INSECT MIMICRY, \&C., UPON SUPPOSED HEREDITARY TRANSMISSION OF, V. $166-8$.

Experience, the Lamarckian interpretation of instinct as inherited, 116 , 154-66; dangers to insects of, 117 , 118, 154-7; not hereditary, 166-8, 316 ; must be acquired by insectivorous birds, $268,269$.

Experimental Proof of the Protective Value of Colour and Markings in Insects in reference to the Vertebrate Enemies (1887), E. B. Poulton, 230.

EXPERIMENTAL EVIDENCE OF SPECIAL PROTECTION IN APOSEMATIC FORMS, X. 316, 317 .

Experimental embryology, 128-30.

Experiments, on birds with distasteful insects, see Finn, F., 269; on Artemia, 73, 74; on power of colour adjustment in larvae and pupae, 305-7; on seasonal forms of Selenia illunaria, $3 \mathrm{II}$; of Teracolus omphale, 311, 312; of - achine, 311, 312; of Belenois severina, 311, 312; of Precis, 340; of Byblia, 341; on winter change of Hudson's Bay Lemming, 310 .

External Causes (food, climate, soil, \&c.) as suggested interpretation of mimicry, 224, 272; the theory most commonly substituted for natural selection as cause of mimicry, 267,272 ; theory of, requires transmission of acquired characters, 267 ; belief in theory of, due to too exclu- sive study of butterflies, 229, 272, 273 ; obviously inapplicable to mimicry between remote species, 229; mimicry a special case of protective (procryptic) resemblance, and yet the latter clearly cannot be due to, 2268 ; various objections to, 227, 229, $233,235-42,244,245,248-50,260-3$, 266-8, 270, 273-82.

Extinction, belief in innate tendency towards, 100 .

Eye, importance of, in rapid colour adjustment, 305 .

Eye-like spots on abdomen of mimetic spider, 368 ; of Choerocampa caterpillars, 326; of Brassolinae, 326.

Eyes of diurnal beetles different from nocturnal, 250.

'Eye-spots' or 'ocellated spots' in wet season broods of Satyrinae and Nymphalinae, 210, 211, 326; examined by lizard, 210 ; pecked by kestrel, 210 ; concealed during prolonged rest, 210; divert attention from vital parts, $210,325,325 \mathrm{n}$. I, 326 ; of butterflies' wings, value of, 281, 282 ; of Brassolinae, 326; of Morphinae (Tenaris), 326; of Papilioninae, 326; Pseudaposematic in snake-like larvae, 326 ; absent from the chief distasteful butterfly groups, 326 ; difficulty in the bionomic classification of, $325,326$.

Eyton, on fertile pairing of two species of goose, 83 .

\section{$\mathrm{F}$}

F.A., criticism of mimicry in Punch by, 21 3-1 5 .

Fabre, on the instincts of Fossores, 118 ; on instincts of Fossorial Hymenoptera, 160, 162 ; Lamarck apparently confused with Darwin by, 162.

Facets of eyes of diurnal beetles smaller than nocturnal, 250.

Factors of Lamarck's theory, 98, 99.

Factors of Natural Selection, 95-6; suggested by name itself, 105 .

fagi, Stauropus, mimicry of ant by, 253, 253 (Fig. 2), 254; composite mimicry by larva of, 369 .

Falconet, 289-91.

Falco subbuteo, 284.

fallax, Myrmecophana, mimicry of, 256, 257, 258 (Fig. 5), 280. 
falkensteinii, Eusemia, Müllerian mimicry of L. chrysippus by, 232.

False warning and signalling colours, 226: see also PSEUDOSEMATIC RESEMBLANCE and its subdivisions, 296, 297.

Families, in classification, subjective, 65 .

Farmer, Professor J. B., on explanation offered by Natural Selection as a bar to inquiry, xliv-xlvii, xliv n. I ; on stimulus and mechanism, 74 n. 2.

Fawcett, Henry, and Natural Selection, 96.

Female parent, Prichard on the supposed influence of, on offspring, I 85-6.

Female often better concealed than male, 246.

Female Catophaga (Pierinae), yellow f. of, specially attacked by beeeater, 285.

Female preferences, 379.

FEMALE, MIMICRY, \&c., LESS CHARACTERISTIC OF MALE THAN, VIII. 244-7: see also 21 5-I7, 279, $347,353,372-5$.

Female Mimetic: Male NonMimetic, examples under this heading, X. 372 .

Female Mimicking Two oR More Different SPecies, Male NON-MIMETIC OR MIMICKING STILL ANOTHER SPECIES, examples under this heading, X. 373 : see also dardanus.

Female, except in mimicry, more ancestral than male, 245-6; advantage of mimicry in, 246, 279; tendencies of non-mimetic males of mimetic, 347.

'Ferns' of Palaeozoic, mostly seedplants, 45 .

Fertility, kept up by selection, $8 \mathrm{r}$, 82 ; of certain hybrids, 83,84 ; promoted by domestication, 83,84 ; between domestic breeds, 77-84, 201 .

Fertilization or zygosis, xxxi ; inferences as to precursors (Allelomorphs) of Mendelian characters in, xxxi-xxxiii; syngamy proposed by Hartog to replace, 60 n. 3 ; zygosis proposed for, 60 n. 3 ; essential nature of, 8o-2; self-, cause of injurious effects of, $9 \mathrm{I}-4$; the union of germplasm from two individuals, 1 27, 128.
Fertilized germ or zygote, Mendelian inferences as to, xxxi-xxxiii.

Final Causes, W. Whewell on the study of, as a stimulus to inquiry, xlvi n. I.

Finn, F., on education of birds, I67 ; conclusions of, on distastefulness of butterflies, 269,317 ; on evidence of distastefulness in mimicked butterflies, 269, 279 n. I ; results obtained by, quoted in Essay X, 293; on unpalatability no defence against hungry enemies, $269,317,317$ n. 4 .

Fish, in early Palaeozoic, 30 : see also 26 ; rapid colour adjustment in, 305 ; defence of Hyas against large, 314 ; small, attracted and devoured by Hyas, 314 ; alluring structures in, 378 ; attracted by lures of Ceratias, 378 ; heightened colouring accompanies other excitement as well as sexual in, 380 .

Fishing-Frog or Angler, bright lure of, 378.

Flatidae, colony of, resembling flowers and buds, 304, 304 n. 3.

Fleece, changes of, in tropics, 190.

Fleeming Jenkin, on the swamping effect of intercrossing on single variations, $x l$, xli; influence upon Darwin of arguments of, xl, xl n. 3, 3 . Flies, see Diptera.

Flight slow in distasteful butterflies, 279, 323; of certain Danainae displays under surface, 323 ; Heliconine mimics of Ithomiinae distinguished by, 33I, $331 \mathrm{n}$. I ; difference between model and mimic in, 349 .

Floras of the Past : their Composition and Distribution, Prof. A. C. Seward, 44 .

florella, Catopsilia, captured by Halcyon chelicutensis, and probably by Buchanga assimilis, 283.

Florida, $H$. misippus ranges to, 216.

Flos Reginae, Lagerstroemia, nest of Microhierax in, 290.

Floor of the ocean, 20-2.

Flower-like alluring Mantidae, 378,378 n. 3 ; appearance of also procryptic, 378 .

Flowers and buds, resembled by Flatidae, 304, 304 n. 3; cryptic resemblance to, 318 ; and surroundings considered by Thayer to be resembled by Ithomiines, \&c., 322 ; 
pseudepisematic (alluring) resemblance to, 378,378 n. 3 .

Fly-catcher seen capturing butterfly, 283 ; seen chasing Lycaenid, 283.

Foes, see enemies.

Food, climate, \&c., as cause of mimicry, 224, 272 (see also External Causes); concealment effected by colour of, 314.

Foraminifera in classification, 25 ; persistence in geological time of, 27 , 28.

Forest country in S. Africa, definition of, 340 .

Form,seasonal change of, in butterflies' wings, 206-8, 310, 31 I.

formica, Synemosyna, mimicry of ant by, 253 (Fig. I $B$ ).

Fossils, limited information conveyed by, 100, 107.

Fossores (see also classification of examples of mimicry, 389-93): instincts of, I I 8 , I 8 n. I, I I 9 , I6o-4 ; prophetic instinct of, $119,163,164$; resemblances between other stinging insects and, 278, 376; see also 232 .

Foster, Sir Michael, on curiosity as the true incentive to inquiry, xlvii; on indirect methods of nature, IOI.

Fowler, Rev. Canon W. W., on ant-like Membracidae, 258 (Fig. 6), 259.

Fox, Arctic, aggressive seasonal change of, 313 .

France and Lamarck's theory, 98.

France, Société Entomologique de, Annales, 211, 326 ; Bulletin, 381, 382 .

fringillarius, Microhierax, nest of, 290, 291.

Fritillaries, pupae of, 152.

Fritillary, resemblance of $A$. levana to, 342 .

Frog, Roux's experiments on egg of, 128-30; allanticryptic resemblance of, 313 .

Frohawk on $P$. phlaeas, 87 n. 1 .

From the Greeks to Darwin, H. F. Osborn, 56 n. 2, I 41 n. I, 175 .

Fry, Sir Edward, on definitions of acquired characters, 143-4.

fuciformis, Haemorrhagia, loss of scales by, 365 .

Fulgoridae of Commentry Carboniferous, 36 .

Fungi, leaf-attacking, effects of resembled by butterflies, 205, 206 ; by moths and Locustids, 302 .

FURTHER INDIRECT EVIDENCE SUPPORTING A MÜLLERIAN OR SYNAPOSEMATIC INTERPRETATION, X. 346,347 .

fuscus, Artamus, capturing Crastia core, 286.

Fusilina in the Carboniferous, 27.

\section{G}

gagates, Polyrrhachis, with ant-like bug, 254, 255.

Gahan, C. J., on mimicry in Coleoptera, 236, 237; on Müllerian and Batesian mimicry in beetles, 237 ; on life-history and mimicry, 243 ; on mimicry of weevils by diurnal Longicorns, 250 ; on Longicorns mimicking weevils and Hispidae, 261 ; on Cingalese Clytinae as models for other Longicorns, 349.

Galapagos Islands, birds greatly modified in, 84 n. 2 ; dull colours of animals in, 225.

Galton, Francis, on 'recession towards mediocrity', 109, 110 ; on transfusion of blood and pangenesis, 125 ; on 'identical' turns, I 32, I 34, I 35, I $38 \mathrm{n}$.; on effect of cessation of selection, 138; definition of acquired characters by, 143 ; on invisibility of zebra, 298.

Gametes, see germ-cells.

Ganoid fish in early Palaeozoic, 30.

Garden White butterflies $(P$. brassicae and $P$. rapae), 93, 147, 148, 213, 301.

Gärtner on sterility between selected races, 78 .

Gastropacha quercifolia, 299, 307.

Gastropoda in early Palaeozoic, 30 ; Pteropoda arose from, 4I, 42; evolution in, 42; appear in Cambrian, 42.

Gauchos, skill in killing cattle, I6I.

Gazaland, S.E. Rhodesia, attacks of birds on butterflies, \&c., witnessed in, 284.

Geddes, P., on anabolic and katabolic tendencies, $100-1$; on internal causes of mimicry, 224.

Geikie, Sir Archibald, on age of the stratified rocks, 16,17 ; on geological record of time, 19 .

Gemmules of pangenesis, 124-6.

Genera subjective, 65 . 

312.

General Aggressive Resemblance,

General Protective ResemBLANCE, X. 297, 298.

General Survey of the Causes which have Produced Varieties in the Human Species, \&c., J. C. Prichard, 176-92.

Genetic, see inherent characters, I4I.

Geneva, attack of bird on butterfly witnessed at, $282 \mathrm{n}$. $\mathrm{I}$.

genutia, Salatura, see plexippus, 373.

GEOGRAPHICAL RACES OR SUbSpecies Traverse Diagnosis, II. 75,76 .

GEOGRAPHICAL TRANSITION FROM APOSEMATIC TO CRYPTIC DEFENCE, $X .320,321$.

Geographical data, necessity of, 75.

Geographical varieties, Rothschild and Jordan on importance for evolution of, xvi ; species and, 62 .

Geological Society of Glasgow, Transactions of, 4 n. 3 .

Geological Society of London, Presidential Addresses of $\mathrm{T}$. $\mathrm{H}$. Huxley to (in 1869), 4, 5, 6, 8, and (in I 862), 6 ; of H. Woodward to (in 1895 and 1896$), 40$.

Geology, Darwin's disappointment at neglect of his early writings on, $196,197$.

geometrica, Doliops, mimicking weevil, 261.

Geometridae, decline of cocoon in certain species of, 149, I50; colour adjustment in pupae of Uropteryx, 150, $150 \mathrm{n.} 2$; dimorphism in larva and pupa of Ephyra, 150; importance of attitude in Hybernia, 156; elimination of shadow in larva of, 300 ; colour adjustment of larvae of, 306 ; colours in different environments of moths of, 307-9; Teracolus mimicked by S. Indian species of, 231 : see also 349.

Gephyrea, in classification, 25 : see also 27 ; slight changes in geological time of, 28 ; of early Palaeozoic, 30 ; evolution in, 42, 43.

Germ-antecedents, early appearance of, in Ascaris egg, 131.

Germ-cells or gametes, Mendelian inferences as to, xxxi-xxxiii; on the halving of the nucleus in preparation for fertilization of the, xxxi ; natural selection decides between, xxxvi, xxxvii, xxxvii n. I, 73 n. I, 135, 137, 183 ; union in fertilization of, 60 n. 3 ; compatability of, secured by Natural Selection, 80-2 ; interspecific sterility and, 80-2; acquired characters and the, III, II2; distinguished from body-cells, 121, 122 ; early appearance of precursors of, in development, I3I ; inoculated by disease germs, I36, 184; influence of environment on, 137 ; variation predetermined in fertilized, $137,183$.

Germ-duct, early appearance of antecedents of, in Ascaris, I3I.

Germinal origin of variation, xxxvi, xxxvii, xxxvii n. I, 73 n. I, $135,137,183$.

Germ-plasm, continuity of, 12736 ; illustrated in Diagram II, 127-8, 130, 131; resides in nucleus, 128; in development of 'identical' twins, I34.

Germs, Natural Selection decides between, rather than between individuals, xxxvi, xxxvii, xxxvii n. I, 73

n. I, 135, 137, I 83 .

Gerstaecker on ant-like bug, 254, 255, 255 (Fig. 3).

gibbicollis, Oxylymma, mimicking Diabrotica, 237.

Glands ventral of Croesus larvae, 320.

Glaucopidae mimicking Lycinae, $23 \mathrm{I}$; mimicking Aculeata, $23 \mathrm{I}$; evidence of distastefulness adduced by Haase, 231 n. 2.

Glenea pulchella, 363.

Gnophos obscurata, 307, 308 .

Goats, Angora, J. C. Prichard on, 187.

Godartia wakefieldii, $52 \mathrm{n} .1$.

Godman, F. D., on the sexual brands of the Dismorphina, 240 ; on Ecuador form of $M$. confusa, 266.

Godman-Salvin Collection, examples of Müllerian mimicry from, exhibited in 1896 and 1897,343 .

Goodacre on fertile pairing of two species of goose, 83 .

Goodrich, E. S., definition of inherent characters, 142.

Goose, fertile offspring of Common and Chinese, 83 .

götzius (acheloia), Byblia, tendency of same seasonal forms of, to inter- 
breed, 87 ; dry f. of, bred from wet, $34 \mathrm{I}$; wet f. of, a mimic of $A$. serena type, dry f. procryptic, $34 \mathrm{I}$.

Gouty diathesis, transmission of, discussed by J. C. Prichard, 183, I84.

Gradual Predominance oF

MÜLLERIAN MIMICRY, X. 342-4.

Grafted tissues and pangenesis, 125-6.

Grainger, Benjamin, of Derby, distinction between inherent and acquired characters suggested to J. C. Prichard by, 179.

Grammostomum in Carboniferous, 27.

Grand Comoro, non-mimetic Pap. humbloti in, 373.

Grapta C-album, 203-5.

Graptolites in Palaeozoic, 28.

Grasses, protective resemblance to, 307 ; syncryptic resemblance to, 312 ; concealment among roots of, $318,323$.

Grasshoppers (Acridiidae) of Commentry Carboniferous, 36, 37 ; mimicry of leaf-carrying ants by, 260 ; value of bright hind wings of, $303,304,325$; colour adjustment of, 307 ; observations on the courtship of, 380 .

Gravitation, evidence for, compared with that for Mimicry, xxvi; accepted, though nature not explained, 97; accepted because consistent with the facts of the Cosmos, $219,271$.

Gravity, EFfect oN Shape of PUPAE OF, V. 15I-2; effect of on pupae not hereditary, 152.

Gray, Asa, see Asa Gray, xxvi, $66,67,68,194$ n. I. 304.

Great Rift Valley, J. W. Gregory,

Green, E. E., on tilt of Melanitis, 300 n. 5 .

Green Hairstreak Butterfly, 301.

Gregarious HaBIT, CONCEALMENT ASSISTED BY, X. 304 .

Gregarious habit in aposematic defence, 318, 323; larvae, transition from cryptic to aposematic defence of, $319,320$.

Gregory, Darwin's work on the primrose compared with that of Bateson and, xxvii-xxxiv.

Gregory, Professor J. W., on flower-like Flatidae, 304 .
Greyhound, origin of, 83 n. 2 .

Groove OF PIERINe PUPAE, ORIGIN OF, V. I 47-9.

'Group', use of, contrasted with 'combination' or 'association', 293.

Grove, W. B., on leaf-perforating fungi, 205 n. I.

GROWTH OF MÜLLERIAN RESEMBLANCE, ADVANTAGE CONFERRED DURING, X. 329-3I : see also 349.

Guianas, character of the chief Ithomiine-centred combination in, 350: see also British Guiana.

Guinea, J. C. Prichard on blackness in man and animals in, 187.

Gymnomyxa, the most primitive animal forms, 25 .

Gymnosperms in the Palaeozoic, 45.

\section{H}

Haase, Erich, on distasteful moths mimicking Coleoptera and Hymenoptera, 23I ; on evidence of distastefulness of Glaucopid moths, 231 n. 2 ; erroneous ideas on 'immune 'species of, 318,375 ; figures of, erroneously reproduced in Weismann's Evolution Theory, 375, 376.

Habit and Instinct, C. Lloyd Morgan, 170, I7 I, 212, 268.

HABITS AND LIFE-HISTORY, IMPORTANCE OF IN DETERMINING Conditions, VIII. 243, 244.

Habits, see Instinct.

Haemorrhagia fuciformis, 365 ; - tityus (= boinbyliformis), 365 .

Hair, of Angora breeds, J. C. Prichard on, I87; protective resemblance to skin or, 359 .

halia, Lycorea, possible increase in mimetic likeness since 1825-7, 356.

Halisarcidae unsuited for fossilization, 28.

halitherses, Euripus, one female f. of mimics $D$. diocletianus (rhadamanthus), another $P$. deione, 373 .

Hambantotte, Ceylon, dorippus f. of $L$. chrysippus at, 70 n. 2.

Hamm, A. H., on cryptic attitude of $H$. leucophaearia, 156 ; on birds attacking cocoons of M.neustria, I57 ; results obtained by, quoted in Essay X, 293; on cryptic attitudes of British moths, 30I; on choice of restingsites by butterflies and moths, 30I. 
Hampson, Sir George, on butterflies mimicked by specially defended moths, 231, 232.

Handbuch der paläarktischen Gross-Schmetterlinge, 1896, M. Standfuss, 310 n. I.

Hardness as the special protection of a model, 261, 369; defence by, compared with sting, smell, \&c., 370 .

Hare, Alpine, protective seasonal changes of, $310,313$.

harrisi, Stictoploea, mimicked by male of $\mathrm{Mel}$. malelas, 372 ; also im. perfectly mimicked by diurnal moth, Callamesia midama, and it allies, 372, 376.

Harrison, A. H., butterflies from the V. Nyanza collected by, 69 .

Hart, Horace, assistance in the study of paper rendered by, I72.

Hartland (Pine Lake), Wisconsin, ant-like beetle at, 255, 255 (Fig. 4), 256.

Hartog, Professor Marcus, use of Syngamy by, 60 n. 3 .

Harvard University, Observatory of, 90 ; Bull. Mus. Comp. Zool. of, 234, 277.

Hawk-moth, attainment of transparency in certain species of, 365 .

Head of model resembled by tail of mimic, 254, 368.

Head-like appearance on hind wing of Lycaenids, 281, 282, 325, 325 n. 1 .

Heat, see external causes; effect of on pupae of Lepidoptera, 31I; effect of on Teracolus and Belenois, 311, 312 ; on Byblia ilithyia pupa, 34 I.

'Heath Butterflies', meaning of eye-spots of, 210.

Heaviside, O., verification of Prof. Perry's calculations by, 10.

Hebomoia captured by bee-eater, 288.

hecabe, Terias, eaten by beeeater, 288.

hector, Papilio, mimicked by female f. of $P$. polytes, 373.

hegesippus, Salatura, mimicked by female $E$. undularis, 373 .

Heifer sterile with one bull, but not with another, 79 .

helcita, Aletis, Müllerian mimicry of L. chrysippus by, 232. helcitoides, Phaeagarista, Müllerian mimicry of L. chrysippus by, 232.

'Heliconidae', as employed by Bates, a composite group, 213, 234, 235 n. I, 327 ; Bates's chief models belong to, 213 .

Heliconinae (see also Heliconius; see also classification of examples of mimicry, $383,386-7)$ : examples of Müllerian mimicry provided by resemblance between Ithomiinae and, 232 ; as models everywhere in tropical America, 233, 273; as models paralleled by Diabrotica, 236 ; as models for Pierinae, 262 ; pigments of, different from those of their Pierine mimics, 262, 263; wanting from transparent-winged Methona-Thyridia-centred combination, 266; darkening in the Guianas of mimetic, 272, 273, 331-3 ; uniformity throughout many species of, 277 ; long confused with Ithomiinae, 278 ; Ithomiinae mimicked by, are not extremely conspicuous, 322 ; absence of eye-spots in, 326; Bates probably misled by mimicry of Ithomiinae by, 327; distinguished by flight from their Ithomiine models, 33I, $331 \mathrm{n}$. I ; mimicry between the two sub-groups of, $331-3,358,358$ n. I ; remarkable resemblance of mimetic pairs within the group, 332 ; models within the group far more abundant than their mimics, 333; good procryptic resemblance wanting in, 332; warning patterns more glaring than those of Ithomiinae, 332 ; first discussion of Müllerian relation of Pier. inae to, 343: see also 213; generally at once distinguishable from Ithomiine models, 350; central members of Eastern Brazilian combination provided by Ithomiinae and, 356; resemblance to Ithomiinae remarkable in mimicry, 343 ; probable recognition of mimetic males by scent, 358 .

Heliconius, geographical variation of, $52 \mathrm{n} .1$; resemblance to Tithorea of, 235; resemblance between Heliconius and Melinaea far closer than between Heliconius and the nearly allied Eueides, 235.

Heliconius numata, 331-3; - telesiphe, 334 n. 2; - thelxiope, 69; vesta, 69 ; - vetustus, 332 . 
Heligoland, colour of grasshopper in, 307 .

Helmholz, on loss of heat by the sun, 13; on energy of sun, 15 n. 2.

Hemaris, mimicry of humble-bees by, 251: see also 365 .

Hemi-embryo transformed into whole embryo, 129.

Hemiptera, mimicry of wasps, \&c. by, 251 ; mimicry of ants by, 254, 255, 255 (Fig. 3), 257 n. I ; mimicking Lycid beetles, 276; attacking specially defended insects, 318 ; mimicked by caudal shield of $S$. fagi larva, 369 ; mimicked by larval Mantis, $378 \mathrm{n}$. 3 .

Herbert Spencer, 7, 58, 98, 102 : see Spencer.

HEREDITARY TRANSMISSION OF ACQUIRED CHARACTERS, QUESTION OF, AND THE STUDY OF INSECTS, Essay V, 139-72.

Hereditary Transmission, Laws of Nature in, J. C. Prichard, 178.

Hereditary transmission of acquired characters : see acquired characters; of inherent peculiarities and predispositions, 180: see also inherent characters.

HEREDITY, THEORIES OF, Essay IV, 120-38: see also $142 \mathrm{n}$. I.

Heredity, a factor of Natural Selection, $96 ;$ a factor of Lamarck's theory, 99 ; problem of, 122 ; the two great theories of, 122, 123; pangenesis and, 123-7; continuity of germ-plasm and, 127-36; 'identical' twins and, 134, 138 n.; monstrosities and, 135-6; darkening of N. moths spread by, 309; di- and polymorphism and, 310; transmission of secondary sexual characters to a single sex by, 380 .

Herlitzka, experiments of, on egg of newt, 130.

Hermit-crabs and crabs, allaposematic defence of British and other, 356, 357 ; sea-anemonies, sponges, and Ascidians carried by, 356, 357 .

Heron, F. A., on need of epigonic evidence, 90 ; on mimicry independent of size, 366 .

Hertwig, O., experiments on frogs' eggs by, 129.

Heterocera, see moths.

Heterochelus, jaw-like third legs of, 368 .
Heteronotus trinodosus, 258 (Fig. 6), 259.

Heterostyled condition, meaning of in life of plant, xxvii-xxix ; Bateson's and Gregory's work upon, xxvii, xxix-xxxiv; Darwin's work upon, xxvii-xxix, 90, 91; interspecific sterility and, 90, 91 .

Heterozygote (as regards any character), a fertilized germ in which the two allelomorphs of the character in question represent respectively its alternative forms, $x x x i, x x x i i$; compare homozygote, xxxi, xxxii.

Hewitson, W. C., disbelief in mimetic females of Pap. dardanus, $57,57 \mathrm{n} . \mathrm{I}$; on pairing of merope and hippocoon, 57 n. I, 72.

Hexapoda in classification, 33 ; of the Palaeozoic, 34-8.

Hieracium, Mendel's discovery that hybrids of do not follow his principle, $\mathrm{xxxv} \mathrm{n}$. I.

Hind wings, bright, of moths, \&c., $303-4,325$.

Hinde, S. L., on flower-like Flatidae, 304 n. 3.

hippocoon, female f. of Papilio dar danus (see also dardanus): captured in copulâ with mercpe, $57 \mathrm{n} .1$; bred from cenea, 72 ; hippocoon, trophonius, and cenea bred from, $72 \mathrm{n}$. I; changes in, near V. Nyanza corresponding to those of models, 338 ; mimicking Amauris niavius or its $\mathrm{E}$. form dominicanus, $338,374,374$ n. I.

Hispidae mimicked by Longicorns, 261.

Hiss, aposematic significance of, 324; mimicked by birds, 324 .

HISTORICAL INTRODUCTION TO

THEORIES OF MIMICRY, VIII. 220-4.

HISTORY AND MIGRATION MAY BE

INFERRED FROM MIMICRY, $X$. 363-5.

HISTORY INFERRED FROM MIMICRY MAY BE CONFIRMED BY OTHER EVIDENCE, X. 365-6.

History and migration inferred from Müllerian mimicry no less than from Batesian, 363 .

History of the Inductive Sciences, W. Whewell, xlvi n. I.

History of the Rise and Pro. gress of a Single Biological Doctrine, T. H. Huxley, 1.

Hive-bee and Eristalis, 243-4. 
Hobby, butterfly found in stomach of, 284 .

Holland, W., on larvae of T.populet $i$ attacked by starlings, 157 n. 1 ;

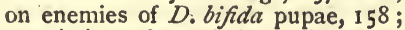
on mimicry of saw-fly larvae by caterpillars, $239 \mathrm{n} .1$; results obtained by, quoted in Essay X, 293; on colour adjustment of Cleonus, 307 .

Holothurians unsuited for fossilization, 43 .

Homoptera of Commentry Carboniferous, 35, 37; mimicry of ants by, 258,258 (Fig. 6), 259, 280, 369 ; resembling leaf-carrying ant, 259, 259 (Fig. 7), 260, 280, 377; cryptic resemblance of to flowers and buds, 304, 304 n. 3.

Homozygote (as regards any character), a fertilized germ in which both allelomorphs of the character in question represent the same one of its alternative forms, xxxi, xxxii ; compare heterozygote, $x x x i$, xxxii.

Honduras, examples of mimicry in, 235.

Hong-Kong, L. chrysippus at, 88.

Hooker, Sir Joseph D., Asa Gray on, 67 ; on effect of external conditions on plants, 74 ; consulted by Darwin on Wallace's essay (1858), 194; with Huxley in the Rhone valley, 202; references to letters from C. Darwin to, $59,60,63,67,76$, 84,86 ; from T. H. Huxley to, 195 ; to C. Darwin from, $48,74,74$ n. 3 .

Hope Department, Oxford University Museum, examples of mimicry in, xxiv, 231, 235, 248, 249, 272 n. 2 ; W. J. Burchell's collection in, 53,53 n. I, 356 ; butterflies from the V. Nyanza in, 69; specimens of $L$. chrysippus in, $321 \mathrm{n} .1$; work on diversity in the modes by which mimicry is attained in, 263 ; distasteful moth injured by drongo in, 284; work on the colouradjustment of larvae carried on in, 306, 307; hermaphrodite planemoides female f. of Pap. dardanus, in, 374 n. 3 . Hope Reports, Oxford, 51 n. 2.

Hopkins, $F$. Gowland, on pigments of Pierinae and their models, 262, 263.

Horae Entomologicae, W. S. Macleay, 220.

Hornets, wasps, and humble-bees mimicked by moths, 365,366 : see also classification of examples of mimicry, 389-93.

Horse, sterile progeny of ass and, 78 ; J. C. Prichard on the production of breeds of, by selection, 186 ; and cattle of mountains compared with those of plains by J. C. Prichard, 189.

Hound, origin of, 83 n. 2.

HOURS WHEN STRUGGLE FOR LIFE MOST SEVERE, X: 303.

'How' and 'Why': both answers essential, xlvi, xlvii.

Howard, Dr. L. O., on moth mimicking beetle, 231 .

Hubbard, H. G., examples of mimicry captured by, 231 .

Hudson's Bay Lemming, experiment on seasonal changes of, 310.

Humble-bees (see also classification of examples of mimicry, $389,391-2)$ : mimetic resemblance of Volucella to, not aggressive, 378 .

humbloti, Papilio, of Grand Comoro, a non-mimetic member of the mimetic African dardanus group, 373: see also dardanus.

Hume, T. H. Huxley on, 1 I I.

Humphries, Colonel, on the ancon or otter sheep, 185 .

Huphina nadina, 342 ; - phryne, 342.

HUXLEY, T. H., AND THE THEORY of Natural Selection: The Huxley Lecture, Birmingham University (1905), Essay VII, 193-219.

Huxley, T. H., On the Reception of the Origin of Species, 196; Life and Letters of, 48, 78, 195, I98, 199, 200, 202 ; President of British Association (1870), I ; at the Oxford meeting of the British Association, 2, 3; acceptance of per saltum evolution by, 4 ; on Biology and Geological Time, 4, 5 ; great demands for pre-Cambrian time made by, 6 ; on tidal retardation, 8 ; special value of letters of, 48 ; on influence of Milton, 56; discussion of interspecific sterility by Darwin and, 77-80,82,201: see also 49; Natural Selection not fully accepted by, 77-80, 193; answer to criticism of Natural Selection by, 80-4; on evidence, III; a great champion of Natural Selection, 193 ; ignorant of contents of joint essay on Natural Selection (1858), 195, 196; 
suggested causes of ignorance of joint essay (1858), 196; mutational views of, 195; belief (1859) in transmutation rather than transition, 195, 200 ; influence of Origin on, 196, 200,201 ; programme of training in science (1856), 198; voyage of Rattlesnake, 199; views of, on evolution before Origin, I99, 200 ; not essentially a naturalist, 200, 202 ; approves system of W. S. Macleay, 200 ; on the basis of scientific conviction, 20I, 202; opinions on Natural Selection, 201, 202; with J. D. Hooker in the Rhone valley, 202; the champion of scientific freedom, 219 ; references to letters from $C$. Darwin to, 78, 79, 80, 82, 91, I26, I96 ; to C. Darwin from, 4,196 ; to J. D. Hooker from, 195; to C. Kingsley from, 77,78 ; to C. Lyell from, 195 , 200 ; to W. S. Macleay from, 200.

Huxley's layer of hair, 198, 199.

Hyas coarctata, 314.

Hybernation, of African insects, 209 ; colour adjustment of L. quercifolia larvae determined before, 307 .

Hybernia leucophaearia, I 56.

Hybrids which do not follow Mendelian principle abundant, $\mathrm{xxxv}$, xxxv n. I ; of Hieracium proved by Mendel not to follow his principle, $\operatorname{xxxv}$ n. 1 ; sterility of, $63,64,77,78$; sterility of, due to Asyngamy, 8o-4; of Common and Chinese goose fertile, 83 ; of Ring Dove and domestic pigeon fertile, 83,84 ; 'illegitimate' seedlings of heterostyled plant compared with, 91 .

Hydrocorallina, affinity between living and Palaeozoic, 28.

Hydrozoa in classification, 25.

Hyelosia as mimics of Ithomiinae, 264 ; method of attaining transparency in, 266.

hylas, Cephonodes, loss of scales by, 365 .

Hylophila (Halias) prasinana, 149.

HYMENOPTERA, THE INSTINCTS OF, V. I60-6: see also 118, 119, I 46,147 .

Hymenoptera (see also Ants, Bees, Fossores, Humble-bees, Ichneumonids, Saw-flies, Wasps, Xylocopidae ; see also classification of examples of mimicry, 389-93): late evolution of, 38 ; unique interest of the, 52 ; di- and polymorphism in, 72 ; transition in mode of defence of Phytophagous larvae of, 319,320 ; best examples of instinct supplied by Fossorial, 118, 119, 146, 147, 160-4; W.S. Macleay and Kirby and Spence on resemblance of Diptera to, 220, 22 I mimicry of, by diurnal forms, 250; mimicry of, in various ways, 250-60; defence of, evident, 268; uniformity in groups of, 278,279 ; many examples of mimicry of Batesian, 376; also Müllerian, 231, 376; Dipterous mimics of, probably not aggressive, 378 .

Hymenopus bicornis, 378 n. 3 .

Hyolithes in Palaeozoic, 42.

Hypanis (Byblia) acheloia (götzius), 87, 34I.

Hyperechia, mimetic of Xylocopid bee in Borneo and S. Africa, 276.

HYPERTELY OF BRUNNER VON WATTENWYL, X. 302, 303.

Hypolimnas a genus mimetic of Danainae, 216; ancestral pattern in non-mimetic males of, 216 ; resemblance between non-mimetic males of, 245 ; probably a distasteful genus, and mimicry of Müllerian, 216, 217 , 372 ; complex nature of mimicry of Euploea by, 24I ; mimetic species of at once distinguished from models, 350.

Hypolimnas (Euralia) anthedon, 338 ; - bolina, 245, 372 ;-dexithea, 216; - misippus, 21 5-18, 245, 247, $347,355,365$ n. 1, 372, 381, 382 ; - (Euralia) wahlbergi, 338.

HYPOTHESES PROPOSED AS SUBSTITUTES FOR NATURAL SELECTION AS THE EXPLANATION OF MIMICRY, \&c., VIII. 224, 225 : see also 271-2.

Hypsidae (Pericopidae) as mimics of Ithomiinae, 264; method of attaining transparency in, 266 ; African Hypsid moth seized and rejected by wild drongo, 284 .

Ibis, vol. i, 195.

Ichneumonids (in the broad sense): see classification of the examples of mimicry, $390,392$.

'Identical' twins, F. Galton on, I32, $134,135,138 \mathrm{n}$. ; of the same sex, 132 ; enclosed in same embryonic membranes, 133 ; product of a single 
ovum, 133 ; distinguished from multiple births, 133; development of, shown in Diagram III, I33, I34; after-lives of, 134, 135; heredity and, $134,138 \mathrm{n}$.; predetermined in the fertilized ovum, 137.

Idiosyncrasies hereditary, 180.

ilithyia, Byblia, intermediate $\mathrm{f}$. bred from wet, 341 ; wet f. conspicuous, dry f. procryptic, 34I; dry warmth apparently the stimulus for pupae to produce the dry f., $34 \mathrm{I}$.

'Illegitimate' unions of heterostyled plants, importance of, xxviii, xxviii n. 1, 90-2.

Illogical Geology, Herbert Spencer, 6.

illunaria,Selenia, seasonal changes of, 3I I.

ILLUSTRATIONS OF MIMICRY, CHIEFLY FROM ORIENTAL LEPIDOPTERA, X. 370-6.

Illustrations of the Relationships existing amongst Natural Objects, \&c., Prof. J. O. Westwood, 221.

Imagination, Prichard on the effect of parental, at the moment of conception, I 86 ; versus memory, 196-8 ; necessity for the training of, in youth, I99.

'Immune', an incorrect term applied by Haase to models for mimicry, 3 I 8 ; also adopted by Weismann, 375 .

IMMUNITY, WARNING COLOURS DO NOT IMPLY COMPLETE, X. 317 , 318.

Imperforata in the Palaeozoic, 27.

IMPORTANCE OF INSTINCTIVE ATTITUDES AND MOVEMENTS FOR MIMICRY, X. 363 .

Inborn: see 'inherent characters', 141.

Independence of mimicry and affinity, $229-37,336,345$; of size as clear in Miillerian as in Batesian mimicry, 363,366 .

India, 70, 269, 317, 324, 342, 349, $363,371,372,373,376$.

Indirect evidence of birds attacking butterflies, 270, 270 n. I, 28I-3, $290-2,325,325 \mathrm{n}$. I.

INDIRECT EVIDENCESUPPORTING MÜLLERIAN MIMICRY, X. 346, 347.

INDIVIDUAL MODIFICATION TRAVERSES DIAGNOSIS, II. 73-5.
INDividual SEasonal Changes, X. 310 .

Individual subordinated to the species, 3I6, 358.

Individual variation a factor of selection, 95-6 ; difference, Weismann on causes of, 127, 128; colour adjustment slow in pupae, 149, 150, $152-4,305,306$; in a cocoon, 149 ; in larvae, $152-4,305-7$; probable in pupae of $U$. sambucaria, I50 n. 2; colour adjustment rapid in certain Vertebrata, Crustacea, and Cephalopoda, 300, 305, 313 .

Influences of locality, inconsistent views of J. C. Prichard on, 191, I92.

Inherent characters, definition of, I 10, I I I , I 22, I 23, I 4 I, I 42 ; heredity and, $96,127,178-85$; somatogenic characters less important than, $132-5$; somatogenic characters compared with, I36; other terms used to express, IIO, III, 123, 14I, I42 ; Weismann's definition of, 142 ; Goodrich's definition of, 142 ; clearly distinguished as congenital or connate from acquired characters by J. C. Prichard (1826), 175, 179.

Injuries to butterfly wings as if caused by enemies, 270, 270 n. I, $28 \mathrm{I}-3,325$ : see also 304 .

Innate, see inherent characters, I4I.

Innate tendencies, Lamarck's belief in, 98.

inornata, Amblyornis, bower of, 379.

Insecta, D. Sharp, 257 n. I.

Insectivora, moles of the, resembled in other Mammalian Orders, 312, 359 .

INSECTS, ESPECIALLY LEPIDOPTERA, PRE-EMINENTLY FITTED FOR DISCUSSION ON SPECIES, II. 50-4.

INSECTS, AND THE QUESTION - ARE ACQUiRED Characters HEREDITARY ?" Essay V, I 39-72. INSECTS, VARIABLE PROTECTIVE RESEMBLANCE IN, V. I52-4.

INSECTS, THE INSTINCTS OF, V. 154-7: see also 117-19, 146, 147, $157-66$.

INSECTS, BEARING ON SUPPOSED HEREDITARY TRANSMISSION OF EXPERIENCE, OF MIMICRY, \&C., IN, V. I66-8.

Insects in the Palaeozoic take 


\section{ANALYTICAL INDEX}

place of Pterodactyles and birds, 18 ; often wingless in oceanic islands, 18 ; great size of Palaeozoic, 18, 37; derived from Chaetopod-like ancestor, 27; in classification, 33 ; of the Palaeozoic, $34-8$; of Commentry Carboniferous, $35-8$; evolution of wings of, 36, 37 ; small advance of, since Carboniferous, 36-8; life-history of Carboniferous, 37 ; pre-eminently fitted for discussion on species, 50-4; disturbed by effect of wind, 75 ; crossfertilization and, 91 ; migration of, 93 ; the struggle for existence and, I I7; prophetic instincts of, 11 7-19, I 57-65; importance of, for the question of transmission of acquired characters, 13968 ; supposed transmission of experience, and the warning and mimetic colours of, 166-8; struggle for life in young birds, and the warning and mimetic colours of, 167,167 n. 2,168 ; importance of, as food, 167,167 n. 2 , I68; less on wing in dry season, 208-11; groups of, bury in dry season, 208 ; Prof. J. O. Westwood on resemblances between, 221 ; luxuriance of, in S. America, 248; great development of mimicry in, 367 ; effects of castration of, 380 .

Instances of variety in the Breed, arising from the operation of external, chiefly of local causes, J. C. Prichard, 187, I88.

Instances showing the Permanenoy of Complexion in different Races, J. C. Prichard, 177, 178.

Instinctive, see instincts.

Instincts and Habits of the Solitary Wasps, G. W. and E. G. Peckham, 118 n. I, 162, I63.

INSTINCTS OF INSECTS, V. I 54-7 : see also $117,118,119,146,147$, I 57-66.

INSTINCTS OF COCOON-MAKING, V. 157-60: see also $117,118,164$, 164 n. 2.

INSTINCTS OF THE HYMENOPTERA, V. 160-6: see also 118 , II9, I 46, 147.

INSTINCTS ALL-IMPORTANT FOR Protective Resemblance, X. 301 , 302 : see also 155-6, 289, 298, 300, $301,318$.

INSTINCTS ALL-IMPORTANT IN DISPLAY OF WARNING COLOURS, X. 323,324 : see also $319,320$.
INSTINCTS ALL-IMPORTANT IN THE AtTainment OF Mimetic RESEMBLANCE, X. 363 : see also 241, $319,341,368$.

Instincts or Instinct : (see also intelligence), Lloyd Morgan on, I54; Fabre on, 160; Lord Avebury on, 160, I6I ; G. J. Romanes on, 160, 161, 166; C. Darwin on, 161, 165; Eimer on, 162; G. W. and E. G. Peckham on, 162, 163; E. B. Poulton on, 163-5; E. Ray Lankester on, 165, 166; G. H. Lewes on, 166; Lamarckian interpretation of, I16, 154; intelligence and, I16, I17; Natural Selection and, I16-9, 138; originated through action of Natural Selection on nervous system, II7; more developed in lower animals, 117 ; of sucking, 117 ; definition of, 154, 301, 302; difficulties of Lamarckian interpretation of, 154$60,163-6$; protect from enemies that are never seen, $155-60$; of larva to protect against enemies of pupa, 157-60; of Fossorial Hymenoptera, I 8, I I9, 160-4; of Vespa, 164-5; of worker ants, 165 ; least developed in highest animals, 165, 166; performed but once in a life, 164, 164 n. 2 ; educability versus, 165,166 ; relation of daylight to mimetic, 249 , 250 ; to procrytic, 303 ; Lewes's and Romanes' view that 'lapsed' intelligence has produced, 166: see also 161; importance of, in Protective Resemblance, 298, 30I-2, 353; in Aposematic display, 323-4; in Müllerian mimicry no less than in Batesian, 363.

Intelligence (see also instinct), a criterion in evolution, 107, 108; of seal and birds, 116; instinct and, I 16, I17: see also I65, 166.

Intemperance, supposed hereditary effects of, discussed by J. C. Prichard, I 83, I 84 .

Interbreeding, advantages of, 93, 94 .

INTERBREEDING, ASYNGAMY A CONSEQUence OF PREFERENTIAL, II. 85-8 : see also 65 .

Interbreeding between similar varieties, 85-8.

Intercrossing, supposed swamping effect of, xl, xl n. 3 , xli ; importance of Mendelian principle in averting swamping effect of, xxxiv, xxxv, xli. 


\section{ANALYTICAL INDEX}

Interest as a stimulus to inquiry, xliv-xlvi.

Internal Causes, theory of, as suggested explanation of mimicry, 224 , 225,272 ; obviously inapplicable to mimicry between remote species, 229 ; also inapplicable to protective resemblances, 227, 228; objections to, as explanation of mimicry, 227-9, 233 , $236-9,241,245,247,249,250,257$, 260-2, 266-8, 273, 275, 276, 278-82.

Internal Sci. Ser., 161 n. I.

INTERSPECIFIC STERILITY AS TEST OF SPECIES, II. 77-80: see also 59 .

INTERSPECIFICSTERILITY CAUSED BY Asyngamy, 11. 8o-4: see also 65 , 91 ; see also sterility.

INTIMIDATING ATTITUDES, $\mathrm{X}$. 324,325 .

INTIMIDATING OR WARNING SoUNDS, X. 324 .

Introduction, Kirby and Spence, utility of mimicry suggested in (1817), $221,222$.

INTRODUCTION :

MENDELISM, AND

Mutation, SElection, xiii-xlviii.

INTRODUCTION TO DISCUSSION 'WhAT IS A SPECIES?' II. 63-5.

INVESTIGATION, THE MOTIVE FORCE OF, Introd., xlvii, xlviii.

iopterus, Promachus, mimicry of Hymenoptera by, 257 n. 1 .

irawada, see splendens, Isamia, 376.

Ireland, dread of snake-like caterpillar in, 367 n. 2.

Iridescence, cryptic effect of, 322. Irrawaddy R., $291 \mathrm{n} . \mathrm{I}$.

Isamia splendens and irawada, 376.

ISLANDS, ANCESTRAL NONMIMETIC FORMS PRESERVED ON, X. $373-6$.

Islands, oceanic, wingless insects in, 18.

Isolation and species production, 76 ; leading to 'mechanical selection', 85.

Ithomia, a central type of Ithomine pattern, 234.

Ithomiinae (see also classification of examples of mimicry, 383-4, 386-8): collected by Burchell in Brazil, 53 n. I; Heliconinae and, as examples of Müllerian mimicry, 232 ; always tend to be mimicked, 233,273 ; number of colours in Neotropical Papilioninae compared with those of, 234,277 ; as models paralleled by Diabrotica, 236 ; pigments of, different from those of Pierine mimics, 262, 263; transparent-winged species of and mimics, 264-6 ; colours of principal combinations grouped round in various localities, 272, 273, 322, 331-3, 350, 351,356 ; darkening of, in the Guianas, 272, 273, 331-3; dominance of, in British Guiana, 332 ; uniformity throughout many species of, 234,277 ; long confused with Heliconinae, 278 ; not extremely conspicuous, 322 ; absence of 'eye-spots' in, 326; equivalent to the Danaoid Heliconidae of Bates, save for inclusion in latter of Danaine Ituna and Lycorea, 327 ; distinguished by flight from mimicking Heliconinae, 33I, 33 I n. I ; resemblance of Heliconinae to, remarkable in mimicry, 343 ; mimicked by an Erycinid which is itself the model of diurnal moth, 346 ; Heliconine close mimics of, generally at once distinguishable, 350 .

Ituna and Thyridia, a remarkable case of Mimicry in Butterflies, Fritz Müller, 222 : see also $212,226,278,327$.

Ituna (Danainae), mimicry of Ithomiinae by, 265; method of attaining transparency in, 265,266 ; included in Ithomiinae by Bates, 327.

\section{$\mathrm{J}$}

Jacob, experiments of, on flocks of Laban, 186.

jacobaeae, Euchelia, larva of a Müllerian mimic of a wasp, 230 ; cryptic and aposematic defence of larva of, aposematic of imago, 318, 319.

Jacoby, M., on mimicry in Coleoptera, 236, 237 .

Jagellon, intermarriage with, the cause of a hereditary peculiarity of lip in Royal House of Austria, 180.

Japan, $L$. chrysippus reported from, 88.

Jardin des Plantes, Paris, $O$. lamarckiana originally described from, xxi.

Jen. Zeit., 317. 
Jenkin, Fleeming, xl, xl n. 3, xli, 3: see Fleeming Jenkin.

Jenkinson, Dr. J. W., on relation between planes of first egg division and position of future embryo, 130.

'Jerusalem Jews' unchanged since 490 A.D. on Malabar Coast, 178 : see, however, 192.

Jews, see circumcision and Jerusalem Jews.

Joints, evolution of forms of, 112 , 113; Lamarckian interpretation of forms of, $114,115$.

Jordan and Rothschild on per saltum evolution and geographical distribution, xvi.

Jordan, Dr. Karl, on museum collections as evidence of change, 53 n. I ; on correlated and independent variation, 66 n. 2 ; on provisional nature of diagnosis, 76,77 ; on peculiarities in Madeiran birds, 84 n. 2 ; on 'mechanical selection', 85 .

JUDGEMENT OF DISCONTINUITY SubJECTIVE, Introd., xvii.

Jung and fixity of species, 56.

Junonia, captured by bee-eater, 288 : see Precis.

Junonia cebrene, 283 ; - orithyia, 291.

\section{K}

Kala Pani Bungalow, Thundiani, King-crow attacking Papilio near, 285.

Kallima, protective resemblance of under surface of, $203-8,302$; seasonal changes in, 206,207 ; resembling different appearances of dead leaves, 3 Io.

Kallima paralekta, 207.

Kandy Road, Ceylon, bee-eaters capturing Pierinae on the, 285, 286.

Karachi, L. chrysippus at, 70 ; dorippus f. of $L$. chrysippus at, 7o n. 2 .

kaschmirensis, Vanessa, captured by King-crow, 285 .

Kaye, W. J., results obtained by, quoted in Essay X, 293 ; on the chief mimetic association of British Guiana, 322,332 ; on exact resemblance of $H$. numata to $M$. mneme, 331 ; assistance in ascertaining dominance of Melinaea mneme in British Guiana, rendered by, 332 ; on upper surface colouring of Protogo- nius, 351 ; on the two sub-groups of the Heliconinae, $358 \mathrm{n}$. I; on means by which transparency may be attained in mimetic Lepidoptera, 366 n. 1 .

Kelvin, Lord, on the age of the earth, 2, 19; works on geological time of, 4 n. 3 ; effect on Darwin of views of, 6 ; jubilee of (1896), 9 ; on the cooling of the earth, 10-13; on the life of the sun, 13-15; meteoric hypothesis of, 22-4.

Kendall, May, parody of Darwinism by, 104 .

Kentish Glory moth, 238.

Kerguelen Land, wingless insects in, 18.

kershawi, the Australian form of $P$. cardui, 85 n. I.

Kestrel pecking out eye-spot of butterfly, 2 IO.

Khandalla, dorippus f. of $L$. chrysippus at, 70 n. 2.

Kikuyu Escarpment, the locality of polytrophus, sub-sp. of Pap. dardanus, 374 .

King-crow attacking butterfies, 285 ; attacking Lepidoptera, 287 ; searching for but unable to detect Melanitis, 288, 289; capturing Catopsilia, 289.

Kingsley, Charles, letters on interspecific sterility from Huxley to, 77, 78 ; on examinations, 197-8.

Kirby, Rev. William, on resemblances between insects, 220 ; utility of mimicry suggested by Spence and, $221,222$.

klugii, see dorippus.

Knight-Darwin Law, F. Darwin on, 92.

Kölreuter on sterility between varieties, 78 .

Kosmo8, 212, 222, 226, 278, 327.

Kupffer's Festschrift, I3I.

'Kuppa' (Echis), 324.

\section{L}

Lacerta viridis, 367.

Lackey moth, 157.

Lactic acid bacillus, beneficial effect of, 121 n. I.

La Garde St. Cast, Brittany, Boulenger's study of $O$. lamarckiana at, xxi.

Lagerstroemia Flos Reginae, 290. 
laglaizei, Papilio, mimicking Alcidis aurora, 371.

lais, Elymnias (Melynias), mimicry and procryptic defence in, 353.

LAMARCK, SECOND LAW OF, INCONSISTENT WITH HIS FIRST, V. 144-7 : see also Lamarckism.

Lamarck, use of term 'changements acquis' by (1809), 141 ; laws of, 141.

lamarckiana, Oenothera, De Vries's evidence for Mutation in Nature derived from, xix, $x x$; never found wild in its supposed native country, xix, xxi ; fixed hybrids obtained by Macdougal, Vail, and Shull between $O$. cruciata and, xxi, xxii ; Mendelian principle not followed by hybrid between $O$. cruciata and, xxxv n. I.

Lamarckism (see also Acquired Characters and External Causes): the theory of evolution originated by Lamarck, 97-9; innate tendency to perfection and, 100; more easily apprehended than Darwinism, IOI ; illustrated by parodies of Darwinism, 103, I04; acquired characters and, 110-15; difficulties of, I10-15; Mammalian skeleton and, 112 ; form of joints and, I1 2, I1 5 ; passive structures (e.g. hair, colour) and, 112 ; lobster's and crab's claws, lizard's tail and, I13, I 14 ; protective appearance and, I13; forms of teeth and, II4, I15; instinct and, I16 ; the cocoon-making instinct and, 117,118 , $157-60,164$; instincts of Hymenoptera and, I1 8, I19, 160-6; variable protective resemblance and, $152-4$; interpretation of instinct and, 154 ; instincts of insects and, 154-66 ; defended by G. J. Romanes, 160-1, 164 n. I, 166; Darwin's argument that instincts of worker ants cannot have arisen by, 165 .

Lamellibranchiata in early Palaeozoic, 30 ; evolution in, 42.

Lamiidae, mimicry of weevils by genus Doliops of, $250,26 \mathrm{I}$.

Lampreys, 26; far lower than earliest fossil fish, 30 .

LANCASHIRE AND YORKSHIRE, RECENT DARKENING OF MOTHS IN, X. 308-10.

Land-plants, see plants.

Language a result of environment, 106.
Lankester, Sir Ray, on animal classification, 25 ; on classification of Appendiculata, 33; on Palaeophonus, 40; assistance rendered in Essays 1,11 , and VI by, 43, 62, 144-6 : see also viii ; on Zygosis, 60 n. 3 ; on discarding word 'species', 62 ; on a historical criterion of species, 63,76 ; on Lamarck's use of term 'acquired', I4I n. 2 ; on Sir Edward Fry's criticisms, 143 n. 3; on inconsistency of Lamarck's laws, I44-6 ; on ' educability' versus instinct, $165-6$.

Lappet moth, 299, 307.

Larvae of British Butterflies and Moths, W. Buckler, 152.

Larvae (for Lepidopterous see caterpillars: see also larval stage) : reasons for passive defence of, 156 ; mimicry by caterpillars of saw-fly (Tenthredinid), 238, 239, 239 n. 1; sudden assumption of aposematic movements and attitude by saw-fly, 238, 239, 319, 320; ant mimicked by Nabis, 257 n. I ; leaf-carrying ant (Atta) with its leaf mimicked by Membracid, 259 (Fig. 7), 260, 280, 377; bugs (Hemiptera) mimicked by Mantid, 378 n. 3 .

Larval stage, a mimetic appearance prepared beforehand in, 242, 243, 244; diverse conditions in same locality determined by, 243, 244, 276, 277 ; seasonal phases determined by influences upon, 3I I, 3 I 2.

Latent Epigamic characters, 380.

latercula, Lycomorpha, mimicking Lygistopterus rubripennis, $23 \mathrm{I}$.

lativentris, Nabis, larva of, mimicking ant, $257 \mathrm{n}$. I.

Latter, O. H., on secretion for opening $D$. vinula cocoon, 159.

Laurentian omitted from discussion of age of earth, 27, 28.

'Laws of Growth' and mimicry, 224, 225.

LAWS OF LAMARCK INCONSISTENT, V. 144-7.

Laws of Lamarck, 141 .

Laws of Nature in Hereditary Transmission, J. C. Prichard, 17885.

Laws of the Animal Economy in regard to the Hereditary Transmission of Peculiarities of Structure, J. C. Prichard, 178-85. 
Lay Sermons, \&c., T. H. Huxley, 198.

Leader, 58 n. I.

'Leaf-butterflies' (Kallima), 2038, 302, 3 I0.

Leaf-carrying ant $(A t t a)$ with its leaf mimicked by larval Membracid, 259, 259 (Fig. 7), 260, 280, 377; mimicked by Acridian (Tettix), 260 .

Leaf-stalk, protective (procryptic), resemblance to, $35 \mathrm{I}$.

Leaves (see also dead leaves) : protective (procryptic) resemblance to, 203-8, 289, 298-9, 300 n. 5, 30I, $302,304,322,360$; procryptic resemblance of butterflies to, 203-8, 289, 299, 300, 300 n. I, 301, 310, 3II, $322,35 \mathrm{I}, 353$; to shadows cast by dead, 299; of moth and Locustid to injuries caused by fungi and larvae in, 302 ; of gregarious larvae to brown patches on, 304 ; colour adjustment of larvae to, 306; procryptic resemblance to drifting, 360 ; aggressive (anticryptic) resemblance to effects of, 313 ; warning (aposematic) conspicuousness against, $3 \mathbf{I} 8$.

Lecture on Mimicry at Leeds meeting of British Association (1890), E. B. Poulton, 293, 299 n. 1, 365, 370, $376,377,377$ n. 2.

Lectures to Working Men, T. H. Huxley, 78 .

Leech Collection, specimens of Limenitis albomaculata, Athyma punctata, and their model in, 381, 382.

Leeches, Chaetopod-like ancestor of, 27.

Leeds, lecture on Mimicry at, see lecture.

Leigh, G. F., on dorippus f. of L. chrysippus in Natal, 71 n. I; males and mimetic females of $P a p$. dardanus bred from single mimetic f. of, by, 72, 72 n. 1 .

Lema mimicking Diabrotica and Cerotoma, 237.

Lemming, experiment on seasonal changes of Hudson's Bay, 310 ; protective (procryptic) seasonal change of, 313 .

Lepidiota bimaculata, 368.

LEPIDOPTERA ESPECIALLY FITTED FOR DISCUSSION ON SPECIES, II. 50-4.

LEPIDOPTERA CHIEFLY ORIENT- al, Illustrating Mimicry, X. 370-6.

Lepidoptera (see also butterflies and moths: see also classification of examples of mimicry, 383-92) : seasonal changes of, see seasonal; late evolution of, 38 ; as sensitive registers of change, 50-4; 'mechanical selection 'in, 85 ; as evidence in discussion of acquired characters, 146 ; adaptation in as evidence for Natural Selection, 203-18; too exclusive study of mimicry in, 229, 272, 273; mimicry in paralleled by that in beetles (Coleoptera), 236, 237 ; predominant mimicry in S. American, 248 ; mimetic likeness attained in various ways by, 262-6; transparency attained in various ways by, 2636 ; evidence of distastefulness in mimicked groups of, 279,279 n. I : see also 268-9, 316-17; majority of mimetic resemblances Müllerian and not Batesian, 348.

Lepidopterorum Rossiae Biologia, 1890, C. Portschinski, 316, 324. Lepidotic acid, see uric acid, 262-3.

Leptalides, see Dismorphina, 23940, 265-6.

leucocyma, Elymnias (Melynias malelas), male and female of, mimicking different Euploeas, 372.

leucophaearia, Hybernia, cryptic attitude of, 156.

Leuthstrom, Dr. C. A., ant-like beetle in grounds of, 256 .

levana, Araschnia, mimetic interpretation of seasonal forms of, 342 .

Lewes, G. H., on instinct as lapsed intelligence, 166.

Lichen, protective (procryptic) resemblance to, 298, 306, 307 ; syncryptic resemblance to, 312,359 ; colour adjustment of larvae to, 306, 307 ; disappearance of, in Lancashire and Yorkshire district, 308, 309.

Life and Letters of Charles Darwin, F. Darwin, xxvi, xxix, xl n. $3,3,4,6,59,60,66$ n. $3,67,75$, $83,86,9$ I, 92, 95, I26, 196, 197, 200.

Life and Letters of Thomas Henry Huxley, L. Huxley, 48, 78, 195, I98, 199, 200, 202.

LIFE-HISTORY AND HABITS, IMPORTANCE OF, IN DETERMINING CONDITIONS, VIII. 243, 244 .

Life of sun, see Sun. 


\section{ANALYTICAL INDEX}

Life, origin of, unknown, 95.

Life, struggle for, and Natural Selection, 96 ; waste of, prevented by warning colours, 316 ; tenacity of, in species with warning colours, 316 ; saved by Müllerian mimicry, 327-8.

Light, stimulus of, in adjustable protective resemblance, 305 .

Limacina appears in Tertiary, 42.

Limbs, origin of Vertebrate, 108-9.

Limenitis, conspicuous and probably distasteful, 2I 8; (Basilarchia) N. American species of, mimicking A. plexippus, 274; resemblance of prorsa $\mathrm{f}$. of $A$. levana to, 342.

Limenitis albomaculata, 217,381 , 382 ; - (Basilarchia) astyanax, 274 ; - populi, 315, 316.

LiMIT TO MÜLlERIAN UNIFICATION OF WARNING COLOURS IN ANY COUNTRY, X. 336-9.

Limnas chrysippus, 70, 71, 88, 89, $215,232,249,320,321,336,354$, $355,364,372,374$.

Limulus, allied forms of, in early Palaeozoic, 30 ; appears in Trias, 40.

Lingula, among the earliest fossils, 5 ; persistence of in time, 43.

LiNNAEAN CONCEPTION OF SPECIES AS FIXED, II. 54-9.

Linnaean definition of species, 54 ; diagnosis of species, 58 .

Linnaean Society of London, Transactions of , 85, $211,220,221$, 222, 246, 279, 327, 327 n. I, 331 ; Zoological Journal of, 218 n. 2, 220,282 n. 2, 300 n. 3; DarwinWallace, Joint Essay read before (1858), 194, 379 ; Author's paper read before, the original form of Essay VIII, 220 ; publication of memoirs on Mimicry by, 222.

Linnaeus (see also Linnaean): on abandonment of conception of, 62 ; interval between Darwin and, 66 .

Lion, aggressive resemblance of, 312.

'List' or tilt of butterflies, 289 , 300,300 n. 5,301 .

Lizard examining eye-spot of butterfly, 2 Io; terrified by snake-like caterpillar, 367.

Lizards, value of power of throwing off tail possessed by, I14, 325; indirect evidence of attacks of, on butterflies, $28 \mathrm{I}-3$; preferences of, 286 ; aposematic sounds of, 324 .
Lobster moth, larva of, 253 (Fig. 2), 254, 369.

Lobster throwing off claw, I 13.

Local conditions, J. C. Prichard on adaptation to, 188-92.

Local influences, inconsistent views of J. C. Prichard on, 187, 191, 192.

Locality, influences of, see External Causes.

Lock, R. H., on the dominance of discontinuity, $x v$ n. 2 ; on discontinuity and colour changes, xvii, xvii n. I ; on Mutation, xvii, xvii n. 2; on Bateson's and Gregory's work on the primrose, xxvij ; exaggerated estimate of the importance of Mendelism by, xxxiii, xxxvi, xxxvii n. 2 ; on the importance of Mendelism in artificial selection, $\mathrm{xxxv}$; erroneous statement of Darwin's opinion by, xl n. 2 .

Locustidae (Protolocustidae) of Commentry Carboniferous, 36, 37 ; mimicry of ants by, 256, 257, 257 n. 1, 258 (Fig. 5), 280; procryptic resemblance to leaves of, 302 ; specially defended insects attacked by, 318.

Longicorn beetles (see also classification of examples of mimicry,390-3): mimicry in relation to life-history of, 243 ; reduction of elytra in mimetic, 252.

Longstaff, Dr. G. B., results obtained by, quoted in Essay X, 293 ; on concealment of $C$. pumilus, 300 ; on reduction of shadow by attitude of butterflies, 300, 301 ; on choice of resting-sites by butterflies, 301, 301 n. 6 ; on daylight hours when butterflies are at rest, 303 ; on epigamic and aposematic scents in African butterflies, $316,317 \mathrm{n}$. 1 ; on jaw-like third legs of Heterochelus, 368.

Lophius piscatorius, 378.

Lord Kelvin, see Kelvin.

Lowell, James Russell, parody of evolution by, 104-5.

Luebo, on $\mathrm{S}$. branch of Congo, type f. of L. chrysippus from, 321 n. I.

Lycaenidae, value of head-like appearance at posterior end of, $28 \mathrm{I}-$ $3,325,325 \mathrm{n}$. I ; meaning of 'tails' and 'eye-spots' on hind wings of, 325 , 325 n. I; wing-fragments probably of, in nest of Microhierax, 291; station different from that of model, 
L. chrysippus, preferred by certain, 349.

Lycidae (see also classification of examples of mimicry, 389-91, 393): moths which mimic are themselves distasteful, 231 ; mimicry in relation to life-history of, $243,276$.

Lycomorpha latercula, a Glaucopid moth mimicking Lycinae, 231.

Lycorea (Danainae) included in Ithomiinae by Bates, 327 .

Lycorea halia, 356.

Lyell, Sir Charles, on ocean basins, 21 ; letters from Darwin to, 56, 75, 83 ; letters from Huxley to, 195, 200; consulted by Darwin on the joint essay (1858), 194.

Lygistopterus rubripennis, 231.

\section{$\mathrm{M}$}

Macan, Dr. R. W., assistance in terminology rendered by, $6 \mathrm{I} n$. 1 .

Macao, L. chrysippus at, 88.

macareus, Papilio, a mimetic species not attacked by bee-eaters, 288.

Macdougal, Vail, and Shull, fixed hybrids between O.lamarckiana and $O$. cruciata obtained by, xxi, xxii : see also xix n. $5, \operatorname{xxxv}$ n. 1 .

Macleay, W. S., Huxley's letter to, approving system, 200; on the principle of Analogy, 220.

Macroclemmys temminckii, 378.

macrophyllum, Eupatorium, frequented by chief mimetic butterflies of British Guiana, 322.

Macrura evolved earlier than Brachyura, 40.

maculosa, Diacrisia, a distasteful moth seized and dropped by a drongo, 284.

Madagascar, 57 n. 1, 216, 245, 373.

Madeira, many beetles wingless in, I 8 ; birds slightly modified in, 84,84 n. 2 .

Maize, Gärtner on, 78.

Malabar Coast, 178,187 : see also 192.

Malacosoma neustria, 157.

Malacostraca in Palaeozoic, 39, 40.

Malaya, 248, 252, 333, 367.

MALE, MIMICRY, \&C., MORE CHARACTERISTIC OF FEMALE THAN, VIII. 244-7: see also $215-17,279$, $372-5$.
Male Mimicking Male of . MODEL, Female its Female, $X$. 371.

Male and Female Miaicking Different SPECIES, X. 372.

Male NON-MiMetic: Female Mimetic, X. 372.

Male, ancestral appearance preserved in non-mimetic, 244-7 ; except in mimicry less ancestral than female, 245.

Male parent, Prichard on the supposed influence of on offspring, 185 .

Males, non-mimetic, of mimetic females tend to warning colours and to become models, 347 ; rivalry between for possession of females, 379.

malelas, Melynias (Elymnias leucocyma), male and female of, mimicking different Euploeas, 372.

Malvern, Durban, Natal, recent incursion of $\mathrm{N}$. butterflies into neighbourhood of, $52 \mathrm{n}$. I ; attack on butterfly witnessed at, 283 .

Mammalia, disputed remote ancestry of, 26 ; rapid evolution of brain in higher, 29; brain of higher, compared with that of man, 29; brain evolution in, 107-8; skeleton of and Lamarckism, 112; experiments on Indian insect-eating, 269; warning colours of, 315 ; mimicry by treeshrews of squirrels, 367,367 n. I ; mimicked by chafer, 368 .

Man, brain of, compared with mammals, 29; evolution in brain of, 108; division of labour among tissues of, 121; J. C. Prichard on adaptation to locality and climate of races of, 190,191 ; snake-like caterpillars terrifying monkeys and, 367 n. 2.

Manchester Microscopical Society, Transactions of, 366 n. I.

Mandalay, $291 \mathrm{n} . \mathbf{I}$.

Manders, Lieut.-Col. N., on dorippus f. of L. chrysippus in Ceylon, 70 n. 2.

Mantidae attacking specially defended insects, 318; alluring flower-like colours of, $378,378 \mathrm{n} .3$; colouring of, also procryptic, 378 ; Reduviid bug mimicked by larvae of, 378 n. 3.

mapurito, Conepatus, warning colours of, 315. 
Mare and quagga, supposed enduring effect of cross (telegony), 185 . Marico wood-shrike, 283.

Marine Invertebrate Eauna near Dublin, G. Y. and A. F. Dixon, 314 n. I.

mariquensis, Bradyornis, capturing Sarangesa eliminata, 283.

Mars, the question of water on, 14.

Marshall, Guy A. K., on dorippus f. of $L$. chrysippus in Rhodesia, $7 \mathrm{I}$ n. I ; experiments on seasonal dimorphism of, $72-3$; on seasonal changes in S. African butterflies, 208 ; on Kestrel examining eye-spot of butterfly, 210 ; members of mimetic combinations captured on one day by, 249; on a Rhodesian ant-like Locustid, 257 n. I; evidence of special defence in conspicuous insects obtained by, 268, 269; on Asilid fly mimicking Xylocopid bee in S. Africa, 276 ; on complex S. African combination with Lycid beetle models, 276 ; indirect evidence of attacks on butterflies obtained by, 281-3; direct evidence of attacks by birds on Lepidoptera obtained by, 282-4; results obtained by, quoted in Essay $\mathrm{X}, 293$ : see also viii, 382 ; experiments on seasonal forms of Pierinae made by, 311,312 ; on absence of 'eye-spots' from the chief distasteful butterfly groups, 326 ; on the bionomic classification of 'eye-spots', 326 ; Batesian mimicry favoured by, 328 ; on 'stink-glands' of Colaenis, 334 n. 2 ; on Precis natalensis, a mimic of Acraeas, 339 ; experiments on the physiological stimulus in seasonal dimorphism of Precis made by, 340, 341; uncertain results of above-named, 340 ; proof by breeding of the specific identity of the wet and dry season forms of following species obtained by-Precis sesamus (1898), 339, 340: $P$. antilope (I 902), 340: $P$. actia (I903), 340: $P$. ceryne (1905), 340 ; dry f. of Byblia götzius bred from wet by, 341 ; intermediate f. of $B$. ilithyia bred from wet by, 34I ; dry warmth proved to be probable stimulus to the pupa of Byblia by, 341 ; on wet f. of B. götzius, a mimic of Acraea serena type, 34I ; on a wonderful Lycid-beetle-centred Müllerian combination, 276, 344 ; on monkeys terrified by snake-like larva, 367 n. 2 ; on S. African Longicorns mimicking weevils, 369 ; on conspicuousness of large African weevils, 370.

Marsupialia, mole-like forms of, 312.

Materials for the Study of Variation, W. Bateson, generally quoted as On Variation, xiii-xvi, xix, xxviii, xxviii n. 2, xxxiv, xxxvii n. 2, xl-xliii, 4: see also Bateson, W.; exaggerated estimate of importance for evolution of, xiv; disparagement of other lines of inquiry in, xli-xliii ; unreasonable disparagement of Embryology in, xlii, xliii.

Maternal impressions, supposed inheritance of, rejected by J. C. Prichard, I86.

Mathematical Statement of Advantage CONFERRED BY PERFECTED MÜLLERIAN RESEMBLANCE, X. 328,329 .

Mauritius, sea-anemones and Ascidians carried by crabs and hermit-crabs in, 357.

Max Müller, Professor, on necessity for defining words, 46 .

Mayer, A. G., on fewness of colours in Ithomiinae as compared with Papilioninae, 234, 277.

'Meadow-brown' butterfly, 2 Io.

MECHANICAL INCOMPATIBILITY, ASYNGAMY AS A CONSEQUENCE OF, II. 85 .

'Mechanical selection', 85 .

Medical faculty [in 1889] and heredity, I 36, 137.

megalocephala, Ascaris, germantecedents in one of first two cells of egg, 13 I.

Melanism, recent increase of, in N. of England, 308, 309, 309 n. 1.

Melanitis, cryptic effect of slanting position of, 289 ; T. R. Bell, C. T. Bingham, and E. E. Green on tilt of, 300 n. 5.

Melanitis zitenius, 288, 289.

Meldola, Professor Raphael, on the power of Natural Selection, I 53; on Müllerian mimicry and transmission of acquired characters, 167 ; on Prichard's anticipation of modern views on evolution, 174; lizard attacking eye-spot of butterfly observed by, 210; Fritz Müller's theory 
of mimicry brought forward and supported by (1879), 212, 213, 223; letters from Darwin to, 225, 228, 233, 272 n. I (although Meldola's name is not mentioned in this footnote); on uniformity throughout nauseous groups of butterflies, 234, 278.

Melinaea, a central type of Ithomiine pattern, 234; Heliconius resembles the nearly related Eueides far less closely than it does the remote, 235 ; Danaini and Euploeini compared with Heliconius and, 334.

Melinaea mneme, 331-3.

Melinda, see Tirumala.

Melsetter, Gazaland,

S.E. Rhodesia, attack of drongo on distasteful moth witnessed at, 284 .

Melynias, see Elymnias.

Melynias malelas (Elymnias leucocyma), 372. 276.

Melyridae mimicking Lycidae,

Membracidae, protective (procryptic) resemblance developed in shield rather than in insect itself, 258,259; mimicry of ant developed in shield rather than in insect itself, 258, 258 (Fig. 6), 259, 280, 369; resemblance to leaf-carrying ant with its leaf, of larval, 259, 259 (Fig. 7), 260, 280, 377.

Memory versus imagination, 196-8.

Mendel, Abbé Gregoire, the great discovery of: see Mendelian principle; Weismann's discoveries appropriated under the name of, xiii, xxxvi, xxxvii, xxxvii n. 1 .

Mendelian principle in heredity, discovery of, xxix ; rediscovery of, by De Vries, Correns, and Tschermak, xxix ; nature of, xxix-xxxiii ; inferences from concerning the germcells, xxxi-xxxiii ; a fascinating addition to knowledge, xxxiii ; value of, xxxiv, xxxv ; probable immense importance of in Artificial Selection, xxxv; the importance of, greatly exaggerated, xiii, xiv, xxxvii n. 2 ; affords but little help in solving the problem of evolution, xxxiii-xxxv; abundant hybrids which do not follow the, xxxv, xxxv n. 1 ; proof by Mendel himself that hybrids of Hieracium do not follow the, xxxv n. I ; Correns on limitation of, to crosses between varieties, $x x x v$ n. 2 : increasing complexity in the hypothetical germinal mechanism suggested by, xxxvii n. 2 ; Natural Selection and, xxvi-xxxv.

Mendelian work on heterostyled condition of primrose, xxix-xxxi ; impossibility of long continuance of, xxx n. I; limited conclusions to be inferred from, $\mathrm{xxx}, \mathrm{xxxi}$.

MENDELISM, MUTATION, AND NATURAL SElection, Introduction xiii-xlviii.

MENDELISM AND NATURAL SELECTION, Introd. xxvi-xxxv.

MENDELISM AND NATURAL

Selection, no Essential DiverGENCE BETWEEN, Introd. xxxvi-xli.

mendica, Spilosorna, aposematic attitude of, 324 .

mephitica, Mephitis, warning colours of, 315 .

Mephitis mephitica, 315 ; - suffocans, 315.

Mercury, susceptibility to, hereditary, 180.

meriones, Papilio, non-mimetic ancestor in Madagascar of African species of Pap. dardanus with mimetic females, 245,373 : see also dardanus.

merope, the W. sub-sp. of Papilio dardanus, 374 : see also dardanus.

Merops philippinus, 285, 286, 289;

- swinhoei, 287.

Merostomata, great development of, in Silurian, 40 .

Merrifield, F., results obtained by, quoted in Essay X, 293; on seasonal changes in British Lepidoptera, 31 I.

Mesozoic time, waste and sedimentation in, I6; Scudder's views on evolution of higher insects in, 35 ; Angiosperms appear late in, 45 .

Metaphyta compared with Protophyta, 120.

Metazoa, originate from Protozoa, 23 ; the meteoric hypothesis and, 24 ; place in classification of, 25 ; evolutionary history of phyla of, 26 , 27; pre-Cambrian evolution in, 31; compared with Protozoa, I2O.

Metazoon, development of illustrated description of Diagram II, $127,128,130,131$.

Meteoric dust on ocean floor, 20 ; hypothesis of origin of territorial life, 22-4. 
Meteors, sun's energy perhaps increased by, 14 .

Methona confiusa, 264-6.

Metschnikoff, Dr. Elias, on the lactic acid bacillus, $121 \mathrm{n}$. $\mathrm{I}$.

Mexico, L. astyanax enters from N., 274.

Microhierax coerulescens, 289-91 ; - eutolmus, 290 ; - fringillarius, 290.

midama, Callamesia, belonging to the distasteful Zygaenidae (Chalcosiinae), a Muillerian mimic of Euploeas, 372, 376; moths allied to, are similarly Müllerian mimics of same Oriental models, 376 .

Midland Naturalist, I20, 142 n. 1 .

Midland Union of Natural History Societies. Author's PRESIDENTIAL ADDRESS (I889) the foundation of ESSAY IV, I 20.

MIGRATION AND HISTORY MAY BE INFERRED FROM MIMICRY, X. 363-5.

Migration of insects, 93 ; of butterflies in Ceylon, 285; in Burma, 289; history and, to be inferred from Müllerian mimicry no less than from Batesian, 363-5.

Migratory birds of W. China, interest in the study of, 217,218 , 382.

Mikado, 302.

Milton, John, influence of, on belief in special creation, 55,56 .

Mimetic, see mimicry.

Mimetic Attraction, F.A. Dixey, $328 \mathrm{n}$. I.

Mimicry, E. B. Poulton, in Dict. philos. and psychol., J. M. Baldwin, 312 n. 2,360 n. I.

Mimicry between Butterflies of Protected Genera, R. Meldola, 234.

Mimicry in Butterflies of the Genus Hypolimnas, E. B. Poulton, 247 n. I.

MIMICRY, \&C., BEARING OF, UPON SUPPOSED HEREDITARY TRANSMISSION OF EXPERIENCE, V. I66-8.

MIMICRY, NEW INTERPRETATION OF AN OLD EXAMPLE OF, VII. 2 II-18.

Mimicry, Natural Selection THE CAUSE OF COMMON WARNING COLOURS AND (THEORIES OF MIMICRY), Essay VIII, 220-70.
MIMICRY AND NATURAL SELECTION, Essay 1X, 271-82 ; APPENDIX to Essay IX, containing evidence of birds attacking butterflies, 282-92.

Mimicry, Place of, in a Scheme of Defensive ColoraTION, Essay X, 293-382 ; for divisions, sub-divisions, sections, \&c., of Essay X see Contents, pp. 293-7.

MIMICRY MÜllerIAN, COMMON WARNING OR SYNAPOSEMATIC Colours, X. 327-56; for sections and sub-sections see 295-6.

Mimicry Müllerian (Synaposematic or Common Warning Colours) see under Mimicry Protective, \&c., Historical Account, where the references to both theories are combined: see also under Mimicry Protective, \&c., Relation to Mïllerian Mimicry, and Bearing upon Theories of Evolution; order in which to undertake study of examples of, xxv, xxvi, 336 ; long delay in appearance of (18621879), 327 n. I ; reasons for slow acceptance of, 213; place of in a scheme of the bionomic uses of colour, 226; logically a section of warning colours, 327 ; mimetic patterns derived from warning and remaining warning, 349 ; protective (pseudaposematic) mimicry is deceptive while Müllerian (synaposematic) is a genuine warning, 360 ; evolution of a hypothetical example of, 329-3I ; associations of, with special (aposematic) protection, 335, 336 ; between models themselves, $211-15$, 222 ; effect of mimics on stability of model in, 336; uniformity in nauseous groups of butterflies, 234, 277-9; uniformity in species of wasps and Fossores, 278, 376; high degree of special protection accompanied by, 335 ; perfect in highest degree when special protection highest, 335,336 ; young enemies and the evolution of, 167, 167 n. 2, 212, 268, 329-31, 366 ; terms 'combination' or 'association' used in connexion with, 293; a combination exhibiting, called 'MimicryRing' by Professor Weismann, 376; methods of defence in the same combination may be various, 2.30 ; more evidence wanted of sirnultaneous occurrence of members of combina- 
tions exhibiting, 248; especially found in female, 244-7 ; mimics exhibiting may extend beyond range of models, 215-18, 247, 349, 381, 382 ; migration and, $363-4$; independent of size, 366,367 ; erroneously supposed not to exist between remote forms, 229-32 ; between groups of various degrees of affinity, 229-34; examples of, probably not truly indistinguishable to enemies except when species are closely allied, 329 ; discriminating features persist even in closest resemblance, 349,350 ; recognition of sexes perhaps specially provided for in, $350,35^{8}$; Dr. F. A. Dixey on Diaposematic or Reciprocal Resem. blance characteristic of, 213,344 , 345 ; Dr. F. A. Dixey on secondary, 345 ; a mimetic common ancestor of divergent mimetic group best explained by, 352, 354; consistent with di- and polymorphism in mimicry, $355,356$.

- Evidence in favour of:-supplied by the tendency of the likenesses to run in groups $(a), 346$; by dominance of mimetic species and groups (b), 346, 347 ; divergent mimicry in species of same group $(c), 347$; warning patterns of non-mimetic males and non-mimetic species of mimetic groups $(d), 347$; occurrence of mimetic species in warningly coloured groups $(e), 347$; mimicry of the non-mimetic males and non-mimetic species of mimetic groups $(f), 347$ : see also $217-18,348$, $349,371,375$; mimics more conspicuous in certain points than models $(g), 347$; closeness of mimicry between the admittedly distasteful groups $(h), 347$.

- Examples of:- - see classification of examples of Müllerian and Batesian (Protective) mimicry, 38393. The examples are not discriminated, inasmuch as the interpretation is still under discussion: see 328 .

MIMICRY, PROTECTIVE AND Aggressive: PSEUdAPOSEMATIC AND PSEUdEPISEMATIC RESEMBLANCES, X. 358-78. For divisions, sections, and sub-sections see 296, 297 ; place of in a scheme of the bionomic uses of colour, 226.
MIMICRY, VARIOUS USES OF TERM: THE ESSENTIAL ELEMENT IN, X. 359-6I.

MIMICRY, PROTECTIVE (BATESIAN) OR PSEUDAPOSEMATIC RESEMBLANCE, X. 361-76. For sections and sub-sections see 296, 297.

- Historical Account of Miillerian Mimicry and:-history of, 220-4 ; recognition of, shown in termination -formis, 221 ; Kirby and Spence (1817) on, 221 ; utility of, suggested by Kirby and Spence, 221 ; W. S. Macleay (1819 and 1821) on, 220; Rev. W. Kirby (1822) on, 220; Boisduval (1836) on, 221; J. O. Westwood (1837) on, 221 ; H. W. Bates (1862) on, 85, 86, 211 , 212,220 , $221,222,223,224,226,327$; theory of, included in cryptic resemblances by, 359; A. R. Wallace (I 866) on, 222, 223, 226, 327; Roland Trimen (1872 and 1897) on, 222, 223 n. 6; Fritz Müller (1879) on, 166-8, 2 I I-1 5, 222-4, 226, 278, 327, 328, $342-4 ; F$. Müller and C. Darwin on sexual selection as cause of, 225, 272 ; R. Meldola (1879 and 1882) on, 223; defence of Müller's theory by, 212, $213,234,278$; F. Moore (1883) on, 223; Blakiston and Alexander (1883, 1884), 328, 329, 329 n. I ; E. B. Poulton (1887, 1890, and 1897) on, 223 ; F. A. Dixey $(1894,1896$, and 1897) on, 213 n. I, 223; support to Muiller's theory afforded by, 213,223 , 343-5; W. F. H. Blandford (1896, I897) on, 343 ; A. G. Mayer (1897) on, 234, 277.

- Study of:-definition of, 358-61 ; place of in a scheme of the bionomic uses of colour, 226; false warning the essential element in, 344,360 ; accidental resemblances distinguished from, 247,257 ; other superficial resemblances distinguished from, 312, 359, 360; confusion caused by term, 140, 361 ; various uses of term, 359,360 ; order in which to undertake the study of, xxv, xxvi, 336; limited examples of studied, 229. 272 ; necessity for study in the field of, 363 ; importance of movements in, 238, 239, 241, 252-4, 256, 257, 368 ; adapted for repose as well as for movement, 360 ; importance of attitude in, 241, 341 ; mimetic sounds, 25 I, 324 ; 


\section{ANALYTICAL INDEX}

space and time relationships of, $247^{-}$ 50; model and mimic may be widely separated provided the enemies can cross the intervening barrier, $217-18,361,382$; both Batesian and Müllerian largely independent of size, 366,367 ; independent of zoological affinity, 229-34, 232-3, 235-7, 336; often closest when affinity is remote, 235 ; essentially superficial, 237-40; mimetic likeness unaccompanied by any other approach, 237-40 ; affects deep-seated parts when superficial likeness is thereby increased, 238,239 ; especially characteristic of female, 215 I7, 244-7, 279, 372-5; special advantages to female of, 246,279 ; ancestral appearance preserved in non-mimetic male, 244-7; Wallace's conditions of, $36 \mathrm{I}, 362$.

- Complexity of:-239; analysed into its components, 240-2 ; made up of colour, pattern, form, attitude, and movement, 24I ; diverse modes of attainment of, 250-67, 280, in members of different Orders, 250$6 \mathrm{I}$, of the same Order, $26 \mathrm{I}-7$; attained in diverse ways in Beetles, $251-2,255-6,257$ n. I, 261-2, in Lepidoptera, 251, 262-6; pigments of mimetic Pierinae different from those of models, 262, 263 ; attained in different ways by Ceria (Diptera), Oberea (Longicorn), \&c., and Membracidae (Homoptera), 280 ; mimetic transparency produced in variety of ways in Lepidoptera, 251, 263-6, $276,365,366$; resemblance not in body but in covering shield of $\mathrm{Mem}$ bracidae, 258, 258 (Fig. 6), 259, 260, 280,369 ; composite resemblance to two objects, 368,369 ; head of model (ant) represented at tail of mimic, 254, 368 ; di- or polymorphism in mimetic species, especially females of, 354, 364,365 n. 1, 372-6; advantage of diand polymorphism in, 354-6, 372 ; seasonal changes of butterflies and, 339-42 ; chiefly seen in imago, but prepared for in the larval and pupal stages, 242-4 ; 'eye-spots' as examples of, 326.

- Inferences as to Origin and Growth of:-pattern of non-mimetic ancestor may determine trend of, 218; favoured by initial resem- blance, 382 ; examples bearing on origin of, 376 ; mimic being younger may present a picture of former condition of model, $364,365 \mathrm{n}$. 1 ; migration and permanence of residence may be inferred from, 363-4; degeneracy of lost scales greatest in best moth mimics of wasps, \&c., $365,366$.

- Evidence in favourof:-evidence for, compared with that for Universal Gravitation, xxvi, 271 ; Lloyd Morgan's observations bearing on, 212 ; evidence of distastefulness in butterfly models, $269,279,279$ n. I ; distasteful moths seized and rejected by wild birds, 284 ; evidence of advantage conferred by, 281 ; evidence that mimicry averts attack, 288 ; insufficient direct evidence of attacks, 268-70 ; indirect evidence of attacks by birds, 281-3: see also evidence and birds.

- Relation to Protective (Procryptic) Resemblance:-relation of, to other resemblances in nature, 225-8; procryptic resemblance closely related to, 225, 226, 312, 314, $315,348,359,360$; combined with procryptic colouring in certain butterflies, 350-4; instantaneous transition from procryptic resemblance to, 367,368 ; suggested interpretation of, as a Syncryptic resemblance, 322 ; distinguished from Syncryptic resemblance, 312, 35961.

- Relation to Müllerian Mimicry:-see also Mimicry Müllerian; Batesian and Müllerian mimicry compared, 211-18, 222-4, 226, $227,329,359-62,370-6$; differences as regard Wallace's conditions of Miillerian theory and, 362 ; gradual predominance of Müllerian theory over Batesian, 212, $213,223,342-4$, 370-6; new interpretation of an old example (H. misippus), $211-18$, 'F. A.' in Punch on, 213-15; Müllerian does not differ from Batesian mimicry in importance of instinct, inferences as to history and migration, independence of size, and confirmation of history by structure, 363; Müllerian mimicry often included in Batesian, 360 ; interpreta. tion as Batesian or Müllerian often 
provisional, 328; Lepidoptera, 348, $370-6$, and Coleoptera, 348 , discussed in relation to Müllerian mimicryand; Protogonius and Elymniinae in relation to, $350-4,372$; Colaenis in relation to, 334 n. 2 ; secondary mimicry probably characteristic of Müllerian mimicry, 345, 345 n. 6 ; mimicry of Hymenoptera in relation to, 376 ; mimicry of snakes in relation to, 376.

- Bearing upon Theories of Evolution of:-supposed transmission of experience and, 166-8; mutation and, xxii-xxvi ; internal causes suggested to account for, 224, 225, 272, but break down when investigated, $227-9,233,236-9,241,245,247$, $249,250,257,260-2,266-8,270,273$, $275,276,278-82$; external or physico-chemical causes suggested to account for, 224, 272, but break down when investigated, $227-9,233,235-$ $42,244,245,248-50,260-3,266-8$, $270,273-82$; contrasted conditions of model and mimic in same locality, $243,244,276$; sexual selection suggested as cause of, 225, 228, 272, but breaks down when investigated, $227,228,233,236,245,246,260,261$, $267,270,273,275,276,278-82$; Common Warning Colours(Müllerian mimicry) and, explained by Natural Selection, Essay VIII, 220-70: see also Essay IX, 27I-82; growth of confidence in interpretation of, by Natural Selection, 218, 218 n. 2, 219, 224; facts of, consistent with interpretation by, Natural Selection, inconsistent with any other suggested explanation, 227-9, $233,235-42,245,246-8,250,258-$ $62,266-70,273,275,276,278-82$; reason for special development in S. America of Müllerian mimicry and, 248.

- Examples of:-see classification of examples of Protective and Müllerian Mimicry, 383-93. (The examples are not discriminated inasmuch as the interpretation is still under discussion: see p. 328.) Batesian or Müllerian interpretation of examples provisional in many cases, 328 ; the clearest examples of Batesian, 367,376 ; development of, in Insecta, 367; captured on one day, in Hope Department, 248, 249; examples in text (except the Leeds series), chiefly selected from Ethiopian and Neotropical Regions, 370 .

MIMICRY OF ADVENTITIOUS OBJECT (PSEUDALlaPOSEMATIC RESEMBLANCE), 377 : see also 359.

MIMICRY AGGRESSIVE, AND ALLURING COLOURS (PSEUDEPISEMATIC RESEMBLANCE), 377, 378 : see also classification of examples of mimicry, 393; place of in bionomic uses of colour, 226; directive characters ('eyespots') may be examples of, 325,326 ; definition of, 358-61 ; false attraction is the essential element in, 360 ; resemblance of Volucella to humblebees, and Asilidae to their victims probably not examples of, 378 .

mira, Myrmoplasta, mimicking ant, 254, 255 (Fig. 3).

misippus, Hypolimnas, female of, mimicking $L$. chrysippus, three forms of female mimicking respectively three forms of model, 355,372 ; three forms of mimetic female transitional, while two out of three corresponding forms of model are sharply marked off, $364,365 \mathrm{n}$. I ; probably a Müllerian mimic, and specially defended, $215-17,247$; dominance of, 216 ; extends beyonds its model into New World, 216, 247, 347; powers of flight, 216 ; swarm of, observed in mid-Atlantic, 216 n. 2 ; conspicuousness of male, 216, 217 ; ancestral appearance of male, 216,245 ; male pattern mimicked by males of two butterflies in W. China far beyond its range, $217,218,381,382$; mimicry of male perhaps due to attacks of migratory birds, $217,218,382$; such a cause, if confirmed, would prove growth of mimicry by selection alone, $36 r$.

Misseltoe, Darwin on the inadequacy of Mutation to account for the, xix.

Misunderstandings arising from term 'Mimicry', I40, 361.

Mivart, St. George, Darwin's reply to criticisms by, 6 .

mneme, Melinaea, exact resemblance of Heliconius numata to, 331 ; parallel transition from barred to black hind wing in both model and 


\section{ANALYTICAL INDEX}

mimic, 331; why considered the model of $H$. numata, 33I-3; far more abundant than $H$. numata, 332 ; abundance of, over Heliconius not necessarily due to greater unpalatability, 332 .

Möbius on Mauritian crabs carrying sea-anemones, 357 ; and Mauritian hermit-crab living in an Ascidian case, 357.

Model OUtranged BY Mimic, X. 349,350 .

MODEL AND Mimic, Both SeXes OF BOTH ALIKE, X. 37 I.

Model, SEXes of DIFFERENT, AND RESPECTIVELY RESEMBLED BY MiMICKING SPECIES, X. 37 I.

MODEL, MIMICRY OF GENERAL APPEARANCE OF GROUP RATHER THAN OF SINGLE, X. 376.

MODELS, MIMICRY OF CRYPTIC, X. 369,370 .

Models, Male and Female

MIMICKING DIFFERENT, X. 372 .

MODELS, TWO OR MORE MIMICKED BY FEMALE, X. 373: see also 374-5.

Models or model (see also Mimicry): resemblance between, 2 II15 ; examples of, far more abundant than their mimics, 332, 333; stability of, influenced by mimics, 336 ; advance of, in direction of mimic, 344 ; range of, exceeded by mimic, 349 ; in one locality mimic, in another, $217,381-2$; one species mimicking two or more, $354-6$; tail of mimic resembling head of, 254, 368 ; Müllerian resemblance no less than Bates. ian implies mimic and, 360 ; mimics may retain a picture of former condition of, 364,365 n. I ; advantages of mimicking two or more, $354-6,372$.

MODERN VIEWS ON EVOLUTION ANTICIPATED BY J. C. PRICHARD, Essay VI, I 73-92.

MOdification, Diagnosis TRAVERSED BY INDIVIDUAL, II. 73-5.

Modification, individual (see also Acquired Characters), definition of, 73 n. 1, 142.

Mogok, Upper Burma, 29 I n. I.

Moisture, see External Causes; Pierinae influenced in pupal or larval state by heat and, 311, 312; in food as suggested cause of wet season broods, 341 .
Mole-like forms in three Mammalian Orders, 312, 359.

molitor, Pachyprora, chasing Tarucus plinius, 283.

Mollusca, in classification, 25; common ancestry with other Phyla, 27 ; evolution in geological time more marked than in lower Phyla, 28; in early Palaeozoic, 30 ; insufficient record of, in the stratified rocks, 42 ; evolution of, 41,42 ; Silurian and Cambrian, 4I, 42 ; environment and, 106 ; procryptic resemblance to coral of, 359 .

Monkeys, brain of compared with man's, 108; terrified by snake-like caterpillar, 367 n. 2.

Monochrome, conspicuousness of, 321.

Monsters formed by experiments on frog's eggs, 129; valueless for the study of evolution, xxxix, xl.

Monstrosities, development of, I 35 , 136 ; hereditary, 135, I36 ; predetermined in ovum, $135,137$.

Moore, Frederick, on Oriental Müllerian mimicry, 223.

Moore, Rev. Aubrey L., on ancient writers on evolution, 54-6.

Moral Reflections at the Natural History Museum, I, F.A., 213.

morania, Papilio, resemblance to Acraea satis, 52 n. I.

More Letters of Charles Darwin, F. Darwin and A. C. Seward, 48,56 n. $4,63,67,68,74,76,78,79$, $80,82,83$ n. $2,84,86,89,174$ n. 2 .

Morfill, Professor W. R., translation of Portschinski by, 254.

Morgan, Professor C. Lloyd, on 'Natural Elimination',105 ; definition of acquired characters by, 142, 143; on instinct, 154 ; on education of birds, 167 ; observations on young birds by, 212,268 ; on trend of human evolution, 170, I7I.

Morgan, Professor T. H., on Roux's experiments, 128-30.

morgeni, Tirumala (Melinda), a mimic of W. African Amauris, 337.

Morphinae (Amathusiinae), ' eyespot' in the mimicked genus, Tenaris, 326 ; as models of the Fastern Elymniinae, 353 .

Moseley, Professor H. N., on Peripatus, 33. 
MOTHS, RECENT DARKENING OF N. ENGLISH, X. 308-IO.

MOTHS AND BUTTER FLIES, CHIEFLY ORIENTAL, Illustrating MIMICRY, 370-6.

Moths (see also Arctiidae, Chalcosiinae, Glaucopidae, Sesiidae, Zygaenidae; see also classification of examples of mimicry, 384-6, 388-92): pigments of, less stable than those of butterflies, xlv; resemblance to leaves of, 299, 302; to splinter, 319 ; to lichen, 359 ; colour of $G$. obscurata in different environments, 307,308 ; seasonal changes of, 311 ; value of bright hind wings of, $303,304,325$; hind wings of, torn as if seized, 304 ; distasteful species of, seized and rejected by wild birds, 284 ; wings of, in nest of Microhierax, 291 n. 1 ; mimicry of butterflies by diurnal, 249 , 250, 275, 276, 372, 376; Müllerian mimics of butterflies, 231-2; Dr. Dixey's discussion of entrance into Müllerian combinations of, 343 ; Müllerian mimics of Erycinid mimics of Ithomiinae, 346; attainment of transparency by, in mimicry of transparent-winged butterflies and $\mathrm{Hy}$ menoptera, 25 1, 266, 365, 366; early recognition of resemblance to $\mathrm{Hy}$ menoptera by, $22 \mathrm{I}$.

MOTIVE FORCE OF InvestigATION, Introd. xlvii, xlviii.

Moulting and seasonal change of colour, 310.

Mountainous country, J. C. Prichard on the horses and cattle of, 189.

MOVEMENTS AND ATTITUDES, IMPORTANCE OF INSTINCTIVE, IN DISPLAY OF WARNING COLOURS, X. 323,324 .

MOVEMENTS AND ATTITUdES, IMPORTANCE OF, FOR MIMICRY, $X$. 363.

Movements (see also flight): importance of, in procryptic defence, 360 ; power of rapid colour adjustment suited to rapid, 304, 305; sudden transition from cryptic to aposematic or pseudaposematic defence caused by, 318-20; importance of, in aposematic defence, 322 ; conspicuousness of slow, 370 ; importance of, as recognition characters, 357,358 ; importance of, in directive marks, 282 ; importance of, in the head-like appearance of Lycaenidae, $325,325 \mathrm{n}$. I ; importance of, in mimicry, 238-9, 241, 25I-4, 256, 257,368 ; in aggressive mimicry, 378 ; aggressive use of, by Hyas, 314.

Moving objects, protective (procryptic) resemblance to, as well as mimicry of, 360 .

Muir, F., direct evidence of attacks by birds on butterflies obtained by, 282 n. I.

mulciber, Trepsichrois, females of, mimic Danaini though themselves models, 334,335 ; females of, mimicked by females of Mel. malelas, 372 ; and with other blue Oriental Euploeas imperfectly mimicked by diurnal moth, Callamesia midama, and allied species, 372,376 .

Mullein Shark Moth, 318, 319.

Müller, Dr. Fritz, interpretation of resemblance between models (Müllerian Mimicry) suggested by (1879), 166-8, 211-15, 222, 223, 226, 278, 327,328 ; on sexual selection as possible cause of mimicry, 225, 228, 272 ; on epigamic scent in male butterflies, 317 ; on 'stink-glands ' of Colaenis, 334 n. 2 ; indirect evidence of birds attacking butterflies obtained by, $270,270 \mathrm{n}$. $\mathrm{r}$.

Müller, Johannes, T. H. Huxley on, III.

Müllerian Mimicry, see Mimicry Müllerian, \&c.

Multiple births of cats, dogs, \&c., distinguished from 'identical 'twins, I33.

Murray, Sir John, on ocean floor, 21.

Museums, necessity for long series in, 75,76 ; as centres of biological research, 77 ; branch tropical biological stations and, 89 , 90 ; storing of epigonic evidence and, 90.

Mutation, MENDElism, AND NATURAL SELECTION : Introduction, xiii-xlviii.

Mutation, DE VRies's EviDENCE IN FAVOUR OF, Introd. xviixxii.

MUtation aND THE Facts OF MIMICRY, \&c., Introd. xxii-xxvi.

Mutation, an old idea, xiv; De Vries on intermittent periods of, $\mathrm{xx}$; definition of, xvii, xvii n. 2 ; known to Darwin, xviii, xix ; in the Vestiges of 


\section{ANALYTICAL INDEX}

Creation, xviii, xix ; does not explain adaptation, xix, xix n. 2 ; Sir W. T. Thiselton-Dyer on cultural conditions and, xxii; evolution by small variations is not, xxxviii, xxxix ; Selection and, I10; Palaeontology and, IIO; Huxley's views on, 195; darkening of N. moths and, 309; doubledayaria as an example of, 309.

Mutations, Variations, and Relationships of the Oenotheras, D. T. Macdougal, A. M. Vail and G. H. Shull, xix n. 5, xxi, xxii.

Mutationists and Darwinians, essential difference between, xxxviii.

Mutilations and Pangenesis, 125 ; not hereditary, 136 ; origin of apparent, 147-9 ; supposed transmission of, discussed and rejected by J. C. Prichard (I826), 180, I8I, 182.

Mycalesis perseus, 291.

Mylothris, ancestral Pierine white retained in males of $\mathrm{S}$. American species of, 240.

Mylothris agathina, 341.

Myriapoda in classification, 33 ; in the Palaeozoic, 34 ; fossil in the Oligocene, 34 ; no approximation of insects towards, in fossiliferous rocks, 38.

Myrmecophana fallax, 256, 257, 257 n. 1, 258 (Fig. 5), 280.

Myrmeleon larva, allanticryptic resemblance of, $3 \mathbf{I} 3$.

3).

Myrmoplasta mira, 254, 255 (Fig.

mystaceus, Phrynocephalus, a lizard with flower-like lures, 378.

\section{$\mathrm{N}$}

Nabis lativentris, 257 n. I.

nadina, Huphina, Müllerian mimicry especially in dry f. of, 342 .

Nansen, Dr. F., on the intelligence of the seal, 116.

Natal (see also Africa, South): recent immigration of $\mathrm{N}$. butterfly species into, $52 \mathrm{n}$. I ; dorippus $\mathrm{f}$. of L. chrysippus in, $71 \mathrm{n}$. I ; preferential mating of butterflies in, 87 ; examples of mimicry from, in Hope Department, 249; attack of fy-catcher on butterfly witnessed in, 283 .

natalensis, Precis, wet season form of $P$. sesamus, 208 ; the dry season form (sesamus) bred from (1898), 208, 339, 340, 340 n. 4 ; attempt to determine the physiological cause of change, 340; under surface similar to but more conspicuous than upper, 339, 340; a rough mimic of an Acraea, 339,339 n. I, 340 ; reasons for supposing a Müllerian mimic of an Acraea, 339; S. African habitat of, 340. natalica, Precis, under side ocellated in wet, procryptic in dry season, 340 ; S. African habitat of, 340 .

Nat. Hist. (Historia Naturalis et Experimentalis, \&c.), Francis Bacon, 55 .

Natural Philosophy, Thomson and Tait, 4 n. 3 .

Natural Selection, On, A. R. Wallace, 51 n. I, 203, 367 n. I, 369.

NATURAL SELECTION, MUTATION, AND MENDELISM: INTRODUCTION, xiii-xlviii.

Natural Selection and MenDELISM, Introd. xxvi-xxxv.

Natural Selection and MenDELISM, NO ESSENTIAL DIVERGENCE BETWEEN, Introd. xxxvi-xli.

Natural Selection, Huxley AND THE THEORY OF, Essay VII, 193-219.

Natural Selection, the Cause OF Mimetic Resemblance and COMMON WARNING COLOURS, Essay VIII, 220-70.

NATURAL SELECTION AND MIMICRY, Essay IX, 27I-82 ; APPENDIX to Essay IX containing evidence of birds attacking butterflies, 282-92.

Natural Selection, Colours PROBABLY ADJUSTED TO ENVIRONMENT BY LOCAL ACTION OF, X. 307,308 : see also $308-10$.

Natural Selection, popular disbelief in, and its cause, xvii, xviii ; creative, xxiii ; Mendelism and, xxvixxxv ; decides between germs rather than individuals, xxxvi, xxxvii, xxxvii n. 1, 135, 183; compared with artificial, xl, xl n. 2, n. 3, xli ; J. B. Farmer on the explanation based on, as a bar to inquiry, xliv-xlvii, xliv n. I, 74 n. 2 ; the stability of pigments in Lepidoptera and, xlv ; rigid selfcriticism required in the study of, xlvii; a fruitful stimulus to inquiry, xlvii, xlviii ; protest against facile speculation based upon, xlvii, xlvii n. I ; Lord Salisbury's criticisms of, 
$2-4$; sexual instinct and, 65 ; renders organisms susceptible to stimulus, 73 ; response to stinulus and, 74 n. 2 ; Huxley's doubts upon, 77-8o ; not the cause of interspecific sterility, $80,89,91$; cessation of, a cause of interspecific sterility, $80-2$; fertility and, 80-2 ; aided by syngamy, 93-4 ; the Darwin-Wallace joint essay upon (1858), 95-7, 194-6: see also xxxvii n. $2,48,58,200,222,379$; does not explain variation, 96-7 ; Lamarck's theory compared with, IOI ; Lamarck's theory confused with, IOI-3, IO4; Duke of Argyll's explanation of belief in, IOI-2 ; diffculty with which apprehended, IOI4 ; parodies on, 102-4; utility and, I05-9; Natural elimination or, 105 ; advantages of name, 105 ; objections to, 105-10; brain evolution and, 1078; Palaeontology and, 107-8 ; origin of organs and, 108-9; a true cause of evolution, I09, 110; mutation and, 110; form of joints and, 112, 113; Crustacean claws and lizards' tails, I13, II 4 ; forms of joints and teeth and, 115 ; instincts and, $116-19,138$, 154-66; cryptic adaptation and, I 54-7; the cocoon-making instinct and, $117,118,157-60,164$; instincts of Fossores and, 118, 119, 160-4; use-inheritance and, 137,138 ; variation and, 137 ; effect of cessation of, 137,138 ; nervous system and, 138 ; variable protective resemblance and, 152-4; struggle in young birds and, 167, 167 n. 2, 168; limited but undoubted use of by J. C. Prichard (1826), 174, 191 ; Huxley and, 193219 ; history of discovery of, 193, 194 ; Huxley's ignorance of, July, 1858-Nov. 1859, 195, 196; Huxley's opinion of, 201,202 ; basis of belief in, 202 ; confirmed by observation of Nature, 202 ; dead-leaf-like butterflies and, 203-6; adaptation in Lepidoptera and, 203-18; seasonal changes in butterflies and, 206-I I ; confirmation of, 218-19; prediction and confirmation as test of, 219 ; Huxley's defence of, 219 ; evidence of advantage conferred by concealment, 288, 289; Hypertely used as an argument against, 302, 303 ; proof of severe struggle in pupal stage of $V$. urticae, 306 ; darkening of N. moths and, 308-IO; seasonal changes and, 206-11, 310, 311, 320, $339-42$; species rather than individual benefited by, 316 ; individual subordinated to species by, 358 .

- Mimicry and:-Essays VIII and $1 \mathrm{X}, 220-82$ : see also $21 \mathrm{I}-18$; the origin of a mimetic likeness and, 218; increasing confidence in, as an explanation of mimicry, 224 ; consistent with facts of mimicry, 225; relation of, to Protective Resemblance and mimicry the same, 227, 237-42, 259 ; criticism of, founded on study of limited examples of mimicry, 229; the interpretation of mimicry when other theories fail, 227-9, 232-3, 235$42,245,246,248,250,258-62,266-8$, $270,273,275,276,278-82$; the interpretation of the fewness of colours in specially protected groups, $234,277-$ 8; the female sex and, 2 I 5-1 7, 244-7, $279,353,372-5$; favourable conditions for operation of, in S. America, 248; production of mimicry in covering shield rather than insect beneath by, 258, 258 (Fig. 6), 259, 280, 369; mimicry by Membracid of ant and leaf carried by it, 259, 259 (Fig. 7), 260, 280, 377 ; the cause of mimicry, 26770 ; belief in because of consistency with facts, 268, 27 I ; evidence of advantage conferred by mimicry, 288 ; Bates's theory of mimicry one first great result of, $36 \mathrm{I}$.

Naturalist in Nicaragua, $T$. Belt, 240.

Naturalist on the Amazons, H. W. Bates, 5I, 5 I n. I.

NATURALIST UPON THE AGE OF THE EARTH, Essay I, I-45.

Naturalist, Natural Selection and the experience of the, 202 .

Nature, xxii, xxxix, xl n. 2, xlvii, $8,11,13,15,19,56$ n. 2,62 n. 1 , 92 , I 40, I 4 I n. 2, I 42 n. 5, I 43 n. I, n. 3,144 n. 2, 1 46, I $52,153,154$, I6i, I63 n. 3,164 n. I, n. $3,165,166$, $167,232,293,329,329$ n. $1,365,371$, 377 n. 2.

Nature stronger than nurture, 1 34, 135.

Nautilidae among the earliest fossils, 5, 30 ; rapid decline of, 41 .

Nearctic, see America, North.

Neave, S. A., on transition between African butterflies, 69 ; results obtained by, quoted in Essay X, 293; 
on mimicry between species of Danaine genus Amauris, 335; on examples of Diaposematic Resemblance, 345 ; on African mimics of L. chrysippus preferring station different from that of their model, 349 ; on terror inspired in natives by African snake-like caterpillar, 367 n. 2 ; discovery of mimicry in planemoides, female f. of Pap. dardanus, by, 374 n. 3.

Neaves, Lord, parody of Darwinism by, 103.

Nebalia, forms allied to in Cambrian, \&c., 39.

Necydalinae, mimicry of Hymenoptera by, 252.

Negroes, unchanged by many generations in United States, 178 ; J. C. Prichard on adaptation to tropics of, I 90 .

Nematophora in classification, 25 ; relation to ancestry of Vertebrata, 26 ; earliest forms of not primitive, 28.

Neobrotica mimicking Diabrotica, 236, 237.

Neotropical Region, see America, South, and America, Central ; the study of mimicry should reach its climax in, xxvi.

\section{Neotropinae, see Ithomiinae.}

Nervous system, see also instinct and intelligence; evolution of, rapid in higher animals, 29; evolution in Mammalian, 107, 108; in man, 108; 'instinctive' mechanisms of the, versus the 'individually acquired', 166 ; in adjustable Protective Resemblance, 305 ; epigamic characters closely associated with, 380 .

Nest of Microhierax with wings of butterflies, \&c., 290, 29I, 291 n. I.

Neuroptera of Commentry Carboniferous, 35-7; unique interest of the social, 52 ; wide difference between the forms of the social, 72.

neustria, Malacosoma, cocoons of, opened by birds, 157 .

Neutralization of Shadow, X. 299-300.

NeUtralization, AdJUSTable, of Shadow, X. 300 .

Neutralization of shadow in Aggressive Resemblance, 313.

New Factor in Evolution, Prof. J. Mark Baldwin, 142 n. 2.
New Guinea, Papilio mimicking Uraniid moth in, 371 ; bower of Amblyornis of, 379.

NEW INTERPRETATION OF OLD EXAMPLE OF MIMICRY, VII. 21 I-I8.

New Phytologist, 74 n. 2.

New World, see America.

Newcomb, Prof. Simon, on loss of heat by the sun, 13 n. 2, I 4 .

Newt, Herlitzka's experiments on egg of, I 30 .

Newton and Gravitation, 97.

Newtonian theory, confirmation of, compared with that of Natural Selection, xxvi, 97, 219, 271.

niavius, Amauris, see also dominicanus; transitional into dominicanus f. at the V. Nyanza, xxxv, 68, 69, 338 ; corresponding changes in Papilionine and Nymphaline mimics, 338 ; mimicked by hippocoon female f. of Pap. dardanus, sub-sp. merope, 338, 374,375 ; niavius figured by Weismann in place of its eastern f. dominicanus, 375.

Niger mouths to Sahara, exclusive occurrence of alcippus f. of $L$. chrysippus from, 321,364 .

nigricornis, Nitocris, mimics $\mathrm{Hy}$ menopteron during life, 363 .

nigrofulva, Eueides, an outlying member of the great distasteful combination of B. Guiana, 332.

Nineteenth Century, IOI.

Niphoninae, mimicry of weevils in isolated section of, 250 .

Nitocris nigricornis, 363 .

Nodosaria, an existing genus in the Carboniferous, 27.

nomius, Papilio, frequenting wet mud, 285 .

Non-Mimetic MaLe: Mimetic FEMALE, X. 372: see also 21 5-17, $244-7,279,347,353,373-5$.

NON-MiMetic ANCESTOR PRESERVED ON ISLANDS, \&C. : REMARKABLE CASE OF PAPILIO DARDANUS (MEROPE), X. 373-6.

North America, see America, North.

North British Review, xl, xl n. 3,3 .

North India, see under India.

North, J.W., A.R.A., assistance in the study of paper rendered by, I72.

North Kanara, experience in, bearing on seasonal forms, $34 \mathrm{I}$. 
Notley, Miss M.E., on pupal stage of $V$. urticae, 306.

Novitates Zoologicae, Tring, xvi, 53 n. 1, 66 n. 2, 77, 85 .

Nuclei of germ-cells in fertilization, $\mathrm{xxxi}, 80-2$; delicacy of mutual adjustment in fertilization, $80-2$; the seat of the germ-plasm, 128.

numata, Heliconius, exact resemblance of to $M$. mneme, 331: see also mneme; probable gradual approach of to $M$. mneme, 332, 333 .

Numbers, effect on mimics of relative, 328-33.

Nummulina in the Carboniferous, 27.

Nyanza, Victoria, see Victoria Nyanza, xxxv, 69, 338, 374, 374 n. 3 .

NYMPHALINAE, PUPAE OF AFFECTED BY GRAVITY, V. I5I, 152.

Nymphalinae (see also classification of examples of mimicry, 383-7): methods of pupation in, 151 ; seasonal changes in, $87,207-8,211$, $310,311,320,320$ n. I, 326, 339-42; eye-spots in wet season forms of, $211,326,340-1$; too exclusive study of mimicry in Pierinae and, 229; darkening of mimetic species of, in the Guianas, 272, 273, 350; mimetic species of, may be Müllerian, 272, 273; unpleasant scent in African species of, 316 ; Dr. F. A. Dixey on entrance into Müllerian combinations of species of, 343; preferring station different from that of model, $L$. chrysippus, 349; combinations of procryptic and mimetic colouring not uncommon in, 350.

\section{0}

Oberea, mimicry of Hymenoptera by, $257 \mathrm{n}$. I ; method of attainment of mimicry by, 280 .

Oberthür, Monsieur Charles, on variation in Heliconia, 69; on the distribution of Athyma punctata and Limenitis albomaculata and their model, and on the females of these species, 381,382 .

obscurata, Gnophos, colour on chalk and on peat of, 307,308 .

Observations on Indian Butterflies, T. R. Bell, 207 n. I : see also $34 \mathrm{I}$.

Observations Selection in Spiders
Family Attidae, George IV. and Elizabeth G. Peckham, 380.

Observations on the Coloration of Insects, Brunner von Wattenwyl, Engl. transl. by E. J. Bles, 256.

Occasional Papers of the Nat. Hist. Soc. of Wisconsin, 252, 253, 380.

Ocean, floor of, 20-2 ; basins, stability of, 21 ; general Protective (Procryptic) Resemblance to, 297, 298.

Oceanic islands, wingless insects in, 18.

ocellatus, Smerinthus, derived chlorophyll passing into eggs and offspring of, 314, 314 n. 2.

ochlea, Amauris, a dominant model in E. Africa, 336.

Odonata (Protodonata) of Commentry Carboniferous, 18,37 .

Odontopera bidentata, 306 .

Odour, see smell.

Odynerus, species of, resemble other Hymenoptera in Australia, 278.

Oecodoma, see Atta.

Oecophylla, mimicry of, by caterpillar, 368.

Oedipoda, value of bright hind wings of, 303,304 .

Oenotheras as the evidence for Mutation, $x i x-x x i i, 4$.

Oenothera cruciata, xxi, xxii, xxxv n. I ; - lamarckiana, $\mathrm{xix}-\mathrm{xxii}, \mathrm{xxxv}$ n. I, 4 .

Of the Causes which have given rise to Varieties in the Human Species, J. C. Prichard, I76, 177.

Of the Relation of particular Varieties of the Human Species to Climates, J. C. Prichard, 19I, 192.

Old World, Euploeini nearly exclusively Austro-Malayan, Danaini in all tropics of the, 333 .

Oligocene, Myriapoda in the, 34 .

omphale, Teracolus, experimentson seasonal forms of, 3II; Müllerian mimicry chiefly in dry f. of, 342 .

On Geological Time, Lord Kelvin, 4 .

On some Diffioulties of Darwinism, Prof. D'Arcy Thompson, 225 n. I.

On the Age of the Sun's Heat, Lord Kelvin, 4 n. 3 . 
On the Law which has regulated the Introduotion of New Series, A. R. Wallace, 194.

On the Reception of the Origin of Species, T. H. Huxley, 196.

On the Secular Cooling of the

Earth, Lord Kelvin, 4 n. 3.

On the Tendency of Varieties to depart indefinitely from the Original Type, A. R. Wallace, 194.

On the Variations of the Evening Primrose, G. A. Boulenger, F.R.S., xix n. 5: see also xxi.

On Variation, see Materials for the Study of Variation, W. Bateson.

Open country in S. Africa, definition of, 340 .

Ophiuroids in early Palaeozoic, 30.

Orchidaceae, self-fertilization of many, 92.

Orchis Bee, self-fertilization of, 64 , 92.

Orders of insects, mimicry between different, 229-31, 250-6I.

Organs, origin of, $108,109$.

ORIENTAL AND OTHER LEPIDOPTERA ILLUSTRATING MIMICRY, X. $370-6$.

Oriental Region: see also Andaman, 373, 373 n. 2 ; Borneo, 257 n. I, $275,276,348,349,353,367$ n. 2 , 369 ; Burma, 286-92, 373; Bombay, 70 n. 2 ; Canara, 70 n. 2 ; Ceylon, 70-1, 285, 286, 349; China, S., 88, 333; Deccan, 70 n. 2; Hambantotte, 70 n. 2 ; Hong-Kong, 88; India, 70, 70 n. 2, 269, 317, 324, 341, 342, $349,363,371-3,376$; Irrawaddy, 291 n. I ; Kala Pani, 285 ; Kandy, 285 ; Karachi 70,70 n. 2 ; Khandalla, 70 n. 2 ; Macao, 88; Malabar, 178, 187; Malaya, 248, 252, 333,367 ; Mandalay, 291 n. 1 ; Mogok, 29I n. I ; Moulmein, 289; North Kanara, 34 I ; Pahpoon, 290; Poona, 70 n. 2 ; Puttalam, 70 n. 2 ; Salween, 289; Siam, 303, 341 ; Sikkim, 373 ; Singapore, 368; Sinzaway, 290 ; Taungyah, 287 ; Tenasserim, 290, 291, 291 n. I ; Thabeitkyin, 29 I n. I ; Thundiani, 285; Trincomalie, 70 n. 2 ; Wabosakhan, 288 ; Yoonzaleen, 290.

- The study of mimicry in relation to, xxvi ; fading in the pigments of certain museum specimens of Lepidoptera from, xlv; A. R. Wallace on mimicry in the, $222 ; \mathrm{F}$. Moore on mimicry in the, 223; uniformity in Euploeini of, $277,333,334$; 'leafbutterflies' (Kallima) of, 203-8, 302, 310; Euploeini nearly restricted to Australian and, 333 ; Precis, seasonal forms of almana of, 340, 341 ; mimicry in the Elymniinae of, 353 ; L. chrysippus in, 70, 364 ; mimetic chafer of, 368 ; blue Euploeas of the, roughly mimicked by diurnal $\mathrm{Chal}$ cosiine moths, 372,376 ; examples of mimicry chiefly selected from Lepidoptera of, 370-6; localities of A. cama in 382 .

Origin of Species, Charles Darwin, xv, xviii, xix, xxii, xxvi, 5, $21,25,46,47,48,57,58,63,67,84$, $91,94,139,162,165,175,175$ n. I, 196, 199, 200, 201, 219, 233 n. 1, 361,379 ; arguments for preCambrian time in, 5 ; definition of species in, 46, 47 ; penetration of ideas of, 48 ; influence on Huxley of, 200-I ; twofold aim of, 200, 201 .

Origin of the Fittest, Professor E. D. Cope, Iog.

OrIGIN OF PUPAL GroOve IN Pierinae, \&c., V. 147-50.

Origin of specific discontinuity, $\mathrm{xv}$, xvi ; importance of geographical distribution for the study of, xvi ; of organs and limbs, 108, 109; of Müllerian mimicry from warning colours, 329-31, 349; of mimicry, examples bearing on, 376 .

Orioles, mimicry of powerful birds by, 367 .

orise, Dismorphia, perfect mimicry of Ithomiinae by, 240, 265, 266 ; method of attaining transparency by, 266 ; Ecuador form of model and mimic, $265,266$.

orithyia, Junonia (Precis), wing of, in nest of Microhierax, 291.

Ornithorhynchus, Song of the, W. J. Courthope, 103, 104.

Orthogenesis der Schmetterlinge, G. H. Eimer, 224.

Orthoptera (see also Acriditidae, Blattidae, Locustidae, Mantidue, Phasmidae): of Commentry Carboniferous, 35-7; great age of, 52 ; mimicking ants, 256, 257, 257 n. I, 258 (Fig. 5), 280; mimicry of leaf- 
carrying ants by, 260 ; procryptic resemblance to leaf of Pterochroza, a genus of, 302 ; value of bright hind wings of Oedipoda, a genus of, 303 , 304 ; colour adjustment of, 307 ; specially defended insects attacked by predaceous, 318 ; colours of procryptic and pseudepisematic, 378, 378 n. 3 ; bug mimicked by larva of, $378 \mathrm{n} .3$.

Osborn, Professor H. F., on early evolutionary ideas, 56 n. 2, I75; on Lamarck and Erasmus Darwin, 141.

Ostracodes in Cambrian and Silurian, 39.

Otter or ancon sheep, sudden origin of, 185 .

Ovipositors possessed by Carboniferous cockroaches, 36 .

Ovun (see also 'germ-cells') : Natural Eelection decides between, xxxvi, xxxvii, xxxvii n. I, 73 n. I, 135, 183; variation predetermined in, 137,183 .

Owl and owl's egg, riddle of the, xxxvi.

Oxford, experiments on colour adjustment of caterpillars at, 306 , 307; colour of Cleonus at Boar's Hill and at Shotover Hill near, 307 ; darkening of moths at, $3 \circ 9$.

Oxford, St. John's College, J. C. Prichard a member of, I73; and gentleman commoner of Trinity College, 173.

Oxford University Gazette (1905), 218.

Oxford University Museum, A. H. Thayer's model in, 299: see also Hope Department.

Oxlip, Bardfield, shown by Darwin to be a true species, xxviii.

Oxlip common, shown by Darwin to be a hybrid, xxviii.

Oxylymma gibbicollis, 237.

\section{$\mathrm{P}$}

Pachyprora molitor, 283 .

Pagurus bernhardus, 356;cuanensis, 357 ; - prideauxii, 357.

Pahpoon, Tenasserim, nest of Microhierax found near, 290.

'Painted Lady' butterfly, 85 .

Palaeacridiidae (Acridiidae) of Commentry Carboniferous, 36, 37.

Palaearctic localities of Athyma and Limenitis mimics of male H. mi. sippus, and their model in British Museum (Leech Coll.), and as given by Monsieur $\mathrm{Ch}$. Oberthür, 382 .

Palaeoblattidae(Blattidae) of Commentry Carboniferous, 36, 37.

Palaeodictyoptera, the Palaeozoic insects, 34, 35 .

Palaeontology, limited records of, I00, I07, 108 ; Mutation and, IIO.

Palaeophonus, possibly an aquatic scorpion, 40.

Palaeozoic, waste and sedimentation in, 16; tranquil deposition in, 17 ; tides, 17; insects, 18, 34-8; corals, 28 ; Graptolites, 28 ; Vertebrata, 30; Mollusca, 30, 4I-2 ; Gephyrea, 30, 42-3; Echinoderma, 30,43 ; Appendiculata, 30 ; Arthropoda, 34-4I ; Myriapoda, 34; Phyllopoda, 39; Malacostraca, 39, 40 ; Phyllocarida, 39, 40; Arachnida, 40, 41 ; Pteropoda, 41, 42 ; Pteridospermeae, 45 ; Gymnosperms, 45 ; Cordaiteae, 45 .

Pallas on origin of domestic animals from more than one wild species, 83,84 .

palliata, Adamsia, carried by Pagurus prideauxii, 357.

palumbus, Columba, fertile pairing with domestic pigeon, 83,84 .

pammon, Papilio, 373 : see polytes.

pamphilus, Coenonympha, 'eyespot ' of, examined by lizard, 2 ro.

Pangenesis, Darwin's theory of, 123 , 124 ; gemmules of, 124-6 ; diagram of, described, 123, 124, 126 ; inheritance of acquired characters and, 123-7; difficulties of, 124-7; mutilations and, 125; transfusion of blood and, 125; grafted tissues and, $125-6$; atavism and, 125 ; useinheritance and, 126; diagram of use-inheritance in relation to, described, 126.

Panmixia, W. Bateson on, xxxvii n. 2.

Pantopoda in classification, 33.

Pantoporia, see Athyma, 382.

Paper, importance of quality of, I 70-2.

Papilio Dardanus (MERope), X. 373-6: see also 57,57 n. I, 71, 72,72 n. I, 337, 338, 354, 355, 370, 371, 373-5.

Papilio agestor, 371 ; - (Drurya) 
antimachus, 366 ; - antinorii, 373, 374,374 n. I, 375; - arcturus, 285 ; - argentus, 57 n. I ; - aristolochiae, 269, 372, 373, 375; - castor, 372 ; caudius, 57 n. I ; - caunus, 291 ; chaon, $372 ;$ - corinneus, $284 ;-$ demodocus, 283 ; - dravidarum, 372 ; - echerioides, 375 ; - erithonius, 288, 291 ; - hector, 373; - humbloti, 373 ; - laglaizei, 371 ; - macareus, 288 ; - meriones, 245, 373; - morania, 52 n. I ; - nomius, 285 ; polyctor, 285; - polytes (pammon), 373 ; - protenor, 371 ; - sarpedon, 288, 290 ; - torquatinus, 57 n. 1 ; torquatus, 57 n. 1 ; - xenocles, 288.

Papilioninae (seealso Papilio: see also classification of examples of mimicry, $385,387-9)$ : compared with Itho. miinae as regards number of colours, 234, 277; as models for Pierinae, 262 ; pigments of, different from those of their Pierine mimics, 262, 263 ; an Indian species of, proved unpalatable, 269; value of 'tails' of hind wings of, 281,282 ; mimetic not attacked by bee-eaters, 288 ; unpleasant scent in African, 316 ; eye-spots of, 326 ; Dixey's evidence of entrance into Müllerian combinations of, $343 ; P$. agestor as probable Müllerian mimic, 371; mimicry in species of, probably Müllerian, $372-3,375$.

Pará, fly from, mimicking Hymenoptera, 257 n. 1 .

Paradise fly-catcher capturing butterflies, 283.

Paradise Lost, John Milton, 56.

Paradise of Birds, W. J. Courthope, 103, 104.

paralekta, Kallima, difference between sexes of, 207 .

Parantica, the Danaine model of E. lais, upper side, 353 .

Parasites, attacks of, on specially defended insects, 318 ; concealed on hair or skin of host, 359.

parasitica, Sagartia, carried by Pagurus bernhardus, 356, 357.

Parents, Prichard on comparison between hereditary influences of, 185 .

Paris, Jardin des Plantes, $O$. lamarckiana originally described from, xxi.

Parodies on theories of evolution, IO2-4.
Part-nuclei of germ-cells concerned in fertilization, $\mathbf{x x x i}, 80-\mathbf{I}$.

Passive, Lamarckism and structures whose use is, 112; development together of active structures and, I 3 ; defence of insects essentially, 156.

Patagonia, J. C. Prichard on height of man in, 187 ; dull colours of animals in, 225 .

Pattern of under surface tends to be the more conspicuous in aposematic species, 323 ; cryptic effect of, 321 ; often similar on the two surfaces of aposematic species, 323 .

Peas, Mendel's researches upon, xxxi-xxxiui.

Peat, procryptic colour of G.obscurata on, 307,308 .

Peckham, George W. and Elizabeth G., on instincts of Fossorial Hymenoptera, $118,162,163$; on ant-like spiders, 252, 253, 253 (Fig. I); on the courtship of Attid spiders, 380 .

Pedipalpi in Carboniferous, 40.

Pénard, Prof. E., direct evidence of attack by bird on white butterfly by, 282 n. I.

Penoa deione, 373.

Pentatomid bug mimicked by caterpillar, 369.

Perforata, six existing genera of, in Carboniferous, 27.

Pericopidae, 264, 266 : see Hypsidae.

Peripatoidea in classification, 33.

Peripatus derived from Chaetopodlike ancestor, 27; ancestral nature of, 33,34 ; no approximation of earliest fossil insects or Myriapods towards, 38.

Perlidae (Protoperlidae) of Commentry Carboniferous, 36,37 .

Permian, Foraminifera, 27.

Perry, Professor John, on the changing shape of the earth, 8 ; on the cooling of the earth, 9-13; on the life of the sun, 14; on Radium and the age of the sun, 15 n. 2 ; letter from Lord Kelvin to, I9.

per saltum evolution, Rothschild and Jordan on, xvi ; Huxley on, 4, 195.

perseus, Mycalesis, wings of, in nest of Microhierax, 291.

perspicillata, Terpsiphone, cap- 
turing Eronia cleodora and attacking Atella phalantha, 283, 284.

Peru, Bolivia, and Ecuador, colours of the chief Ithomiinecentred combination in, $35 \mathrm{I}$; character of under surface of mimetic Protogonius in, 351.

Phaeagarista helcitoides, 232.

phalangium, Stenorrhynchus, alloprocryptic resemblance of, 313 .

phalantha, Atella, chased and injured by fly-catcher, $283,284$.

Phaneropterides, mimicry of ants by, 256, 257,257 n. 1, 258 (Fig. 5), 280.

Phasmidae of Commentry Carboniferous, 36,37 .

philenora, Epicopeia, a mimic (probably Müllerian) of Papilio protenor, male and female respectively mimicking sexes of model, $37 \mathrm{I}$. philippinus, Merops, attacking Pierinae in Ceylon, 285, 286; persistently capturing Catopsilia, 289.

Phillips, Professor John, conversation of, with Darwin on species, 68.

Philosophical Transactions of the Royal Society, I 50, 185, 262.

Philosophie Zoologique, Lamarck, I4I.

Philosophy of the Inductive Sciences, W. Whewell, xlvi n. I. phlaeas, Polyommatus, evidence of preferential mating in, $87 \mathrm{n}$. I.

phryne, Huphina, Müllerian mimicry chiefly in dry f. of, 342 .

Phrynocephalus mystaceus, 378.

Phyllidae, wings of Palaeozoic Protophasmidae resemble those of female, 36.

Phyllocarida in Palaeozoic, 39, 40.

Phyllopoda in Palaeozoic, 39.

Phyllosticta, attacking leaves, 205 n. I.

Physico-chemical causes suggested for mimicry : see External Causes.

Physiological Society, Proceedings of, 314 n. 2.

Physiological Selection, Asyngamy the consequence of sterility according to, 84 .

Physiology, Journal of, 314 n. 2.

Phytophagous beetles (see also classification of examples of mimicry, 390-1): as models comparable with the great distasteful butterfly groups, $236,237$. picata, Synageles, mimicry of ant by, 253, 253 (Fig. I $A$ ).

picipes, Euderces, mimicking ants, 255,255 (Fig. 4), 256.

Pictet, Adolphe, anticipated by

J. C. Prichard, 173.

Pierinae, Origin of Groove in Pupae of, V. I 47-50.

Pierinae (see also classification of examples of mimicry, 384, 386-9: see also Pieris): pupae of, paralleled by those of Zonosoma (Ephyra), 150; attacked by beeeaters in Ceylon, 285, 286; seasonal changes in, 3II, 312, 34I ; Belenois, 311, 312, 34I ; Teracolus, 311, 312, 341, 342; Huphina, 342; Muillerian mimicry in relation to the seasonal changes of, 341, 342 ; chief examples of mimicry adduced by Bates, 213; too exclusive study of mimicry in Nymphalinae and, 229; ancestral white retained in males of mimetic species, 240; especially liable to mimicry, 262; pigments of, different from those of models, 262-3; probably Müllerian mimics, $262,272,273$; method of attaining transparency in, 266; darkening of mimetic in the Guianas, 272, 273; Dr. Dixey's evidence of entrance into Müllerian combinations, 343 ; combination of procryptic and mimetic colouring in, 350 ; an Indian species of, proved unpalatable, 269.

Picris, attack of bird on species probably of, $282 \mathrm{n}$. I.

Pieris brassicae, I 47; - rapae, 93, 1 47, 301 ; - spilleri, 52 n. 1.

Pigeon, fertile pairing of Ring Dove with domestic, 83,84 ; origin of domestic, 83 n. 2 .

Pigments, Natural Selection and the stability of, in Lepidoptera, xlv ; of the Pierinae, chemistry of, 262, 263 ; control of, in adjustable protective resemblance, 305 .

Pigmy hawk capturing butterfly, 289,290 ; wings of butterflies, \&c., in nests of, 290, 291, $291 \mathrm{n} .1$.

Pin-eyed and thrum-eyed primrose, xxvii-xxxiv; Darwin's work on, xxviixxix, xxxiv; Mendelian work on, xxix-xxxi.

Pine Lake, Hartland, Wisconsin, ant-like beetle at, 255,256 . 
Pine-needles, syncryptic resemblance to, 312 .

Pionia, an Arctiid moth mimicking Lycinae, 231.

Pipe-fish, 299.

pisiatorius, Lophius, bright lure of, 378 .

P. L. AND A. (Popular Lectures AND ADDRESSES), Lord Kelvin, I9, 19 n. 2.

Place of Mimicry in Scheme of Defensive Coloration, Essay X. 293-382. For divisions, subdivisions, sections, \&c., of Essay X, see Contents, pp. 293-7.

Plains, J. C. Prichard on the horses and cattle of, 189 .

Planema poggei, 338, 374, 374 n. 3 .

planemoides, the only female f. of $P$. dardanus mimicking (from Victoria Nyanza to W. Coast) a non-Danaine model, viz. Planema poggei, an Acraeine, $338,374,374$ n. 3,375 : see also dardanus.

Plants, land, first appear in Devonian, 44; specialization of earliest, 44, 45 ; wide distribution of, 44 ; evolution in, 44,45 ; seed-bearing appear in Devonian, 45 ; fossil record reveals only small fraction of evolution of, 44, 45 ; response to stimulus of, 74,$75 ;$ dwarfed by wind, 75 ; Asyngamy from cross-fertilization in, 90,91 ; cause of injurious effects of self-fertilization in, $9 \mathrm{I}-4$; variation in, caused by environment, 137 ; adjustable protective (procryptic) resemblance to different kinds of, 305-7.

Plastidozoa (Protozoa), 23-6, 28, 30, 31, 121 : for analysis of text see Protozoa.

plexippus (archippus), Anosia, mimicry proves $\mathrm{N}$. America the ancestral home of, 274, 364; mimicked by indigenousLimenitis(Basilarchia), 274.

plexippus (genutia), Salatura, mimicked by female, and imperfectly by male, of E. caudata, and by female E. undularis, 373 .

plinius, Tarucus, chased by Pachyprora molitor and Pratincola torquata, $283,284$.

Plumes in sexual selection, 379.

Podmore, Rev. I'. St. M., on fertile pairing of Ring dove and domestic pigeon, 83,84 .

poggei, Planema, mimicked by planemoides female f. of Pap. durdanus, sub-sp. merope and polytrophus, 338, 374, 374 n. 3.

POINTS IN THE RESEMBLANCE OF BUTTERFLIES TO DEAD LEAVES, VII. 203-6: see also 206-8, 289, 298-302, 310, 311 , 35 I, 353.

Poison-fang associated with warning characters, $315,316,324-5$.

Polar animals, J. C. Prichard on whiteness of, 187 ; seasonal changes in colour of, $310,313$.

Polar bear the enemy of the seal, 116.

Pole, capture of dorippus f. of L. chrysippus in Ceylon by, 70 n. 2.

polyctor or arcturus, Papilio, attacked by king-crow, 285 .

Polydectus cupulifer, 357 .

Polygonia (Grapta) C-album, 203-5.

POLYMORPHISM AND DIMORPHISM TRAVERSE DIAGNOSIS, II. 70-2.

POLYMORPHISM AND DIMORPHISM IN PROCRYPTIC DEFENCE, X. 3 IO.

POLYMORPHISM AND DIMORPHISM IN Mimicry, $\mathrm{X}$. 354-6: see also 372-5.

Polymorphism, value of, 310.

Polynesia, Euploeini in, 333.

Polyommatus phlaeas, $87 \mathrm{n}$. I.

Polyrrhachis gagates, 255.

polytes (pammon), Papilio, male of, non-mimetic and conspicuous; one female a mimic (probably Müllerian) of $P$. aristolochiae, another of $P$. hector, 373.

polytrophus, the Kikuyu Escarpment sub-sp. of Papilio dardanus, 374, 375: see also dardanus.

Polyzoa in early Palaeozoic, 30 .

Ponera tarsata, 255.

Poona, dorippus f. of L. chrysippus at, 70 n. 2 .

Poplar kitten moth, 158-9.

Popular Astronomy, Simon Newcomb, 13.

Popular Lectures and Addresses (P. L. and A.), Lord Kelvin, 19.

Population, On, Malthus, relation of, to Darwin's and to Wallace's discovery of Natural Selection, 194. 
populeti, Taeniocampa, larvae of, attacked by starlings, $157 \mathrm{n}$. I.

populi, Limenitis, remarkable defence of pupae of, 315, 316 .

Populus nigra, cocoons on bark of, 158, 159 ; - tremula, I $57 \mathrm{n}$. 1.

'Porcupine family', peculiarity of, transmitted, $180,185$.

Porifera in classification, 25 ; in early Palaeozoic, 28.

Porritt, G. T., on darkening of N. moths, 308, 309.

Portschinski on ant-like larva of $S$. fagi, 254 ; on composite mimicry of $S$. fagi larva, 369 ; on pupa of $L$. populi, 316 ; on aposematic attitudes of disturbed Spilosoma, 324 .

POSSIBLE INSTANCE OF OBSERVABLE ChaNGE IN MEMBER OF MÚlLERIAN GROUP SINCE 1825-7, X. 356.

Post-generation of missing embryonic parts, 129.

Potaro River, British Guiana, dominance of Melinaea mineme on the, 332.

Poulton, E.B., definition of acquired characters by, 142, 143 ; on Lamarckism and instincts of Hymenoptera, I $18-9,163-5$; on Müllerian mimicry or Common Warning Colours, 223, 328 ; on mimicry of saw-fly larvae by caterpillars, 238, 239; on ant-like Membracid larva, 259, 259 (Fig. 7), $260,280,377$; on unpalatable forms eaten under stress of hunger, 269 ; on concealment of $C$. pumilus by adjustable neutralization of shadow, 300 ; on attitude of Thecla rubi, 301 ; on enemies of pupae, 306 ; on colour adjustment of larvae, 306, 307 ; on colour adjustment of grasshopper, 307 ; experiments on colours of $G$. obscurata, 308 ; on examples of Diaposematic Resemblance, 345; Müllerian as against a Batesian interpretation of mimicry supported by generalizations of, 346,347 ; suggestion of, that special development of male scent-brands enables the females to recognize males which closely mimic other species, 350,358 , $358 \mathrm{n} . \mathrm{I}$ and n. 2.

Power of Loose Analogy, Duke of Argyll, IOI-2.

prasinana, Hylophila (Halias), colour adjustment of cocoon of, 149.
Pratincola torquata, 284.

Pre-Cambrian evolution, evidence of, $31-3,38$.

Precis, comparison of under sides of wings in dry and wet season forms of, 208, 209, 320, 320 n. I, 339-4I ; procryptic resemblance, e.g. to dead leaf in dry forms of, 205, 208, 320 , 339-4I; mimetic resemblances in wet forms of, 339,339 n. I, 340 ; conspicuousness in wet forms of, 208 , 209, 320, 320 n. I, 339-41 ; eye-spots in wet forms of, 340,341 ; advantage in seasonal changes of, 206-11, 310 , 3II, 320, 339-41 ; attempt to determine physiological cause of seasonal changes of, 340,341 ; captured by bee-eater, 288.

Precis actia, 208, 340;- almana, 340, 341 ; - antilope, 208, 340; archesia, 208, 320, 320 n. 1, 340 ; artaxia, 340 ; - asterie (wet f. of almana), 340-1 ; - ceryne, 340 ; elgiva, 340 ; - natulensis (wet $\mathrm{f}$. of sesamus), 208, 339, 340; - natalica, 340 ; - sesamus, 208, 339, 340 ; tugela, 340.

Predaceous insects, attacks of, on specially defended insects, 318 .

Prediction and verification as test of theory, 202, 219.

Predisposition to morbid affections (e.g. to disorders of the nervous system, to deafness, to scrofulous complaints) inherited, 180 ; what is inherited is not disease but, 183,184 .

PREDOMINANCE GRADUAL OF MÜllERIAN MIMICRY, X, 342-4: see also $212-13,223,370-6$.

Preferential Mating a cause of AsYNGamy, II. 85-8: see also 65.

Preferential mating of butterflies, H. W. Bates on, $85-8$; C. Darwin on, $85-8$; R. Trimen on, $86-8$; of Lepidoptera, T. A. Chapman on, 87 n. 1.

Pre-formation in frog's egg, 128-30.

Pre-localization in frog's egg, conclusions as to, 128-30.

Present Position of Palaeozoic Botany, Dr. D. H. Scott, 44 .

Pretoria, dorippus f. of L. chrysippus at, 71 n. I.

Prichard, James Cowles, life of, 173 ; anthropological discoveries of, 173; anticipation of Adolphe Pictet 


\section{ANALYTICAL INDEX}

by, 173 ; reasons for neglect of illuminating thoughts of, 175 ; inconsistencies in arguments of, 174 n. 2, 175, 1912 ; on the obscure origin of variation, 176 ; contention of, that acquired darkness of complexion cannot be inherited, and is not cause of dark races, 177,178 ; the use of term ' acquired characters' by (1826), 177 , 179 ; on varieties predetermined in the germ, 183: see also xxxvii $n$. I; on comparison between influences of two parents in heredity, 185 ; on origin of domestic breeds, 186,187 ; limited but undoubted use of Natural Selection by, 191 .

prideauxii, Pagurus, carrying Adamsia palliata, 357.

PRIMARY AND SECONDARY MÜLLERIAN MIMICRY; PROTO- AND DEUTEROSYNAPOSEMATIC RESEMBLANCE, X. 345, 346.

Primrose, Darwin's work compared with that of Bateson and Gregory on the, xxvii-xxxiv ; primrose, cowslip, and Bardfield oxlip shown to be true species by Darwin, xxviii, 47,63 .

Principles of Biology, Herbert Spencer, $58 \mathrm{n} .2$. 288.

Prioneris, captured by bee-eater,

PROCRYPTIC AND ANTICRYPTIC COLOURS, X. 297-315. For the various divisions, sections, and subsections see pp. 293, 294.

ProcRYPTIC RESEMBLANCE, $X$. 297-312. See pp. 293, 294 for the various sections and sub-sections.

PROCRYPTIC DEFENCE, POLYMORPHISM AND DIMORPHISM IN, X. 3 IO.

Procryptic Defence, Seasonal DIMORPHISM IN, X. 310-12.

Procryptic colours, see Protective (Procryptic) Resemblance.

Progressus Rei Botanicae, 44.

Promachus iopterus, 257 n. 1 .

pronuba, Tryphaena, derived chlorophyll employed by larvae of, 314 n. 2.

Prophetic instincts of insects, 118 , I19, 155-65.

prorsa, Araschnia, resemblance to Limenitis of, and earlier levana f. to fritillary, 342 .

Protective AND Aggressive MIMICRY, X. 358-78. For the various divisions, sections, sub-sections, \&c., see pp. 296, 297.

PROTECTIVE OR BATESIAN MIMICRY : PSEUdAPOSEMATIC RESEMBLANCE, X. 36I-76. For the various sections, \&c., see pp. 296, 297.

Protective Mimicry, see Mimicry Protective, \&c.

Protective Resemblance, $X$. 297-312. For the various sections, \&c., see pp. 293, 294.

PROTECTIVE RESEMBLANCES, AND AGGRESSIVE, X. 297-315. For the various divisions, sections, subsections, \&c., see pp. 293, 294.

Protective (Procryptic) Resemblance (see also Syncryptic) : defined, 297; place of, in a scheme of the bionomic uses of colour, 226 ; external and internal causes obviously inapplicable as causes of, 227, 228; Lamarckism and, 113; female often better concealed than male, 246 ; protective mimicry a form of, 225, 226, 348 ; parallelism with mimicry, 259 ; mimicry only appears in special subordinate groups of chief groups with, 348 ; included in mimicry by $\mathrm{H}$. W. Bates, but separated by A. R. Wallace, 359 ; distinction between Protective Mimicry and, 225, 226, 358-61 ; mimetic appearance combined with, $319,339-41,348,350-4,367,368$; instantaneous transition from one to the other, $319,367,368$; warning or aposematic defence combined with, 318,319 ; e.g. in cobra, 324 ; transition to aposematic from, $318-20$; transition from aposematic to, in desert (dorippus) f. of $L$. chrysippus, 320 , 321 ; may be more advantageous on pupa than on cocoon, 148, 149; relation to daylight of, 303 ; in C. verbasci larva and imago, 318, 319; in E. jacobaeae larva, 318 ; iridescence and, 322 ; importance of 'sham death' in, 323 ; evidence of advantage conferred by, 288, 289; habits essential for, 353 ; examples of, more ancient than those of mimicry, 246.

protenor, Papilio, male and female of, respectively mimicked by sexes of E. philenora, $37 \mathrm{I}$.

PROTO- AND DEUTEROSYNAPOSEmatic ReSEMblanCE, X. $345,346$.

Protoephemeridae (Ephemeridae) of Commentry Carboniferous, 37. 
Protodonata (Odonata) of Commentry Carboniferous, 37 ; great size of, 18,37 .

Protogonius, changes in species of, in accordance with changes of Müllerian combinations, 338; rough inimics on upper side, beautifully dead-leaf-like on under, $350,35 \mathrm{I}$; imperfect mimicry in all species of, 350,351 ; directive "tails" of hind wing of, 351 ; mimetic upper surface of, effective in flight, 351 ; procryptic under surface of, effective at rest, $35 \mathrm{I}$; Müllerian interpretation suggested by probable mimetic ancestor of, 352 ; Elymniinae compared with, 353, 354 . Protolocustidae (Locustidae) of Commentry Carboniferous, 36,37 .

Protoperlidae (Perlidae) of Commentry Carboniferous, 36,37 .

Protophasmidae of Commentry Carboniferous, 36.

Protophyta compared with Metaphyta, 120.

Protoplasm, unknown origin of living, 95 .

Protozoa, meteoric hypothesis and, 23, 24 ; evolution of Metazoa from, 23,26 ; in classification, 25 ; rate of Metazoan evolution compared with that of, 27-30, 31 ; compared with Metazoa, 120.

Provisional, AdVANTAGES of ADMISSION THAT DIAGNOSIS IS, II. 76,77 .

Provisional Müllerian interpretations, 328.

psamathe, the Ecuador f. of Methona confusa, 265, 266. psaphon, Charaxes, 286.

PSEUDALLAPOSEMATIC

RESEMBLANCE: MIMETIC REPRESENTATION OF ADVENTITIOUS OBJECT AsSOCIATED WITH MODEL, X. 377 : see also $259-60,280$.

Pseudallepisematic Resemblance, examples of, may hereafter be found, 377.

Pseudaposematic

RESEMBLANCE, OR PROTECTIVE (BATESIAN) MIMICRY, X. 361-76. For sections, \&c., see pp. 296, 297 : see Mimicry Protective.

PSEUDEPISEMATIC RESEMBLANCE, OR AGGRESSIVE MIMICRY, INCLUDING Alluring Colours, $\mathrm{X}$. 377, 378: see Mimicry Aggressive, \&c.
PSEUdosematic Resemblance, OR Protective (BATEsian) AND AgGressive Mimicry ; PSEUdAPOSEMATIC AND PSEUDEPISEMatic Resemblances, X. 358-78. For divisions, sections, sub-sections, \&c., see pp. 296, 297: see Mimicry Protective and Aggressive, \&c.

Pseudoseme, directive characters a form of, $325,326$.

psi, Acronycta, uniformity in broods of, $87 \mathrm{n}$. I.

psidii, Thyridia, as model, $264^{-6}$; method of attaining transparency in, 265.

Ptarmigan, protective seasonal change of, 310,313 .

Pterocera, see Volucella, 221, 378.

Pterochroza, resemblance to dead leaves of, 302.

Pterodactyles take place of birds, I8.

Pteropoda, Silurian and Cambrian, $30,41,42$; evolved from Gastropoda, $41,42$.

Pteridospermeae, Palaeozoic, 45; relation to ferns, 45 .

Pterotheca in Palaeozoic, 42.

pulchella, Glenea, mimics Ichneumonid during life, 363 .

pumilus, Chamaeleo, adjustable neutralization of shadow in, 300 ; resemblance of, aggressive as well as protective, $3 \mathrm{I} 3$.

Punch, parody of Darwinism in, 103 ; criticism of Batesian mimicry by F. A. in, 213-I 5 .

punctata, Athyma, of W. China, mimetic of male $H$. misippus, 217, 218 ; male only mimics misippus, 381 ; female differs and resembled by female of $L$. albomaculata, $38 \mathrm{r}$; distribution of, 382 ; probable ancestor of, 382 .

Pupa, position of Pierine, 147 ; fatal effect of abnormal position of Pierine, 148 ; adapted for effective cryptic colouring, 149; individual colour adjustment in, 149, 152-4, 305,306 ; effect of gravity upon, not hereditary, 152 ; value of individual colour adjustment to, 305 ; value of dimorphism in, 310 ; sensitiveness of, in seasonal changes, 311,312 ; derived chlorophyll in, 314 ; of $L$. populi rejected by birds, 315-16.

PUPAE, EFFECT OF GRAVITY UPON SUSPENDED, V. 151, 152. 
PuPAl Groove, ORIGIN OF, IN Pierinae, V. 147-50.

Pupation, method of, in Vanessidae, I 5 I.

Puritan movement opposed to evolution, 56.

Puss moth, I 59.

Puttalam, Ceylon, dorippus f. of $L$. chrysippus at, 70 n. 2.

Pymma tree, nest of Microhierax in, 290.

Pyrameis cardui, 85.

Quagga and mare, supposed enduring effects of cross (telegony), 185.

Quarterly Journal of Microscopical Science, 60 n. 3.

Quarterly Review, 49, 82.

quercifolia, Gastropacha, concealed among dead leaves, 299 ; colour adjustment to lichen, \&c., by larva of, 307.

quercinaria, Eugonia, slight cocoon of, 149, I50; cryptic colouring of larva and pupa of, 149, 150.

$\mathrm{R}$

Rabbits, differences in skeletons of domestic, 76 ; in-and-in breeding and, 93; J. C. Prichard on Angora, 187 ; value of recognition marking of, 357 ; episematic characters of, compared with aposematic of skunk, 358 .

RACES, DIAGNOSIS TRAVERSED BY SUB-SPECIES OR GEOGRAPHICAL, II. 75,76 .

Races, importance in the origin of species, of sub-species or geographical, xvi, 75,76 .

Radiolaria in classification, 25 ; consideration of, omitted, 28.

Radium, life of the sun and, I5 n. 2 ; heat conductivity argument and, 15 n. 2.

Raindrops, prints of, as evidence of uniformity, I9.

rapae, Pieris, in-and-in breeding and, 93 ; pupal groove of, 147 ; choice of resting-site by, 30I.

RAPID ADJUSTable PRotective RESEMBLANCE, X. 304, 305.

Rattle of Crotalus, meaning and origin of, 324 .

Rattlesnake (Crotalus), warning sound of, 324 .
'Rattlesnake', Huxley's voyage in the, 199.

Ray, John, fixity of species and, 56.

RECENT DARKENING OF N. ENGLISH MOTHS, X. 308-10.

RECENT EVIDENCE IN SUPPORT OF Batesian MimicRY, X. 350-6.

Receptaculites in early Palaeozoic, 27.

'Recession towards mediocrity,' I IO.

Recessive and dominant characters, $\mathrm{xxx}$-xxxiii.

Recherches pour servir a l'histoire des insectes fossiles des temps primaires, \&c., Charles Brongniart, 35.

Reciprocal mimicry, see RECIPROCAL WARNING COLOURS, \&c.

RECIPROCAL WARNING COLOURS; Diaposematic Resemblance, $X$. 344,345 : see also 2I 3-I 5, 330, 33 I. RECOGNITION AND WARNING Characters, X. 315-58: see Warning Colours and Signalling Colours. For divisions, sections, subsections, \&c., see pp. 294-6.

RECOGNITION OR EPISEMATIC ChaRACTERS, X. 357,358 .

Recognition characters, place in a scheme of the bionomic uses of colour, 226; defined, 315, 357; warning (aposematic) characters compared with, 357,358 ; sounds and movements as, 357,358 ; scents as, 350 , $358,358 \mathrm{n}$. I ; of Ungulates, e.g. of red deer, 357 , of rabbit, $357-8$; Wallace's interpretation of epigamic characters as, 380 .

Recognition of sexes perhaps aided by discriminating features persisting in closest mimicry, 350; probably aided by special scent-brands of males, 358,358 n. I.

Red deer, recognition marking of, 357 .

REDUCTION OF SHADOW BY Attitude, X. 300, 301 .

Reduviidae, ant-like larva of species of, 257 n. 1 ; mimicked by larva of Hymenopus bicornis, $378 \mathrm{n} .3$.

Regeneration, Professor T. $\mathrm{H}$. Morgan, 128.

regina, Teracolus, mimetic of Belenois in wet season, procryptic in dry, 34I.

Reid, Archdall, on the different 
origin of domestic and natural varieties, $x l$ n. 2.

Relation between Symmetry of Egg and Symmetry of Embryo in Frog, J. W. Jenkinson, 130.

RELATION OF MIMICRY, \&c., TO OTHER RESEMBLANCES IN NATURE, VIII. 225-8: see also 258-9, 312, 358-61.

REMARKABLE ANTICIPATION OF MODERN VIEWS ON EVOLUTION, Essay VI, 173-92.

REMARKABLE EXAMPLES OF MIMICRY, X. 367-9.

Renewal of lost parts, explanation of, 136.

Reorganization of injured parts of egg, 129.

Repair, explanation of, 136.

REPOSE, CHOICE OF APPROPRIATE SURFACES FOR, X. 301 .

Reproduction the foundation of Syngamy and Epigony, 64 .

Reptiles, 26; rapid evolution of brain in higher, 29; the ancestors of birds, 32 ; brain in mammals and, 108; rapid colour adjustment in, 305 .

Research, the ultimate justification of, xlvii, xlviii ; importance of earliest, 197,198 ; educational value of, 198 , 199.

Researches into the Physical History of Mankind, Ed. 2, 1826, J. C. Prichard, 174, 176, and throughout Essay VI, 173-92.

Researches on Mimicry, Erich Haase, 231, 318, 375.

RESEMBLANCE OF BUTTERFLIES TO DEAD LEAVES, VII. 203-6: see also 206-8, 299, 302, 310, 311, 351, 353.

Resemblance, Mimetic, BETWEEN SPECIES OF VERY DIFFERENT SIZE, X. 366-7.

RESEMBLANCE, MIMETIC, CRYPTIC MODELS, X. 369, 370.

RESEMBLANCE, MiMETIC, TO GENERAL APPEARANCE OF UNPALATABle GroUP, X. 376.

Resemblance OF W. Chinese ATHYMa AND Limenitis to MALE OF HYPOLIMNAS MISIPPUS, X. 381, 382: see also $217-18$.

Resemblances, relation between mimetic and other, 225-8, 258-9, $312,358-61$.
'Responsive' characters, 144, 145.

Reticularia (Foraminifera) in classification, 25 ; remarkable persistence in geological time of, 27,28 . rhadamanthus, Danisepa, see diocletianus, 373.

Rhinotraginae, mimicry of $\mathrm{Hy}$ menoptera by, 252.

Rhodesia, dorippus f. of L. chrysippus from S., 71 n. I; ant-like Locustid and models from, in S., 257 n. 1 ; attacks of birds on Lepidoptera witnessed in S., 283, 284: and in S.E. (Gazaland), 284 .

Rhopalocera, see butterflies.

Rhynchophora, see classification of examples of mimicry, 390-I : see Anthribidae, 369, Brenthidae, 369, 370 , Weevils, 250, 261, 307, 369, 370.

Rhynchota, see Hemiptera and Homoptera.

Ridley, H. N., discovery of antmimic with head represented at posterior end, by, 368 .

Ring Dove, fertile pairing with domestic pigeon of, 83,84 .

'Ringlet' butterflies, 2 10.

Robertson, Captain (Major), on larvae of $T$. populeti, 157 n. 1 .

Rock, Conferva-covered, resembled by Macroclemmys, 378 .

Rock Pigeon, 84 .

Rodentia, mole-like forms of, 312, 359.

Rolleston, George, President of Zoological Section British Association, $1870,1$.

Romanes, G. J., hypothesis of 'physiological selection' of, 84 ; on instinct as inherited experience, 118 ; on transfusion of blood and pangenesis, 125 ; on Lamarckism and variable protective resemblance, 152 ; on instincts of Fossorial Hymenoptera, I6o, 16I, I64 n. I ; on instinct as lapsed intelligence, 166.

Roots of grass, protective (procryptic) resemblance to, 323 .

rosa, Crenis, recent entrance into Natal of, $52 \mathrm{n}$ I.

Rosako, Usaramo, E. Africa, antlike bug from, 255 .

Ross, Herefordshire, birthplace of J. C. Prichard, 173.

Ross, Captain James, experiment on seasonal changes of Hudson's Bay Lemming, by, 310. 
Rotation in relation to shape of earth, 8, 9 .

Rothschild and Jordan on per saltum evolution, xvi.

Rotifera derived from Chaetopodlike ancestor, 27; in classification, 33.

Roux, experiments of, on frog's egg, 128-30.

Royal Dublin Society, 12.

Royal Irish Academy, Proceedings of, $314 \mathrm{n}$. I.

Royal Physical Society of Edinburgh, Proceedings of, 303.

Royal Society, Philosophical Transactions of, 150, 185, 262 ; Proceedings of, 262, 314 n. 2.

Royal Society of Edinburgh, Proceedings of, 4 n. 3 .

rubi, Thecla, reduction of shadow in, 301 .

rubripennis, Lygistopterus, mimicked by Lycomorpha latercula, 231.

Rudimentary stalks and sockets of scales in certain mimetic moths, 251, $365-6$.

Rugose corals in Palaeozoic, 28.

rusina, Draconia, resemblance to 'skeletonized' leaf of, 302 .

\section{$\mathrm{S}$}

Saccamina, an existing genus in the Carboniferous, 27.

Sagartia parasitica, 357.

Sahara to Niger mouths, exclusive occurrence of alcippus $\mathrm{f}$. of L. chrysippus from, 321, 364 .

Salamander, $130 \mathrm{n} . \mathrm{I}$.

Salatura hegisippus, 373.

Salatura plexippus (genutia), 373.

salina, Artemia, experiments on, 73,74 .

Salisbury, Rhodesia, dorippus f. of L. chrysippus at, $7 \mathrm{I} \mathrm{n}$. I ; ant-like Locustid and models from, $257 \mathrm{n}$. I ; attacks of birds on butterflies witnessed at, 283, 284 .

Salisbury, the late Lord, objections to Natural Selection by, 2-4, 9, Io.

Salix, Wichura's proof that Mendel's principle is not followed by hybrids of, $\operatorname{xxxv} n$. I.

Salvin, O., on the sexual brands of the Dismorphina, 240; on Ecuador form of $M$. confusa, 266.
Salween R., below Shwègon, Burma, butterflies attacked by birds on, 289.

sambucaria, Uropteryx, slight cocoon of, I 50 ; cryptic pupa of, I 50 ; variable protective resemblance probable in pupa of, $150 \mathrm{n} .2$.

Sand (see also desert): protective resemblance to, $298,307,321$; allanticryptic use of, 313.

Sand-wasps, see Fossores.

Sanders, Cora B., on Burchell's Brazilian butterflies, $53 \mathrm{n}$. I ; on pupal stage of $V$. urticae, 306 .

Sanger-Shepherd, illustrations of mimicry prepared by, $272 \mathrm{n} .2$.

sanguifua, Amesia, with allied Chalcosiine moths, rough Müllerian nimics of blue Oriental Euploeas, 376 : see also 372.

Sarangesa eliminata, 283.

Sargasso Sea, 298.

sarpedon, Papilio, eaten by beeeater, 288 ; captured by Microhierax coerulescens, 289, 290.

satis, Acraea, recent entrance into Natal of, $52 \mathrm{n}$. 1 ; resemblance to Papilio morania of, $52 \mathrm{n}$. I.

Satyrinae, Burchell's Brazilian, 53 n. I ; seasonal changes in, resemble those of other sub-families, 207, 210, $211,310,311,326$; concealment of eye-spots of, during prolonged rest, 210 ; eye-spots in wet season forms of, $210,211,326$; tilt or 'list' of, 289, 300,300 n. 5 ; Elymniinae often united with, 353 .

Saw-flies (Tenthredinidae), larvae of, mimicked by larvae of $E$. versicolor, $238,239,239$ n. I ; sudden assumption of aposematic defence by, 320 .

Scales, diverse modifications of, to promote mimetic resemblance to same transparent Ithomiine models, 263-6 ; mimicry attained by loss of, $251,276,365,366$; by transparency of, $25 \mathrm{I}, 266,366$; degeneracy in lost scales greatest in best mimics of wasps, \&c., 365, 366; great size an element in the loss of, 366 ; of Echis and the production of sound by, 324 .

Scent brands of the male Euploeini, $334 \mathrm{n}$. I ; probable episematic use of, in butterflies, $358,358 \mathrm{n}$. I.

Schmankewitsch, on Artemia salina, 73,74 . 
Schulze, experiments on frog's egg by, 129 .

Schuster, Professor, on internal electric conductivity of earth, I1, 12.

schreiberi, Charaxes, isolated wings the only evidence of, in two countries, 292.

Science, I 59.

Science and the Empire, 169.

Science and the Faith, Aubrey L. Moore, 54 .

Science Progress, 173, 310 n. I ; Author's Paper in, original form of Essay VI, 173.

Sclater, W. L., example of pseudallaposematic resemblance of Membracid larva to ant with its leaf, discovered by, 259 (Fig. 7), 260, 280, 377.

Scorpions, Chaetopod-like ancestor of, 27 ; Carboniferous and Silurian, 30,40 ; perhaps aquatic in Silurian, 40.

Scott, D. H., on evolution in land-plants, $44,45$.

Scudder, S. H., on fossil insects, 35.

Scytasis, mimicry of Hymenoptera by, $257 \mathrm{n}$. I.

Sea-anemones in classification, 25 ; hermit-crabs carrying sponges, Ascidians, and, 356, 357 ; crabs carrying, 357 .

Sea-urchin, see Echinoderm, 130.

Seaweed as covering of Stenorrhynchus, 313-14.

Seal, intelligence of, I 6.

SEASONAL DIMORPHISM TRAVERSES DIAGNOSIS, II. 72, 73.

SEasonal Changes of ButTerFLIES, VII. 206-11 : see also 310-12, 320, 326, 339-42.

Seasonal broods with epigonic not syngamic relations, 72 .

Seasonal dimorphism probably a reaction to stimulus, 73 ; changes of butterflies and Natural Selection, 206-11, 310, 311, 320, 339-42; change of form in butterflies' wings, 206-8, 310, 311 ; change of butterflies in relation to Müllerian mimicry, 339-42.

- Changes in: SATYRINAE, 207, 210, 211, 310, 311, 326. NYMPHALINAE, 211, 310, 311, 326 ; Araschnia, 342 ; Byblia (Hypanis), 87, 341 ;
Kallima, 206-8 ; Precis, 208, 209, 320, 320 n. I, 339-41. Pierinae, 311, 312, 341; Belenois, 311, 312, 341; Teracolus, 311, 341, 342; Huphina, 342. MoTHS, 311 .

- Changes, experimental investigation of physiological causes of, 311 , $312,340,341$; changes of Alpine Hare, Ptarmigan, Hudson's Bay Lemming, 310,313 ; changes aggressive in Arctic Fox and Ermine, 313.

Seasons, difference between the struggle in wet and in dry, 208-11, $311,317,320$.

Secondary mimetic resemblance supports Müllerian interpretation, 345,345 n. 5 ; sometimes closer than primary, 345,346 .

Secondary reptiles, brain of, conpared with Tertiary, 29.

Secondary sexual characters, see Epigamic Characters and Sexual Selection.

Sedgwick, Adam, on Peripatus, 33 ; on relation between acquired and genetic characters, $144 \mathrm{n}$. I.

Seed, Bacon's views on restraining power of, 55 .

Segregation of species, H. W. Bates on, 85-7: see also 65 .

SElection, DiagNosis TRAVERSED BY RESULTS OF ARTIFICIAL, II. 76 .

Selection, J. C. Prichard on the importance of in domestic races, I74, 186.

Selection, Mechanical, 85.

Selection, Natural, see Natural Selection.

Selection, Sexual, see Sexual Selection and Epigamic.

Selenia illunaria, 311.

'Self-adaptation,' failure of, 153; indistinguishable from 'internal developmental force', 153; J. C. Prichard on, 190-2.

Self-bred plants, cause of injurious effects seen in, 9I-4.

SELF-FERTILIZATION, ADAPTATIONS FOR CROSS-FERTILIZATION THE CAUSE AND NOT THE CONSEQUENCE OF INJURIOUS EFFECTS OF, II. 91-4.

Self-fertilization of many Orchidaceae, 92.

SEMatic Colours or WARNING AND Signalling (RECOGNITION) 
COLOURS ; APOSEMATIC AND EPISEMATIC CHARACTERS, X. 315-58. For divisions, sections, sub-sections, \&c., see pp. 294-6.

Sematic Colours (see Warning Colours and Signalling Colours): place in scheme of the bionomic uses of colour, 226 ; defined, 315.

Semper, Karl, on Natural Selection not creative, xxii; letter from Darwin to, 74 .

Senses, Instincts, and Intelligence of Animals, \&c., Sir John Lubbock, 16I.

septentrionalis, Croesus, habits of larvae of, 238,239 ; transition from cryptic to aposematic defence in gregarious larvae of, $319,320$.

serena, Acraea, model of wet $\mathrm{f}$. of B. götzius, 341 .

Serpents, 312, 319, 324, 326, 367, 367 n. $2,368,376$. For analysis see snakes.

sesamus, Precis, seasonal forms of, 208 ; dry form (sesamus) bred (1898) from wet (natalensis), 208, 339, 340, 340 n. 4 ; attempt to determine the physiological cause of change, 340 ; procryptic under surface of, while natalensis is a rough mimic of Acraea, 339, 339 n. I, 340 ; S. African habitat of, 340 .

Sesia (Trochilium), transparency of scales in, 25 I, 366: see also Trochilium, 25 I, 365, 366.

Sesiidae, mimicry of Aculeata by, 25I, 365, 366.

severina, Belenois, experiments on seasonal forms of, 3II-12.

SEVERITY OF STRUGGLE GREATest at Certain Hours, X. 303.

Seward, A. C., on the earliest landplants, 44; F. Darwin and, on Prichard as an evolutionist, I74 n. 2, $175 \mathrm{n} . \mathrm{I}$.

Sex, predetermined in ovum, 133.

SEXES ALIKE OF BOTH MODEL AND MIMIC, X. 371 .
Sexes
DIFFERENT,
MIMICKING MALE,
MALE

FEMALE, X. 371.

Sexes of insects, and Natural Selection, 246, 247; mimicry and the, 215-18, 244-7, 279, 347, 353, $372-5$; recognition between perhaps aided by smell in close mimicry, 358 .
Sexual reproduction, Weismann's interpretation of, 127, 128, 137.

Sexual Selection, EpIgamic Colours, X. 379, 380 .

Sexual Selection: see also Epigamic ; a cause of asyngamy, $65,85-8$; suggested as cause of mimicry, 225, 228,272 ; objection to as explanation of protective resemblance, 227,228 ; objections to as explanation of mimicry, 227, 228, 233, 236, 245, 246, 260, 261, 267, 270, 273, $275,276,278-82$; objections to less strong than to other alternatives to Natural Selection, 236; T. Belt on white patch of male Dismorphina, 240; first suggested by Darwin (1858), 379; difficulty of theory of, 379 ; selection proved by diversity of elements co-operating to produce effect, 379 ; supported by observations on courtship of spiders, 380 ; and of grasshoppers, 380 .

Shadow, NeUTralization OF, X. 299-300: see also 298, 313.

Shadow, Adjustable NeUtralIZATION OF, X. 300.

SHADOW, REDUCTION OF, BY ATtitudE, X. 300, 30I: see also 289.

Shadow, importance in desert of, 298 ; parallelism of main pattern lines of moth with main lines of, 156, 301 ; cast by dead leaves, resemblance to, 299; elimination of, in aggressive resemblance, 313 .

'Sham death', meanings of, 323 , 324; appearance of real death different from that of, 324 ; procryptic in spiders, beetles, caterpillars, 323 : see also 155; aposematic in unpalatable moths, 323,324 .

Shape, relation to general and special protective resemblance of, 297, 298: see also xxiv n. 2.

Sharks, teeth of, on ocean floor, 20 ; in early Palaeozoic, 30 .

Sharp, David, on ant-like bug larva, 257 n. I.

Sheep, Jacob's experiments on, I86; J. C. Prichard on changes of fleece of, in tropics, 190.

Shelford, R., results obtained by quoted in Essay X, 293 ; on mimicry of Hymenoptera by Bornean Longicorns, 257 n. 1, 280; on Bornean Clytinae as models for other Longi- 
corns, 348,349 ; on mimicry by Longicorns of Bornean Rhynchophora, 369 ; on habits of Bornean Brenthidae, 370; on Asilid fly mimicking Xylocopid bee, 276 ; on larvae of Bornean Hymenopus bicornis mimicking bugs, 378 n. 3 ; on mimetic Bornean Chalcosid moths, 275, 275 n. I ; on Protogonius as example of Batesian mimicry, 351 ; on Elymnias lais as a Batesian mimic, with combination of mimetic and procryptic defence, 353 ; on the Elymniinae as examples of Batesian mimicry, $372 \mathrm{n}$. I ; on head of model represented at tail of mimic, 368 ; on snake-like Bornean caterpillar, 367 n. 2 ; on possible former southward extension of Athyma and Limenitis mimics of male H.misippus, 381,382 ; on mimicry of squirrels by tree-shrews, $367 \mathrm{n}$. I.

Shield, caudal, of $S$. fagi larva resembles bug, 369 ; of the Membracidae, mimicry of ant developed in rather than insect itself, 258 , 258 (Fig. 6), 259, 280, 369; in other cases protective (procryptic) resemblance developed in, 258, 259 .

Shrew-like mammal mimicked by posterior end of chafer, 368: see also tree-shrews, 367,367 n. I.

Shrike, Ashy swallow-, capturing butterflies, 286. xxii.

Shull, see Macdougal, xix n. 5, xxi,

Siam, insects' enemies in, 303 ; wet season f. of Precis almana permanent in, 341 .

Sidgwick, Arthur, assistance rendered in the terminology by, $60 \mathrm{n} .3$, 6I n. I, 223, 226, 312 n. 2, 344, 381.

SIGNALLING AND WARNING Colours, \&c., X. 315-58: see also 226. For divisions, sections, subsections, \&c., see pp. 294-6.

SIGNALLING OR RECOGNITION MARKS, \&c., X. 357, 358: see also 226.

SIGNIFICANCE OF CERTAIN Seasonal Changes of ButterFLIES, VII. 206-II.

Sikkim and N.E. India, comparison of mimicry by $E$. undularis in, with that in other parts of range, 373 .

Silicospongiae in early Palaeozoic, 28.
SILKEN LOOP, ORIGIN OF GROOVE FOR RECEPTION OF, IN PIERINE PUPAE, 147-50.

Silken Loop, may be a trace of former cocoon, $\mathbf{I} 48$.

Silkworm, disease of, 136 .

Silurian, life long antecedent to, 5, 6 ; tides, 17: Foraminifera, 27 ; sponges, 28 ; Coelomate phyla, 30 ; specialized forms in, 30,31 ; Cirrhipedes, 39; Ostracodes, 39 ; Entomostraca, 39; Arachnida, 39, 40; Merostomata, 40; scorpions, 40 ; Mollusca, 41, 42 ; Chiton, 42.

Singapore, ant-like spider and caterpillar from, 368 .

Sinzaway Chaung, Tenasserim, 290.

Siphonostoma typhle, 299.

SIZE, MIMICRY INDEPENDENT OF, X. 366 .

Size, independence of, as clear in Müllerian as in Batesian mimicry, 363 ; a question of distance, 366 .

Sjöstedt, Professor Yngve, on alcippus f. of $L$. chrysippus in the Cameroons, $321 \mathrm{n}$. I.

Skeleton, Lamarckism and the Mammalian, II 2.

Skin, J. C. Prichard on advantage of black, I90; protective (procryptic) resemblance to hair or, 359 .

Skunks, warning colours of, 315 ; episematic characters of rabbit compared with, 358 .

Slow Adjustable Protective RESEMBLANCE, X. 304-7.

Small Garden White, see also rapae, 93, 147, 301 .

'Small Heath' Butterfly, 2 Io.

Small Tortoiseshell Butterfly, 306.

Smell, unpleasant, associated with warning characters, 315 ; unpleasant in aposematic butterflies, 316 ; pleasant epigamic in male butterflies, 316,317 ; emission by gregarious larvae of Croesus of, 320 ; aposematic in Colaenis, 334 n. 2 ; recognition by females probably aided by special scent-brands of males, $358,358 \mathrm{n}$. 1 .

Smerinthus ocellatus, 314, 314 n. 2.

Smith, S. S., on origin of skin pigments of dark human races, 176 , 177.

Smoke, effect of, in Lancs. and Yorks. district, 308-10.

Snakes, aggressive (anticryptic) 
resemblance of constricting, 312 ; aposematic sounds of, made in various ways, 324 ; birds mimicking hiss of, 324 ; caterpillars which mimic cobralike and other, 319, 326, 367, 367 n. 2 , 368 , 376; latter mimicry Batesian, 376 ; mimicry of venomous (e. g. Elaps) by harmless, 367,376 .

Soc. de Biol. Paris, 166.

Sockets, loss of scales by rudimentary stalks and, 365 .

Solidity, appearance of, removed by eliminating shadow, 299, 300, 313 .

'Solution' of heterostyled condition arrived at by Bateson and Gregory, xxvii, xxix-xxxiv.

Somali Desert, dorippus f. of L. chrysippus adapted to, $32 \mathrm{I}$.

Somatogenic characters, see Acquired, I10, 127, 142; defined, I22, 123, 140-4 ; less important than blastogenic, I 32-5.

Some Problems of Reproduction, Prof. M. Hartog, 60 n. 3 .

Song in sexual selection, 379.

SOUNDS, WARNING OR INTIMIDATING, X. 324 .

Sounds of warning significance :snakes' hiss, rattle, vibration of tail, swish of serrated scales (Echis) 324; mimetic, of insects, $25 \mathrm{I}$; of birds, 324 ; importance of, in recognition, 357.

South, R., on Palaearctic localities of Hypolimnas, Athyma, and Limenitis, 382.

South Africa, F. Galton, 298.

South, S.E., \&c., Africa, see Africa, South, S.E., \&c.

South African Museum, Cape Town, 87.

South America, see America, South.

South China, see China, South.

South India, see India, South.

South United States, see United States, South.

South-East Rhodesia,see Rhodesia, South-East.

SPACE AND TIME RELATIONSHIP OF MimicRY, VIII. 247-50.

Spanish colonists unchanged after many generations in the tropics, 178.

SPECIAL AGgRESSIVE (ANTICRYPTIC) RESEMBLANCE, 312, 313.

Special Creation a theological dogma, 56, 57; contrasted with evolution by $H$. Spencer, 58 ; Lamarck's theory and, 98.

SPECIAL PROTECTIVE (PROCRYPTIC) RESEMblaNCE, X. 298, 299.

Special Protection, Evidence OF, in APOSEmatic Forms, X. 316, 317.

Special protection accompanied by mimicry, within and without the group, 335 ; often associated with highest perfection of mimicry, 335 , 336.

Specially protected insects, the enemies of, 317,318 .

Species and Varieties, Hugo De Vries, xx n. I.

Species Général des Lépidoptères, Boisduval, 22 I.

Species, What is a? Essay II, 46-94.

SPECIES WITH WARNING COLOURS DEPEND FOR THEIR EXISTENCE UPON THE CO-EXISTence of Palatable Species, $X$. 317.

SPECIES OF VERY DIFFERENT Size Mimetic, X. 366.

Species (see also sterility): Aquinas, St. Thomas, on, 55 ; Augustine, St., on, 55 ; Bacon, Francis, on, 54,55 ; Bates, H. W., on segregation of, 86 ; Bauhin, Kaspar, on, 56 ; Cuvier on, 56 ; Darwin, Charles, definition of, by, 46,47 ; on various definitions of, 59 ; on 'close species', 67 ; attempts to produce physiological species by 79,80 ; Dixey, F. A., on, 56, $62 \mathrm{n} .1$; Huxley, T. H., on, 56 ; on physiological and morphological species, 78 ; Jung on, 56 ; Lankester, E. Ray, on discarding the word, 62 ; on historical criterion of, 63 ; Linnaeus, Carolus, on the fixity of, 54-8; diagnosis of, by, 58; Milton, John, on creation of, 55,56 ; Moore, Aubrey L., on, 54-6; Poulton, E. B., on, 46-94 ; Prichard, J. C., on the comparison of adaptation in varieties and, 189,190 ; Ray, John, on, 56; Thiselton-Dyer, W. T., on, 56,66 ; species and varieties, $47,66-8$; sterility between, $49,59,77-80,80-4,201$; discussion of, best illustrated by insects, 50-4; theological aspects of, 56, 57 ; various conceptions of, 59-63; systematic work not affected by 
disbelief in permanence of, 59 ; subjective element in describing, 59,60 ; diagnosis of, $60,65-8$; interbreeding and, 60 ; structural relationships of, 60 ; syngamic, 60 ; importance of asyngamy in relation to, 60,65 ; descent from common ancestors and, 6I ; synepigonic, 61 ; geographical distribution (Sympatry) and, 62 ; introduction to discussion of, 63-5; constancy a criterion of, 63 ; sterility of hybrids between, 63,64 ; importance of transition in relation to, 64 ; diagnosis of, provisional, $65,76,77$; origin by preferential interbreeding of, 65; asyngamy the barrier between, 65 ; sterility between, caused by asyngamy, 65 ; objective reality of, 65 ; definition by diagnosis of, 65-8; transition underlying diagnosis, 66 ; the subjective element in diagnosis, 66, 67; only strongly defined varieties, 66; discontinuity as a test of, 66,67 ; failure of diagnosis of, 69-76; dimorphism, \&c., and, 70-2; seasonal dimorphism and, $72-3$; individual modification and, $73-5$; geographical races or sub-species and, 75-6; results of artificial selection and, 76 ; provisional conclusions of diagnosis of, 76,77 ; sterility as test of distinction between, 77-80; sterility between certain artificially selected races, 78-80; sterility reduced by domestication, 79 ; attempts to produce physiological, 79, 80; sterility between, caused by asyngamy, $80-4$; by asympatry, 84,85 ; by mechanical incompatibility, 85 ; by sexual selection, 85-8; importance of recording captures in coitu, 87; asyngamy from breaking of syngamic chain, 88; subordination of the individual to the, 316,358 .

Specific Stability and Mutation, Sir W. T. Thiselton-Dyer, xxii. 324.

'Spectacles' of Cobra, meaning of,

Spencer, Herbert, great demands for pre-Cambrian time made by, 7 ; evolution and special creation contrasted by, 58; Lamarck's theory and, 98 ; on survival of the fittest, 102.

Sphex, stinging ganglia of insect prey, I6I : see also $118,119,160-4$.
Spiders, remote ancestor of, Chaetopod-like, 27 ; Carboniferous, 40 ; 'sham death' of, 323 ; mimicry of ants by, 252, 253, 253 (Fig. I), 368 ; methods by which mimicry of ant is attained by, 252, 253, 253 (Fig. I) ; colour adjustment of flowerhaunting, 307; courtship of, 380 .

spilleri, Pieris, recent entrance into Natal of, $52 \mathrm{n}$. 1 .

Spilosoma mendica, 324 ; - urticae, 324 .

Spirialis appears in Tertiary, 42.

splendens and irawada, Isamia, and other blue Oriental Euploeas roughly mimicked by diurnal Chalcosiine moths, 376 : see also 372 . Splinter of wood, protective resemblance to, 319.

Spolia Zelanica, 300.

Sponges in classification, 25 ; long persistence with little change of, 28 ; sea-anemones, Ascidians, and, carried by hermit-crabs, 356,357 .

Spontaneous tendencies are alone hereditary, J. C. Prichard (1826), 183.

Squirrels, value of tails of, 325 ; mimicked by tree-shrews, 367 , $367 \mathrm{n}$. I.

Stability of Lepidopterous pigments and Natural Selection, xlv.

Stalks, loss of scales by rudimentary sockets and, 365-6.

Standfuss, M., on Melanism, 3 IO n. I; on seasonal changes of Lepidoptera, 311 .

St. Anne's-on-the-Sea, N. Lancashire, C. Bailey's study of $O$. lamarckiana at, xxi.

Starlings attacking $T$. populeti larvae, 157 n. I.

Static conditions, slow colour adjustment a response to, 305-7 ; syncryptic resemblance caused by similarity in, 312 . 369 .

Stauropus fagi, 253 (Fig. 2), 254,

Stems, protective resemblance to, 299; aggressive resemblance to, 313.

Stenorrhynchus phalangium, 313. STERILITY AS A TEST OF SPECIES, II. 77-80: see also 59.

STERILITY BETWEEN SPECIES AN INCIDENTAL CONSEQUENCE OF ASYNGAMY, II. 80-4: see also 65,91 . 


\section{ANALYTICAL INDEX}

Sterility, of hybrids, bearing of Darwin's work on heterostyled plants upon, xxviii, 90, 91 ; between species, 49 ; difference between Darwin's and Wallace's views on, $49,80,89$; between Darwin's and Huxley's views on, $49,77-80,82,201$; of hybrids, $63,64,77,78$; between species characteristic, but between domestic races very rare, 7780 ; between certain artificially selected races, 78-80; reduced by domestication, 79; attempt to induce by selection, 79,80 ; not due to Natural Selection, 80, 89 ; causes of, $80-2$; germinal causes of, $80-2$; various causes of, 81 n. I ; possible between ends of 'syngamic chain', 89; incidental rather than selected, 91 ; crossfertilization and, 90, 91: see also xxviii; not a test of specific distinctness, 91.

Sticks, protective (procryptic) resemblance to, 370 .

Stictoploea harrisi, 372, 376.

Stillness essential in protective resemblance, 298.

Stimulus and Mechanism as Factors in Organization, J. B. Farmer, 74 n. 2.

Stimulus to inquiry, interest as a, xliv-xlvi.

Stimulus of light in adjustable protective resemblance, 305 ; experimental investigation into seasonal changes and physiological, 311, 312, 340-2.

Sting, associated with warning colours, 315, 316; no defence if food scanty, 317; hardness as a defence, compared with smell, \&c., and, 370.

Stinging insects, Batesian mimics of, 376; Müllerian mimics of, 376 : see also 230-1; sce also bees, Fos. sores and wasps.

Stockholm Natural History Museum, type f. of L. chrysippus from Cameroons in, 321 n. 1 .

Stone, protective (procryptic) resemblance to, 298,301 .

Stonechat, South

Lycaenid chased by, 284 .

African,

Stratified rocks, thickness of, 16 ; lapse of time during deposition of, I6, I7 ; uniformity of conditions during deposition of, 17-19.

Stray Feathers, 290. strigosa, Acronycta, fertile with wild but not with bred males, 87 n. 1 .

STRIKING EXAMPLES OF MÜLLERIAN MIMICRY, X. 33I-6; (a) THE NEW WORLD, 33I-3; (b) THE OLD WORLD, 333-6.

Stripes of zebra, invisibility produced by, 298.

STRUGGLE FOR LIFE, HOURS WHEN MOST SEVERE, X. 303.

Struggle for life : see also Natural Selection; a factor of selection, 96 ; utility in the, 105-9; Palaeontology and, 107-8; conditions of, in insects, II7, I55-7; especially severe in winter, 148 ; in the dry season, I48, 208-11 ; during pupal period, 157-60; in young birds, 167,167 n. 2, 168; insufficiently appreciated by J. C. Prichard, I91 ; in S. America, 248 ; curious evidence of, 291, 292 ; imperfect knowledge of details of, 302,303 ; complexity of, 323; effect upon insect life of enemies', 328.

Strutt, Hon. R. J., on radium in rock, 15 n. 2.

STUdy of Adaptation STIMU. LATES AND DOES NOT BAR INQUIRY, Introd. xliv-xlvii : see also 74 n. 2.

STUDY OF INSECTS AND QUESTION 'ARE ACQUIRED CHARACTERS HEREDITARY?' Essay $V$, I 39-72.

Stylops, effect of, upon bees, 380 .

subbuteo, Falco, Terias found in stomach of, 284 .

Suberites domuncula, 357.

SubJective JuDGemeNT OF

DisconTINUITY, Introd. xvii.

SUB-SPECIES OR GEOGRAPHICAL RACES TRAVERSE DIAGNOSIS, II. 75-76.

Sub-species, importance for the study of evolution, of geographical, xvi ; united by syngamy, 75,76 .

Sucking, an instinctive action, 117. Sudan, ant-like Locustid from, 256, 257, 258 (Fig. 5), 28 o.

suffocans, Mephitis, warning colours of, 315.

sulcirostris, Cleonus, colour adjustment probable in, 307.

Summa Theol., St. T. Aquinas, 55. 
Sun, life of the, 13-15; radium and life of, 15 n. 2 ; hypothesis that the colours of human races have been caused by, 176; pinhole images of, said to be resembled, 313.

Superfluous causes, elimination of, 113 .

Supernumerary digits markedly hereditary, I80, 185.

SURFACES, ChOICE OF APPROPRIATE FOR RESTING ON, X. 3OI.

SURFACES, VALUE OF BRIGHTLYCOLOURED, CONCEALED DURING REST, X. 303, 304 : see also 325.

Surinam, examples of mimicry in, 235 ; darkening of mimetic butterflies in, 272.

Survival of the fittest, see Natural Selection, 102.

Swainson, W., letters from W. J. Burchell to, 49 n. 3 .

Swallows attacking butterflies in S. Africa, 284 .

Sivallow-tail butterfly, eye-spot of, pecked by kestrel, 210.

Swallow-tail butterfly, value of 'tails' of hind wings of, 281, 282.

Swallow-tail Moth, 150.

'Swamping effect of inter-crossing', importance of Mendelian principle in preventing, xxxiv, $x x x v$; Darwin impressed by Fleeming Jenkin's argument upon, $x l, x l$ n. 3,3 .

Swine, J. C. Prichard on Cuban, 187 ; relation to localities of, $189,190$.

Swinhoe, Col. C., on dorippus f. of L. chrysippus in India, 70 n. 2.

swinhoei, Merops, capturing butterflies, $287,288$.

Swynnerton, C. F. M., attacks on butterflies and birds witnessed by, 283,284 .

Sykes, Mark L., on means by which transparency may be attained and on different forms of scales in mimetic Lepidoptera, 366 n. I.

Symmetrical injuries to wings of Lepidoptera, $281-3,325$ : see also 270, $270 \mathrm{n}$. I.

Sympatric groups, 62 .

Sympatrid, 6r n. I.

Sympatriote, 61 n. I.

Sympatry, definition of, 62 .

Symphaedra dirtea, 291.

Synageles picata, 253 (Fig. 1. A).

SYNAPOSEMATIC OR COMMON WARNING COIOURS (MÜLLERIAN
MIMICRY), X. 327-56. For sections and sub-sections see pp. 295, 296.

Synaposematic Defence, SeaSONAL TRANSITION FROM CRYPTIC TO, X. 339-4I.

Synaposematic Defence, SeaSONAL TRANSITIONS IN, OR FROM Aposematic TO, X. 34 I, 342.

Synaposematic Resemblance: see Mimicry Müllerian : introduction of term (1897), 223, $328 \mathrm{n}$. I.

SYNCRYPTIC OR COMMON PROTECTIVE RESEMBLANCE, X. 312.

Syncryptic Resemblance, 312, 312 n. 2, 359, 360 n. I ; definition of, 312 ; distinguished from mimicry and common warning colours, 312, 359, 360; analogy with syntechnic resemblance, 312 ; suggested as interpretation of mimicry, 322 .

Syndiagnostic groups, 60.

Synemosyna formica, 253 (Fig. 1. B).

Synepigonic groups, 6I, 61 n. I : see also epigony ; of Pap. dardanus (merope), 72, 72 n. 1 .

Syngamic Chain, Asyngamy as A CONSEQUENCE OF THE BREAKING OF, II. 88-90: see also 94.

Syngamic groups, 60.

SYNGAMY UNDERLIES DIAGNOSIS, II. 68,69 .

Syngamy, definition of, 60 ; history of word, $60,60 \mathrm{n} .3,61 \mathrm{n} .1$; proposed by $M$. Hartog to replace fertilization, 60 n. 3 ; E. B. Poulton's use of, 60,60 n. 3 ; summary of significance of, in study of species, 64,65 ; as test of species when diagnosis fails, 69 ; in Limnaschrysippus, 70, 71; in Pap. dardanus (merope), 72 ; rare between individuals of the wet season brood and the dry, 72-3: sub-species united by, 75,76 ; the test when structural differences are great, 76 ; importance of, to the systematist, 77 ; implied in transition, 84 ; mechanical prevention of, 85 ; widespread in $P$. cardui because of powers of dispersal, 85; preferential, 85-8: see also 65 ; cross-fertilization and, 9I ; advantages of, 93, 94 .

Syntechnic Resemblance, 312, 312 n. $2,359,360$ n. I ; definition of, 312 ; analogy with syncryptic, 312 ; distinguished from mimicry, \&c., 312, 359, 360 . 


\section{ANALYTICAL INDEX}

Syphilis, apparent hereditary transmission of, explained by ' $\mathrm{a}$ peculiar mode of infection' (I826), 184.

Systematic work, provisional nature of conclusions of, 76,77 .

Systematist, continuity the difficulty of the, xv, 59, 60, 67; how affected by views of the Origin, 46 , $47,59$.

\section{$\mathrm{T}$}

Taeniocampa populeti, I57 n. I.

Tail of lizard and Lamarckism, I14; directive value of lizard's, dormouse's, and squirrel's, 325 ; warning sound made by vibration of snake's, 324 ; head of model resembled by mimic's, 254, 368.

Tails and ears, mutilation of, not hereditary, 180, I8I.

'Tails' of butterflies' wings, value of, 281, 282, 325, 325 n. I, 351.

Tait, Professor, on the age of the earth, 2, 8, 15, 24; on the cooling of the earth, II, 12 .

Tardigrada in classification, 33.

tarsata, Ponera, with ant-like bug, $254,255$.

Tarucus plinius, $283,284$.

Ta-tsien-lu, W. China, home of mimics of male H. misippus, 217: see also 382-3.

Taungyah Pass, Dawnat Range, Burma, 287.

Teeth, Lamarckian interpretation of forms of, 114, 115 .

Tegetmeier, W. B., breeding experiment suggested by Darwin to, 79.

Telegony, supposed example of, 185. 276.

Telephoridae mimicking Lycidae,

telesiphe, Colaenis, a mimic of a rarer Heliconius, 334 n. 2.

telesiphe, Heliconius, though rarer, the model of $C$. telesiphe, 334 n. 2.

temminckii, Macroclemmys, with worm-like lures, 378 .

Temperature (see also External Causes): increment of, with depth into earth's crust, Io; a stimulus to change in the pupae of moths, 311 ; of Byblia, 34I ; of Araschnia, 342 ; seasonal changes of Pierinae effected by moisture and, 311, 312.
Tenacity of life and warning colours, 316.

Tenaris, 'eye-spots' of, 326 ; much mimicked (by Elymniinae, Hypolimnas, and Papilio), 326.

Tenasserim, nests of Microhierax with insects' wings found in, 290, 29I, 291 n. I.

Tenthredinidae, see Saw-flies, 2389, 320.

Teracolus, seasonal changes in, 3I I, 312, 34I, 342; experiments on physiological cause of seasonal changes in, 31 I, 312; combination of procryptic and mimetic colouring in, 341, 350 .

Teracolus achine, 311, 342; antigone, 342 ; - etrida, 231, 349 ; - evenina, 342 ; - omphale, 311 , 342 ; - regina, 341 .

Teratology, the material of, valuable for study of individual development, valueless for evolution, xxxix, $\mathrm{xl}$; Prof. Windle on, $136 \mathrm{n}$. 1 .

Terias, found in stomach of Falco subbuteo, 284.

Terias hecabe, 288.

Ternate, Moluccas, Wallace discovers Natural Selection at, 194-5.

Terpsiphone perspicillata, 283.

Terrapin, with worm-like lures, 378.

Terror, in man and animals, inspired by snake-like caterpillars, 367 367 n. 2,368 .

Tertiary, brain of Secondary reptiles compared with, 29; brain of later mammals compared with early, 29 ; oldest Pteropoda not known before, 42 .

tessellata, Melia, carrying seaanemones, 357 .

Tettix, mimicry of leaf-carrying ant by, 260 .

Textularia, an existing genus in the Carboniferous, 27.

Thabeitkyin, Upper Burma, 291 n. I.

THAYER, CRITICISM OF THE STATEMENT THAT ANIMALS ARE CoNspicuOUS BY, X. 32I-3.

Thayer, A. H., results obtained by, quoted in Essay X, 293; on resemblances to dead leaves, 299; on neutralization of shadow, 299, 300 ; adjustable form of principle of, 300 ; on conspicuousness of the 
monochrome and cryptic effect of pattern, $321-3,321$ n. 3 ; on cryptic effect of iridescence, 322 ; mimicry interpreted as syncryptic resemblance by, 323 .

Thecla rubi, 301 . 69.

thelxiope, Heliconius, varieties of,

TheORIES OF Eyolution, Essay III, 95-II9.

THEORIES OF HEREDITY, Essay

IV, I20-38: see also 142 n. 1 .

THEORIES OF MIMICRY, Essay

VIII, 220-70.

THEORY OF NATURAL SELECTION AND T. H. HuXLEY, Essay VII, I93219.

Theory of the Origin of Varieties, J. C. Prichard, I 85-7.

Theory, the Evolution, A. Weismann, Eng. transl., I64 n. 2, 375.

Thiselton-Dyer, Sir W. T., on mutations due to cultural conditions, xxii ; on Deductive Biology, xlvii, xlvii n. I ; on older writers on species, 56 ; on diagnosis of species, 66.

Thompson, D'Arcy, on Laws of Growth, 224, 225.

Thomson, Sir W., see Kelvin, Lord.

'Throwing back', see atavism, 125.

Thrum-eyed and pin-eyed primrose, Darwin's, Bateson's, and Gregory's work on, xxvii-xxxi.

Thundiani, king-crow attacking butterflies at, 285 .

thyodamas, Cyrestis, eaten by beeeater, 288.

Thyridia psidii, 264, 265.

thysa, Belenois, Müllerian mimicry of Mylothris far more developed in dry than in wet f. of, 341 .

Thysanoptera of Commentry Carboniferous, 35 .

tibullus, the E. sub-sp. of Papilio dardanus (merope), 337, 338, 374, 374 n. I, 375 : see also dardanus.

Tidal retardation, 7,8 .

Tides, did not prevent tranquil deposition in Silurian, I7.

Tiger, aggressive resemblance of, 313.

Time aND SPace RelationSHIPS OF MIMICRY, \&C., VIII. 247-50.

Times, 78.

Tirumala (Melinda) morgeni, 337.
Tissues, animal, derived from cells, I21.

Tithorea, resemblance of Heliconius to, 235.

tityus, Haemorrhagia, loss of scales by, 365 .

Tobacco, Kölreuter on varieties of, 78.

Tongue, worm-like lures of Macroclemmys beneath, 378 .

Toro, W. Uganda, overlapping of eastern Danaine (Amauris) and western Acraeine (Planema) models in, 338 .

Toronto meeting of the British Association (1897), 263.

torquata, Pratincola, chasing Tarucus plinius, 284.

torquatinus, Papilio, W. C. Hewitson on, 57 n. I.

torquatus, Papilio, W. C. Hewitson on, 57 n. I.

Tradition as an incentive to research, xlii; paper the material basis of, $170-2$.

Training, results of, not hereditary, I36.

Transfusion of blood and pangenesis, 125.

TRANSITION FROM CRYPTIC TO Aposematic Defence, X. 318-20.

TRANSITION GEOGRAPHICAL FROM APOSEMATIC TO CRYPTIC DEFENCE, $X$. 320-I.

Transition, importance to the systematist of, 64: see also Continuity, xiv, xv; the foundation of diagnosis, 64; diagnosis and, 66; as a test of varieties, 66,67 ; subjective element in, 66, 67; Huxley's belief (1859) that species are unconnected by, 195.

Transitions seasonal, in modes of protection, 320, 339-42.

TRANSMISSION OF ACQUIRED Characters, Bearing of StUdy OF INSECTS UPON, Essay V, 139-72.

TRANSMISSION OF ACQUIRED CharaCtERS (EXPERIENCE), BEARING OF INSECT MIMICRY AND WARNING COLOURS UPON, V. I66-8.

TRANSMISSION OF ACQUIRED Characters IMPLIED BY THE THEORY OF EXTERnal CaUses, VIII. 267.

Transmission of Acquired Characters by heredity : see also Acquired 
Characters; essential to Lamarck's theory, 99; forms of teeth and, 114 , II5; forms of joints and, I12, I14, 115; the germ-plasm and, 131-2; discussed and rejected by J. C. Prichard (1 826), 177-84; required by the interpretation of mimicry by the theory of external causes, 267.

Transmutation of species, Huxley's belief in (1859), 195; older beliefs in, 54-6.

Transparency, attained in diverse ways in Lepidoptera, 263-6 ; by loss of scales in mimetic moths, 25 I, 276, 365 ; by transparency of scales, 251 , 266,366 ; in oceanic forms, 298.

Tree-shrews mimicking squirrels, 367,367 n. I ; distasteful qualities of, $367 \mathrm{n}$. 1 .

Trees, fossil, as evidence of uniformity of conditions, $18,19$.

Trepsichrois mulciber, 372, 376.

Trias, appearance of Limulus in, 40 .

tridens, Acronycta, uniformity in broods of, $87 \mathrm{n}$. I.

Trilobites among the earliest fossils, 5, 30; preserved with antennae, 17, 39; ancestral position of, 38,39 ; dominance of, in oldest rocks, 39 ; rapid decline of, 41 .

Trimen, Roland, on recent changes in the distribution of African butterflies, 52 n. I ; discovery of mimetic females of Pap. dardanus by, 57, $57 \mathrm{n.} 1$; on dorippus f. of L. chrysippus in S. Africa, 71 n. 1 ; on preferential mating of African butterflies, 86-7; on seasonal forms of Hypanis (Byblia) acheloia, 87 ; on tropical biological stations, 89,89 n. I, 90 ; on African mimicry, 222 ; on African Müllerian mimicry, 223 n. 6; on Müllerian mimicry of Aletis, \&c., for L.chrysippus, 232 ; description of planemoides female f. of Pap. dardanus by, 374 n. 3 .

trimeni, a primitive female f. of the Papilio dardanus group, 374, 375 ; roughly mimicking Amauris niavius f. dominicanus, 374 n. 2 : see also dardanus.

Trincomalie, Ceylon, dorippus f. of $L$. chrysippus at, 70 n. 2.

Tring Zoological Museum, researches on geographical distribution at, xvi; specimens of $L$. chrysippus in, $321 \mathrm{n}$. 1 .
Trinidad, examples of mimicry in, 235 ; colour of the chief Ithomiinecentred combination in, 350 ; character of under surface of mimetic Protogonius in, $35 \mathrm{I}$.

trinodosus, Heteronotus, mimicry of ant by, 258 (Fig. 6), 259.

Tristram, Canon H. B., on colours of desert animals (1859), 195, 196.

Triton, see newt, 130 .

Trochammina, an existing genus in the Permian, 27.

Trochilium (see also Sesia): method of attaining transparency in mimicry of wasps by, $251,365,366$.

Trochilium (Sesia) apiforme, 365 ; - crabroniforme (bembeciforme), 366.

trophonius, a female $\mathrm{f}$. of the Papilio dardanus group, mimicking Limnas chrysippus, 374, 374 n. I ; bred from female forms trophonius and hippocoon, 72 n. I: see also dardanus.

Tropical America: see America, Central and South.

Tropics, change of fleece in, 190.

Tryphaena, value of bright hind wings of, 303,304 .

Tryphaena pronuba, 314 n. 2.

Tschermak, rediscovery of Mendel's principle by, xxix.

Tse-tse fly, limit imposed on higher animals by, 100 .

tugela, Precis, under side procryptic in both wet and dry seasons, 340 ; S. African habitat of, 340 .

Tunicates, uncertain ancestry of, 26.

'Tussocks', fine branched hairs of, 325 ; defence afforded by, 325, 326.

Tutt, J. W., on darkening of $\mathrm{N}$. moths, 309, 309 n. 1 .

Twins, see 'identical' twins.

Twins with differences greater than between ordinary brothers and sisters, 135 .

Twigs, protective (procryptic) resemblance to, 298, 299; procryptic resemblance to swaying, 360 .

Tylor, Professor E. B., on origin of implements, 109 ; life of J. C. Prichard by, 173.

typhle, Siphonostoma, concealed among leaves of Zostera in shallow water, 298, 299.

tytia, Caduga, mimicked by Pap. agestor, 371 . 
$\mathrm{U}$

Uganda, overlapping of eastern Danaine (Amauris) and western Acraeine (Planema) models in, 338.

Umbelliferae, $E$. picipes on, 255.

undularis, Elymnias, female of mimics Salatura plexippus (genutia) in N. E. India and Sikkim, and $S$. hegesippus in Burma, 373.

Ungulates, episematic markings in, 357.

Uniformity of conditions during depositions of stratified rocks, 17-19; shown by flying organisms, 18; shown by fossil trees, 18, 19; shown by prints of raindrops, 19 ; of pattern throughout nauseous groups, reasons for, 234, 277-9; of Australian Hymenoptera Aculeata, 278.

United States and Lamarck's theory, 97,98 ; opinions on evolution in, I00; negroes unchanged by many generations in, 178 ; mimicry in butterflies of, 274 ; Terrapin (Macroclemmys) with worm-like lures in southern, 378 .

\section{Universal Review, 7.}

Unpalatability associated with warning colours, 315 ; no defence if food scanty, 269, 317, 317 n. 4 .

Unpalatable insects, special enemies of, 317,318 .

Unpleasant sinell as a protection, see smell.

Untersuchungen über die Mimicry, Erich Haase, 231, 318, 375.

Upper Amazon, see Amazon, Upper, 273.

Uraniidae, Papilio mimicked by moth (Epicopeia) belonging to, 371 ; Papilio mimicking moth (Alcidis) belonging to, $37 \mathrm{I}$.

Uranium and radium, bearing upon life of the sun of, I 5 n. 2 .

uranoscopus, Ceratias, phosphorescent lure of, 378 .

Uric acid and derivatives in Pierine pigments, 262, 263. 163.

urnaria, Ammophila, instincts of,

Uropteryx sambucaria, I50, I 50 n. 2 .

urticae, Spilosoma, aposematic attitude of, 324 .

urticae, Vanessa, struggle severe in pupal stage of, 306 ; power of colour adjustment of pupae of, 306 .
Usaramo (Rosako), E. Africa, antlike bug from, 254, 255, 255 (Fig. 3).

Use and disuse of parts, hereditary transmission of (use-inheritance) : see also Acquired Characters; Lamarck's theory and, 98 ; an attractive conception, IOI ; transmission of 'acquired characters' involved by, I10; arguments against, II4, II 5 ; pangenesis and, 126 ; continuity of germ-plasm and, 131, 132; heredity and, 137 ; Natural Selection explains effects apparently caused by, 137, I 38 .

Utility, see also Natural Selection; Natural Selection and, 105-7; Palaeontology and, 107, 108; Kirby and Spence on mimicry and, 221 .

\section{V}

Vail, see Macdougal, xix n. 5, xxi, xxii.

VALUE OF BRIGHTLY-COLOURED SURFACES CONCEALED DURING REST, X. 303, 304: see also 325.

Valvulina, an existing genus in the Carboniferous, 27.

Van Beneden, on the preparation for fertilization of the germ-cells, xxxi.

Vanessa kaschmirensis, 285; - urticae, 306.

Vanessidae, method of pupation in, 151 ; pupae of, affected by gravity, I51, 152; compared with nauseous groups as regards uniformity, 277 ; species of, captured by king-crow, 285; colour adjustment of pupae of, 306 ; struggle for life in pupae of, 306 .

variabilis, Estigmenida, mimicking Hispidae, 26I.

VARIABLE PROTECTIVE RESEMBLANCE IN INSECTS, V. 1 52-4: see also 149, 150, and ADJUSTABLE Protective Resemblance, $X$. 304-7.

Variation des Heliconia Thelxiope et Vesta, M. Charles Oberthür, 69.

Variation, Heredity and Evolution, R. H. Lock, xv n. 2, xvii n. I and n. 2, xix n. 5, xx, xx n. 2, xxiv, xxiv n. 2, xxvii, xxix, xxxvi, xxxvii n. 2 .

Variation in Animals and Plants, H. M. Vernon, xxxv n. 2. 
Variation under Domestication, C. Darwin, xxiii, 79.

Variation, independent and correlated, $66 \mathrm{n} .2$; modification distinguished from, $73 \mathrm{n}$. I ; interbreeding checks excessive, 94 ; a factor of selection, 95-6 ; not explained by selection, 96, 97 ; sudden large, 110; Weismann's hypothesis on causes of, $127,128,137$; believed to be due to hereditary influence of environment, 137; predetermined in fertilized ovum, 137, 142, 183: see also xxxvi, xxxvii, xxxvii $\mathrm{n} . \mathrm{I}$; the raison d'être of sexual reproduction, 137 ; variable protective resemblance and the causes of, 153,154 ; Prichard on the obscure origin of, 176 ; Prichard on adaptation as caused by laws of, 190 .

Varieties, species and, 47, 66-8; transition as test of, 66, 67; tendency towards interbreeding between similar, 85-8; 'produced in the race, have their beginning in the original structure of some particular ovum or germ' (1826), Prichard, 183 ; sudden origin of human, 185 ; Prichard on adaptation in species and, 189, 190.

VARIOUS CONCEPTIONS OF SPECIES, II. 59-63.

VARIOUS USES OF TERM MIMI. CRY : EsSENTIAL Element IN MIMICRY, X. 359-61.

Venation, importance of, as compared with colour, xvii.

Venezuela, character of chief mimetic butterflies in, 273 .

Venezuela and Central America, colours of a chief Ithomiine-centred combination in, 350 .

Ventral glands of Croesus larvae, $239,320$.

Venus, the question of water on, 14. verbasci, Cucullia, cryptic resemblance of moth of, 319 ; transition from aposematic to cryptic defence of larvae of, 318 ; evidence of distastefulness of, 318 .

Verbascum, Gärtner on, 78 ; Darwin on sterility between varieties of, 79.

Verhandl. der k.-k. zool.-botan. Ges. in Wien (1883), 256, 258, 302.

Verhandl. d. V. Internat. Zool. Congr. z. Berlin, 27I.

Vernon, H. M., introduction to the study of Mendelism by, xxxv n. 2. versicolor, Endromis, mimicry of saw-fly larvae by larvae of, 238, 239, 239 n. I.

VERTEBRATA, BEARING OF INSECT MIMICRY, \&C., UPON SUPPOSED HEREDITARY TRANSMISSION OF EXPERIENCE IN, V. I66-8.

Vertebrata, 43: see also classification of examples of mimicry, 393; evolution of, xliii, 26, 27, 30, 31 ; in classification, 25 ; progressive changes of lower Phyla even slower than those of, 28; of early Palaeozoic, 30, 31 ; specialized character of earliest known, 30,31 ; past history inferred from comparative anatomy of, 32 ; origin of limbs of, 108, 109; intelligence of the higher, 116, 117 ; instincts of, 116,117 .

Vespa, comb-making instinct of, prior to experience, 164,165 .

vesta, Heliconius, varieties of, 69.

Vestiges of the Natural History of Creation, R. Chambers, xviii, xix, 104, 105, 175.

Vetch, ant-like Locustid and models on Rhodesian, $257 \mathrm{n}$. 1 .

vetustus, Heliconius, mimics Melinaea in B. Guiana, 332.

Victoria Nyanza, eastern and western sub-sp. of Amauris meeting at, xxxv, 69: see also 335 ; the meeting place of certain E. and W. African models and their nimics, 338 ; range of merope, sub-sp. of Pap. dardanus, from W. coast to, 374,374 n. 3 .

Vines, Prof. S. H., on the study of adaptation as a stimulus to inquiry, xlvi n. I.

vinula, Dicranura, caustic potash for softening cocoon secreted by, 159 . violae, Acraea, proved to be un. palatable, 269.

viridis,Lacerta,terrified by, but ultimately relished snake-like caterpillar, 367.

Volcanic dust on ocean floor, 20.

Volucella, resemblance to humblebees of, 221 : see also 251 ; resemblance not aggressive, 378 ; larvae of, probably beneficial to humble-bees, 378 .

\section{W}

Wabosakhan Camp, Burma, kingcrow unable to detect Melanitis at, $288,289$.

wahlbergi, Hypolimnas (Euralia), 
replaced by western $H$. anthedon near V. Nyanza, in accordance with corresponding geographical replacement of Danaine models, 338.

wakefieldii, Godartia, recent entrance into Natal of, 52 n. 1 .

Walker, Commander J. J., on enemies of $D$. bifida pupae, 158 .

Wallace, Statement of CoNDITIONS UNDER WHICH PROTECTIYE MIMICRY OCCURS, BY, X. 36I, 362.

Wallace, Alfred Russel, letters from Darwin to, on individual differences and single variations, $x l$ n. 3, 3; and on geological time, 6; minute differences the basis of evolution according to Darwin and, 3 ; conception of Natural Selection by Darwin and, 48 ; controversy with Darwin on interspecific sterility, 49, 80, 89; Bates quoted by, $51 \mathrm{n}$. I ; joint essay of Darwin and (1858), 95-7, 194-6: see also xxxvii n. 2, 48, 58, 200, 222, 379; on selection and self-fertilization, 92 n. 4 ; on in-and-in breeding, 93 ; on struggle for life in young birds, $167 \mathrm{n} .2$; J. C. Prichard as a remarkable predecessor of Darwin and, 192 ; writings on evolution by, before discovery of Natural Selection, 194; discovery of Natural Selection by, 194, 195; on protective resemblance of Kallima, $203,206,207$; on mimicry in the Oriental Region, 222 ; early views of, on mimicry between models, 222; early acceptance of Muillerian mimicry by, 223, 327; on mimicry a form of protective resemblance, 226, 348 ; on advantages of female mimicry, 246, 279; on similarity of conditions in W.Africa, S. America, and Malaya, 248 ; on mimicry in vertebrates, $367,367 \mathrm{n}$. I ; on the mimicry of Rhynchophora by Longicorns, 369 ; on hardness the special defence of weevils and Anthribidae, 369; rejection of sexual selection by, 379 ; interpretation of epigamic characters as recognition marks and as due to surplus activity, 380 .

Walsingham, Lord, on the value of bright hind wings of moths, \&c., 303.

WARNING COLOURS AND MIMICRY, BEARING ON SUPPOSED HEREDITARY TRANSMISSION OF EXPERIENCE OF, V. 166-8.
WARNING AND SIGNALLING (RECOGNITION), OR SEMATIC Colours; APOSEMATIC AND EPISEMATIC CHARACTERS, X. 31 5-58. For divisions, sections, sub-sections, \&c., see pp. 294-6.

WARNING OR Characters, X. 315-26. For sections see pp. 294, 295.

WARNING IN COMMON OR SYNAPOSEMATIC CHARACTERS, X. 32756. For sections and sub-sections see pp. 295, 296.

Warning colours (aposematic characters), see also Mimicry Müllerian; place of, in a scheme of the bionomic uses of colour, 226, 227 ; definition of, 315 ; introduction of term 'aposematic' (1890), 223 ; recognition characters compared with, 357,358 ; protective (procryptic) resemblance contrasted with, 315; education of enemies and insect, 166-8 ; supposed hereditary transmission of experience and, 166-8, $268,269,316$; especial development in wet season of, 208-9, 317, 339-42 ; male $H$. misippus and, 217 ; flight slow in insects with, 323 ; patterns of upper and under surface often similar in butterflies with, 323 ; special conspicuousness of the under surface of butterflies with, 323; Finn's experiments on insects with, 269, 279 n. $1,317,317$ n. 4 ; evidence of rejection by wild birds of moths with, 284 ; species rather than individual benefited by, 316 ; tenacity of life in species with, 316 ; waste of life prevented by, 316 ; various means of special defence associated with, 315 ; evidence by F. A. Dixey and G. B. Longstaff of unpleasant smell in butterflies with, $316,317,317 \mathrm{n}$. I ; more evidence required of special defence in insects with, 317; chiefly developed when insect life abundant. 317 ; a danger in time of hunger, 317 ; special enemies (e.g. cuckoo), of forms with, 317,318; no real immunity of forms with, 318 ; forms with, compelled to hide in time of stress, 320 : see also Dry Season and Winter; importance of instincts for display of, 323, 324; importance of 'sham death' in forms with, 323,324 ; gregarious habit in forms with, 318,320 ; transi- 
tion to a measure of protective (procryptic) resemblance from, in L.chrysippus, 320, 321 ; transitions between protective resemblance and warning colours, 318-21, 323, 324; limits to effect of, in Aculeates, Euploeas, Ithomiines, \&c., 322, 323; conditions of struggle determine degree of conspicuousness of, 323; advantage of resemblance between forms with, 327-8 ; mimicry often combined with, 347 ; mimicry especially found in groups with, 347,348 ; habits of certain Brenthidae and weevils bring about, 369-70.

Wasp-beetle, 238, 25I, 252, 348, 363.

\section{Wasps, Social and Solitary,} G. W. and E. G. Peckham, II 8 n. I.

Wasps (see also classification of examples of mimicry, 389-93) : mimicked by diverse methods, $250-2$, 280 ; uniformity throughout many species of (Müllerian mimicry), 232, 278 ; advantage of resemblance to, 281 ; limit to conspicuousness of, 322 ; many examples of mimicry of, Batesian, 376: others Müllerian, 230-2, 376 .

Waste of life prevented by warning colours, 316.

Waterhouse, G. R., on wide difference between domestic races, 76 .

WATTENWYL, BRUNNER VON, HYPERTELY OF, X. 302, 303.

Weevils (see also classification of examples of mimicry, 390-1): colour adjustment probable in Cleonus, 307 ; hardness as the defence of, 261, 369, 370 ; conspicuousness of certain large African, 370.

Weir, J. Jenner, on the value of bright hind wings of moths, \&c., 303,304 .

Weismann, August, appropriation under the name of Mendel of discoveries made by, xiii, xxxvi, xxxvii, xxxvii $\mathrm{n} . \mathbf{I}$; on characters predetermined in the germ, xxxvi, xxxvii, xxxvii n. I, 135; Amixia of, 60 ; Amphimixis of, 60 n. 3 : on Acquired characters or Somatogenic characters, 110, 123; on causes of germ variation and significance of sexual reproduction, 127, 128, 137; continuity of the germ-plasm of, 127-36; on germ-plasm in the nucleus, 128 ; on heredity and transmission of acquired characters, 132 ; on effect of cessation of Natural Selection (panmixia), 138 : see also xxxvii n. 2 ; stimulating effect of writings of, 139 ; definition of acquired and inherent characters by, 142 ; on Lamarckism and the cocoon-making instinct, 164 n. 2 ; views of, on heredity and acquired and inherent characters anticipated by J. C. Prichard, 174, I75, 178, I 79, I83 ; first led to doubt transmission of acquired characters on theoretical grounds, 181; on seasonal changes of Lepidoptera, 3II ; on seasonal forms of Araschnia, 342 ; use of incorrect term 'immune' adopted from Haase by, 375 ; mimicry in Pap. dardanus (merope) and in butterflies of Eastern Brazil erroneously figured by, 375,376 ; 'Mimicry-ring' of, 376.

West Africa, see Africa, West.

West China, see China, West.

West Indies, J. C. Prichard on English colonists unchanged after many generations in, 178: see however $187 ; H$. misippus ranges to, 216.

Westminster Review, 78.

Westwood, Prof. J. O., on nonmimetic species of mimetic genera, 274,275 ; on a wonderful example of secondary Müllerian mimicry, 346.

Wet season, the time of plenty, $208,209,317,326$; form of butterflies' wings in, 206, 207, 310, 311 ; warning colours and 'eye-spots' specially characteristic of, 208-II, $317,326,339-341$; aposematic forms of African Precis in, 208, 209, 320, 320 n. I, 339-4I ; butterflies much upon the wing in, 209; advantage of warning colours and 'eye-spots' in, 209-II, 317, 320, 326; mimicry developed in broods (Precis, Byblia, Teracolus) of, 339, $339 \mathrm{n} .1$, 340-I ; mimicry less developed in broods (Belenois, Teracolus, Huphina) of, $34 \mathrm{I}, 342$.

Wetzel, experiments on frog's egg of, 129.

Whale, ear-bones of, on ocean floor, 20.

'What is a Species?' Essay II, 46-94.

'What IS a SPECIES?' INTRO- 
DUCTION TO DISCUSSION ON, II. 63-5.

Whewell, W., on the study of Final Causes as a stimulus to inquiry, xlvi n. 1.

White Admiral, 342: see also Limenitis, 218, 274, 342.

White under surface of animals interpreted by A. H. Thayer, 299.

Whiteness, J. C. Prichard on local development of, 187 .

'Why' and 'How', both answers essential, xlvi, xlvii.

Wichura, proof that hybrids of Salix do not follow Mendel's principle by, $\operatorname{xxxv} \mathrm{n}$. I.

Wiggins, C. A., butterflies from the V. Nyanza collected by, 69 ; on $H$. misippus and its model, 216 n. 1.

Wight, Isle of, effect on plants of wind in, 75.

Windle, Prof. B. C. A., on Roux's researches, $128 \mathrm{n}$. I ; on Teratology, $136 \mathrm{n}$. I.

Wings, stability of pigments in butterflies', xlv, xlv n. I, 53; as evidence of uniformity of conditions in geological times, 18; insects in oceanic islands often without, 18; immense size of, in Carboniferous dragon-flies, 18, 37 ; fully developed in Carboniferous Phasmids, 36 ; evolution of insects', 36,37 ; ancient insects probably with six, 37; seasonal change of form in butterflies', 206, $207,310,311$; eye-spots especially developed on under surface of, 210 , 2 I I, 326, 340, 34I ; of butterflies injured as if by enemies, 270, $270 \mathrm{n}$. I, $281-3,325$; darkening of hind, in Guiana mimetic butterflies, 272, $273,331,332,350$; of dragon-flies, butterflies, moths, flies, and cicadas in nests of Microhierax, 290, 291, 291 n. 1.

Winter moth, 156.

Winter, the time of stress, 148, 209, 317, 320: see also dry season. 380 .

Wisconsin, I I 8 n. I, 252, 253, 256,

Wisconsin Geological and Natural History Survey, II 8 n. I.

Wood splinter, protective resemblance to, 319.

Woodland in S. Africa, definition of, 340 .

Woodpecker, Darwin on the in- adequacy of Mutation to account for the, xix.

Woodward, Henry, on evolution of Crustacea, 40 n. I.

Worms, prey allured by pseudepisematic resemblance to, 378 .

Wortman, Dr., on formation of joints by pressure, 115.

Wright, Miss F. A., on pupal stage of $V$. urticae, 306 .

\section{X}

xenocles, Papilio, a Danaine mimic not attacked by bee-eaters, 288 .

Xylocopidae, see classification of examples of mimicry, $389,391-2$.

\section{Y}

Yerbury, Col. J. W., on forms of Limnas chrysippus, 70 n. I, n. 2 ; on Pará fly mimicking Hymenoptera, 257 n. 1 ; direct evidence of the attacks of birds on butterflies obtained by, $283,285,286$.

Yoonzaleen River, Burma, 290.

Yorkshire and Lancashire, recent darkening of moths in, 308-10.

Young enemies, Müllerian mimicry and, $166-8,212-15,222,278,327-$ 31,366 ; advantage of episematic markings to, 357 .

\section{Z}

Zea, Darwin on sterility between selected varieties of, 79 .

Zebra, invisibility of, 298.

Zeitschr. f. Wissenschaft. Zool., 84 n. 2, 334 n. 2.

zitenius, Melanitis, king-crow unable to find, 288, 289 .

Zittel, Karl A., Palaeontologie by, consulted for Essay I, 43 .

Zonosoma (Ephyra), cocoon replaced by loop, \&c., in, 150 ; parallelism with Pierinae, 150; cryptic colours of larva and pupa of, 150 ; unique dimorphism in larva and pupa of, 150.

Zool. Ergeb. einer Reise in OstAfrika, F. Stuhlmann, Hemiptera, Gerstaecker, 255.

Zoological Congress at Berlin (I901), Author's English Address to, the original form of Essay IX, 27I ; Report of the, 271.

Zoological Society of London, 


\section{ANALYTICAL INDEX}

Proceedings of, 70 n. 2, I 53 n. I, $223,230,257$ n. 1, 259, 260, 275, $276,280,286,317,318,319,319$ n. I, $349,353,367$ n. $2,368,369,378$, $378 \mathrm{n} .3$.

Zoologist, 84,155 n. I, 159 n. 2, 291 n. I.

Zoonomia, Erasmus Darwin, 140, 141.

Zostera, S.typhle concealed among leaves of, 298, 299.

Zygaenidae, a distasteful family of diurnal moths, Müllerian mimicry in, 372 ; Chalcosiinae, a sub-family of, mimicking Danainae and Papilio. ninae, 231 ; rough Müllerian mimics of blue Oriental Euploeas, 372, 376. Zygosis or fertilization, xxxi ; inferences as to precursors (allelomorphs) of Mendelian characters in, xxxi-xxxiii; proposed by Lankester to replace fertilization, $60 \mathrm{n} .3$.

Zygote or fertilized germ, Mendelian inferences as to, xxxi-xxxiii; the immediate product of fertilization, 60 n. 3. 
OXFORD

PRINTED AT THE CLARENDON PRESS

BY HORACE HART, M.A.

PRINTER TO THE UNIVERSITY 



\section{CNIVERSITY OF CALIFORNIA LIBRARY}

Les Angeles

This book is DUE on the last date stamped below.

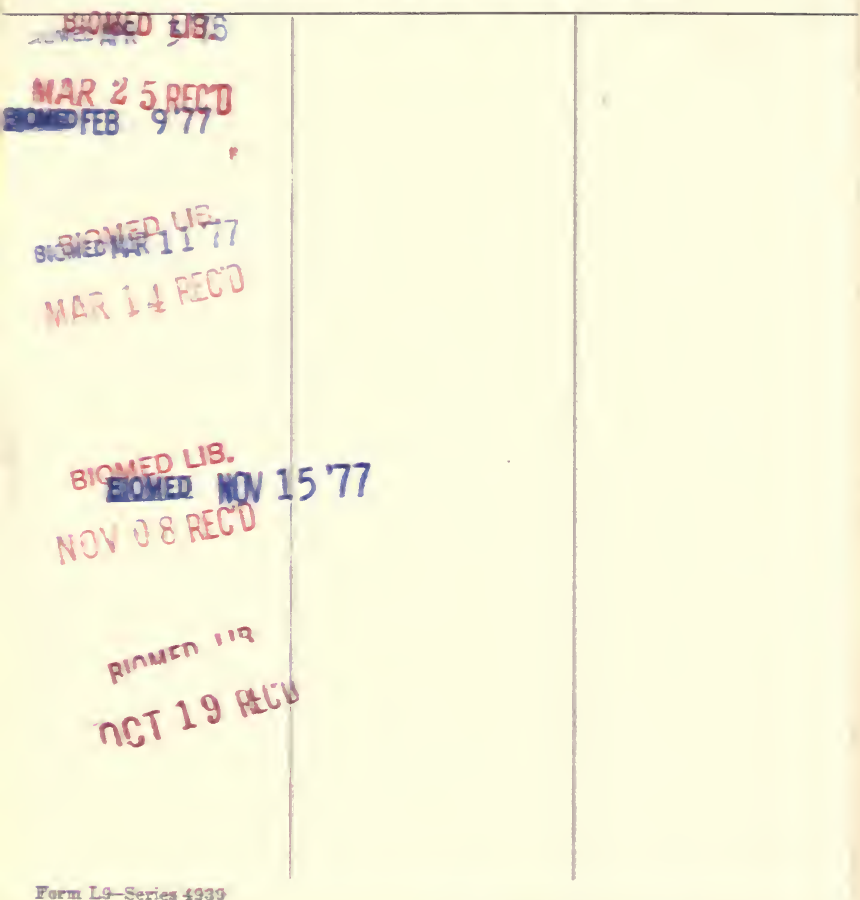




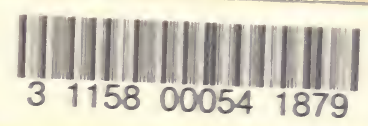

UC SOUTHEAN REGIONOW IBRAPN FNCLTIN

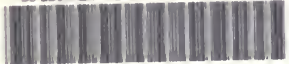

A $000333918 \quad 1$ 
(1) 